\title{
Influence of cutting sequence and time effects on cutters and roof falls in underground coal mine - numerical approach
}

\author{
Anil Kumar Ray \\ West Virginia University
}

Follow this and additional works at: https://researchrepository.wvu.edu/etd

\section{Recommended Citation}

Ray, Anil Kumar, "Influence of cutting sequence and time effects on cutters and roof falls in underground coal mine -- numerical approach" (2009). Graduate Theses, Dissertations, and Problem Reports. 3491. https://researchrepository.wvu.edu/etd/3491

This Dissertation is protected by copyright and/or related rights. It has been brought to you by the The Research Repository @ WVU with permission from the rights-holder(s). You are free to use this Dissertation in any way that is permitted by the copyright and related rights legislation that applies to your use. For other uses you must obtain permission from the rights-holder(s) directly, unless additional rights are indicated by a Creative Commons license in the record and/ or on the work itself. This Dissertation has been accepted for inclusion in WVU Graduate Theses, Dissertations, and Problem Reports collection by an authorized administrator of The Research Repository @ WVU.

For more information, please contact researchrepository@mail.wvu.edu. 


\title{
Influence of Cutting Sequence and Time Effects on Cutters and Roof Falls in Underground Coal Mine \\ - Numerical Approach
}

\author{
Anil Kumar Ray \\ Dissertation submitted to the \\ College of Engineering and Mineral Resources \\ at West Virginia University \\ in partial fulfillment of the requirements \\ for the degree of \\ Doctor of Philosophy \\ in \\ Mining Engineering \\ Syd S. Peng, Ph.D., (Chair) \\ A. W. Khair, Ph.D \\ Keith A. Heasley, Ph.D. \\ Y. Luo, Ph.D. \\ Bruce S. Kang, Ph.D.
}

Department of Mining Engineering

2009 


\section{ABSTRACT \\ Influence of Cutting Sequence and Time Effects on Cutters and Roof Falls in Underground Coal Mines - Numerical Approach}

\section{Anil Kumar Ray}

Roof falls are among the most serious safety hazards faced by underground coal mines worldwide. Due to the stringent safety measures and development of the innovative support systems in the past few decades, their numbers were drastically reduced but have not been eliminated. Underground observations reveal that a number of larger roof falls are preceded by the development of shear failures near pillar ribs, termed cutters or guttering. In the past, many factors were identified as responsible for the development of cutters and ultimately roof falls. These factors can be broadly classified as stress related and non stress related. Although some useful work on the stress related aspects was conducted in the past, in this dissertation the cutter instability is investigated in more details while including some finer aspects of the mining process in particular the cutting sequence, which were not given due consideration before.

Three dimensional finite difference modeling has been carried out to accomplish the research objectives in this dissertation. The strain softening material behavior with cutting sequence has been used to realistically simulate the cutter formation as suggested by Gadde and Peng, 2005. A few cutting sequences employed by some U.S. coal mines have been considered in this study. This was done to understand if the cutting sequence has any significant influence over cutter formation. Apart from cutting sequence, factors such as the cut length, step cutting and the turning direction of crosscut into and away from major and minor horizontal stress are also examined for their effect on cutter development. Further, in contrast to past work, the effect of change in the immediate roof rock properties and horizontal stress directions are studied in several multiple entry models while simulating some realistic cutting sequences.

Field observations show that some cutters develop after a significant amount of time is elapsed since the area has been mined. While such time-dependent effects could be simulated with numerical modeling by using appropriate creep laws, due to the lack of knowledge on creep properties of coal measures rocks, realistic analysis is difficult at this stage. However, to consider the time effect on development of roof instability, a simple methodology has been suggested in this dissertation. The effect of different parameters like, entry and pillar width, intersection geometry has been correlated with the standup time for the observed roof falls at an IL Basin coal mine.

The combination of weak immediate roof and high horizontal stresses could have a devastating effect on roof stability. It's very difficult to completely avoid roof instability in such conditions. In this research, based on the understanding of cutter development and roof falls, a few simple and practicable recommendations are made to minimize such instabilities. While these suggestions may not completely eliminate the roof failures, they may enhance the standup time to levels that will allow safer extraction of the reserve. 


\section{To \\ My Parents \\ and \\ Late Mother-in-Law}




\section{ACKNOWLEDGEMENT}

The writing of this dissertation has been one of the most significant academic challenges I have ever faced. Without the support, patience and guidance of the following people, this work would not have been completed. It is to them I owe my deepest gratitude.

My deepest gratitude is to my advisor, Dr. Syd S Peng for his excellent supervision, guidance and constant interest in this dissertation. I have been amazingly fortunate to have an advisor who gave me the freedom to explore on my own and at the same time the guidance to recover when my steps faltered. I have benefited enormously from his knowledge of Coal Mine Ground Control and have learned a great deal from him. I have appreciated his seemingly endless supply of ideas, many of which have been incorporated in the dissertation and his willingness to read my work.

I am also grateful to Dr. Keith Heasley, Dr. Yi Luo, Dr. A. Wahab Khair and Dr. Bruce Kang, my graduate committee members, for their suggestions and valuable recommendations. I would like to appreciate the valuable time they have spared by serving on my graduate committee.

I am also grateful to John Rusnak and Murali from Peabody Engergy, for their help extended to me during the final phase of this dissertation. Their patience and support are highly appreciated. I would like to specially mention here that Murali is the man who encouraged me to pursue my doctorate study in USA and helped me a lot during my stay at WVU.

I am also grateful to Dr. Khalid Morsey for numerous discussions and lectures on related topics that helped me improve my knowledge in the area. Working in many projects with Dr. Morsey was really a wonderful experience for me.

I would like to express my sincere thanks to Karen and Karla for providing administrative support during my study at WVU.

I would like to thank my Indian friends Brijes, Tapas, Arun, Ajit and Reddy for their constant support throughout my stay at WVU.

I would like to thank Director, CMRI (Central Mining Research Institute) my parent organization for providing me an ideal foundation for conducting research in Longwall Mining in India and granting me the study leave to pursue my higher studies in USA

I am also grateful to Dr. S.K. Sarkar, an expert in Longwall Mining for building my research career. His authority on the subject of Longwall Mining in India is unmatched and I had the privilege of working with him for almost two years. I would also like to thank Dr. Gautam Banerjee, currently heading Longwall Research Group, for providing the freedom to conduct research at CMRI. I can not forget my dearest friend Arun Singh, who supported my family needs in my absence at Dhanbad. I would like to thank him from bottom of my heart.

Most importantly, none of this would have been possible without the love and patience of my family. My immediate family, to whom this dissertation is dedicated to, has been a constant source of love, concern, support and strength all these years. I would like to thank my beloved wife, Shefali and my kids, Kunal, Tushar and Twinkle, for supporting me throughout this work. It is the best stage to dedicate this work to my parents. I can not forget my mother-in-law for her love and affections. Its very unfortunate that she is no more with us to see me graduated. I appreciate the contributions, dedication and sacrifice made by my family members. Their unconditional love for me helped me to overcome various challenges in my life. 
TABLE OF CONTENTS

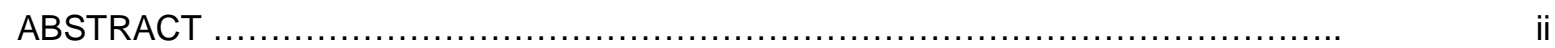

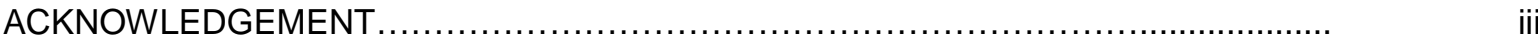

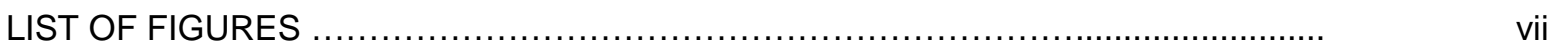

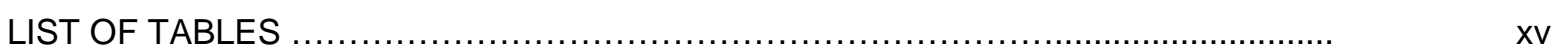

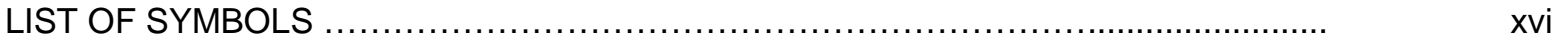

CHAPTER 1 INTRODUCTION

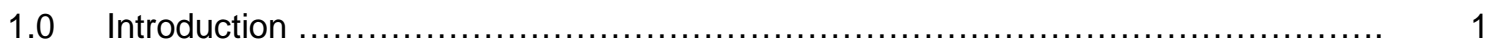

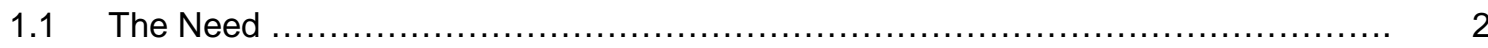

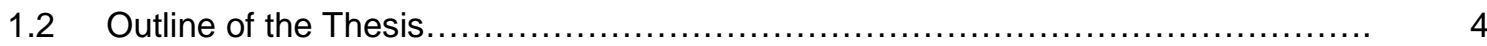

\section{CHAPTER 2 LITERATURE REVIEW}

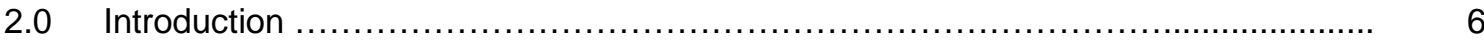

2.1 Stress Related Factors Influencing Cutter Development $\ldots \ldots \ldots \ldots \ldots \ldots \ldots \ldots \ldots \ldots \ldots \ldots \ldots \ldots \ldots \ldots \ldots$

2.1.1 In-situ stress magnitude effect on cutter development .................... 10

2.1.2 Horizontal stress orientation effect on cutter roof development............. 13

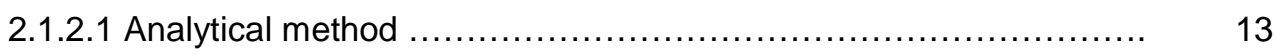

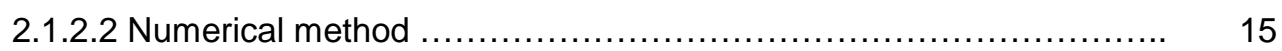

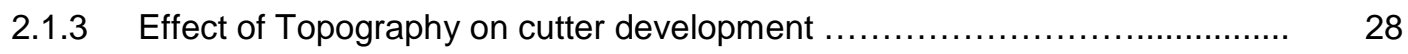

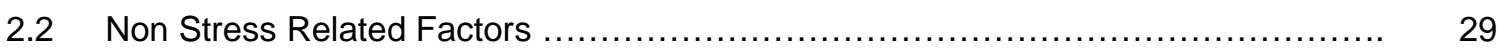

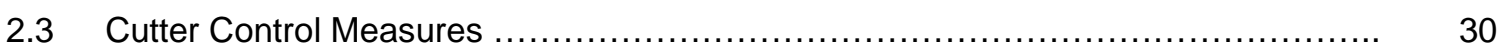

2.4 Summary and Scope of Present Research ................................ 32

CHAPTER 3 IN-SITU STRESS AND STRESS MEASUREMENT IN USA

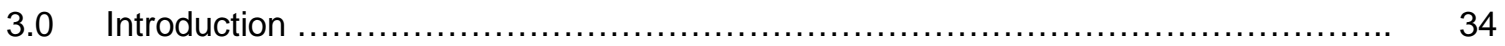

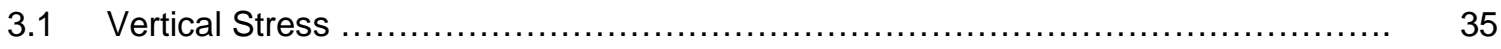

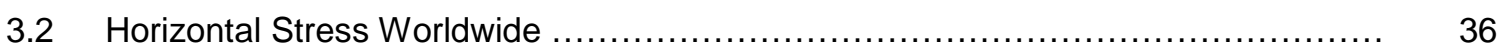

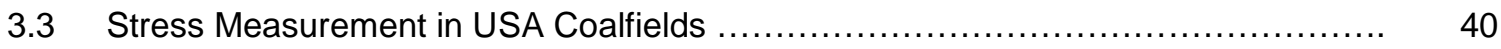

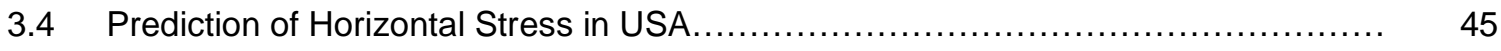

CHAPTER 4 CUTTER ROOF - FEW CASE STUDIES

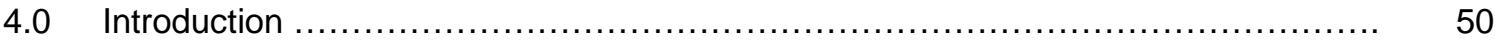

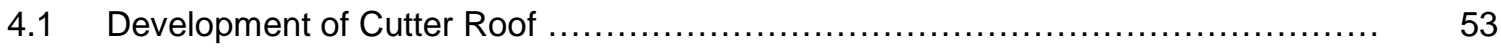

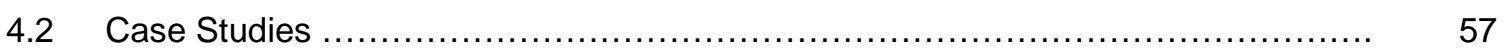

4.2.1 Case study 1- cutters in the Eagle seam .......................... 57

4.2.2 Case study 2- cutters in the Lower Kittanning seam..................... 59

4.2.3 Case study 3 - cutters in the Herrin \# 6 seam ........................... 63

4.2.4 Common observations from case studies................................... 66

4.3 Understanding Cutter Development for Numerical Modeling ....................... 67

CHAPTER 5 MODELING TECHNIQUE FOR CUTTER SIMULATION

5.0 Introduction 


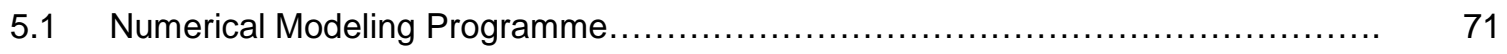

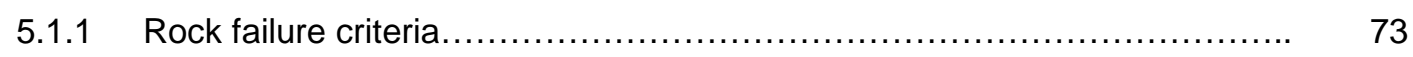

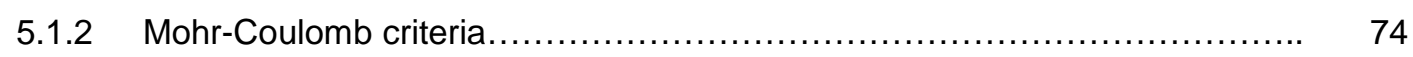

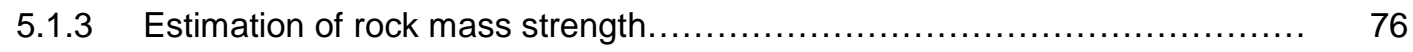

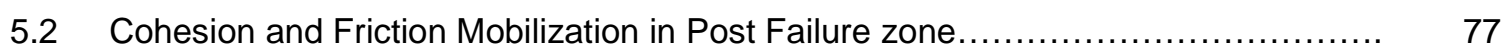

5.3 Laboratory method to Estimate the Cohesion and Friction in Post Failure Region ... 81

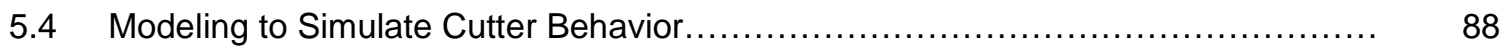

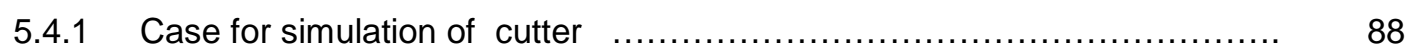

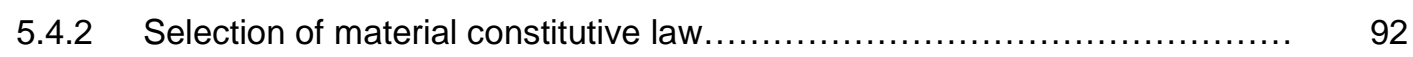

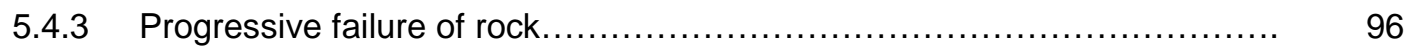

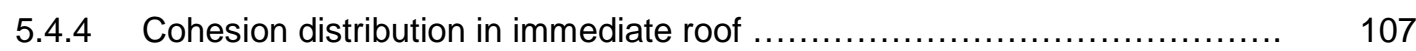

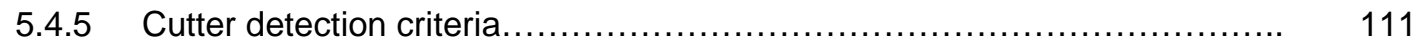

5.4.6 Effect of friction and dilation mobilization on cutter pattern................ 111

5.4.7 Effect of discontinuities on cutter pattern................................. 118

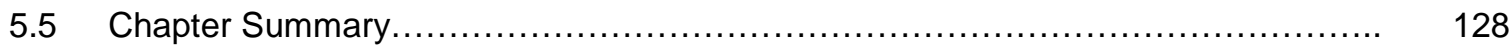

\section{CHAPTER 6 INFLUENCE OF CUTTING SEQUENCE}

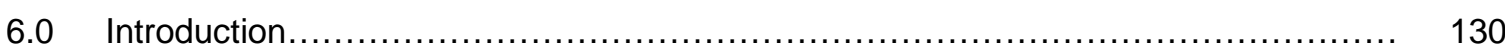

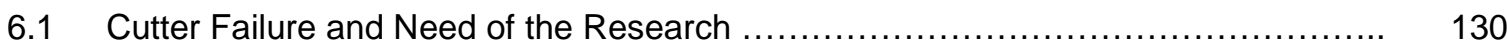

6.2 Cutter Sequence and Multi Excavations Needs Attention for Cutter Simulation ....... 132

6.2.1 Stress distribution pattern for single cut and multi-cut excavation 132

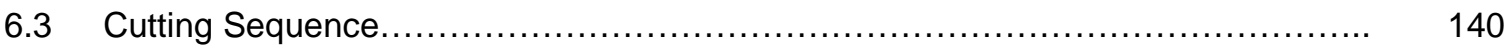

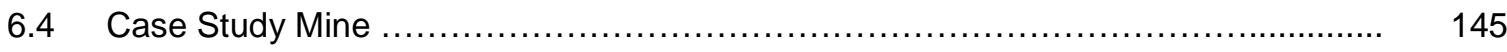

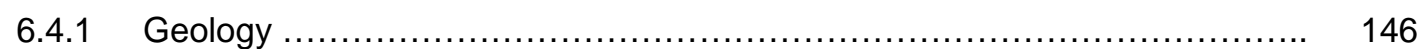

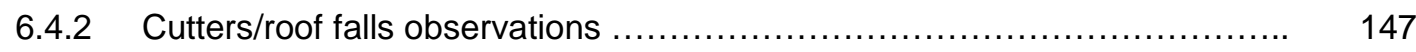

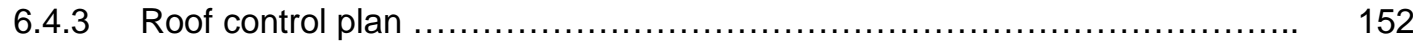

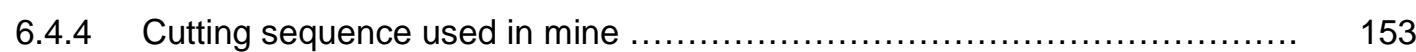

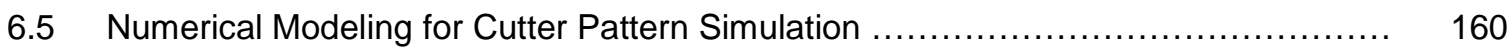

6.6 Effect of Roof Rock Strength and In-situ Stress ratio on Cutter Pattern .............. 172

6.6.1 Effect of Strength of the Immediate roof and CMRR on Cutter pattern........ 172

6.6.1.1 Correlation of rock mass cohesion with CMRR .................... 176

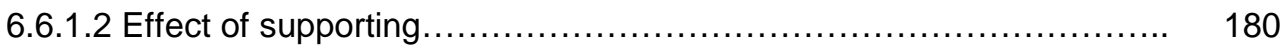

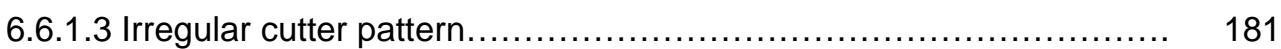

6.6.2 Effect of In-situ stress orientation .................................... 183

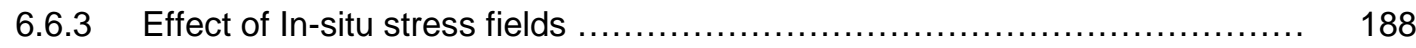

6.6.3.1 Effect of ratio of maximum horizontal stress to vertical stress ......... 188

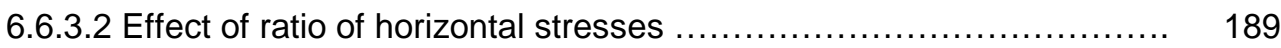

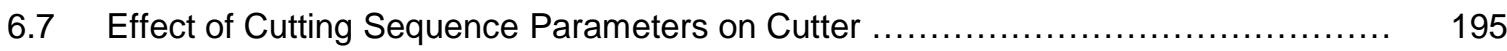

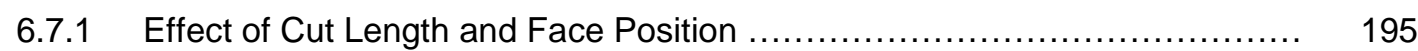

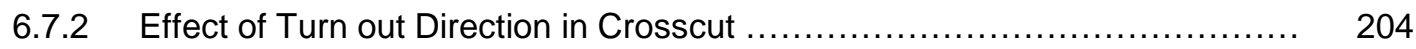


6.7.3 Effect of Step Face Cutting on Cutter Severity .............................. 206

6.7.4 Effect of Pillar Size ...................................................... 211

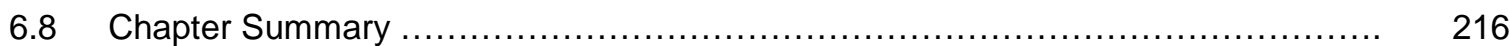

\section{CHAPTER 7 TIME EFFECT ON ROOF FALLS}

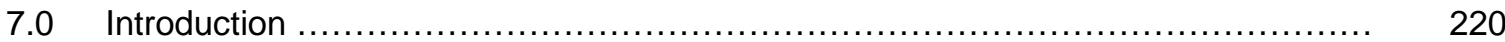

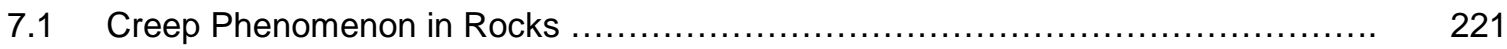

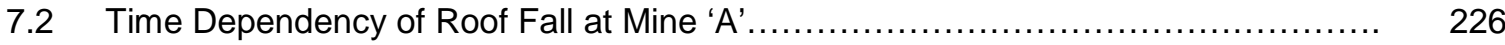

7.2.1 Standup time of roof falls observed at Mine 'A' ............................. 227

7.3 Factors Affecting Standup Time for the Roof Fall ................................. 236

7.3.1 Effect of pillar size and entry width on standup time and roof fall ............. 236

7.3.2 Effect of turn outs/ slab on roof fall ....................................... 237

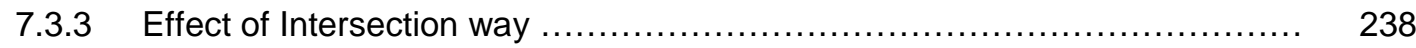

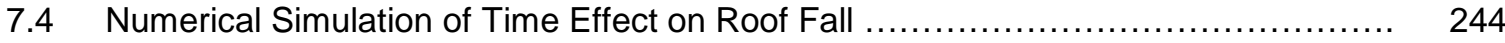

7.4.1 Single component power law ........................................... 244

7.4.2 Creep in coal measure rocks ............................................ 244

7.4.3 Difficulty in mathematical modeling of creep of coal measure rocks ............. 245

7.4.4 Modeling methodology ................................................. 246

7.4.5 Numerical simulation of creep behavior for coal measure rocks .............. 248

7.4.6 Strength degradation of the rock with time ................................. 258

7.5 Chapter Summary ..................................................................... 261

\section{CHAPTER 8 CONCLUSIONS AND RECOMMENDATIONS}

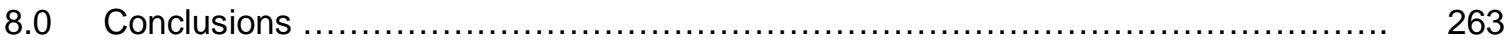

8.1 Recommendations for Prevention of Cutter/Roof Falls 265

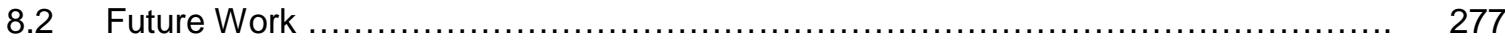

$\begin{array}{ll}\text { REFERENCES } & 278\end{array}$ 


\section{LIST OF FIGURES}

Figure 2.1 Distribution of forces in the vicinity of a narrow headway

Figure 2.2 Roof failure by slip along bedding planes (top) and low angle shearing (below) for $\theta=90^{\circ}$

Figure 2.3 Change in safety factor and percent of rock failure at the face with change in $\theta$

$\begin{array}{lll}\text { Figure 2.4 Effect of entry orientation, } \theta_{S R} \text {, with major horizontal stress } & 16\end{array}$

$\begin{array}{lll}\text { Figure } 2.5 & \text { Typical shear stress changes vs. } \theta \text { at right and left ribs in an entry } & 17\end{array}$

Figure 2.6 Design layouts for a room-and-pillar mine developed by Wang and Stankus........ 20

Figure 2.7 Measured roof movement as a function of maximum horizontal stress direction, $\theta$ $\begin{array}{ll}\text { from British coal mines } & 20\end{array}$

Figure 2.8 Location of measurement points across the entry and the lines along the entry 21

Figure 2.9 Von mises stress (shear stress) change with $\theta$ (Peng and Chen 2000) 21

Figure 2.10 Effect of maximum horizontal stress $\left(\sigma_{\mathrm{h} 1}\right.$ or $\left.\sigma_{\mathrm{hmax}}\right)$ on entry stability for different entry orientation

Figure 2.11 Layout orientations with respect to $\sigma_{\text {hmax }}$ and associated ground conditions for (a) entry or crosscut and (b) intersection

Figure 2.12 Yielded zones in the immediate roof of the development entry in longwall gateroad

Figure 2.13

Horizontal stress concentrations due to longwall retreat

Figure 2.14

Horizontal stress abutment and shadowing for head and tail-gates

Figure 2.15

Horizontal stress abutment location for longwall panels

Figure 2.16

Stress relief created by an arched entry

Figure 2.17

Angled crosscut orientation of two 4-entry gateroad development

Figure 3.1 Vertical stress measurements from mining and civil engineering projects around the world

Figure 3.2 Variation of average horizontal to vertical stress ratio with depth

Figure 3.3 Ratio of horizontal to vertical stress for different deformation moduli based upon Sheorey's equation

Figure 3.4 Variation of the k-ratio with depth according to information in Stacey and Wesseloo

Figure 3.5 World stress map, the release 2005 of the World Stress Map (after Reinker etal, 2005) (available online at www.world-stress-map.org).

Figure 3.6 Variation in the measure maximum horizontal stress for USA

Figure 3.7 Stress ratio ' $k$ ' for the USA coalfields

Figure 3.8 Horizontal stress ratio ' $l$ ' for the USA coalfields

Figure 3.9 Maximum horizontal stress orientations in the eastern USA coalfields 43

Figure 3.10 Maximum horizontal stress orientations in the western USA coalfields 43

Figure 3.11 Maximum horizontal stress orientations in the central USA coalfields........

Figure 3.12 Direction of maximum horizontal stress and associated stress regimes for North America

Figure 3.13 Predicted vs measured in-situ maximum horizontal stress 
Figure 4.2 Remaining cavity following overall roof collapse (courtesy; Bureau of Mines, Pittsburgh Research Center)

Figure 4.3 Initial stage of a cutter with multiple fractures 51

$\begin{array}{lll}\text { Figure } 4.4 \quad \text { Cutter progressed to a caved void } & 51\end{array}$

Figure 4.5 Cutter roof develops a short distance behind the face and follows entry advance 52

Figure 4.6 Cutters in the immediate roof on the face of a longwall gateroad development entry in immediately after cutting. It most likely occurred during the continuous miner's cutting. $A$ is the overall view and $B$ is a close-up view of the circled area in A

Figure 4.7 Cutters found in the newly developed faces at the left side corner of the roof and rib

Figure 4.8

Spatial distribution of cutters noticed in a mine

Figure 4.9 Progressive sequences of events leading to overall roof collapse resulting from cutter roof failure

Figure 4.10

Conceptual process of cutter roof development

Development of a cutter. $a, b$, and c are the same cutter in different views

Figure 4.12 Mine layout showing location of cutters for case study I

Figure 4.17 Experimental gateroad system showing different types of roof support and pillar systems in different sections

Figure 4.24 Typical stress strain curve showing confinement effect

Figure 5.2 Cohesion and friction degradation with plastic strain

Piecewise liner approximations for cohesion and friction degradation with plastic strain

Figure 5.4 Mobilization of the strength components in the CWFS model in the laboratory compression test

Figure 5.5 Mobilization of Cohesion and friction with plastic strain 
Figure 5.9 Plot of sigma1 vs sigma3 for different plastic strain $\quad 85$

Figure 5.10 Idealized relation for dilation angle, from tri-axial test results $\quad 85$

Figure 5.11 Variation of cohesion of rock specimen tested in laboratory with plastic strain 86

$\begin{array}{lll}\text { Figure 5.12 Variation of cohesion of rock mass with plastic strain } & 87\end{array}$

Figure 5.13 Typical variation of cohesion for different type of rocks with plastic strain $\quad 87$

Figure 5.14 Three entry system representing the mains in case 3 89

Figure 5.15 Lithology used in the modeling (representative for case 3) 90

Figure 5.16 Geometry of the model showing the dense grid for the entries and crosscuts 92

$\begin{array}{lll}\text { Figure 5.17 } & \text { The extent of unstable roof for different material behavior } & 94\end{array}$

Figure 5.18 Distribution of cohesion in the immediate roof on cross-section A-A shown in Figure 5.14 after final cut $14 \quad 95$

$\begin{array}{lll}\text { Figure 5.19 Plan view of the geometry modeled in five cuts } & 97\end{array}$

Figure 5.20 Zones at which the stresses were monitored at face location F-F as shown in Figure 5.19 (RE1 to 7 are in immediate week roof while RE7 is in stronger roof) 98

Figure 5.21 Variation of major principal stress for different cuts at zones shown in Figure 5.20 98

Figure 5.22 Variation of minor principal stress for different cuts at zones shown in Figure 5.20 99

Figure 5.23 Variation of major principal stress for different cuts at zones shown in Figure 5.20 99

Figure 5.24 Major principal stress plot for the bottom zone of the weak immediate roof showing asymmetric behavior along the entry width after cut 3

Figure 5.25 Major principal stress plot for the top zone of the weak immediate roof showing asymmetric behavior along the entry width after cut 3

Figure 5.26 Distribution of cohesion in the immediate roof on cross-section F-F in Figure 5.19 during cut 3 , after cut 4 and cut 5 for single entry created in 5 cuts

Figure 5.27 Distribution of cohesion in the immediate roof on cross-section A-A shown in Figure 5.2 after final cut 14 for 3-entry system

Figure 5.28 The progressive development of stress relief zone and stress concentration zones in the immediate roof due to sequential excavation in the roof during cut 3 and after cut 4 and cut 5

Figure 5.29 Cohesion distributions (cutter) in the immediate layer of roof

Figure 5.36 Cutter distribution in the immediate roof layer for different friction mobilization for excavation made in one cut

Figure 5.37 Cutter distribution cross section near the face after cut 5 for different dilation angle 
angle

Figure 5.41

Shear strain rate in the immediate roof layer after cut 5 for different dilation angle

Figure 5.47 Cutter pattern near the face (Figure 5.19) in the immediate roof after cut 5 due to incorporating numbers of interface in the model

Figure 5.48 Cutter pattern far behind the face (section FF Figure 5.19) in the immediate roof after cut 5 due to incorporating numbers of interface in the model

Figure 5.49 Cutter pattern in the immediate roof layer after cut 5 due to incorporating numbers of interface in the model

Figure 5.50 Cutter pattern in the immediate roof after cut 5 with 4 interfaces having cohesion value of 50 psi

Figure 6.1 Effect of maximum horizontal stress orientation on cutter development for single entry created in one cut

Figure 6.2 Effect of maximum horizontal stress orientation on cutter development for single entry created in five cuts

Figure 6.3

Cut sequence for 4-entry system

Effect of maximum horizontal stress orientation on cutter development for 4-entry system created in 12 groups of cut for theta $=60$ degree A simple cut sequence for development of 8 entry system with two continuous miner 
Figure 6.22b Cutting sequences for representative 4 entry systems with group of cuts in entry and individual cut in crosscuts

Figure 6.22c Cutting sequences used for the modeling for representative 4 entry systems with 12 group of cuts

Figure 6.22d Cutting sequences for representative 3-entry systems with 13 groups of cut instead of 20 individual cuts

Figure 6.23 Cohesion distribution pattern for cutting sequence having individual cuts and a group of cuts in a solving step

Figure 6.24 Nomenclature and locations of cross sections

Figure 6.28 Irregular pattern of cutter observed at another Illinois mine using cutting sequence shown in Figure 6.15

Figure 6.35 Cohesion distributions for different orientation for weak roof with peak cohesion, 96 psi for a 4-entry system

Figure 6.36 Effect of variation of ' $k$ ' on cutter development for a constant horizontal stress ratio, 'l' of 1.75

Figure 6.37 Effect of variation of 'l' on cutter development for high horizontal stress condition $(k=2)$

Figure 6.38 Effect of variation of ' "' on cutter development for low horizontal stress condition $(k=0.5)$

Figure 6.39 Orientation effect on cutter development for high horizontal stress difference $(k=1.5$ and $I=4)$ 
Figure 6.52 Cutting sequence for different size of pillar

Figure 6.53 Cohesion distributions in immediate roof layer for different pillar size for cut sequence shown in Figure 6.52

Figure 6.54 Shear strain rate in immediate roof layer for different pillar size for cut sequence shown in Figure 6.21b

Figure 7.1 Primary, secondary and tertiary creep in a uni-axial creep test

Figure 7.3 Intact specimen creep at three different stress levels 224

Figure 7.4 Effect of single joint normal to applied stress 225

Figure 7.5 Effect of joint inclination on axial creep strain 225

Figure 7.6 Part plan of the Mine 'A' showing roof falls location 228

$\begin{array}{lll}\text { Figure 7.7a } & \text { Enlarged view of ' } A \text { ' } & 229\end{array}$

$\begin{array}{lll}\text { Figure 7.7b } & \text { Enlarged view of 'B' (east panel) } & 229\end{array}$

Figure $7.8 \quad$ Standup time of the falls observed at the mine 230

Figure 7.9 Variation in the standup time for the roof falls 230

Figure 7.10 Variation in the height of the roof falls 231

Figure 7.11a Roof fall showing highly laminated rocks (stack rocks) 231

Figure 7.11b Roof fall showing irregular fractured rock layers 232

Figure 7.11c Roof falls with highly laminated rock (rock failing both in shear, red color line and tension, blue color line)

Figure 7.11d Roof fall starting right from the edge of the entry (roof rocks better than stack rock)

Figure 7.11e Roof falls at intersection and bolts exposed in the entry 233

Figure 7.11f Minor roof failure up to the competent strata 234

Figure 7.11g Separation started in the immediate roof 234

Figure 7.11 h Already failed roof rock and rock holded by bolts in the entry 235

Figure 7.11i Immediate fractured roof supported by Roof bolts with W-straps 235

Figure 7.11j Stable Immediate roof supported by W-strap, wooden prop with header and wire mesh 236

Figure 7.12 Stand up times for the roof falls observed in SE and SW mains 239

Figure 7.13 Stand up times for the roof falls observed in East panels 239

Figure 7.14 Stand up times for the roof falls with Pillar size 60x60 ft 240

Figure 7.15 Stand up times for the roof falls with Pillar size $60 \times 90 \mathrm{ft} \quad 240$

Figure 7.16 Stand up times for the roof falls with Pillar size $70 \times 70 \mathrm{ft} \quad 241$

Figure 7.17 Stand up times for the roof falls with Pillar size $80 \times 70 \mathrm{ft} \quad 241$

Figure 7.18 Stand up times for the roof falls with Pillar size 80x80 ft 242

Figure 7.19 Average standup time of the roof falls with different pillar size 242

Figure 7.20 Standup time of the roof falls at intersection with turnout 243

Figure 7.21 Standup time of the roof falls at normal intersection without turnout 243

$\begin{array}{lll}\text { Figure 7.22 } & \text { Stress-Volumetric Strain curve for hard rock } & 247\end{array}$

Figure 7.23 Comparison between roof convergence, micro-seismic event frequency, and local 250 
stability conditions

Figure 7.24 Roof displacement history prior to roof falls during panel retreat 250

Figure 7.25 Model rock beds description 252

Figure 7.26 2D elastic model for creep study 253

Figure 7.27 Change in roof displacement with time 254

Figure 7.28 Change in roof displacement with step number 255

Figure 7.29 Change in major principal stress with time 255

Figure 7.30 Change in minor principal stress with time 256

Figure 7.31 Safety factor contours after 3 months (white zones have SF more than 5) 257

Figure 7.32 Safety factor contours after 2 years (white zones have SF more than 5 ) 258

Figure 7.33 Effect of strength reduction on cutter pattern under high stress 260

Figure 7.34 Effect of strength reduction on cutter pattern under low horizontal stress 261

Figure 8.1 Direction of turning into crosscuts to avoid longer diagonal span at intersection; A. Normal cut B. CM Turn (generally practiced) C. Modified CM Turn (arrow marks the entry from which turn out will be made) 270

$\begin{array}{lll}\text { Figure 8.2 } & \text { Layout of pillars to avoid 4-way intersection } & 271\end{array}$

Figure 8.3 Development with smaller pillar (left) and bigger pillar (right) 274

Figure 8.4 Pillar retreat options 1 with bigger pillars during development 275

Figure $8.5 \quad$ Pillar retreat options 2 with bigger pillars during development 276 


\section{LIST OF TABLES}

Table 3.1 Maximum horizontal stress prediction coefficients determined for the individual coal regions

Table $3.2 \quad$ Minimum horizontal stress prediction coefficients determined for the individual coal regions

Table 3.3 Estimation of maximum and minimum horizontal stresses for typical immediate roof rocks at shallow depth in Illinois basin based on Equation 3.4

Table 3.4 Estimation of maximum and minimum horizontal stresses for typical immediate roof rocks at shallow depth in Illinois basin as per modified Equations 3.5 and 3.6

Table $5.1 \quad$ Plastic strain vs major principal stress

Table 5.2

Variation of cohesion and friction with plastic shear strain

Table $5.3 \quad$ Laboratory tested rock properties for the base model

Table $5.4 \quad$ Joint properties used by various researchers

Table 6.1

Variation in uni-axial compressive strength of immediate roof at the mine

Table 6.2 Rock mass cohesion estimated from CMRR

Table 6.3

Summary of past work on in-situ stress orientation 


\section{LIST OF SYMBOLS}

\begin{tabular}{|c|c|}
\hline a & Exponent in the Hoek-Brown rock mass failure criterion \\
\hline G & SI Geological Strength Index \\
\hline$k$ & Ratio of the maximum in-situ horizontal to the vertical stress \\
\hline I & Ratio of the in-situ maximum horizontal to the minimum horizontal stress \\
\hline$q$ & Mohr-Coulomb triaxial rock strength constant \\
\hline$R F$ & Uniaxial compressive strength reduction factor \\
\hline SF & Safety factor \\
\hline$s, m$ & Intact rock constants in the Hoek-Brown rock failure criterion \\
\hline$s_{r m}, m_{r m}$ & Rock mass constants in the Hoek-Brown rock mass failure criterion \\
\hline $\begin{array}{l}\theta \\
\text { direction) }\end{array}$ & in-situ maximum horizontal stress angle (measured from entry width \\
\hline$\sigma_{c}$ & Uniaxial compressive strength of intact rock \\
\hline$\sigma_{c r m}$ & Uniaxial compressive strength of rock mass \\
\hline$\sigma_{\mathrm{hmax}}$ & In-situ maximum horizontal stress \\
\hline$\sigma_{\mathrm{hmin}}$ & In-situ minimum horizontal stress \\
\hline$\sigma_{t}$ & Uniaxial tensile strength of intact rock \\
\hline$\sigma_{t r m}$ & Uniaxial tensile strength of rock mass \\
\hline$\sigma_{v}$ & In-situ vertical stress \\
\hline$\sigma_{1}$ & Maximum principal stress \\
\hline$\sigma_{2}$ & Intermediate principal stress \\
\hline$\sigma_{3}$ & Minimum principal stress \\
\hline$\sigma_{1 i}$ & Maximum induced principal stresses \\
\hline$\sigma_{2 i}$ & Intermediate induced principal stresses \\
\hline$\sigma_{3 i}$ & Minimum induced principal stresses \\
\hline d & Step distance \\
\hline
\end{tabular}




\section{CHAPTER 1}

\section{INTRODUCTION}

\subsection{INTRODUCTION}

Roof falls continue to be one of the greatest hazards in underground coal mines worldwide. Although due to stringent safety measures and extensive support systems, the number of fatalities from roof falls have reduced drastically in recent years. Still, in 2003, more than 1400 major reportable roof collapses were reported in the USA according to the Mine Safety and Health Administration (MSHA) (Mark et al., 2004). The majority of these roofs falls may initiate with the cutter roof problems which further aggravates as roof falls with matter of time (Peng, 2007). Cutter roof failure is one of the most common ground control problems affecting the safety and economy of an underground coal mine operation. Cutter roof problems are generally considered to be most prevalent in Eastern United States coal mines.

Hill (1986) defines a cutter as "a failure process that initially begins as a fracture plane in the roof rock parallel to, and located at, the roof-rib intersection. The fracture propagates at an angle usually steeper than $60^{\circ}$ from the horizontal." Some researchers have expanded the cutter definition to include fractures and roof falls found in all areas of the entry roof. The simple and tradition meaning of cutter refers to the 'fractures that occur at upper corners (i.e. the intersection between the roofline and the pillar ribline)' (Peng, 2007).

Sometimes, especially under weak roof conditions, a cutter forms as a precursor to a major roof fall, if appropriate preventive measures are not taken. Since roof falls still constitute a major portion of coal mine injuries/fatalities and lost 
production time, the fundamental processes involved in cutter falls must be understood to reduce mishaps due to such failures. Further, there is an urgency to begin more research on this important issue as coal deposits under favorable geologic conditions are fast exhausting and more and more coal mines will operate under more hostile conditions in coming decades.

Several attempts were made in the past to understand the processes responsible for cutter development and to devise appropriate mitigating measures. Yet, many cutter failures still happen and their advance prediction remains as elusive as ever. Despite the commendable informative efforts of past researchers, the basic mechanics of cutters, to a large extent, still remain inscrutable, especially under weak roof conditions. In light of the tremendous advances made in computing and numerical modeling over the last decade, more realistic analysis (with less assumptions) of cutters is now possible and thus may be used to probe into some of the unexplained territories of the cutter roof problem.

\subsection{THE NEED}

Even though cutter failures have been recognized for their detrimental effects on underground coal mining for a long time, our success in controlling them is far from satisfactory. Undoubtedly, the lack of a complete understanding of the different mechanisms responsible for the failures is the main reason for our shortcomes. For example, although under some circumstances the cutters were found to display very inconsistent spatial trends at different parts of a working section, the reasons for such behavior are still not known.

One of the reasons for the impasse in predicting cutters lies in the limitations of the numerical modeling technologies. The development and propagation of cutters 
is a progressive phenomenon and continuum models can only approximate this process. The limitation becomes even more pronounced if an improper modeling approach is used. For instance, if a problem warrants three-dimensional modeling, then using two-dimensional models would only reveal limited information. Similarly, if progressive failure behavior, cutting sequence etc., are ignored, then the models may not serve the intended purpose. Although the inappropriateness of some of the assumptions in modeling in past, perhaps the state of the art in numerical modeling at the time did not allow them to go beyond what was done. However, the availability of better numerical codes in conjunction with the recent astonishing developments in the computer processing speeds and memory capacities no longer poses as many restrictions on modeling as they did a decade ago. These computer software and hardware developments, like multiprocessor and the modeling software capabilities to support multiprocessor, allow us to include more detailed geometries and complicated material behavior in numerical models and thus may be exploited to gain more detailed understanding of cutter roof failures.

The main goal of this research is to develop realistic approaches to simulate cutter roof failures using continuum numerical modeling. Further, the work also encompasses a more thorough understanding of the basic processes involved in cutter roof failures. Much emphasis has been given to understanding the irregular cutter patterns which are frequently observed under weak rock conditions. It is hypothesized that the irregular cutter pattern often seen in room and pillar mine may be related with the cutting sequence adopted at a particular mine apart from the effect of in-situ stress magnitude and orientation. Hence in this present research, many of the possible parameters related to cutting sequence like cut length, cutting order, direction of turning into the crosscut from entry and cutting pattern were 
considered for different roof rock strength and insitu stress conditions. Thus, the ultimate goal will be to understand whether the cutter development can be reduced by modifying the cutter pattern or not.

Further, apart from knowing the location of cutter initiation or roof fall severity , it is very essential to know the time interval between the mine openings development and its failure. In the present work further emphasis has been given to the time effect on roof falls with a case study where a fixed cutting sequence is used. Field observations show that some cutters/roof falls develop after a significant amount of time is elapsed since the area has been mined. Hence one goal of this research is to understand and develop a simple methodology to study the time effect.

\subsection{OUTLINE OF THE THESIS}

The complete work carried out in this present research, has been organized in 8 chapters commencing with chapter 1 defining cutters and the scope of present work. Chapter 2 includes a thorough review of the literature related to the world wide work done in past for the problems associated with cutters and roof falls. It includes the current knowledge of the affect of in-situ stresses and their orientation, mainly responsible for the stability of coal mine excavation. It has been discussed by almost every researcher in the past that in-situ stress is one of the most important factors controlling the initiation of a cutter or roof fall problem. Hence chapter 3 elaborates on the variation in magnitude and orientation of in-situ stress fields in different coalfields of the USA. Chapter 4 deals with the development of cutters/roof falls and presents few case studies related to these ground control problems encountered in the underground coal mine. These case studies are very useful for understanding the basic features of the cutter/ roof fall problems. Chapter 5 presents the numerical 
modeling technique and cutter detection criteria used for the simulation of cutter and roof falls. It includes the selection of material model, excavation geometry, and the effect of various rock properties like cohesion, friction and dilation angle on the numerical development of a cutter. It also describes the effect of the presence of discontinuities (bedding planes) on the cutter pattern. Chapter 6 discusses the influence of the cutting sequence and its various parameters responsible for irregular cutter patterns observed in coal mines particularly under very weak roof rock. The cutting sequence parameters like: cut length, order, turning direction of crosscut with respect to the stress field has been studied to observe their influence on cutter development. Further this chapter also discusses the effect of change in the immediate roof rock properties and, the effect of stress concentration and orientation on cutter development in conjunction with multiple excavations and cutting sequences. Chapter 7 deals with the case study of roof falls at a mine and the variation in the standup time with respect to pillar width, entry width, intersection geometry etc. In this chapter further simple numerical models have been performed to understand the time effect. Chapter 8 provides a list of major conclusions of this work and simple ways to minimize the occurrence of cutters or roof falls. Finally, chapter 8 also gives an outline of possible areas for future research work. 


\section{CHAPTER 2}

\section{LITERATURE REVIEW}

\subsection{INTRODUCTION}

After so many years of worldwide research, it has been recognized that the main contributing factors to the success of design and stability of any underground excavation includes; rock mass properties, overburden rock thickness and its stratigraphic sequences, stress environment particularly in-situ stress, excavation geometry, etc. Similarly, underground excavation stability in the underground coal mines also depends upon the same mentioned factors. The most common stability problem for the entries development may be due to cutter roof or roof falls. In the past 4-5 decades, plenty of research work has been performed worldwide to identify the root causes and to mitigate cutter roof problems. The published work encompass a broad range of underground mining activities involving both development and retreating operations. A major portion of the literature on cutter failures comes from the United States starting in 1948 (Roley,1948; Wang et al.,1974; Aggason,79; Agapito et al.,1980; Kripakov,1982; Blevins et al., 1985; Lizak et al.,1985; Hill,1986; Su and Peng,1987; Bauer,1990; Mark et al.,1991,1994,1998,2004; Molinda et al.,1991; Ahola et al., 1991; Mucho and Mark,1994; Peng and Chen, 2000; Dolinar et al., 2000; Gadde and Peng, 2005) with some cases from Australia (Enever and Mckay,1980; Gale and Blackwood, 1987) the United Kingdom (Phillips, 1945; Kent et al., 1999, Meyer et al.,1999), Canada (Jeremic,1981; Barron et al.,1999), South Africa (Frith, 2002; Stacey and Wesseloo,1998) and India (Sheorey,1994; Kushwaha et al., 2003). In most of this literature, the in-situ stress has been addressed as the key player with the geology for the development of the cutters. 
While going through the literature review, it seems that the first well documented literature on roof falls was provided by Rolf W. Roley in 1948 . He then termed that particular type of fall as "pressure-cutting" which is today termed as 'cutter failure' in the USA. Those failure was predominantly observed in many counties such as Vermilion, Christian, Montgomery, Madison, Macoupin and St. Clair counties in the Illinois basin. Roley mentioned that the "pressure cutting" is generally revealed by the presence of an advancing crack in the roof, near the center or against the 'rib' of the place, moving forward with the advancing face. The cutting may extends from a few feet to up to several hundred feet. He believed that the high lateral pressures or stress conditions resulting from movement of weak floor were responsible for such pressure cutting failures.

Philips (1945) has also observed the same type of phenomenon in British mines and his explanation developed a theory for this stress location (Robert's 1945). He explained that due to mining the stress is re-distributed around the entries (Figure 2.1). The resulting lateral pressures in the floor and roof strongly tend to produce heave and creep in the floor and bending in the roof. He hypothesized that due to relief of vertical stress in the roof and horizontal stress in the rib, the condition favors a progressive increase in shear forces concentration which causes roof failure. 


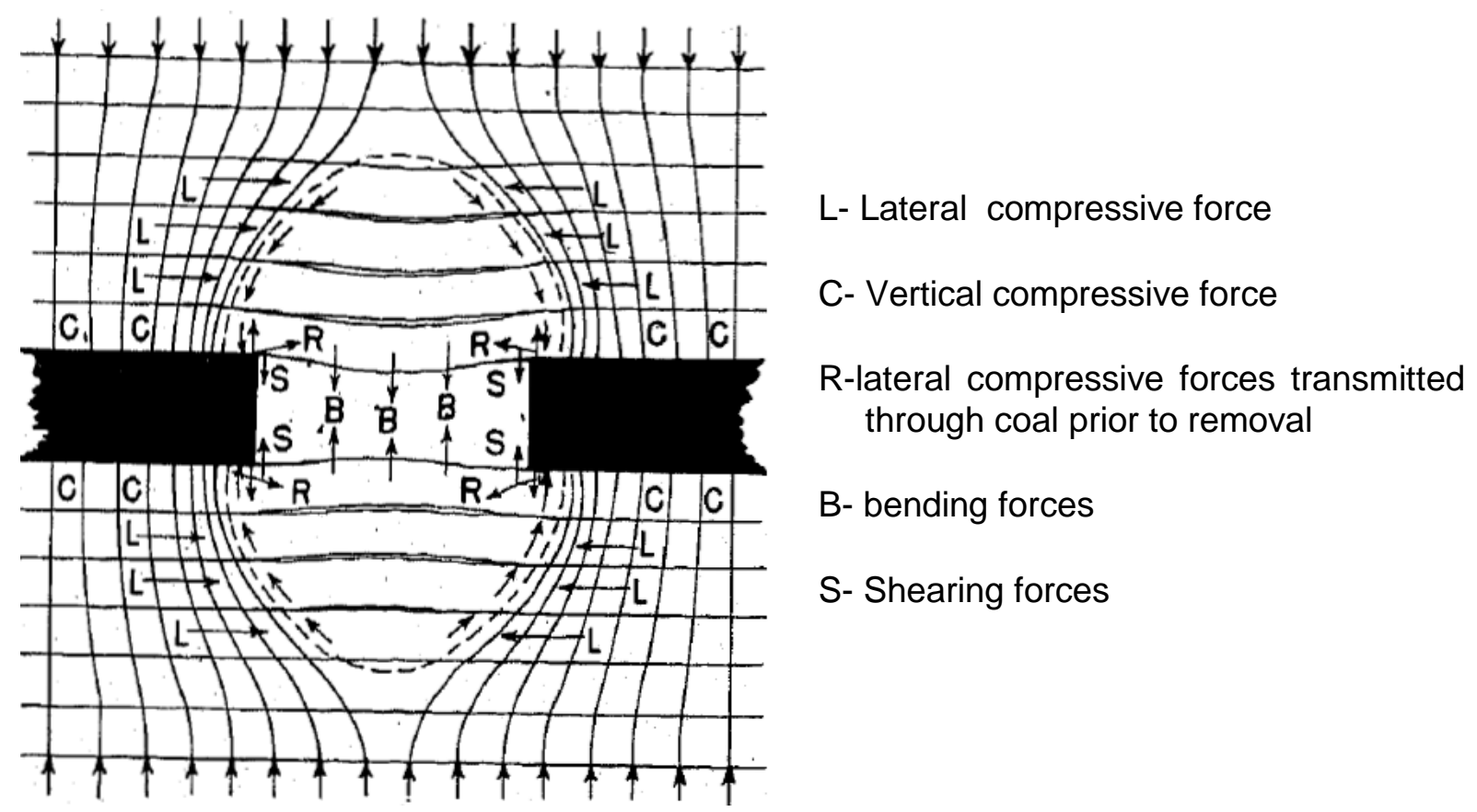

Figure 2.1 Distribution of forces in the vicinity of a narrow headway (after Philips, 1945)

Until 1970, the effect of horizontal stress on entry stability was not known. Major horizontal stress in the near east-west direction was found for the first time to cause roof falls and cutters in the north-south rooms and heavy rib spalling and tensile roof cracks in the east-west rooms of a northern West Virginia coal mine (Dahl and Parson, 1972).

It was in 1974, when Wang and others (Wang et al., 1974) took up detailed two-dimensional finite element modeling, that a systematic effort had begun to delve into the root causes of the cutter problem. Following Wang et al., several other researchers studied cutter roof problem mainly using numerical modeling or field observations or a combination of both.

A simple glance and survey of the past work indicates a consensus among researchers on most of the factors affecting cutter roof failures. In summary, the following factors were identified for their role in cutter failures: 
- magnitude and direction of in situ stresses,

- stress inducing activities like retreating, multiple seam extraction, etc,

- geometry (entry width, pillar size, etc.),

- mechanical properties of roof rocks and coal,

- geologic anomalies.

Among the different factors listed above, the insitu stresses have been identified as the most important influencing factor by almost every critics. The remaining factors were mainly seen on a case by case basis. From the listed factors, they could broadly be categorized as stress related and non-stress related. Accordingly, the reviewed literature will be discussed under these two headings in more details in the following sections.

\subsection{STRESS RELATED FACTORS INFLUENCING CUTTER DEVELOPMENT}

Design of excavations in rock is partly unique because of the presence of stresses in the earth even before any opening is made in it. Such stresses are generally called in situ stresses. The stability of an excavation is primarily determined by a combination of the stress field and the strength of the surrounding rockmass. The total stress field in the rockmass is dependent on in situ stresses, properties of the rockmass and geometry of the excavation. With other factors being equal, it is likely that an excavation driven in a high in situ stress field or oriented in a poor orientation with respect to the stress directions, is likely to experience more stability problems than one made in a lower in situ stress field. The following sections present the findings for the impact of both magnitude and direction on entry stability in underground coal mines. 


\subsubsection{In-situ Stress Magnitude Effect on Cutter Development}

The first systematic numerical modeling effort to identify different factors influencing cutters was performed by Wang et al. in 1974. They found that high horizontal stresses play an important role in cutter roof failures. In the late 1970's, cutter roof and floor heave problems in the Beckley and Sewell seams of southern West Virginia coalfield provided an opportunity for researchers to measure horizontal stresses in the field and verify some of the previously identified factors for their role in cutter failures. The Investigations (Aggason, 1978,1979; Agapito et al., 1980) showed that the horizontal stresses were quite high and exceeded vertical stress. These studies also revealed the biaxial nature of the horizontal stresses. A series of in-situ stress measurements were performed in five coal mines within a 25 mile area with mine depth varying from 350 to $1,148 \mathrm{ft}$. The major horizontal stresses measured, 1,484-6,109 psi, were much higher than the vertical stress of (390 to 1275 psi) at these depths. Their studies demonstrated the influence of high horizontal stresses on cutter roof failures in the cases studied (Aggason,1978-79; Agapito et al.,1980.

Further, it was suggested that cutter roof is caused mainly by the shear stress at the entry corner being larger than the shear strength (Nicholas, 1978; Peng, 1978) as earlier suggested by Philips back in 1945. In 1982 Kripakov conducted further two-dimensional finite element modeling and assessed some previously proposed concepts concerning cutter failures. From his models, he inferred that high shear stresses at the entry corner caused the cutters at the analyzed mine (Kripakov, 1982). These modeling results were in accordance with the postulation of Nicholas (1978). 
But the most extensive early numerical modeling work was perhaps by Su and Peng in 1987. Three West Virginia coal mines experiencing cutter roof problems prompted them to perform comprehensive numerical modeling to understand the development of the cutter roof problems. Using finite element models, they conducted an exhaustive number of parametric studies to identify different factors affecting the cutter roof failures. Their study examined the effect of high vertical stress, excess horizontal stress, relative stiffness between coal and its immediate roof, large topographic relief, bed separation, gas pressure, and geologic anomalies. They found that the high vertical stress was the dominant factor controlling the behavior of the immediate roof at the entry corner, while the magnitude and direction of the in-situ horizontal stress field were the controlling factors for the location and the nature of cutter roof occurrences in the coal mine entries (Su and Peng, 1987).

While the previous researchers were investigating the cutter problem using some form of numerical modeling, a few researchers reported some case studies of cutter failures with details on the trial-and-error approaches used to combat them. For instance, Blevins and Dopp (1985) reported on cutter problems at Inland Steel coal company No.2 mine in the Illinois basin. At this mine, persistent roof falls were noticed in the North-South openings while those oriented East-West experienced minimum problems. The roof failed immediately after the box cut in N-S entry to a height of 2 to $4 \mathrm{ft}$. However, widening the entry to full width didn't cause any more falls. In addition, failures were also occurring outby the face. The height of the outby falls was approximately 6-15 ft. Investigations later revealed that the instability was mainly due to an East-West $\left(\mathrm{N} 86^{\circ} \mathrm{E}\right)$ trending in situ maximum horizontal stress $\left(\sigma_{\text {hmax }}\right)$ and reorienting the openings by $45^{\circ}$ reduced the number of falls considerably (Blevins and Dopp, 1985). 
Similarly, Lizak and Sembourski (1985) reported a case history of Nelms No.2 mine from Ohio. At this mine, nine-entry mains oriented due North, were experiencing roof falls outby the face about a month after development. Both the entries and crosscuts were $18 \mathrm{ft}$ wide with crosscuts developed at $90^{\circ}$ and $60^{\circ}$ angle with respect to the entries. There was no reduction in the roof falls even after the support system was changed. In situ stress measurements at the mine showed that the maximum horizontal stress was oriented $\mathrm{N} 69^{\circ} \mathrm{E}$ with a magnitude of 2 to 3 times the vertical stress. Based on these findings, entry orientation was changed with a modified support system, which provided better roof conditions (Lizak and Sembourski, 1985).

A summary on six case studies involving cutter roof failure in Northern Appalachian was provided by Bauer (1990) with a brief description of possible causes and remedial measures. He concluded that high stress, surface topography and geological anomalies were responsible for the cutters in the mines studied (Bauer, 1990).

Ahola et al. (1991) performed numerical modeling with finite element, boundary element and discrete element methods to study the different techniques used to control the cutter roof. They analyzed the results obtained from all three numerical modeling techniques in terms of their applicability and effectiveness in analyzing cutter roof failure. They used linear-elastic, isotopic material response under plane strain conditions. They tested the rock properties from actual immediate roof rocks and further used Kidybinksi estimates for reduced values of effective stiffness to be incorporated into the modeling. 
Recently, a severe cutter roof problems encountered in a room-and-pillar mine in Illinois under very weak roof conditions has been described (Mark et al., 2004).

Most recently, Dr. Peng has dedicated a chapter on 'Cutters' in his new book (Peng, 2007). He has described the cutters development from its initial to advanced stage. He has presented 4 cases of cutter roof problems from the Eagle seam, Lower Kittanning seam, Herrin \#6 seam and the Powelleton seam. A few of these case studies will be discussed in Chapter 4.

\subsubsection{Horizontal stress orientation effect on cutter roof development}

There is a considerable amount of work on the issues of in-situ maximum horizontal stress angle effects. These include observational approach as well as some form of analysis methods like numerical or analytical.

\subsubsection{Analytical methods}

Jeremic's (1981) work is one of the earliest done on the effect of the orientation of high horizontal stress, $(\theta)$ on the opening stability that employed some kind of semianalytical approach. He used beam theories to explain the effect of maximum horizontal stress direction on cutter locations at some Canadian mines. From this analysis, roadways perpendicular to the lateral stress were reported to experience maximum instability and about $80 \%$ of roof falls were recorded in roadways in this condition. Two types of roof failures were hypothesized to take place when $\theta=90^{\circ}$ as shown in Figure 2.2. For roadways parallel to the maximum lateral tectonic stress, it was assumed that lateral extension would develop along its width. It was concluded that roadways oriented in line with the maximum tectonic stress would 
experience better conditions than those at right angles to it. Based on further analysis Jeremic concluded that openings oriented at $45^{\circ}$ to the lateral stress would have the best stability (Jeremic, 1981). Although this work explained some broad field observations, it was very rudimentary in its approach. The beam theory equations used in the paper did not clearly explain the conditions reported for different orientations. Also, the description of lateral stresses was qualitative and how different magnitudes of these stresses would affect the stability was not clear from the analysis.

Barron and Baydusa (1999), using limit equilibrium theory, estimated the conditions conducive to cutter type failures. They tried to estimate the support force necessary to prevent the development of the cutter mode of failure and maximum unsupported caving height.
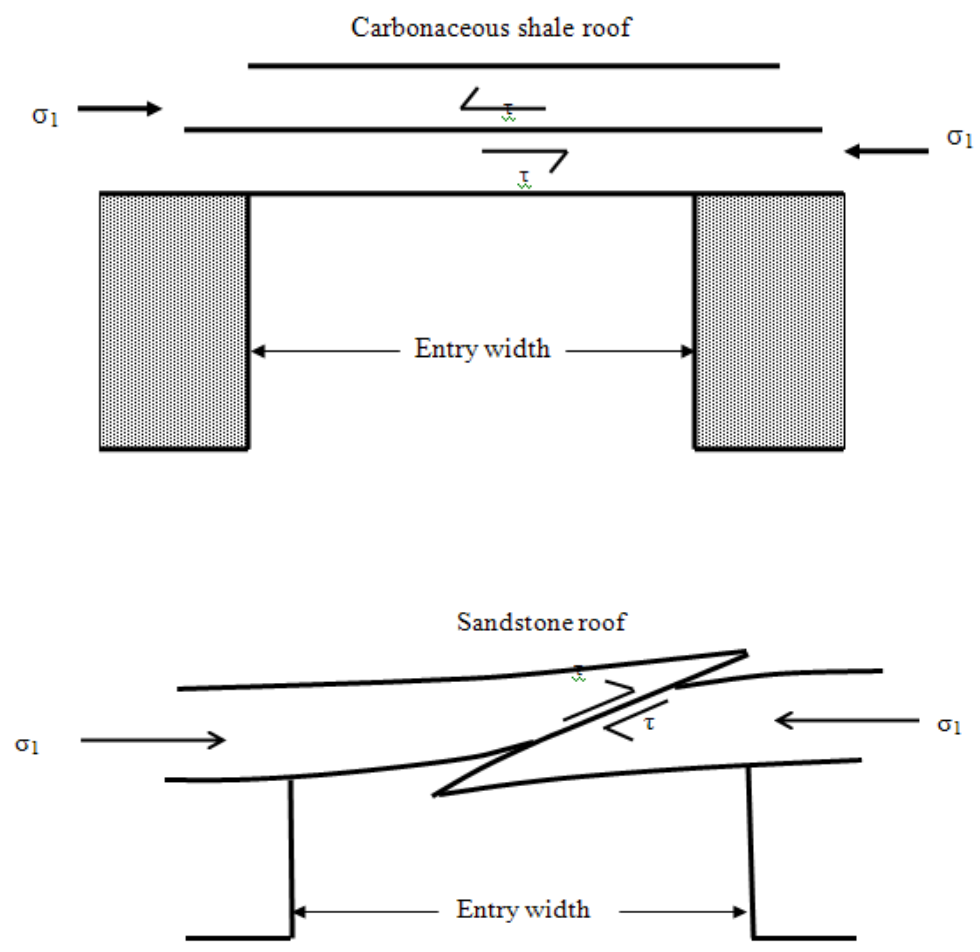

Figure 2.2 Roof failure by slip along bedding planes (top) and low angle shearing (below) for $\theta=90^{\circ}$ (Jeremic, 1981) 


\subsubsection{Numerical method}

Gale and Blackwood (1987) were the first to include the effect of not only the magnitude of horizontal stresses but also their direction on cutter roof failure. Based on single-entry 3-D boundary element models, they concluded that the direction of an excavation with respect to horizontal stresses is critical in determining the stability of the opening. They deduced that entries aligned with the maximum horizontal stress $\left(\sigma_{\text {hmax }}\right)$ would have the least problems while those oriented at right angles would have the worst conditions; at intermediate orientations, biased failure would occur at the entry face (Gale and Blackwood, 1987). The results of their analysis indicate that safety factor decreases with an increase in angle between the entry and $\sigma_{\mathrm{hmax}}\left(\theta_{S R}\right)$ and has the minimum value at $90^{\circ}$. The rate of decrease is higher from $45^{\circ}$ onwards as shown in Figure 2.3. This figure also shows the percentage of roadway drivage affected by shear failure at the face area from two cases in the Southern Coal Field, NSW, Australia. In other terms, they found that during development, the percentage of good roof is the highest when the angle, $\left(\theta_{S R}\right)$ between the roadway direction and the major horizontal stress is less than $38^{\circ}$. The percentage of good roof decreases rapidly when the angle is between $38^{\circ}$ and $55^{\circ}$, and reaches the lowest point when the angle is between $65^{\circ}$ and $90^{\circ}$ (Figure 2.4). It was concluded that the observed conditions at the mine could be explained by the orientation of the entry face with respect to $\sigma_{\text {hmax }}$. 


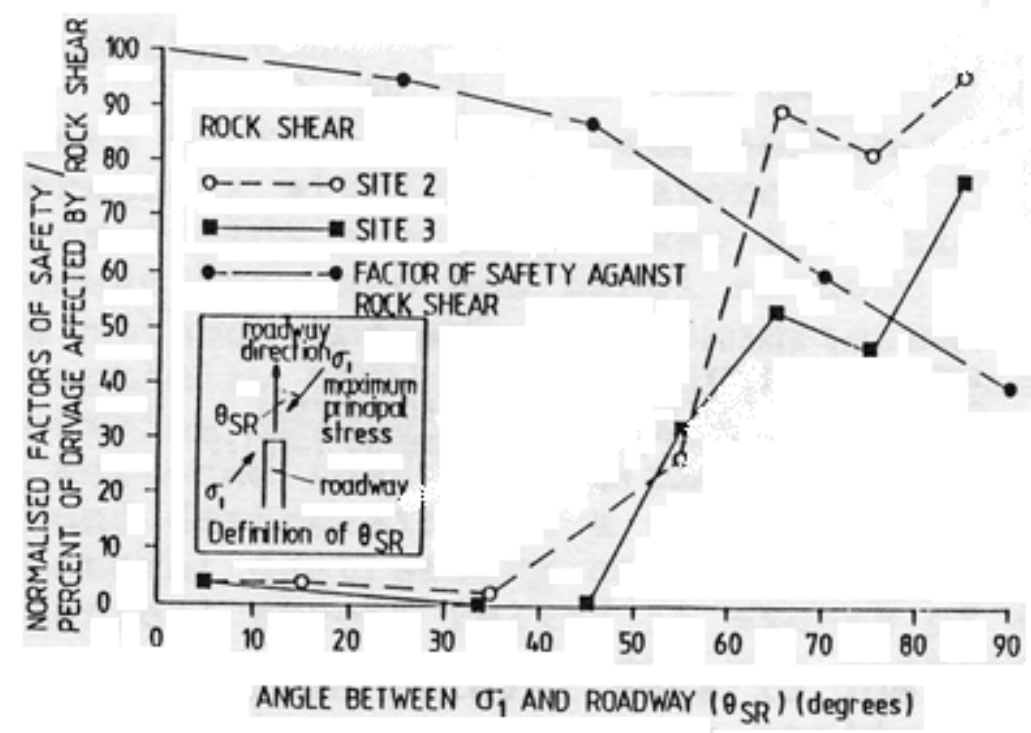

Figure 2.3 Change in safety factor and percent of rock failure at the face with change in $\theta$ (Gale and Blackwood, 1987)

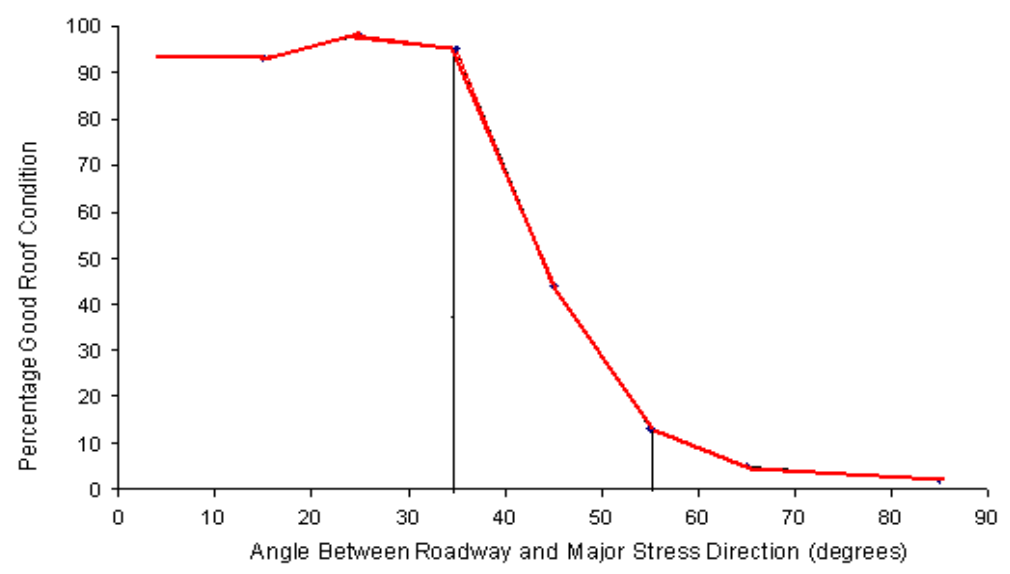

Figure 2.4 Effect of entry orientation, $\theta_{S R}$, with major horizontal stress (Gale and Blackwood, 1987)

Subsequent to Gale and Blackwood's work, there are only a few more papers that address the effect of in situ stresses on cutter failures using some form of numerical modeling. Wang and Stankus (1998) conducted a study to explain roof control problems at a room and pillar mine using the three-dimensional finite element method to simulate the problem. Only five, three-entry longwall development models were studied for stress distributions with different $\left(\sigma_{\mathrm{hmax}}\right)$ orientations between $0^{\circ}$ and $90^{\circ}$ on $22.5^{\circ}$ increments. The ratio of the maximum horizontal stress to the vertical 
stress, and the maximum to the minimum horizontal stresses used in the model were 10.9 and 2.57, respectively. The description of Von Mises stress values obtained in the immediate roof surface at one point each in the entry (P2) and crosscut (P1) was shown in Figure 2.5. Roof fall observations in the mine and the results of these five numerical models were used to construct a panel design layout.

Based on the stress analysis performed in this research, the following conclusion was made:

- the orientation of the entry with respect to the high horizontal stress field is a significant factor affecting the roof stability of an underground excavation .

- in the entry, generally the shear stress increases as $\theta$ increase, at a horizontal stress angle of $\theta=0^{\circ}$, the entry is in the best condition and when $\theta$ is about $70^{\circ}$ the entry is in the worst condition.

- in the crosscut, overall the stress decrease, as $\theta$ increase, when the angle $\theta$ $=90^{\circ}$ the shear stress is minimum, and when the angle, $\theta$ is in the range from $0^{\circ}$ to $45^{\circ}$, the crosscut is in the worst condition .

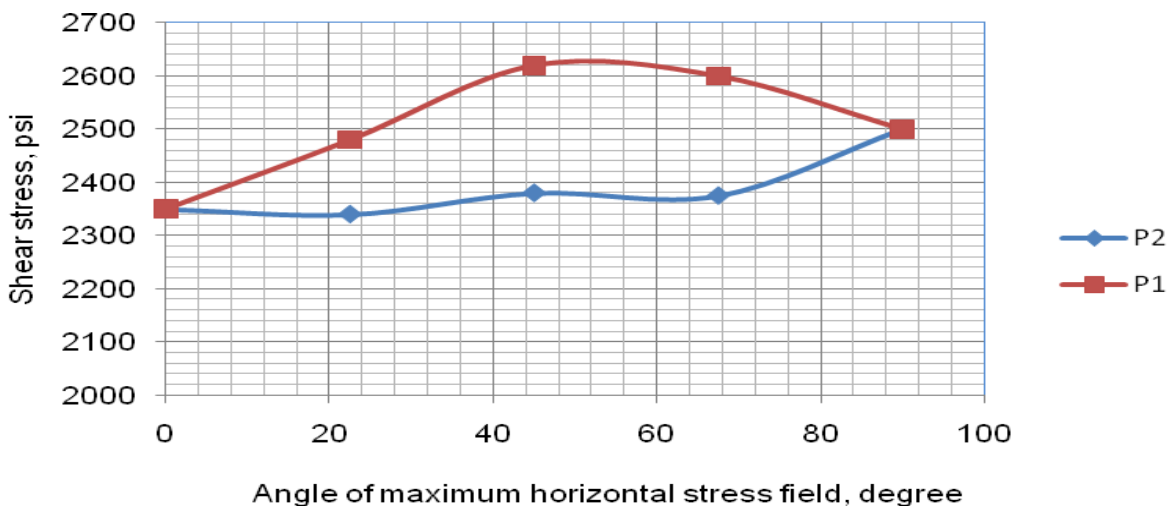

Figure 2.5 Typical shear stress changes vs. $\theta$ at right and left ribs in an entry (Wang and Stankus, 1998) 
The main defects in this research are:

- the numbers of models run and the number of variables considered are too few to make any general conclusions as those made in this paper.

- the ' $k$ ' value assumed is very large (out of range) according to the field measurements conducted by many researcher in many region all over the world.

- this study is limited to a few points in the immediate roof.

Based on a careful analysis of roof fall data at the mine, geologic factors had been eliminated as the cause and in-situ horizontal stresses were identified as the factor responsible for the falls. At the mine, out of 73 roof falls, 33 took place in entries oriented at $52^{\circ}$ and 37 in entries oriented at $68^{\circ}$ with respect to $\sigma_{\text {hmax }}$ (Wang and Stankus, 1998). Based on the Von mises stress distributions obtained from 5 three-entry longwall development models, a design diagram was developed as shown in Figure 2.6.

Meyer et Al. (1999) extended the work of Gale and Blackwood (1987) using the three dimensional finite difference software, $\mathrm{FLAC}^{3 \mathrm{D}}$. The same model data as that of Gale and Blackwood were used in this work. Besides elastic analysis used by Gale and Blackwood, they used elastic-perfectly plastic analysis for performing the modeling. Roadway convergence data obtained from the British coal mines by Kent et al. (1999) was used to verify the modeling results. The British data show that the convergence in openings that make a $90^{\circ}$ angle with $\sigma_{\text {hmax }}$ is higher than in entries aligned with the stress as shown in Figure 2.7. 
Chen (1999) and Peng and Chen (2000) used three dimensional finite element modeling for the evaluation of in situ stress effects on the stability of a typical three-entry longwall gate road system. The model geometry and lithology were kept the same in all models with different in situ stress input. The model results were analyzed at a few selected points (P1, P2, P3 in Figure 2.8) in the immediate roof surface, and Von Mises, major and minor principal stresses were obtained at these points. Analyzing the model stresses, the following conclusions were made (Peng and Chen, 2000):

- For a single entry, the maximum Von Mises stress occurrs at $\theta=90^{\circ}$.

- For each entry in a three entry system, the $\theta$ value at which the maximum Von Mises stress occurs is not the same for different points in different crosssections (Figure 2.9).

- The stress distribution is asymmetrical across the cross-section of the entry for stress angles other than $0^{\circ}$ and $90^{\circ}$.

- In general, the maximum Von Mises stress occurs when the stress angle equals to $60^{\circ}$.

- Limited study in the cross-cuts showed the maximum Von Mises stress occurs at stress angles between $60^{\circ}$ and $75^{\circ}$.

- The properties of the immediate roof only affect the magnitude of induced stress but not the pattern of stress distribution.

- For this specific set of input data analyzed, the sequence of development of entries showed no influence on the stress distributions. However, the sequence of development has some influence on the stresses in the crosscuts. 


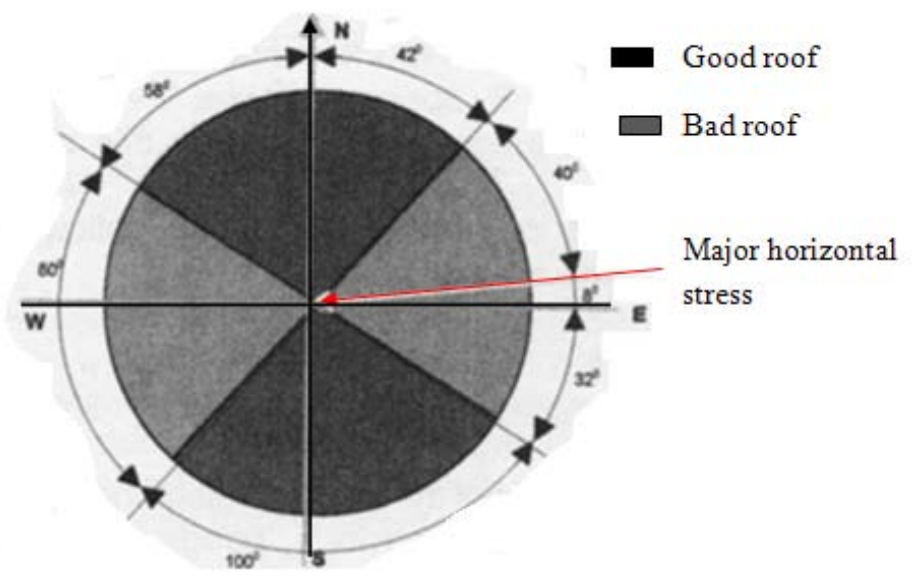

Figure 2.6 Design layouts for a room-and-pillar mine developed by Wang and Stankus (1998)

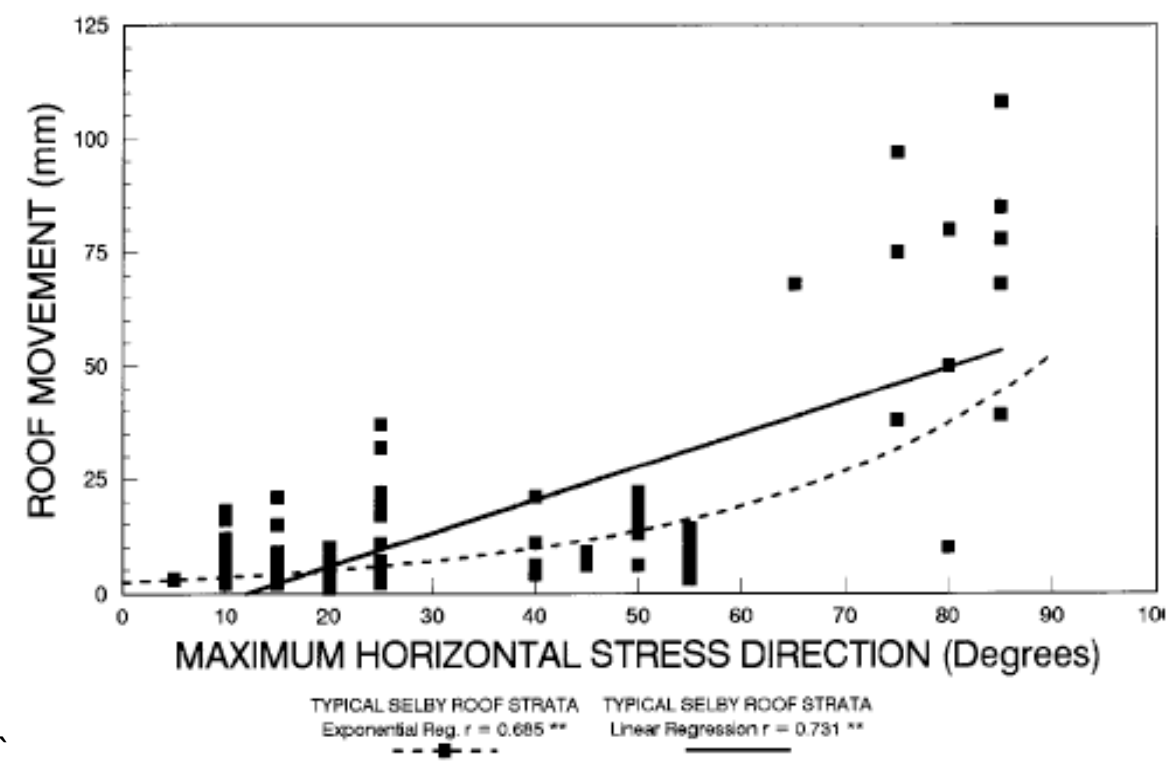

Figure 2.7 Measured roof movement as a function of maximum horizontal stress direction, $\theta$ from British coal mines (after Kent, 1996)

The last of the above conclusions from Chen is interesting as it shows that the cutting sequence has no influence on stress distribution in the immediate roof. Such a conclusion is not surprising as perfectly linear elastic constitutive behavior was used in all of the Chen's models (Chen, 1999). 


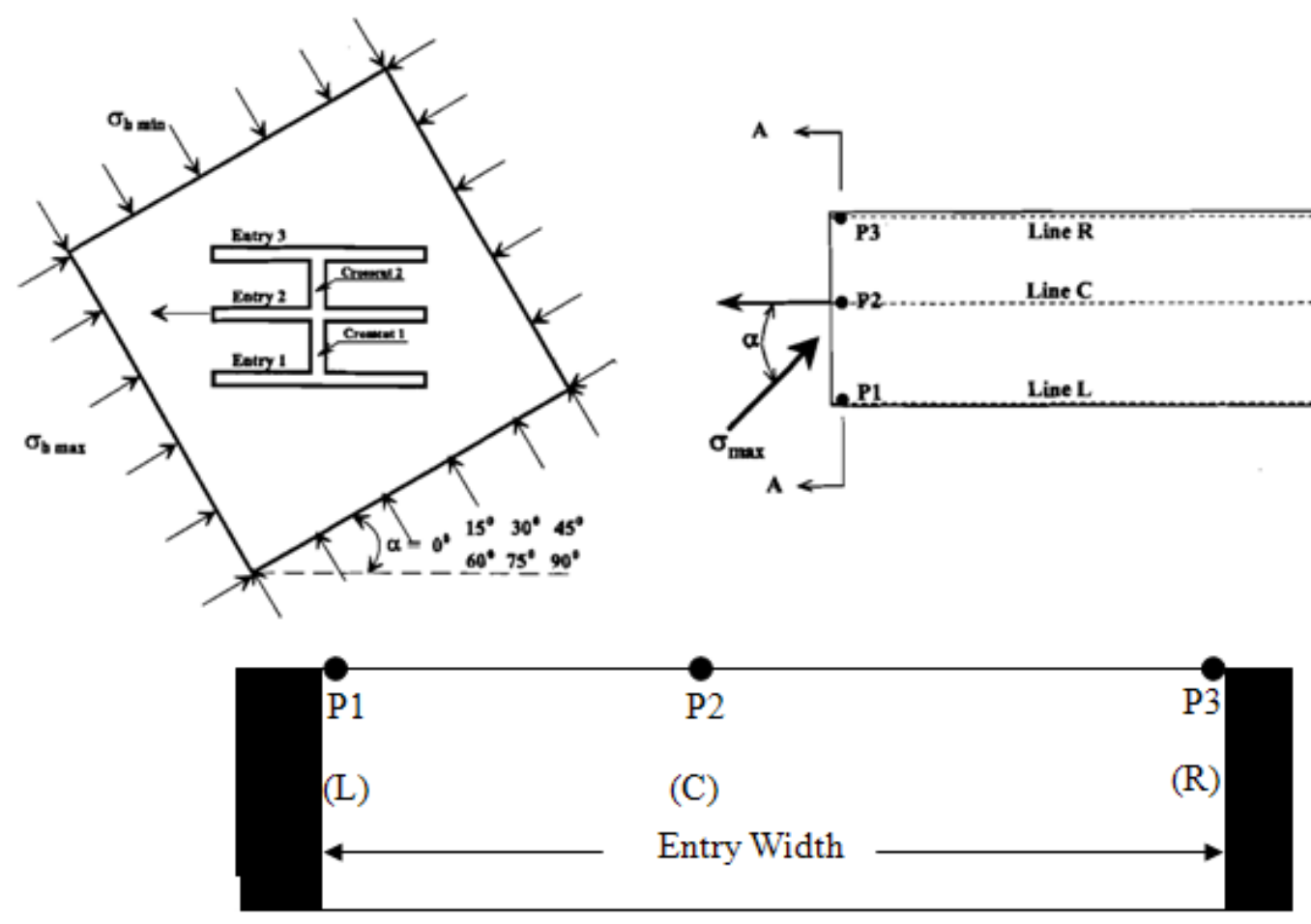

Figure 2.8 Location of measurement points across the entry and the lines along the entry (Peng and Chen, 2000)

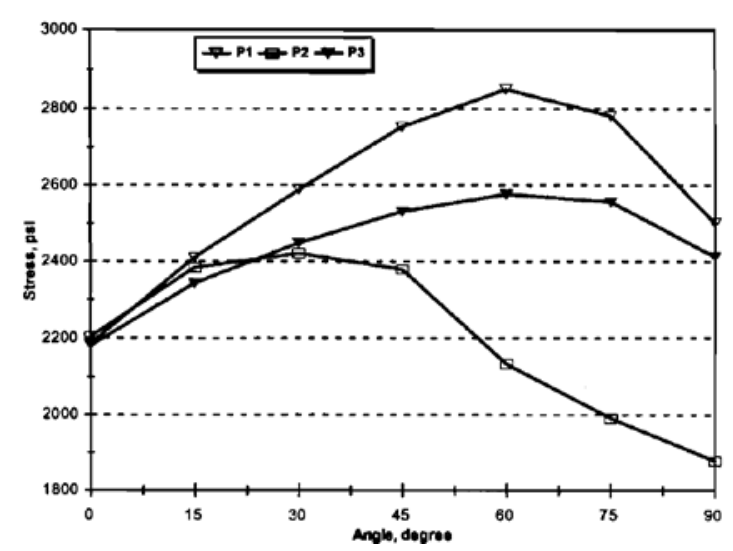

At cross section A-A in Entry 1

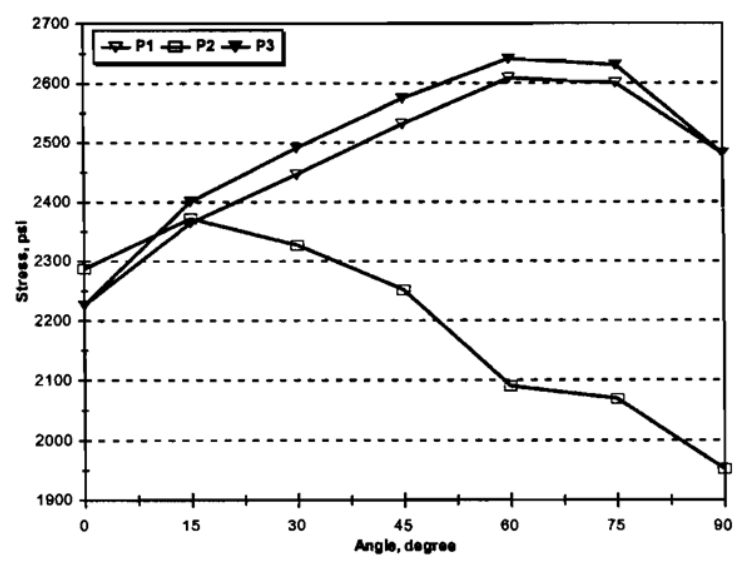

At cross section A-A in Entry 2

Figure 2.9 Von-mises stress (shear stress) change with $\theta$ (Peng and Chen, 2000)

In 1995, Strata Control Technology (SCT) published a conceptual model which describes the effect of orientation of major stress with respect to entry direction (Figure 2.10). The stability problem in the entry has been explained with the concentration of high horizontal stress. Again the best condition is when the entry 
length is parallel to the major horizontal stress direction and worst when is perpendicular. For an oblique orientation the stress concentration develops towards the side of entry which first intersects the major horizontal stress direction and cutter roof develops.

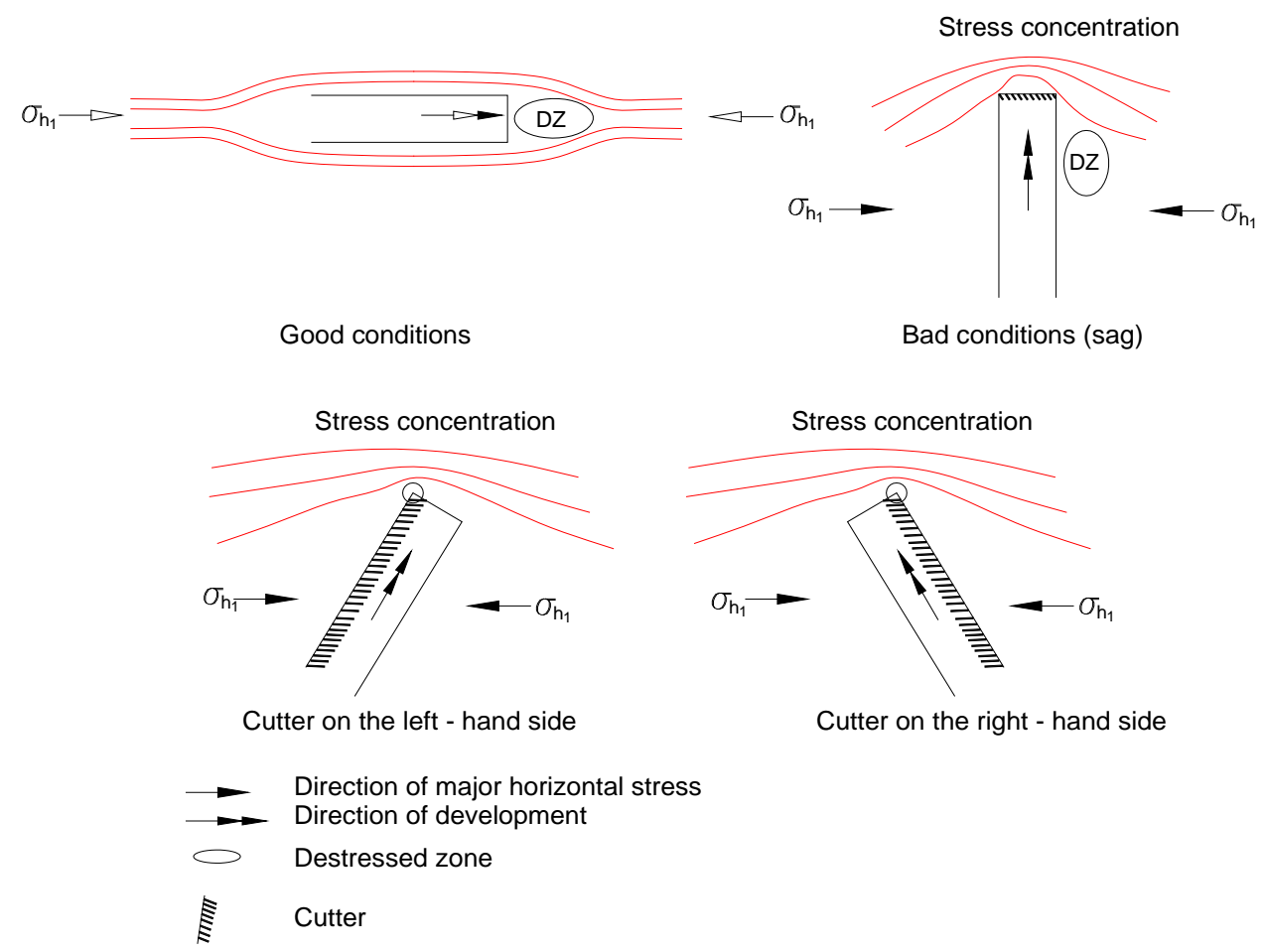

Figure 2.10 Effect of maximum horizontal stress $\left(\sigma_{h 1}\right.$ or $\sigma_{h \max }$ ) on entry stability for different entry orientation (SCT, 1995)

The latest of the numerical modeling work on mine opening stability problems is by Gadde and Peng (2004). Again, three-dimensional finite element modeling was used to investigate the effect of in situ stresses (direction and magnitude) on the stability of coal mine development openings. The study identified possible ground conditions for different orientations of the maximum horizontal stress for both entries/crosscuts and intersections as shown in Figure 2.11. Further, the research 
showed that poor ground conditions and cutter could develop not only in high horizontal stress fields but also in lower ones (Gadde and Peng, 2004).
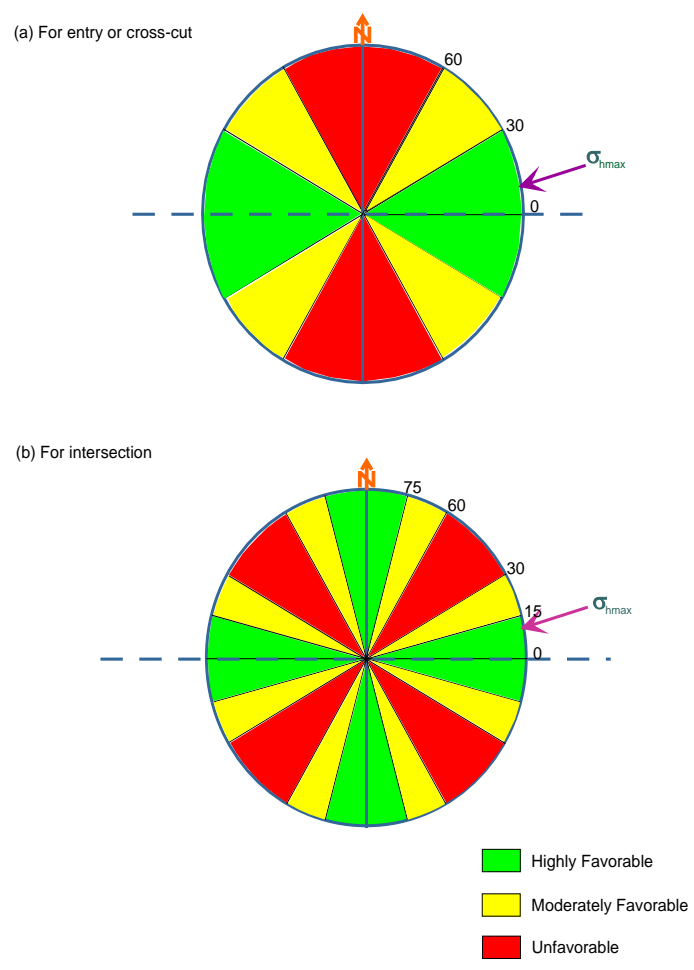

Figure 2.11 Layout orientations with respect to $\sigma_{\mathrm{hmax}}$ and associated ground conditions for (a) entry or crosscut and (b) intersection (Gadde and Peng, 2004)

Although the work done by Gadde is more detailed, the following discrepancies are observed:

- Although it has been recognized that the interface sliding and strata separation significantly influence the roof stability, this work ignores this aspect.

- The finite element program used in this analysis (ABAQUS ) assumed that the material is elastic in its behavior. The output of the model is used in estimating a safety factor based on the Hoek -Brown rock failure criteria. 
- The best and worst orientation based on this study does not cover the effect of immediate roof strength.

Recent work on the simulation of cutter roof is by Gadde and Peng (2005). They used 3D finite difference numerical modeling with material behavior as strain softening to simulate the cutter roof. They performed few models and suggested that with strain softening material model and implementation of cutting sequences, the cutter problem can be simulated up to a satisfactory level.

Recently underground mapping by Thomas and Wagner (2006) showed that when the entry intersects the major horizontal stress at $\theta=30^{\circ}$ to $70^{\circ}$, the majority of roof deformation will concentrate on the side of entry that the major horizontal stress, $\sigma_{H}$ first intersects, which only supports the previous hypothesis by SCT and Kent.

Morsey and Peng (2005) investigated the effect of the horizontal stress angle on the stability of the face and T- junction of longwall panels by using FEM software (ABAQUS). He assumed in-situ stress ratio ' $k$ ' as 3 and ' ' ' as 1.5 and they used 3dimensional failure criterion (Drucker-Prager) to evaluate the stability of the gateroad system. The intermediate principal stress $\left(\sigma_{2}\right)$ is taken into account in addition to the minor and major principal stresses $\left(\sigma_{3}, \sigma_{1}\right)$. Figure 2.12 shows the variation of the predicted yielded zones (black cell) in the immediate roof of the headgate for different entry orientations $\left(\theta=0^{\circ}, 30^{\circ}, 60^{\circ}\right.$ and $\left.90^{\circ}\right)$. To evaluate the effect of the maximum horizontal stress angle on the stability of the development entry, the percentage of yielded zones were estimated at various elevations inside the roof $(y$ $=11,16,20,26,46 \mathrm{ft})$. Based on this concept they also found the same conclusions 
in accordance with earlier researcher as entries were most stable for $\theta=0^{\circ}$ and worst for $\theta=90^{\circ}$.

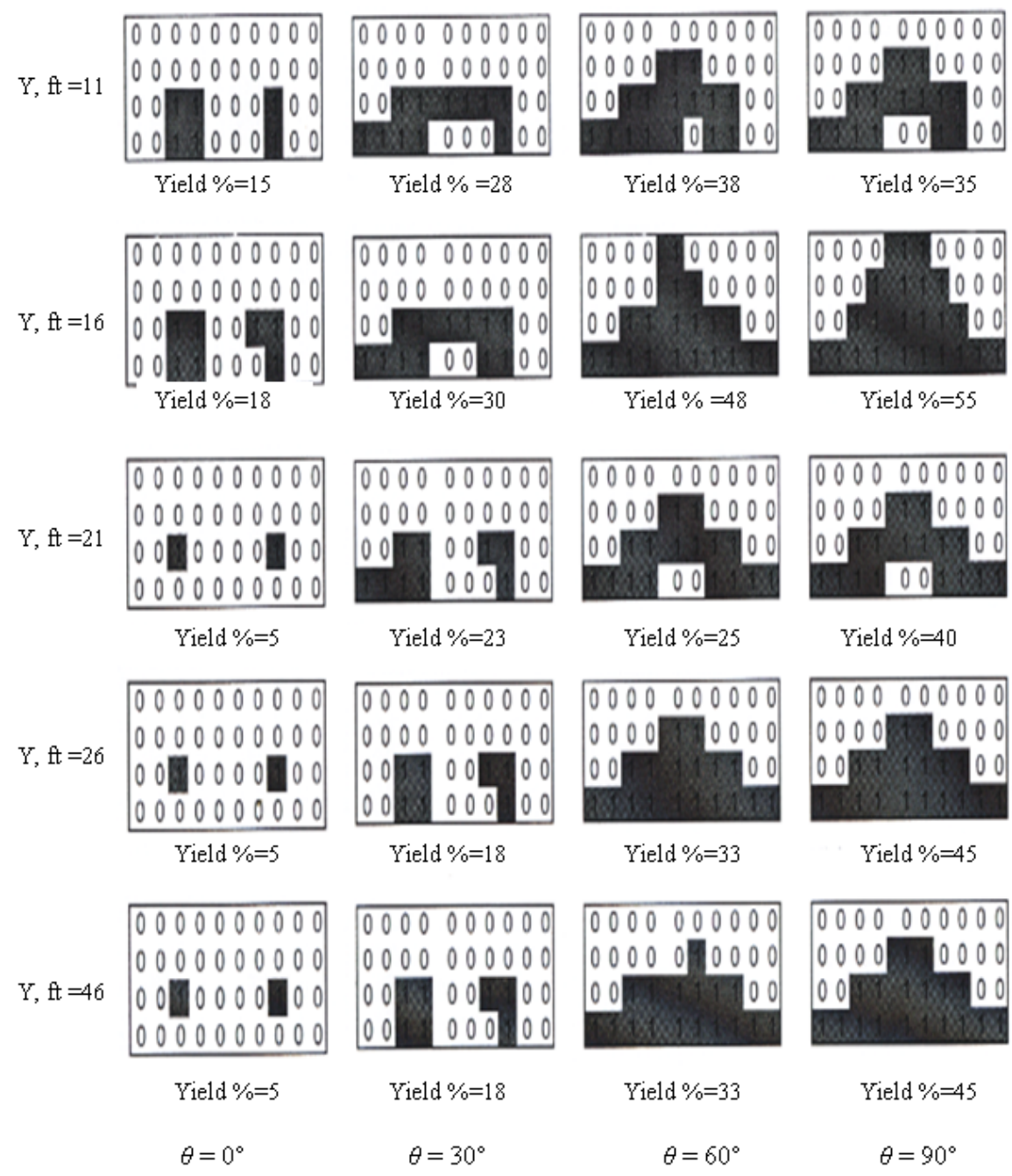

Figure 2.12 Yielded zones in the immediate roof of the development entry in a longwall gateroad (Morsey and Peng, 2005)

At this development stage the results of Morsey and Peng (2005) did not differ from the results obtained by Gale \& Blackwood (1987) and Gadde (2003) who used two dimensional stability criteria but with an elastic model.

Most recently in South Africa guttering were observed at a mine roof mainly towards the center of the entry. Ndlovu and Stacy (2007) performed various constitutive model like isotropic elastic, perfectly plastic, strain softening with and without interfaces to explain the roof guttering. But they concluded that these 
constitutive models are not able to predict the location of guttering as observed in the model. They found that the 'extension strain criterion' gave the best result. He said that the failure of rock could be taking place at strain values that are about three times the failure initiation strain values. The initiation strain value is simply calculated by-

$$
e_{i n i}=\sigma_{t} / E
$$

where: $e_{i n i}$ is extension strain at initiation of fracture, $\sigma_{t}$ is tensile strength of rock, and $E$ is the Young's modulus.

Except for Chen (1999), the rest of the research discussed above address cutters only during mine development. However, in some mines, it was also noticed that retreat workings cause stress concentrations at a few locations and develop cutters at those places in a panel. Based on field observations, Mark (1991), Mark and Mucho (1994) and Mark et al. (1998) suggested that such biased failures were mainly due to horizontal stress abutments developed as a consequence of full extraction mining conducted in a particular direction with respect to horizontal stresses as shown in Figure 2.13. For instance, based on six case histories from Pennsylvania, West Virginia, Kentucky and Alabama, Mark et al. (1998) concluded that the difficult ground conditions in headgates noticed at those mines were due to the unfavorable orientation of the longwall panels with respect to $\sigma_{\text {hmax }}$. Based on these field studies, they concluded that the best orientation for retreat panels was not parallel to the maximum horizontal stress but it was rather at $20^{\circ}$ in the stress shadow of the gob. 


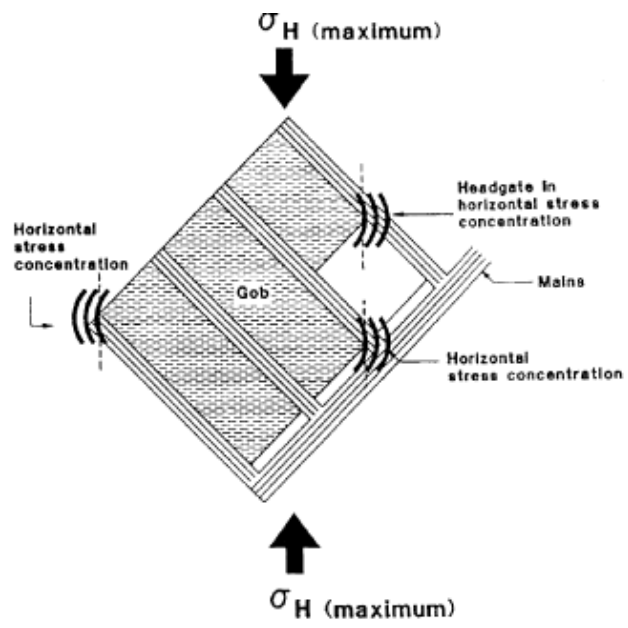

Figure 2.13 Horizontal stress concentrations due to longwall retreat (Mark et al., 1998)

The horizontal stress abutment concept was later verified by numerical modeling studies of Su and Hasenfus (1995), Wang and Peng (1996) and Chen (1999). Further Hasenfus and Su (2006) explained the stress concentration and stress shadow depending upon the retreat direction with respect to maximum horizontal stress in the gateroads for a retreat longwall panel with gob on one side (Figures 2.14 and 2.15).

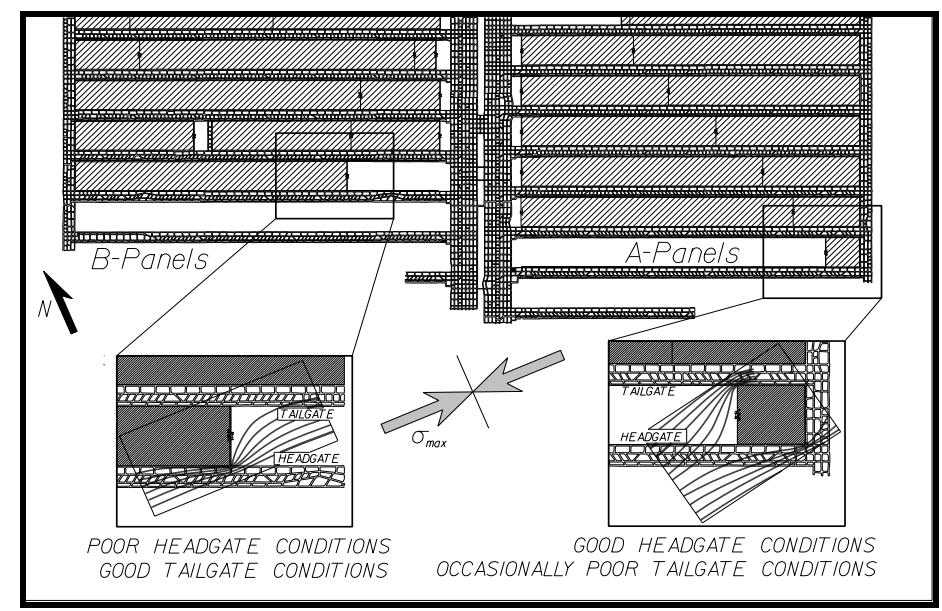

Figure 2.14 Horizontal stress abutment and shadowing for head- and tail-gates (Hasenfus and Su, 2006) 


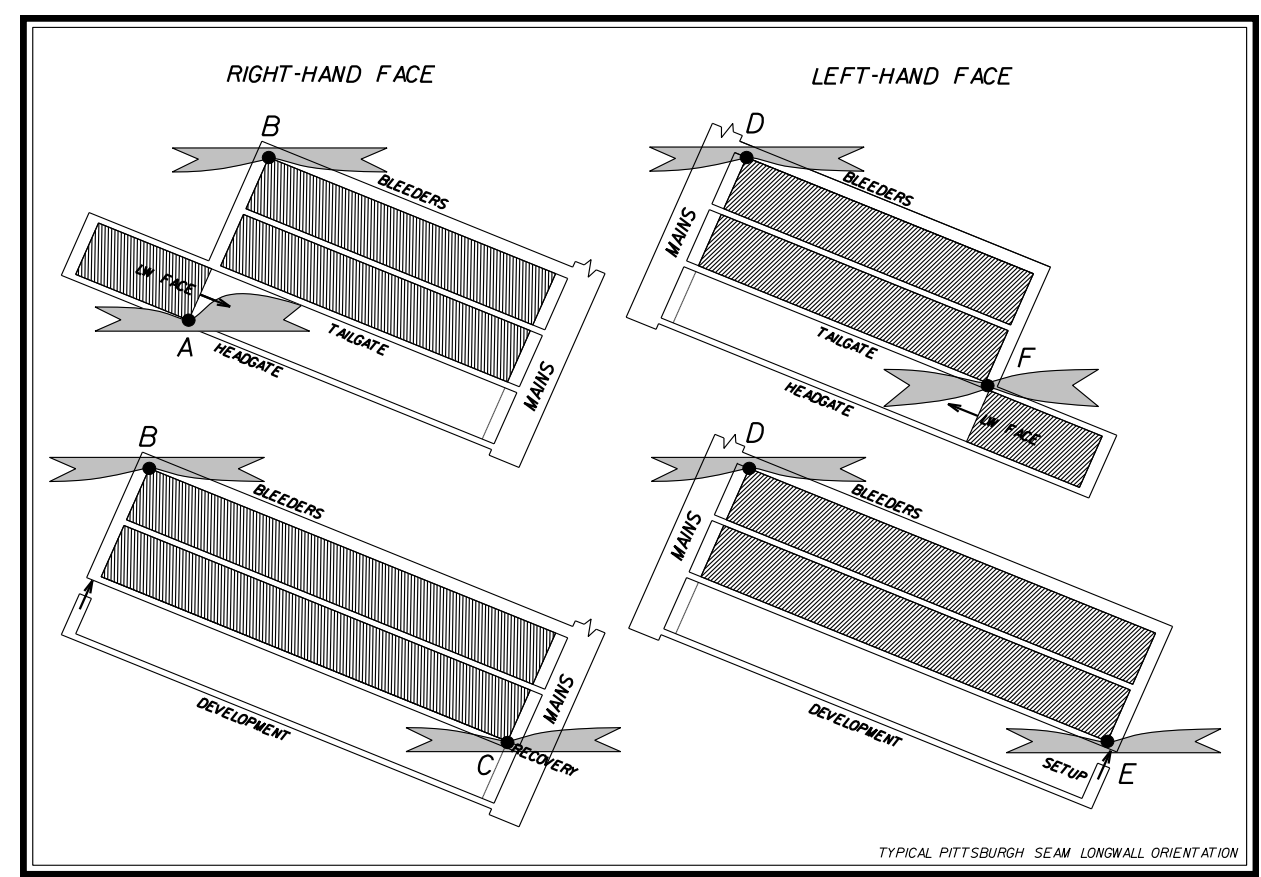

Figure 2.15 Horizontal stress abutment location for longwall panels (Hasenfus and Su, 2006)

\subsubsection{Effect of Topography on Cutter Development}

Localized cutter failures in otherwise trouble free mines were sometimes noticed near stream valleys, stress concentration zones due to near-by mining or sudden change in local geology (Hill, 1986). Numerical modeling studies show that stream valleys can concentrate higher stresses in openings driven directly under them and thus could trigger cutter type failures (Wang et al., 1974). Su and Peng's (1987) numerical models show that large topographic relief in combination with high horizontal stresses can cause asymmetric failures in openings. Some case studies from U.S. coal mines that had roof control problems due to high horizontal stresses near stream valleys were given by Molinda et al. (1991). Australian experience with stream valleys shows that both the magnitude and direction of horizontal stresses in such areas could be different (Enever et al., 1980). 


\subsection{NON-STRESS RELATED FACTORS}

Cutter failures are generally considered to be stress driven as can be seen from the deluge of publications discussed above. However, some researchers have also considered the influence of other parameters, e.g., mechanical properties of rocks, on cutter type instability. For example, Wang et al. (1974)) using 2-D finite element modeling studied the influence of changes in the elastic properties of rocks surrounding a single coal entry. The model results showed that the relative stiffness of different roof rocks or the relative stiffness of coal seam with respect to the roof made a difference to stress concentrations and hence the potential for cutter failure. Su and Peng's (1987) research also confirms the importance of elastic properties of rocks to cutter failures. From the modeling results they found that coal pillars with higher stiffness tend to increase the likelihood of cutter roof failures at the entry corner while stiffer immediate roof under high horizontal stress increases the possibility of cutter roof. Su and Peng also found that pillar and entry size could make a difference to the potential for cutter failures. They also found that the large topographic relief on the surface significantly influence on the occurrence of cutter roof in coal mine entries. With surface topography sloping uniformly, cutter roof tends to occur at the upper right corner of a coal mine entry on the lower overburden side and floor cracks tend to occur at the lower left corner of the entry on the higher overburden side.

Based on observations in a West Virginia mine, Kripakov (1982) found that hydraulic pressure, gas pressure and variations in temperature and humidity may also contribute to cutter roof failure. Some researchers also correlated cutter failures with the presence of some kind of geological anomaly. Stress concentrations due to 
geological anomalies could trigger cutters or worsen the situation if work in unison with high in situ stresses (Hill, 1986). Bedding planes, coal cleats, clastic dykes or clay veins, paleo channels and rolls can all contribute to cutter roof instabilities (Hill, 1986). It is therefore suggested that a detailed geological mapping must be an integral part of ground control studies in mines facing cutter problems.

\subsection{CUTTER CONTROL MEASURES}

An important aspect of the cutter roof problem is: control. Again, a large number of techniques are suggested in the literature - some of them being general and others site-specific. To deal with cutters, the first option often tried is to modify the artificial support system, which may include a change in support type or the length and type of bolts, using angle bolting, truss bolting, heavy cribbing, etc (Hill, 1986).

If changing the supports alone does not produce the desired effect, then modifications are attempted in the mine design with or without, altering the support system any further. From the discussion in sections 2.1 and 2.2, it is apparent that a designer faced with cutter roof problem generally doesn't have any control on any of the factors listed there except for the geometry. Therefore, it is the geometry that is often modified (e.g. entry orientation) to deal with cutters along with a proper design of artificial supports. The suggested remedial measures that require some change in mine design include: altering the orientation of openings, employing sacrificial entries, yield pillars, advance and relief techniques, pillar softening, angled crosscuts, staggered development, etc. 
The sacrificial arch entry (Figure 2.16) has been used to relieve the excess high horizontal stress's effect on its adjacent longwall entries (Aggson and Mouyard, 1988). The stress relieved zone extended up to $80 \mathrm{ft}$ from the arched entry.
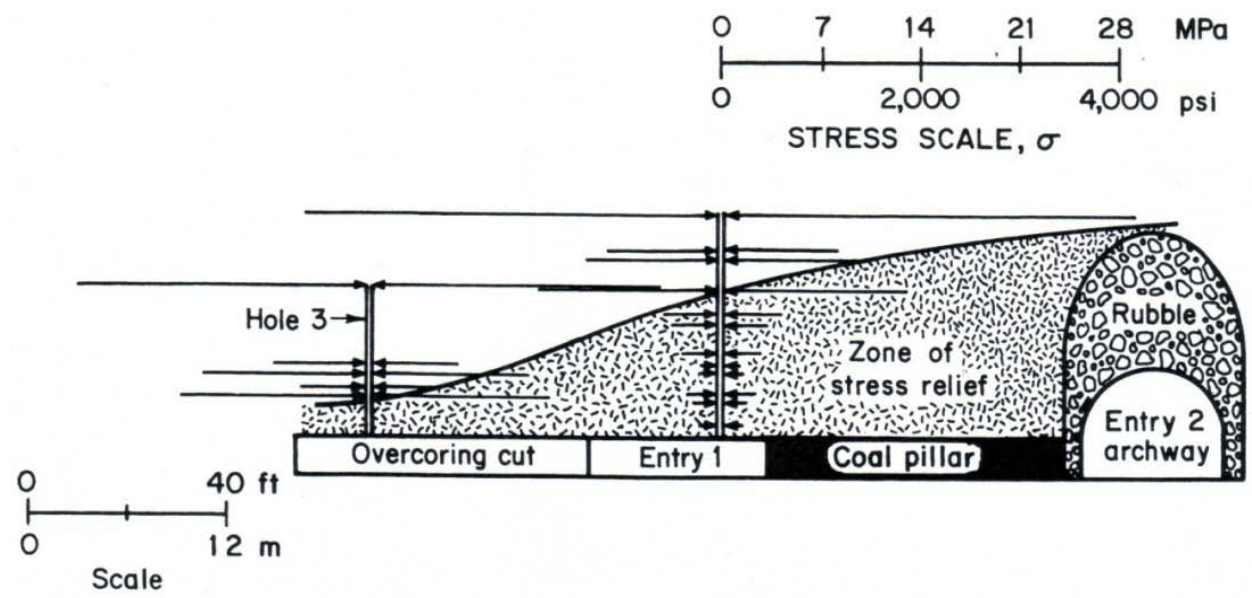

Figure 2.16 Stress relief created by an arched entry (Aggson and Mouyard, 1988).

It is well known now that if the entry is orientated in a direction parallel to the maximum horizontal stress direction, it will be most stable. But this creates a stability problem for the crosscuts. To avoid cutters roof or roof fall in the cross cut by changing the crosscut orientation (Figure 2.17) a considerable amount of cutter roof control can be achieved (Hasenfus and Su, 2006).

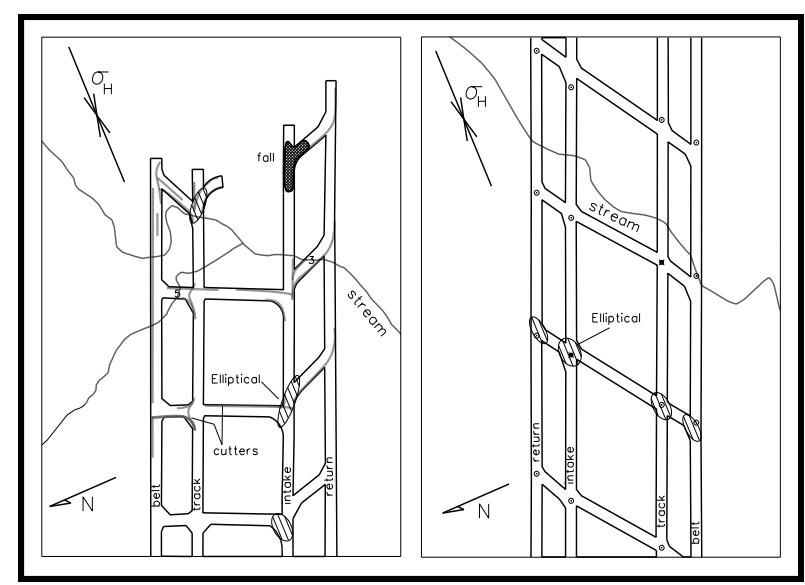

Figure 2.17 Angled crosscut orientation of two, 4-entry gateroad developments (Hasenfus and Su, 2006) 
It often appears that the final support system and mine design used at a mine are chosen mainly based on a trial-and-error approach with different supports installed on different patterns at the mine. The support system and mine design that ensured workable conditions are then chosen for subsequent mining.

\subsection{SUMMARY AND SCOPE OF PRESENT RESEARCH}

From the discussions in this chapter, it is clear that there is a general concurrence among researchers on several issues concerning cutters. The literature review also shows that the pace of cutter research has dramatically slowed down after the fruitful 70's and 80's. This deceleration has left some enigmatic parts of the cutter problem still unresolved and unexplained. For instance, the erratic spatial distribution of cutters in a working section has long been noticed, but the reasons for such behavior have not been explored enough. Or the progressive propagation of cutters in a multiple entry development setup as noticed in the field was not adequately modeled.

While each of the above described work was unique in its own way and has its own merits, some common behavior could be observed among them. The following is a summary of such characteristics:

a) Prior to 1985, almost all of the works were two-dimensional and hence have limited applicability for actual designs;

b) All past modeling was done using elastic material behavior except Meyer et al., 1999, who used elastic perfectly plastic constitutive behavior and Morsey and Peng, 2005, who used a 3-dimension Drucker Prager criteria. Unfortunately, the plastic modeling done was not comprehensive enough to gain a more detailed understanding of cutter failures, particularly in the case of weak immediate roof. 
c) The best and worst orientation based on past study does not cover the effect of immediate roof strength. Most of the conclusions are based on immediate roof as moderate to strong. This may not be true for weak to very weak rock.

d) All previous three-dimensional modeling ignored the cutting sequence used in the development of the geometry in the modeling except some initial studies conducted by Gadde and Peng (2005).

e) The modeling was done mainly to explain site specific conditions noticed at some mines, or when parametric studies were conducted, the range of values used for the variables was not large enough to make the research general.

The first of the above five conclusions was mainly due to the limitations of the available computing resources than anything else. But then, such is the case with any new development and the 2D modeling might have served the purpose at that time. However, the second and the third have more serious implications towards our understanding of the cutter problem and will be discussed in some details in the following chapters. It will be shown in the following discussions that cutter failures are progressive in nature and are also controlled by the interactions of multiple openings and the cutting sequence used in the development. It is the main purpose of the proposed research to address the cutting sequences in the numerical modeling for better simulation of cutter development in underground coal mines. Further, the influence of cutting sequences in conjunction with varying stress conditions and immediate roof properties will be investigated for understanding the cutter development. 


\section{CHAPTER 3}

\section{IN-SITU STRESS AND STRESS MEASUREMENT IN THE USA}

\subsection{INTRODUCTION}

Rock at depth is influenced to vertical stress due to the cover weight and horizontal stresses resulting from the tectonic movement. When an opening in underground is excavated in this rock, the stress field is disturbed surrounding the opening and a new set of stresses are induced. The magnitudes and orientation of these insitu and induced stresses around underground excavation is of prime concern from the design and stability point of view. If the magnitude of stresses exceed the strength of the rock, will cause instability problem in the vicinity of the underground openings. In this chapter the most of the information related to insitu stress has been collected from chapter 10 of "Practical Rock Engineering" edited by Hoek (2007).

The stress state at any point in a continuum can be expressed by the six components of the stress tensor or by the three principal stresses and their directions. Often, the in-situ stress state at a point in the earth's crust is expressed in its principal components with assumptions made about their directions. Generally, one of the principal stresses is assumed to be in the vertical direction and its approximate value can be estimated by the weight of the overburden at that point (Amadei, 1997). Actual stress measurements support this presumption about the magnitude of pre-mining vertical stress (Hoek, 1980 ; Dolinar, 1982). The remaining two horizontal stresses are assumed to be in the horizontal plane but their magnitudes and directions are highly variable and no methods are available to estimate their values accurately without field measurements or observation. 
Many factors contribute to the current in-situ stress state at a point in the earth's crust, e.g., plate tectonics, the earth's internal structure (Aggson, 1979), etc. The interaction of these parameters is so complex that an exact prediction of in-situ stresses in rock and their spatial variation is very difficult and for all practical purpose impossible. In-situ stresses not only vary in space but also with time due to tectonic events, erosion, glaciations, etc. Several authors have proposed expressions for the variation of the magnitude of the vertical and horizontal in-situ stresses with depth at specific site or for different regions in the world (Brown and Hoek, 1978).

\subsection{VERTICAL STRESS}

Typically, the vertical stress estimation is based on the weight of the overburden. At any given location below the surface, the vertical stress is a primarily a function of depth and the density of the overlying strata.

The vertical stress is:

$$
\sigma_{V}=\gamma Z
$$

where, $\quad \sigma_{v}$ is the vertical stress,

$\gamma$ is the unit weight of the overlying rock,

$z \quad$ is the depth below the surface

In general, the overburden rock stratum consists of rock layers of different density. But an average value for the rock unit weight of $0.027 \mathrm{MN} / \mathrm{m}^{3}$ is often assumed, which gives an average vertical stress gradient of $0.027 \mathrm{MPa} / \mathrm{m}$ (Brown and Hoek, 1978). The measurements of vertical stress at various mining and civil engineering locales worldwide supports this relationship, although, as shown in Figure 3.1, there is a significant amount of scatter in the measurements. 


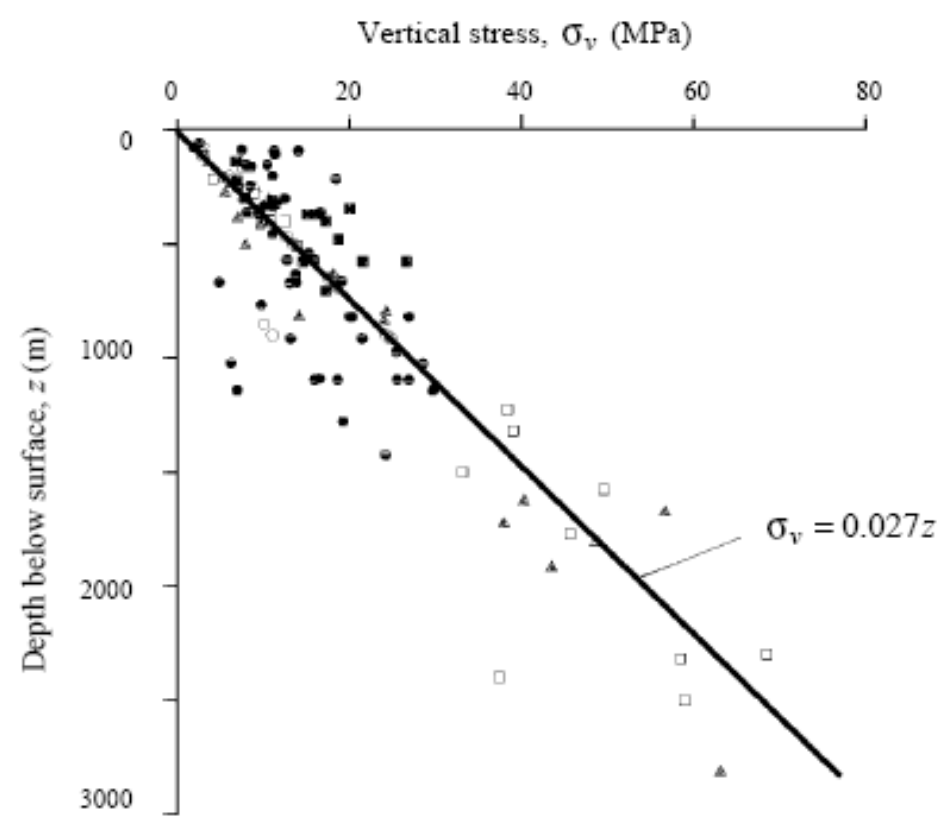

Figure 3.1 Vertical stress measurements from mining and civil engineering projects around the world (after Brown and Hoek, 1978)

\subsection{WORLDWIDE HORIZONTAL STRESS ESTIMATION}

The horizontal stresses acting at any point of interest below the surface is difficult to estimate in comparison to the vertical stresses. Normally, the ratio of the average horizontal stress to the vertical stress is denoted by the letter ' $k$ ' (such that:

$$
\sigma_{h}=k \sigma_{v}
$$

Terzaghi and Richart (1952) suggested that, for a gravitationally loaded rock mass in which no lateral strain was allowed during the formation of the overlying strata, the value of ' $k$ ' is independent of depth and is given by $k=v /(1-v)$, where $v$ is the Poisson's ratio of the rock mass. This relationship was frequently used in the early days of rock mechanics but, now a days this is not correct way of estimation of 
horizontal stress and not acceptable for use in underground excavation design (Mark and Gadde, 2008).

Measurements of horizontal stresses at different sites around the world show that the ratio ' $k$ ' tends to be high at shallow depth and that it decreases with increase in depth. This is due to local geological features or active tectonic zones. This is clear in Figure 3.2.

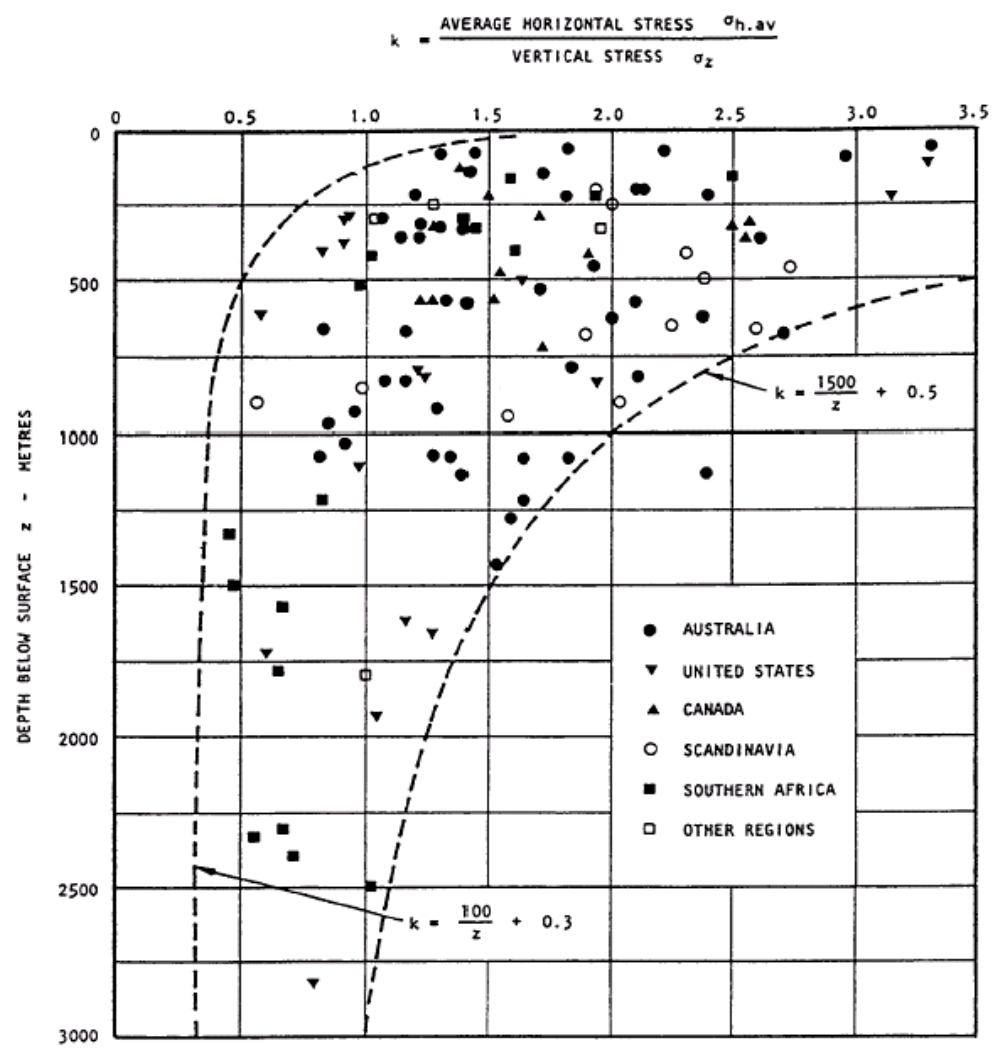

Figure 3.2 Variation of average horizontal to vertical stress ratio with depth (Brown and Hoek, 1978)

Sheorey (1994) developed an elasto-static thermal stress model of the earth. This model considers curvature of the crust and variation of the elastic constants, density and thermal expansion coefficients through the crust and mantle. He 
provided a simplified equation which can be used for estimating the horizontal to vertical stress ratio $k$. This equation is:

$$
k=0.25+7 E_{h}\left(0.001+\frac{1}{z}\right)
$$

Where, $z$ is the depth below surface in (meter) and $E_{h}$ is the average deformation modulus of the upper part of the earth's crust measured in a horizontal direction in (GPa). This direction of measurement may affect the estimation of horizontal stress mainly in layered sedimentary rocks, in which the deformation modulus may be different in different directions. A plot for Equation 3.3 is shown in Figure 3.3 for a range of deformation moduli from 10 to $100 \mathrm{GPa}$. The curves relating ' $k$ ' with depth below the surface looks similar to that published by Brown and Hoek (1978) and Herget (1988) for measured in situ stresses. Therefore Equation 3.3 may be considered to provide a satisfactory basis for estimating of ' $k$ '.

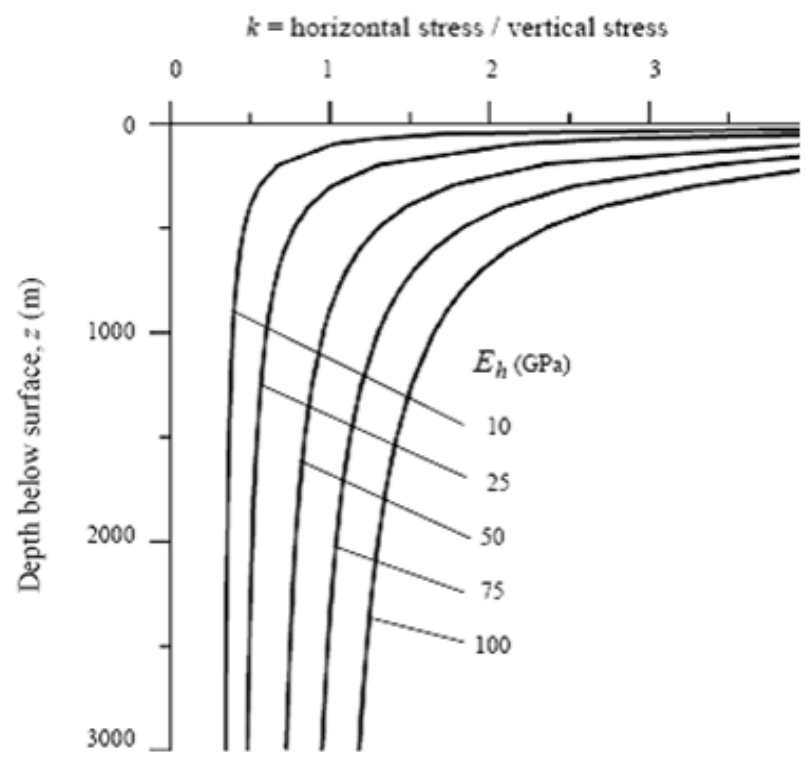

Figure 3.3 Ratio of horizontal to vertical stress for different deformation moduli with Sheorey's equation (after Sheorey, 1994) 
Measurements conducted in South Africa confirmed that the horizontal stresses at shallow depths are usually greater than the vertical stress resulting from the overburden as indicated in Figure 3.4 (Stacey and Wesseloo, 1998). This conclusion is coincident with the results obtained by the Brown and Hoek (1978) and the results obtained from the elasto-plastic model of Sheorey ( 1994). This increase in horizontal stresses is mainly due to the tectonic stresses and geological feature such as faulting, folding, etc.

Horizontal stress direction (Figure 3.5) is based on the compilation of a global database of contemporary tectonic stress data (Reinker etal, 2005). The data included in the World Stress Map are derived mainly from geological observations on earthquake focal mechanisms, volcanic alignments and fault slip interpretations. Less than $5 \%$ of the data is based upon hydraulic fracturing or overcoring measurements of the type commonly used in mining and civil engineering projects. The recent world stress map is shown in Figure 3.5. The tectonic regime of the Focal Mechanism system (FMS) reflects the plate boundary kinematics, i.e. thrust faulting (TF, TS) near subduction zones, strike-slip faulting (SS, NS, TS) near oceanic and continental transforms, and normal faulting (NF, NS) near oceanic spreading ridges.

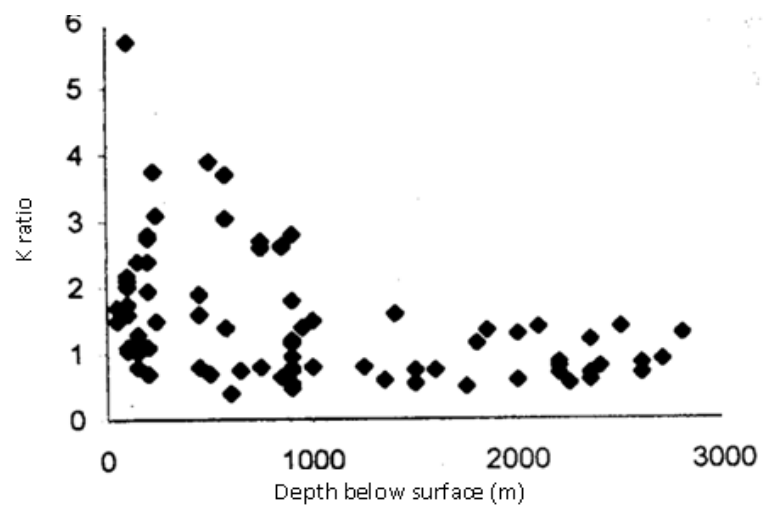

Figure 3.4 Variation of the $k$-ratio with depth according to information in Stacey and Wesseloo (1998) 


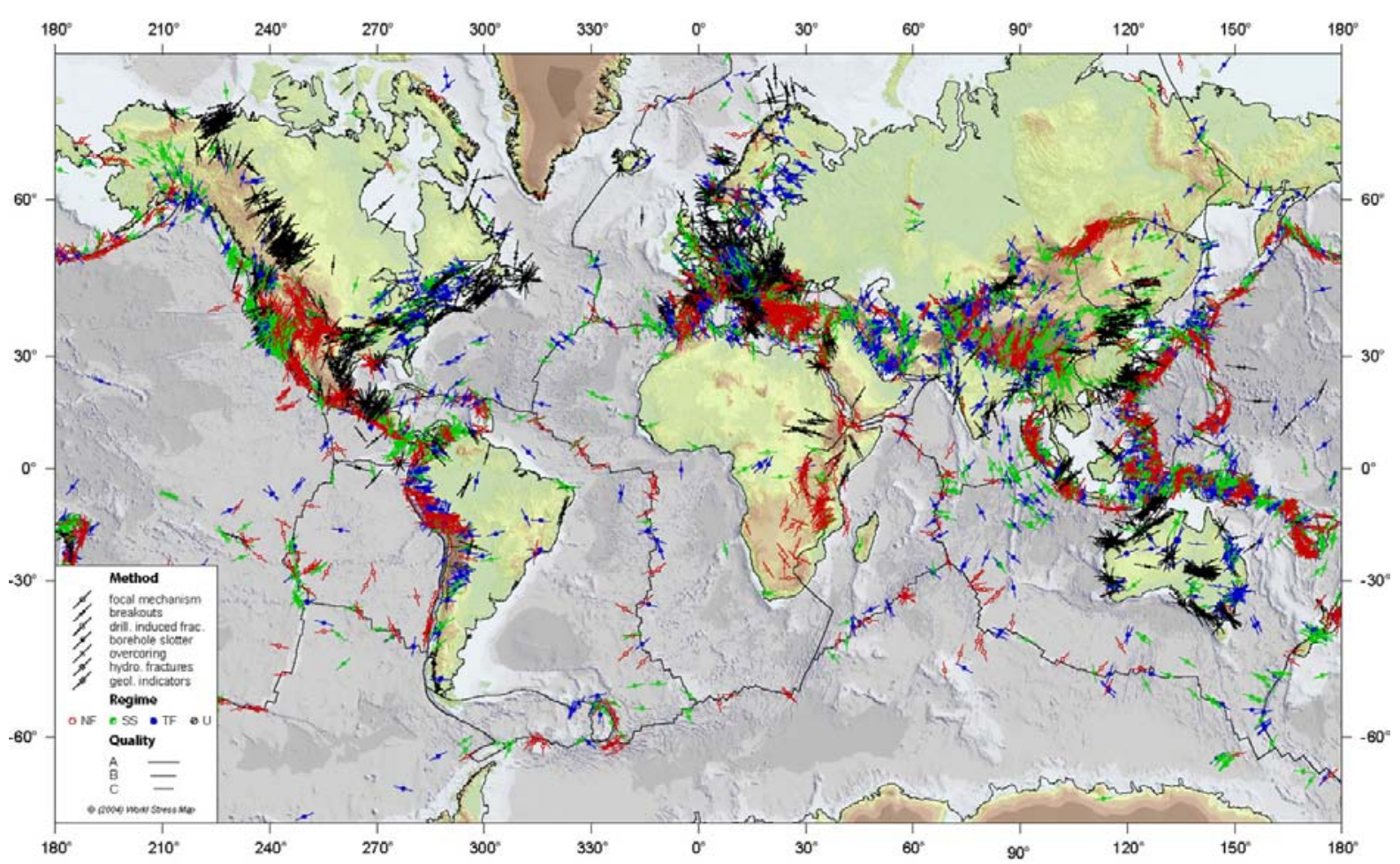

Figure 3.5 World stress map, the release 2005 of the World Stress Map (after Reinker et al., 2005) (available online at www.world-stress-map.org)

\subsection{STRESS MEASUREMENT IN USA COAL FIELDS}

In-situ stress measurements were conducted in the USA coalfields since 1979 (Agapito, 1979). Till now going through various literature 93 sets of in-situ horizontal stress measurements data were collected (Agarwal and Mayer, 1979; Blevins 1982,1986; Bauer and Hill, 1987; Ingram and Molinda 1988; Barron,1990; Cole et al., 1990; Mark and Mucho 1994; Peng and Kelley,1990; Su and Hasenfus, 1990; Agapito et al., 2005). Among these, most of the measurement data are from eastern USA coalfields. All sets of test data are grouped in three coalfields namely, eastern USA, central USA, and western USA coalfields. Figure 3.6 shows the variation of maximum horizontal stress with overburden depth. From Figure 3.6, it can be seen that there is no strong correlation between the maximum horizontal stress magnitude and the depth. In general, the value varies from 200 to 6000 psi for an overburden 
depth range of 400 to $3,000 \mathrm{ft}$. Most of the tests were conducted for the depth below $1,500 \mathrm{ft}$. Very few test were performed at higher depth. From the random plot of maximum horizontal stress it can be said that the depth is not the only influencing factor, rather the strata rock types in which test were conducted may also matters

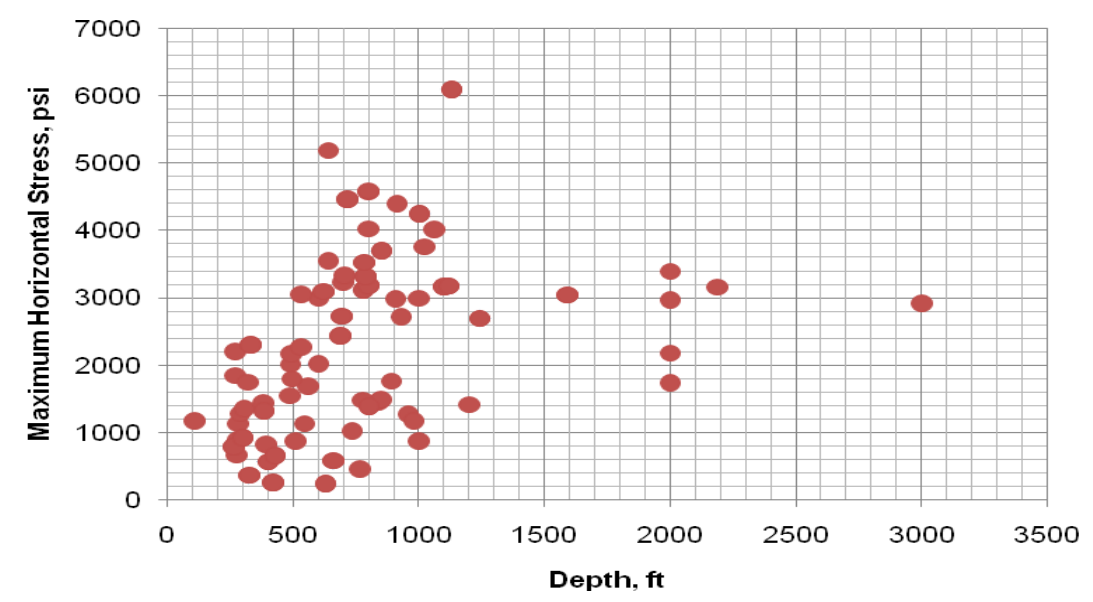

Figure 3.6 Variation in the measure maximum horizontal stress for USA coalfields

Further the magnitude of maximum and minimum horizontal stress is not important rather the ratio of horizontal stress to vertical stress is much more useful. This has been described by many researchers in the past. Figure 3.7 shows the ratio of maximum horizontal stress to the vertical stress for all three USA coalfields. The vertical stress in (psi) has been calculated as multiplying depth by 1.11. From Figure 3.7 it can be seen that the ratio ' $k$ ' varies from 0.4 to 10.0 . But more than $70 \%$ of the data fall within 1.5 To 4.0. We have some ' $k$ ' values also less than 1.0.

Similarly Figure 3.8 shows the plots of horizontal stress ratio, I (ratio of maximum to minimum horizontal stresses) for all three USA coalfields. The value of 'l' varies from 1.1 to 3.3 but the majority of the data falls in the range of 1.3 to 2.2 . 


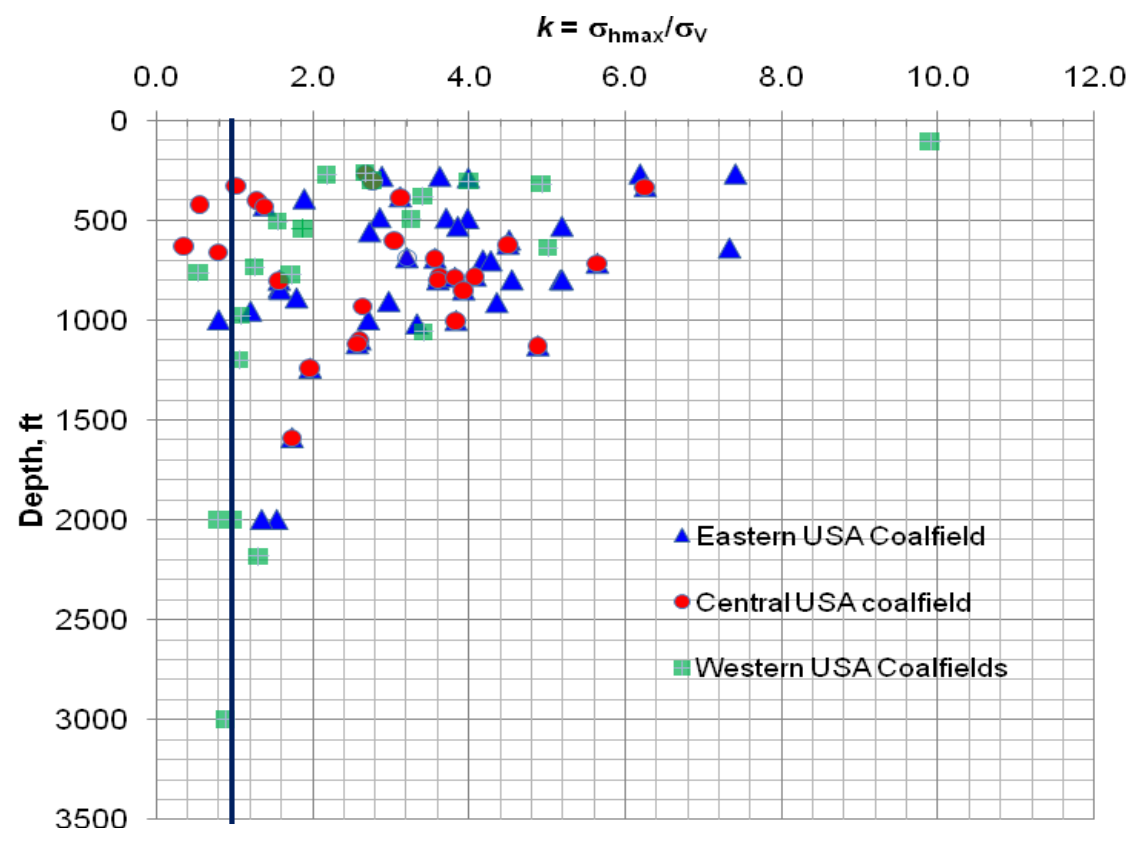

Figure 3.7 Stress ratio ' $k$ ' for the USA coalfields

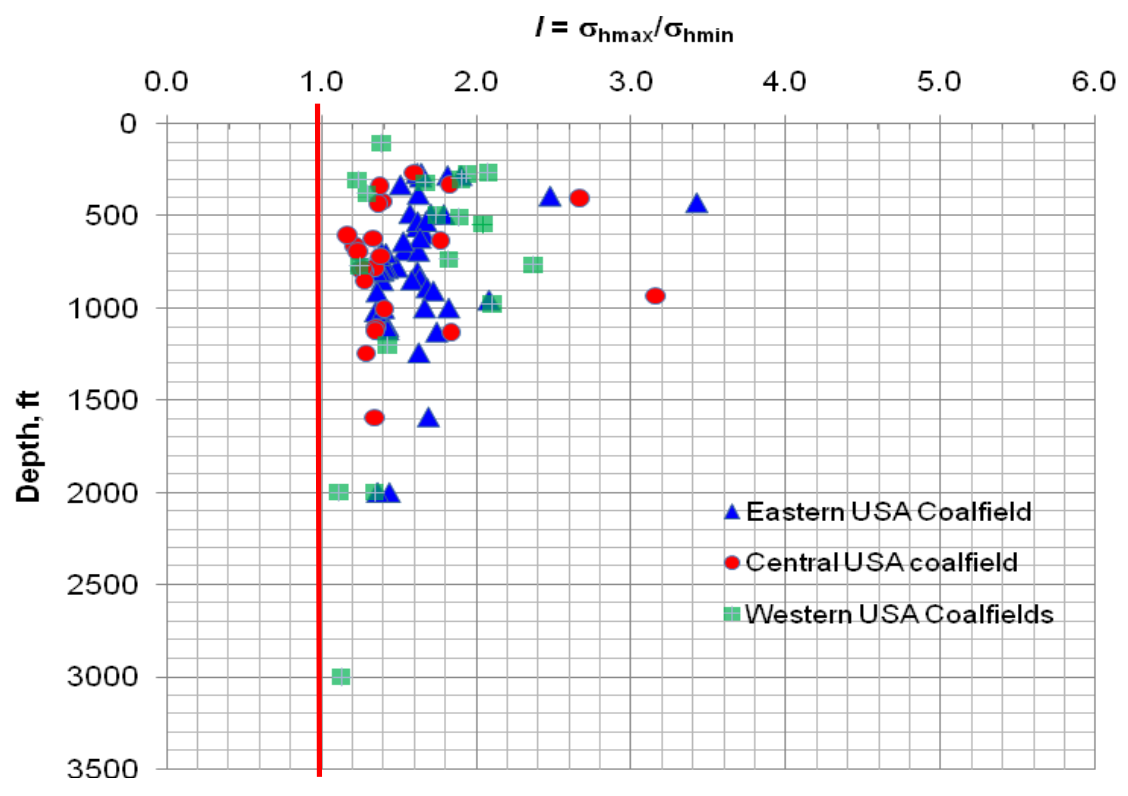

Figure 3.8 Horizontal stress ratio 'l' for the USA coalfields

Figures $3.9,3.10$, and 3.11 show the orientation of maximum horizontal stress for the eastern, western and central USA coalfields. For eastern USA coalfields the maximum horizontal stress is orientated between $\mathrm{N} 30^{\circ} \mathrm{E}$ to $\mathrm{N} 90^{\circ} \mathrm{E}$ (or $\mathrm{E}-\mathrm{W}$ ). In contrast in western USA coalfield the maximum horizontal stress is orientated 
towards both $\mathrm{N}-\mathrm{E}$ and $\mathrm{N}-\mathrm{W}$ with majority lies within NS to $\mathrm{N} 50^{\circ} \mathrm{W}$. The orientation of maximum horizontal stress is almost the same like eastern coalfields for central USA coalfields.

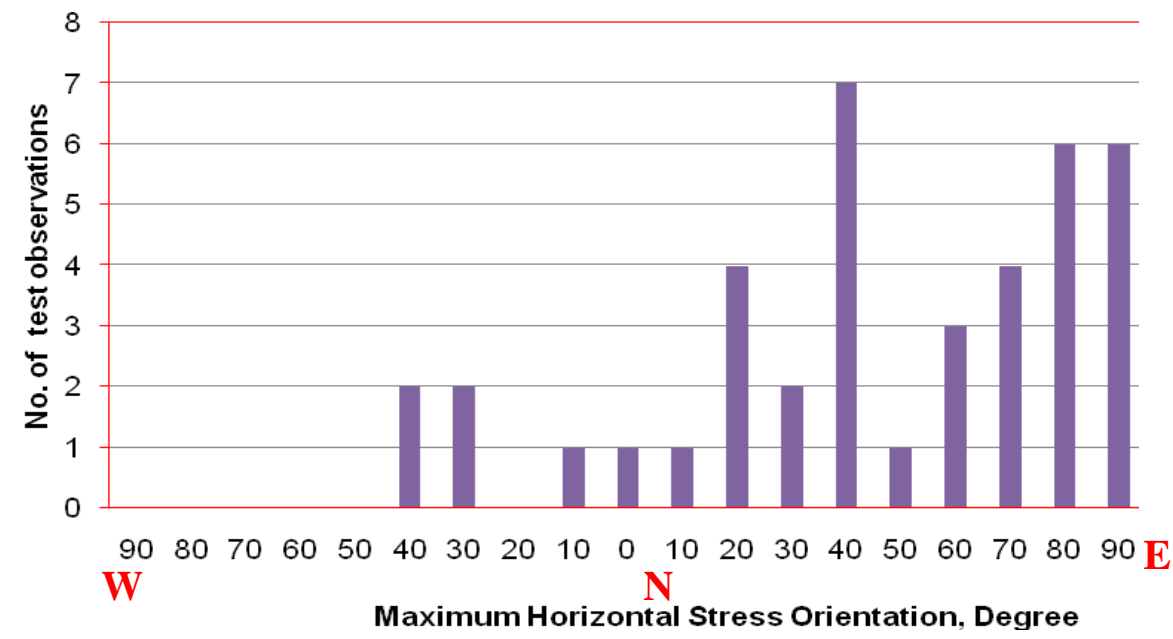

Figure 3.9 Maximum horizontal stress orientations in the eastern USA coalfields

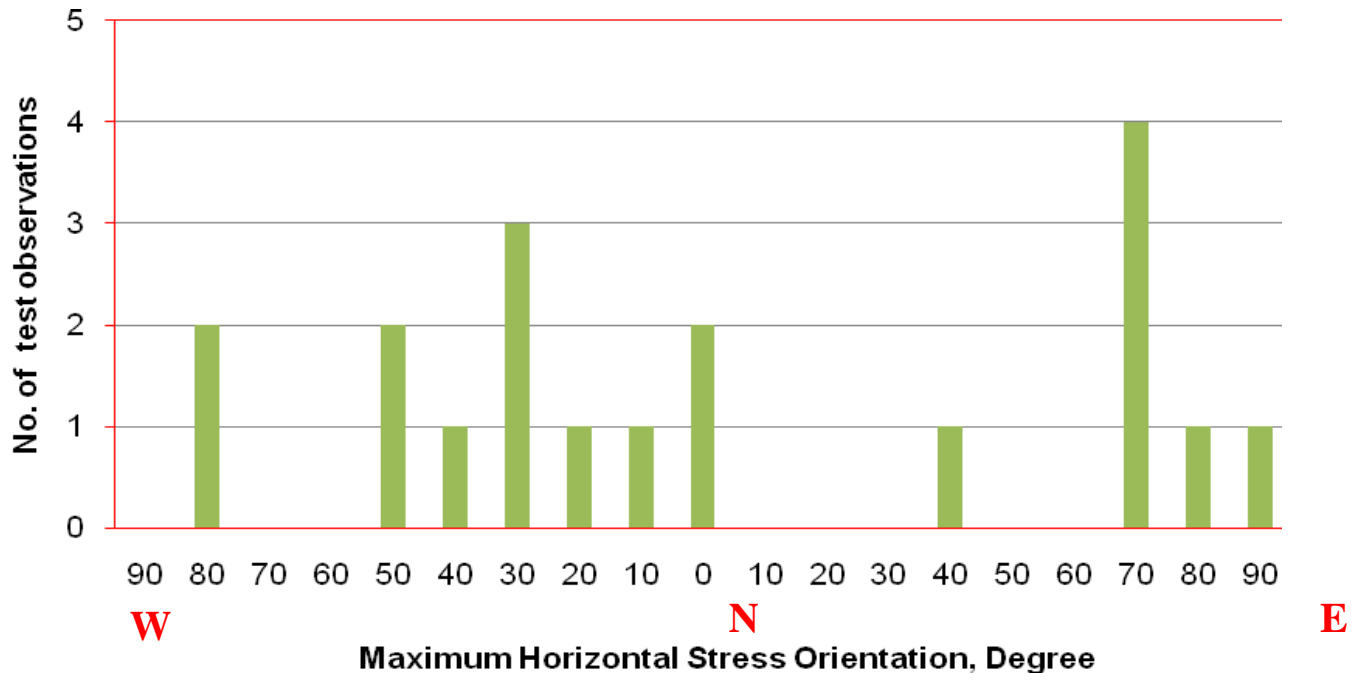

Figure 3.10 Maximum horizontal stress orientations in the western USA coalfields 


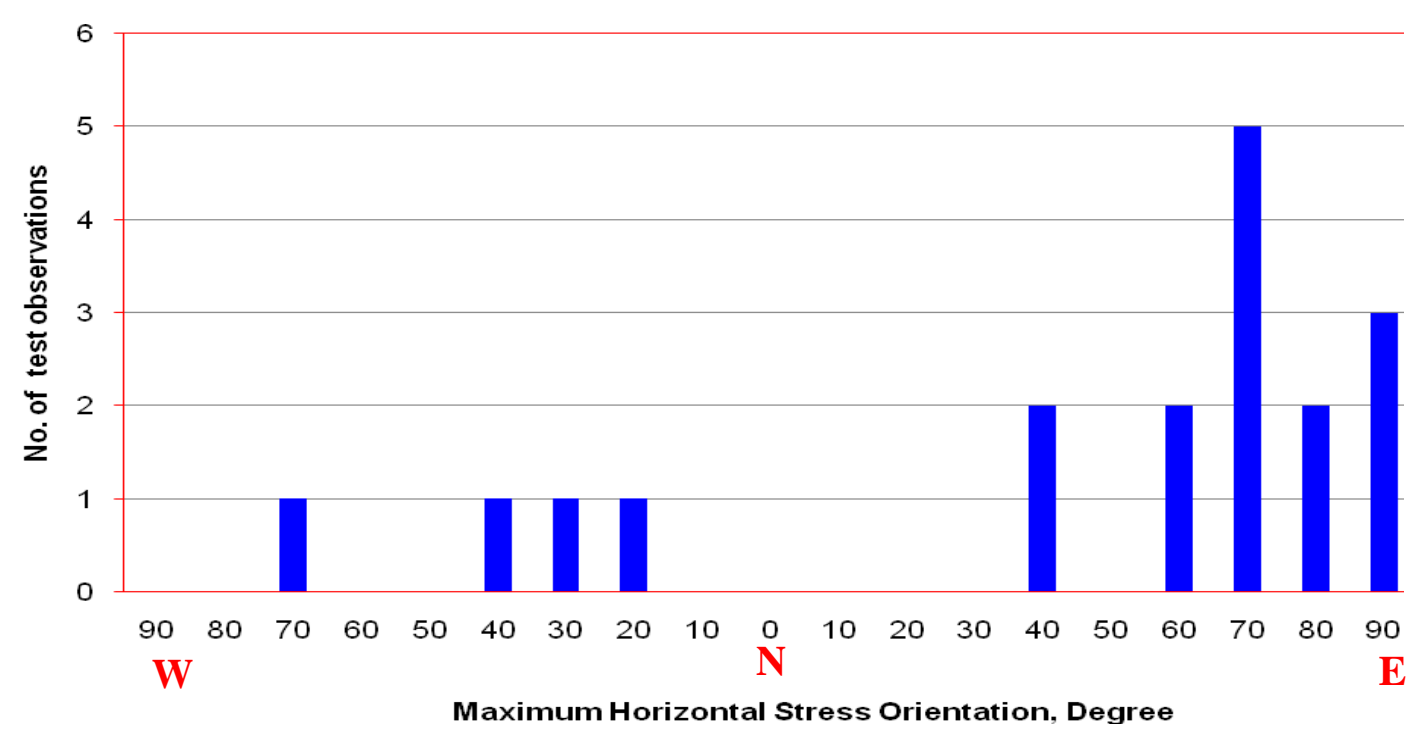

Figure 3.11 Maximum horizontal stress orientations in the central USA coalfields

Figure 3.12 shows the stress mapping and associated stress regimes in the North America. From this map it can be seen that in the major coalfield region, the stress field is thrust and strike-slip fault.

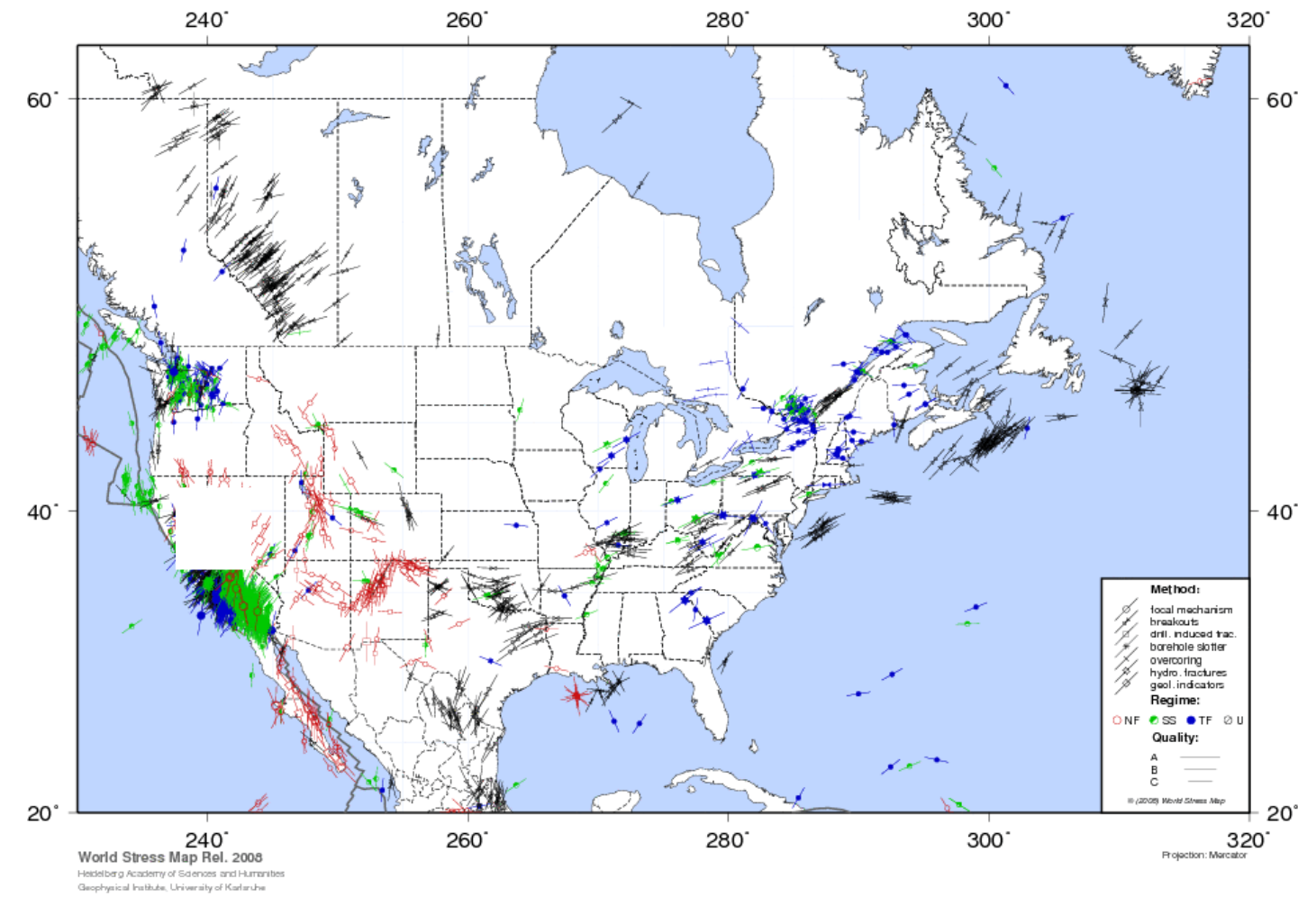

Figure 3.12 Direction of maximum horizontal stress and associated stress regimes for North America (source: World stress map) 


\subsection{PREDICTION OF HORIZONTAL STRESS IN USA}

From Figure 3.6 it can be seen that there is not a strong correlation between horizontal stress with the depth. There is a wide variation in the measured horizontal stress magnitudes for the same depth. So, it's really very tough to predict the horizontal stresses magnitudes based on the previously measured in-situ horizontal stress data by considering the depth parameter only.

The most recent empirical relationship to estimate the maximum and minimum horizontal stress has been developed by Mark and Gadde (2008). They have collected the worldwide in-situ stress measured data for both coal and non-coal fields. They developed an empirical relation using the unified analysis regression technique. These regression equations are governed by both the depth and the young's modulus of the rock in which the test was conducted. The relationship is in the following given form:

$$
S_{\max / \min }=B_{0}+B_{1} \text { (depth) }+B_{2} \text { (Young's modulus) }
$$

where $B_{0}, B_{1}$ and $B_{2}$ are the regression coefficients. These coefficients are shown in Tables 3.1 and 3.2 to estimate the maximum and minimum horizontal stress respectively.

Table 3.1 Maximum horizontal stress prediction coefficients determined for the individual coal regions

\begin{tabular}{|l|c|c|c|c|}
\hline & $\begin{array}{c}\text { No. of test } \\
\text { data, } \mathrm{n}\end{array}$ & $\begin{array}{c}\text { Intercept, } \mathrm{B}_{0} \\
\mathrm{psi}(\mathrm{MPa}))\end{array}$ & $\begin{array}{c}\text { Depth gradient, } \mathrm{B}_{1} \\
\mathrm{psi} / \mathrm{ft}(\mathrm{MPa} / \mathrm{m})\end{array}$ & $\begin{array}{c}\text { Modulus factor } \\
\mathrm{B}_{2}\left(10^{-3}\right)\end{array}$ \\
\hline East U.S. coal & 42 & $-298(-2.1)$ & $1.64(0.037)$ & 0.41 \\
\hline West U.S. coal & 20 & $-298(-2.1)$ & $0.78(0.018)$ & 0.41 \\
\hline UK/Ger coal & 52 & $-298(-2.1)$ & $0.71(0.016)$ & 0.41 \\
\hline South Africa coal & 22 & $-298(-2.1)$ & $1.11(0.025)$ & 0.41 \\
\hline India coal & 5 & $-298(-2.1)$ & $0.44(0.010)$ & 0.41 \\
\hline NSW coal & 170 & $-298(-2.1)$ & $1.84(0.041)$ & 0.41 \\
\hline
\end{tabular}




\begin{tabular}{|l|l|l|l|l|}
\hline Qld coal & 64 & $-298(-2.1)$ & $1.36(0.031)$ & 0.41 \\
\hline
\end{tabular}

Table 3.2 Minimum horizontal stress prediction coefficients determined for the individual coal regions

\begin{tabular}{|l|c|c|c|}
\hline & $\begin{array}{c}\text { No. of test } \\
\text { data, } \mathrm{n}\end{array}$ & $\begin{array}{c}\text { Depth gradient } \\
\mathrm{B}_{1} \mathrm{psi} / \mathrm{ft}(\mathrm{MPa} / \mathrm{m})\end{array}$ & $\begin{array}{c}\text { Modulus factor } \\
\mathrm{B}_{2}\left(10^{-3}\right)\end{array}$ \\
\hline East U.S. coal & 42 & $1.34(0.030)$ & 0.15 \\
\hline West U.S. coal & 20 & $0.56(0.013)$ & 0.15 \\
\hline UK/Ger coal & 52 & $0.42(0.009)$ & 0.15 \\
\hline South Africa coal & 22 & $0.20(0.005)$ & 0.15 \\
\hline India coal & 5 & $0.42(0.009)$ & 0.15 \\
\hline
\end{tabular}

To estimate the minimum horizontal stress the intercept constant $B_{0}$ is absent in the Equation 3.4. The strength of the predicted maximum horizontal stress (psi) with the measured for all the coalfields, except the Australian region, can be seen in the Figure 3.13.

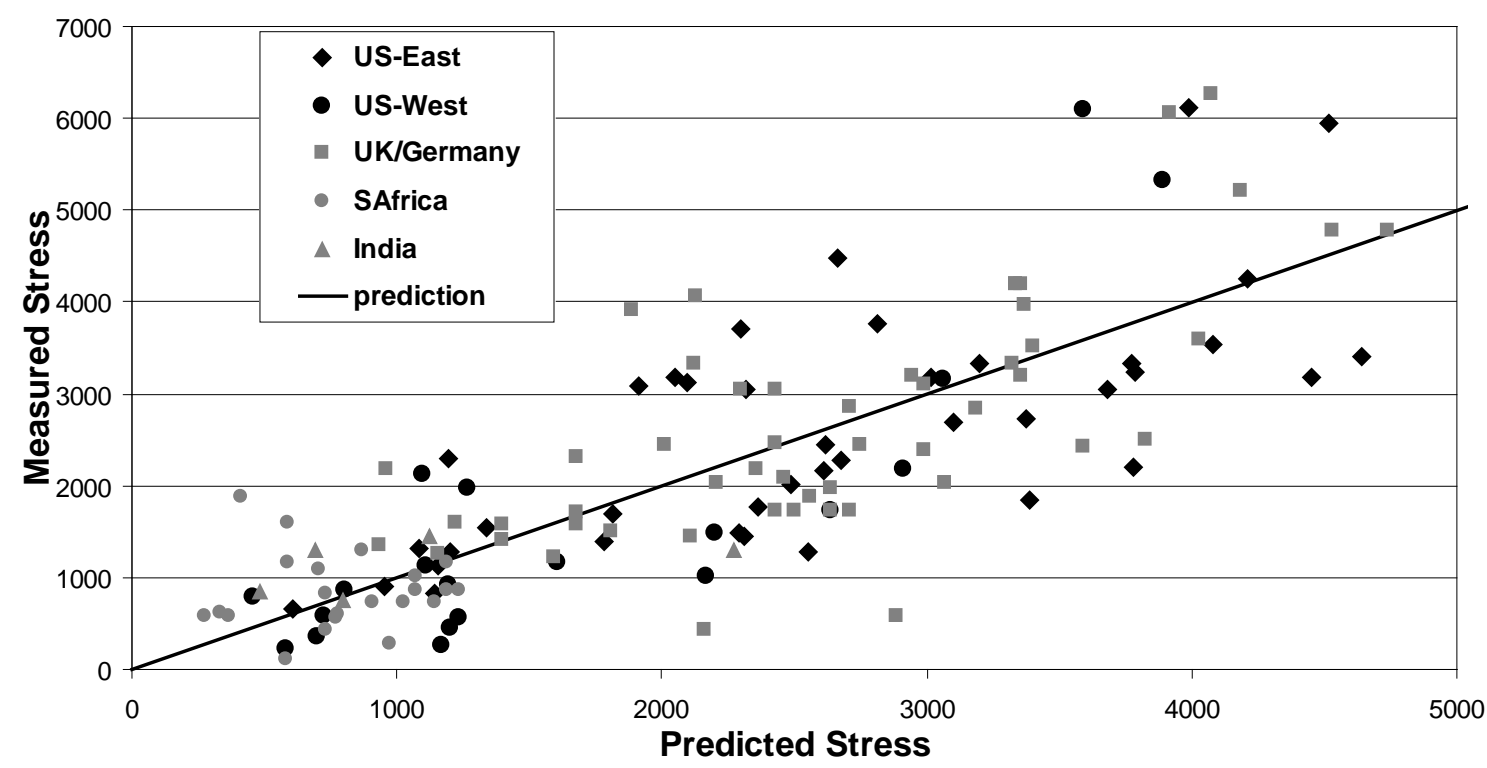

Figure 3.13 Predicted vs measured in-situ maximum horizontal stress (Mark and Gadde, 2008) 
This equation has been used to predict the horizontal stress in the Illinois basin coal mines where the depth is around 200 to $300 \mathrm{ft}$ and the immediate coal roof is very weak having Young's modulus in the range of 0.16 to $0.36 \times 10^{6} \mathrm{psi}$. The estimated maximum and minimum horizontal stresses are shown in Table 3.3.

Table 3.3 Estimation of maximum and minimum horizontal stresses for typical immediate roof rocks at shallow depth in Illinois basin based on Equation 3.4

\begin{tabular}{|c|c|c|c|c|c|c|}
\hline $\begin{array}{c}\text { Depth, } \\
\mathrm{ft}\end{array}$ & $\begin{array}{c}\text { Young's } \\
\text { Modulus, } \\
10^{6} \mathrm{psi}\end{array}$ & $\begin{array}{c}\text { Minimum } \\
\text { Horizontal } \\
\text { stress, } \mathrm{S}_{\text {hmax }}, \\
\mathrm{psi}\end{array}$ & $\begin{array}{c}\text { Maximum } \\
\text { Horizontal } \\
\text { stress, } \mathrm{S}_{\mathrm{hmin}}, \\
\mathrm{psi}\end{array}$ & $\begin{array}{l}\text { Vertical } \\
\text { stress, } \\
\mathrm{psi}\end{array}$ & $\begin{array}{c}\mathrm{k}= \\
\mathrm{S}_{\mathrm{hmax}} / \mathrm{S}_{\mathrm{v}}\end{array}$ & $\mathrm{S}_{\mathrm{hmax}} / \mathrm{S}_{\mathrm{hmin}}$ \\
\hline 200 & 0.16 & 95.6 & 292 & 225 & 0.4 & 0.3 \\
\hline 250 & 0.16 & 177.6 & 359 & 281 & 0.6 & 0.5 \\
\hline 300 & 0.16 & 259.6 & 426 & 338 & 0.8 & 0.6 \\
\hline 350 & 0.16 & 341.6 & 493 & 394 & 0.9 & 0.7 \\
\hline 200 & 0.36 & 177.6 & 322 & 225 & 0.8 & 0.6 \\
\hline 250 & 0.36 & 259.6 & 389 & 281 & 0.9 & 0.7 \\
\hline 300 & 0.36 & 341.6 & 456 & 338 & 1.0 & 0.7 \\
\hline 350 & 0.36 & 423.6 & 523 & 394 & 1.1 & 0.8 \\
\hline 200 & 0.6 & 276 & 358 & 225 & 1.2 & 0.8 \\
\hline 250 & 0.6 & 358 & 425 & 281 & 1.3 & 0.8 \\
\hline 300 & 0.6 & 440 & 492 & 338 & 1.3 & 0.9 \\
\hline 350 & 0.6 & 522 & 559 & 394 & 1.3 & 0.9 \\
\hline 250 & 0.8 & 440 & 455 & 281 & 1.6 & 1.0 \\
\hline
\end{tabular}

From Table 3.3, it can be seen that Equation 3.4 with the coefficients given in Table 3.1 and 3.2 for Eastern US coalfield, is not satisfactory as the ratio ' $"$ ' is always less than 1.0 up to a depth of $350 \mathrm{ft}$ for the Young's modulus of $0.6 \times 10^{6} \mathrm{psi}$. This is completely unrealistic value and physically impossible as 'l' can not be less than 1.0. The ratio ' $k$ ' is also less than 1.0 up to a depth of $250 \mathrm{ft}$ for the Young's modulus of $0.36 \times 10^{6} \mathrm{psi}$ in contrast to the measured value. The measured value doesn't show 
any trend like this. This error may be due to not sufficient test data available at shallow depth as well as lack of tested results for the weak rock. Hence it may not be suitable to use for shallow depth with very weak immediate roof.

Further Mark and Gadde (2008a) have modified the equation to correct the discrepancies observed with the earlier mentioned regression Equation 3.4. The constant term 'intercept' $B_{0}$ is removed and the modified equations are as given below-

For Eastern US coalfield:

$$
\begin{aligned}
& S_{\max }(p s i)=1.56 \times \text { depth }+354 \times \text { Young's modulus } \\
& S_{\min }(p s i)=1.34 \times \text { depth }+150 \times \text { Young's modulus }
\end{aligned}
$$

\section{For Western US coalfield:}

$$
\begin{aligned}
& S_{\max }(p s i)=0.69 \times \text { depth }+354 \times \text { Young's modulus } \\
& S_{\min }(p s i)=0.56 \times \text { depth }+150 \times \text { Young's modulus }
\end{aligned}
$$

where the depth is in $\mathrm{ft}$ and Young's modulus in $10^{6} \mathrm{psi}$.

The estimated maximum and minimum horizontal stresses estimated from Equations 3.5 and 3.6 for the same conditions as used in Table 3.3 is shown in Table 3.4. From Table 3.4, it is very clear that this time the ' $"$ 'values are always more than 1 for any conditions. Hence, in the present work these equations will be used for estimation of maximum and minimum horizontal stresses in absence of any tested values.

One important thing to be noted is the Young's modulus values used in all the above mentioned equations are the modulus value, tested along the rock bedding planes. The over-coring method of in-situ stress measurement generally considers 
Table 3.4 Estimation of maximum and minimum horizontal stresses for typical immediate roof rocks at shallow depth in Illinois basin as per modified Equations 3.5 and 3.6

\begin{tabular}{|c|c|c|c|c|c|c|}
\hline $\begin{array}{c}\text { Depth, } \\
\mathrm{ft}\end{array}$ & $\begin{array}{c}\text { Young's } \\
\text { Modulus, } \\
10^{6} \mathrm{psi}\end{array}$ & $\begin{array}{c}\text { Maximum } \\
\text { Horizontal } \\
\text { stress, } \mathrm{S}_{\text {hmax }}, \\
\mathrm{psi}\end{array}$ & $\begin{array}{c}\text { Minimum } \\
\text { Horizontal } \\
\text { stress, } \mathrm{S}_{\text {hmin }}, \\
\mathrm{psi}\end{array}$ & $\begin{array}{l}\text { Vertical } \\
\text { stress, } \\
\mathrm{psi}\end{array}$ & $\begin{array}{c}k= \\
\mathrm{S}_{\mathrm{hmax}} / \mathrm{S}_{\mathrm{v}}\end{array}$ & $\begin{array}{l}I= \\
\mathrm{S}_{\mathrm{hmax}} / \mathrm{S}_{\mathrm{hmin}}\end{array}$ \\
\hline 200 & 0.16 & 369 & 292 & 225 & 1.6 & 1.3 \\
\hline 250 & 0.16 & 447 & 359 & 281 & 1.6 & 1.2 \\
\hline 300 & 0.16 & 525 & 426 & 338 & 1.6 & 1.2 \\
\hline 350 & 0.16 & 439 & 322 & 225 & 2.0 & 1.4 \\
\hline 200 & 0.36 & 517 & 389 & 281 & 1.8 & 1.3 \\
\hline 250 & 0.36 & 595 & 456 & 338 & 1.8 & 1.3 \\
\hline 300 & 0.36 & 673 & 523 & 394 & 1.7 & 1.3 \\
\hline 350 & 0.36 & 524 & 358 & 225 & 2.3 & 1.5 \\
\hline 200 & 0.6 & 602 & 425 & 281 & 2.1 & 1.4 \\
\hline 250 & 0.6 & 680 & 492 & 338 & 2.0 & 1.4 \\
\hline 300 & 0.6 & 758 & 559 & 394 & 1.9 & 1.4 \\
\hline 350 & 0.6 & 673 & 455 & 281 & 2.4 & 1.5 \\
\hline 250 & 0.8 & & & & \\
\hline
\end{tabular}

the modulus parallel to the bedding planes. Hence, if in the laboratory the Young's modulus obtained is in loading condition perpendicular to the bedding planes that should be converted to along the bedding planes with proper correction factor. In past it has been seen during rock testing in laboratory that modulus varies significantly, in directions parallel and perpendicular to the rock bedding planes. The elastic modulus parallel to bedding planes are 50 to $60 \%$ more than that of perpendicular to bedding planes (Vutukuri et al., 1974, Alam et al., 2008). Ndlovu and Stacy (2007) have tested rock specimens and found that the uni-axial compressive strength of rock is much lower for rock tested in a direction parallel to the bedding planes than in a direction normal to the bedding planes. Hence the strength and young's modulus may depend upon the frequency of bedding planes or laminations in the rock specimen. 


\section{CHAPTER 4}

\section{CUTTER ROOF- A FEW CASE STUDIES}

\subsection{INTRODUCTION}

Cutter roof failure is a specific type of ground control problem which frequently results in massive roof failure. It is a common occurrence in coal mines of the Northern Appalachian Coal basin. In general, all cutters don't always cause or lead to roof fall. But cutter, does can and will lead to roof falls if no proper and timely measures are implemented to prevent continuing development. However, the initiation and propagation of fractures leading to roof falls vary considerably in time. Some occur suddenly, while others take a few days or weeks. Hence, the cutters observed underground are in general at various stages of the process leading to roof falls.

Cutter roof initiates and propagates nearly vertically from one or both upper corners of an entry and is difficult to control by conventional roof support, as shown in Figures 4.1 and 4.2.

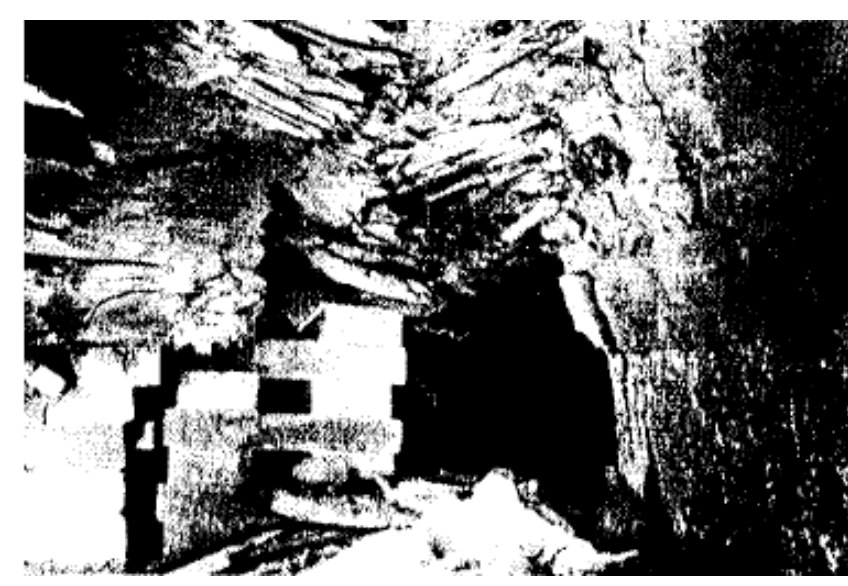

Figure 4.1 Typical cutter roof failure at entry corner (after Hill, 1984)

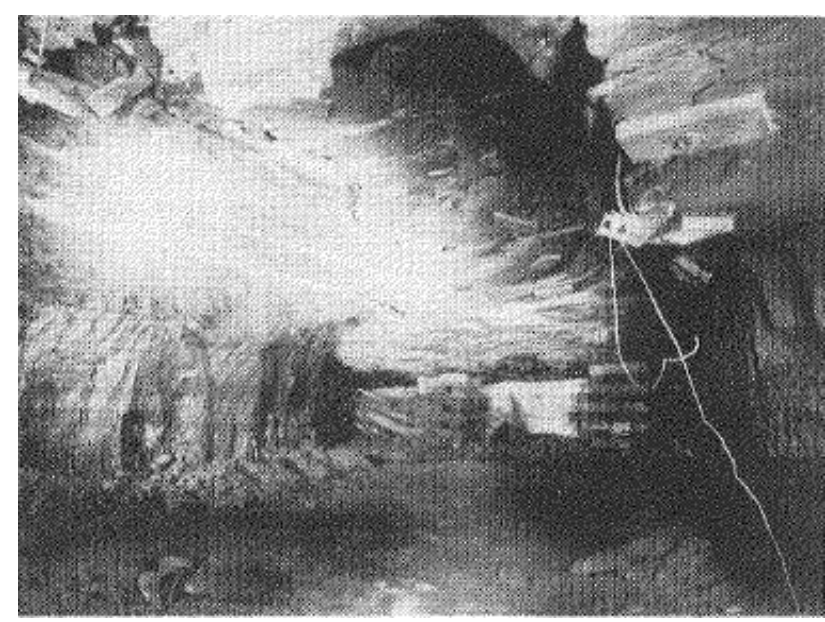

Figure 4.2 Remaining cavity following overall roof collapse (courtesy; Bureau of Mines, Pittsburgh Research Center) 
In practice, when an operator identifies roof instability as a cutter, the failure characteristics need not necessarily be restricted to those outlined in "classic" cutter failure definition (Hill's 1986). In regular use, the term cutter refers to all roof failures at the roof-rib intersection including single or multiple fracture planes, a zone of heavily fractured and/or caved void as shown in Figure 4.3 and Figure 4.4 (Gadde and Peng 2005).

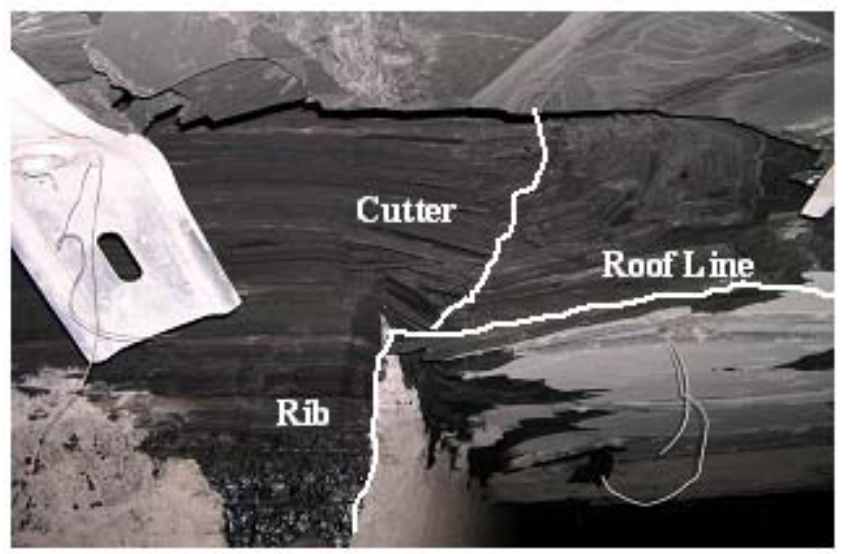

Figure 4.3 Initial stage of a cutter with multiple fractures (Gadde and Peng, 2005)

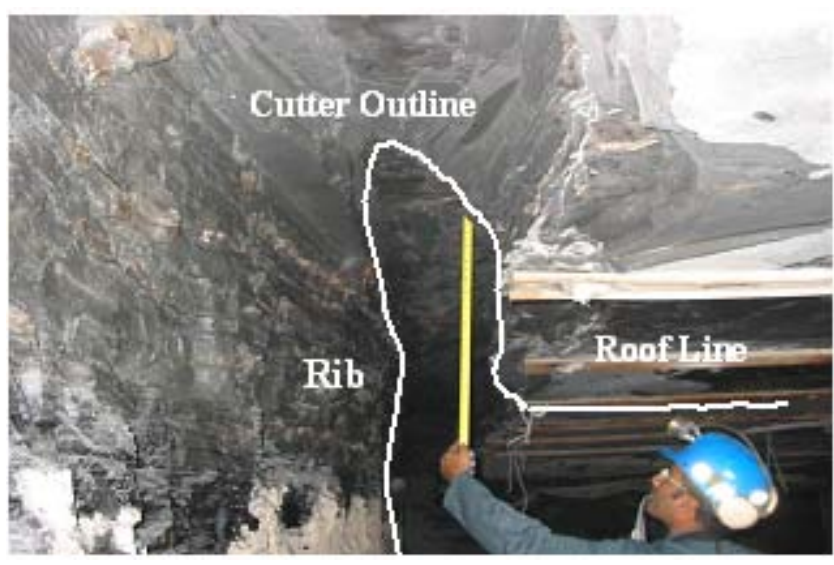

Figure 4.4 Cutter progressed to a caved void (Gadde and Peng, 2005)

Cutter type roof failure can happen right at the face (Figures 4.5, 4.6, and 4.7) some distance outby the face or in intersections. Failure may develop in only the entries or in both the entries and the crosscuts and may be restricted to one side of an opening or to both sides. It may also start on one side of an opening and run across its width at some angle to continue to develop on the other side as shown in Figure 4.8. Also, as noticed in Figure 4.8, the persistence of cutters could be highly local or extend over several hundred feet. 


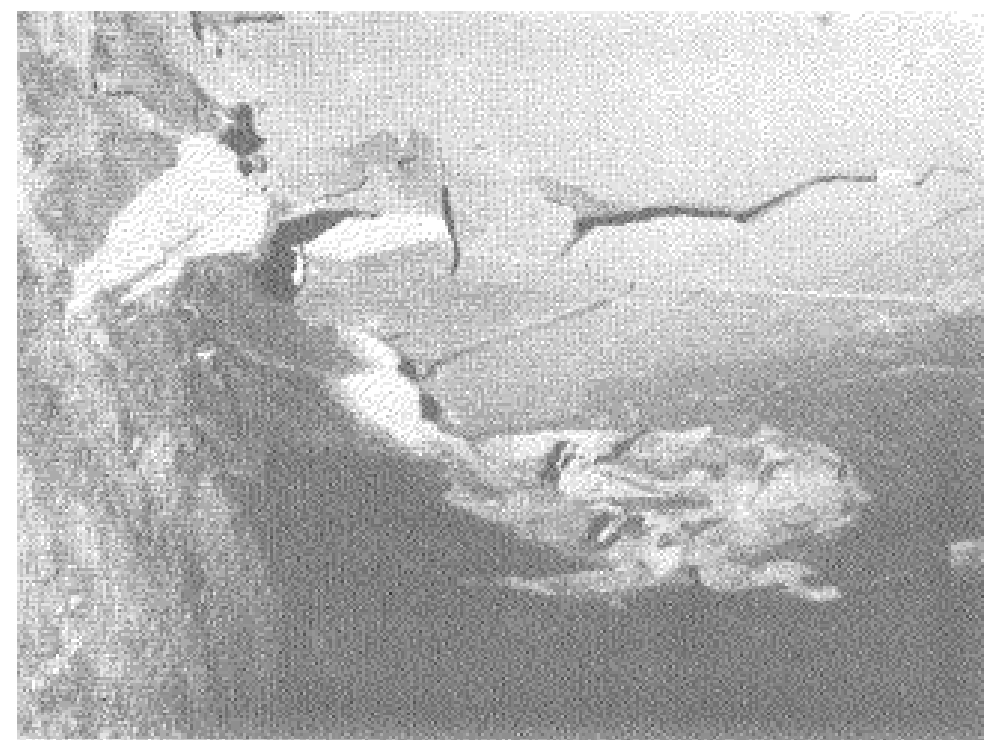

Figure 4.5 Cutter roof develops a short distance behind the face and follows entry advance (after Krupa and Khair, 1991)

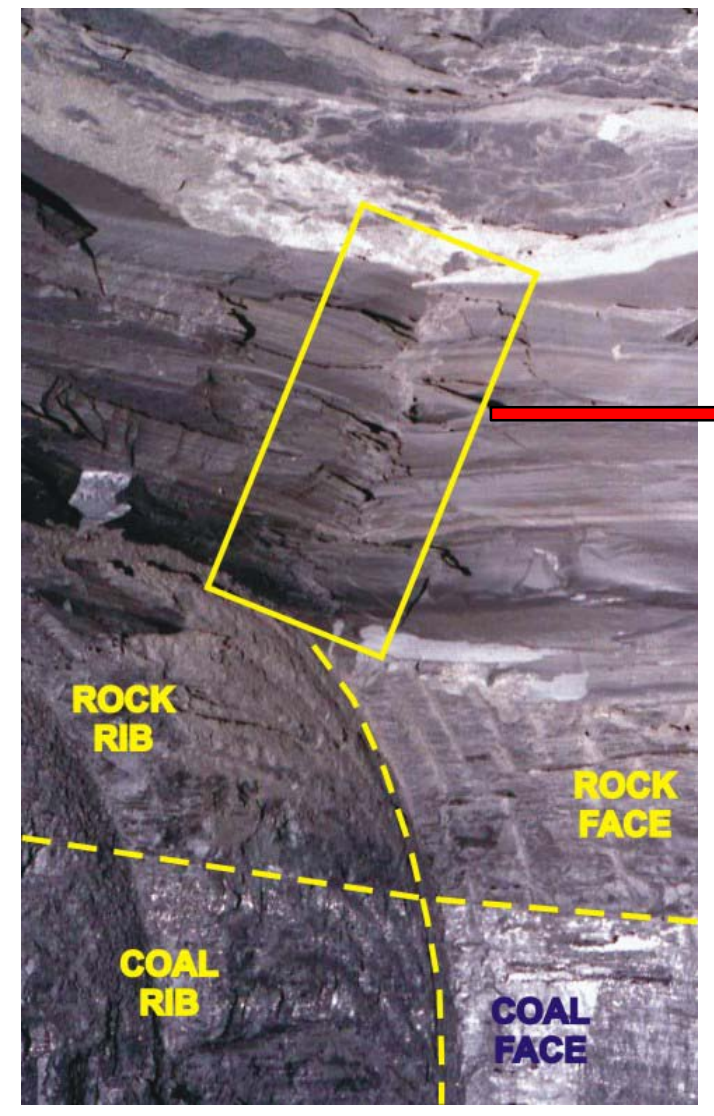

a

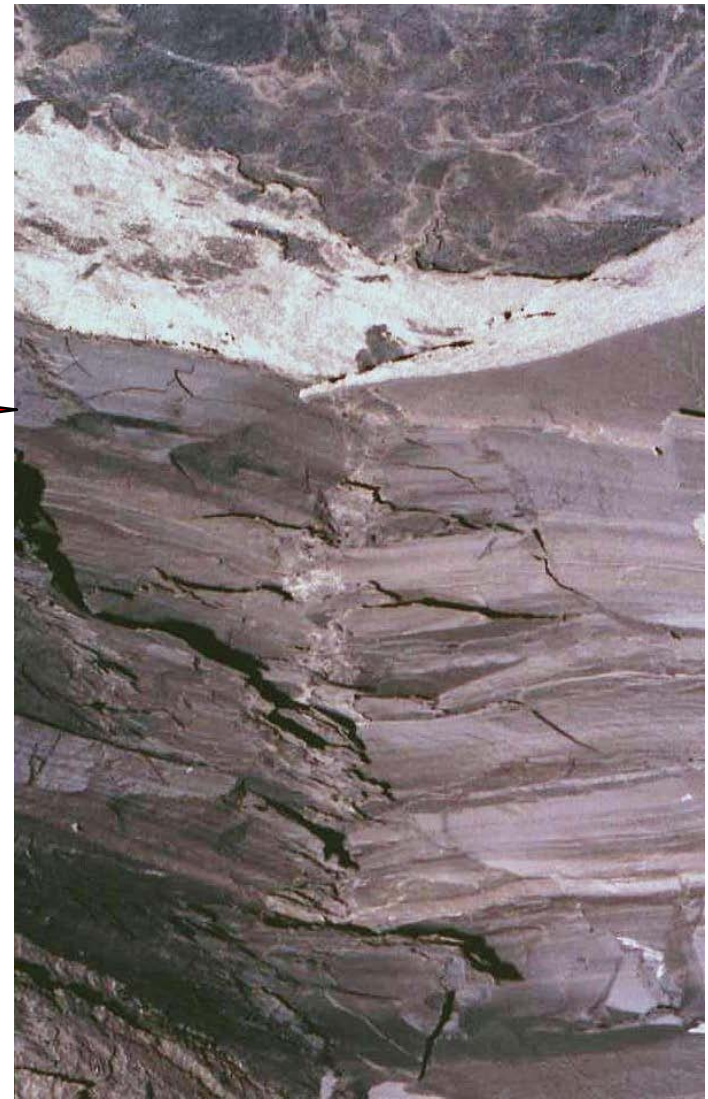

b

Figure 4.6 Cutters in the immediate roof on the face of a longwall gateroad development entry immediately after cutting. It most likely occurred during the continuous miner's cutting. ' $a$ ' is the overall view and ' $b$ ' is a close-up view of the rectangular area in ' $a$ ' (Peng, 2007) 

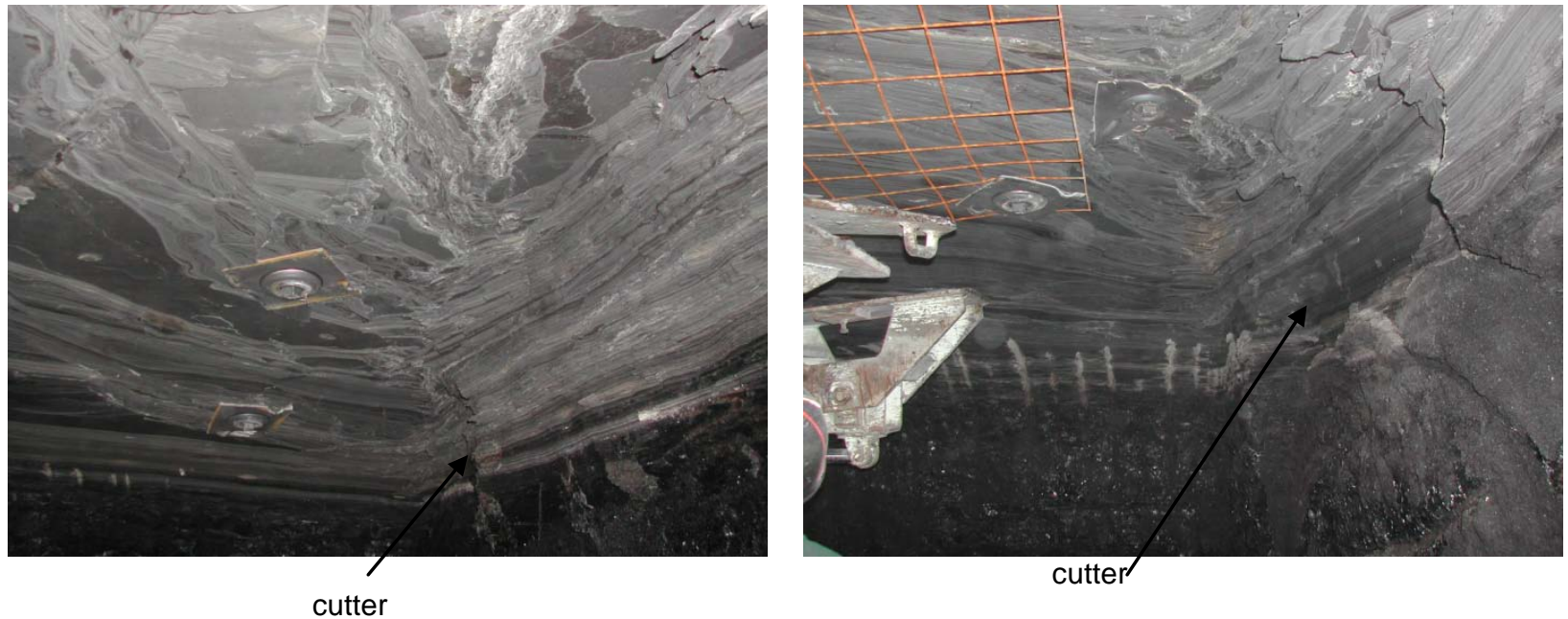

Figure 4.7 Cutters found in the newly developed faces at the left side corner of the roof and rib (Peng, 2007)

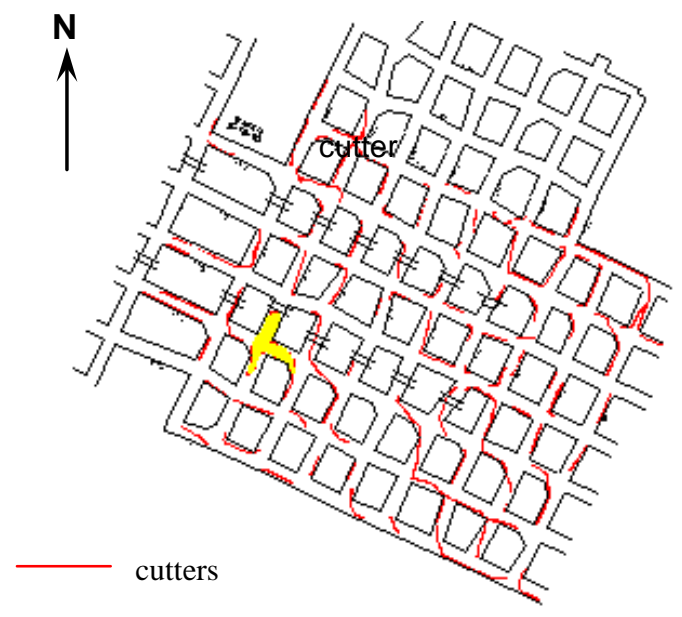

Figure 4.8 Spatial distribution of cutters noticed in a mine (Mark, 2004; Peng, 2007)

\subsection{DEVELOPMENT OF CUTTER/ROOF FALL}

It has been suggested that cutter roof is caused by the shear stress at the entry corners being larger than the shear strength. This high shear stress at the corners results from either a large overburden weight and/or high horizontal stress at the rib. If separations between strata or a weak bedding plane exist, shear failures 
that originate at the corners and propagate upward may stop at the first separation of a weak bedding plane. Traditionally, the kind of problem encountered with supporting roof conditions of this nature is that, regardless of the length of roof bolt installed, with time, a massive roof collapse still results, usually to a height equal to the bolt length as shown in Figure 4.9.

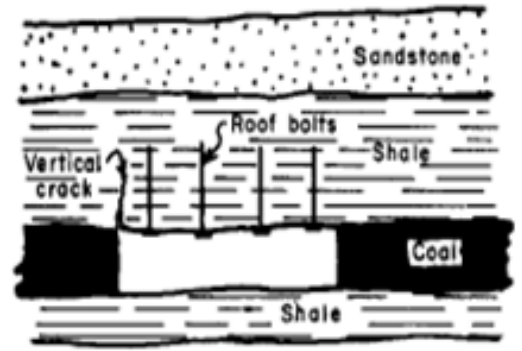

a. initial crack initiation

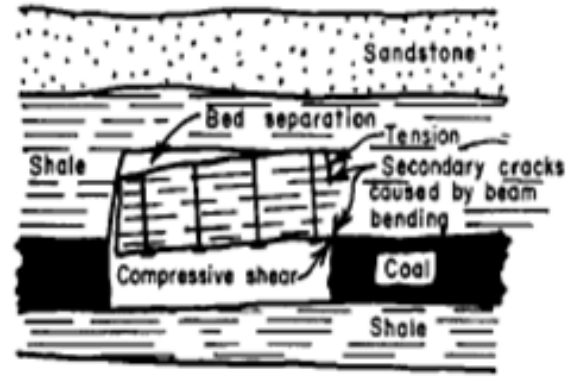

c. final bed separation

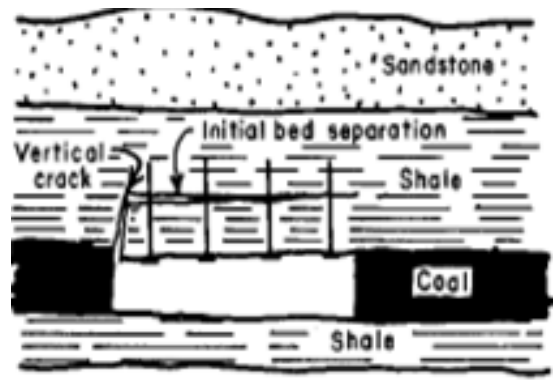

b. Initial bed separation

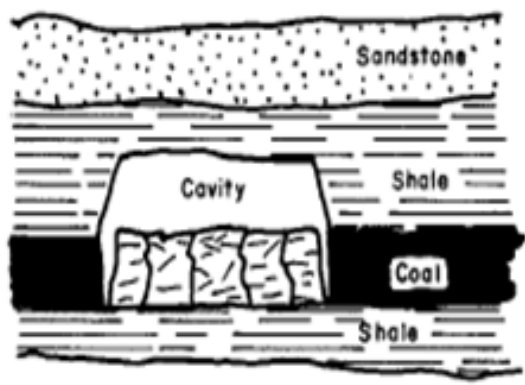

d. Massive roof collapse

Figure 4.9 Progressive sequences of events leading to overall roof collapse resulting from cutter roof failure (after Kripakov, 1982)

Initially, when stress concentrations at one, or both, corners of an opening exceed the rock mass strength, typically, rock fails in shear at these locations. With the development of such a fractured zone, the failed rock mass loses some of its load-bearing capacity, or the rock mass enters into its post failure state as illustrated in Figure 4.10a. Depending on the amount of strain and confinement in the postfailure zone, the rock mass may lose some or total resistance to withstand loads. In addition to altering the strength characteristics, a fracture may also affect the 
deformability of the rock mass. With further advance of the face and a change in the geometry of workings, the failed rock mass will be deformed further in the postfailure state, which will further alter the stress state around the fractured region as explained in Figure 4.10b. Such a progressive process may eventually lead to complete failure of rock mass leading to roof collapse in a part, or across the whole width, of an entry (Figure 4.10c).

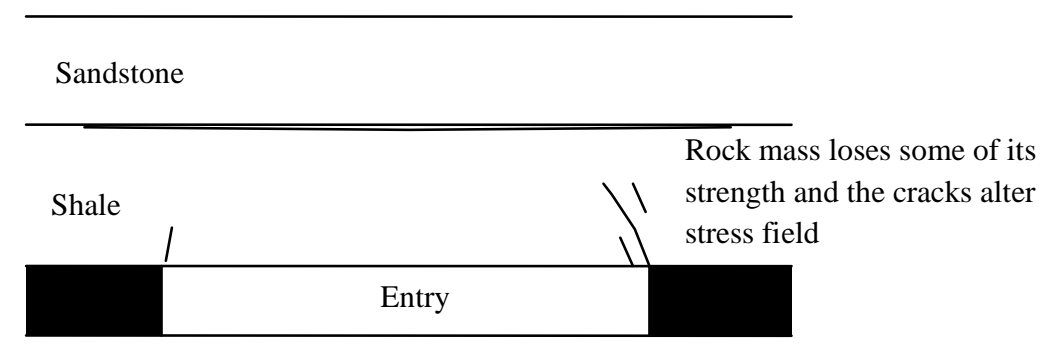

(a) Single or multiple cracks at one or both corners of the entrv.

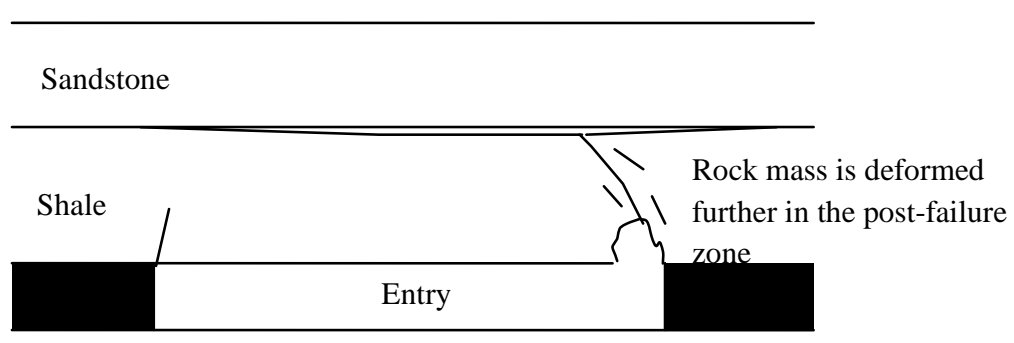

(b) With a change in geometry or increasing stand-up time, major cracks extend and cracked zone grows in size; rock that has been deformed most in the post-failure state may fall down or lose its total load bearing capacity.

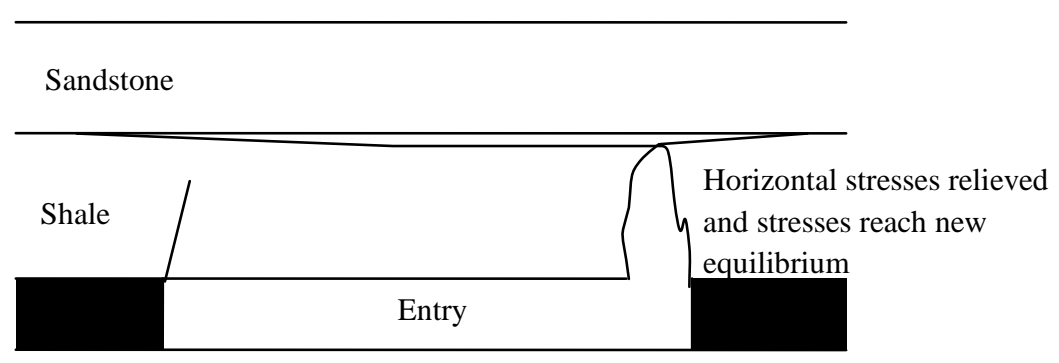

(c) The caved zone grows in size or if the stresses at the other corner (abutment of cantilever) also exceed strength, then the whole roof may collapse.

Figure 4.10 Conceptual process of cutter roof development (Gadde and Peng, 2005) 
Figure 4.11 shows a field example how a cutter developed. The 1st roof layer (layer 1) separated from the layer 2 above and broke up first. Thereafter, both parts of layer 1 ( $1 \mathrm{a}$ and $1 \mathrm{~b})$ dropped down, except $1 \mathrm{~b}$ also moved laterally toward the rib. As time went by, layer 2 would do the same, followed by layer 3 and then layer 4 .
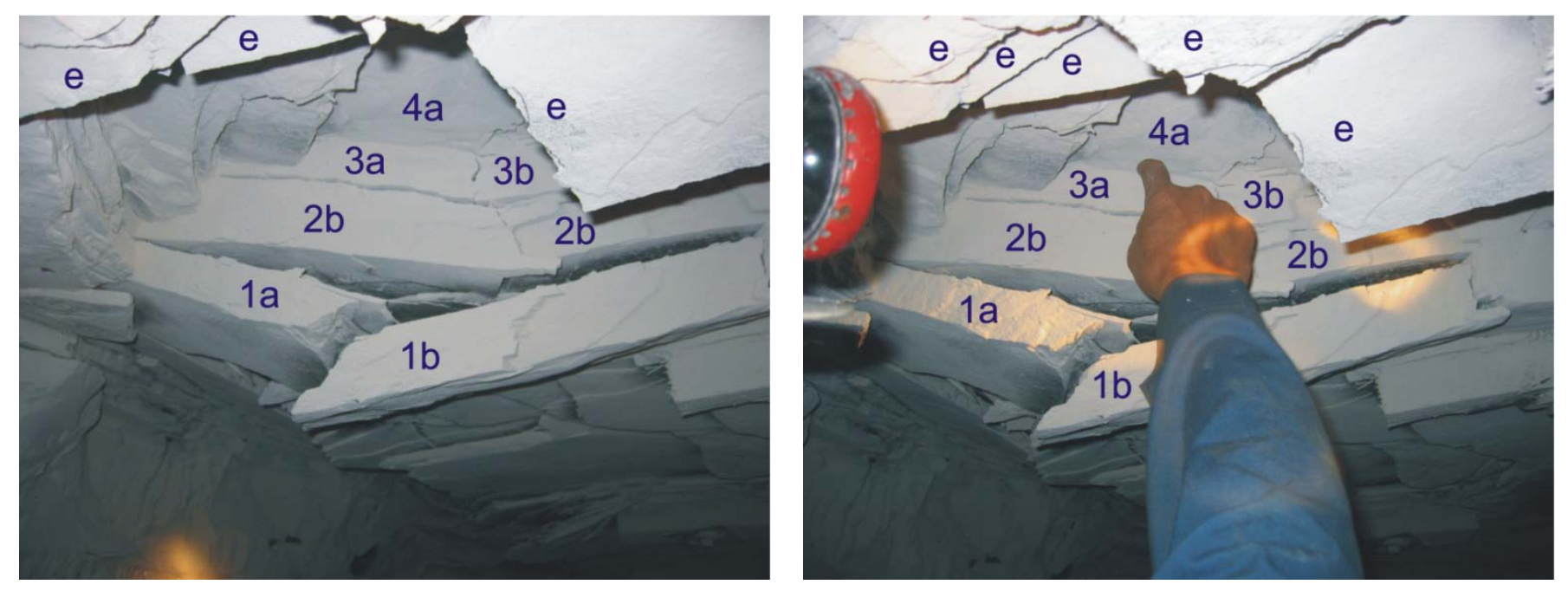

a

b

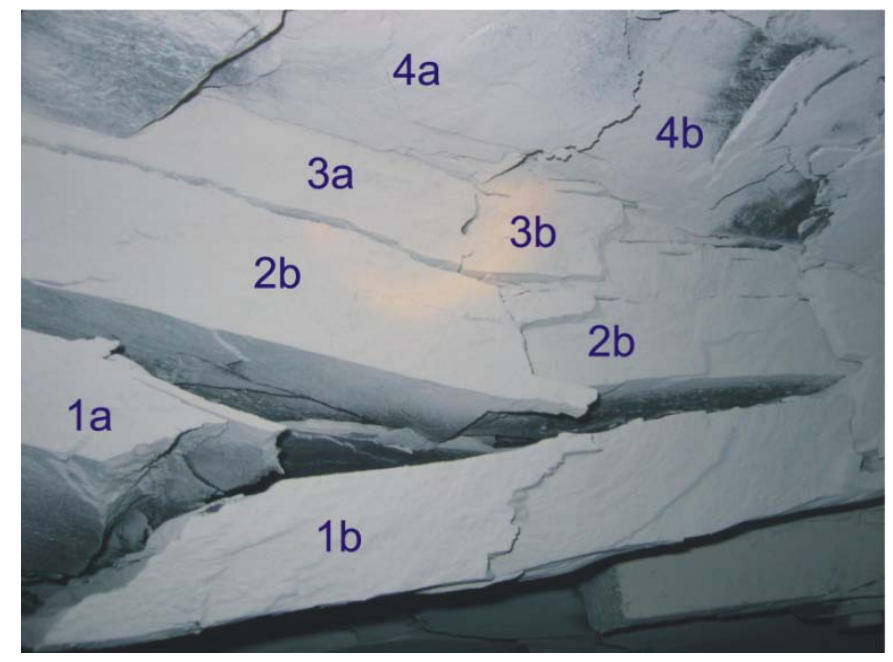

c. Enlarge view of ' $b$ '

Figure 4.11 Development of a cutter. a, b, and c are the same cutter in different views (Peng, 2007) 


\subsection{CASE STUDIES}

In the following sections, the cutter roof problem and their impact can be seen. These case studies have been chosen from from Dr. Peng's book on 'Ground control failures- A Pictorial view of case studies (Peng, 2007) to explain the development of cutters and roof falls.

\subsubsection{Case Study I - Cutters in the Eagle Seam}

This case occurred in 2000. Figure 4.12 shows the mine map at the time of inspection. The salient feature of the mining parameters are-

- The North and West mains were developed by the nine-entry system.

- Chain pillars were $70 \times 70 \mathrm{ft}$. rib-to-rib with entry/crosscut $20 \mathrm{ft}$. wide.

- The Eagle seam was 3-4 ft. thick under a cover of 800-1,000 ft. deep.

- In the North mains, the immediate roof was laminated gray shale, 4-7 ft., overlain by gray sandy shale or sandstone. The laminated gray shale allowed on average only 10-20 ft. cutting depth. The roof rock was frequently cut out, sometimes as thick as 48 in. above the roofline. The gray shale contained many dark plant remains aligned to form weak laminations.

- In the West Mains, the immediate roof was also laminated shale, but interbedded with laminated sandy shale. Besides the coal, the entry height contained up to $2.5 \mathrm{ft}$ of roof rock. In some areas, the sandy shale formed a stable roof, while in other areas; the sandy shale disappeared, leaving the weak gray shale as the immediate roof. In comparison to the North Mains, the roof in the West Mains was stronger and drilling for the roof bolt holes often emitted a loud noise. 


\section{Cutter characteristics}

- In the North mains, cutters occurred predominantly on the left side when looking inby of the entry

- Cutters occurred mostly outby the face (i.e., sometimes after mining), but sometimes, right after the continuous miner's cutting

- Cutters were not consistent, like at the face area inby crosscut \#24, cutters occurred in \#7 entry five minutes after cutting. But, there were no cutters in the\#5, $\# 6$, and \#8 and \#9 entries even after 12 hours of cutting.

- Cutters in entries were in advance stages compare to the crosscuts (i.e. shear fracture were larger for entries)

Figures 4.13 and 4.14 show some of the cutter developed at entries \# 1 and \#6 while Figure 4.15 shows the cutter in the crosscut.

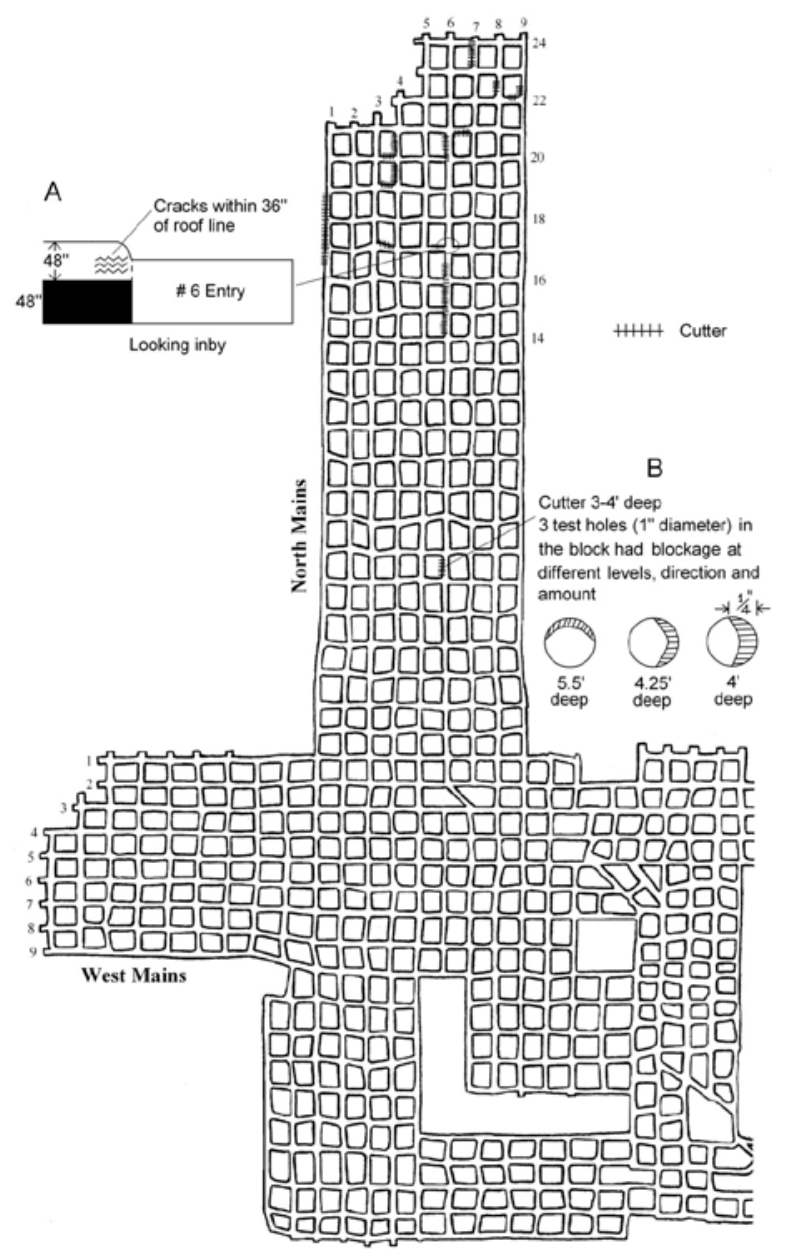

Figure 4.12 Mine layout showing location of cutters for case study I (Peng, 2007) 

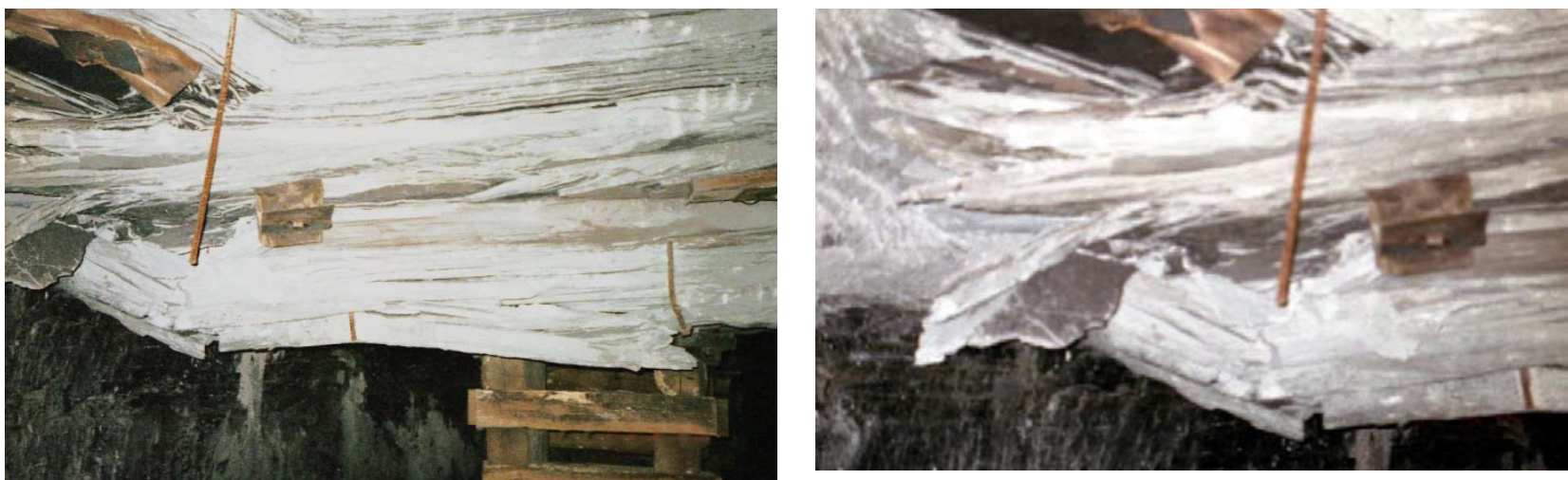

Figure 4.13 The outby end view of the cutter between crosscut \# 16 and \# 19 in the \#1 entry (Peng, 2007)

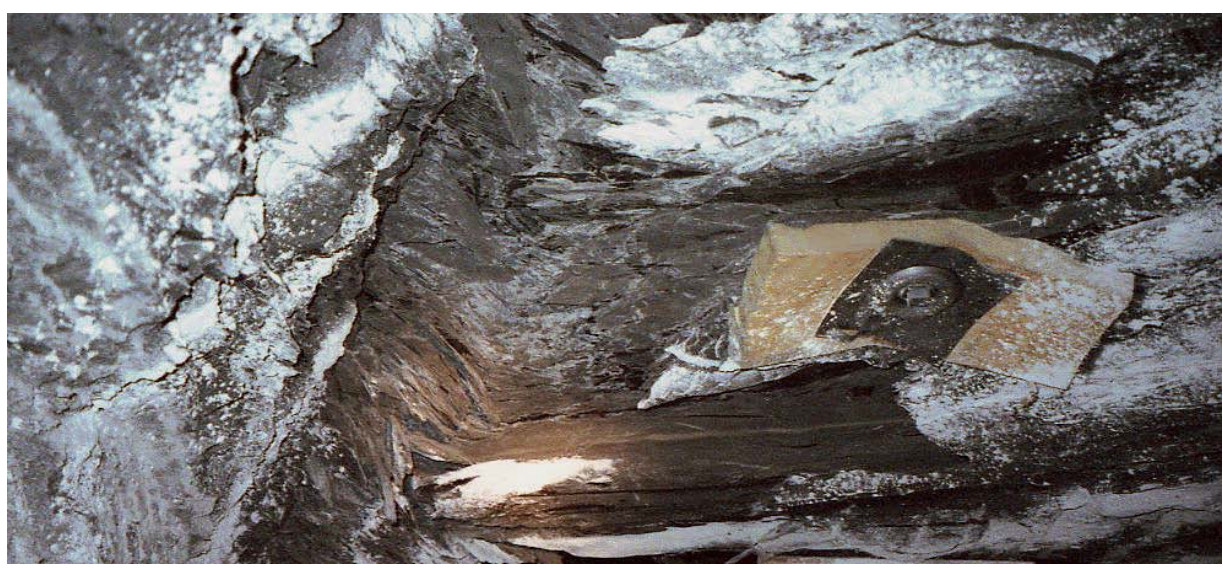

Figure 4.14 Cutter at the left corner of the \#6 entry between crosscut \#15 and \#17 (Peng, 2007)

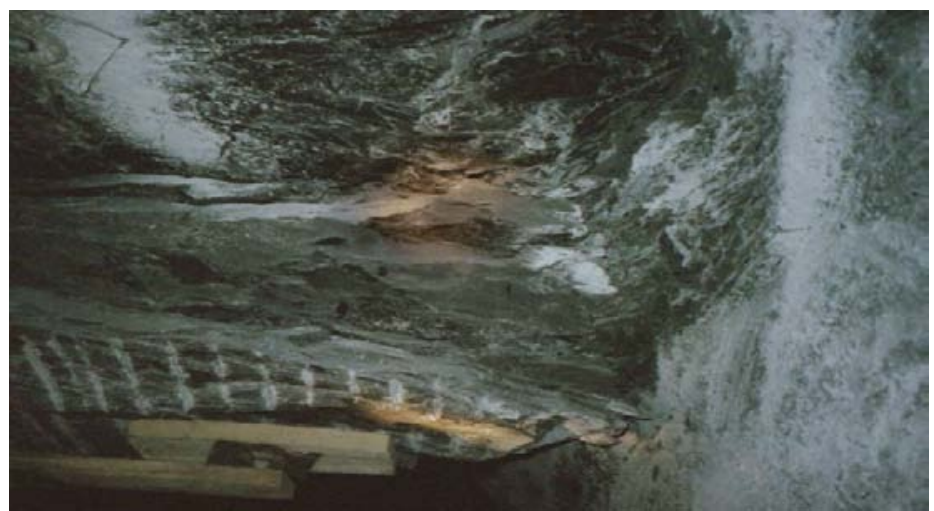

Figure 4.15 Cutter in crosscut \#17 between \#3 and \#4 entries (Peng, 2007)

\subsubsection{Case II- Cutters in the Lower Kittanning Seam}

This case took place between 1988 and 1990. The Lower Kittanning seam was about 3.3 to $4.2 \mathrm{ft}$ thick under a cover of $600-800 \mathrm{ft}$. The immediate roof was 
thinly laminated gray or dark shale at least 2-3 ft. thick. The immediate floor was shale, fireclay, or sandstone. All roof strata had visible vertical joints that were subparallel to north-south direction.

\section{Mining and Geological Conditions}

The mining method was longwall. The longwall panels were $600-700 \mathrm{ft}$. wide (rib-to-rib) by $3,500 \mathrm{ft}$. long and developed by the three-entry system. The entry and crosscut were $18 \mathrm{ft}$. wide, and the two rows of chair pillars were $80-100 \mathrm{ft}$ wide by $100 \mathrm{ft}$ long center-to-center. The panels were oriented such that the retreat mining direction was toward SW at $\mathrm{S} 32.5^{\circ} \mathrm{W}$ or the entries in the gateroad system were driven toward NE at $\mathrm{N} 57.5^{\circ} \mathrm{E}$ (Figure 4.16).

\section{In-situ stress field}

A number of inclined holes were drilled into the coal seam and in-situ stresses were measured using the USBM overcoring method. The measured in-situ stresses were:

$$
\begin{aligned}
& \sigma_{1}=3,750 \mathrm{psi} \\
& \sigma_{2}=3,229 \mathrm{psi} \\
& \sigma_{3}=1,233 \mathrm{psi}
\end{aligned}
$$

In the horizontal plane, the maximum principal stress and minimum principal stress were:

$$
\begin{aligned}
& \sigma_{\text {hmax }}=3,539 \text { psi oriented at } \mathrm{N} 52^{\circ} \mathrm{W} \\
& \sigma_{\text {hmin }}=2,, 020 \text { psi oriented at } \mathrm{S} 38^{\circ}
\end{aligned}
$$

Figure 4.16 Panel orientation with respect to stress direction

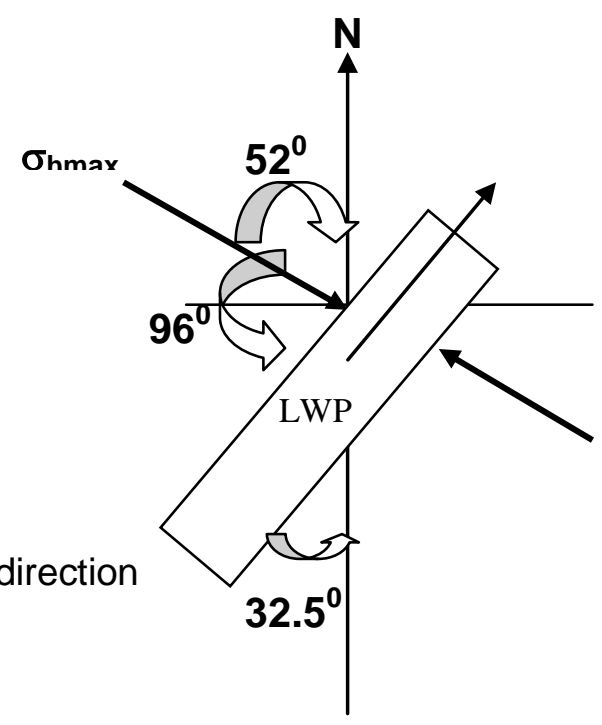


Since the longwall panels were oriented at $\mathrm{S} 32.5^{\circ} \mathrm{W}$, the maximum horizontal principal stress, $\mathrm{P}$, was intersecting the entries and crosscuts in the gateroad systems at $84^{\circ}$ and $6^{\circ}$ respectively (Figure 4.16). This is the worst direction from entry stability point of view, but not to crosscut stability.

\section{Cutter development}

The mine had a history of severe cutter roof problems in the gateroad development, including the entry and crosscut. Cutters occurred before, during, and mostly after mining in all entries, whether they were north-south oriented in the mains or east-west oriented in the panel gateroads.

An experimental gateroad system was developed to study the effects of various pillar and roof bolting system. An experimental gateroad system was designed to study the effects of various pillar and roof bolting systems on entry stability (Figure 4.17). Three pillar systems were laid out for trial-

- Two 4-entry yield-stiff-yield (40-140-40 ft. pillar system for two blocks followed by a $35-150-35 \mathrm{ft})$.

- One 3-entry stiff-yield systems. (120-40 ft. system, and finally a 120-33 ft system.)

The roof conditions were monitored in altogether at 8 different stages of gateroad development. From various stages monitoring, the most problematic entries were \#1 and \#4. There were almost no cutter roof problems in the crosscut. The pattern of cutter roof and its advance may have some correlation with high horizontal stress along with laminated immediate roof.

A few cutters developed in the entries are shown in Figures 4.18 and 4.19. 


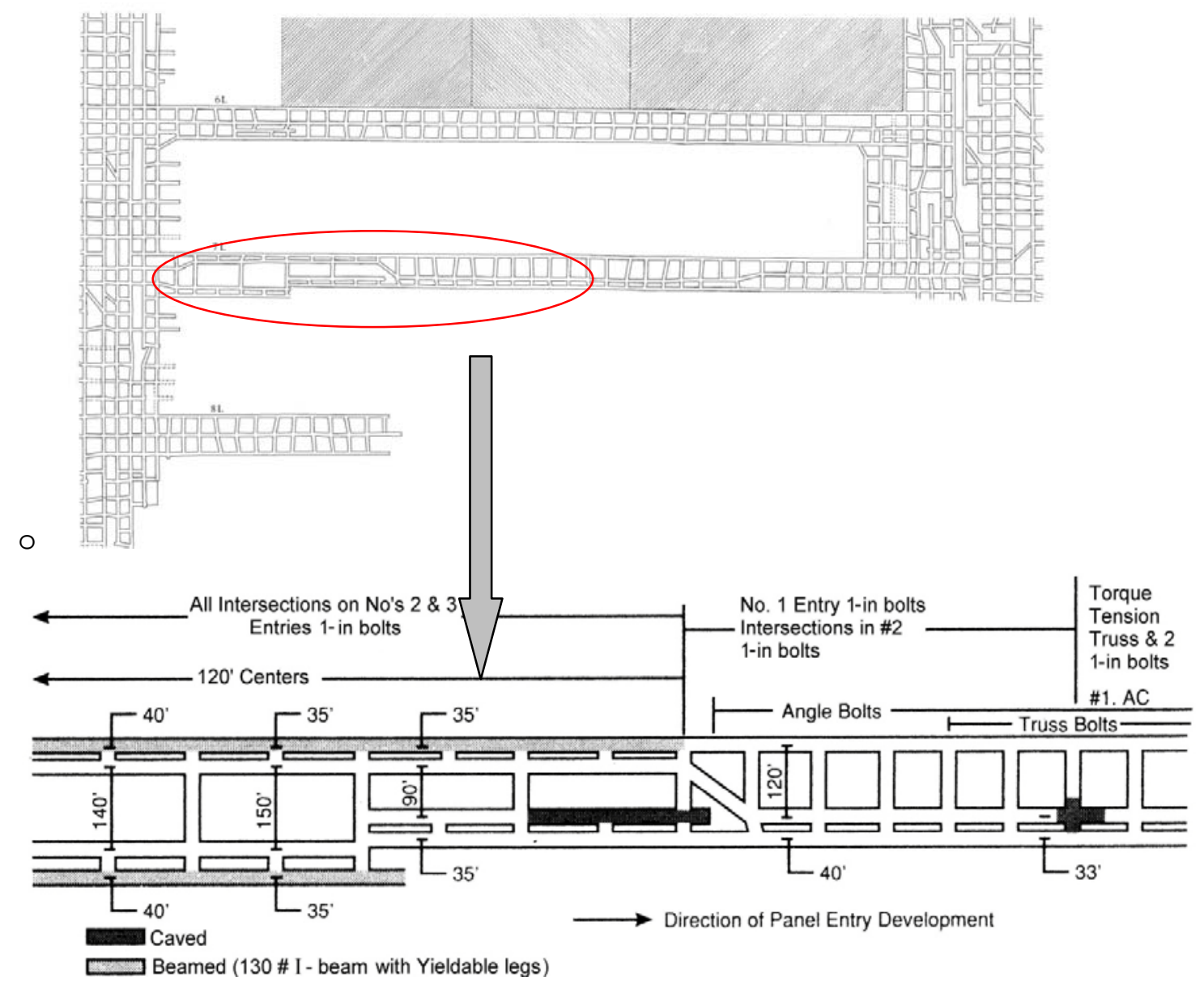

Figure 4.17 Experimental gateroad system showing different types of roof support and pillar systems in different sections (Khair, 1990; Peng, 2007)

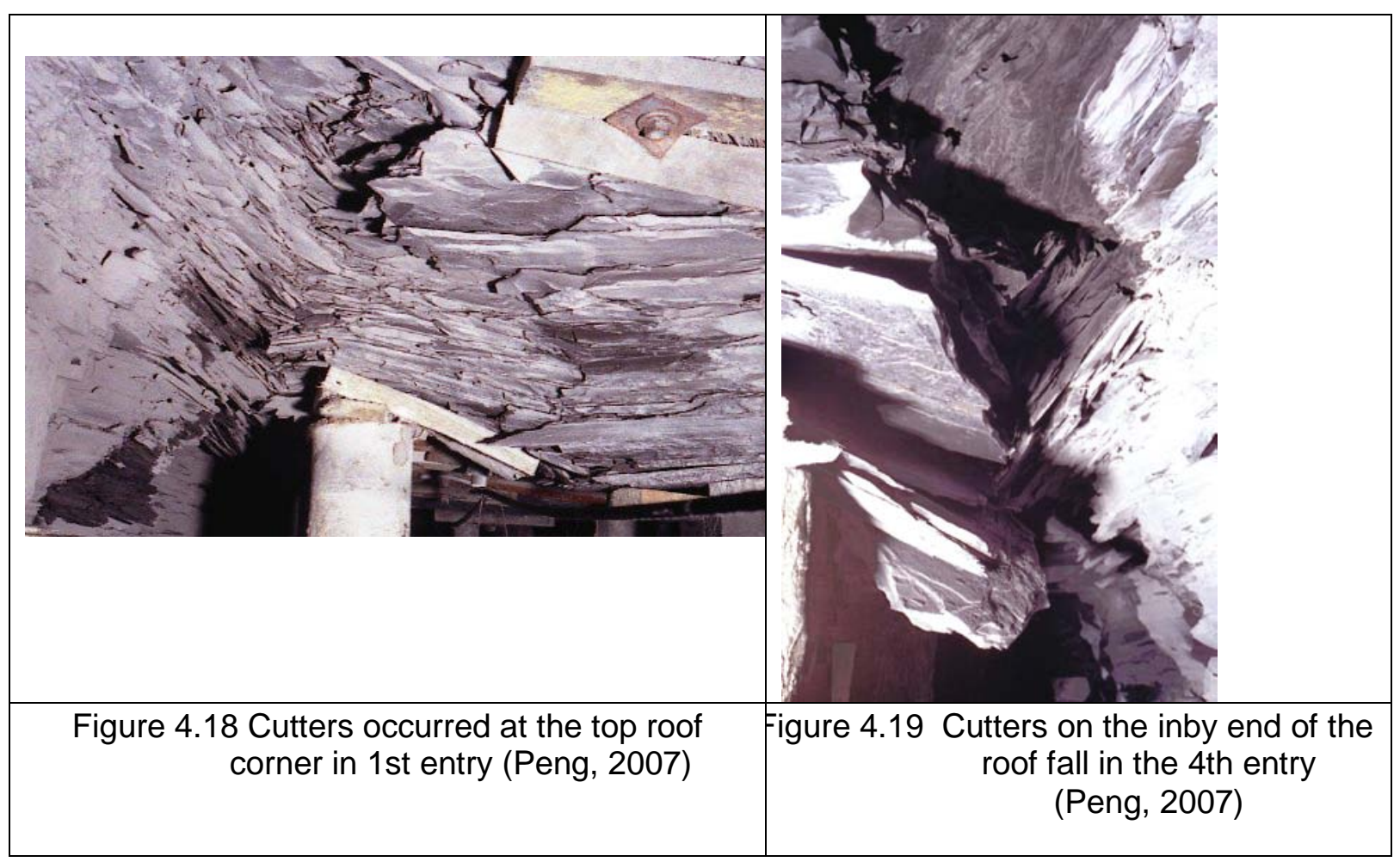




\subsubsection{Case 3- Cutters in Herrin \#6 Seam}

This case occurred between 2003 and 2004 and involved a room and pillar mine extracting the Herrin \# 6 seam. The seam averaged $5.8 \mathrm{ft}$. thick under a cover of approximately $240 \mathrm{ft}$.

The mine was developed by the 7 - or 8-entry system with the 3rd and 4th entries from the left as the track and belt entries, respectively (Figure 4.20). The production panels were also 7-entry systems developed in 4-5 blocks deep on advance and retreat. Entries and crosscuts were 18-19 ft wide. Chain pillars were 40 x $50 \mathrm{ft}$. rib-to-rib in mains and $40 \times 40 \mathrm{ft}$. rib-to-rib in production panels.

The immediate roof was very thinly laminated shale, 5-6 ft thick in the west, but 8-9 $\mathrm{ft}$ thick in the northeast of the mine property. There were thin films of darker siderite layers that tended to form the roof top, or when roof falls occurred, the top of the cavities. Overlying this thinly-laminated shale was firm shale of varying thickness and occasionally sandstone. The floor was unconsolidated claystone of varying thickness.

\section{Observations during first visit}

During first follow up trip various roof falls and cutters were observed (Peng, 2007). The following features of roof falls and cutters were observed-

- The roof fall occurred about one week after mining, some rapidly, while some slowly, more in the north-south direction than in the east-west direction

- The height of roof fall was either 5-6 or more than $9 \mathrm{ft}$ high.

- The roof fall occurred randomly either at intersections or between pillars and began normally less than one pillar block in size and then connected with adjoining entries/crosscuts to become stepwise 
- Mapping of cutters on the 2 nd southeast (SE) panel showed that cutters formed in all entries and crosscuts, some independently and others inter-connected (Figure 4.21). The cutters were distributed on irregular pattern.

Figure 4.22 shows the cutter at different stage which ultimately leads to massive roof fall.

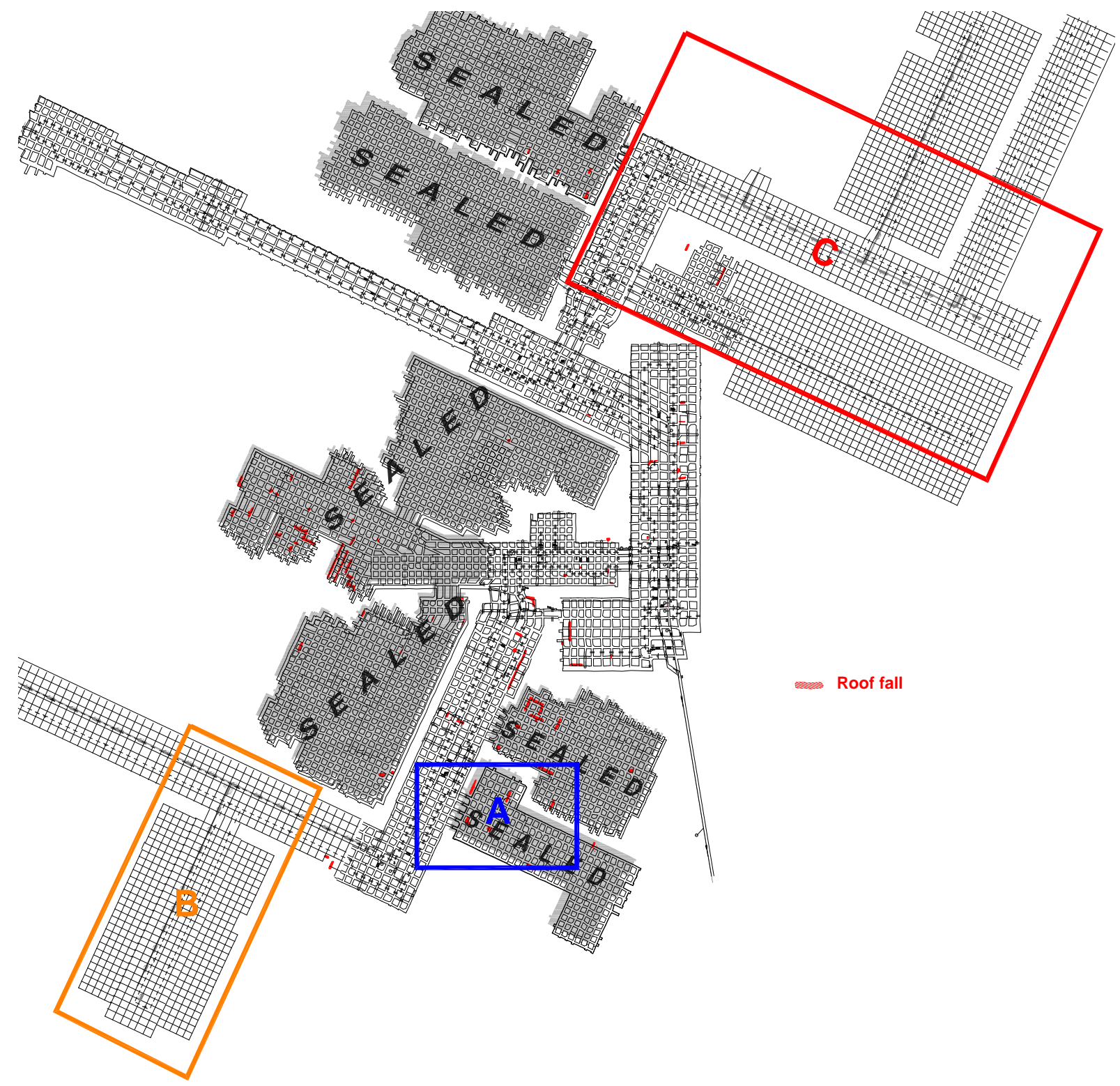

Figure 4.20 Mine layout and development when the investigation began (Peng, 2007) 


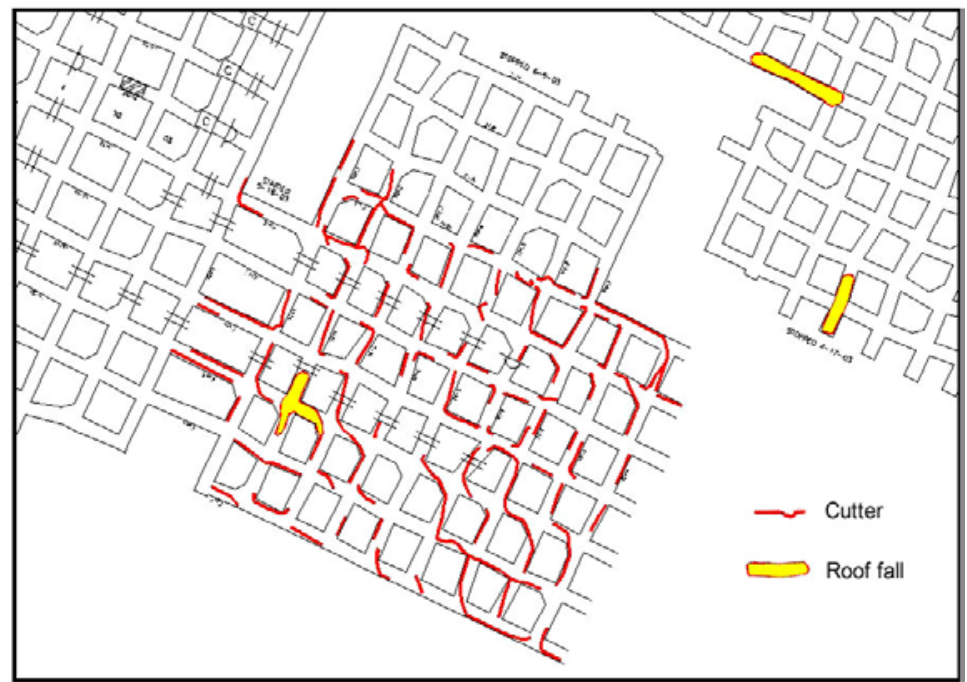

Figure 4.21 Mapping of cutters in the 2nd SE panel (Block A in Figure 4.24)
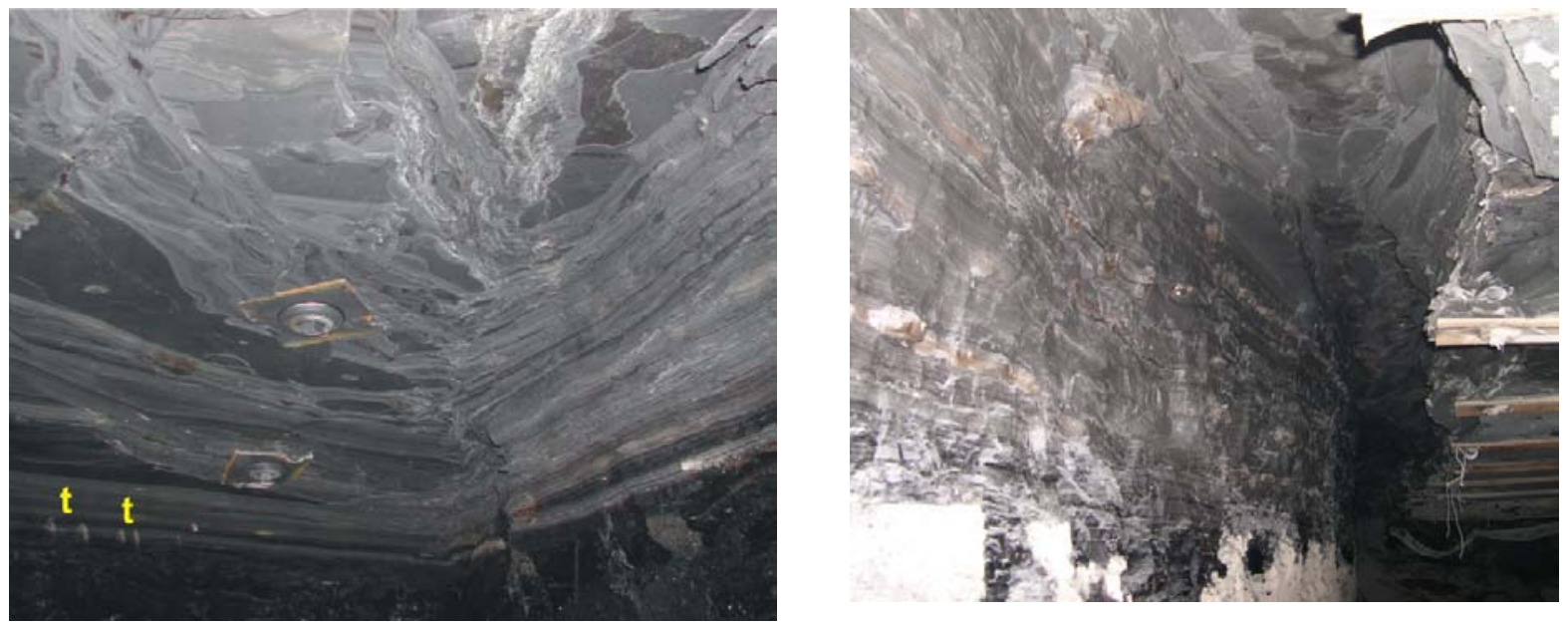

a. Cutters in development stage

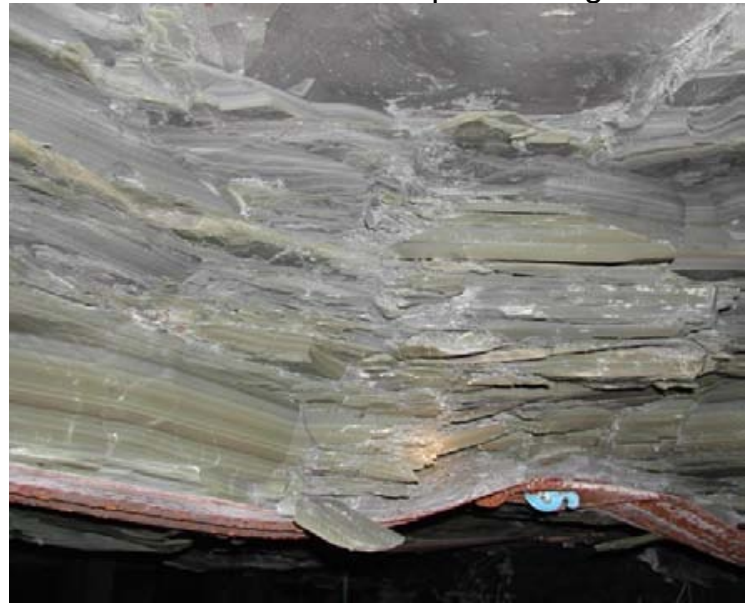

b. Cutters in advance stage

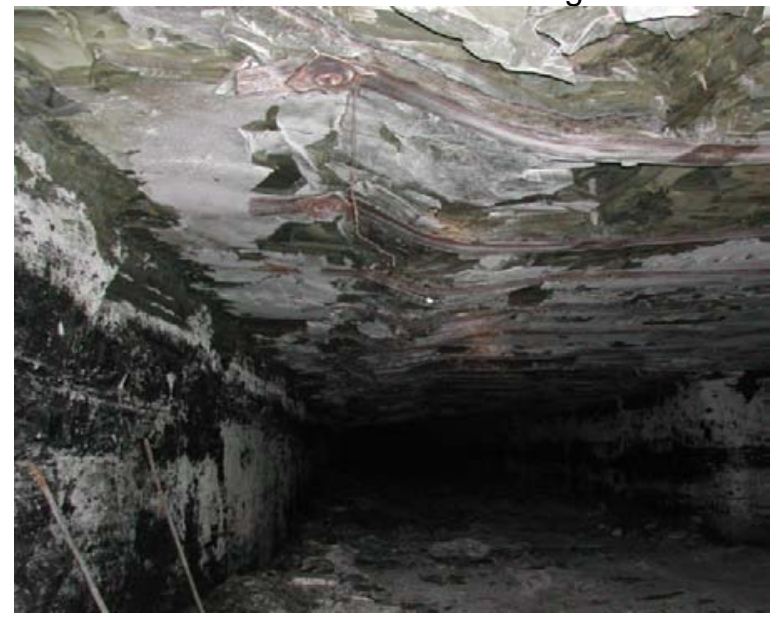

c. Broken roof between two adjacent bolts that were held up by straps, contd.. 

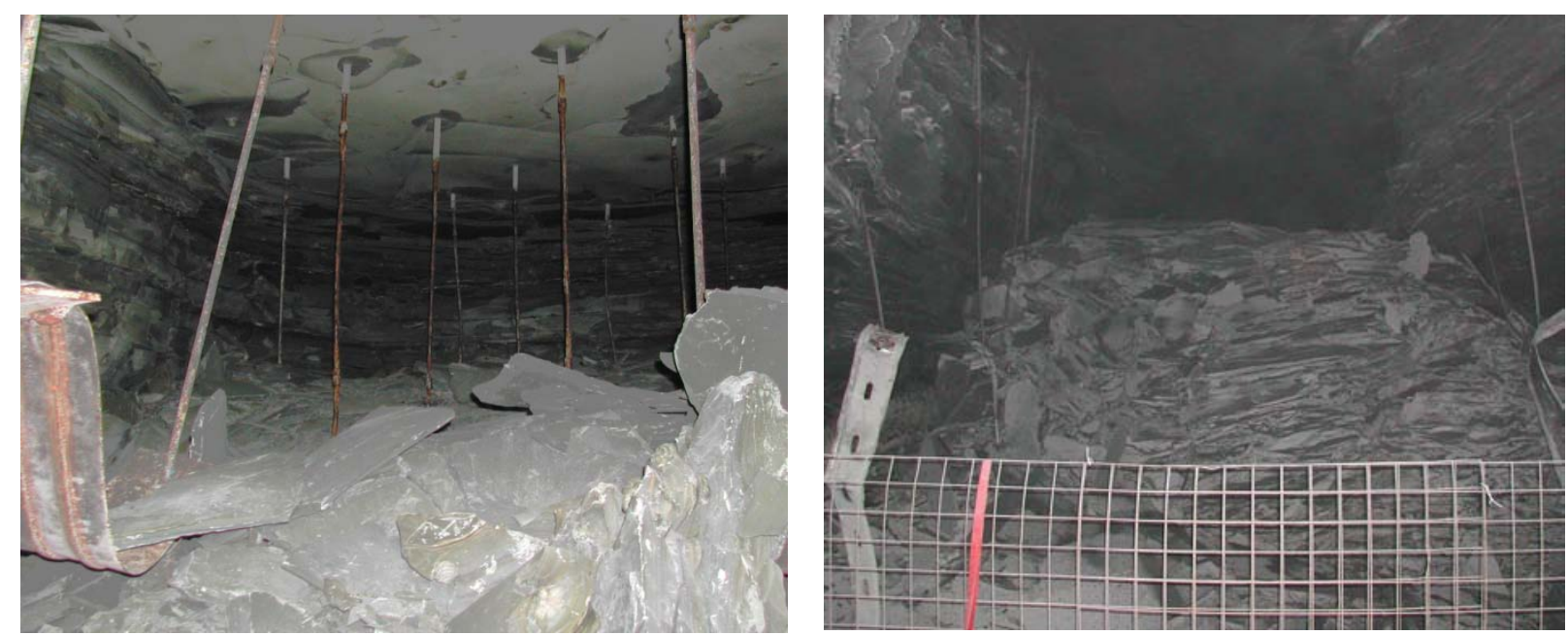

d. Massive roof falls

Figure 4.22 Cutters and roof falls observed at Herrin \#6 seam (Peng, 2007)

\subsubsection{Common observations from case studies-}

- The cutters can form at all working places in entries and crosscuts.

- The duration for the cutter development was from 5 minutes to several hours. Thus it can form immediately after the continuous miners cut or after several feet of face advance.

- The stages of cutters can be different depending upon the site specific parameters.

- The immediate roof was typically highly laminated and it may be one of the important reason for the immediate development of the cutter.

- The maximum horizontal stress orientation has significant influence on cutter formation as revealed from case 2.

- The cutters develop in sequences and progressively extend upward away from the roof and rib corner.

- $\quad$ The cutters are sometimes very irregularly distributed as shown in Figure 4.21 for case 3 . 


\subsection{UNDERSTANDING CUTTER DEVELOPMENT FOR NUMERICAL MODELING}

Even though rock is generally classified as a brittle material, it can exhibit ductility if sufficient confining pressure or temperature is applied (Figure 4.23) (Mogi 1966, 1974). In typical coal mining conditions, temperature is not a major variable, rock strength behavior is generally controlled by confinement at the point of interest. A typical set of complete stress-strain curves in compression for a rock at different confining pressures is shown in Figure 4.24. It must be noted from this figure that rock can exhibit strain-softening (curves I and II), perfectly-plastic (curve III) or strainhardening (curve IV) behavior depending on the amount of confining pressure $\left(\sigma_{3}\right)$ applied. The confining pressure corresponding to curve III is generally called the brittle-ductile transition pressure.

Tests on some hard rock show that for the rock to behave perfectly-plastically or strain-hardening, the magnitude of confining pressure needed is quite high. In fact, based on a series of tests, Mogi (1966) proposed that the rock will have a brittle to ductile transition if the confining pressure $\left(\sigma_{3}\right)$ exceeded $\sigma_{1} / 4.4$, with $\sigma_{1}$ being the major principal stress. In a typical coal mine entry immediate roof, confining pressures of the order needed for ductile behavior do not generally exist. This can easily be verified by running an elastic model of the problem under investigation. Therefore, realistically, the constitutive behavior used for modeling coal mine roof rocks should behave like Curves I or II in Figure 4.24. Since real materials always have a finite strength, simulating rock as an elastic material (curve $\mathrm{V}$ ) - with infinite strength - may not produce realistic results. This is particularly the case when the rock strength is small in comparison to the stress field acting on it. 


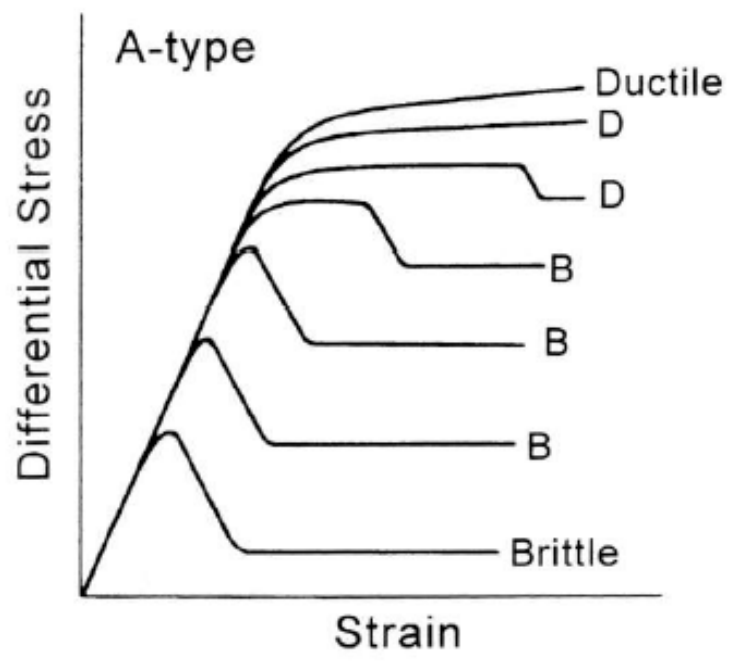

Figure 4.23a Typical stress strain curves for ' $A$ ' type rocks for different confining pressure (Mogi 1966)

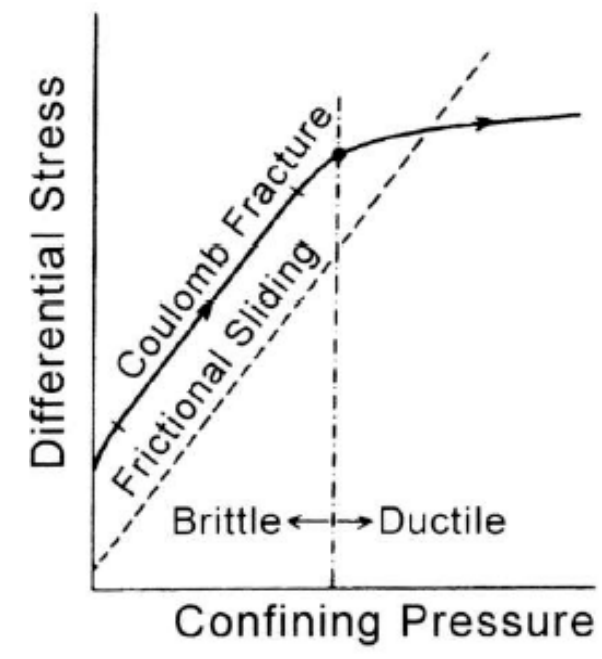

Figure $4.23 \mathrm{~b}$ Strength versus pressure curve and the failure behavior (Mogi 1974)

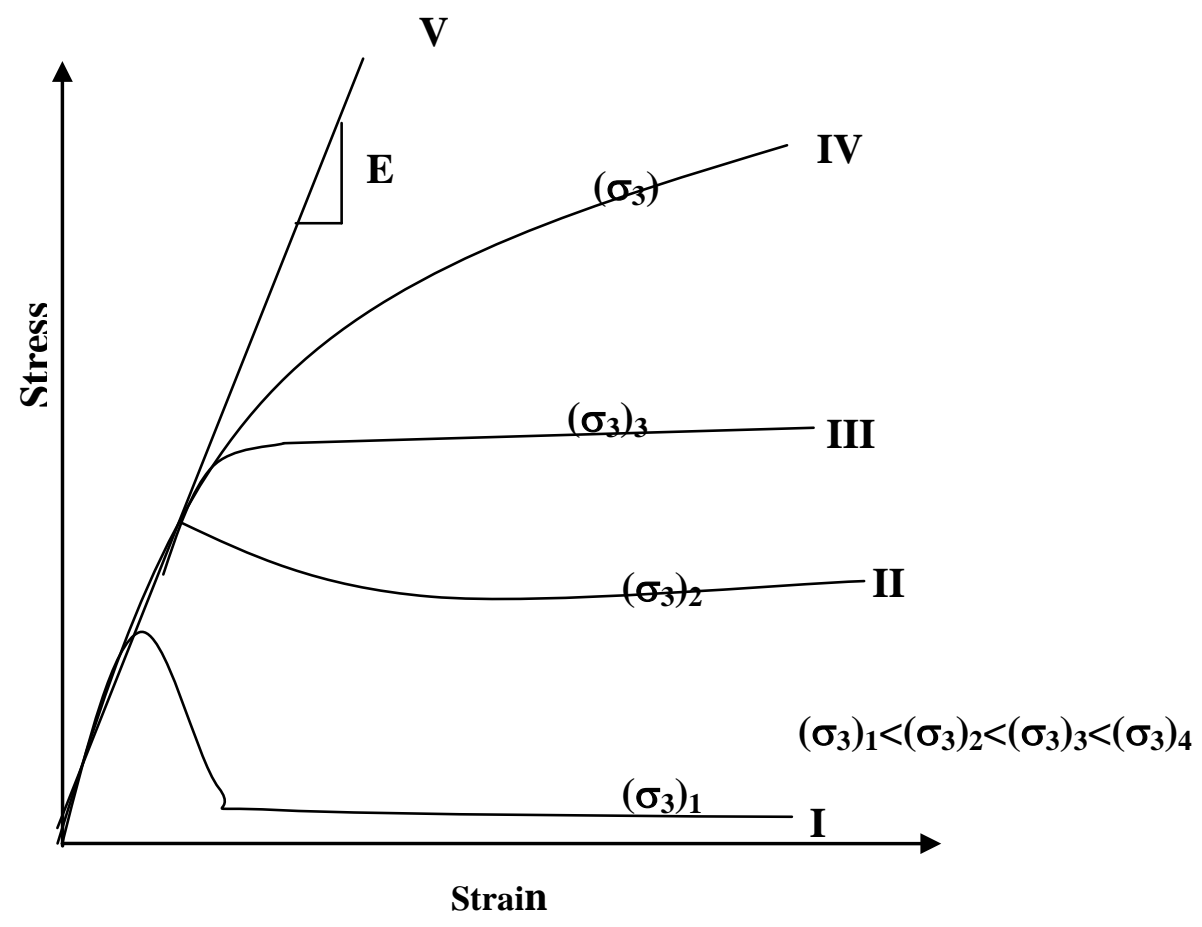

Figure 4.24 Typical stress strain curve showing confinement effect

When the finite strength of rock is considered in the modeling, the final material behavior in the post-failure (or plastic) state is also dependent on the stress history. If that were the case, then due consideration must be given to the sequential 
process of coal mine development to make any simulation realistic. This important feature has always been conspicuously ignored in past research, probably because of the very long model solving times needed. Entry formation in coal mines is a sequential process that involves extraction of coal by machines or blasting. The cutting sequence and the way coal is cut in each step are important in determining the final roof behavior. After each cutting step, the stresses in the surrounding rockmass reach a new state of equilibrium corresponding to the loads imposed by that particular geometry. With further advance of the face, the geometry of excavation changes and this alters the stress distribution in the surrounding rockmass. If due consideration is not given to this sequential process and only the final geometry is simulated in modeling, then stress states and rockmass response (i.e. failure) for the intermediate stages are completely ignored, which may have an influence on the final model response. Simulating such a step-by-step process is not critical for an elastic analysis, but the stress history is extremely important when elastic-plastic constitutive behavior with failure is used.

Based on the foregoing explanations, it is apparent that numerical cutter roof simulation is a daunting task and any modeling undertaken to reproduce failure patterns or explain phenomenon noticed in the field must take into account the particular features (both field and laboratory) discussed above. Therefore, a realistic numerical model must consider the progressive failure behavior of cutters in a multiple excavation setup that is created in several sequential cuts. Modeling approaches short of this would only produce results applicable under limited conditions. 


\section{CHAPTER 5}

\section{MODELING TECHNIQUE FOR CUTTER ROOF SIMULATION}

\section{$5.0 \quad$ INTRODUCTION}

In order to simulate the cutter development processes involved in cutter roof failure, the material model used should be able to incorporate the physical mechanism as shown in Figures 4.9, 4.10 and 4.11 as closely as possible. For better understanding of cutter mechanism, the model should include discrete fractures. There is not a criterion available for generating fractures in rocks and their inclusion in numerical software while solving the models. The best possible way is to use the suitable material models within the limitations of the currently easily available modeling tools. One possibility is to 'remove' elements in the roof in a model once they satisfy some user defined failure criterion. The problem with the element removal approach, however, is that the element size plays a role in cutter development and propagation. In this approach, to get a realistic cutter pattern, the element size must be very fine, which in turn makes the modeling extremely time consuming and difficult to perform (Gadde and Peng, 2005)

To simulate the load transfer phenomenon associated with cutter roof failure, the best available alternative in continuum modeling is to use a strain-softening (SS) materail model (Gadde and Peng, 2005). In strain-softening, the material loses its load bearing capacity once it is loaded beyond its peak strength. The amount of post-failure resistance or strength is generally dependent on the amount of plastic strain and confinement offered by the rock. Therefore, such a constitutive behavior may realistically reproduce the rock behavior typified by Curves I and II in Figure 4.24 . 
Considering the cutter mechanisms described in Figure 4.10 and rock behavior in Figure 4.24, it is anticipated that continuum models that incorporate cutting sequence and strain-softening material behavior would produce realistic cutter patterns such as those in Figure 4.21.

\subsection{NUMERICAL MODELING PROGRAMME}

Because of complexity involved in the geometry, material, and boundary conditions in mining excavations no analytical solution can solve this problem. When the problem can not be solved analytically; it often now appropriate to use numerical methods that provide an approximate and possibly acceptable solution. In this research, a commercial 3-dimensional finite difference package has been used, this software can solve three dimensional problems with complex material and geometry conditions accurately.

For the present study, an explicit finite-difference based three-dimensional numerical modeling code; FLAC3D 3.1 (Itasca, 2007) has been used. FLAC3D is essentially an explicit finite difference program to numerically study the mechanical behavior of a continuous three dimensional medium as it reaches equilibrium or steady plastic flow. FLAC 3D is used in analysis, testing, and design by geotechnical, civil, and mining engineers. It is designed to accommodate any kind of geotechnical engineering project where continuum analysis is necessary. At present this is most powerful and popular numerical software and widely used for mining applications. This code is based on an explicit solution technique, in which the evolution of a system is computed by means of a time-stepping numerical integration of Newton's equations of motion for grid points or blocks within the model. Nonlinear effects arising from material yield in shear or tension can be treated using Mohr- 
Coulomb and other elasto-plastic constitutive models, as can nonlinear response associated with large strains and deformations. Interface elements can be placed between regions of a rock mass, to simulate slip and separation on a major fault or other discontinuity. 'Cable' elements are available to represent the behavior of grouted bolts or anchors, and beam elements for modeling tunnel linings, etc.

For every time step, the calculation sequence can be summarized as follows.

- New strain rates are derived from nodal velocities.

- Constitutive equations are used to calculate new stresses from the strain rates and stresses at the previous time.

The equations of motion are invoked to derive new nodal velocities and displacements from stresses and forces. The sequence is repeated at every timestep, and the maximum out-of-balance force in the model is monitored. This force will either approach zero, indicating that the system is reaching an equilibrium state, or it will approach a constant, non-zero value, indicating that a portion (or all) of the system is at steady-state (plastic) flow of material. The calculation may be interrupted at any point in order to analyze the solution (Itasca, 2007).

In order to set up a model to run a simulation with FLAC 3D, three fundamental components of a problem must be specified:

- a finite difference grid;

- constitutive behavior and material properties; and

- boundary and initial conditions.

The grid defines the geometry of the problem. The constitutive behavior and associated material properties dictate the type of response the model will display upon disturbance (e.g., deformational response due to excavation). FLAC 3D can 
accommodate various types of constitutive behavior of the material. Boundary and initial conditions define the in-situ state (i.e., the condition before a change or disturbance in the problem state is introduced).

\subsubsection{Rock Failure criteria}

Among the many constitutive behavior the Mohr-Coulomb and Hoek-Brown rock failure criteria are most popular. Gadde et al. (2007) has performed the performance of these two criteria for the coal measure rocks (Figure 5.1). It has been found that Hoek-Brown criteria performs well both in compressive and tensile zone where as Mohr-coulomb criteria well suits for the compressive region while overestimates the strength in the tensile region. But a provision of tensile cut-off, which is available in FLAC3D, the Mohr-Coulomb criterion has been used in this research.

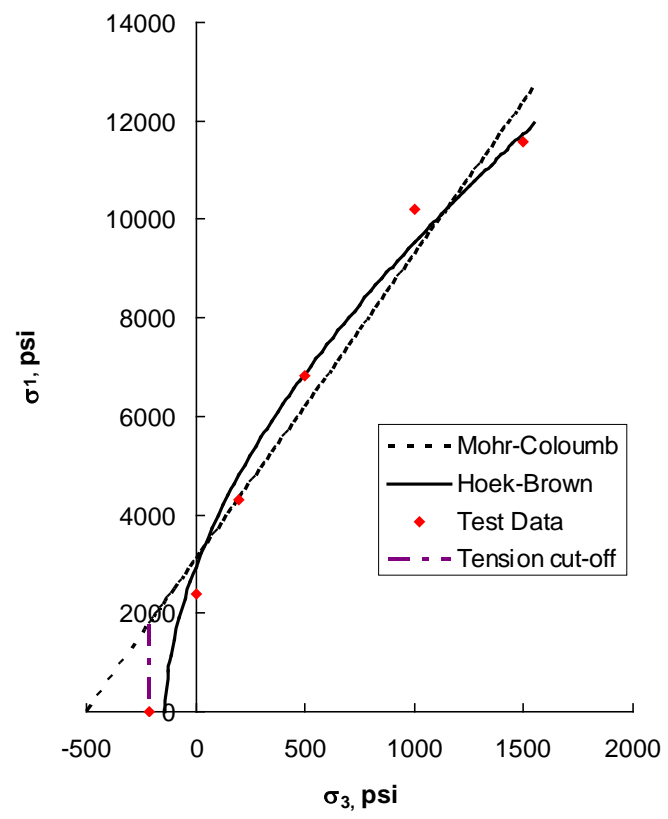

Figure 5.1 Performance of Mohr-Coulomb and Hoek-Brown criteria for the measured coal measure rock data (Gadde et al.,2007) 


\subsubsection{Mohr Coulomb criteria}

The Mohr-Coulomb failure criteria is basically a linear failure surface corresponding to shear failure as represented by: (Itasca, 2007)

$$
\begin{gathered}
f_{s}=\sigma_{1}-\sigma_{3} N_{\phi}+2 c \sqrt{N_{\phi}} \\
\text { Where } N_{\phi}=(1+\sin \phi) /(1-\sin \phi) \\
\sigma_{1}=\text { major principal stress } \\
\sigma_{3}=\text { minor principal stress } \\
\phi=\text { friction angle } \\
C=\text { cohesion }
\end{gathered}
$$

Shear yield is detected if $f_{s}<0$. The two strength constants, $\phi$ and $C$ are estimated from the laboratory tri-axial tests.

The Mohr-Coulomb failure criterion can be re-written in normal stress-shear stress space as

$$
\tau=c_{\text {peak }}+\sigma \tan \phi_{\text {peak }}
$$

where $\tau$ and $\sigma$ are shear and normal stresses at the point of interest respectively, $c_{\text {peak }}$ is the peak cohesion of rock, and $\phi_{\text {peak }}$ is the peak angle of internal friction. The Mohr-coulomb criteria for strain softening material can be written as

$$
\tau=c\left(\varepsilon_{p}\right)+\sigma_{n}\left(\varepsilon_{p}\right) \tan \phi
$$

The first term in the right side of the equation is the plastic-strain dependent cohesive strength component and second term is the plastic-strain dependent 
frictional strength component. Since the effect desired in strain-softening modeling is a reduction of rock strength in the post failure state, from above Equation 5.3 , it is apparent that reducing the values of $c$ and $\phi$ with plastic strain, $\varepsilon_{p}$ will provide the desired effect.

FLAC 3D employs Mohr-Coulomb failure criterion to detect the onset of material failure and adopts cohesion, (c) and angle of internal friction, ( $\phi)$ degradation method with plastic strain, $\mathrm{e}^{\mathrm{ps}}$ to implement the strain-softening behavior as shown in Figure 5.2.

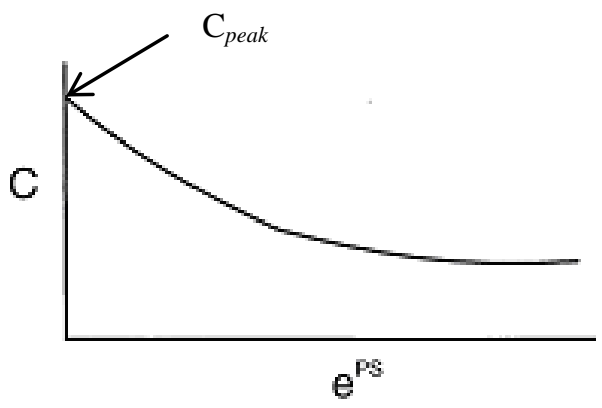

(a)

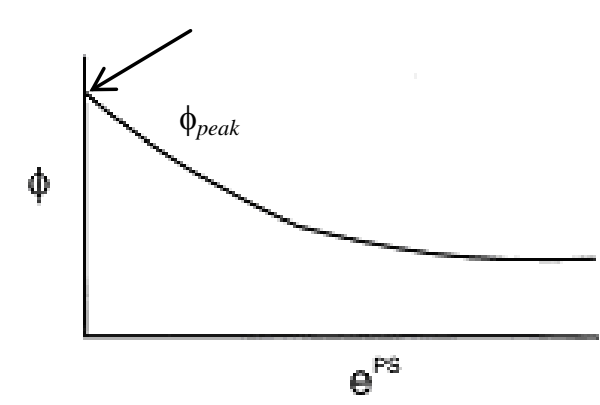

(b)

Figure 5.2 Cohesion and friction degradation with plastic strain

In $\mathrm{FLAC}^{3 \mathrm{D}}$, piecewise linear degradation of cohesion and internal friction is used to implement the strain-softening effect (Itasca, 2007, Figure 5.3). In FLAC 3D the user can define the cohesion, friction and dilation as piecewise-linear functions of hardening parameters measuring the plastic shear strain. The detail about this material behavior has been explained in FLAC3D manual of 'Theory and background' (Itasca 2007). 

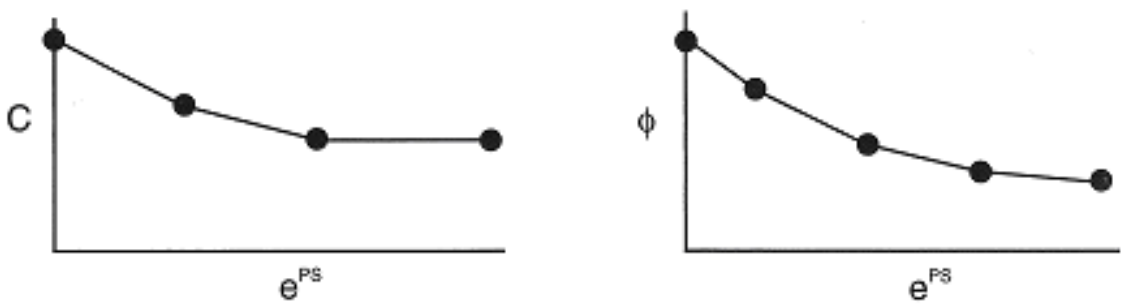

Figure 5.3 Piecewise liner approximations for cohesion and friction degradation with plastic strain

\section{1.3 Estimation of Rock Mass Strength}

To estimate the strength of the rock mass particularly in jointed one is a gigantic task for any researcher. In coal measure rocks, which most of the time comprises several discontinuities can not be represented by the laboratory scale testing and on the other hand in-situ strength testing of the rock mass is seldom practically or economically feasible. Back analysis of observed failures can provide representative values for large scale rock mass strength, but obviously, this is only when possible for cases in which rock mass failure has occurred. The more general problem of forward strength prediction for large scale in-situ rock mass is still one of the greatest challenges in ground control.

In laboratory, various test on rock specimens can be performed to estimate the uni-axial compressive strength (UCS), Brazilian tensile strength, and Young's modulus. If a triaxial test is conducted, which is not often done, then cohesion (c) and friction angle $(\phi)$ can be easily evaluated which required for the Mohr-Coulomb failure criteria. Similarly, the constant ' $m$ ' can be estimated for the Hoek Brown failure criteria. 
Even after estimation of laboratory strength parameters the main task is how to use a suitable reduction factor applicable to the actual in-situ rock mass. Most of the time researchers use a multiplying factor which may vary from 0.2 to 0.6 suited to their conditions and ability to simulate the known rock mass behavior. For example, Gale et al.(2004) used a strength reduction multiplying factor of 0.58 for the rock matrix to simulate the rock as ubiquitous joint type material.

Recently Gadde et al. (2007) have developed a very simple approach to estimate the strength reduction factor when the UCS tests are not available for different size of the specimen. The reduction factor, $R F$ is given by-

$$
\begin{aligned}
& R F=\left[\frac{T}{d}\right]^{-0.5} \text { if } T<48 \text { inches } \\
& R F=\left[\frac{48}{d}\right]^{-0.5} \text { if } T \geq 48 \text { inches }
\end{aligned}
$$

Where $T$ is the thickness of the stratum between any two adjacent bedding planes, and $d$ is the diameter or the edge length of the sample tested in the laboratory for UCS. $T$ and $d$ should have the same units. For rock mass strength estimation the procedure described by Gadde et al. (2007) has been used.

\subsection{COHESION AND FRICTION MOBILIZATION IN POST FAILURE ZONE}

For a strain softening material model, the post failure behavior of rock is expressed in terms of variation in the cohesion and friction of the material with the amount of plastic strain. There is no permanent cohesion in rocks, particularly for the brittle rocks at relatively low confinement, where the cohesional strength component is gradually lost when the rock is strained beyond its peak strength. In the strain 
softening model, the plastic strain limit at which the cohesional component of strength reaches a residual value and the frictional strength component mobilizes are two material properties that in reality, depend primarily on heterogeneity and grain characteristics. Till date, there is no sufficient real laboratory testing data are available for coal measure rock to be used for different rock material type. Hence the academicians and researchers use these properties of rock as per their assumption suitable for their modeling work. Most of the time researchers have used mobilization of cohesion and friction simultaneously in the post failure region. Some researchers used mobilization of friction in the post failure region at higher plastic strain more comparable to cohesion mobilization. Most of the strain softening models in the past has been used to simulate the coal behaviour rather than the immediate roof rocks.

Morsey and Peng (2001) uses Drucker- Prager failure criteria to simulate strain softening behaviour of coal. They used the coal strength of 900 psi (6.2 MPa) and assumed it drops at the rate of 4.8 psi $(0.03 \mathrm{MPa})$ in steps of 0.0039 plastic strain. The peak friction angle was assumed as $50.19^{\circ}$ and increases to $53.13^{\circ}$ in steps of 0.0039 plastic strain.

Badar et al. (2003) has used strain softening material model to simulate the coal pillar behaviour. He has used a peak strength of coal as 319 psi (2.2 MPa) which drops at the rate of 7,250 psi (50 MPa)/plastic strain until it reaches a residual cohesion of $14.5 \mathrm{psi}(0.1 \mathrm{MPa})$. The friction angle increased from $23^{\circ}$ to $30^{\circ}$ for plastic strain in steps of 0.005 and become constant until the plastic strain reaches 0.0078 (7.8 miliistrain).

Karl zipf (2005) has made some assumptions related to the rock properties to be used for strain softening material to carry out numerical modeling. He has assumed that cohesion decreases from its peak value to a residual value of $10 \%$ of 
peak over 5 millistrain of post failure strain. The friction angle remains constant and dilation angle reduces from 10 to $0^{0}$ over over 5 millistrain of post failure strain.

Hajiabdolmajid et al. (2002) proposed a material model called as Cohesion weakening -frictional strengthening (CWFS) model to simulate the brittle failure of hard rocks like granite in low confinement environments. This behavior was explained with the help of Figure 5.4. The cohesional component of strength is the predominant strength component at the early stage of brittle failure and cohesion loss is the predominant failure process leading to the observed brittle behavior. The cohesive strength is gradually destroyed by tensile cracking and crack coalescence. The normal stress-dependent frictional strength gets fully mobilized after the cohesional component of strength is significantly reduced, much damage has accumulated and when the rock fragments can move relative to each other in shear. In Figure 5.4, $\mathrm{c}_{\mathrm{i}}$ and $\mathrm{c}_{\mathrm{r}}$ are the initial and residual cohesion and $\varepsilon_{c}^{p}$ and $\varepsilon_{f}^{p}$ represent the plastic strain components when the frictional and cohesive strength components have reached the ultimate values.

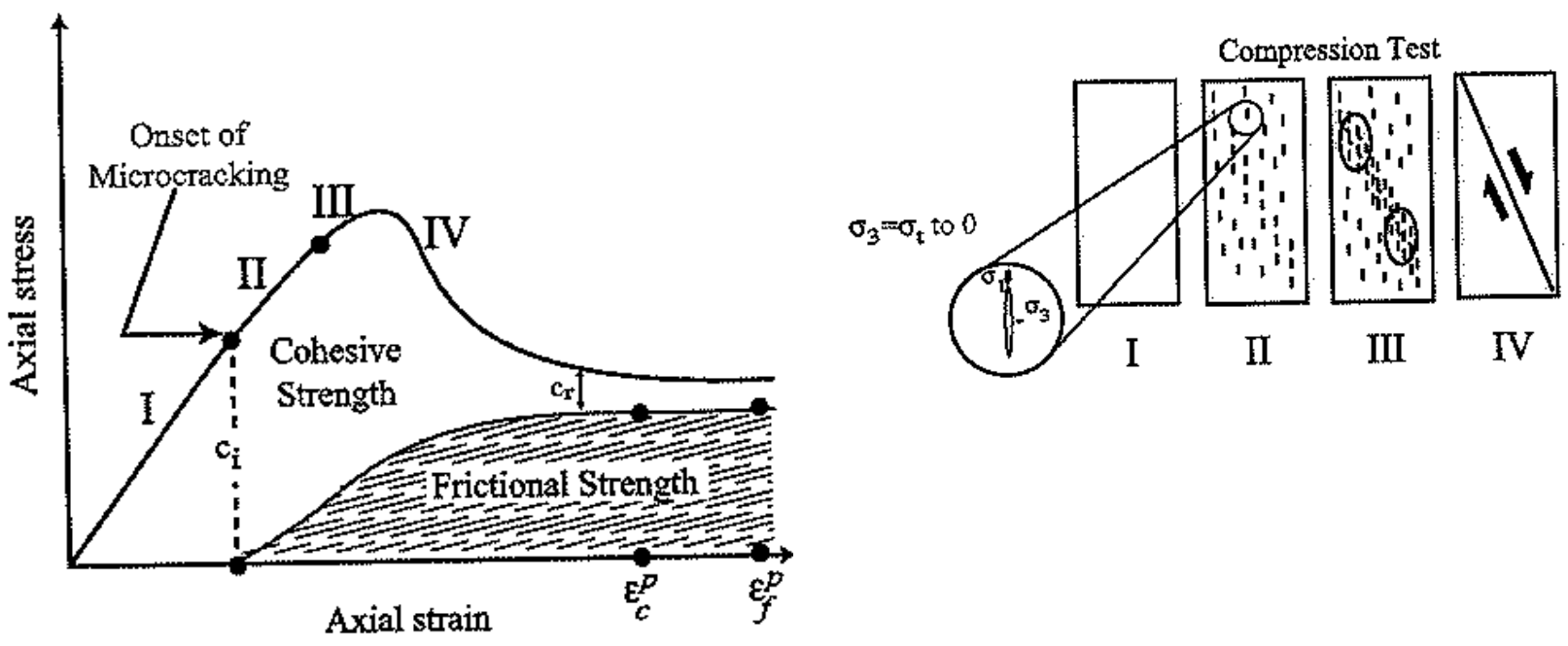

Figure 5.4 Mobilization of the strength components in the CWFS model in the laboratory compression test (Hajiabdolmajid, 2002) 
The illustration of the cohesion loss and frictional strength mobilizations as a function of plastic strain is shown in Figure 5.5.
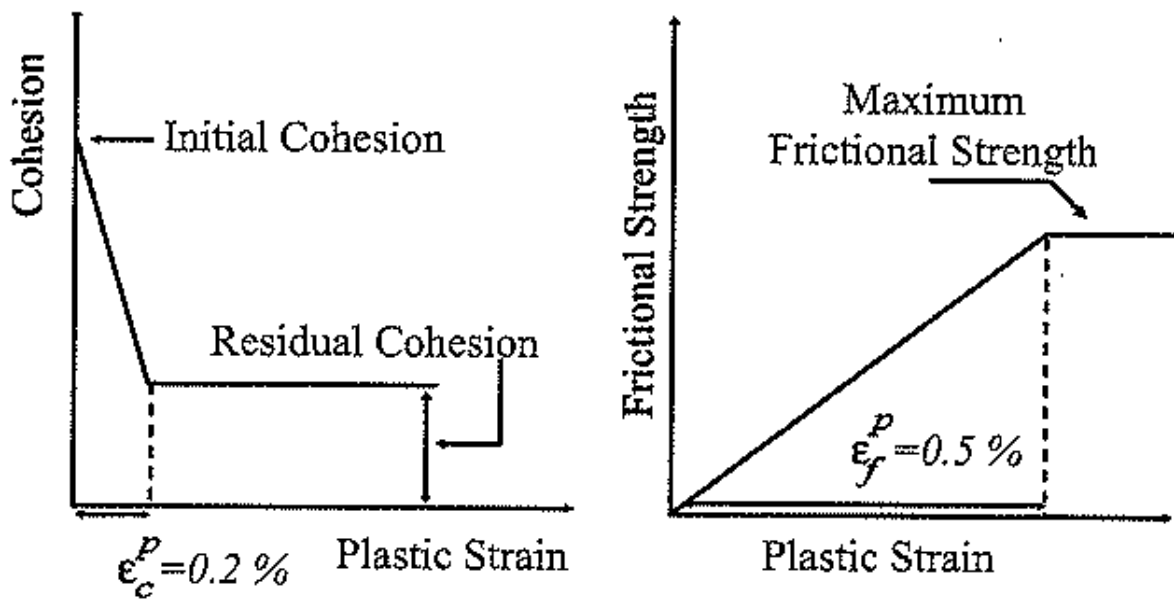

Figure 5.5 Mobilization of Cohesion and friction with plastic strain (Hajiabdolmajid, 2002)

Further, Gadde and Peng (2005) have used the cohesion and angle of internal friction degradation method to implement the strain-softening behavior of weak rocks as shown in Figure 5.6.

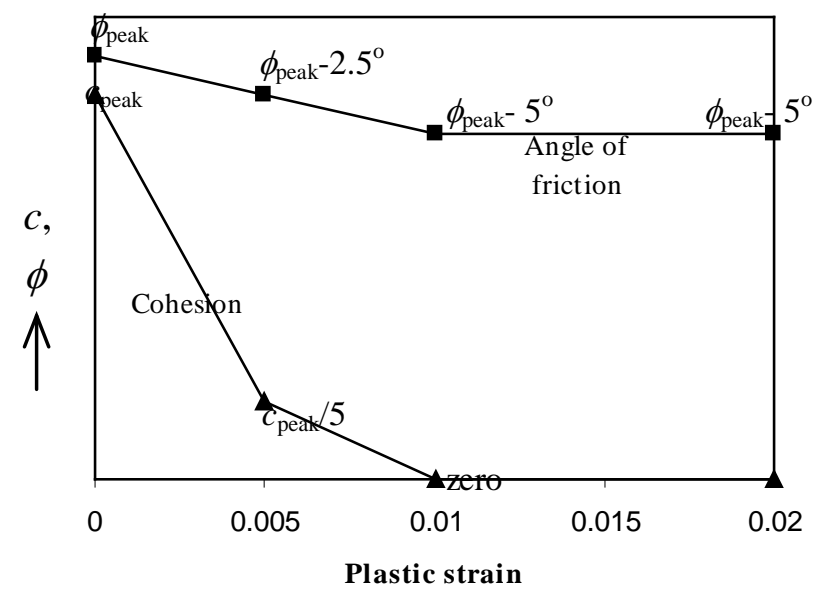

Figure 5.6 Variation of cohesion (c), and friction angle $(\phi)$, with plastic strain (Gadde and Peng, 2005) 
Based on the above literature it is very tough to decide which degradation method should be used. The best way is to get these rock properties based on the laboratory test results or by back analysis of the post-failure behavior of a material.

\subsection{LABORATORY METHOD TO ESTIMATE COHESION AND FRICTION IN POST FAILURE REGION}

In the following section, a displacement controlled tri-axial test for a rock specimen from a case study mine has been presented to describe the procedure to estimate the cohesion and friction angle with the plastic strain. These tests are required in order to get the real post failure properties for the simulation or calibration of the model.

The estimation of cohesion and friction variation with plastic strain for a FLAC 3D model to simulate the post failure behavior of the material consists of the following steps-

(i) Strain controlled tri-axial test is conducted using a rate of displacement of $3 \mathrm{~mm} / \mathrm{minute}$, i.e. $90 \mathrm{~mm}$ in 30 minutes.

(ii) At least 5 to 6 tests of same rock specimen at different confinement pressure are tested.

(iii) The stress-strain curve for all tested rock specimens are plotted (Figure 5.7 )

(iv) The maximum elastic strain is determined at the peak stress level or where yielding starts (Figure 5.8).

(v) Sigma1 is determined with varying linear plastic strain for a particular confinement pressure (sigma3). This calculation is repeated for all specimens having tested for different confinement pressure (Table 5.1). 
(vi) From the previous step, for a particular value of linear plastic strain the sigma1 and sigma3 is plotted (Figure 5.9). From this a linear relationship between sigma1 and sigma3 is developed by linear regression with a good correlation coefficient.

(vii) From the linear relationship the intercept provides the uniaxial compressive strength (UCS) and the slope gives the tri-axai factor $\left(N_{\phi}\right)$. By using the Mohr-Coulomb strength model the cohesion (c) and friction angle $(\phi)$ can be estimated for a particular linear axial strain.

(viii) In FLAC the input is required to be given in the form of plastic shear strain and corresponding cohesion and friction values. The plastic shear strain is estimated by the following equation (Itasca, 2007)-

$$
\Delta K^{s}=\frac{1}{\sqrt{2}} \sqrt{\left(\Delta \varepsilon_{1}^{p s}-\Delta \varepsilon_{m}^{p s}\right)^{2}+\left(\Delta \varepsilon_{m}^{p s}\right)^{2}+\left(\Delta \varepsilon_{3}^{p s}-\Delta \varepsilon_{m}^{p s}\right)^{2}}
$$

where, $\Delta \varepsilon_{m}^{p s}$ is the volumetric plastic shear strain given by

$$
\Delta \varepsilon_{m}^{p s}=\frac{1}{3}\left(\Delta \varepsilon_{1}^{p s}+\Delta \varepsilon_{3}^{p s}\right)
$$

The volumetric strain can be estimated from Figure 5.10 assuming a dilation angle of 5 or 10 degrees which are a typical value for a coal measure rocks. Knowing volumetric strain, $\Delta K^{s}$ can be determined. For this case the dilation angle of 10 degrees is assumed to estimate the volumetric strain. The cohesion and friction values estimated with plastic strain are given in Figure 5.11. 


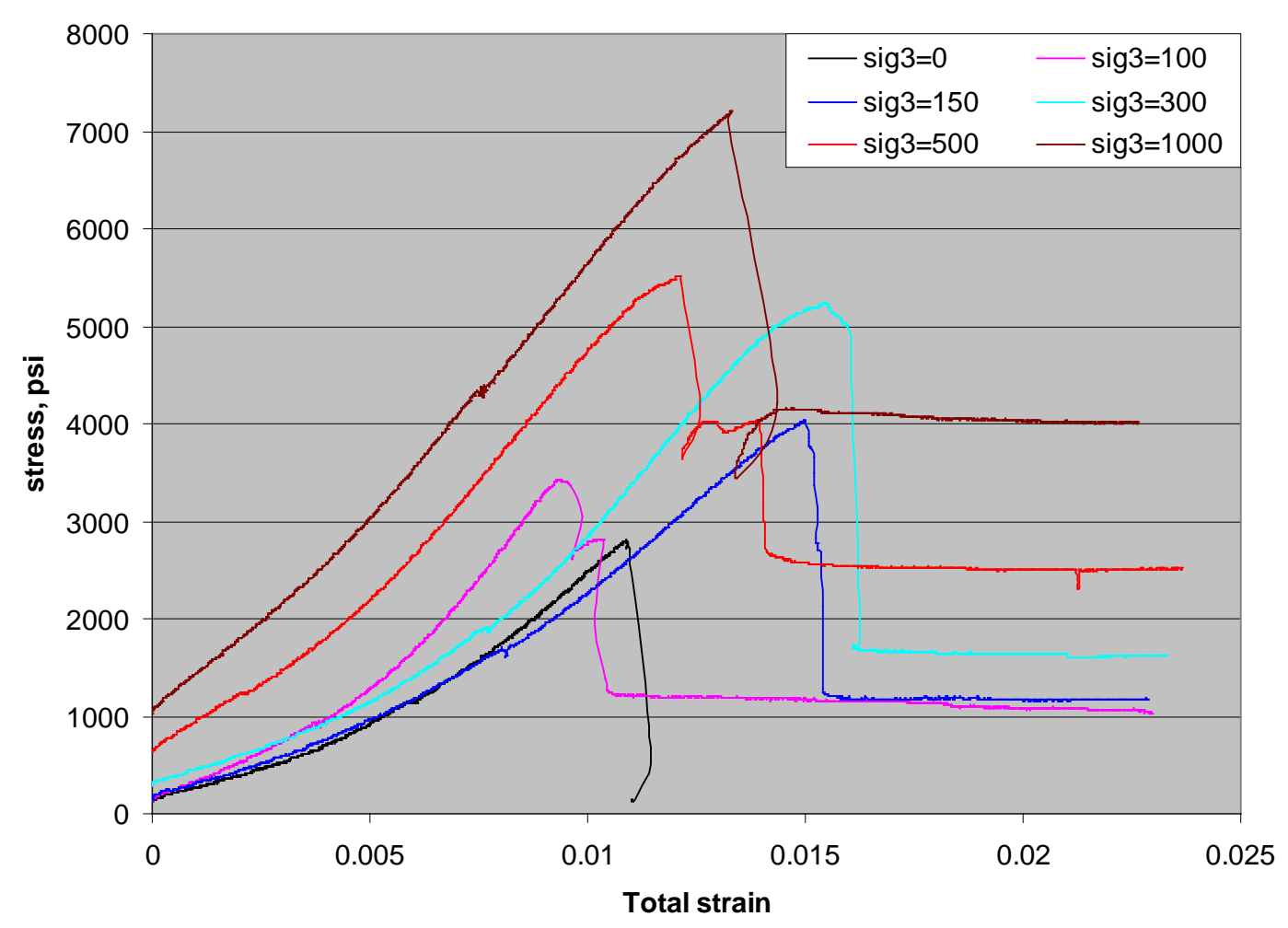

Figure 5.7 Typical stress vs strain curves for a tri-axial test of sandyshale rock

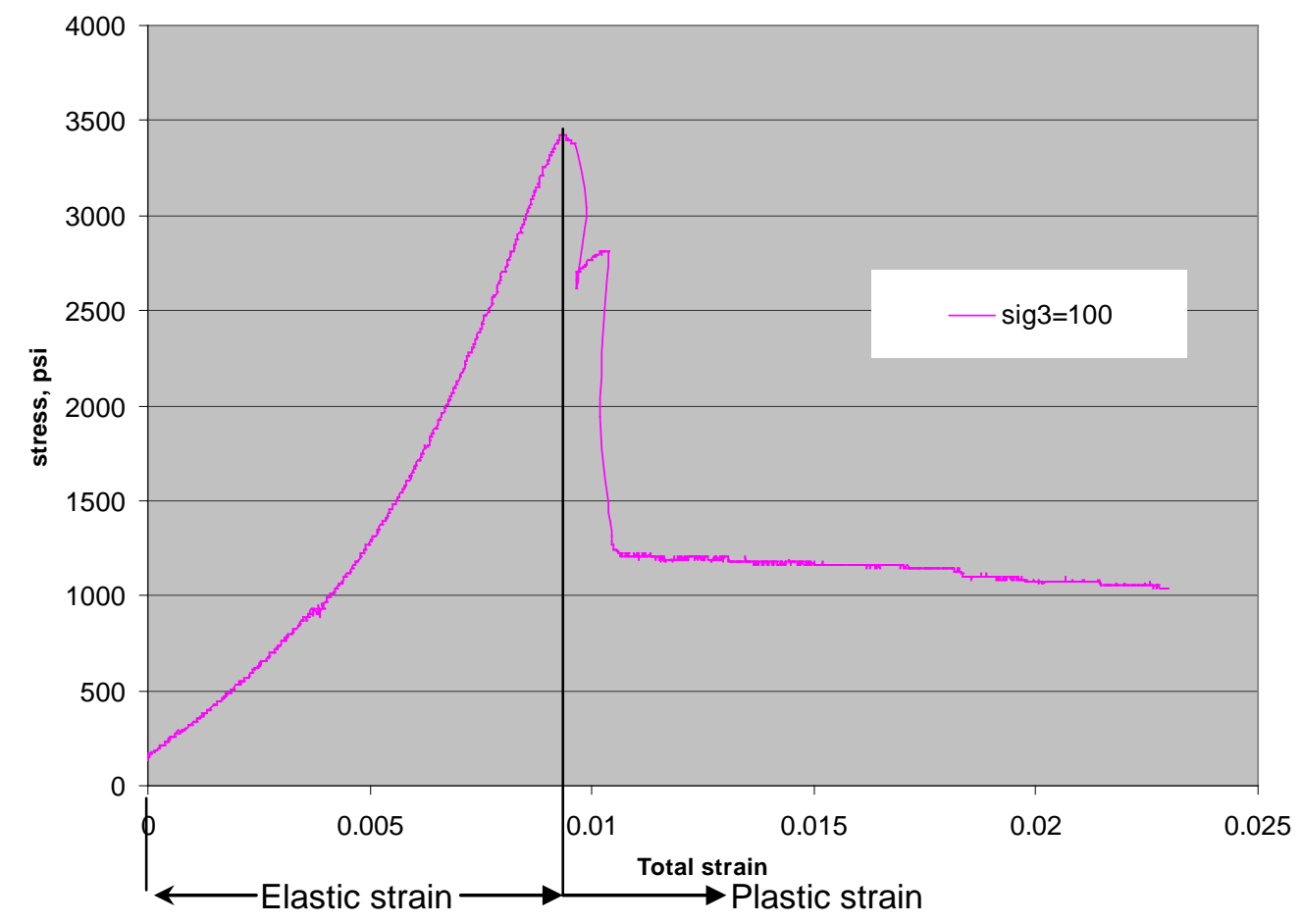

Figure 5.8 Stress-strain curve showing elastic and plastic strain 
Table 5.1 Plastic strain vs major principal stress

\begin{tabular}{|c|c|c|c|}
\hline $\begin{array}{l}\text { Confining pressure } \\
\text { (sigma3), psi }\end{array}$ & $\begin{array}{l}\text { Peak } \\
\text { elastic } \\
\text { strain }\end{array}$ & plastic strain & sigma1, psi \\
\hline \multirow[t]{3}{*}{0} & 10.9 & 0.00 & 2796 \\
\hline & & 0.10 & 2634 \\
\hline & & 0.50 & 589 \\
\hline \multirow[t]{10}{*}{100} & 9.41 & 0 & 3419 \\
\hline & & 0.19 & 3378 \\
\hline & & 0.48 & 3039 \\
\hline & & 0.79 & 1941.5 \\
\hline & & 0.99 & 1393 \\
\hline & & 1.19 & 1230 \\
\hline & & 1.69 & 1208 \\
\hline & & 2.29 & 1187 \\
\hline & & 6.29 & 1161 \\
\hline & & 9.29 & 1098 \\
\hline \multirow[t]{8}{*}{150} & 15 & 0.00 & 4039 \\
\hline & & 0.20 & 2825 \\
\hline & & 0.30 & 2630 \\
\hline & & 0.40 & 1284 \\
\hline & & 0.60 & 1199 \\
\hline & & 1.00 & 1199 \\
\hline & & 3.00 & 1183 \\
\hline & & 5.00 & 1160 \\
\hline \multirow[t]{8}{*}{300} & 15.5 & 0 & 5218 \\
\hline & & 0.2 & 5112 \\
\hline & & 0.4 & 5028 \\
\hline & & 0.5 & 4671 \\
\hline & & 0.8 & 1745 \\
\hline & & 1.9 & 1667 \\
\hline & & 5.4 & 1641 \\
\hline & & 7.8 & 1625 \\
\hline \multirow[t]{11}{*}{500} & 12.1 & 0 & 5483 \\
\hline & & 0.5 & 4160 \\
\hline & & 1.8 & 4018 \\
\hline & & 1.9 & 3766 \\
\hline & & 2 & 2774 \\
\hline & & 2.4 & 2610 \\
\hline & & 3.6 & 2547 \\
\hline & & 4.9 & 2541 \\
\hline & & 5.9 & 2522 \\
\hline & & 7.9 & 2500 \\
\hline & & 9.9 & 2500 \\
\hline \multirow[t]{8}{*}{1000} & 13.3 & 0 & 7203 \\
\hline & & 1 & 4222 \\
\hline & & 1.1 & 4137 \\
\hline & & 1.7 & 4137 \\
\hline & & 2.7 & 4116 \\
\hline & & 4.7 & 4075 \\
\hline & & 6.7 & 4031 \\
\hline & & 8.7 & 4011 \\
\hline
\end{tabular}




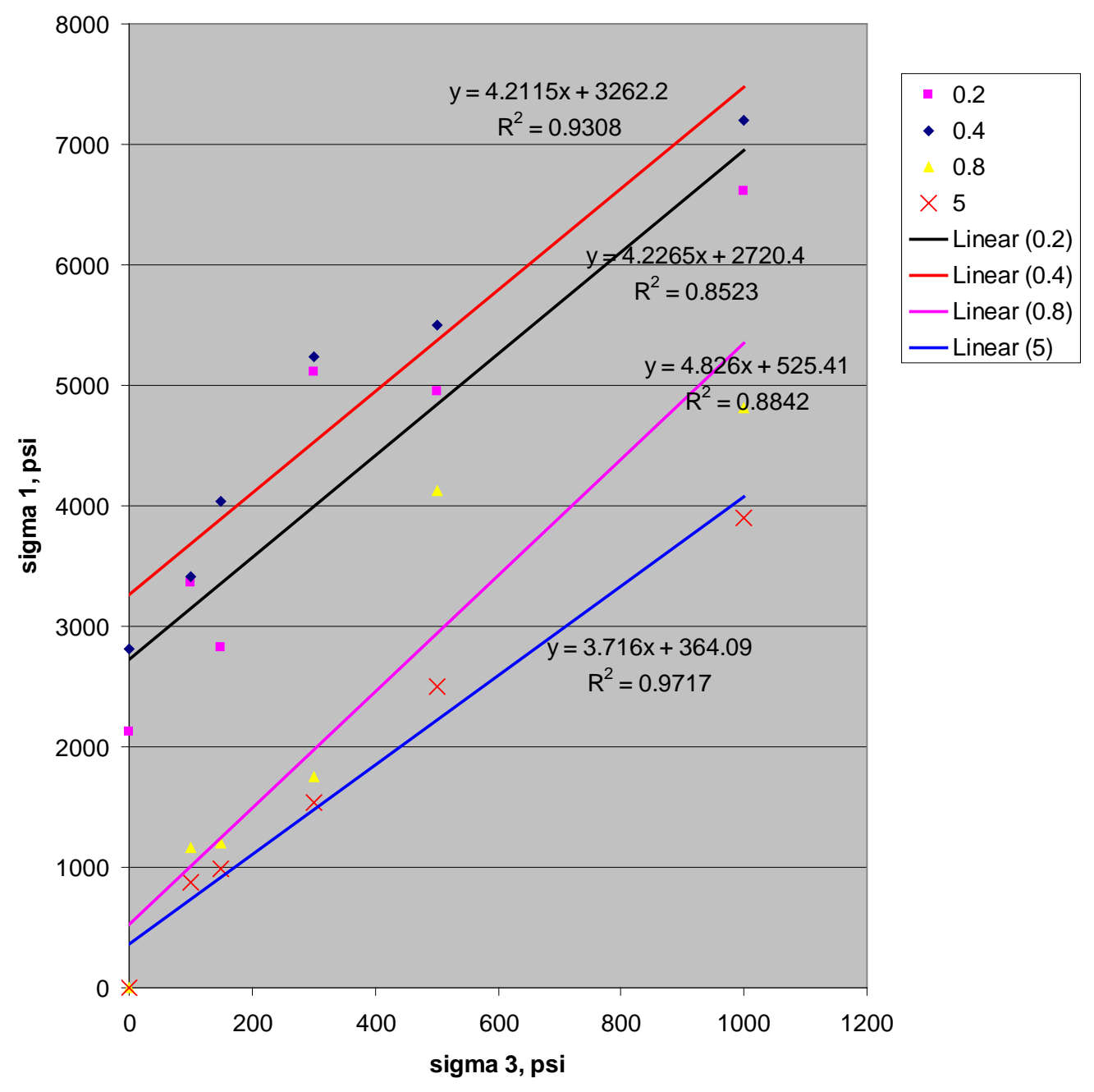

Figure 5.9 Plot of sigma1 vs sigma3 for different plastic strain
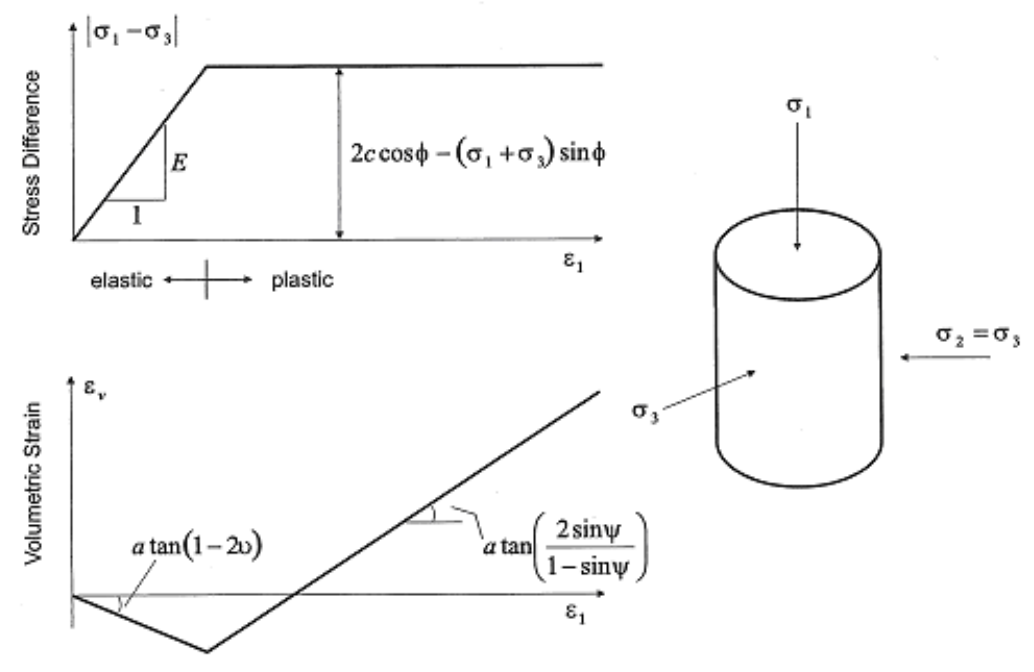

Figure 5.10 Idealized relation for dilation angle, from tri-axial test results (Vermeer and de Borst, 1984; Itasca, 2007) 
Table 5.2 Variation of cohesion and friction with plastic shear strain

\begin{tabular}{|c|c|c|c|c|c|}
\hline $\begin{array}{l}\text { Axial } \\
\text { strain, } \\
\text { milli strain }\end{array}$ & $\begin{array}{l}\text { Plastic } \\
\text { shear } \\
\text { strain, } \\
\text { milli strain }\end{array}$ & $\begin{array}{c}N_{\phi}= \\
(1+\sin \phi) /(1-\sin \phi)\end{array}$ & $\begin{array}{l}\text { UCS, } \\
\text { psi }\end{array}$ & $\begin{array}{l}\text { Cohesion, } \\
C, \text { psi }\end{array}$ & $\begin{array}{l}\text { Friction, } \\
\phi, \text { degree }\end{array}$ \\
\hline 0.2 & 0.15 & 4.21 & 3262 & 794.90 & 38.03 \\
\hline 0.4 & 0.31 & 4.22 & 2720 & 662.04 & 38.09 \\
\hline 0.8 & 0.61 & 4.55 & 745 & 174.63 & 39.76 \\
\hline 5 & 3.82 & 3.71 & 364 & 94.49 & 35.13 \\
\hline
\end{tabular}

From Table 5.2 and Figures 5.11/5.12, it can be seen that more than $80 \%$ of cohesion reduction takes place within 0.6 milli strain. Rock Mass cohesion has been estimated based on reduction factor. So there is a steep decrease in cohesion in the post failure regime. This type of behavior represents nearly a typical brittle failure. For a weak rock having very low uni-axial compressive strength or a highly laminated rock it may show more flatter than this behavior. The behavior of various rocks will fall between brittle to perfectly plastic. A typical plot for variation in cohesion mobilization with plastic shear strain for different rock types are shown in Figure 5.13

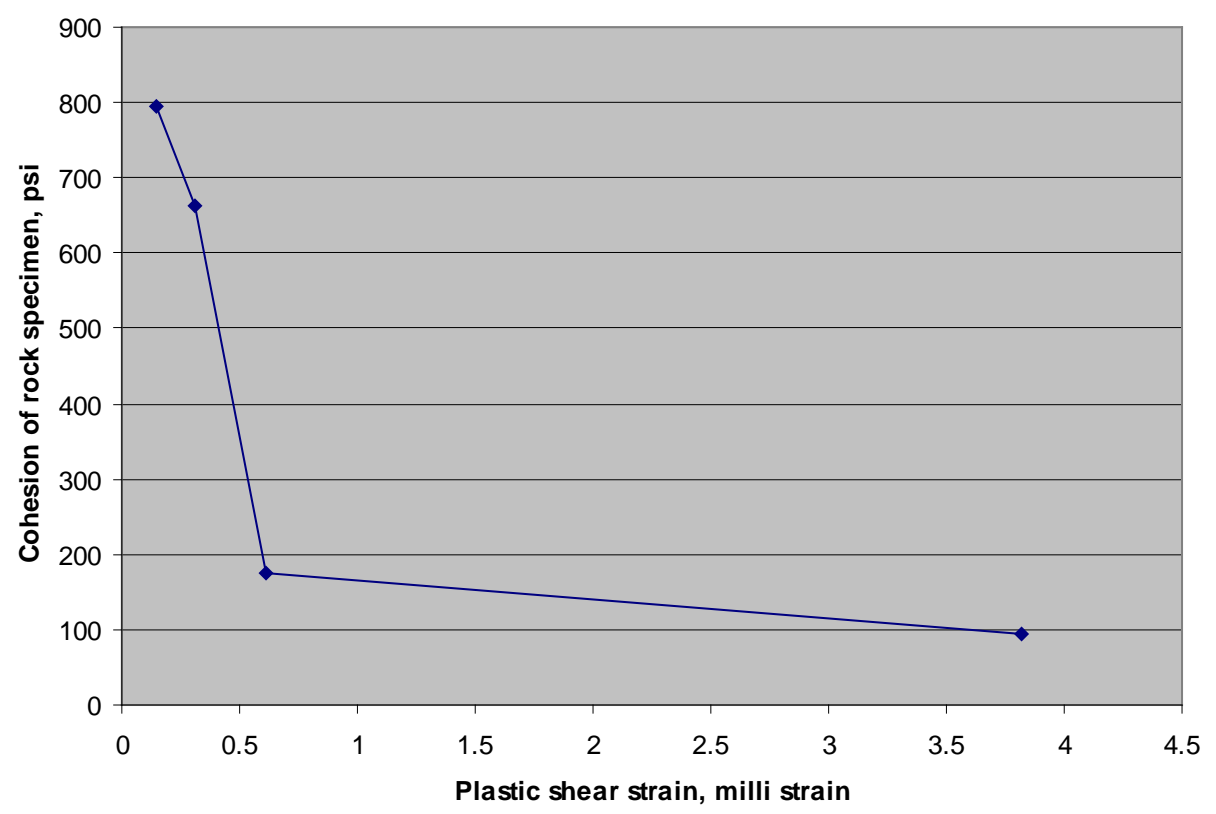

Figure 5.11 Variation of cohesion of rock specimen tested in laboratory with plastic strain 


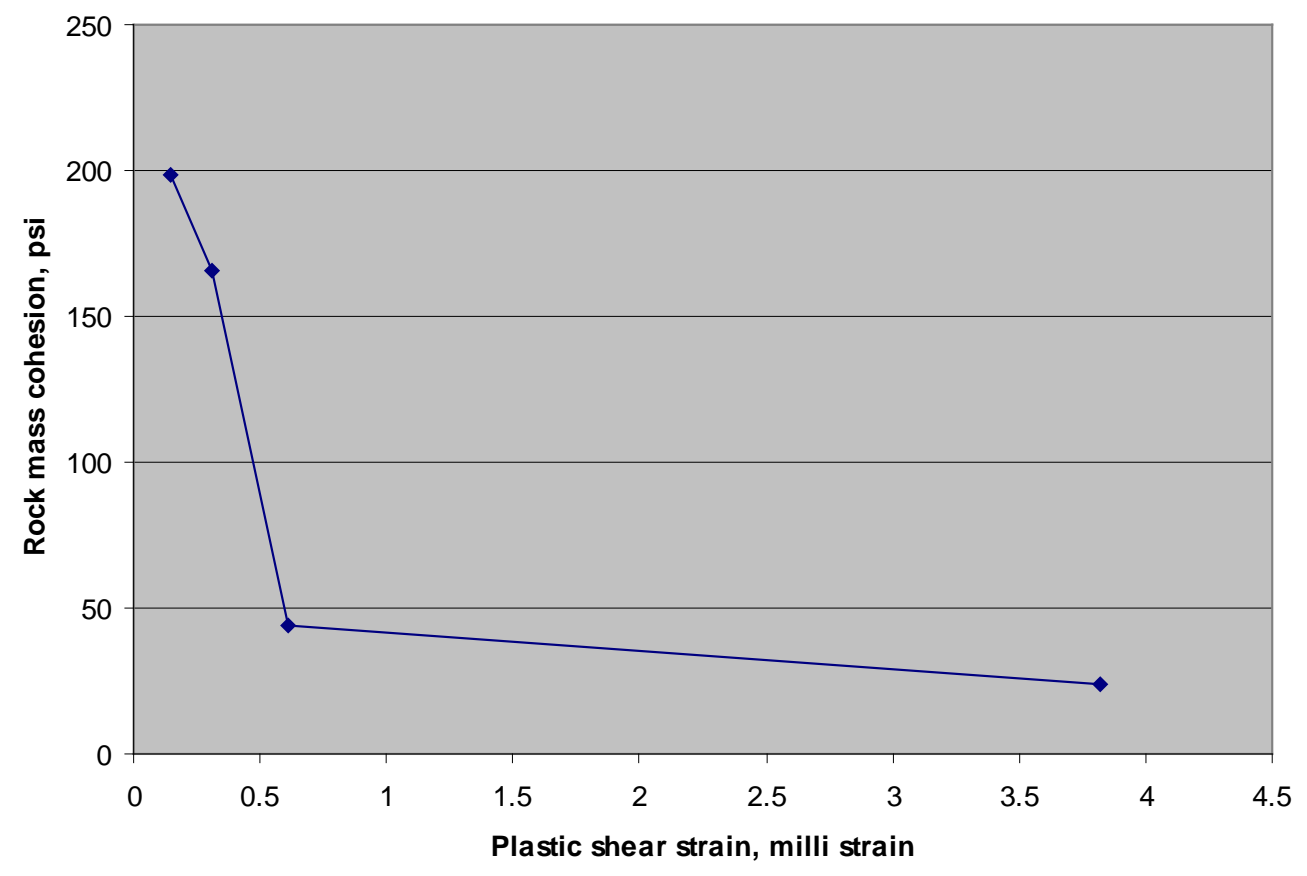

Figure 5.12 Variation of cohesion of rock mass with plastic strain

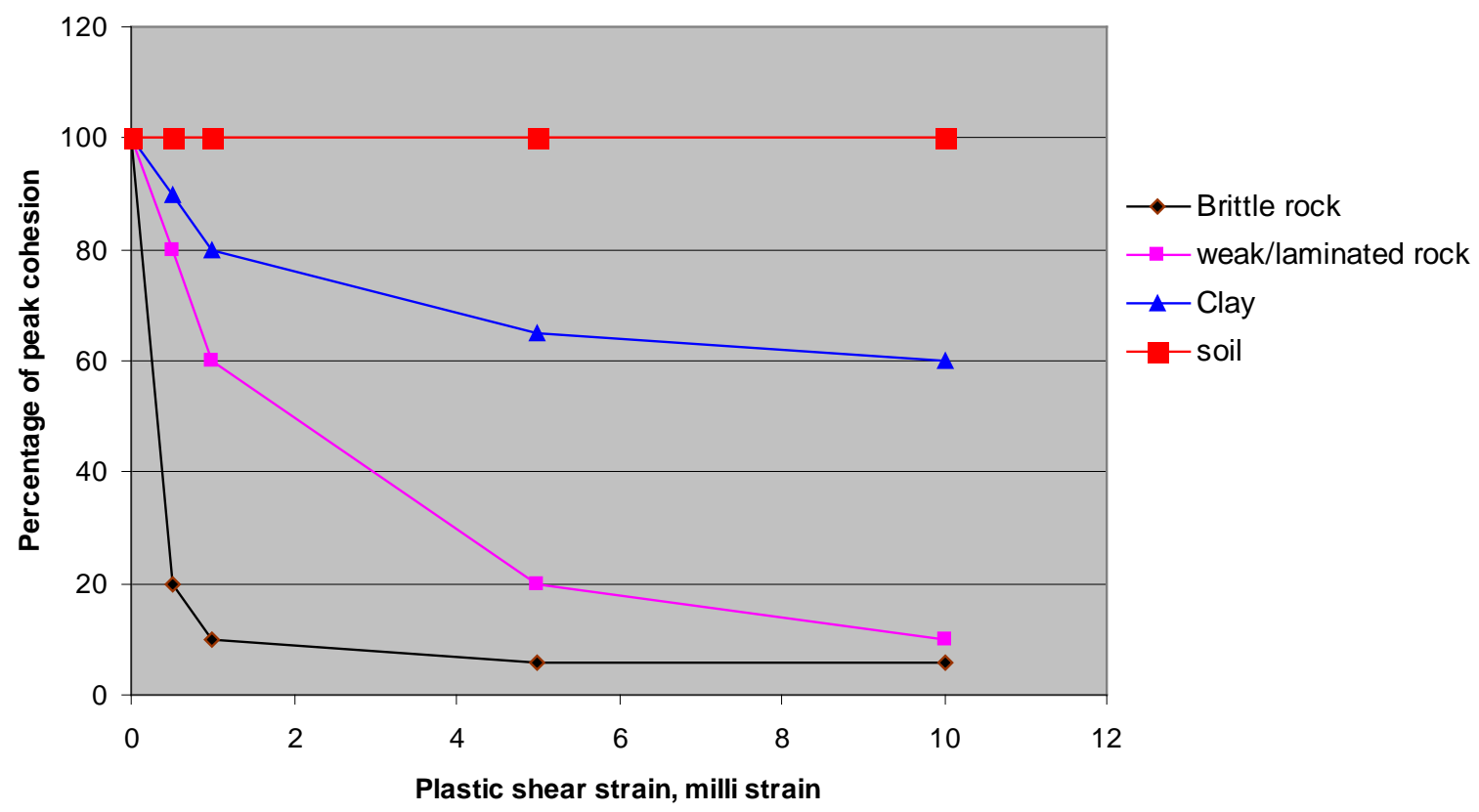

Figure 5.13 Typical variation of cohesion for different type of rocks with plastic strain 


\subsection{MODELING TO SIMULATE CUTTER BEHAVIOR}

Initial models were performed mainly to select the proper constitute law for the rock material behavior and to show the advantages of strain softening behavior over the other material modeling used in the past by various researchers like elastic and elastic-perfectly- plastic modeling. Further modeling was conducted to show the onset of progressive failure which is a typical characteristic for the cutter roof development (Gadde and Peng, 2005).

\subsubsection{Case for Simulation of Cutter}

The case 3 discussed in Chapter 4 has been selected to see the effect of various material modeling and to define the cutter detection criteria by numerical modeling. This mine is working in the Herrin \#6 seam in Illinois basin. The seam averaged $6 \mathrm{ft}$. thick under a cover of approximately $240 \mathrm{ft}$. The mine was developed using a 7 - or 8entry system with the 3rd and 4th entries from the left as the track and belt entries, respectively (Figure 4.20).

For the initial modeling, a three -entry system instead of a 7 entry system has been made due to practical modeling constraints to avoid large model size and solving time. The details about the cut sequences will be discussed in Chapter 6 . The 3 entry systems were developed in many stages as shown in Figure 5.14. In model the excavations were also made in several stages. In Figure 5.14 the numbers and arrow show the cutting sequence and direction respectively. The pillar dimensions were $52 \times 42 \mathrm{ft}$ (rib-to-rib) and entries were $18 \mathrm{ft}$ wide. The extended cut lengths were taken as $40 \mathrm{ft}$ in the entries and half of the pillar width $(26 \mathrm{ft})$ in the crosscuts. The maximum extended cut in USA underground coal mines is $40 \mathrm{ft}$ or less. 
The lithology is shown in Figure 5.15 and the material properties used for initial model is given in Table 5.3. These properties have been used to estimate the rock mass strength properties. This lithology and properties are taken from a mine in Illinois (case-3 in Chapter 4) that has been experiencing severe cutter/roof failures of different intensities. The immediate roof at the mine is a very weak black shale with a variable thickness. For modeling, it has been considered as about $8 \mathrm{ft}$ thick. The immediate blackshale is highly laminated and fails easily along the weak laminations and also appears to be moisture sensitive. The falls ranged from small cutters at a single corner to massive falls involving the entire weak immediate roof. Some tensile failures were also noticed at a few places in this mine. The floor was unconsolidated claystone of varying thickness.

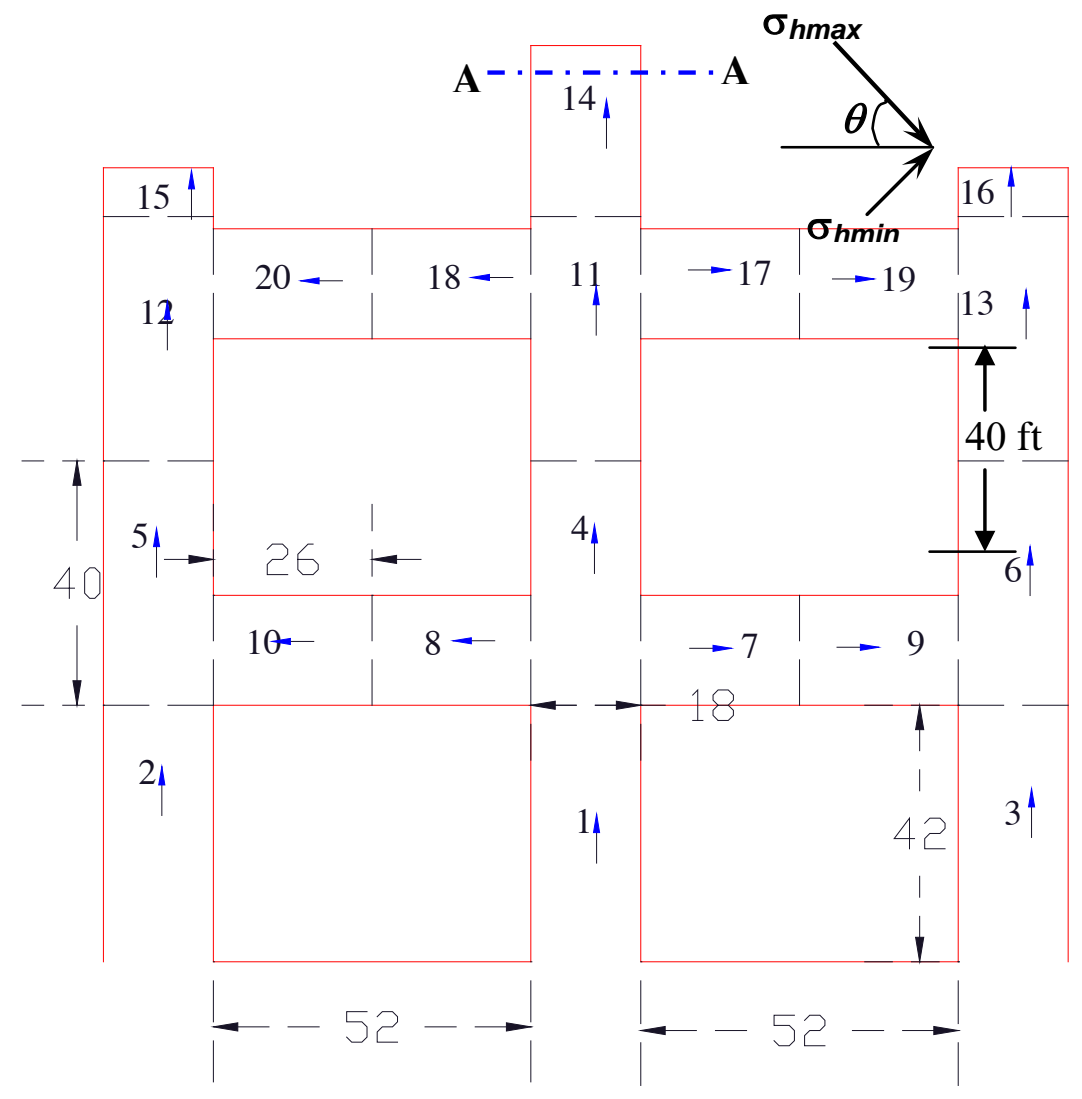

Figure 5.14 Three entry system representing the mains in case 3 
Table 5.3 Laboratory tested rock properties for the base model

\begin{tabular}{|l|c|c|c|c|c|}
\hline \multicolumn{1}{|c|}{ Rock type } & $\begin{array}{c}\text { Thickness, } \\
\mathbf{f t}\end{array}$ & $\begin{array}{c}\text { Young's } \\
\text { modulus, } \mathbf{x 1 0 ^ { 6 }}\end{array}$ & $\begin{array}{c}\text { Poisson's } \\
\text { psi }\end{array}$ & $\begin{array}{c}\text { Uni-axial } \\
\text { strength, } \\
\text { psi }\end{array}$ & $\begin{array}{c}\text { Friction angle, } \\
\text { degree }\end{array}$ \\
\hline claystone & 12 & 0.3 & 0.3 & 1440 & 27.5 \\
\hline coal & 6 & 0.3 & 0.3 & 3372 & 28 \\
\hline $\begin{array}{l}\text { laminated } \\
\text { black shale }\end{array}$ & 8 & 0.16 & 0.3 & 1580 & 27.5 \\
\hline shale & 40 & 0.35 & 0.3 & 2883 & 28 \\
\hline sandyshale & 20 & 0.5 & 0.25 & 3378 & 30 \\
\hline
\end{tabular}

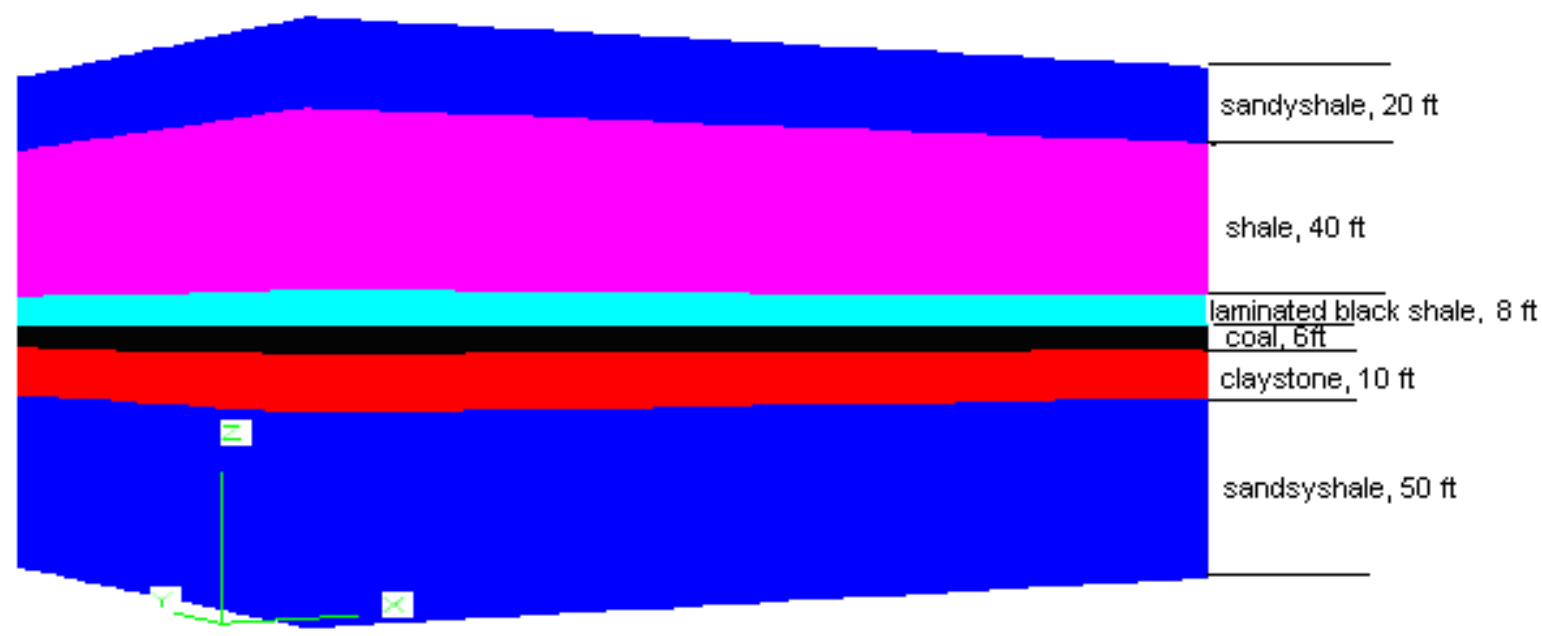

Figure 5.15 Lithology used in the modeling (representative for case 3)

The numerical modeling was done in four stages. First stage is the preparation of suitable model geometry and elements for better performance based on the FLAC guidelines. The next three stages are for solving the model. The models built for this work were run in three major stages (stage 2, 3, and 4) and then after stage 4 the model output was analyzed and interpreted. The steps involved in the model are listed sequentially below: these stages are viewed as pre-processing, processing and post processing. 
- $\quad$ stage 1, The model geometry is created such that the area of interest has a finer grid. In this case the entries and cross cuts were made finer while pillar has coarser elements. The geometry is created keeping in mind that the aspect ratio should not be more than 4 and size ratio is less than 3 . The grid of the geometry is shown in Figure 5.16. The mesh was fine in the areas of interest with typical element sizes of $2.25 \mathrm{ft} \times 5 \mathrm{ft} \times 1.3 \mathrm{ft}$.

- stage 2, in situ stresses were developed in the model, to apply in-situ stresses that oriented differently from the reference co-ordinate system, a FISH function has been developed to apply stress orientation in the model.

- Stage 3, the model is solved elastically for few steps (100 time steps) after the principal in-situ stresses were applied in the specified direction and the first cut is made as shown in the Figure 5.14. Few steps were solved in elastic mode to avoid any sudden shock to the system. This is particularly important when a large excavation is made in one stage otherwise model would not converge when run directly in plastic mode.

- Stage 4, After solving few steps as elastic the model is solved as perfectly plastic or strain softening. The excavation is created in 20 sequences of $40 \mathrm{ft}$ cut length in entries and $26 \mathrm{ft}$ in crosscuts as shown in Figure 5.14. For each cut, the entry was developed to its full width and the model was solved. Then the face was advanced to the next cut to solve the model again. This process was repeated for all cuts. 


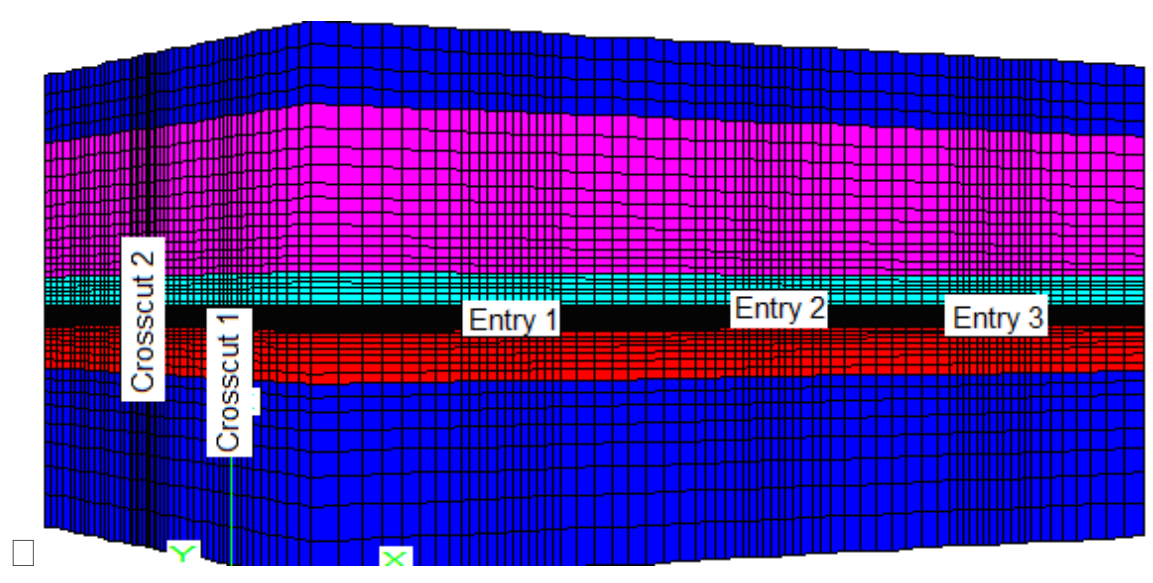

Figure 5.16 Geometry of the model showing the dense grid for the entries and crosscuts

For this initial model the in situ stresses $\left(\sigma_{v}\right.$ corresponding to $240 \mathrm{ft}$ depth, $\sigma_{h \max }=1.8 \sigma_{v}$ and $\left.\sigma_{h \min }=\sigma_{h \max } / 1.30\right)$ were used with maximum horizontal stress oriented at an angle, $\theta$ of $60^{\circ}$ (i.e. $30^{\circ}$ from the entry drivage direction). The in-situ stresses were estimated as per Equations 3.5 and 3.6. The peak cohesion for the plastic models has been estimated as 96 psi for the immediate roof as estimated from the rock mass strength criteria discussed in previous section 5.1.3. The friction angle has been kept constant and the dilation angle has been assumed as zero degree.

\subsubsection{Selection of Material Constitutive Law}

In order to investigate whether the strain softening model provides a feasible solution for cutter simulation using continuum models, comparison is made between the results obtained with different material behavior models under exactly identical geomining conditions as mentioned above (Gadde and Peng, 2005). The material behavior models used were-

- Elastic,

- Perfectly-plastic and

- Strain-softening material model 
The model results obtained at cross section A-A (Figure 5.14) are shown in Figures 5.17a-c. To estimate the extent of the unstable zone for elastic model, the safety factor of immediate roof elements less than 1.0 has been considered. While for perfectly plastic and strain softening material, the yielded zone has been used as criteria to mark the unstable roof. For the strain softening material, the cohesion and friction degradation has been used as per Figure 5.13 for weak/laminated rock.

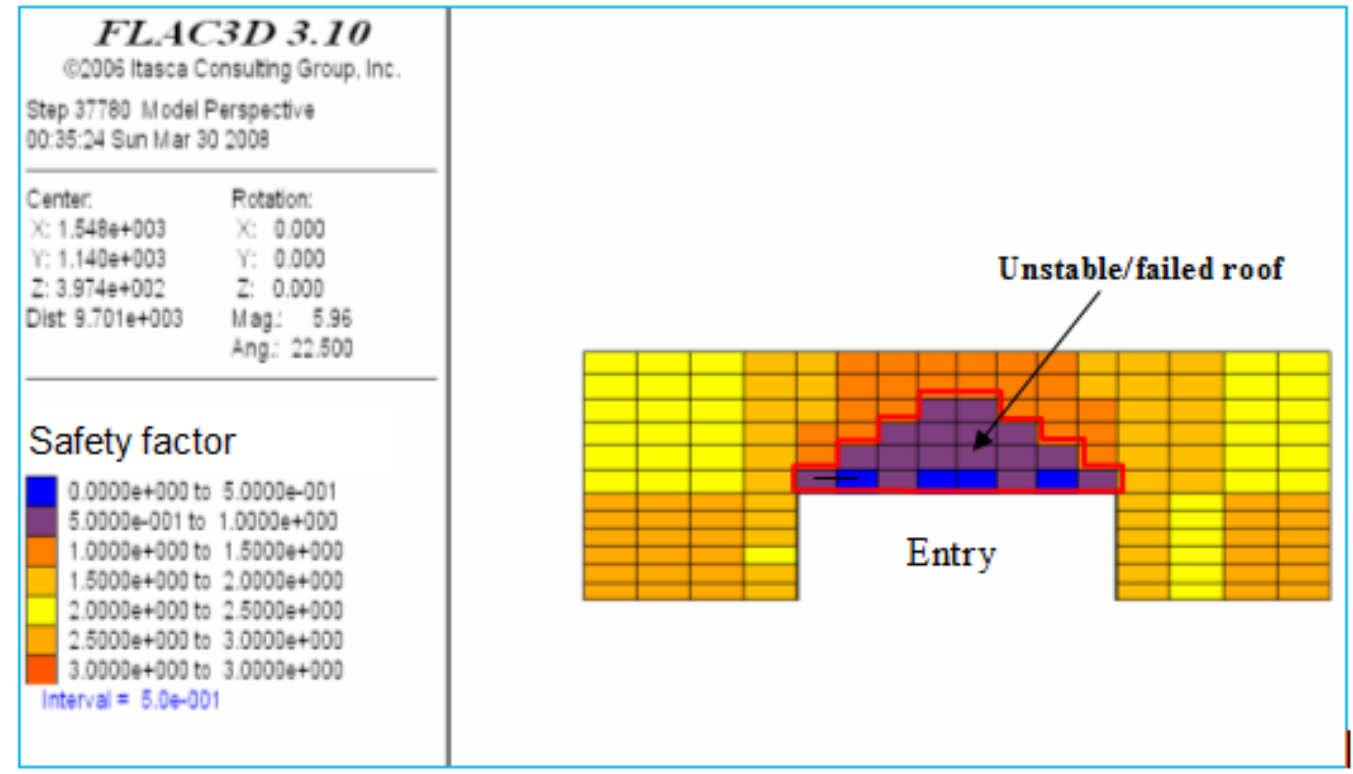

a. Unstable roof for elastic material (The zone under dark red polygon have safety factor less than 1.0)

\begin{tabular}{|c|c|c|}
\hline \multicolumn{2}{|c|}{$\begin{array}{c}\text { FLACBD } \mathbf{3 . 1 0} \\
\text { (2006 Itasca Consulting Group, Inc. } \\
\text { Step } 36873 \text { Model Perspective } \\
00: 51: 59 \text { Sun Mar } 302008 \\
\end{array}$} & Yielded zones \\
\hline $\begin{array}{l}\text { Center: } \\
\text { X: } 1.613 e+003 \\
Y: 1.140 e+003 \\
Z: 3.003 e+002 \\
\text { Dist: } 9.701 e+003\end{array}$ & $\begin{array}{l}\text { Rotation: } \\
X: 0.000 \\
Y:=0.000 \\
Z: \quad 0.000 \\
\text { Mag.: } 5.96 \\
\text { Ang.: } 22.500\end{array}$ & l \\
\hline \multicolumn{2}{|c|}{$\begin{array}{l}\text { Block State } \\
\text { Live mech zones shown } \\
\text { None } \\
\text { shear-n shear-p } \\
\text { shear-p }\end{array}$} & Entry \\
\hline
\end{tabular}

b. Perfectly plastic material (The zone except dark blue all are yielded zone) 


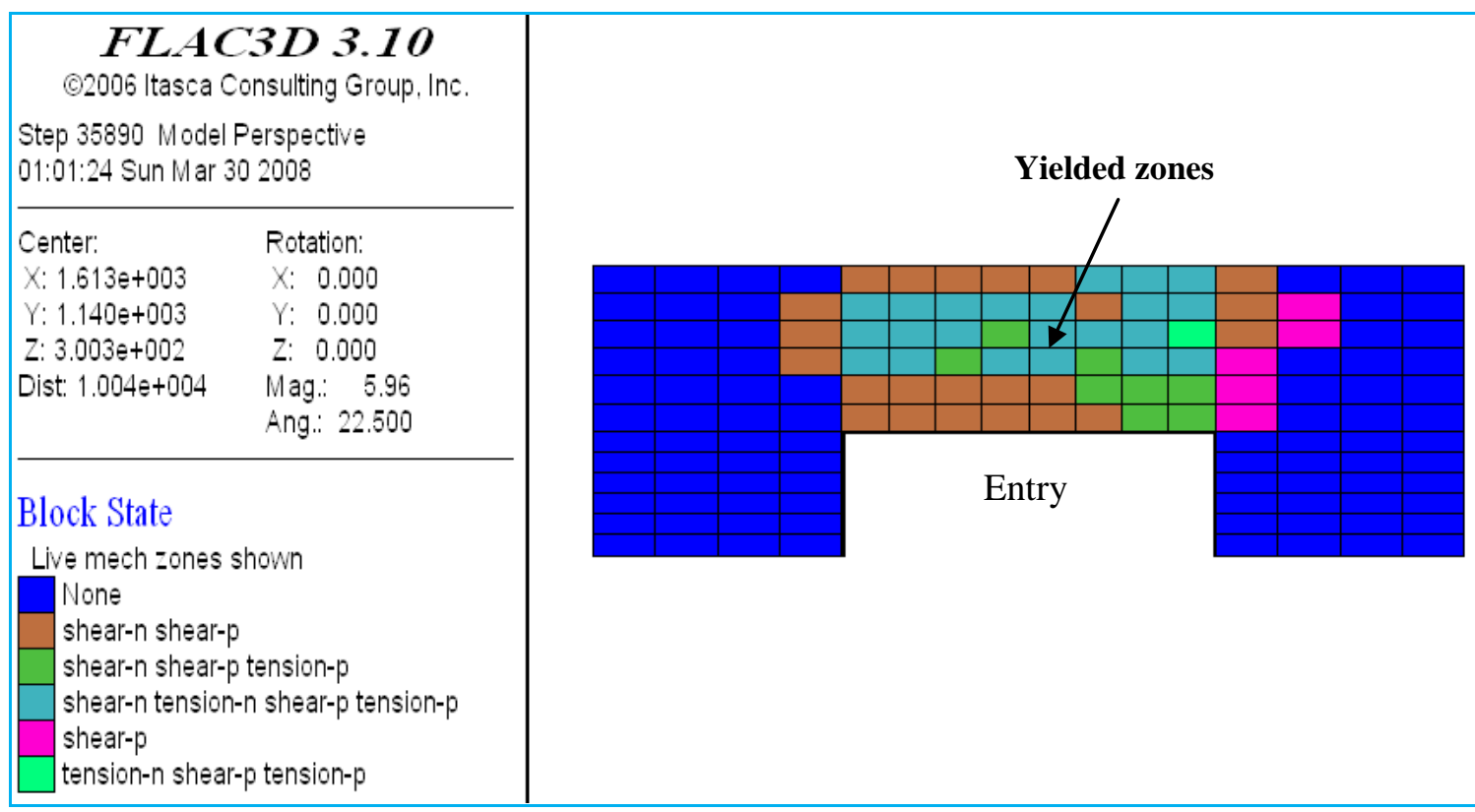

c. Strain softening material (The zone except dark blue all are yielded zone)

Figure 5.17 The extent of unstable roof for different material behavior

From Figure 5.17, it is clear that the size of the unstable zone is slightly larger for the perfectly-plastic model as compared to the elastic one and is even larger for the strain-softening model. In the perfectly plastic model, all elements yielded in shear where as we can see in strain softening model some of the elements also have yielded in tension. In the perfectly plastic model, the material sustains the peak load beyond the elastic limit irrespective of the amount of deformation whereas in the strain softening model the load bearing capacity of the material decreases with increasing strain beyond the elastic limit. Hence it shows much more yielding than perfectly plastic material.

In Figure 5.17c, all the elements that satisfy the failure criterion are shown as unstable. However, the unstable elements need not be the elements that might collapse as we know that depending on the amount of strain and confinement at the point, even a yielded element can retain significant amount of post-failure strength as seen from Figure 4.24. More information on the failure characteristics could be 
drawn by estimating the post-failure strength of different zones in the roof studied (Gadde and Peng, 2005) The post failure strength can be estimated by MohrCoulomb failure criteria by estimating cohesion, major and minor induced principal stresses for the each element in the failure zone. The post failure cohesion can indirectly indicate the post failure strength of each element. When the normal stress (major and minor principal stress) becomes zero, then the cohesion strength becomes equal to the shear strength of the material. Again for constant friction in post failure regime, cohesion may represent the strength of the material. The elements having higher post failure cohesion will have more strength than the lower one. The plot of cohesion at section A-A is shown in Figure 5.18. In Figure 5.18, the darkest blue element shows having zero or residual cohesion and these elements can be treated as completely failed. From the cohesion plot it can be seen that the roof will fall right from the edge of the pillar ribs in the entry. The mechanism of this failure will be discussed in next section.
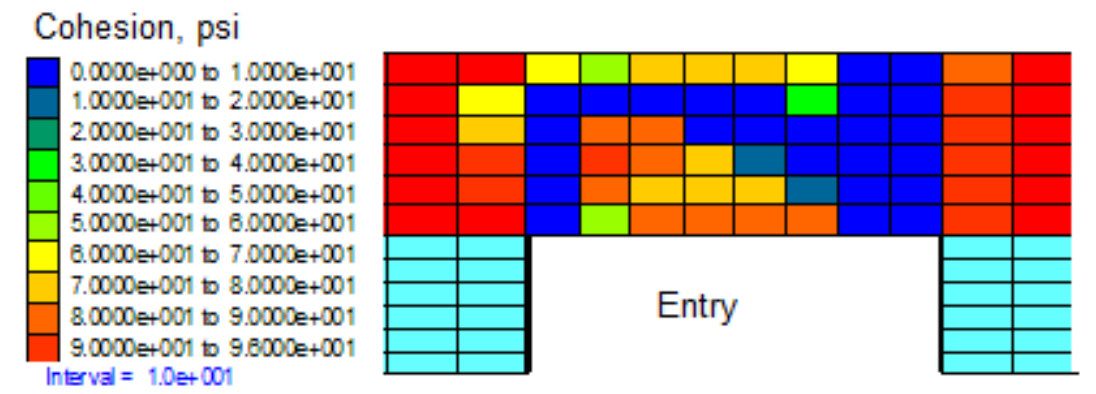

Figure 5.18 Distribution of cohesion in the immediate roof on cross-section A-A shown in Figure 5.14 after final cut 14

In mine which has been considered as the case for the present study, numerous roof falls involving the entire immediate roof occurred along with many smaller falls at one or both corners of the entry/crosscut (case study- 3). From the 
roof outline, it was observed after a massive fall, the edges at the rib side were nearly vertical as shown in Figure 4.22. For the smaller falls at the corners, the failed roof looked similar to that shown in Figure 4.4b, and was typically restricted to a single corner of the entry. In addition to these shear type roof failures, some tensile fractures were also noticed in the central part of the openings.

For the high horizontal in situ stress field expected at the mine, the fall profiles noticed in the field do not fully match with the previous research findings. It is generally anticipated that the failure zone would be inclined towards the entry center for high horizontal stresses (Kripakov, 1982). While this is perhaps true for stronger roofs, it may not necessarily be the case in very weak roof formations as witnessed at the study mine. The discrepancy is mainly because of the hypothesized used in the previous numerical models. If the progressive cutter failure process is not properly incorporated in the numerical models, then the failure zones would look as in Figures 5.17a and 5.17b, similar as observed in the past. The profile and extent of failure obtained for the strain-softening model shown in Figure 5.17c are closer to the observations at the Illinois mine mentioned earlier in chapter 4.

\subsubsection{Progressive Failure of Rock}

After selection of the material model, the next step towards verifying the proposed methodology is to see if the progressive failure behavior as described schematically in Figure 4.10 is replicated in modeling. The next model was done for a single entry instead of a multiple entry system as shown in Figure 5.19 because the main purpose is to examine the progressive nature of failure. The entry was driven in 5 equal cut lengths of $30 \mathrm{ft}$. The model was solved for a stress ratio ' $k$ ' and ' $l$ ' for 1.80 and 1.30 , respectively with the maximum horizontal stress orientated at 
$60^{\circ}$. The change in stresses at a few zones (Figure 5.20) in the roof was monitored along the cross section F-F as the model was solved. The change in the magnitude of major and minor principal stress against different cut is shown in Figures 5.21 and 5.22. The zones of monitoring were selected in the immediate roof, towards the right edge of entry as the insitu maximum horizontal stress acts at an angle such that it is expected to be more stress concentration on right side which is supported by the Figure 5.24 .

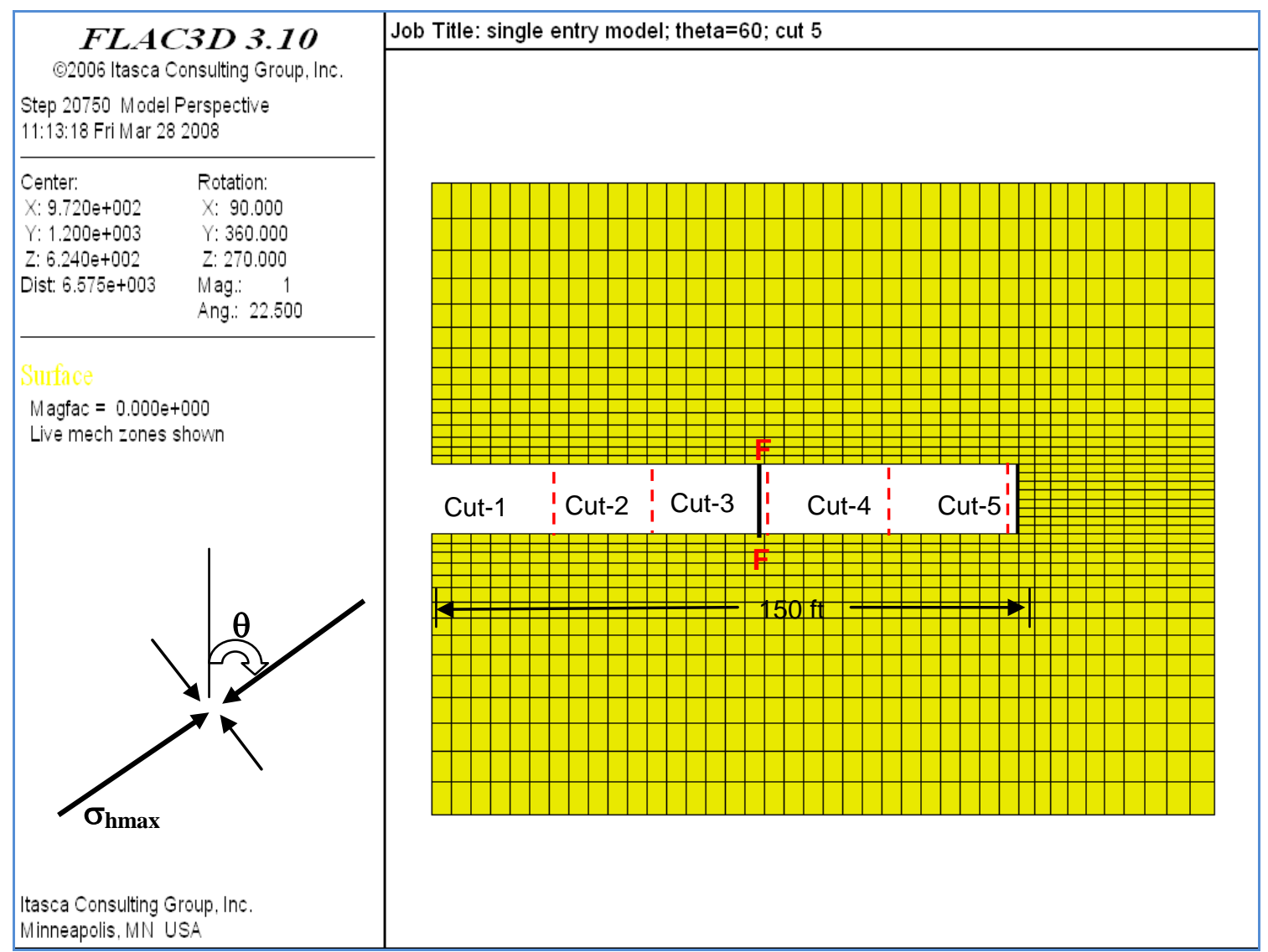

Figure 5.19 Plan view of the geometry modeled in five cuts 


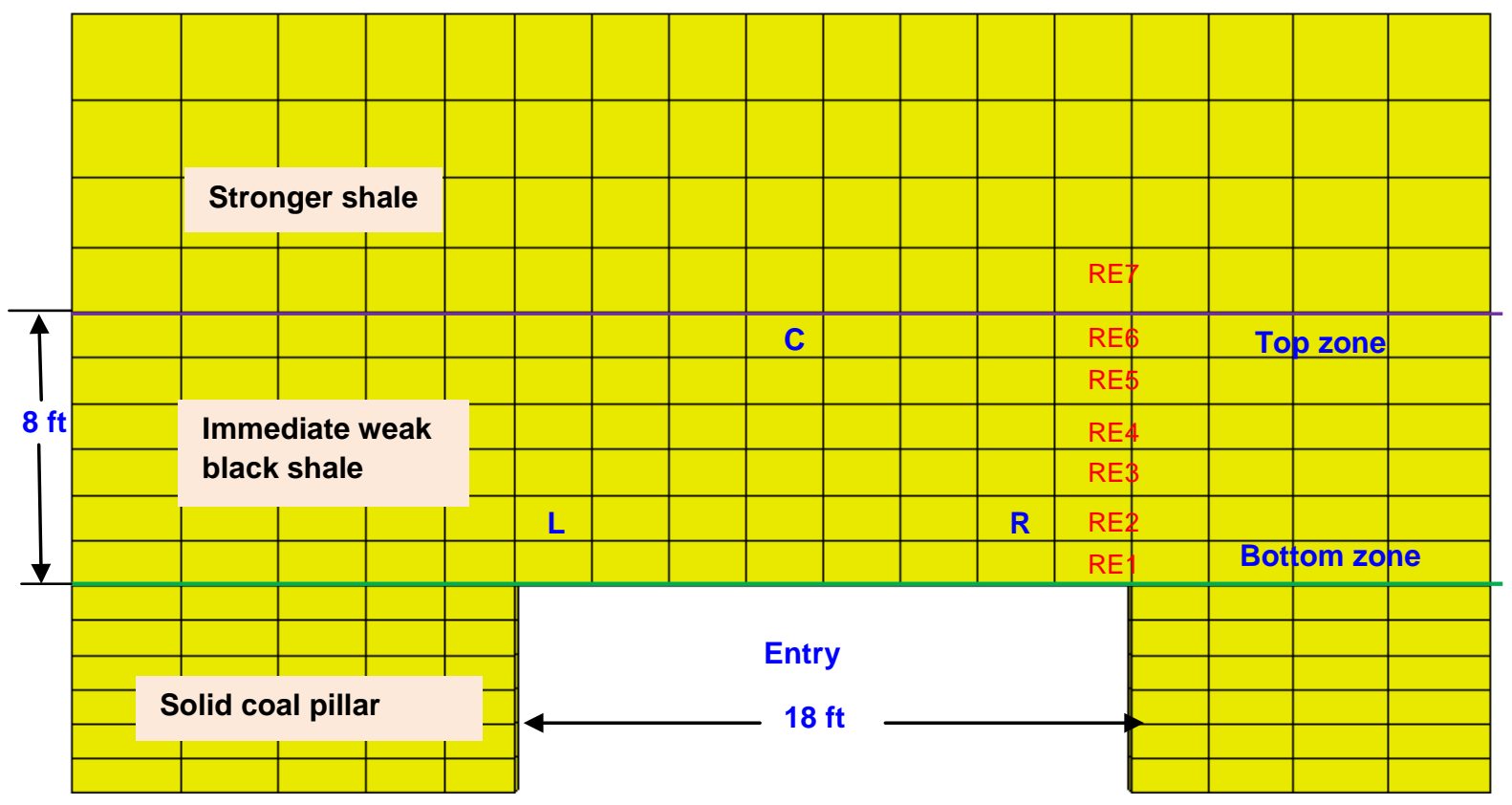

Figure 5.20 Zones at which the stresses were monitored at face location F-F as shown in Figure 5.19 (RE1 to 7 are in immediate week roof while RE7 is in stronger roof)

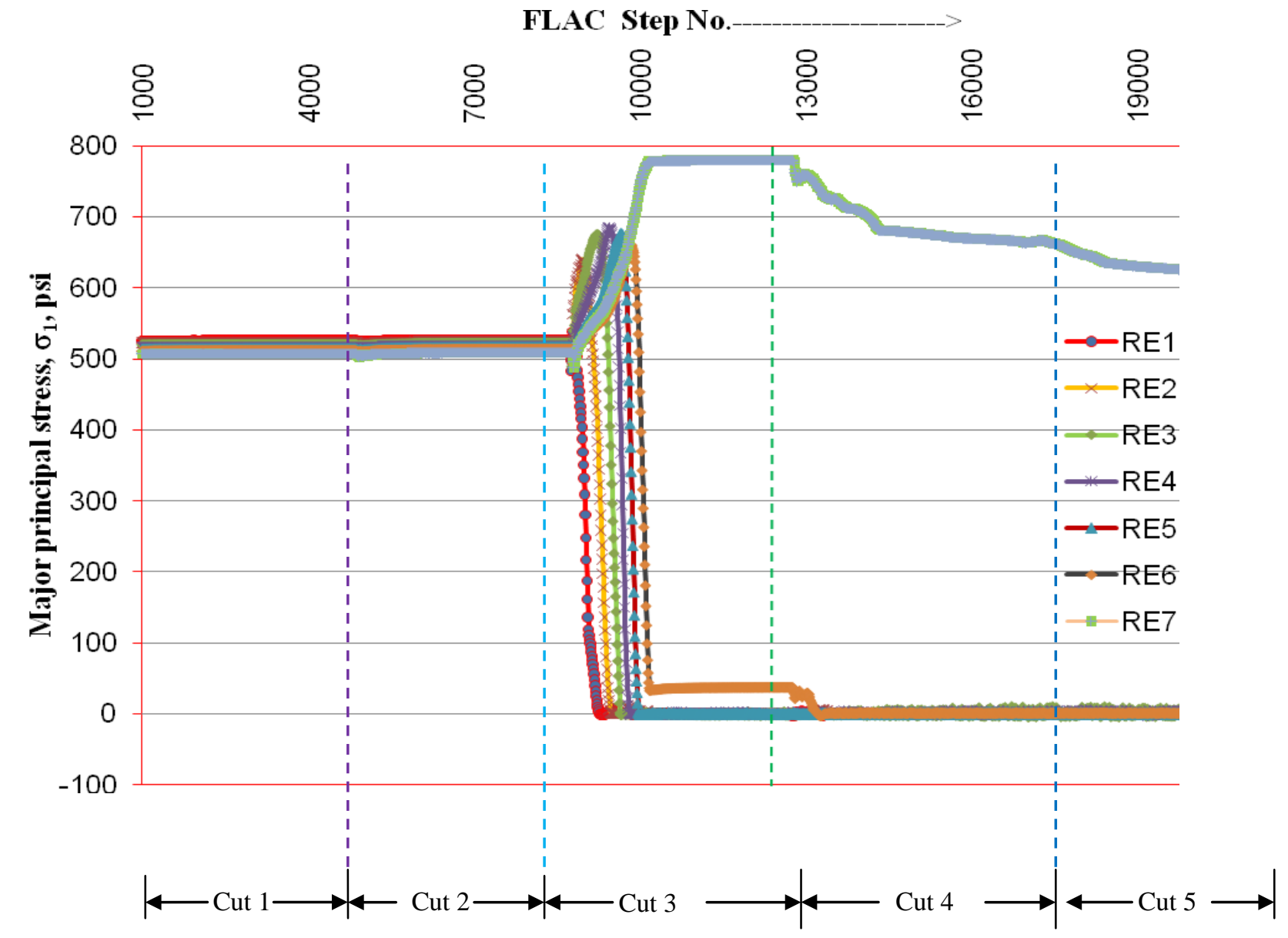

Figure 5.21 Variation of major principal stress for different cuts at zones shown in Figure 5.20 


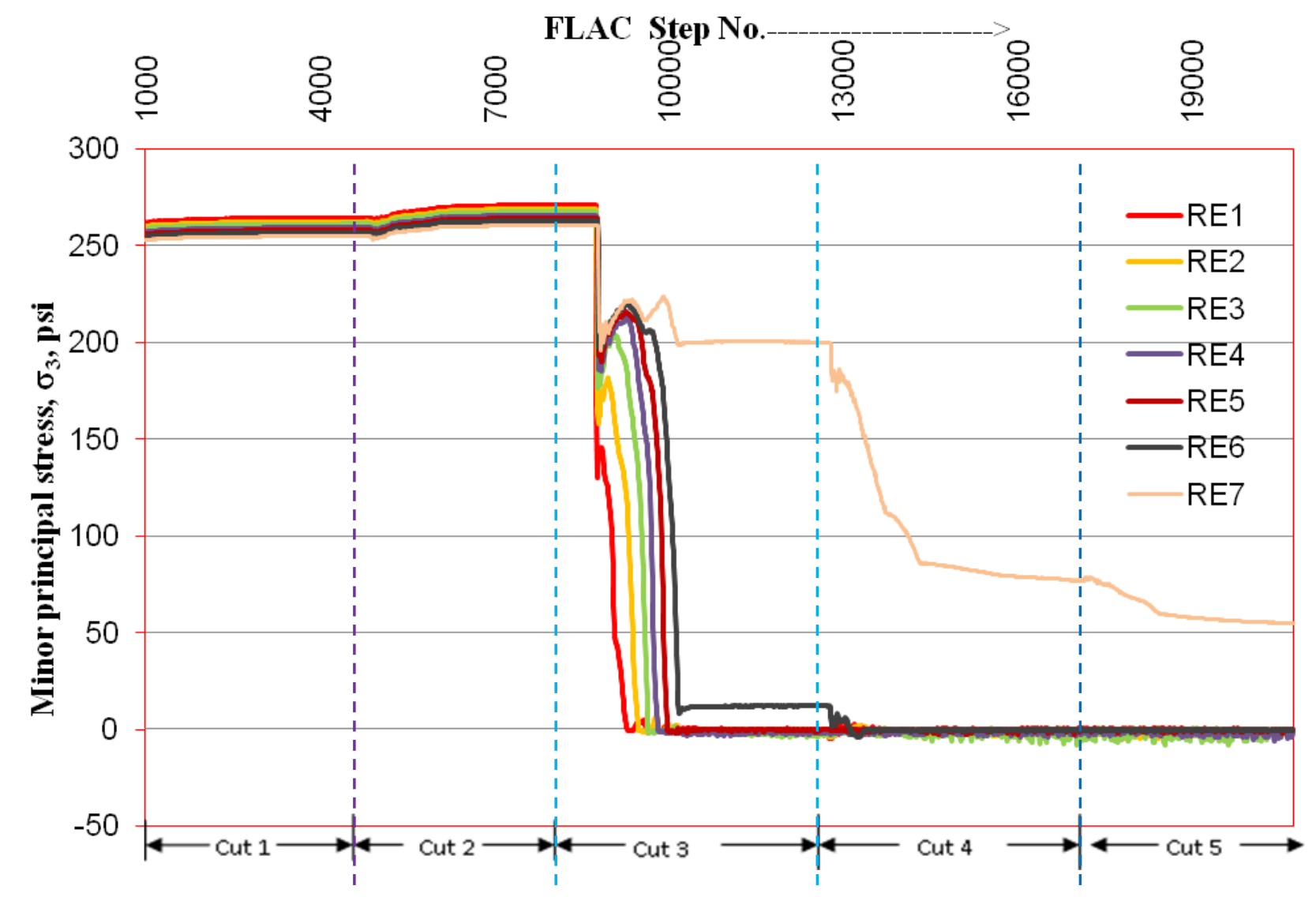

Figure 5.22 Variation of minor principal stress for different cuts at zones shown in Figure 5.20

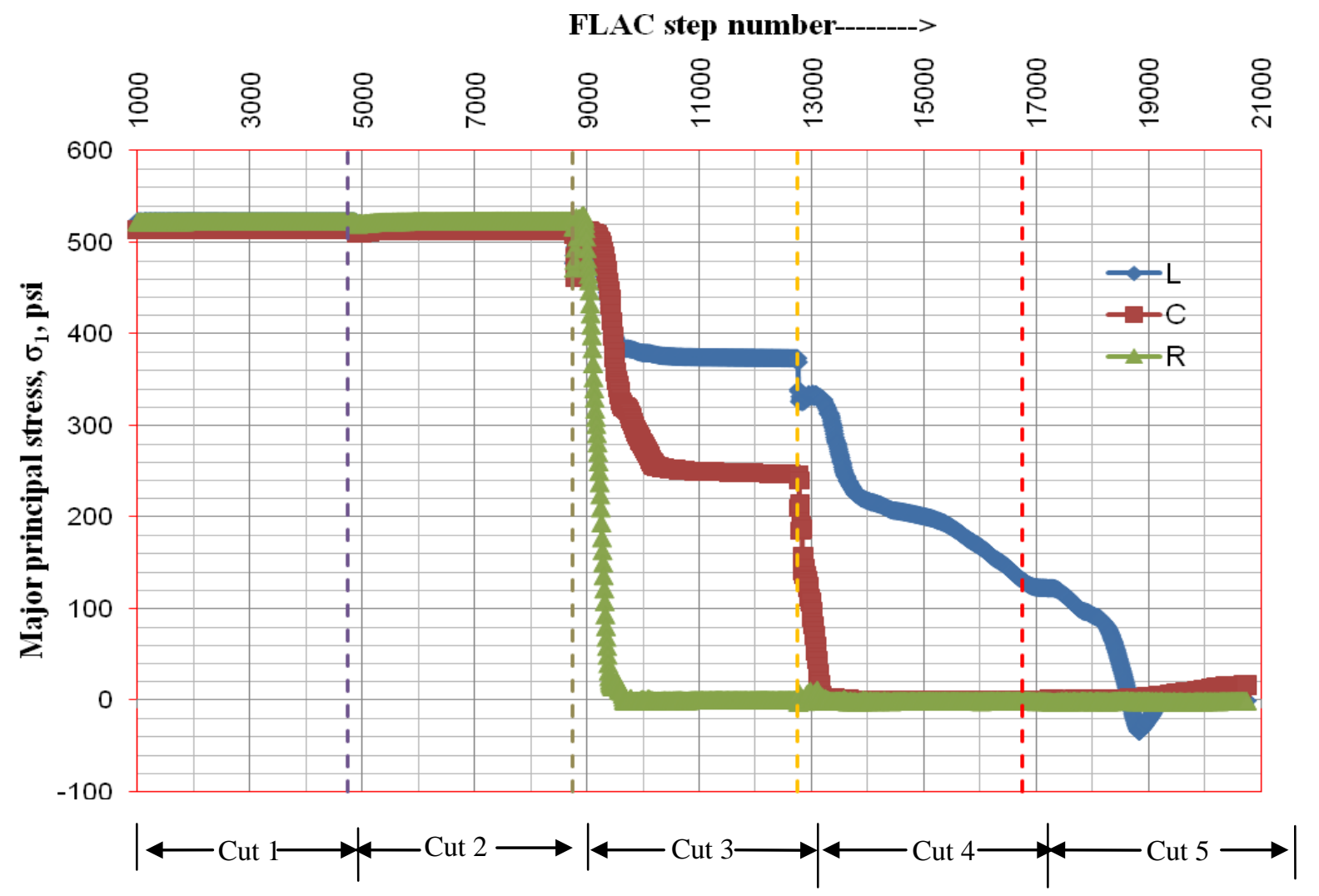

Figure 5.23 Variation of major principal stress for different cuts at zones shown in Figure 5.20 


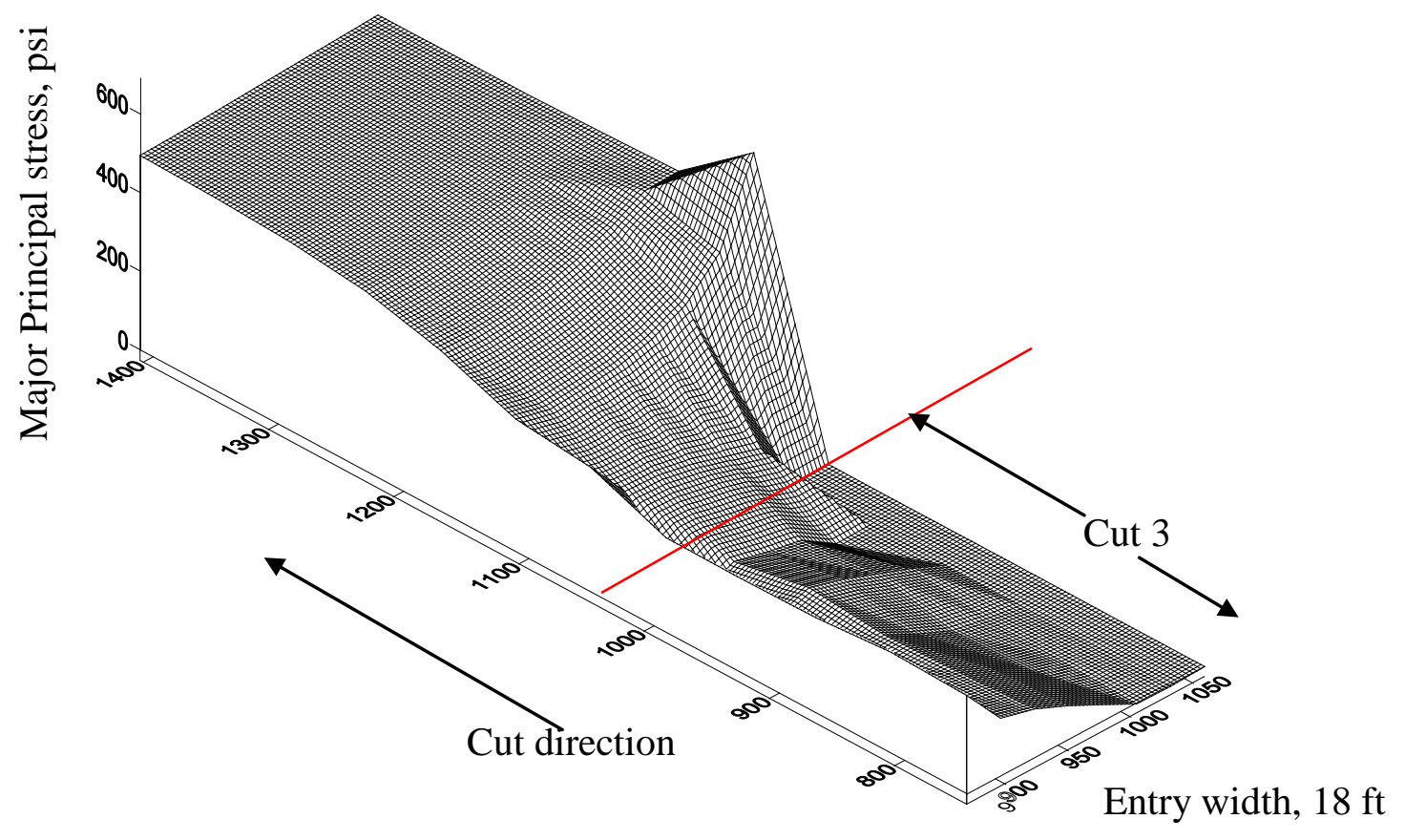

Figure 5.24 Major principal stress plot for the bottom zone of the weak immediate roof showing asymmetric behavior along the entry width after cut 3

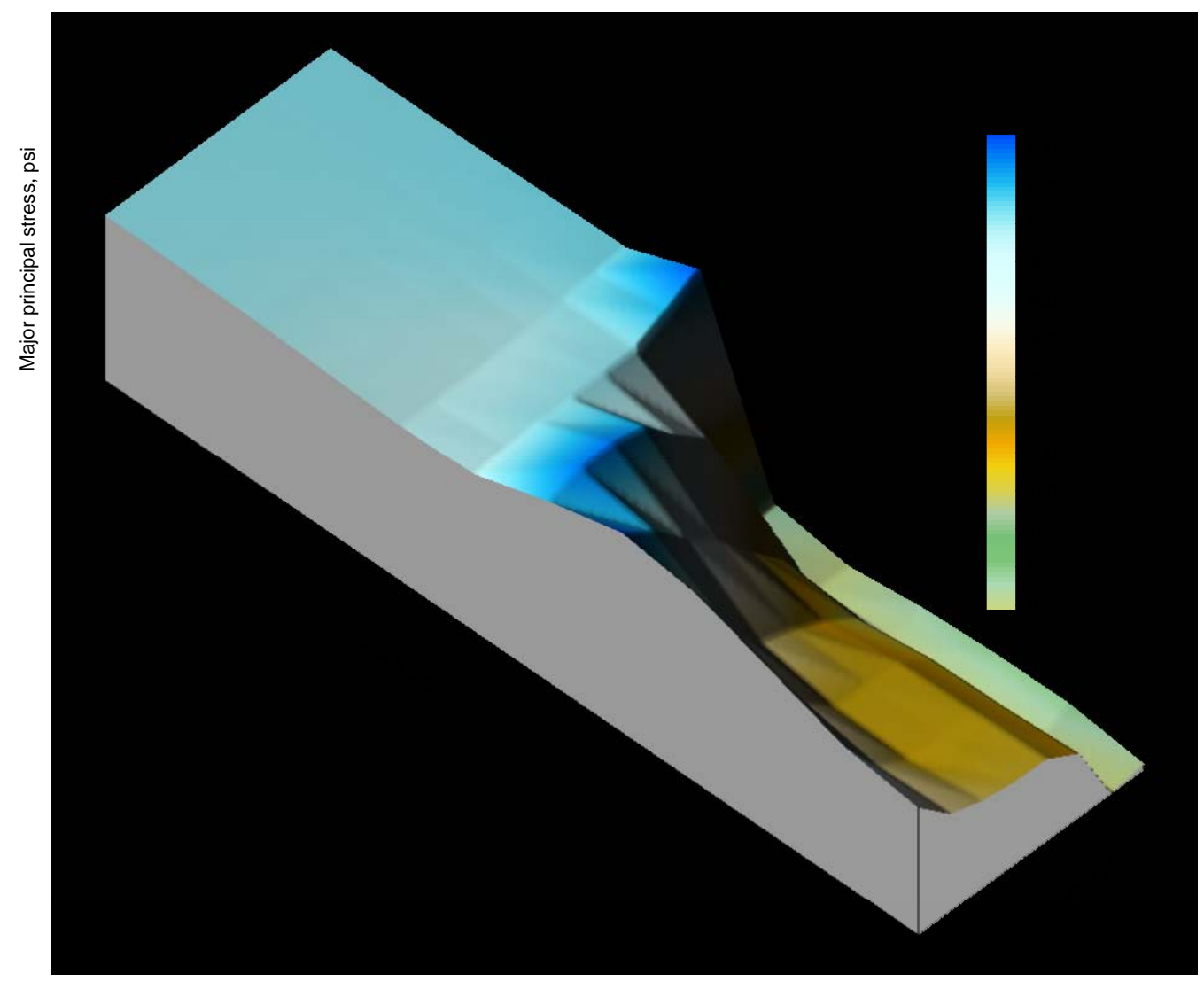

Figure 5.25 Major principal stress plot for the top zone of the weak immediate roof showing asymmetric behavior along the entry width after cut 3 
The results in Figures 5.21, 5.22, and 5.23 show the progressive nature of failure. Initially, the stresses at all the points stayed at the applied in situ stress level (500 psi) until the end of cut 2 . When the excavation reached the location of face F-F (Figure 5.19), initially, stresses got concentrated at zone RE1 at the right edge corner of the entry. As the magnitude of stresses at zone RE1 satisfied the failure criterion, the element entered into the post-failure region and started shedding load as indicated by the falling stress values. While the stress increase and failure took place at zone $R E 1$, the neighboring zones $R E 2$ and $R$ started picking up the load shed by zone RE1 until they also reached the strength limit. At this stage points RE2 and $R$ failed and entered into post-failure zone. This process of stress-increasefailure-and-stress-reduction happened to all the remaining adjacent zones from RE2 to RE6 and $R$ (Figures 5.21 and 5.23). After a certain number of model solution steps, zones RE1 to RE6 along with zone $R$ reached to their residual strength as indicated by the flat portion of the curves in Figures 5.21 and 5.23 . Subsequent cuts 4 and 5 did not affect the stress distribution of the already failed zones during cut 3. Further zone RE7 located in stronger shale did not fail and continued to accept increasing load. Similar behavior was observed with the minor principal stresses in the different zones (Figure 5.22)

The asymmetric stress distribution can be explained with the Figures 5.24 and 5.25. Figure 5.24 shows the variation in major principal stress in the bottom zone of the immediate roof across the entry width. While Figure 5.25 shows the same for the top zones of the weak shale roof. Figure 5.24 clearly shows that the stress is concentrated towards the right edge of the entry which is mainly due to the maximum horizontal stress orientated at $60^{\circ}$ to the entry width (Figure 5.19). The asymmetry associated with the stress distribution when $\sigma_{\text {hmax }}$ acts at angles different from 0 or 
90 degrees could also be seen from the difference in stresses at zones $L$ and RE2 (Figure 5.23). Zone $L$ was not stressed as much as zone RE2 and hence did not lose much of its load bearing capacity until the end of cuts 3 and 4 .

Further, the continuing change in stresses at cross-section $F-F$ even after cut 4 clearly indicates the interaction effects involved in sequential excavation process. Zone $\mathrm{C}$, which is in the mid upper portion of the entry shows load-deformation characteristics intermediate to the extremes displayed by the corner points as seen from Figure 5.23.

Again this progressive failure behavior can be understood from the cohesion distribution and the stress relieves zones created during the excavation. Figure 5.26 shows the cohesion distribution in the immediate roof for a single entry at cross section F-F from the Figure 5.19. The post-failure cohesion values were plotted during cut 3 for every 200 time steps and after cut 4 and 5. The distribution of postfailure cohesion values in Figure 5.26 reveals the progressive characteristics of cutter roof failures which have been explained in previous paragraphs.

Similarly Figure 5.27 shows the cohesion distribution in the immediate roof at cross section A-A for the Figure 5.14 after the last cut-14. The distribution of postfailure cohesion values in Figure 5.27 also reveals the progressive characteristics of cutter roof failures.

At the right hand corner of the entry, the lateral extent of zero cohesion elements (dark blue in color) is increasing with increasing distance inside the roof. Initially, due to the in situ horizontal stress orientation with respect to the entry axis, elements closest to the roof line at the right hand corner of the entry start failing as the stresses get concentrated here (Figure 5.28). When these elements fail, they 
shed some of their load on to the surrounding elements, the amount of load shed being dependent on the amount of plastic strain the elements experienced. With higher stresses acting on the neighboring elements, they may also enter into postfailure state and consequently distribute some of their load to their adjacent elements. This process will continue until stable equilibrium conditions are achieved in the roof.
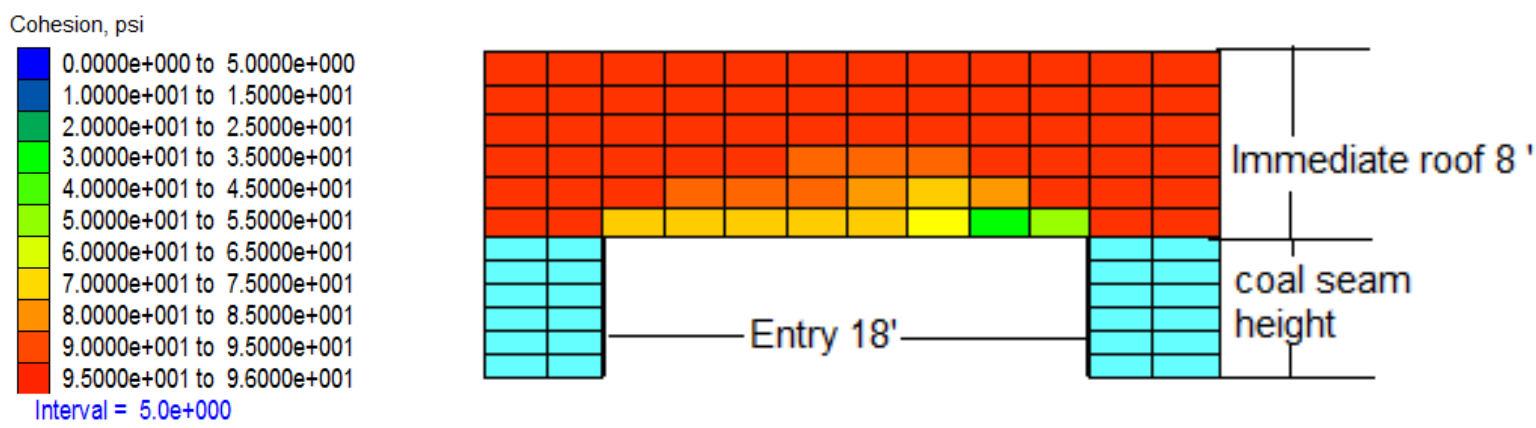

a. after 100 time step

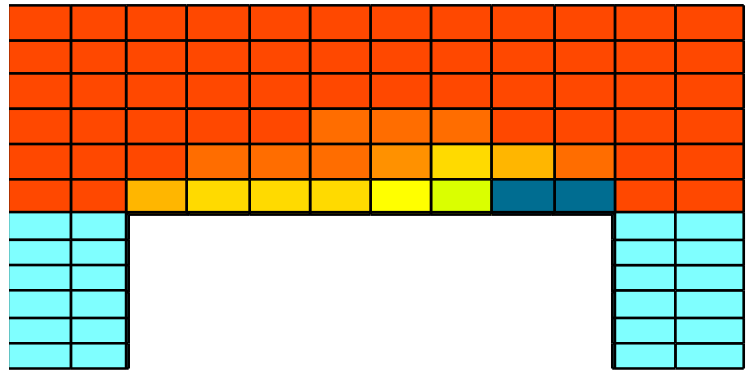

b. after 300 time step

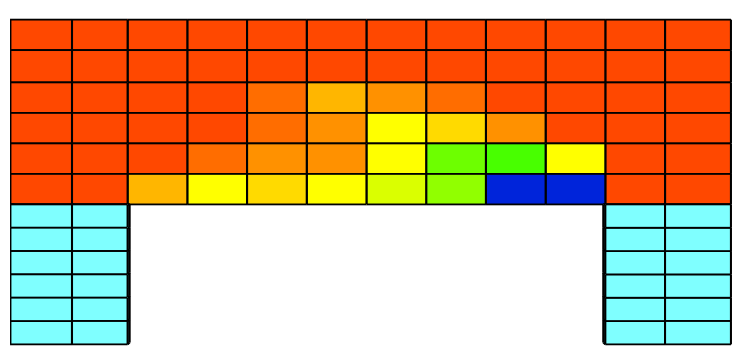

d. after 700 time step

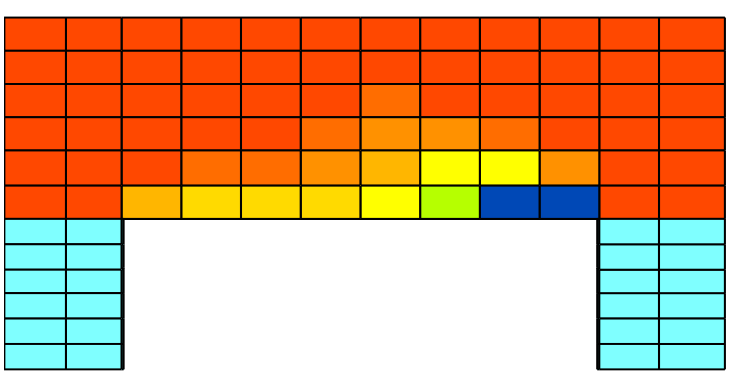

c. after 500 time step

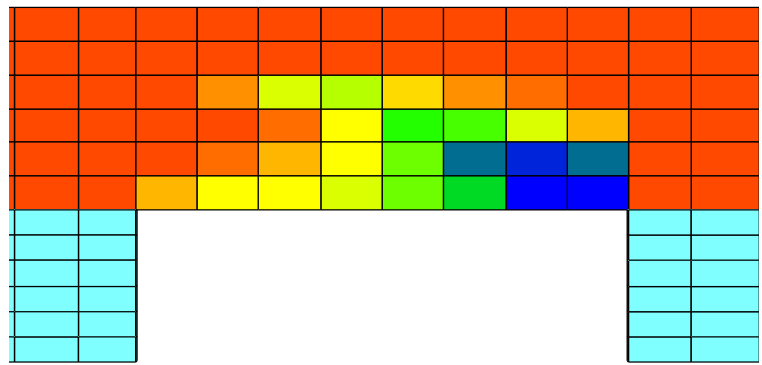

e. after 900 time step

Figure 5.26 contd. 


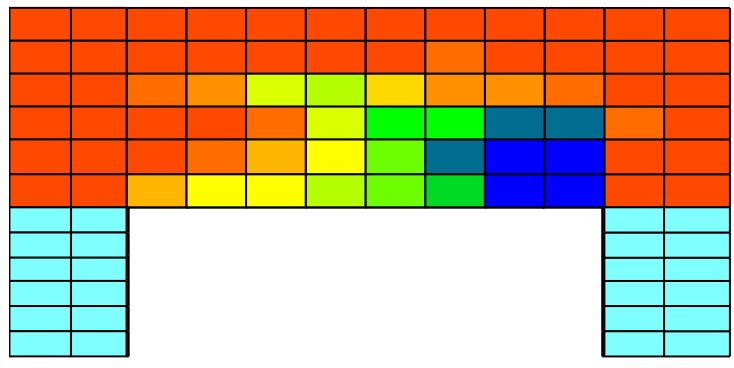

f. after 1100 time step

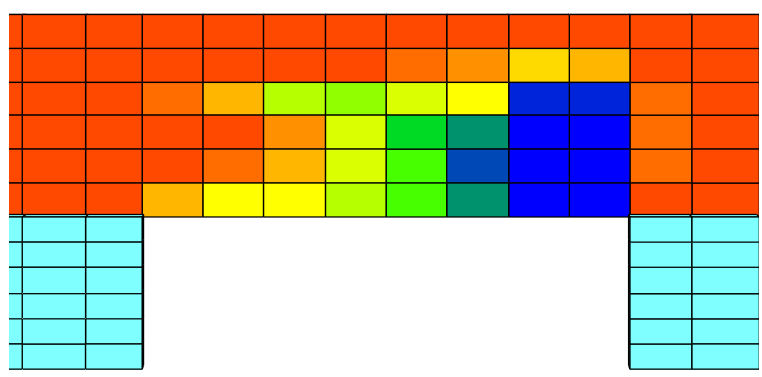

h. after 1500 time step

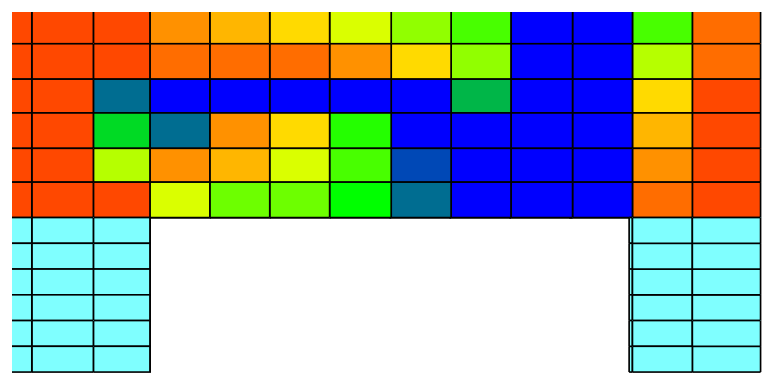

j. after 8000 time step (after cut4)

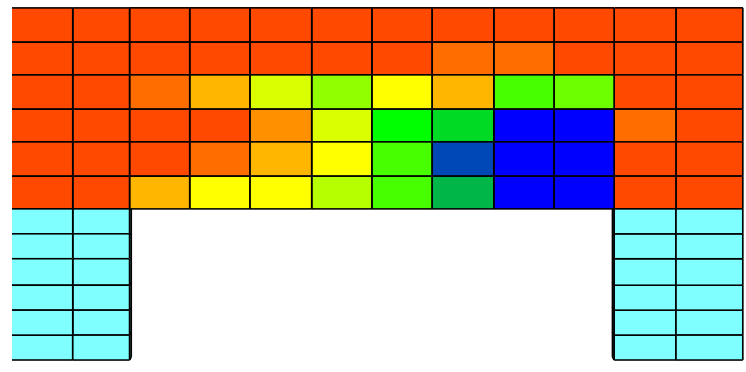

g. after 1300 time step

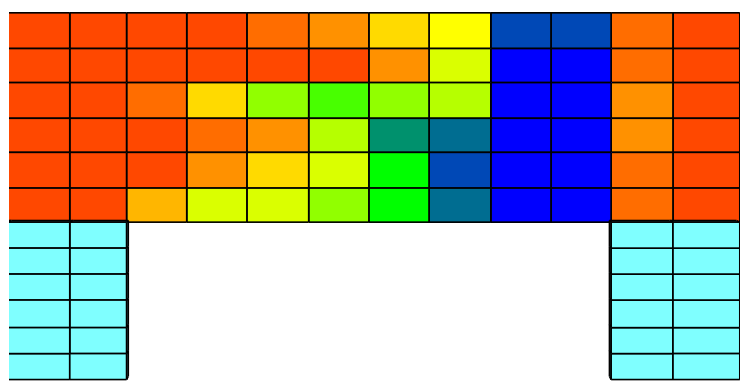

i. after 4000 time step (at the end of cut 3)

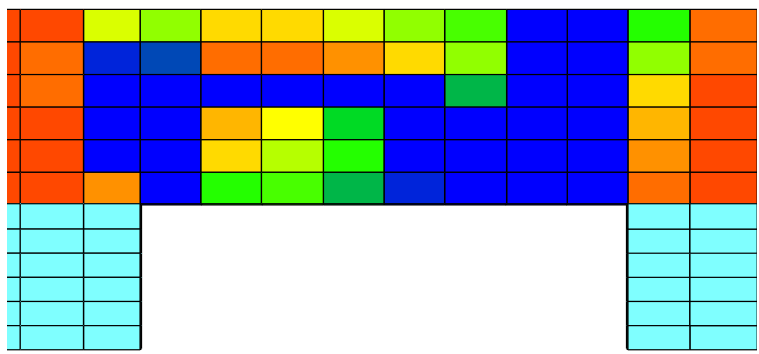

k. after 12000 time step (after cut 5)

Figure 5.26 Distribution of cohesion in the immediate roof on cross-section F-F in Figure 5.19 during cut 3 , after cut 4 and cut 5 for single entry created in 5 cuts

Cohesion, psi
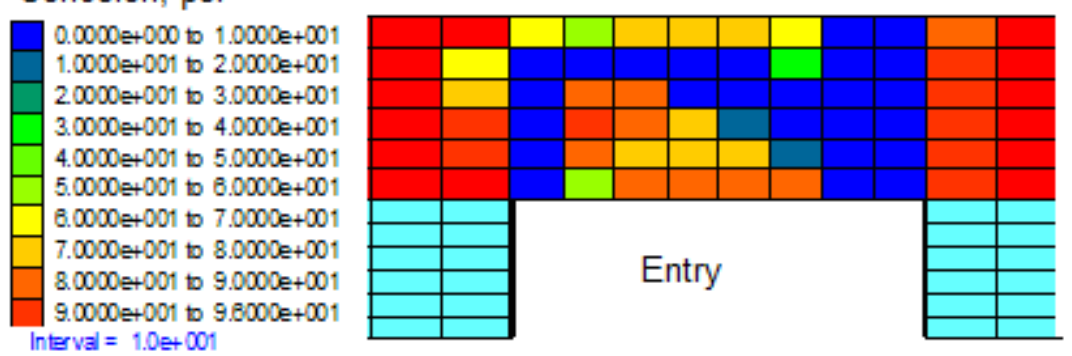

Figure 5.27 Distribution of cohesion in the immediate roof on cross-section A-A shown in Figure 5.2 after final cut 14 for 3-entry system 
stress is concentrating

Major principal stress

$-6.4065 e+002$ to $-6.0000 \mathrm{e}+002$

$-6.0000 \mathrm{e}+002$ to $-5.5000 \mathrm{e}+002$

$5.5000 \mathrm{e}+002$ to $-5.0000 \mathrm{e}+002$

$5.0000 e+002$ to $-4.5000 e+002$

$4.5000 e+002$ to $-4.0000 e+002$

$-4.0000 \mathrm{e}+002$ to $-3.5000 \mathrm{e}+002$

$-3.5000 \mathrm{e}+002$ to $-3.0000 \mathrm{e}+002$

$-3.0000 \mathrm{e}+002$ to $-2.5000 \mathrm{e}+002$

$-2.5000 \mathrm{e}+002$ to $-2.2688 \mathrm{e}+002$

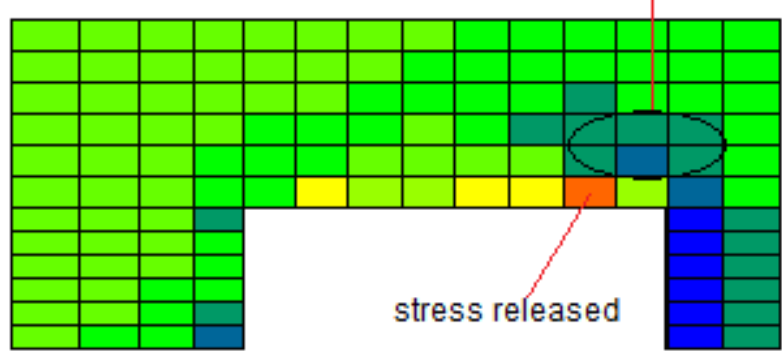

a. after 200 time step

\section{Major principal stress, psi}

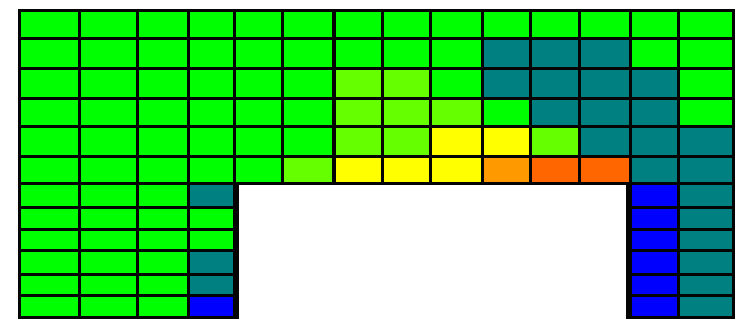

b. after 500 time step

Major prinicipal stress, psi

$-8.9049 e+002$ to $-6.0000 e+002$

$-8.0000 \mathrm{e}+002$ to $-5.0000 \mathrm{e}+002$

$-5.0000 e+002$ to $-4.0000 e+002$

$-4.0000 e+002$ to $-3.0000 e+002$

$-3.0000 e+002$ to $-2.0000 \mathrm{e}+002$

$-2.0000 e+002$ to $-1.0000 \mathrm{e}+002$

$-1.0000 e+002$ to $0.0000=+000$

$0.0000=+000$ to $5.5856=001$

Interval $=1.0 \mathrm{e}+002$

Stress concentration increase and shifted upwards

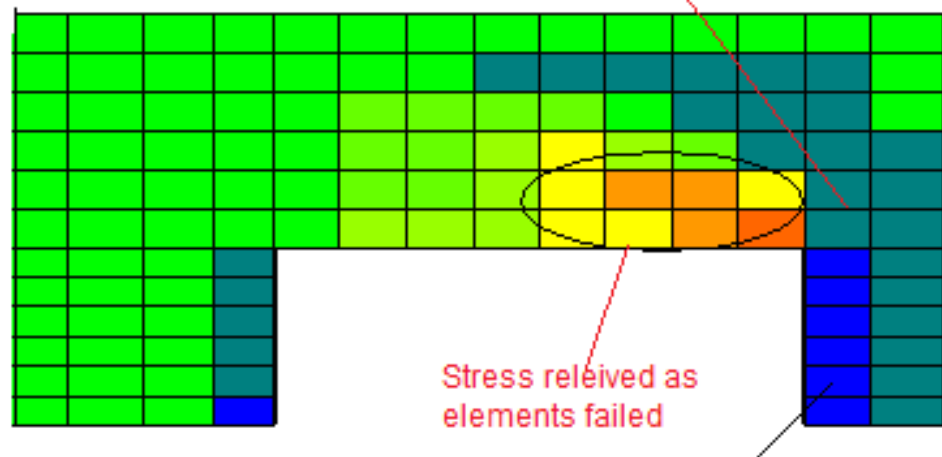

Pillar rib has high stress concentartion

c. after 900 time step 
Major principal stress, psi

$-7.1092 \mathrm{e}+002$ to $-7.0000 \mathrm{e}+002$

$-7.0000 \mathrm{e}+002$ to $-6.0000 \mathrm{e}+002$

$-6.0000 \mathrm{e}+002$ to $-5.0000 \mathrm{e}+002$

-5.0000 e +002 to -4.0000 e +002

-40000 e +002 to -30000 e +000

$-3.0000 \mathrm{e}+002$ to $-2.0000 \mathrm{e}+002$

$-2.0000 \mathrm{e}+002$ to $-1.0000 \mathrm{e}+002$

-1.0000 e +002 to $0.0000 e+000$

0.0000 e +000 to $8.0962 e-001$

$\mid$ ine $n a \mid=1.0 e+002$

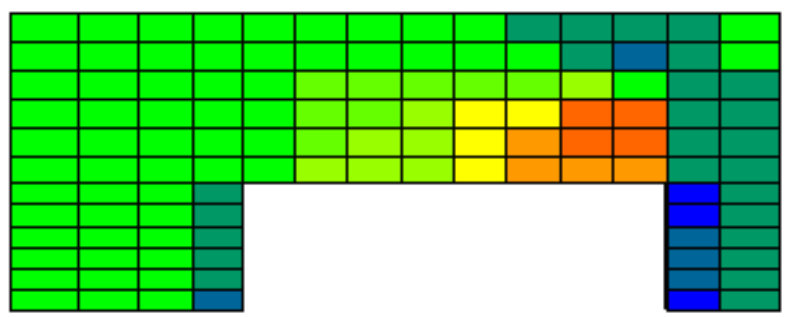

d. after 1300 time step

Major principal stress, psi

$-7.2233 e+002$ to $-7.0000 e+002$ $-7.0000 \mathrm{e}+002$ to $-6.0000 \mathrm{e}+002$

$-6.0000 e+002$ to $-5.0000 \mathrm{e}+002$

$5.0000 e+002$ to $-4.0000 e+002$

$-4.0000 e+002$ to $-3.00000+002$

-3.0000 e +002 to $2.0000 e+002$

$2.0000 e+002$ to $-1.0000 e+002$

$-1.0000 e+002$ to $0.0000=+000$

$0.0000 \mathrm{e}+000$ to $6.7564=-001$

Interval $=1.0 \mathrm{e}+002$

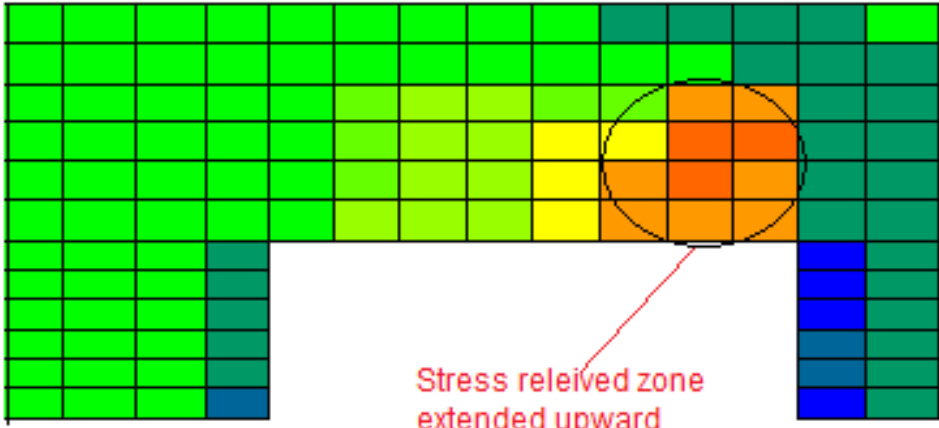

extended upward

e. after 1500 time step

Major principal stress, psi

$-7.5226 \mathrm{e}+002$ to $-7.0000 \mathrm{e}+002$

$7.0000 e+002$ to $-8.0000 e+002$

$-6.0000 e+002$ to $-5.0000 e+002$

$5.0000 e+002$ to $-4.0000 e+002$

$4.0000 e+002$ b $-3.0000 e+002$

$-3.0000 e+002$ to $-2.0000 e+002$

$2.0000 e+002$ to $-1.0000 e+002$

$-1.0000 e+002$ to $0.0000=+000$

$0.0000=+000$ to $1.4926 \mathrm{e}+000$

Interval $=1.0 \mathrm{e}+000$

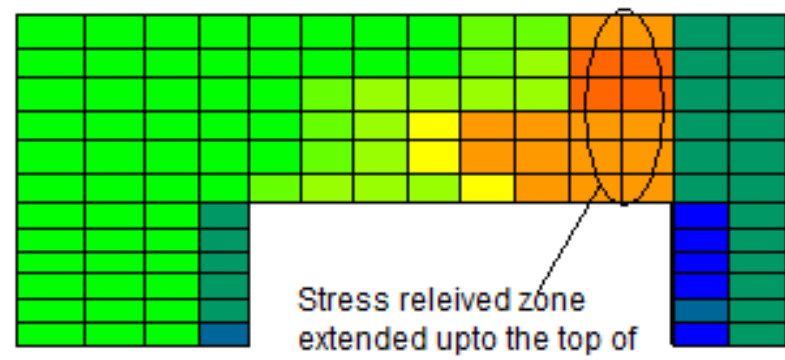

the roof at entry and pillar

rib edqe

f. after 4000 time step (at the end of cut 3 ) 
Major principal stress, psi

$-8.8206 e+002$ to $-8.0000 e+002$ $-8.0000 \mathrm{e}+002$ to $-7.0000 \mathrm{e}+002$ $-7.0000 e+002$ to $-6.0000 e+002$ $-6.0000 e+002$ to $-5.0000 \mathrm{e}+002$ $5.0000 e+002$ to $-4.0000 e+002$ $4.0000 e+002$ to $-3.0000 e+002$ $-3.0000 e+002$ to $-2.0000 e+002$ $-2.0000 e+002$ to $-1.0000 e+002$

$-1.0000 \mathrm{e}+002$ to $0.0000 \mathrm{e}+000$ $0.0000=+000$ to $8.1730 e+000$ Interval $=1.0 \mathrm{e}+00 \mathrm{R}$

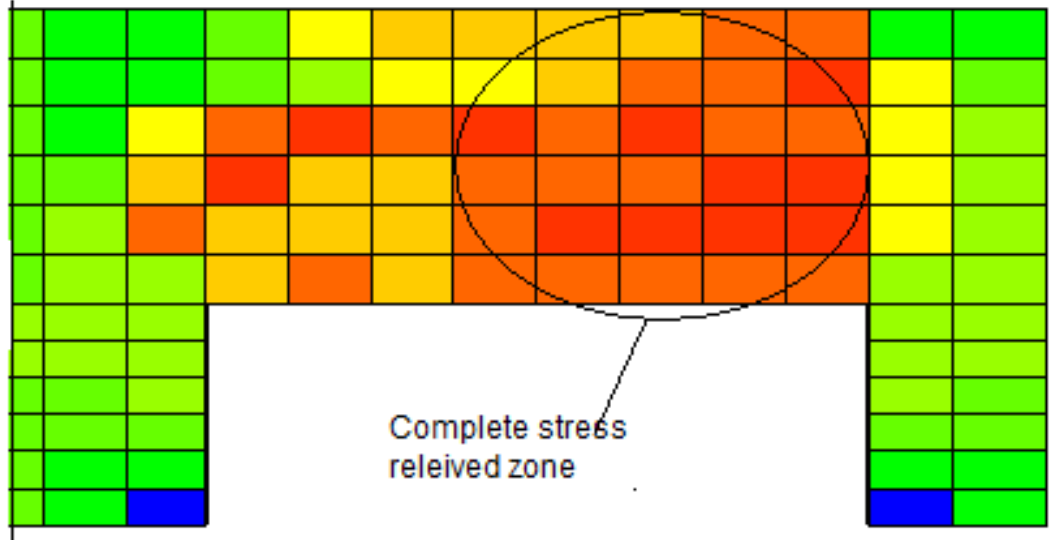

g. after 8000 time step (at the end of cut 4 )

Figure 5.28 The progressive development of stress relief zone and stress concentration zones in the immediate roof due to sequential excavation in the roof during cut 3 and after cut 4 and cut 5

\subsubsection{Cohesion distribution in immediate roof layer}

Figure 5.29 shows the cohesion distribution in the immediate roof layer for the single entry created in one cut and in five individual cut. The cohesion distribution is exactly opposite for entry created in single cut and multi-cuts. For entry created in single cut the zero cohesion elements are more concentrated on left edge of the entry while it is on right edge of the entry created in multi-cuts. The progressive development of cutter can be seen in Figure 5.29 b. After cut 1 there are no zero cohesion elements behind the face. After cut 2 the zero cohesion zones developed up to the face position on the right edge of the entry which further advances after each cut. The cohesion of the zones started to decrease at the previous face position in earlier cuts and also towards the left edge of the entry up to cut 4 . After cut 5, the elements on the left edge also reached to zero cohesion. 
Cohesion, psi

$0.0000 e+000$ to $5.0000=+000$

$5.0000 \mathrm{e}+000$ to $1.0000 \mathrm{e}+001$

$1.0000 \mathrm{e}+001$ to $1.5000 \mathrm{e}+001$

$1.5000 \mathrm{e}+001$ to $2.0000 \mathrm{e}+001$

$2.0000 \mathrm{e}+001$ to $2.5000 \mathrm{e}+001$

Interval $=5.0 e+000$
$2.5000 \mathrm{e}+001$ to $2.5000 \mathrm{e}+001$
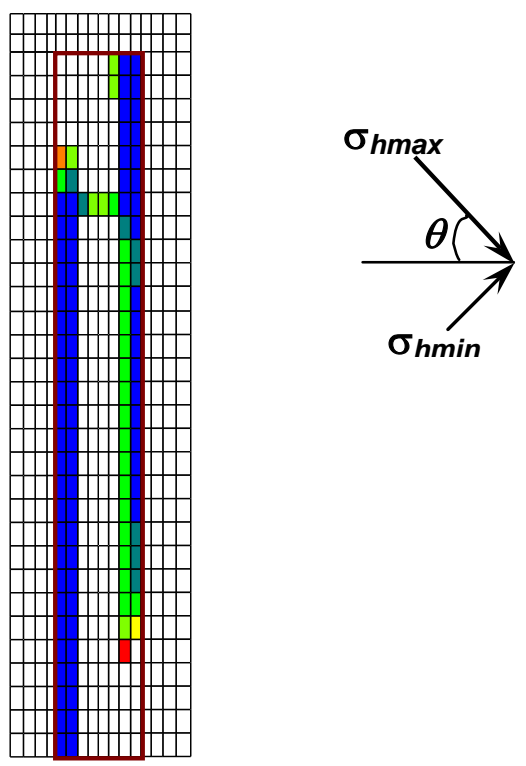

a. Cohesion distribution for entry created in one cut
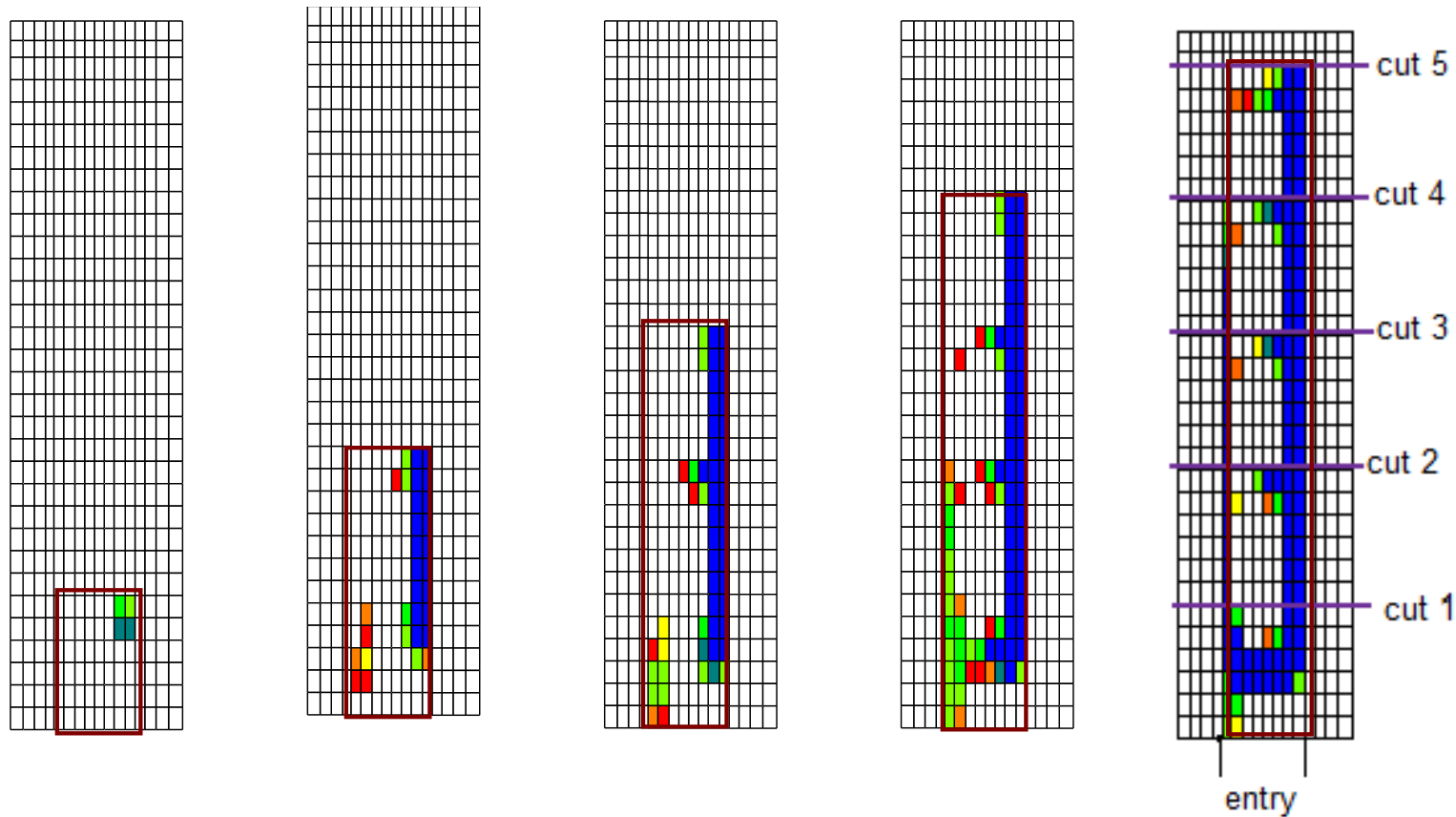

$(18 \mathrm{ft})$

after cut 5

after cut 1

after cut 2

after cut 3

after cut 4

b. Cohesion distribution for entry created in five individual cut of $30 \mathrm{ft}$

Figure 5.29 Cohesion distributions (Cutter) in the immediate layer of roof 


\section{Plasticity Indicators}

There are several indicators that can be used to assess the state of the numerical model-e.g., whether the system is stable, unstable, or in steady-state plastic flow. For the plasticity models in FLAC ${ }^{3 \mathrm{D}}$, those zones in which the stresses satisfy the yield criterion termed as plastic zone. The yield state indicates whether stresses within a zone are currently on the yield surface (i.e., the zone is at active failure now, $-n$ ) or the zone has failed at earlier stage of solving of the model but at present the stresses fall below the yield surface (the zone has failed in the past, $-p$ ). Initial plastic flow can occur at the beginning of a simulation, but subsequent stress redistribution unloads the yielding elements so that their stresses no longer satisfy the yield criterion, indicated by shear-p or tension-p (on the plasticity state plot).

It is important to look at the whole pattern of plasticity indicators to see if a mechanism has developed (Itasca, 2007). A failure mechanism is indicated if there is a contiguous line of active plastic zones (indicated by either shear-now or tensionnow) that join two surfaces. The diagnosis is confirmed if the velocity plot or shear strain rate also show a continuous band of high strain rate.

Figure 5.30 shows the block state of the elements in the roof at section F-F after cut 5. For better clarity in Figure $5.30 \mathrm{~b}$, the shear now or tension zone has been made of same color. Further Figure 5.31 shows the shear strain rate contour at same location. Shear strain rate is basically the square root of the second invariant of the deviatoric strain rate. This plot shows that shear strain rate is very high at the right edge and the band of shear strain rate looks similar to cohesion plotted (Figure 5.26k). The high shear strain indicates the more plastic flow and early failure will take place at those locations. The strain rate more than $1 \times 10^{-4}$ (Itasca, 
2007) can be treated has severe failure/fracture zone. Higher strain rate mean total strain accumulated will be more and hence failure will take place sooner compare to a location where strain rate is lower.

Block State

None

shear-n shear-p

shear-n shear-p tension- $p$

shear- $n$ tension- $n$ shear- $p$ tension- $p$

shear-p

shear- $p$ tension- $p$

tension-n shear-p tension- $p$

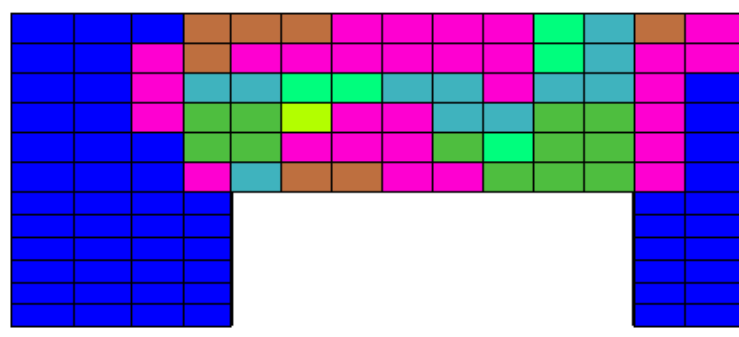

a.

\section{Block State}

None

shear-n shear-p

shear- $n$ shear-p tension- $p$

shear- $n$ tension- $n$ shear- $p$ tension- $p$

shear-p

shear- $p$ tension- $p$

tension- $n$ shear-p tension-p

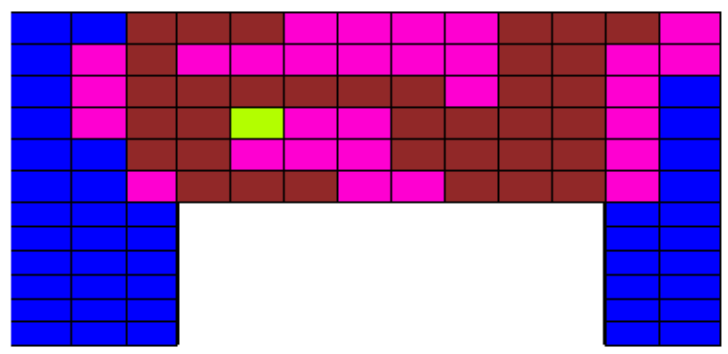

b.

Figure 5.30 Yield state in the immediate roof at section FF after cut 5

\section{Shear strain rate}

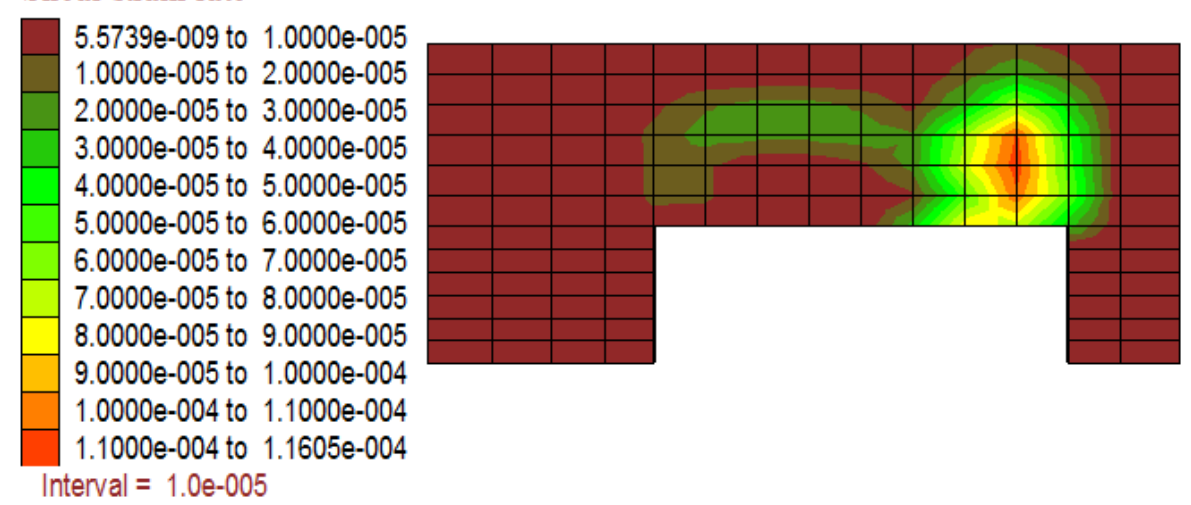

Figure 5.31 Shear strain rate in the immediate roof at section FF after cut 5 


\subsubsection{Cutter Detection Criteria}

In general if we see the post failure stress and strain curve for any rock, it always poses some residual strength. For simplicity it has been assumed that at high plastic strain the residual cohesion becomes zero. From the pattern of induced major principal stress and the cohesion, it is evident that as the stress is relieved in the zone, the cohesion also approaches to zero for those zones. Same trend can be also seen from the yield state and shear strain rate in the roof. Thus criteria for cutter detection are taken as a total loss of cohesive strength, which means the rock's resistance is solely due to friction. Such a criterion seems realistic from a physical view point also since a fractured rock loses its cohesion along the fracture and its resistance will depend mainly on friction across the fracture surface. This can be seen from failed specimens in laboratory compression test. Hence cohesion of zones having values 0 to 5 psi can be termed as cutter formation zones. Further as it has been mentioned that shear strain rate is a qualitative indicator of the active plastic flow occurring. Hence the shear strain rate in conjunction with cohesion element of zero plots can show where the chances of roof fall are higher.

With this criterion, the above figures showing cohesion, stress redistribution, yield state and shear strain rate in the roof, it can be said that the strain softening material model almost mimics the mechanism of cutter and roof falls as explained in the Figures 4.9, 4.10 and 4.11. The cutter/roof fall from numerical modeling will be explained in terms of both zero cohesion as well as high shear strain rate value.

\subsubsection{Effect of Friction and Dilation Mobilization on Cutter Pattern}

In the above models discussed the friction angle has been kept constant and dilation angle is zero during the post failure region. There is no doubt about the cohesion 
degradation with the increase in the amount of plastic strain but there is always a debate that whether friction will decrease or increase or remains constant once the rock enters in the plastic mode. There is very little work done on this subject. From the few rock testing conducted in the laboratory (Table 5.2) the pattern of friction degradation can not be established. Although from test results it can be inferred that the friction angle remains constant for lower plastic strain values and it may decrease with higher plastic strain. In section 5.2 few works conducted in the past has been discussed. To see the effect of friction angle mobilization on cutter development three models were solved. In the first model the friction angle was kept constant at 27.5 degrees and in another two models it was decreased or increased as shown in Figure 5.32.

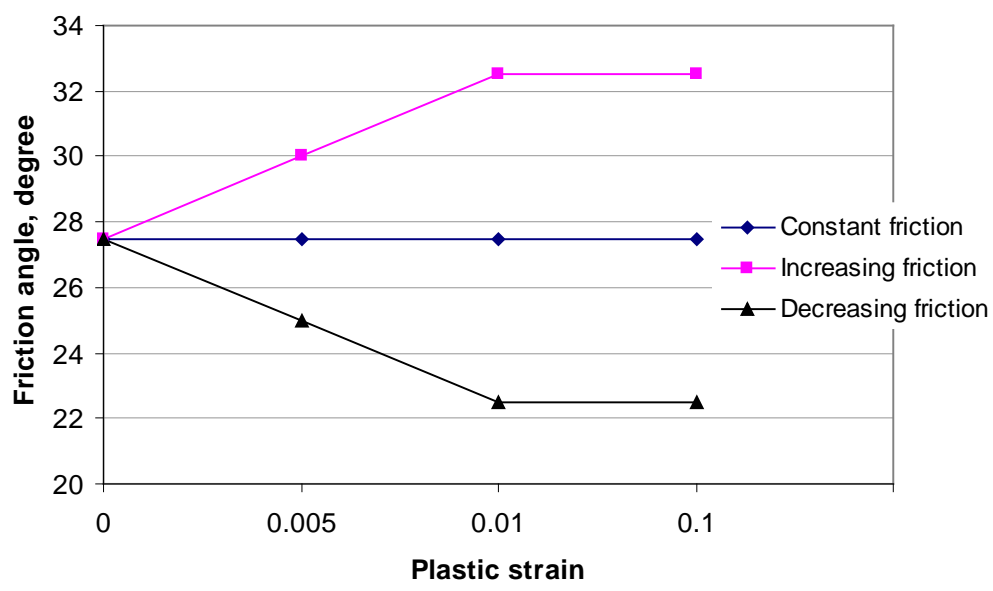

Figure 5.32 Friction mobilizations for strain softening model

Figures 5.33 and 5.34 show the cutter pattern/cohesion distribution in the immediate roof layer, at section FF and near the face after cut 5. From the Figures of cohesion distribution plot in the immediate roof layer, it can be seen that for constant friction model cutter development starts at the left edge of the entry and then after 5 cuts, it extends at the both edge of the entries. The development and progress of cutters 
with cut sequence in the entry will be discussed in next chapter. More or less behavior is the same for friction increasing model except there is no cutter near the left edge at the beginning of cutting. For strain softening model the cutter development looks similar at the entry edges but major difference is at the locations where face stops after each cutting sequence. At face stop position the zero cohesion elements joins both edges of the entry. The cohesion distribution looks similar near the face (Figure 5.35) while some distance behind the face the friction decreasing model shows more zero cohesion zone (Figure 5.34) in comparison to other two models. Hence from these simple initial models it can be said that the friction constant and increasing models behaves similar with insignificant change in the cohesion pattern while friction decreasing model has minor difference in cohesion pattern particularly behind the face with other two models .

Figure 5.36 shows the cohesion distribution for different friction model when excavation is made in one cut. From this cohesion plot, it can be seen that there is not much difference in constant friction and decreasing friction model. For Increasing friction model, the patterns are the same but only difference is that zero cohesion zones shifts from left edge to right edge of the entry after certain distance behind the face. In broader sense it can be said that the friction mobilization has no significant effect when excavation is made in one cut, i.e., mine geometry is created in a single step. Thus it can be concluded that cutting sequence affects the cohesion distribution or cutter pattern. Further effect of cutting sequence will be discussed in next chapter. 


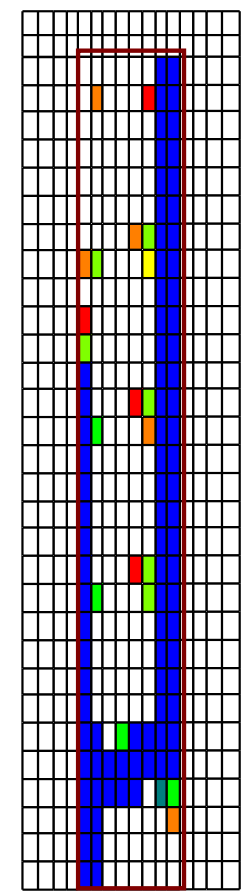

Friction constant
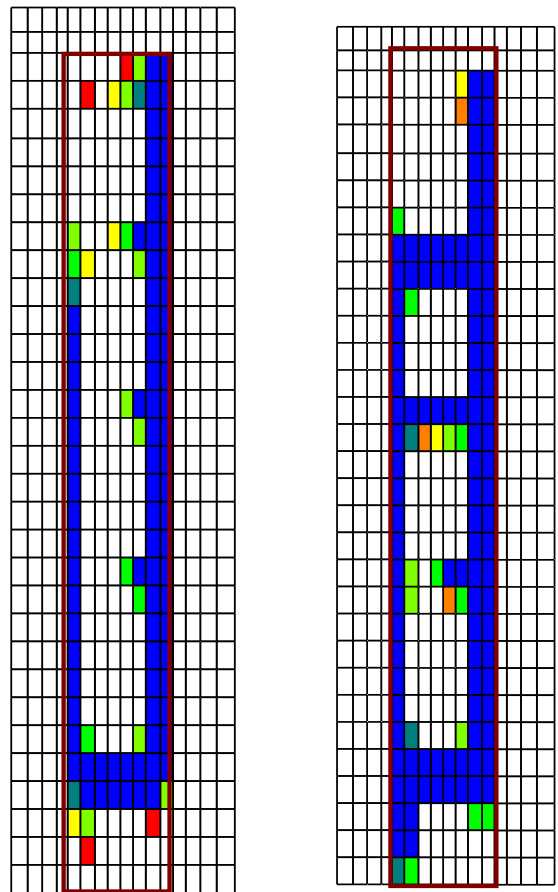

Cohesion, psi

$0.0000 \mathrm{e}+000$ to $5.0000 \mathrm{e}+000$ $5.0000 \mathrm{e}+000$ to $1.0000 \mathrm{e}+001$ $1.0000 \mathrm{e}+001$ to $1.5000 \mathrm{e}+001$ $1.5000 \mathrm{e}+001$ to $2.0000 \mathrm{e}+001$ $2.0000 \mathrm{e}+001$ to $2.5000 \mathrm{e}+001$ $2.5000 \mathrm{e}+001$ to $2.5000 \mathrm{e}+001$ Interval $=5.0 \mathrm{e}+000$

Figure 5.33 Cutter distribution in the immediate roof layer for different friction mobilization

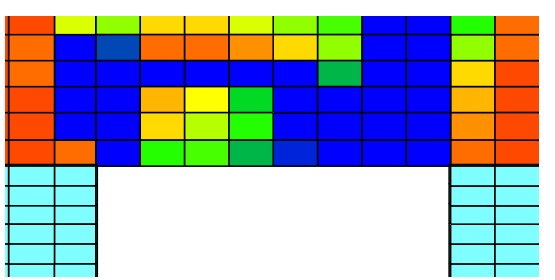

Friction constant

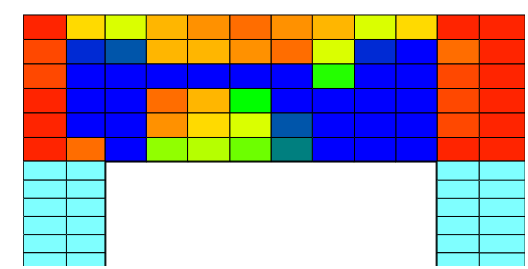

Friction increasing

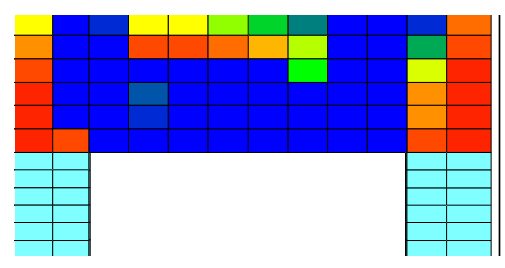

Friction decreasing

Figure 5.34 Cutter distribution at cross section FF after cut 5 for different friction mobilization

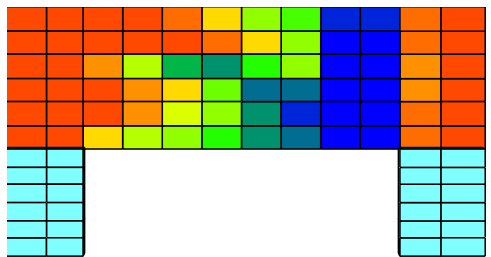

Friction constant

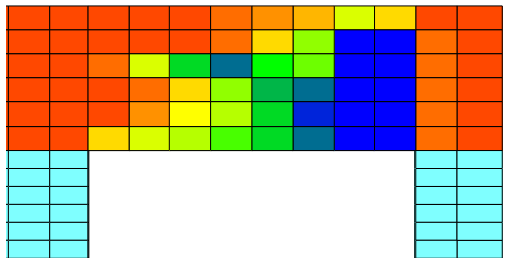

Friction increasing

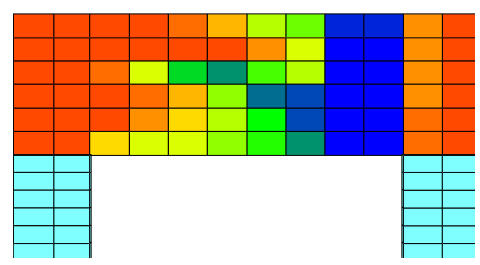

Friction decreasing

Figure 5.35 Cutter distribution at cross section near the face after cut 5 for different friction mobilization 


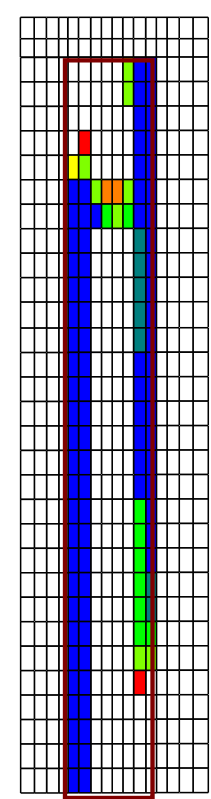

Friction constant

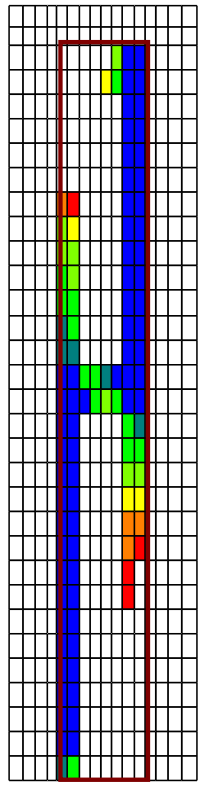

Friction increasing

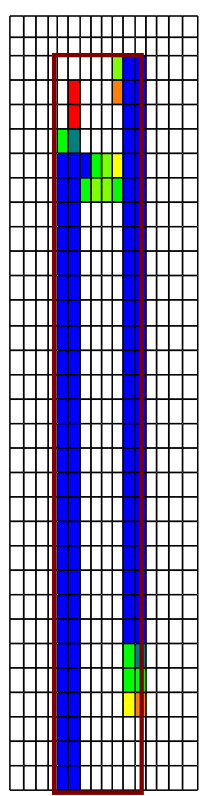

Cohesion, psi

$0.0000 \mathrm{e}+000$ to $5.0000 \mathrm{e}+000$ $5.0000 \mathrm{e}+000$ to $1.0000 \mathrm{e}+00$ $1.0000 \mathrm{e}+001$ to $1.5000 \mathrm{e}+001$ $1.5000 \mathrm{e}+001$ to $2.0000 \mathrm{e}+001$ $2.0000 \mathrm{e}+001$ to $2.5000 \mathrm{e}+001$ $2.5000 \mathrm{e}+001$ to $2.5000 \mathrm{e}+001$ Interval $=5.0 \mathrm{e}+000$

Figure 5.36 Cutter distribution in the immediate roof layer for different friction mobilization for excavation made in one cut

\section{Effect of dilation angle}

The flow rules in plastic model actually links the plastic stresses and strains in one small increment at a time instead of the total stresses and strains as in the case of elastic material. Further the flow rule also tells if there is a volume change in the post failure region or not. In classic plasticity, the plastic volume change is generally assumed to be zero. But experiments on rock show that its volume increases when it fails due to bulking. Such volume increase can be accounted for by treating the flow rule as non-associated.

Shear dilatancy or simple dilatancy, is the change in volume that occurs with shear distortion of a material. Dilative behavior is found to have great influence on the apparent strength behavior of granular soils or rocks. In most cases the material reach their maximum volume change at their peak strength stages and starts to exhibit plastic flow (Chen and Lin, 2003). The peak dilation angle is simply defined as the dilation angle when material has its peak strength. The dilatancy is characterized 
by a dilation angle $(\psi)$ and is the ratio of plastic volume change to plastic shear strain:

$$
\tan \psi=-\frac{\delta \varepsilon_{v}}{\delta \gamma}
$$

Where $\psi$ is dilation angle, $\varepsilon_{v}$ is volumetric strain and $\gamma$ is shear strain

Vermeer and de Borst (1984) first reported the typical values of dilation angles of various geological materials based on empirical data. He observed that the values of dilation angle lie approximately between $0^{\circ}$ to $20^{\circ}$ whether the material is soil, rock or concrete. The dilation angle for the rock is generally assumed some where between $0^{0}$ to $10^{\circ}$. Two models were solved for the value of dilation angle of $5^{0}$ and $10^{0}$ assuming friction angle as constant in post-failure zone..

Figures 5.37 and 5.38 show the cutter distribution near the face (cut 5) and at cross section F-F (cut 3 position) respectively after cut 5 for different dilation angle. Figure 5.39 shows the cutter distribution in the immediate layer. The cutter pattern near the face in the immediate roof looks same but it has different pattern at section F-F. For dilation angle of $0^{0}$ and $5^{0}$ the cutter patterns is almost same but there is more cutter and up to a maximum height above the entry for dilation angle of $10^{\circ}$. In the immediate layer the cutter patterns doesn't differ too much except with increase in dilation angle the cutters joins the entry edges near the face. The effect of dilation angle may be seen from Figure 5.40 which shows that the shear strain rate increases with increase in dilation angle. The maximum shear strain rate is $1.2 \times 10^{-4}, 1.55 \times 10^{-4}$ and $2.06 \times 10^{-4}$ for dilation angle of $0^{0}, 5^{0}$ and $10^{0}$ respectively. So the shear strain rate becomes twice when dilation angle is increased from $0^{\circ}$ to $10^{\circ}$. So higher dilation angle can initiate the cutters or roof fall faster or earlier compare to a rock having smaller dilation angle. 


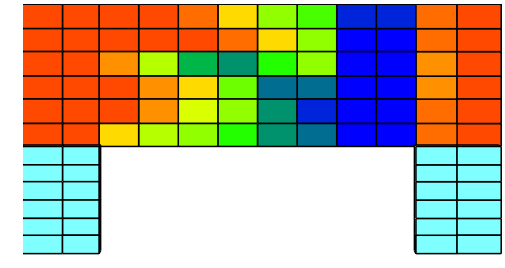

Dilation angle $0^{0}$

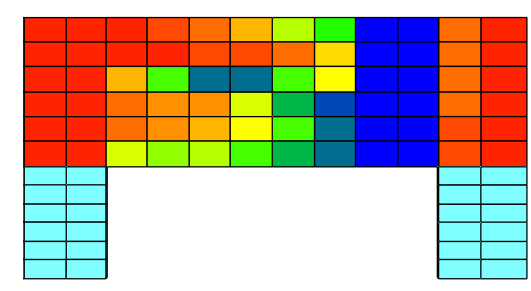

Dilation angle $5^{0}$

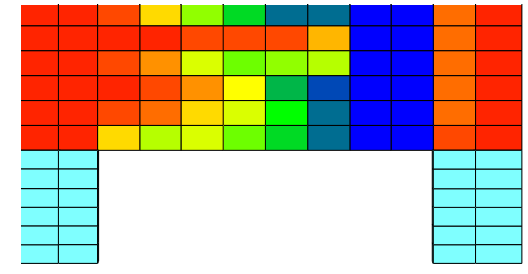

Dilation angle $10^{\circ}$

Figure 5.37 Cutter distribution cross section near the face after cut 5 for different dilation angle

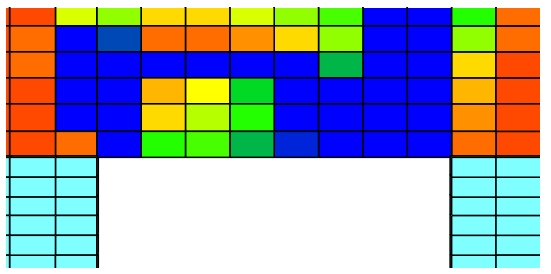

Dilation angle $0^{0}$

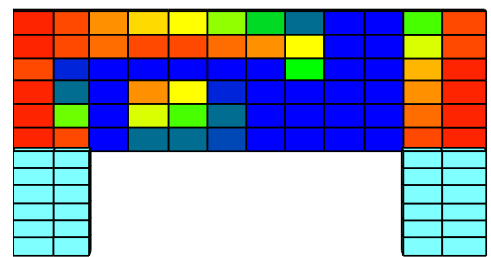

Dilation angle $5^{0}$

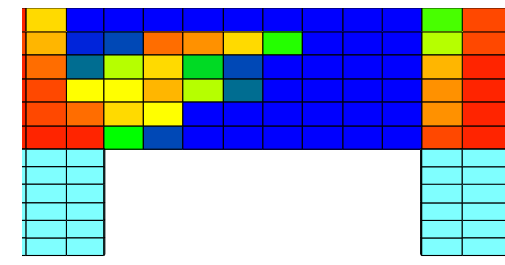

Dilation angle $10^{\circ}$

Figure 5.38 Cutter distribution cross section FF after cut 5 for different dialation mobilization

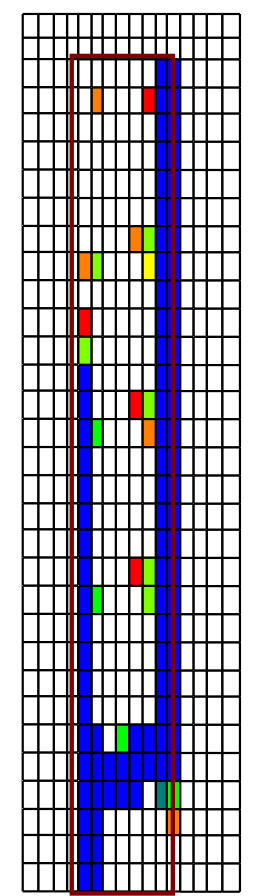

Dilation angle $0^{0}$

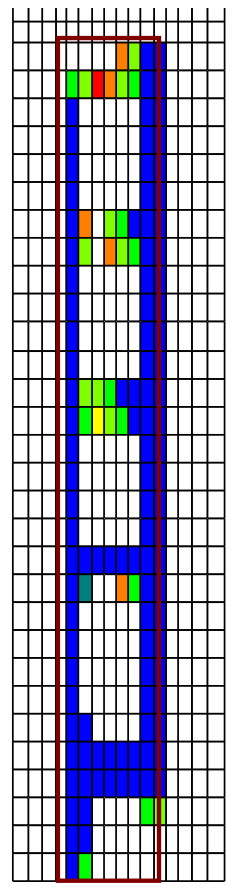

Dilation angle $5^{0}$

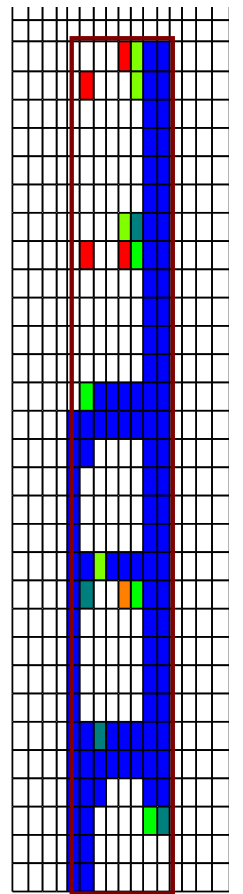

Dilation angle $10^{\circ}$
Cohesion, psi

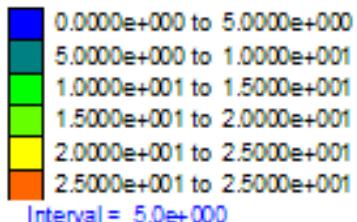

$\mid$ nterval $=5.00+000$

Figure 5.39 Cutter distribution in the immediate roof layer after cut 5 for different dilation angle 

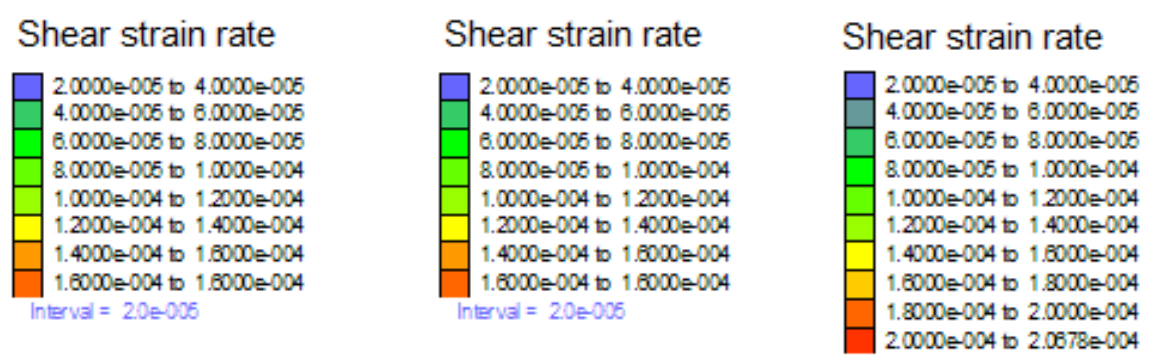

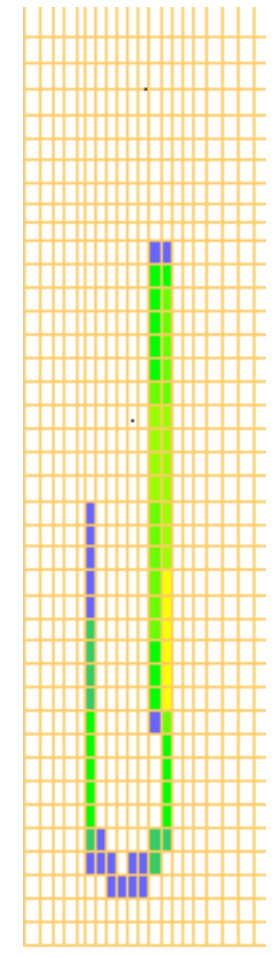

Dilation angle $0^{0}$

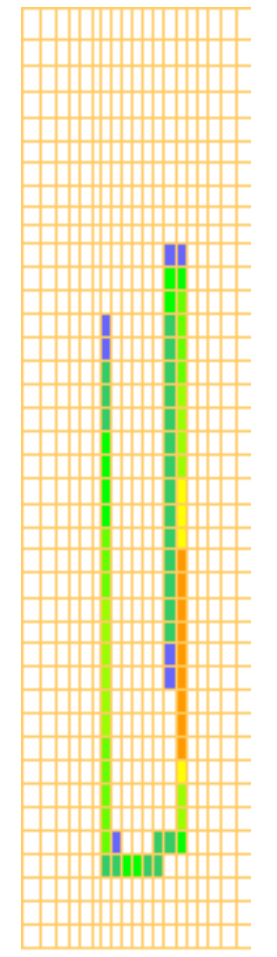

Dilation angle $5^{0}$

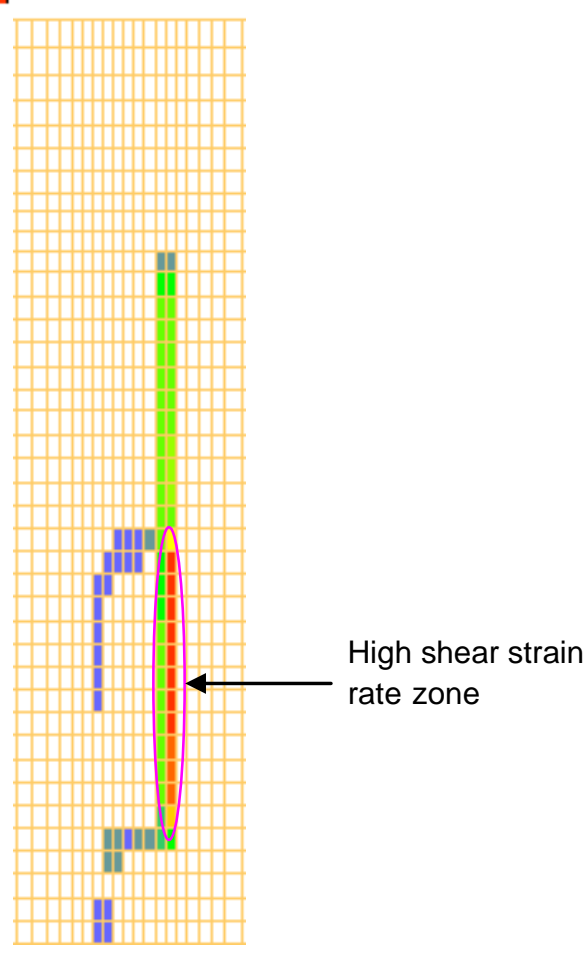

Dilation angle $10^{\circ}$

Figure 5.40 Shear strain rate in the immediate roof layer after cut 5 for different dilation angle

\subsubsection{Effect of Discontinuities Planes on Cutter pattern}

The actual behavior of the rock mass is very complex, so nearly all the researcher far from this sophistication by assuming that the rock is elastic in its behavior and there are no planes of weakness (bedding planes and joints). But these assumptions are far from the true behavior of in-situ rock mass. Presence of joints or discontinuities in rocks can change the strength of the rock mass and it may make the rock mass anisotropic. If rock behaves anisotropic, no rock failure criteria like Mohr-Coulomb or Hoek-Brown can be used as these are valid only when the 
strength behavior is isotropic. In real world, no rock mass in-situ can be found without any discontinuity.

The effect of single discontinuity on the strength of rock has been investigated both theoretically and experimentally by Jaeger and Cook (1979), Hoek and Brown (1980), and Sheorey (1997). These study show that failure will take place along the discontinuity for some combination of principal stresses if the discontinuity is oriented at certain angle. In such studies it was found that when the discontinuity is oriented between $20^{\circ}$ to $65^{\circ}$ with the major principal stress, the stability is affected. The stability is least when discontinuity is oriented at an angle of $30^{\circ}$ with respect to major principal stress (Figure 5.41). Further from Figure 5.41 it can be seen that the discontinuity doesn't affect the strength/stability of the rock when it is oriented at $0^{0}$ to $90^{\circ}$ with respect to major principal stress. In such case failure will be through the rock mass matrix itself.
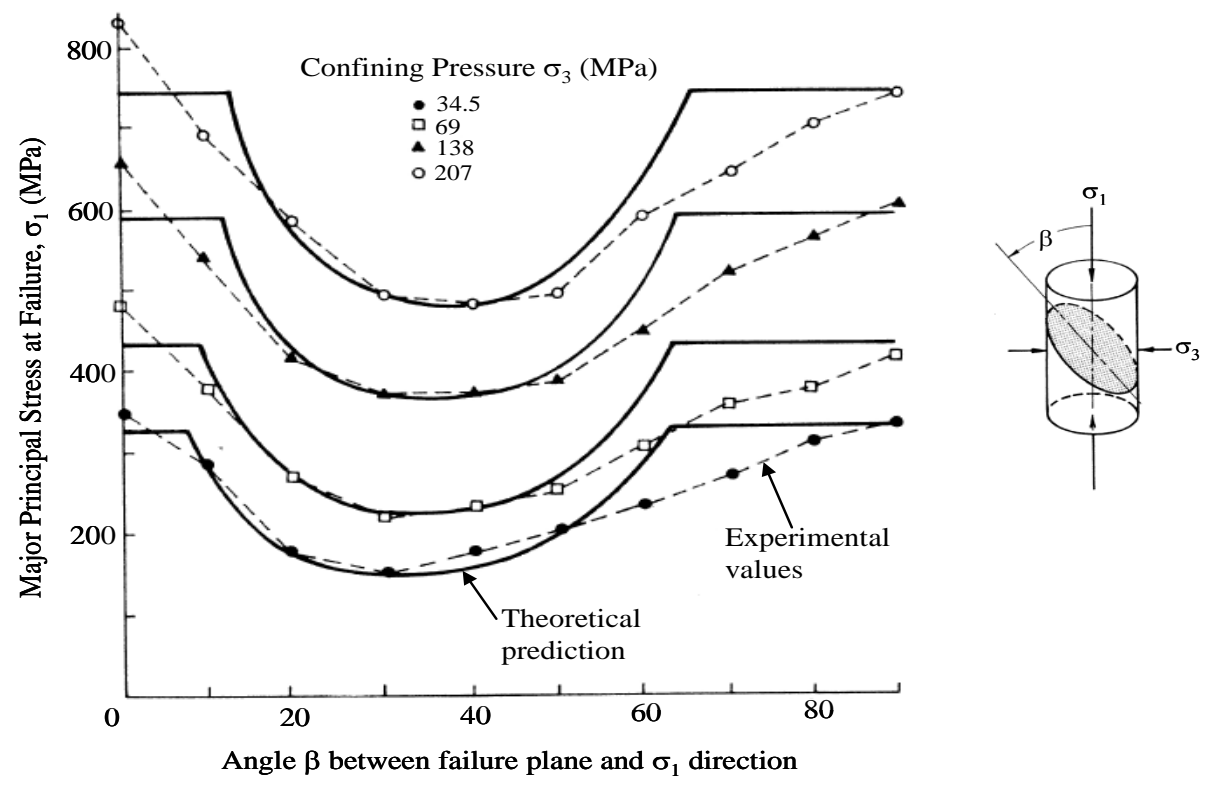

Figure 5.41 Tri-axial test results for slate with different discontinuity orientations (after Gadde et al., 2007) 
However it has been shown that if the rock mass contains four or more randomly oriented discontinuities with similar strength characteristics, then the overall strength behavior can be treated as nearly isotropic (Jaeger and Cook, 1979, Hoek and Brown, 1980; Sheorey, 1997; Gadde et al., 2007).

Rock often comprises of many joints which are formed parallel to bedding or stratification as a response to a reduction in the vertical stress due to erosion. According to Smart (1992) these natural bedding joints are dominant partings that exist in the overlying immediate and main roof. These dominant partings are defined as a laterally extensive but thin natural feature, parallel to bedding which allows both relative motion (separation) and parallel motion (shear) between adjacent strata, to release strain energy accumulated with increasing excavation span.

In the present we have concentrated on the horizontal discontinuities such as bedding planes in the immediate roof, which are most often oriented parallel to the underground excavation. Hence from the foregoing discussions it is clear that these planes of weakness will not control the strength of the rock mass. However, these discontinuities will affect the stress distribution in the rock especially in the region close to the discontinuities because of the slip and separation along them.

\section{Modeling of joints/bedding planes in FLAC}

In FLAC3D joints, faults or bedding planes in the geological medium in which sliding or separation can occur are simulated by interfaces. The models were solved with incorporating interfaces, at the base and in the immediate roof of the excavation, planes of weakness were considered along which slip and separation can take place. In the immediate roof the 1 to 7 interfaces has been incorporated at an interval of 1.3ft (Figure 5.42). The details about interfaces simulation can be found in 
FLAC3D manual. In FLAC, Interfaces are represented as collections of triangular planes (interface elements) and points in space (interface nodes) as shown in Figure 5.43. Each interface node has an associated representative area. When another grid known as target surface, comes into contact with an interface element, the contact is detected at the interface node. This contact is defined by the normal and shear stiffness. For the simulation of interfaces it requires joint stiffness properties which essentially comprises of two parts; shear stiffness ' $k_{s}$ ' or resistance to shearing or sliding of joint surfaces, and normal stiffness ' $k_{n}$ ' acting at right angles to the joint surfaces. These stiffness terms are illustrated in the Figure 5.44. The behavior of a typical rock joint in shear (Eve and Gray, 1994) is shown in Figure 5.45. The constitutive model for interface is shown in Figure 5.46.

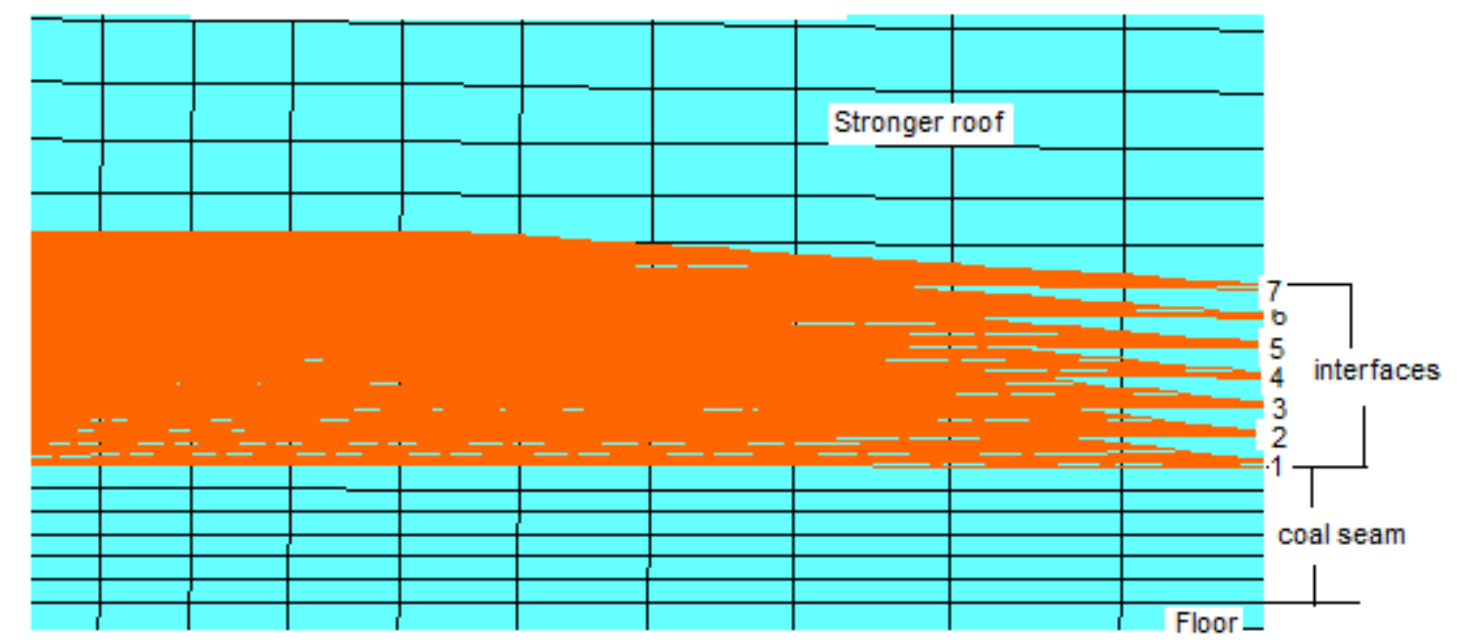

Figure 5.42 Interface locations in the immediate roof

During each time step of FLAC3D run the absolute normal penetration $\left(u_{n}\right)$ and the relative shear displacement $\left(u_{s}\right)$ are calculated for each interface node and target face. These values along with the stiffness property and representative are then used by the interface constitutive model to calculate a normal force and a shear 
force vector. The normal direction of the interface force is determined by the orientation of the target face.

FLAC 3D provides the simplest Mohr Coulomb linear model for joint behavior, implemented as an elasto plastic constitutive law. These interfaces are characterized by Coulomb sliding and/or tensile separation. Interfaces have the properties of normal and shear stiffness, cohesion, friction, dilation and tensile strength. The constitutive model is defined by a linear Coulomb shear strength criterion that limits the shear force acting at an interface node, a dilation angle that causes an increase in effective normal force on the target face after the shear strength limit is reached, and a tensile strength limit. These interfaces are used for sliding and separation in the overlying layers due to an excavation. Figure 5.46 illustrates the components of the constitutive model at interface node $(P)$.

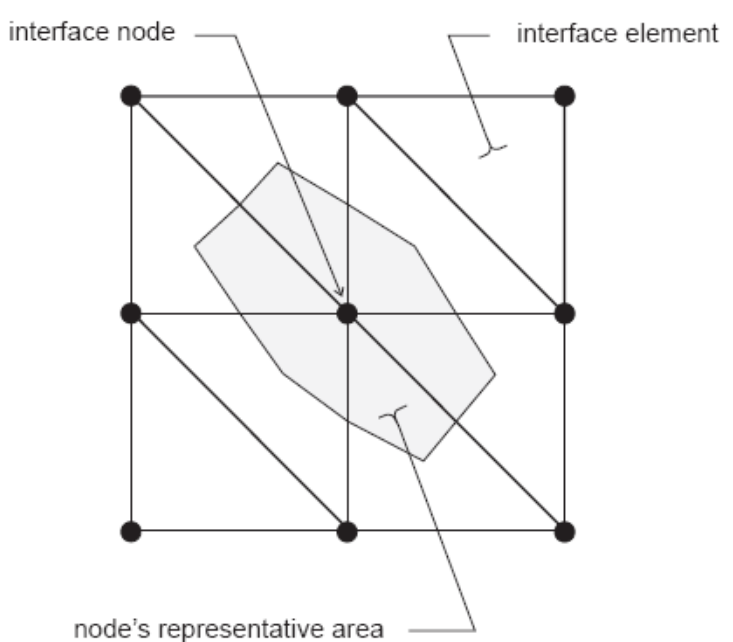

Figure 5.43 Distribution of representative areas to interface nodes (Itasca 2007)

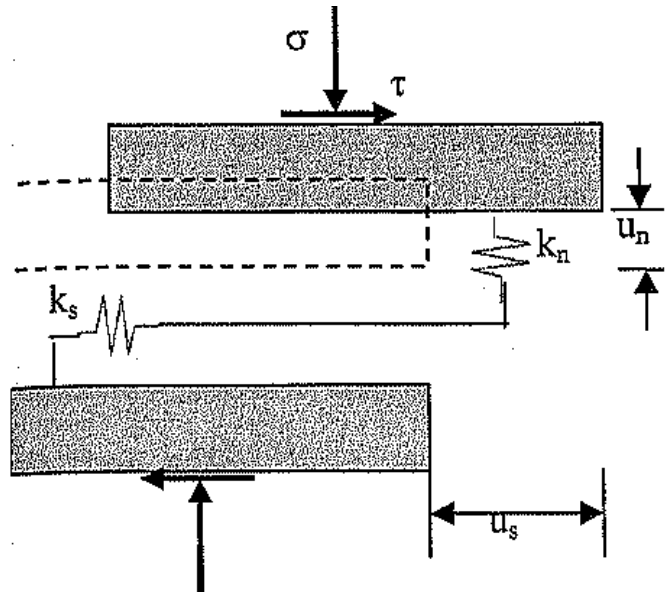

Figure 5.44 Normal and shear stiffness (Itasca 2007) 


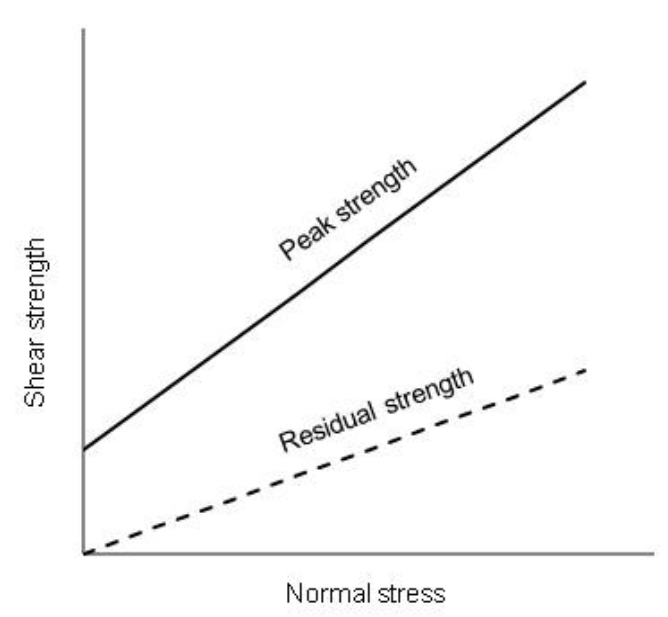

Figure 5.45 Variation of pick and residual strength with normal stress (Banerjee, 2006)

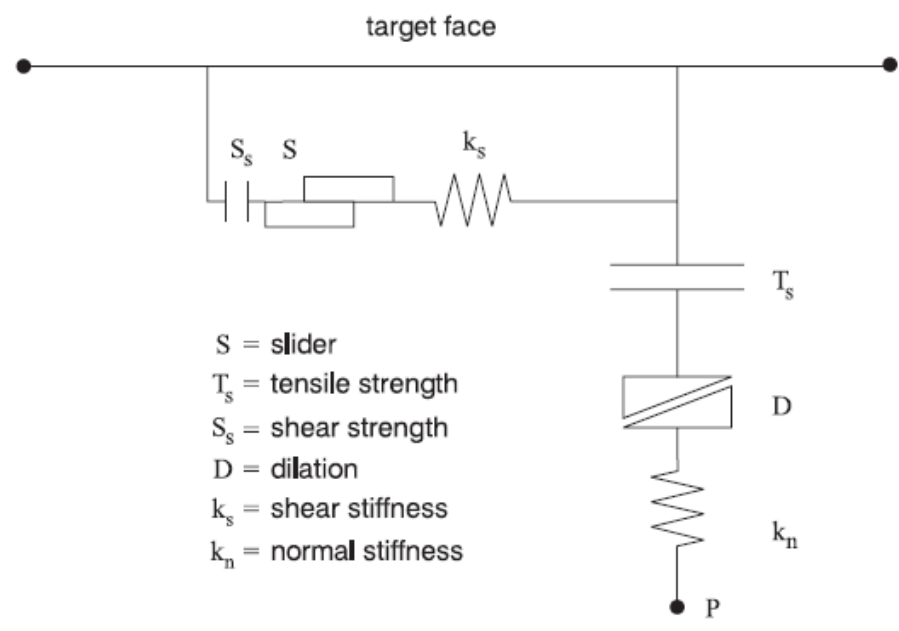

Figure 5.46 Components of interface constitutive model (Itasca 2007)

The Coulomb shear-strength criterion limits the shear force by the following relation.

$$
F_{\text {smax }}=c A+\tan \varphi F n
$$

where $c$ is the cohesion (stress) along the interface; $\varphi$ is the friction angle (degrees) of the interface surface; and If the criterion is satisfied (i.e., if $|F s| \geq F s m a x$ ), then sliding is assumed to occur, and $|F s|=F_{\text {smax }}$, with the direction of shear force preserved. If tension exits across the interface and exceeds the tension strength of the interface, then the interface breaks and the shear and normal forces are set to zero. As the residual tensile strength of the weak bedding planes is negligible compared to the rock mass, the tensile strength limit of the interface is set to a small number are assumed zero

\section{Interface properties}

The interface properties are not readily available for bedding planes or joints for coal measure rocks. In the past very little has been done to derive the input properties needed to define the constitutive behavior of bedding planes. Barton et.al. (1974) provide some estimates for peak and residual cohesion and friction for filled 
discontinuities and filling material. Bandis et. Al. (1983) studied normal deformation ( $\mathrm{kn}$ and un) of joints conducting loading/unloading and repeated load cycling test on a wide variety of fresh and weathered joints in different rock types. Bandis et al $(1983,1990)$ provide some values of $k s$ for different rock types. Typical value of normal and shear stiffness for rock joints can range from roughly 10 to $100 \mathrm{MPa} / \mathrm{m}$ for joints with soft clay in-filling, to over $100 \mathrm{GPa} / \mathrm{m}$ for tight joints in hard rock like granite and basalt (Itasca 2007). Friction angle can vary from less than $10^{\circ}$ for smooth joints in weak rock to over $50^{\circ}$ for rough joints in hard rock. Joint cohesion can range from zero to values approaching the compressive strength of the surrounding rock (Itasca 2007). In FLAC the selection of suitable value of joint properties is very important to improve solution efficiency. The normal and shear stiffness value of joints should be less than 10 times the equivalent stiffness of adjacent size. If this ratio is more than 10 , the solution time required is significantly higher. Similarly even low value of normal stiffness, $k_{s}$ also causes problem. The rough estimates can be made based on joint normal displacement. The normal displacement should be smaller to a typical zone size. Table 5.4 shows the joint properties used by various researchers to simulate the brick-mortar interface and rock joints for various applications. In the Table 5.4, the shaded cells represents the joint properties used for rock joints. There is a wide variation in all the properties selected by different researchers due to lack of laboratory tested values. The joint property which has been used in the present study is also given in Table 5.4. 
Table 5.4 Joint properties used by various researchers

\begin{tabular}{|c|c|c|c|c|c|c|c|c|c|}
\hline \multirow[t]{2}{*}{ Researcher } & \multirow{2}{*}{$\begin{array}{l}\text { Interface } \\
\text { type/joints }\end{array}$} & \multirow[t]{2}{*}{ Application } & \multicolumn{2}{|c|}{$K_{n}$} & \multicolumn{2}{|c|}{$K_{s}$} & \multicolumn{2}{|c|}{ Cohesion } & \multirow{2}{*}{$\begin{array}{c}\text { Friction, } \\
\text { degree }\end{array}$} \\
\hline & & & $\mathrm{GPa} / \mathrm{m}$ & Psi/in & $\mathrm{MPa} / \mathrm{m}$ & Psi/in & MPA & psi & \\
\hline $\begin{array}{l}\text { R. Schlegel } \\
\text { and K. } \\
\text { Rautenstrauch } \\
(2004)\end{array}$ & $\begin{array}{l}\text { Brick and } \\
\text { mortar }\end{array}$ & $\begin{array}{l}\text { Massonary } \\
\text { wall }\end{array}$ & 764.30 & $2.82 E+06$ & 246.70 & $9.09 E+05$ & 0.50 & 72.50 & 39 \\
\hline $\begin{array}{l}\text { R.Schlegel, K. } \\
\text { Rautenstrauch } \\
\& \text { J. Will } \\
(2004)\end{array}$ & $\begin{array}{l}\text { Brick and } \\
\text { mortar }\end{array}$ & $\begin{array}{l}\text { Massonary } \\
\text { wall }\end{array}$ & 25.00 & $9.21 E+04$ & 17.50 & $6.45 E+04$ & 0.03 & 4.64 & 30 \\
\hline $\begin{array}{l}\text { Nagwa R. El- } \\
\text { sakhawy et. } \\
\text { al. (2002) }\end{array}$ & $\begin{array}{l}\text { Brick and } \\
\text { mortar }\end{array}$ & $\begin{array}{l}\text { Massonary } \\
\text { wall }\end{array}$ & 4.00 & $1.47 E+04$ & 2.50 & $9.21 E+03$ & 0.55 & 80.00 & 59 \\
\hline \multirow{2}{*}{$\begin{array}{l}\text { M. } \\
\text { Dolezalova, } \\
(2004)\end{array}$} & $\begin{array}{l}\text { P3 } \\
\text { system }\end{array}$ & $\begin{array}{l}\text { Massonary } \\
\text { wall }\end{array}$ & 3.00 & $1.11 E+04$ & 1.00 & $3.68 E+03$ & 2.00 & 290.00 & 35 \\
\hline & Bedding & & 0.20 & $7.37 E+02$ & 0.07 & $2.58 \mathrm{E}+02$ & 0.07 & 10.15 & 20 \\
\hline $\begin{array}{l}\text { Y. Mitani, T. } \\
\text { Esaki \& Y. Cai } \\
(2004)\end{array}$ & rock joints & $\begin{array}{l}\text { Rock } \\
\text { slope }\end{array}$ & 18.30 & $6.74 \mathrm{E}+04$ & 0.88 & $3.24 \mathrm{E}+03$ & 0.00 & 0.00 & 30 \\
\hline $\begin{array}{l}\text { R. } \\
\text { Glamheden, } \\
\text { H. Hökmark \& } \\
\text { R. } \\
\text { Christiansson } \\
\text { (2004) }\end{array}$ & rock joints & $\begin{array}{l}\text { Creep } \\
\text { study of } \\
\text { jointed } \\
\text { rockmass }\end{array}$ & 100.00 & $3.68 E+05$ & 50.00 & $1.84 \mathrm{E}+05$ & 1.00 & 145.00 & 35 \\
\hline $\begin{array}{l}\text { U. Lendel } \\
(2004)\end{array}$ & rock joints & $\begin{array}{l}\text { Rock } \\
\text { bolting }\end{array}$ & 0.50 & $1.84 \mathrm{E}+03$ & 0.50 & $1.84 \mathrm{E}+03$ & 0.10 & 14.50 & 30 \\
\hline $\begin{array}{l}\text { G Banerjee } \\
(2006)\end{array}$ & $\begin{array}{l}\text { Bedding } \\
\text { planes }\end{array}$ & $\begin{array}{l}\text { Longwall } \\
\text { strata } \\
\text { behavior }\end{array}$ & 10.0 & $3.68 E+04$ & 5.0 & $1.84 \mathrm{E}+04$ & 0.0 & & 16 \\
\hline $\begin{array}{l}\text { Present work } \\
\text { (author's } \\
\text { value) }\end{array}$ & $\begin{array}{l}\text { Bedding } \\
\text { planes }\end{array}$ & $\begin{array}{l}\text { Cutter } \\
\text { roof/roof } \\
\text { fall }\end{array}$ & 18.0 & $6.6 \mathrm{E}+04$ & 9.0 & $3.3 E+04$ & $\begin{array}{c}0 \\
\text { and } \\
0.3\end{array}$ & $\begin{array}{l}0 \text { and } \\
50\end{array}$ & 15 \\
\hline
\end{tabular}

* Dilation and tensile strength for joints has been assumed zero by almost every researcher

\section{Modeling results}

Figures 5.47, 5.48 and 5.49 show the cutter pattern or cohesion distribution in the roof close to the face, far behind the face and in immediate roof layer. From the figures it can be seen that when interface is incorporated in the model at coal pillar and roof contact, there is no difference in the cohesion distribution compared to the model having no interface (Figure 5.26K). For all other interface models, the cohesion distribution in the roof remains almost same near the face. But far behind the face, the pattern looks complete different from what observed without interfaces (Figure 5.26K). For interface models the zero cohesion elements developed one 
element away $(2.25 \mathrm{ft})$ from the right edge of the entry and it further extends in the roof towards the center of the entry up to the location of interface.

For cutter simulation discussed so far, effective stress transfer of stress in vertical direction is necessary. In lack of any discontinuities ensure such condition in the model so far. However when some discontinuity (interface in FLAc3D) is introduced in the model depending on where measurable separation occurred along the bedding planes, the continuity necessary for upward cutter propagation doesn't exist in the model. As a result the cutter either terminates at the discontinuity or propagates more towards the center of the entry.

Hence to simulate the cutter roof failure in continuum model the discontinuity planes should be selected properly to represent the actual change in the rock type not merely for the thin lamination as encountered in highly laminated strata. The real bedding planes can affect the cutter pattern as well its extension in the roof depending upon its location.

Further the cohesion pattern may also depend upon the joint stiffness and cohesion properties. Figure 5.50 shows the cohesion pattern for model with 4 interfaces with cohesion value of 50 psi. In all previous models the cohesion value for the interface were assumed zero. With increase in cohesion value of interfaces, zero cohesion elements are not observed (Figure 5.50b) during a cut in the immediate roof behind the face in comparison to interface with zero cohesion (Figures 5.49d). The height of failure in the roof also reduces (Figure 5.50a). 


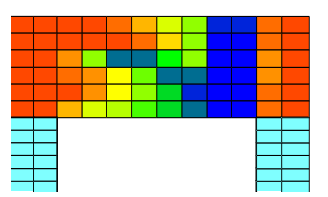

a. Interface at entry roof (interface 1)

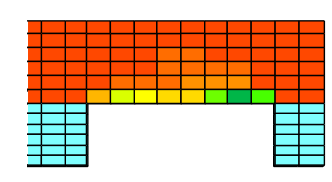

b. Interface at $1.3 \mathrm{ft}$ above the entry

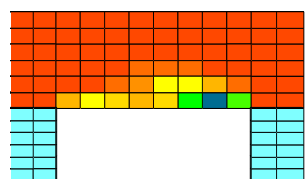

c. Interface at $2.6 \mathrm{ft}$ above the entry roof (interface 3)

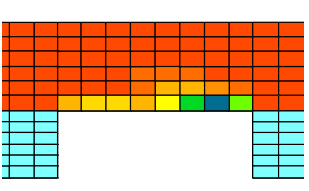

d. Interface at $4 \mathrm{ft}$ above the entry

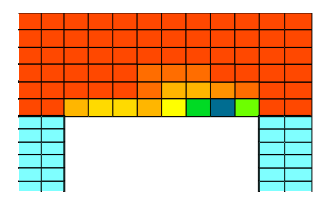

e. Interface at $5.3 \mathrm{ft}$ above the entry

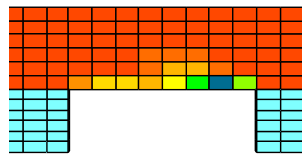

f. Interface at $6.6 \mathrm{ft}$ above the entry roo (interface 6)

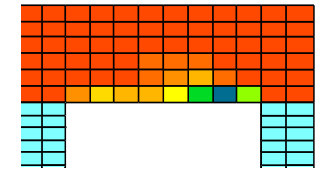

g. Interface at $8 \mathrm{ft}$ above the entry roof (interface 7)

Figure 5.47 Cutter pattern near the face (Figure 5.19) in the immediate roof after cut 5 due to incorporating numbers of interface in the model

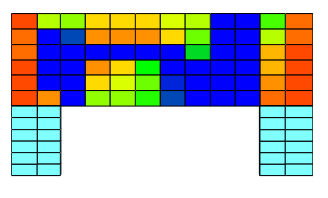

a. Interface at entry roof (interface 1)

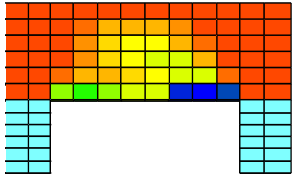

b. Interface at $1.3 \mathrm{ft}$ above the entry roof (interface 2)

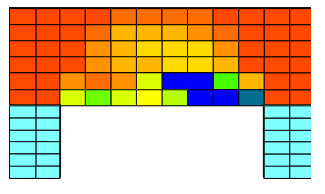

c. Interface at $2.6 \mathrm{ft}$ above the entry roof (interface 3)

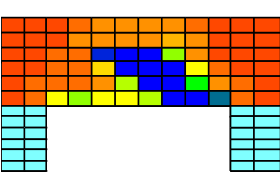

d. Interface at $4 \mathrm{ft}$ above the entry roof (interface 4)

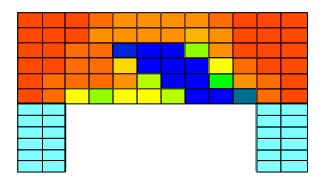

e. Interface at $5.3 \mathrm{ft}$ above the entry roof (interface 5)

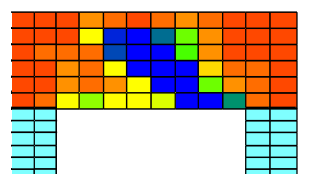

f. Interface at $6.6 \mathrm{ft}$ above the entry roof

(interface 6)

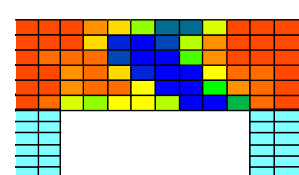

g. Interface at $8 \mathrm{ft}$ above the entry roof (interface 7)

Figure 5.48 Cutter pattern far behind the face (section FF Figure 5.19) in the immediate roof after cut 5 due to incorporating numbers of interface in the model

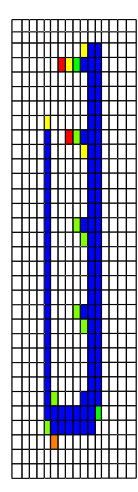

a. Interface at entry roof (interface 1)

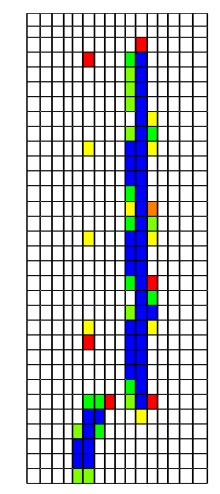

b. Interface at $1.3 \mathrm{ft}$ above the entry roof (interface 2)

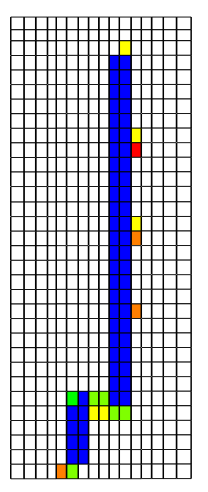

c. Interface at $2.6 \mathrm{ft}$ above the entry roof (interface 3)

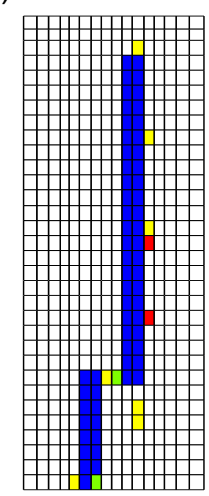

d. Interface at $4 \mathrm{ft}$ above the entry roo (interface 4)

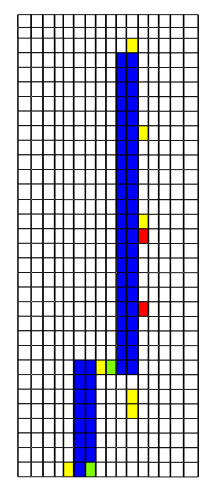

e. Interface at $5.3 \mathrm{ft}$ above the entry roof (interface 5)

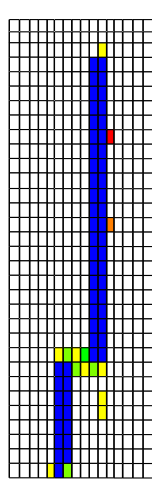

f. Interface at $6.6 \mathrm{ft}$ above the entry roof (interface 6)

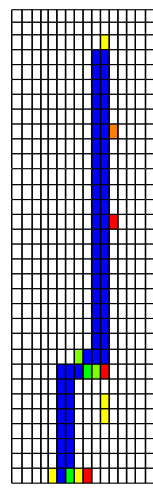

Interface at $8 \mathrm{ft}$ above the entry roof (interface 7)

Figure 5.49 Cutter pattern in the immediate roof layer after cut 5 due to incorporating numbers of interface in the model 

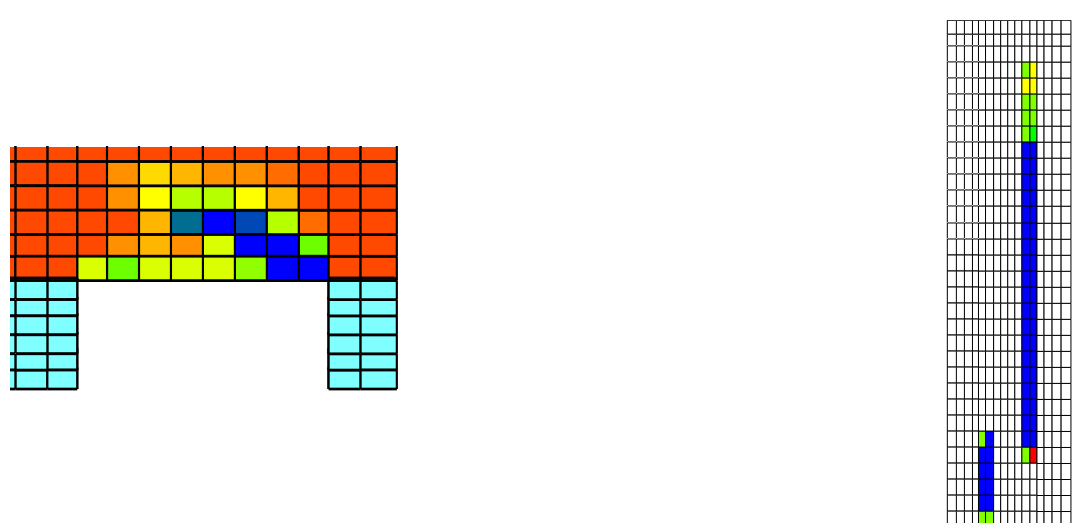
a. Cohesion distribution in immediate roof far
b. Cohesion distribution in immediate roof layer behind the face

Figure 5.50 Cutter pattern in the immediate roof after cut 5 with 4 interfaces having cohesion value of $50 \mathrm{psi}$

\subsection{CHAPTER SUMMARY}

Following concluding remarks can be made based on the results of modeling performed in this chapter:

When analyzing the cutter roof problem using continuum numerical models, assigning the strain-softening constitutive behavior to the roof rocks provides the most realistic cutter patterns. The accuracy of the simulation is significantly affected by the variation of the cohesion and friction angle values with post-failure shear strain.

$>$ It appears that the change in the angle of internal friction with plastic shear strain does not have a significant effect on the cutter patterns if the entire panel is created in a single step in the numerical models, and when the peak friction angle is smaller. In this case, it was noticed that the cutter patterns did not differ much whether the mobilized friction angle decreased, increased or kept constant with post-yield shear strain. In contrast, if the excavations in the models were created 
in several small cuts, then the cutter patterns varied depending on how the friction angle was varied against plastic shear strain.

The presence of bedding plane discontinuities in the roof affects the severity of the cutter problem. From the models run in this dissertation, it was found that the discontinuities did not significantly alter the cutter patterns noticed near the roof surface. The depth to which cutters propagated in the roof, however, depended on the number and position of the bedding planes. As a consequence of the break in the roof's continuity in presence of bedding planes, it appeared that the cutter propagation deep into the roof has been arrested by the discontinuities. With increasing plastic strain in the roof, however, due to the presence of bedding planes, cutters propagated horizontally as the failed roof elements shed their load to the adjacent stronger elements.

Finally, it can be said that strain softening material behavior for the immediate roof in conjunction with cutting sequences can be an appropriate modeling tool to simulate the cutter development in underground coal mines as observed by the Gadde and Peng (2005). This modeling methodology will be used to study the influence of various parameters related to typical mining cutting sequences for single, three and four entry system. 


\section{CHAPTER 6}

\section{INFLUENCE OF CUTTING SEQUENCE}

\subsection{INTRODUCTION}

In Chapter 5, it was explained that with 3 dimensional numerical modeling with strain softening material behavior, cutter roof can be simulated even with the continuum numerical programms. In previous chapter just the concept of multi-cut sequence was introduced. In this chapter the influence of cut sequence along with multiexcavations will be explained. The major task of this research is to simulate the cutter development in real mine environment conditions and to understand the irregular cutter pattern as observed in the mine. The first major task is to calibrate the model with a case study. Since there is always uncertainty associated with the input data as most of them are based on empirical relations developed, modeling will be conducted for a range of strength properties and in-situ stress conditions. These empirical relations are not necessarily based on similar geo-mining conditions. Further, the several factors associated with a cutting sequence and their influence on cutters/roof falls will be discussed.

\subsection{CUTTER FAILURE AND NEED OF THE RESEARCH}

In chapter 2, going through the various works done by researchers, most of the works were limited to $2 \mathrm{D}$ modeling with material behavior as either elastic or perfectly plastic. A few researchers also conducted 3D models, but only Meyer (1997, 1999) and Gadde \& Peng (2005) have conducted 3D non-linear model. Many of the researchers didnot give due importance to the sequence of cutting, rather they just considered the final geometry of the excavation except Gadde and Peng (2005). 
Most of the researchers works were case specific so they didn't consider the variation in the range of ratio of high horizontal to vertical stress. Similarly the effect of ratio of maximum to minimum horizontal stress is also not so much evident in their studies. No past studies were able to explain the irregular cutter pattern as observed in the mines.

From the case studies and typical cutter formation pattern, following are some of the fundamental issues associated with coal mine excavation response that may have significant influence on cutter roof simulation and must be addressed in numerical modeling:

- Under the pressure and temperature conditions anticipated in a typical coal mine, the rock mass in the immediate vicinity of an opening will exhibit brittle behavior or strain-softening in the post-failure zone;

- Coal mine development is a sequential process which includes several small cuts of coal block removal before the final geometry (e.g. a panel or mains system) is created;

- Interactions occur between multiple excavations associated with mine development

The objective of the research is to throw more light on the mechanics involved in cutter development as witnessed in reality. The emphasis will be mainly on the development of cutters at particular location in a particular cut or after several cuts. Further, three-dimensional modeling with more detailed excavation geometries emphasizing the cutting sequence will help identify the interactions of multiple excavations for their role in cutter propagation. In the past some of the basic ideas and design guidelines concerning the orientation effect of maximum horizontal stress, are based on elastic analysis of single entry and that also not giving much 
emphasis on immediate roof rock strength. In this present research the same will be analyzed with single and multiple excavations using strain softening material approach and taking into consideration of the immediate roof rock strength.

The study encompasses cutter formation at the face area and some distance outby, in intersections, reasons for the change in the cutter direction, variability in size and severity of related roof falls.

\subsection{CUTTING SEQUENCE AND MULTI EXCAVATIONS NEEDS ATTENTION FOR CUTTER SIMULATION?}

From the initial modeling conducted by Gadde and Peng (2005), they found that different cutter patterns for the excavation may be created in one cut and in a series of cuts. The following section will shed some more light on this aspect of modeling technique incorporating cutting sequence and their influence to see the effect of horizontal stress orientation.

A single entry (Figure 5.19) is developed $150 \mathrm{ft}$ in length in one cut. Then the same entry is developed in five cuts of each $30 \mathrm{ft}$. The mining conditions, stress ratio and orientation are kept the same. The material properties and litholgy are taken the same as given in Figure 5.15 and Table 5.3

\subsubsection{Stress distribution pattern for single cut and multi-cut excavation}

As it has been explained in the earlier section that at zones where stress is more concentrated, the elements fail and it is shown as cohesion with zero value. Figure 6.1 shows the development of cutter for a single entry when created in one cut while Figure 6.2 shows for the entry created in five cut for a stress orientation, $\theta$ of $60^{\circ}\left(30^{\circ}\right.$ from entry drivage direction). From the cohesion plots we can see that for single cut 
excavation the stress concentration, i.e., zero cohesion zones are located towards the left side of the entry except near the face. While for multi-cut excavation these zones are located towards the right edge of the entry except for the first cut. If we see the cutter observed in the field or stress concentration as depicted in Figure 2.10 (SCT Australia) the stress distribution or cohesion matches when the excavation is made in multi-cuts, whereas it matches just near the face for single cut. When first cut is made for multi-cut system, it behaves exactly like excavation made in one cut near the face.

To observe the pattern of cutter distribution in immediate roof above model is repeated for other orientations. At the same time to see how multi excavations affects the in cutter pattern a 3-entry system (Figure 5.14) and 4-entries system (Figure 6.3) is created in several cuts. The arrows in the figures indicate the cutting direction. For four entries system actually one cut comprises of several cuts. This has been done in order to save lot of time without affecting the model results as these cuts are grouped in such a way that it doesn't interact with each other. Thus 38 numbers of individual cuts reduce to 12 cuts for the same geometry. The all models are solved for maximum horizontal stress orientation, $\theta$ of $0^{\circ}, 30^{\circ}, 60^{\circ}$ and $90^{\circ}$. For all the cases the cohesion distribution in the immediate roof is plotted. Figures 6.1 , 6.2, 6.4 and 6.5 show the cohesion distribution for single entry in one cut, single entry in five cuts, 3-entry system in 13 cuts and 4-entry system in a group of 14 cuts respectively; for different orientation, $\theta$. It can be noted in all the figures that ' $\theta$ is measured with respect to the $\mathrm{X}$-axis and the entry is aligned with the $\mathrm{Y}$-axis. 
Cohesion, psi

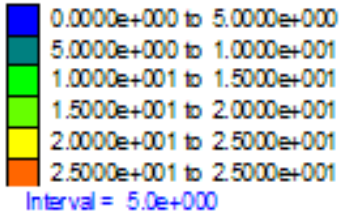

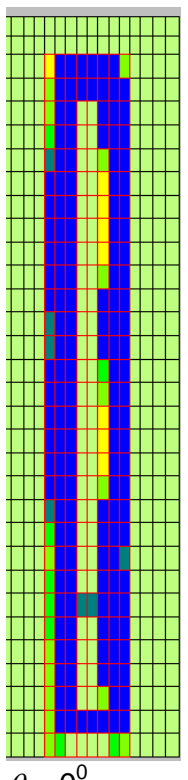

$\theta=0^{0}$
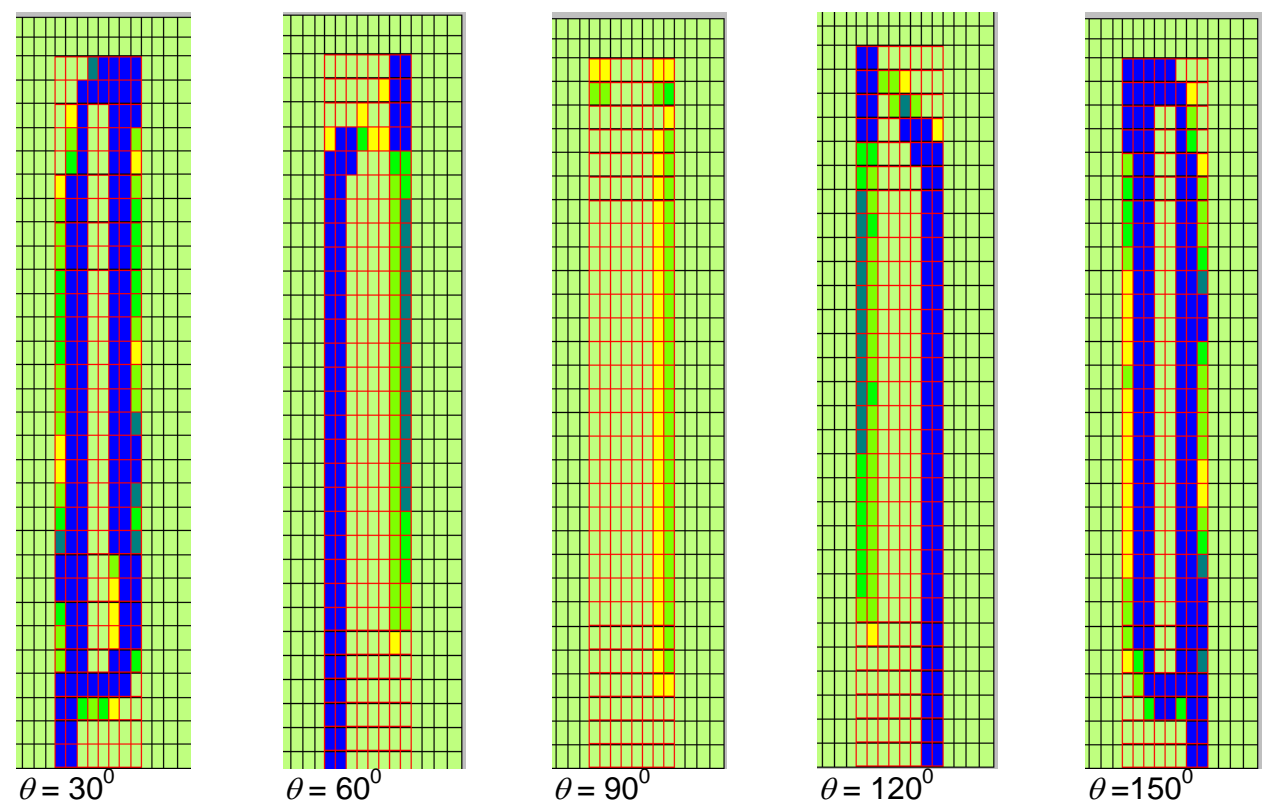

Figure 6.1 Effect of maximum horizontal stress orientation on cutter development for single entry created in one cut
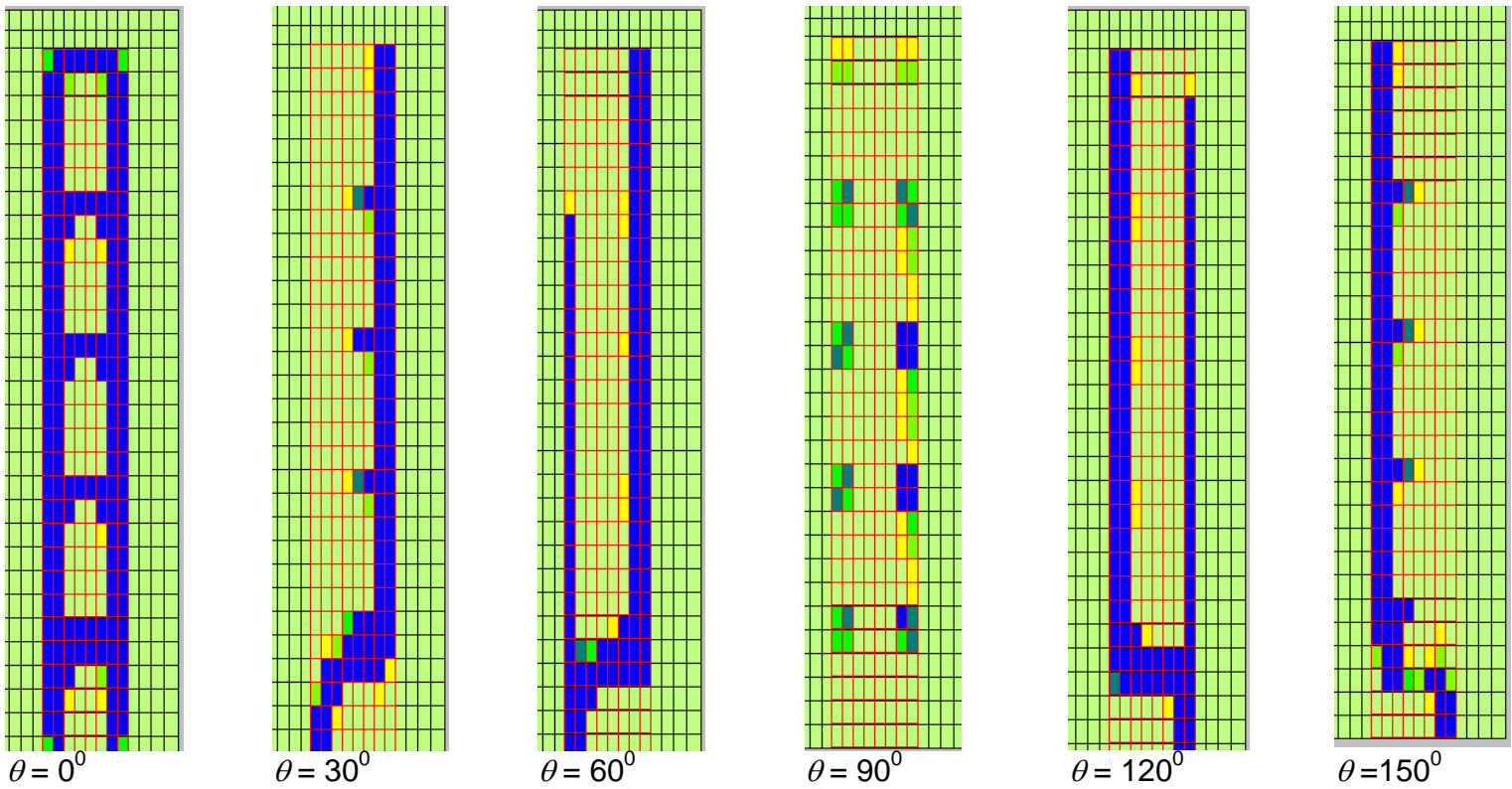

Figure 6.2 Effect of maximum horizontal stress orientation on cutter development for single entry created in five cuts 


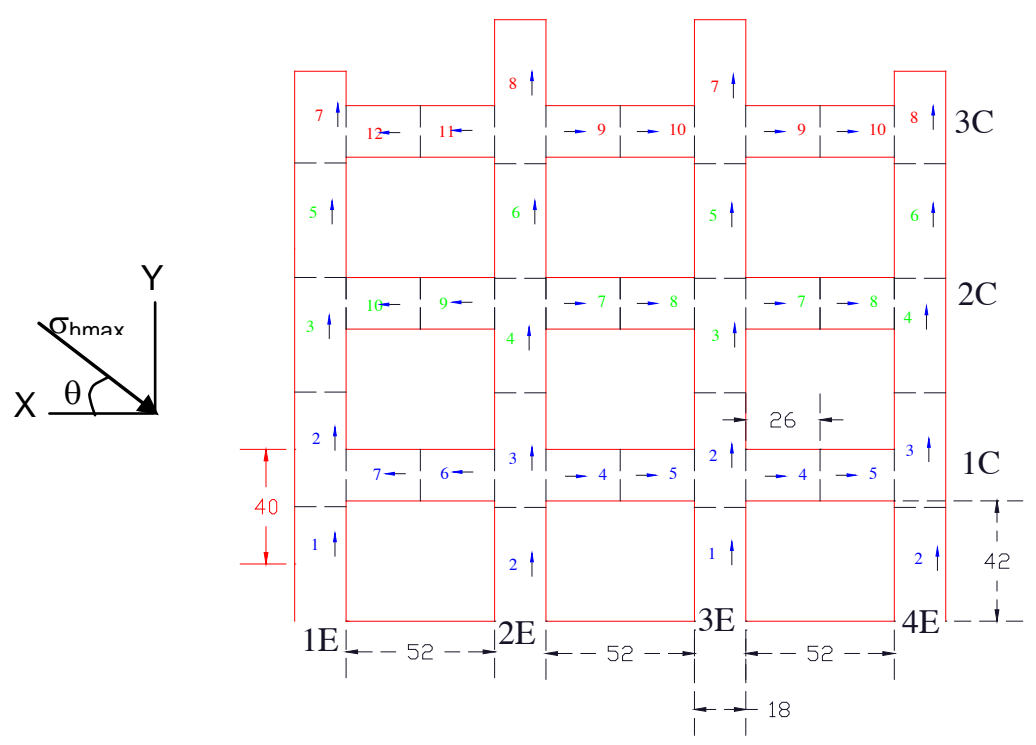

Figure 6.3 Cut sequence for 4-entry system

In all the above figures the cohesion of the elements in the first layer of the immediate roof is shown. The darkest elements show zero cohesion, and as noted in Chapter 5, can be correspond to the cutter.

For single entry system, it can be seen that the cutter distribution doesn't match for single entry created in one cut and with a combination of five cuts except when entries are either aligned or perpendicular to the maximum horizontal stress orientation. For an oblique/ inclined stress orientation the cutter distribution mismatch for both cases. The location of cutter in the entry roof is exactly opposite to each other. The results clearly show that the higher the angle of $\sigma_{\text {hmax }}$ with respect to the entry drivage direction, the higher the stability problems and when $\theta$ was different from 0 or 90 degrees, asymmetric failure occurs as indicated by the location and the extent of the darkest elements. But, the difference to be noted is between $\theta=30^{\circ}$ and $\theta=60^{\circ}$; it is normally anticipated that the stability would be better for the latter angle than the former as it makes lower angle with respect to the axis of the entry. But, Figure 6.2 shows the opposite. For $\theta=60^{\circ}$ failure is noted on both sides of the 
entry as opposed to one side failure at $\theta=30^{\circ}$. On the contrary, the result of the single cut simulation as shown in Figure 6.1 matches exactly with general expectations. The match is because the models were run in the same manner as all the past works, i.e. excavation was made in one single cut irrespective of considering different constitutive behavior.

More differences in results could be seen if multiple excavations shown in Figure 5.14 and Figure 6.3 are modeled with the proposed modeling technique. The cohesion pattern for 3 entries system created in one-cut and multi-cuts are shown in Figures 6.4 and 6.5 in and the same for 4-entry system in Figures 6.6 and 6.7.
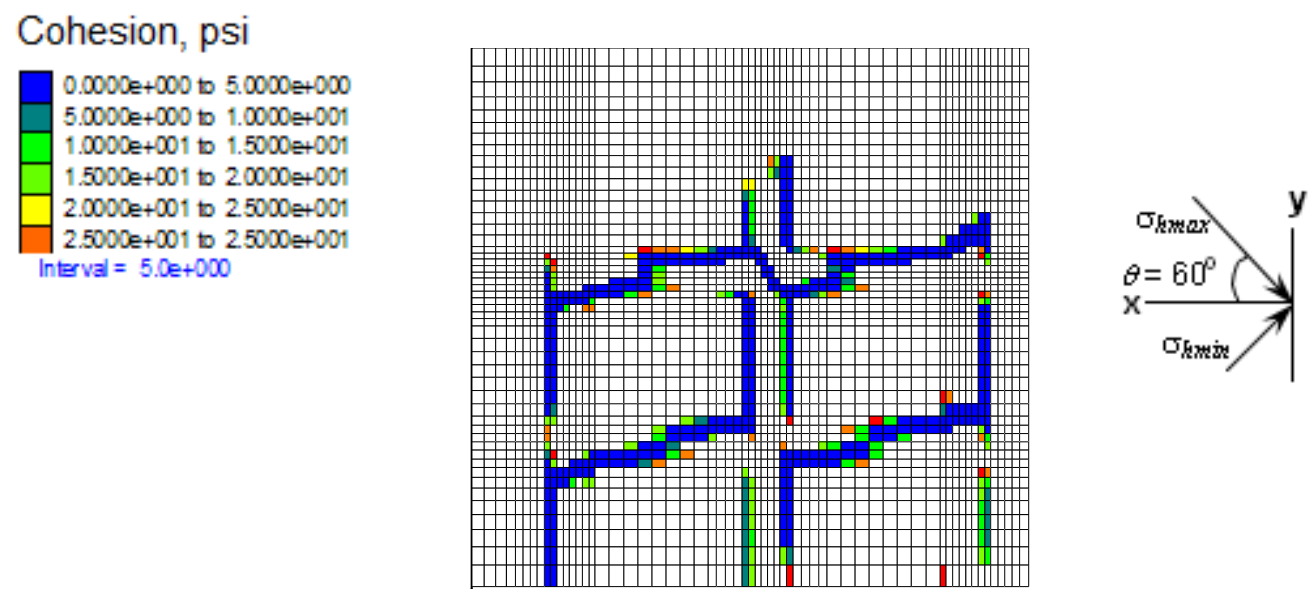

Figure 6.4 Cutter development for 3-entry system created in one cut
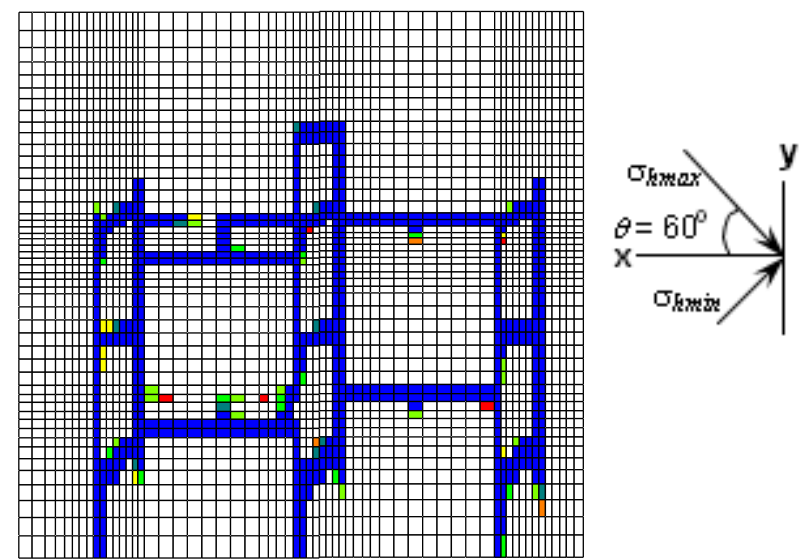

Figure 6.5 Effect of maximum horizontal stress orientation on cutter development for 3-entry system created in 14 cuts 


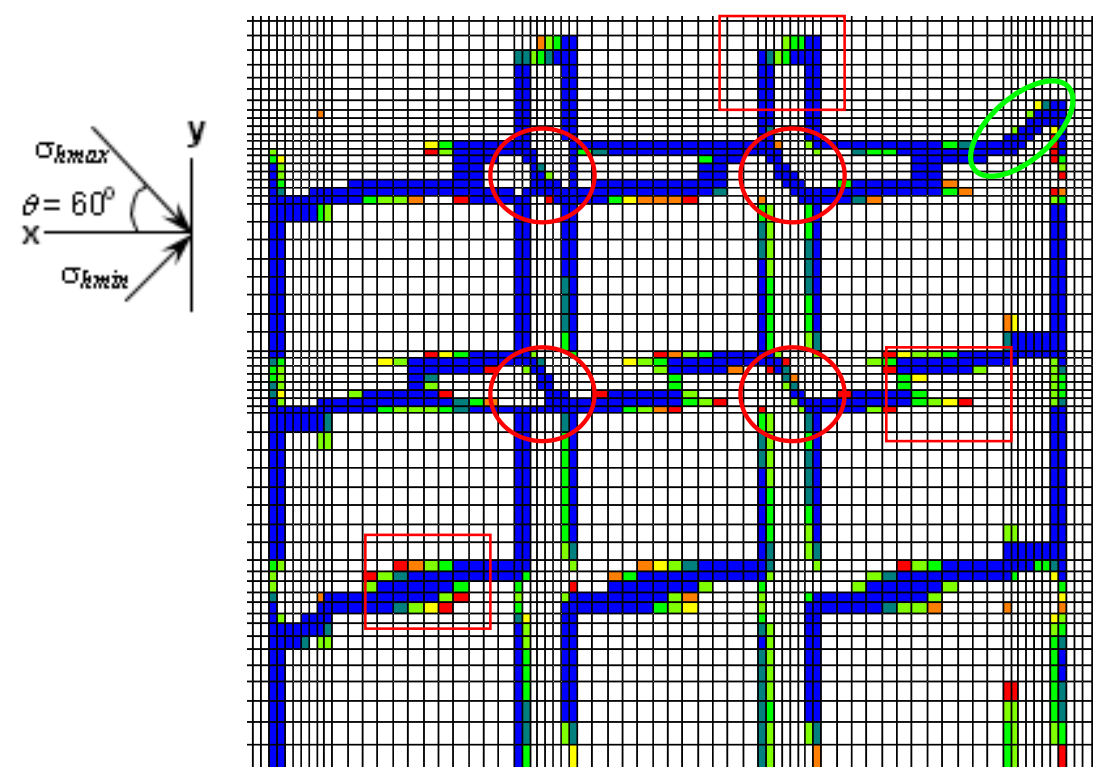

Figure 6.6 Cutter development for 4-entry system created in one cut for $\theta=60$ degrees

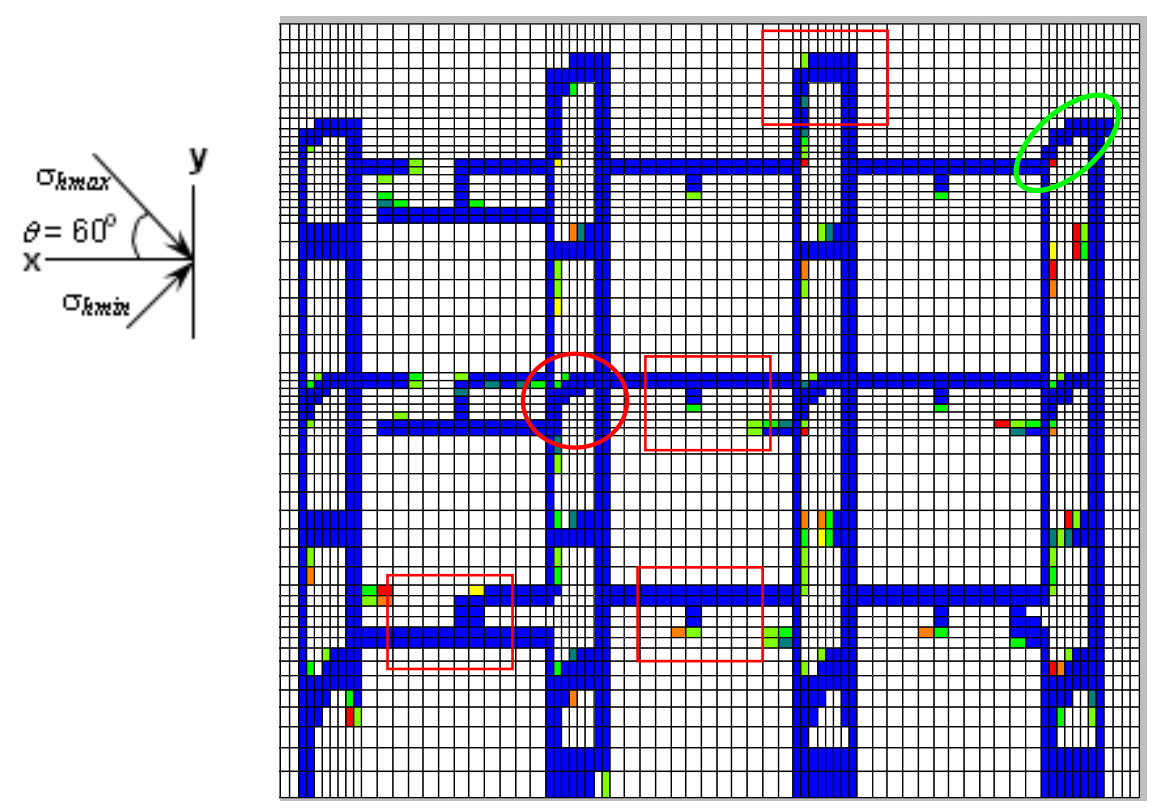

Figure 6.7 Effect of maximum horizontal stress orientation on cutter development for 4-entry system created in 12 groups of cut for $\theta=60$ degrees

From these figures it can be seen that the cutter pattern is completely different for one-cut and multi-cut excavations. The cutter patterns are different for entries and crosscuts. The major difference in single-cut and multi-cut created excavations is again the location and running of cutters in crosscuts and at intersections. For single 
cut the cutters run across the intersection in the direction of the major principal stress (red circles in Figure 6.6) while for multi-cut it runs near the minor horizontal stress (red circles in Figure 6.7). Similarly for single-cut excavation the cutters run across from one edge to another edge of the crosscut almost in center of the crosscut (red rectangle in Figure 6.6) which is generally not found in the actual field conditions. In real case, the cutters may run either one side or both side of the entry as shown by multi-cut excavation (red rectangle in Figure 6.7). The results obtained further supports the stress mapping technique (Mucho and Mark, 1994) which implies two major principles-

- The direction of failures is in the direction of the minor principal horizontal stress and 90 degree to the major horizontal principal stress.

- Where permitted to do so, such as crossing intersections and failures across openings, major failure features, such as cutters and bottom floor heave, will try to be aligned in the direction of the minimum principal stress and perpendicular to the major principal stress. Roof potting and shear failures will exhibit this trend at all times

So with this concept, the cutter patterns obtained for single-cut is not acceptable where as multi-cut excavation supports the technique behind the stress mapping. Here cutters cross the intersection at an angle but not at right angle to the direction of maximum horizontal stress as hypothesized in stress mapping. As it is now a well proven fact that the shear failure surface in the rock lies in general at an angle of $45^{\circ}-\varphi / 2$ ( $\varphi$ is friction angle of rock) from the direction of major principal stress and not at right angles as assumed in the stress mapping technique. Further the actual directions of cutters in the entry or cross section depends upon the induced principal stresses. 
This directional propagation of cutter across the intersections could not be explained by either elastic or plastic model without incorporating cutting sequences (Gadde, 2003; Rasheed, 2007). Again we can see that the cutter pattern matches for one-cut and multi-cuts near the face (green ellipse in Figures 6.6 and 6.7). Hence it can be said that any sort of analysis which is done near the face, the cutting sequence may not affect result significantly but the results obtained with one-cut at any other part of excavation may not be true behavior.

To understand the effect of multi-entry excavations, a few results in the form of the cohesion in the first layer of the immediate roof are shown in Figure 6.8 for single entry, 3-entry and 4-entry systems created in multi-cuts for maximum stress oriented at $60^{\circ}$.
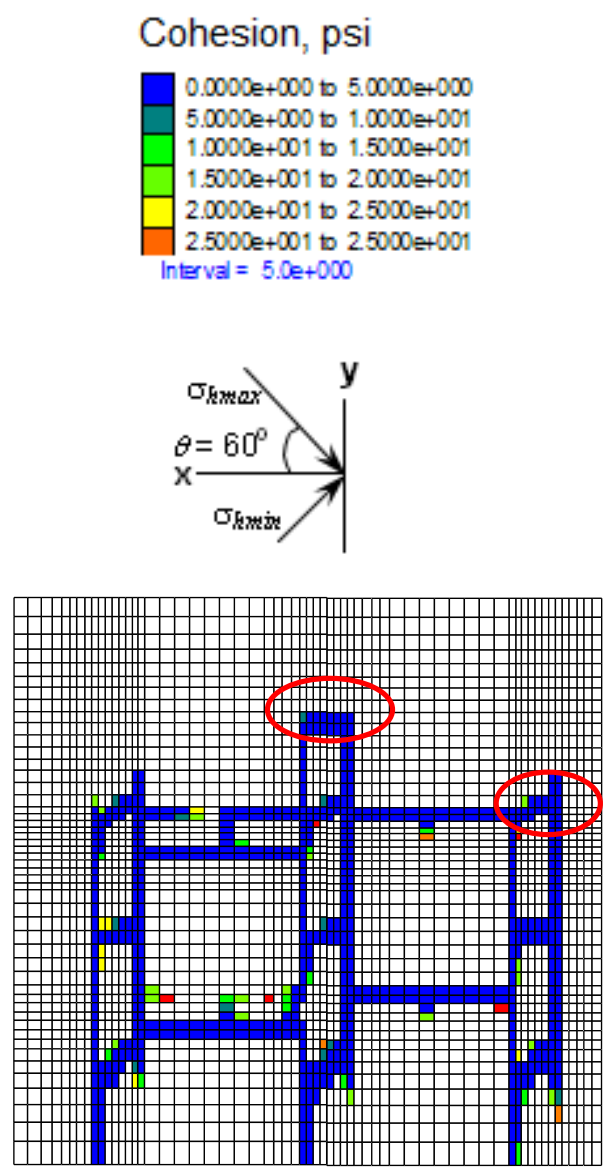

3-entry system created in 14 cuts

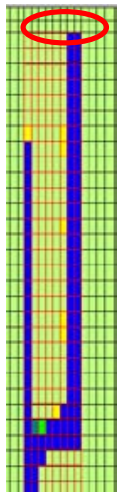

Single entry in 5 cuts

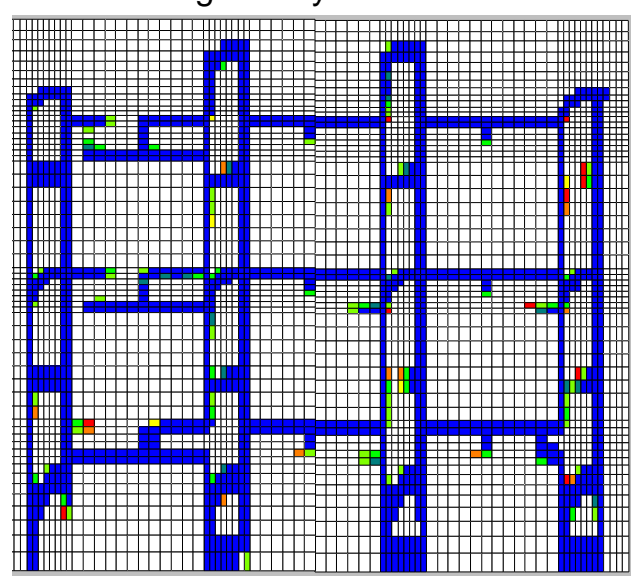

4-entry system created in 12 groups of cut

Figure 6.8 Variation in cutter pattern for different entry system 
From the above figure if we compare the cutter patterns, it can be seen that the cutter pattern obtained for single entry do not match entirely with any entries for multi-excavation models like 3-entry or 4-entry system. The difference can be seen near the final face position (red ellipse), intermittent face stoppage and intersections. It appears that the interaction among different areas of a multiple excavation setup will result in failure patterns entirely different from those expected from the simple models such as single-entry model. Further if we compare the results obtained for 3-entry and 4-entry system, the cutter patterns are consistent for both side entries and middle entries. Again we can see that the cutter pattern is significantly different even the multi-entry system are created in one cut (Figures 6.4 and 6.6). For the 4-entry system the cutter pattern is almost the same in $2^{\text {nd }}$ and $3^{\text {rd }}$ entry but the cutter pattern is different for each crosscuts. So either 3-entry or 4-entry system geometry can be a true representative for main, sub-mains or panels comprising of any number of entries.

In summary it can be said that the influence of incorporating multiple excavations, and cutting sequence can have significant influence on the final model results. Hence in all the future modeling for the present work, cutting sequences and multiple excavations will be considered. Further since these observations are based on a particular stress conditions and very weak rock strength. In latter section the cutter pattern will be explained with varying mining conditions.

\subsection{CUTTING SEQUENCE}

In USA more than $50 \%$ of underground mines are worked with continuous miner (CM) that comprises room and pillar mining, development of mains and sub-mains in room and pillar and longwall mines, and gate road development in longwall mining. 
$\mathrm{CM}$ cuts the coal in a particular order in different entry of the system to ultimately create the desired geometry of the structures like mains, sub-mains, panel, etc. The cutting operation generally follows a pre-defined sequence which is called 'cutting sequence'. Cutting sequence refers to the order in which an excavation (entry or crosscut) is advanced from its previous position to a new position. While 'cutting steps' refers to the series of operations performed during a particular 'cutting sequence'. A 'cutting step' generally involves creation of a boxcut and widening it to the full width of an entry/crosscut (Figure 6.9).
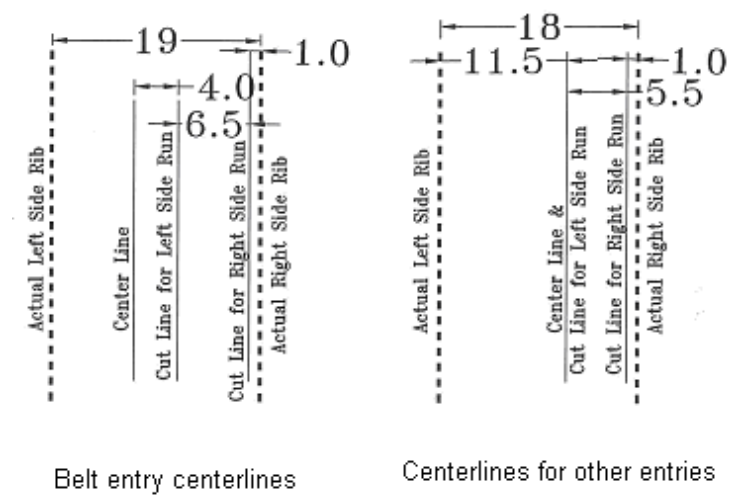

Centerlines for other entries

Figure 6.9 CM position for Box cut and final cut for belt entry and other entries of the system Figures 6.10 to 6.15 show various cutting sequence used in coal mines for continuous miner. Figures $6.10,6.11$ and 6.13 shows a very simple cutting sequence in which cut sequence is in very simple order. The individual cut is made first in all entries and once the entry developed by a length more than crosscut spacing, cut is made in crosscut between the entries.

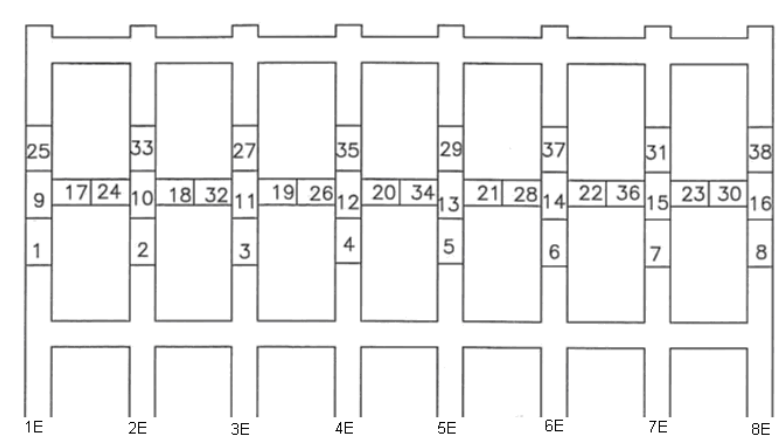

Figure 6.10 A simple cut sequence for development of 8 entry system comprising of 38 cuts 


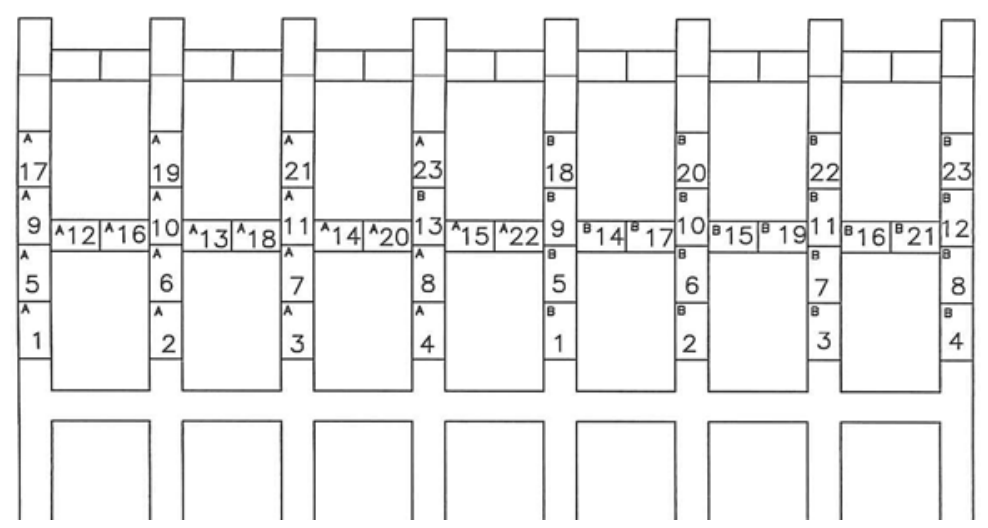

Figure 6.11 A simple cut sequence for development of 8 entry system with two continuous miner

Figure 6.12 shows the cutting sequence and haul routes while cutting in different entries for a 3-entry system with entry centers at $90 \mathrm{ft}$ and crosscut centers at $140 \mathrm{ft}$. In this particular cutting sequence the final cut sequence is in step shape and the first entry (1E) is always ahead. CM makes cut-1 in entry $3 \mathrm{E}$ first then makes cut-2 in entry $1 \mathrm{E}$ and finally cut-3 in entry $2 \mathrm{E}$. So here cuts made on alternate pillar basis in contrast to earlier cut sequence in Figures 6.10 and 6.11 where cuts are made on regular pillar basis. This type of cut sequence may influence the stress distribution while working in adjacent entries or crosscuts. Further the cut sequence are designed keeping in mind the time required for place change of equipment and loading distance/time from the CM position to belt discharge point of belt conveyor as these are factors which governs the productivity.

Figure 6.14 shows a cutting sequence for 5-entry system with entry width as $19 \mathrm{ft}$ and entry centers at $72 \mathrm{ft}$ and crosscut centers at $91 \mathrm{ft}$. The major difference from a common cutting sequence is that the middle entry (3E) is in center and much ahead from the rest of the entries. The turns outs are made form the middle entry (also belt entry) only. The CM cable move and belt move is performed after cut -14 and cut-18 respectively. There are 2 cuts each of $36 \mathrm{ft}$ and 1 cut of $19 \mathrm{ft}$ in each entries. In crosscuts the cut length are of $36 \mathrm{ft}$ and 19 or $24 \mathrm{ft}$. Figure 6.15 shows 
the cut sequence using two continuous miners to develop a 9-entry system. 26 numbers of cuts are made by each $\mathrm{CM}$ as shown by red and blue colors.

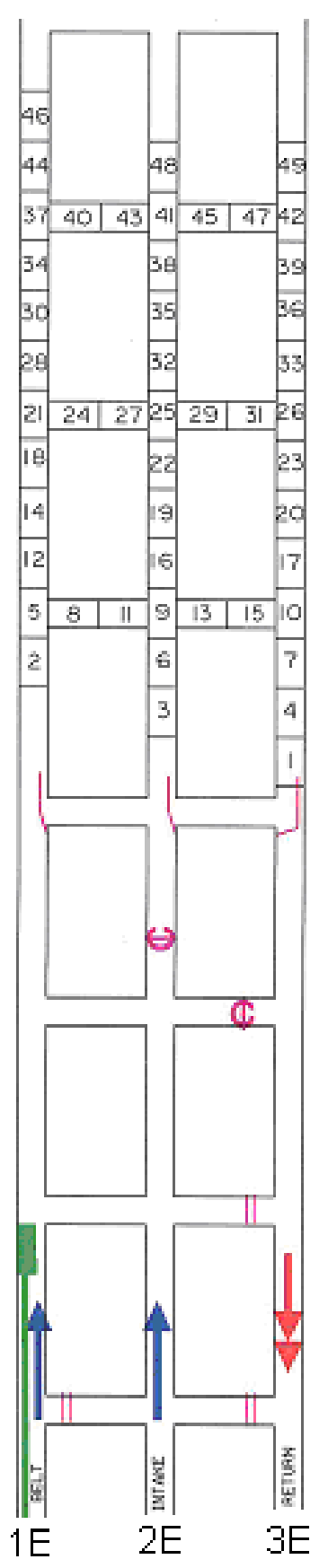

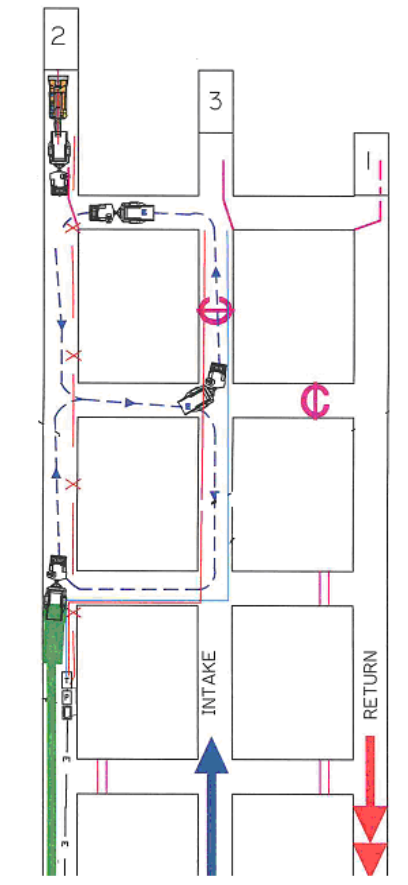

Haul route for cut 2 in entry\#1

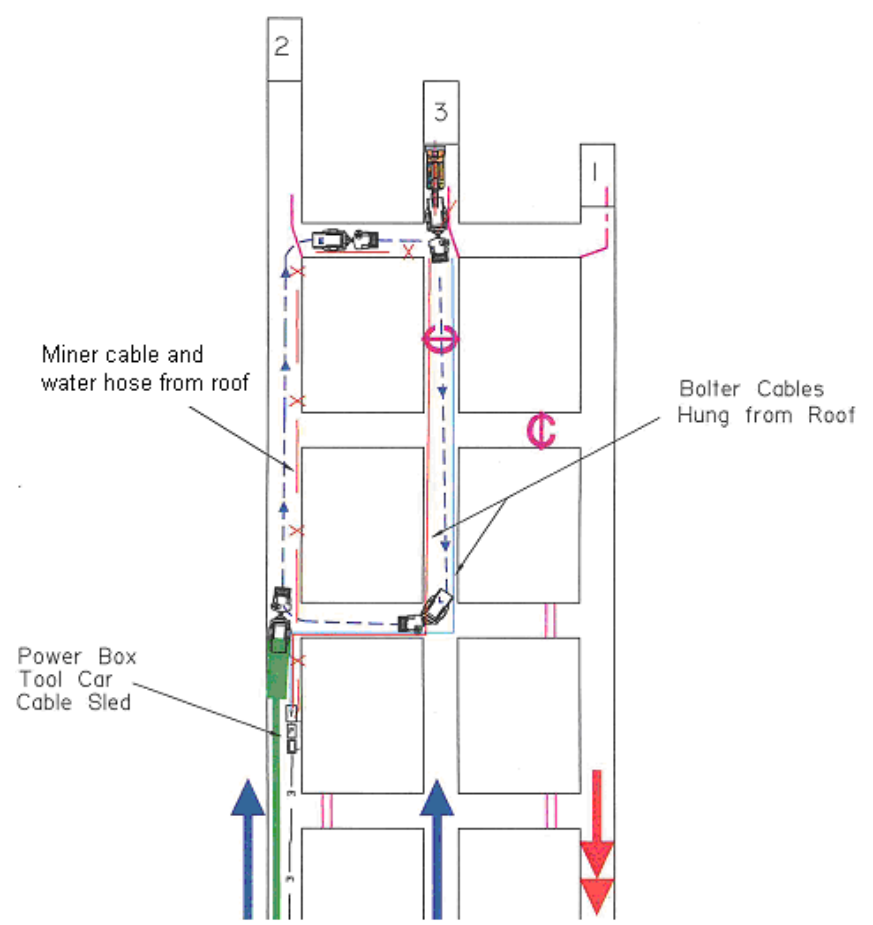

Haul route for cut 3 in entry\#2

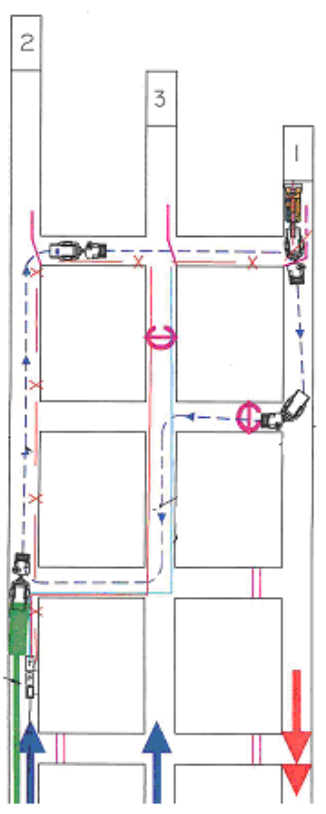

Haul route for cut 1 in entry\#3 


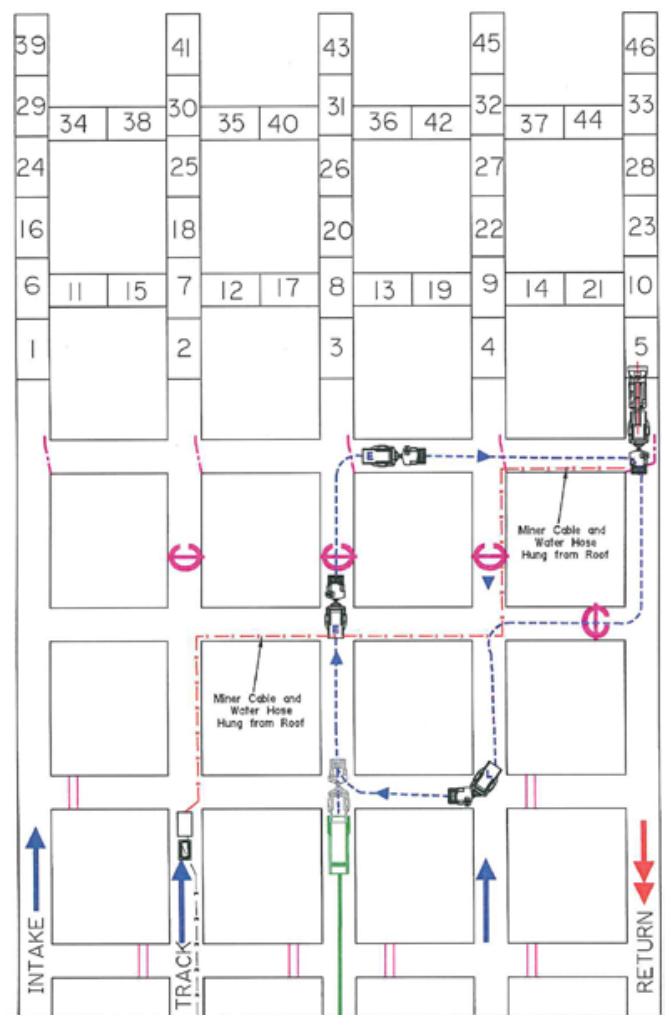

Figure 6.13 Cutting sequence and haul route for cutting in entry 5 from left
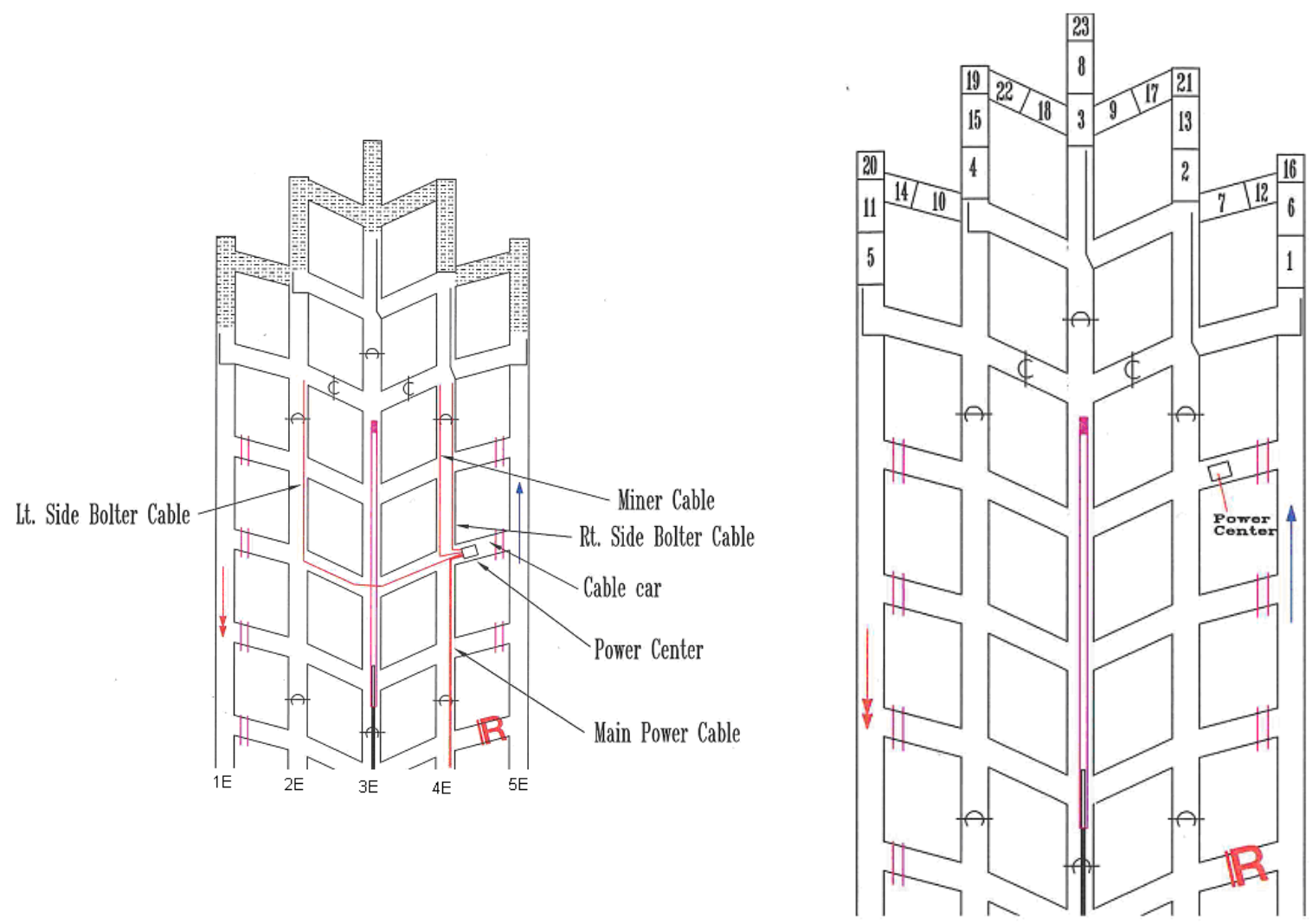

Figure 6.14 Cut sequence with face in a step shape with center entry ahead 


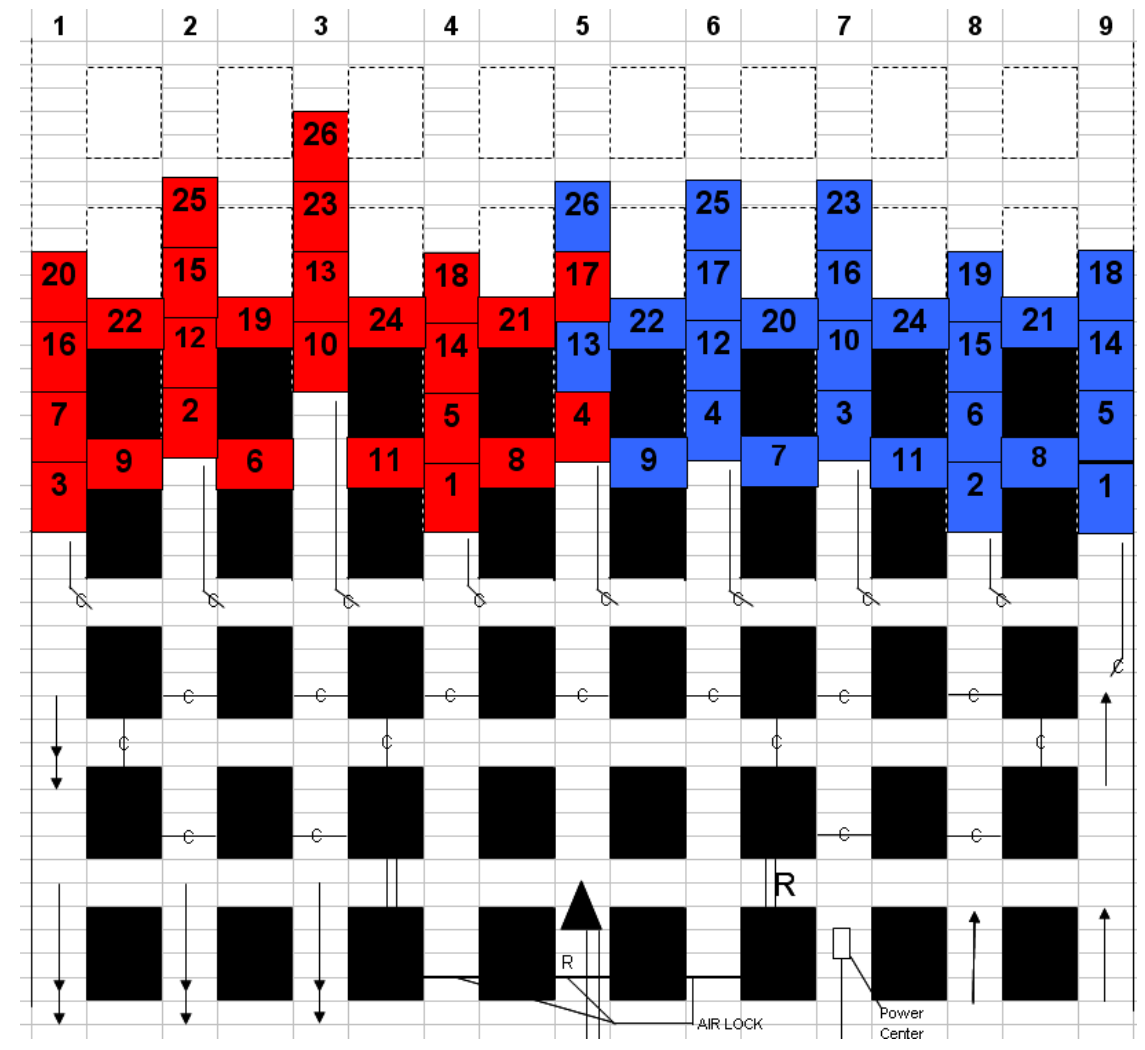

Figure 6.15 Cut sequence practiced at a mine for development of 9-entry system panel

\subsection{CASE STUDY- (Case 3 in chapter 4)}

This mine is working in Herrin \#6 seam in Illinois basin. The coal seam is generally 6 $\mathrm{ft}$. thick and horizontal to slightly undulating beneath $250 \mathrm{ft}$ of overburden. This mine has room and pillar mining operation with only development and no secondary extraction, i.e., pillar retreating is done. Entry and crosscut widths are normally 18 to $19 \mathrm{ft}$. Entry and crosscut centers range from $60 \mathrm{ft}$ in panels to $70 \mathrm{ft}$ in mains resulting in pillar block dimensions of 42 to $52 \mathrm{ft}$. The mine was developed by the 7- or 8entry system. The part plan of the mine is shown in Figure 6.16. 


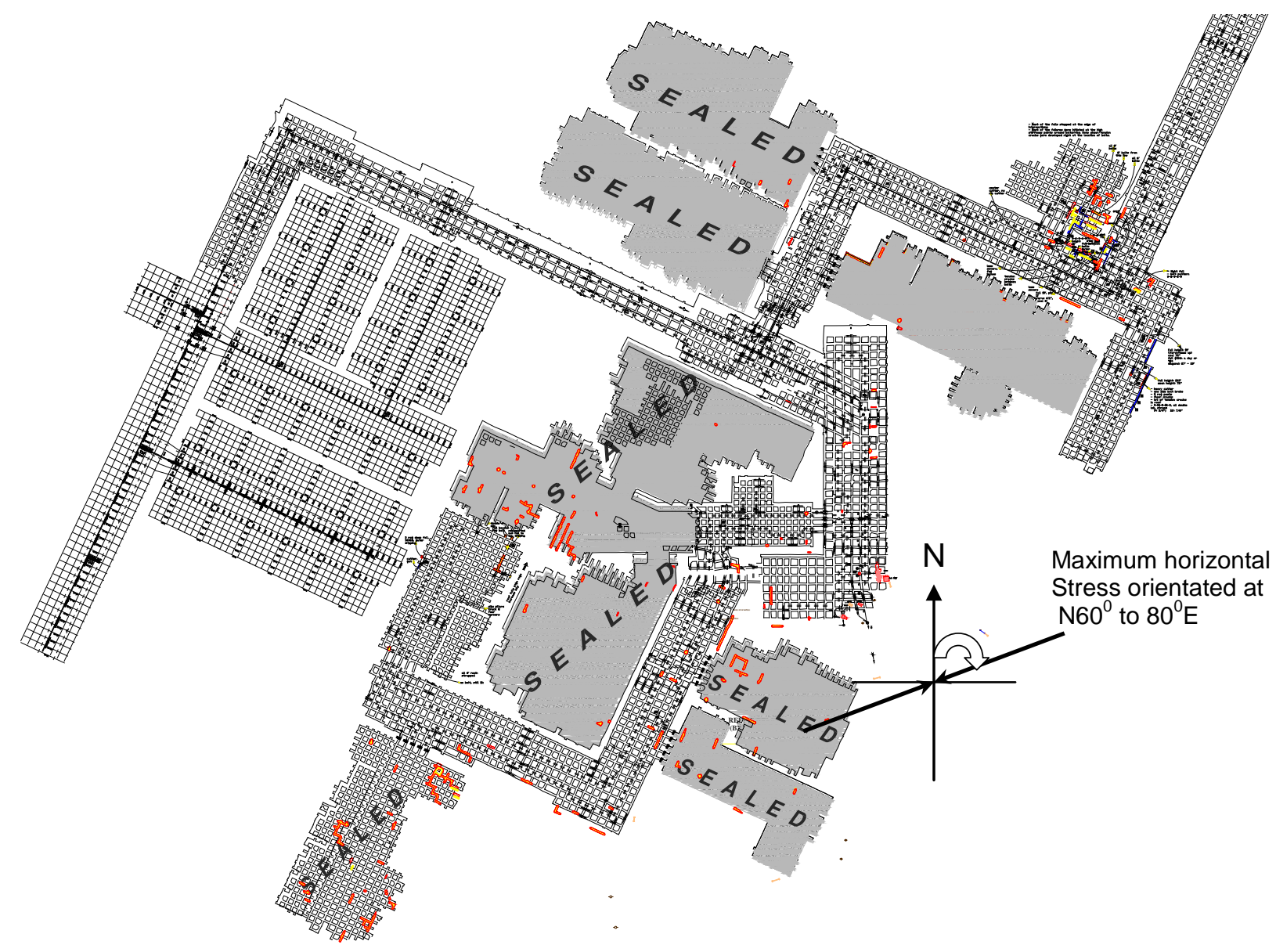

Figure 6.16 Mine map showing different sections of working

\subsubsection{Geology}

The immediate floor is approximately $3 \mathrm{ft}$ of claystone underlain by calcareous claystone with limestone nodules. The immediate roof consists of the Energy shale member. Three different mappable roof types are contained within the reserve: "varve' Energy shale, transitional and typical energy shale (Figure 6.17). The 'varve' roof is a finely interlaminated clay shale and carbonaceous clay shale sequence with low rock strength (1500 to 2000 psi compressive strength) and weak bedding plane cohesion resulting in Coal Mine Roof Rating of less than 40. The transitional roof type is characterized by numerous coal seam splits and stringers, roof rolls, horsebacks, slickensides and abundant disarticulated fossil plant debris. The typical Energy shale roof type is a massive to well bedded sandy shale with abundant well- 
preserved fossil plant debris. This type of roof is most competent among all three mentioned.

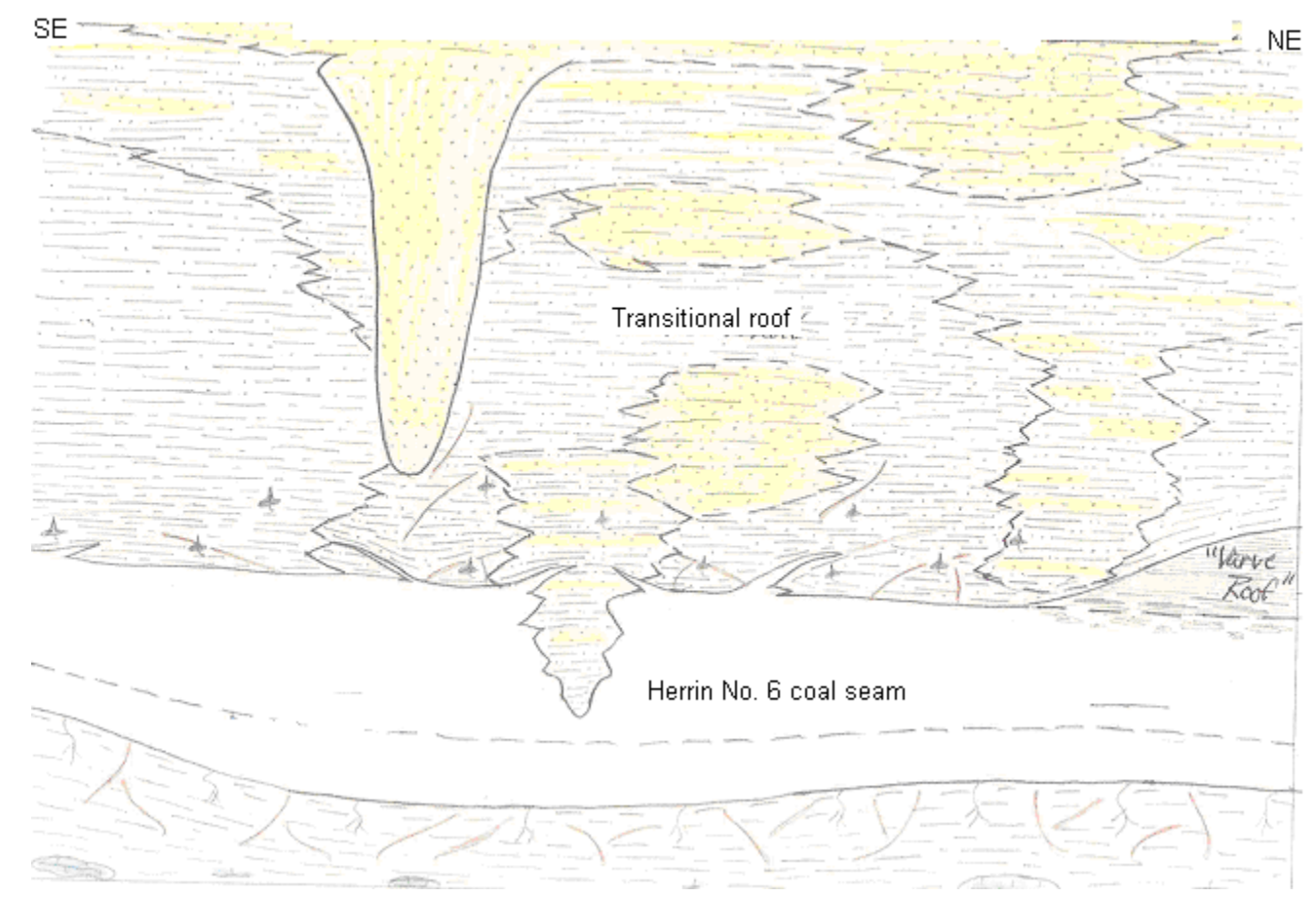

Figure 6.17 Variation in immediate roof characteristics above Herrin N0. 6 seam

\subsubsection{Cutters/ Roof Falls Observation}

The mains were initially developed in North-South direction. However roof control became an immediate concern in the 'varve' roof, with 3 to $8 \mathrm{ft}$ thick roof material falling in the North main entries. The crosscuts in these area were more stable, indicating that the major horizontal stress was oriented more East-West direction than North-south. In early 2002 numerous mining orientation were tested to reduce the impacts of the high horizontal stress on the immediate roof. Stankus (2002) concluded that the principal stress direction at that mine was $\mathrm{N} 60^{\circ}-70^{\circ} \mathrm{E}$ (Figure 6.16) similar to another Illinois basin mine where he had conducted extensive work. After this finding, the mine was reoriented to headings of $N 65^{\circ} \mathrm{W}$ to $\mathrm{N} 25^{\circ} \mathrm{E}$ to address the effects of low rock strength in the immediate roof and direction of the horizontal 
stress. The new orientation has some immediate positive impact on roof control in the face area. But with passage of time and at thicker 'varve' roof locations, even this orientation was not working effectively with same roof control plans. In $2004 \mathrm{NIOSH}$ (Mark, 2004) observed that the maximum principal horizontal stress was $\mathrm{N} 80^{\circ} \mathrm{E}$ slightly greater than previous orientations observed by Stankus (2002). NIOSH observed that the roof cutting followed a directional pattern, occurring in the leading edge (relative to stress field) of the entry being mined. This edge was dependent on the direction of mining. They observed the following sequence regarding failure mechanism of the 'varve' roof-

- On development, a cutter forms on one side of the entry due to horizontal stresses.

- As the cutter works its way up into the roof, the rock around the roof bolt plates tends to unravel. If the bolts are point-anchor, they may lose their effectiveness at this point.

- If the cutter works its way above the bolts, a rock fall may occur.

Figure 6.18 (a-j) shows the roof falls and cutter observed in the mine at various locations. From these figures it is evident that roof fall took place for all orientation of the entry. The extent and standup time before fall may varied due to combined effect of various factors like varve roof thickness, roof control plan and pillar dimension. The pillar dimension may be important as for any orientation the falls are minimum in mains / submains (larger pillar) compare to panels (smaller pillar). During a mine visit following observations were made -

- Massive roof fall has been observed at many zones of the entries and crosscuts. It may be due to thicker 'varve' roof. 
- Cutters/roof falls were noticed both in entries and crosscuts. Majority of them found to be restricted to one side of the entry/crosscut. Some cutters were also observed to develop on both sides on an excavation. Cutters were crossing at intersection and advancing in a step shape (Figure $6.18 \mathrm{i}$ and j).

- At few places some fractures were noticed in the middle portion of the entry / crosscut. The tensile cracks were developed with an opening of $1 / 2$ inch.

- Skin failures were also observed.

- Irregular pattern of cutters were observed at many locations (6.18 j)

Some massive roof falls exhibited a strange behavior; the falls were typically restricted to the entry between pillars and were terminated sharply at the intersection with intersection itself being stable (Figure $6.18 \mathrm{a}, \mathrm{f}$ and $\mathrm{h}$ ). After comparing the falls at other intersection location it was thought that this may happen due to presence of roof straps at the intersection. The presence of roof straps may have stabilized intersections thus restricting the falls to the entries. This could be supported by the fact that out of the six intersection area which didn't have falls while the adjacent entries collapsed, four had roof falls terminated at roof straps. 


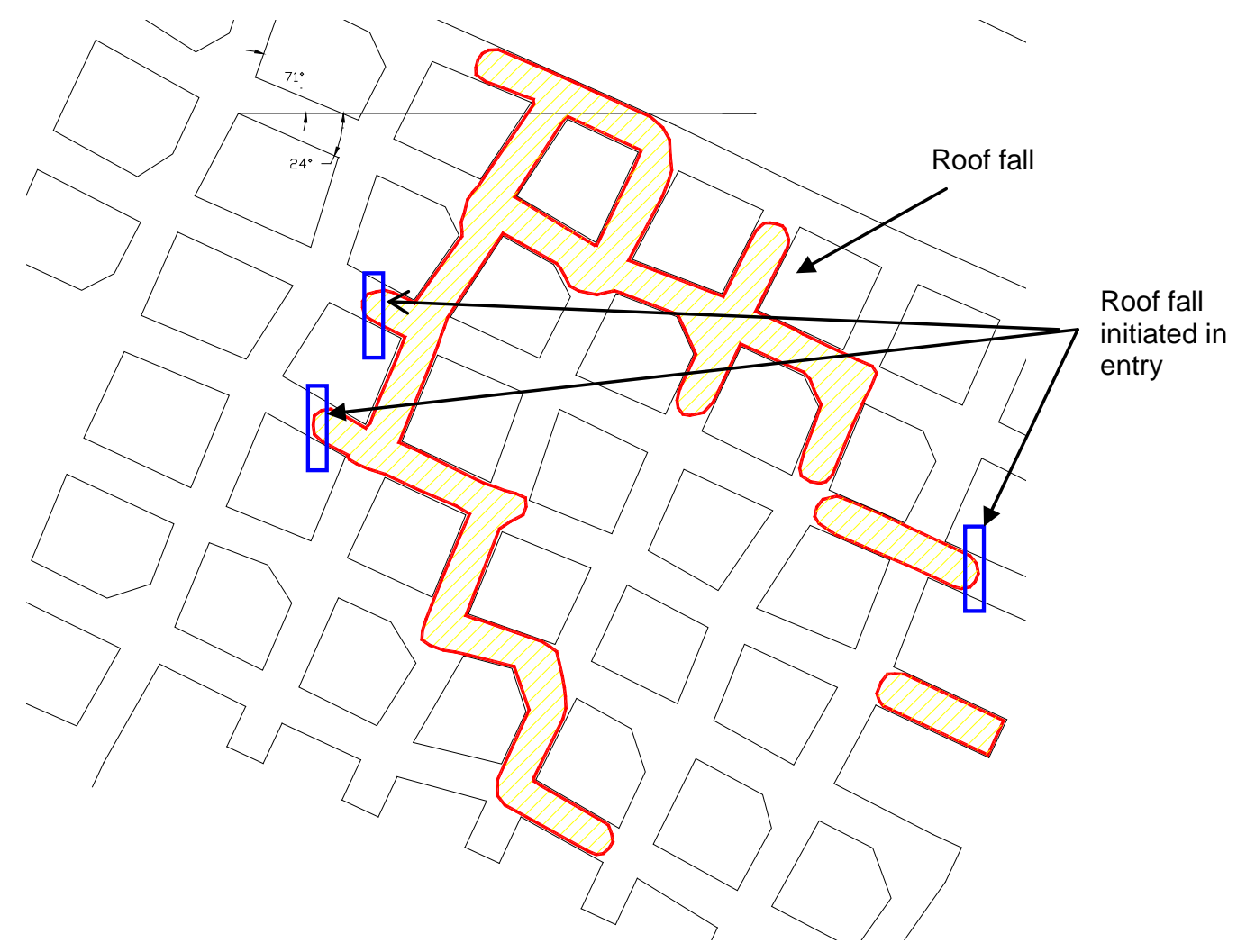

a. Roof falls in entries, crosscuts and at intersection

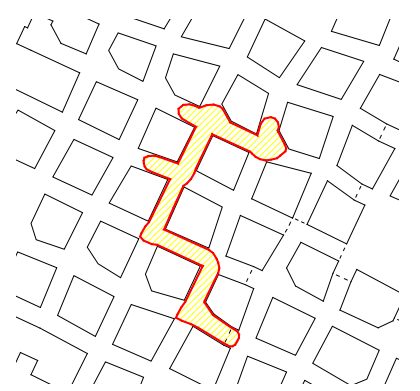

b. Working in South East Direction

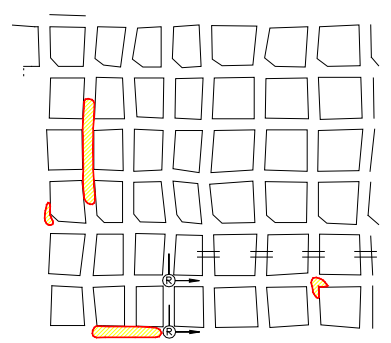

d. East West driven entries

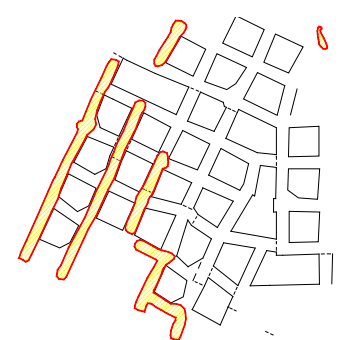

c. Workings in North East direction

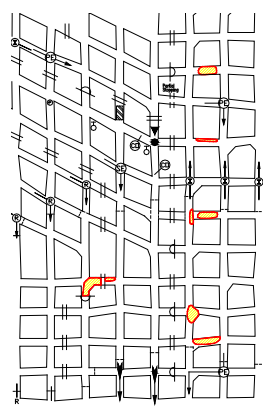

e. North South mains 


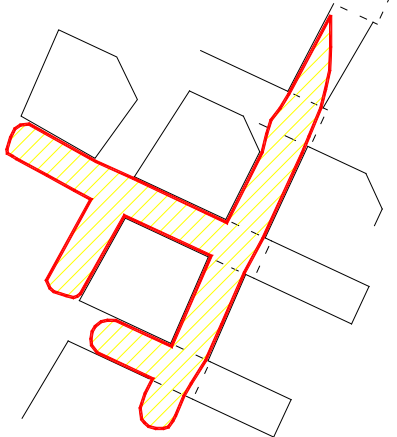

f. Roof failure around the pillars

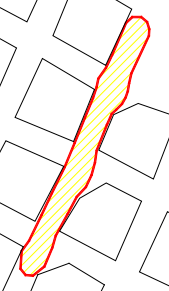

g. Roof falls in the turnout entries

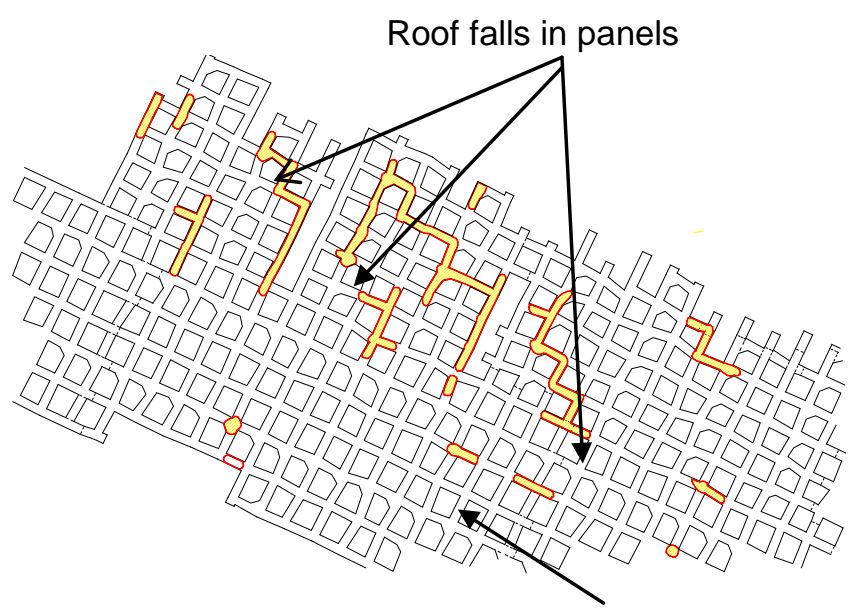

Sub-mains pillar

h. Roof falls at sub-mains and panels

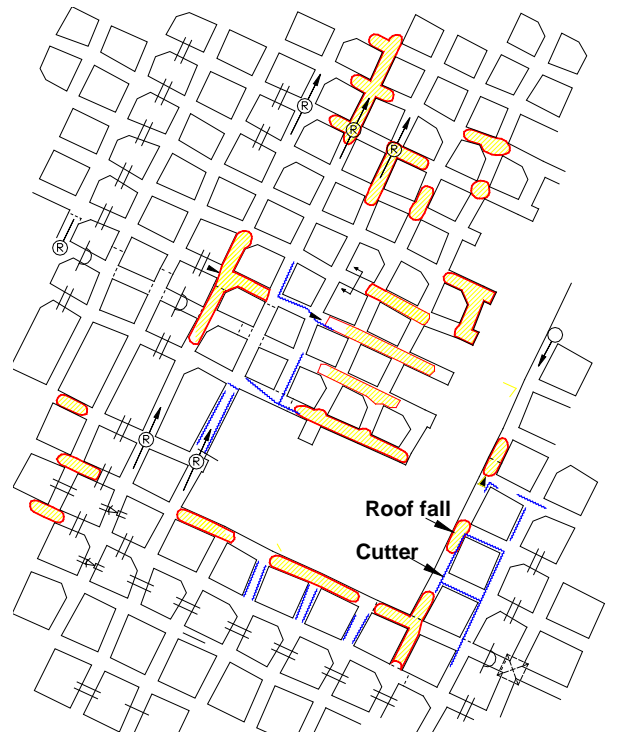

i. Roof falls and cutter developed at sub-mains and panel

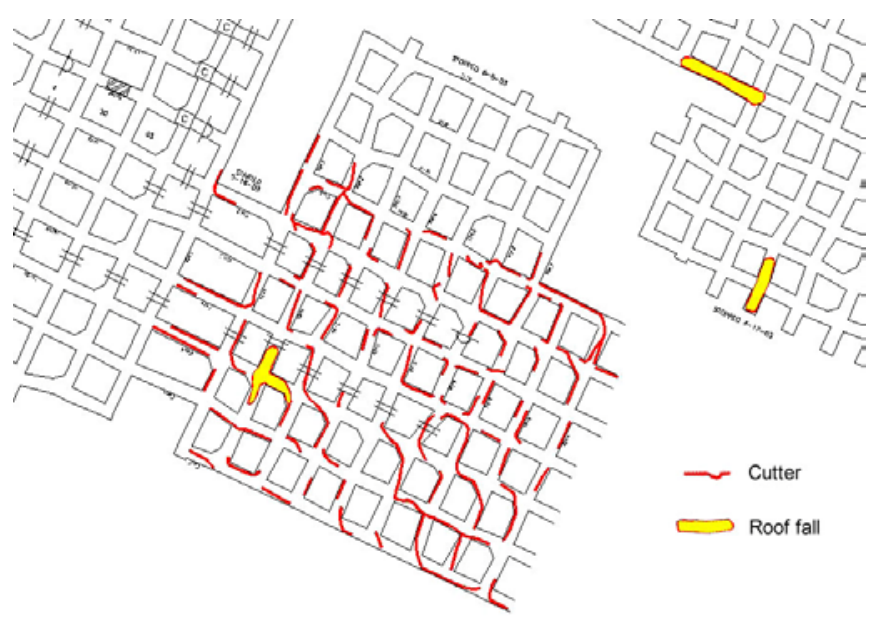

j. cutter pattern and roof fall observed

Figures 6.18 Cutters and roof fall at various locations of the mines 


\subsubsection{Roof Control Plan}

Initially the typical roof bolting patterns at this mine was 5 bolts across the entry on $4 \frac{1}{2}$ foot row spacing. Initially, the bolting pattern consisted of three 5 foot fullygrouted resin bolts (\#6 Grade 60 headed rebar) and two 12 foot Double Lock bolts (7/8 inch SRD Grade 75 assisted with mechanical shell and 2 foot equivalent resin). Roof straps (8 inch by 14 foot by 12 gauge) were often used in conjunction with the roof bolts. The two longer bolts were used in the middle of the entry to anchor high into the immediate roof horizon. Cable trusses and screen panels ( 5 foot by 15 foot by 8 gauge) were also used in some areas.

When cutter and roof fall were observed with this roof bolting pattern, it was further modified. In order to address cutter in the roof the, the bolting pattern was changed in late 2002 . Three $7 / 8$ inch by 9 foot Double Lock (2 foot equivalent resin) roof bolts with 8 inch by 8 inch Grade 3 plates were used along the ribs and center in conjunction with two \#6 by 6 foot headed rebar (fully-grouted) roof bolts with 8 inch by 8 inch Grade 2 plates. In addition, the roof strap was increased to 10 inches by 16 feet by 14 gauge. This system provided a zone for cutter roof failure (at the 6 foot horizon) and suspension above this zone (9 foot horizon).

Although roof control at the face improved with the revised bolting pattern, long term roof support continued to be a significant issue in varve roof areas. Mining was concentrated in the varve roof areas through most of 2004 . Both production units were relocated into the transitional roof area by 2005. Roof control in the transitional roof area generally consisted of 6 foot (\#5 headed rebar with offset head) fully grouted resin bolts in panel development and 8 foot Double Lock roof bolts in 4 of the 7 entries in main and submain development. 


\subsubsection{Cutting Sequence used in Mine}

The general 'cutting sequence' used at the Herin\#6 mine is depicted in Figure 6.19. It may be mentioned that two continuous miners are used in the development of mains and depending on their availability; the 'cutting sequence' shown in Figure 6.19 is shared between the two. However, in general, each continuous miner develops pillars on one side of entry \#4. The cutting sequence and many other details about the mine has been taken from a technical report prepare for the mine by Peng (2004).

A 'cutting step' generally involves creation of a boxcut and widening it to the full width of an entry/crosscut. For the ventilation purposes, the boxcut at mine portal is always made on the right hand side (looking inby at the face) of an excavation. The boxcut is generally $11 \mathrm{ft}$ wide and $20 \mathrm{ft}$ long. After the boxcut is made, the entry/crosscut is widened to full width of about $18 \mathrm{ft}$ by taking a cut of about $7 \mathrm{ft}$ in the next cycle (if it is an extended cut, then another $10-20 \mathrm{ft}$ box cut is made on the right side and widened to $18 \mathrm{ft}$.). Sumping at the face is made at the top up to a depth of about $2 \mathrm{ft}$ and then 'sheared' downwards to the full height of the entry/crosscut. These 'cutting steps' are always maintained at the mine. After cutting for a sequence is complete, the continuous miner is retracted and a roof bolter comes to the face to reinforce the roof. To develop crosscuts, turns are made in \#2 and \#5 entries on the pattern shown in Figure 6.20. This turning process results in a round corner for the pillar and longer intersection span (one cut intersection was measured at 33.5' by $28.8^{\prime}$, the uncut intersection was $27^{\prime}$ by $29.2^{\prime}$ ).

The modeling of 7 entry system as shown in Figure 6.19 is very tedious as the model size will be too big and running time for the plastic model will be exceptionally high. In order to make model a representative case for this it has been reduced to a 
3 or 4 entry system. Figure 6.21 shows the cutting sequence representing 7 entry systems as 3 entry system for modeling with 20 and $40 \mathrm{ft}$ cut length. Figure 6.22 a-c shows the cutting sequence representing 7 entry systems as 4 entry system for modeling with $40 \mathrm{ft}$ cut length. In all the figures numbers mentioned indicates the order in which cuts were made in the model and arrow indicates the direction of cutting. Solving the numerical model considering the individual cut is a very time consuming affair even with very efficient computer system. Hence few initial models were done to check the effects of individual cuts and with a group of two, three or four cuts. The special precaution while selecting the group of cuts in a particular step was followed such that no two cuts are in adjacent entries and they do not interact with each other or adversely influences results in other part of the model. Figure 6.23 shows the cohesion distribution in the immediate roof layer for 3-entry and 4entry system with individual cut and multi-cuts in a step. From the cohesion plots it can be seen that there is no significant noticeable difference for both case except at few locations (shown as red circle and rectangular shape). The minor difference can be noted mostly near the face positions in individual cuts. This insignificant difference can be ignored to reduce the solving time. Hence to save the time more than one cut was made in one step for both 3 and 4-entry system for further study as shown in the Figures $6.22 \mathrm{~b}, \mathrm{c}$, and d. So most of the modeling works will be carried out assuming the cutting sequence as shown in Figure $6.22 \mathrm{c}$ and $\mathrm{d}$ for 4 and 3-entry system respectively. Figure 6.24 shows the location of cross-section in the entry and crosscuts and nomenclature for the intersections for a 3entry system. Same nomenclature has been followed for the 4-entry system. 


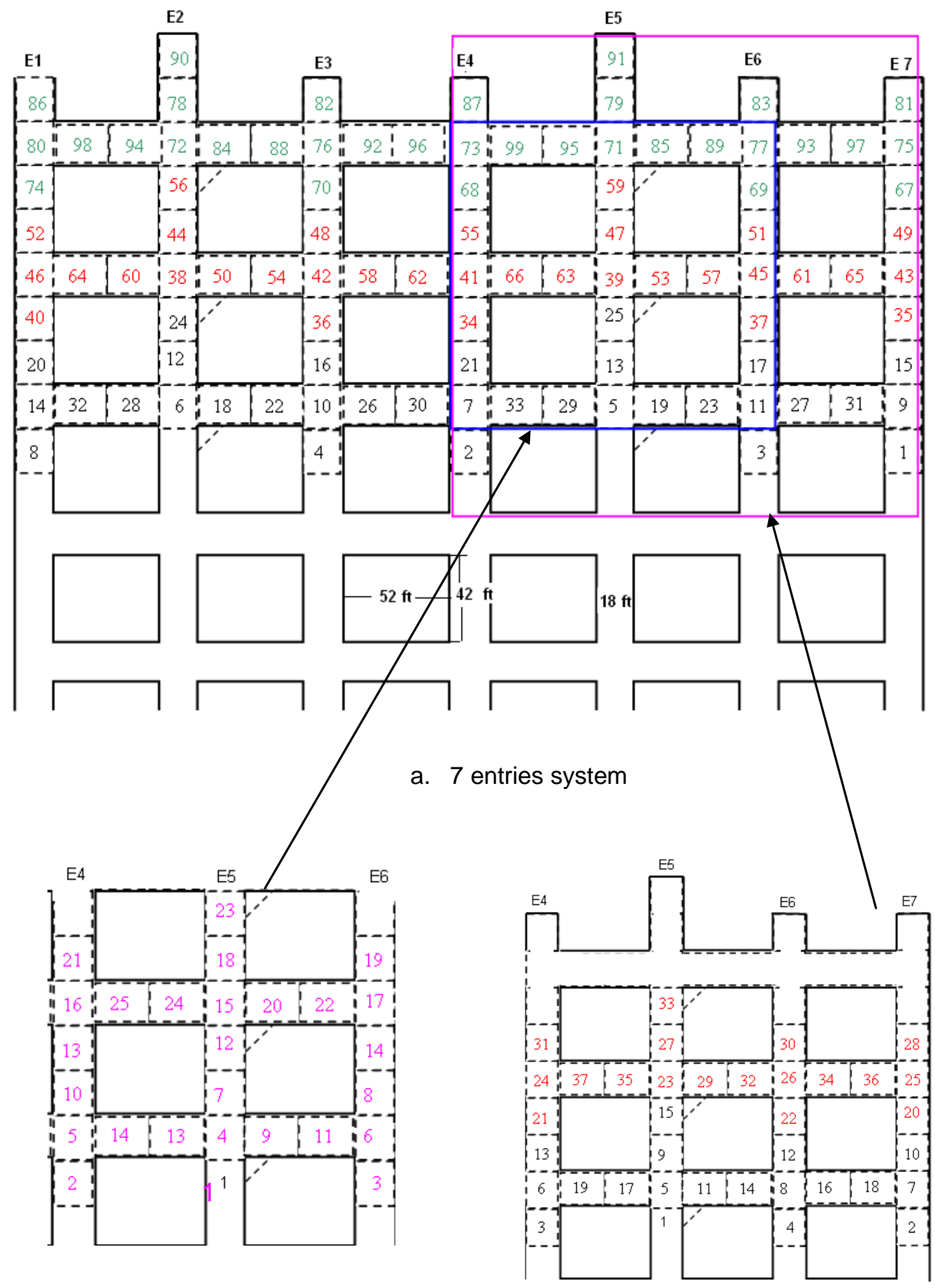

b. representative 3 entry system for modeling

c. representative 4 entry system for modeling

Figure 6.19 Typical cutting sequence used in mine working Herrin \# 6 seam 


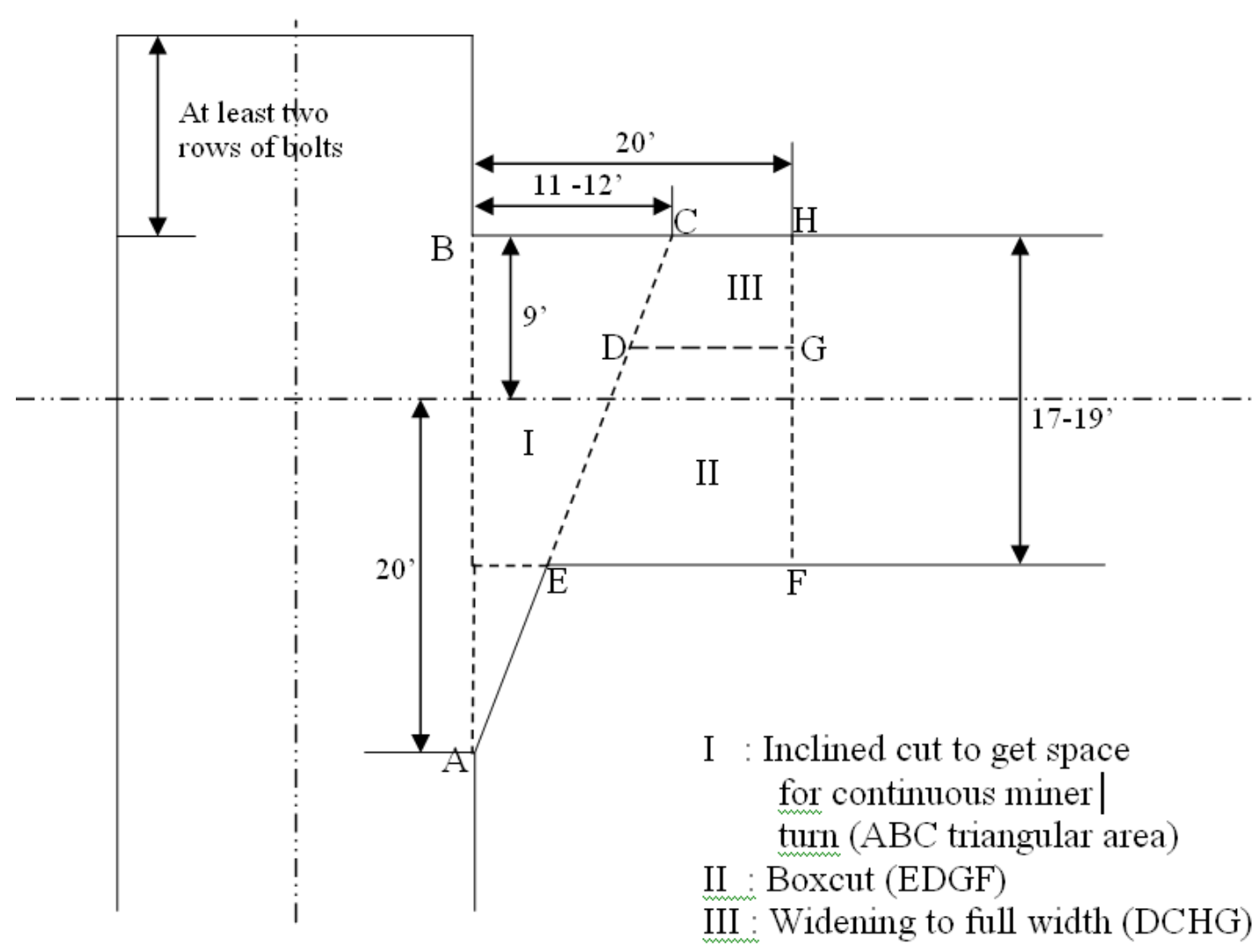

Figure 6.20 Steps in creating a turn for crosscut development

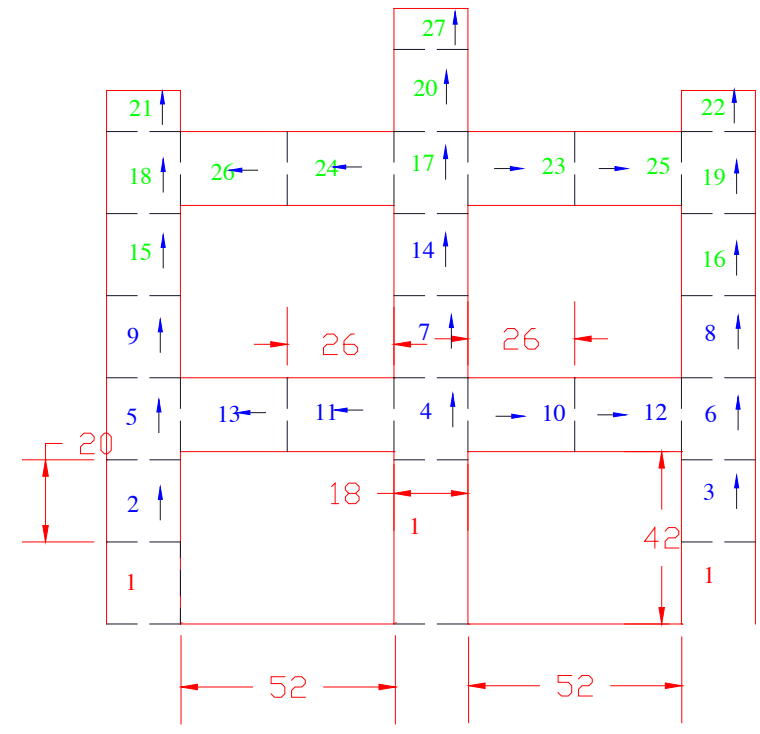

a. cut length of $20 \mathrm{ft}$

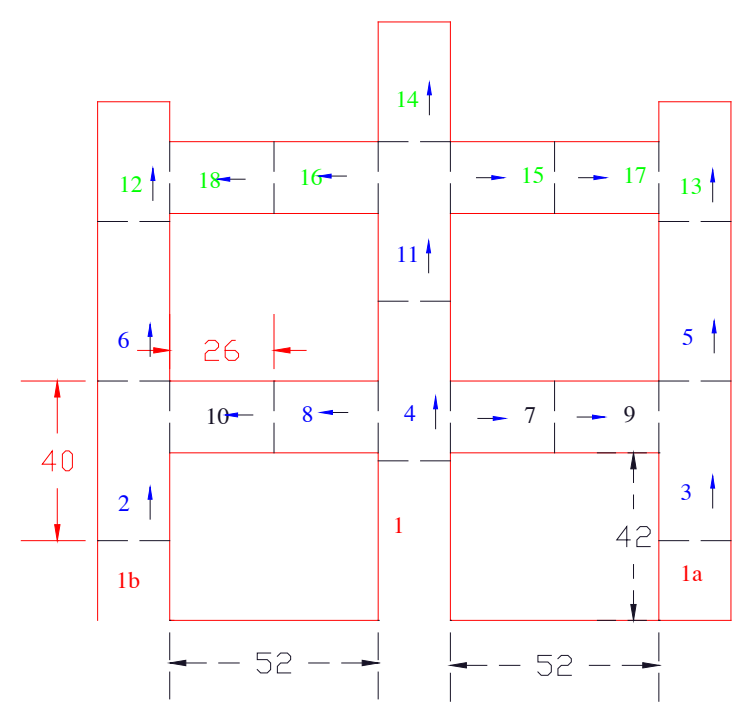

b. cut length of $40 \mathrm{ft}$

Figure 6.21 Cutting sequences for representative 3 entry systems 


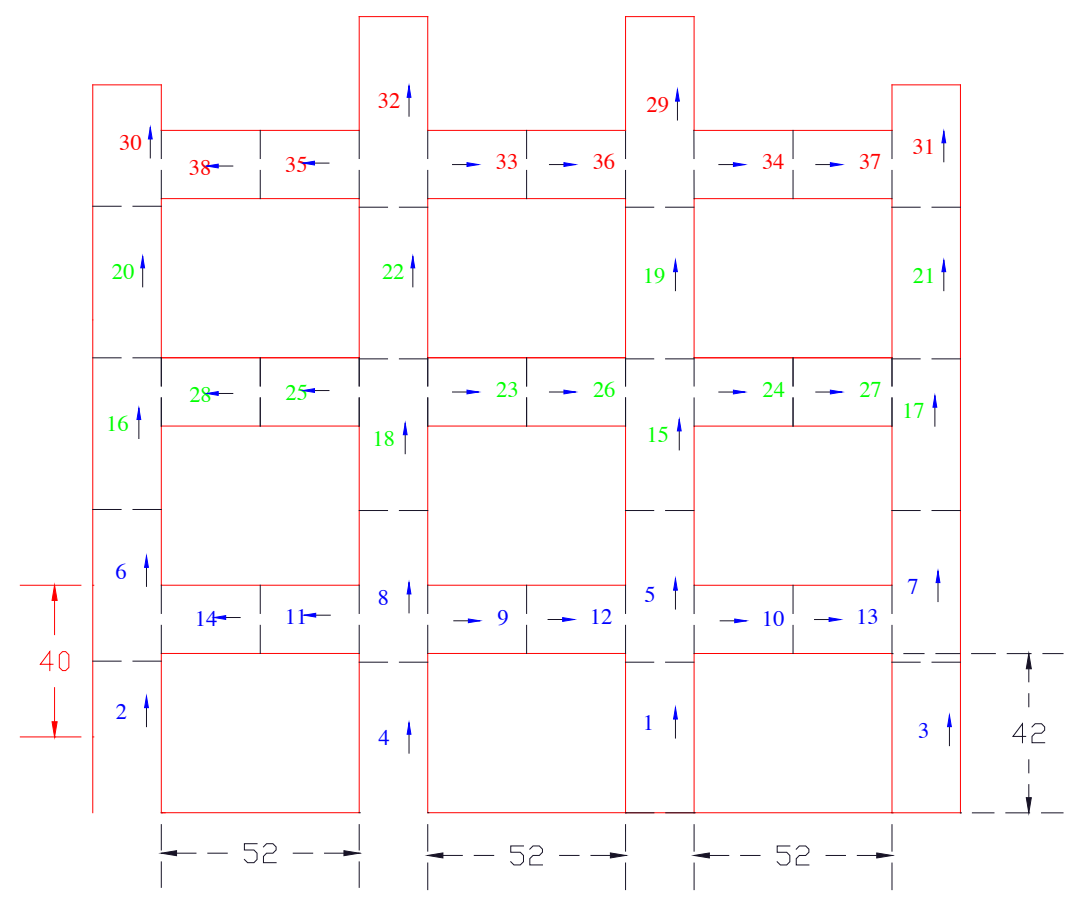

Figure 6.22a Cutting sequences for representative 4 entry systems with individual cuts

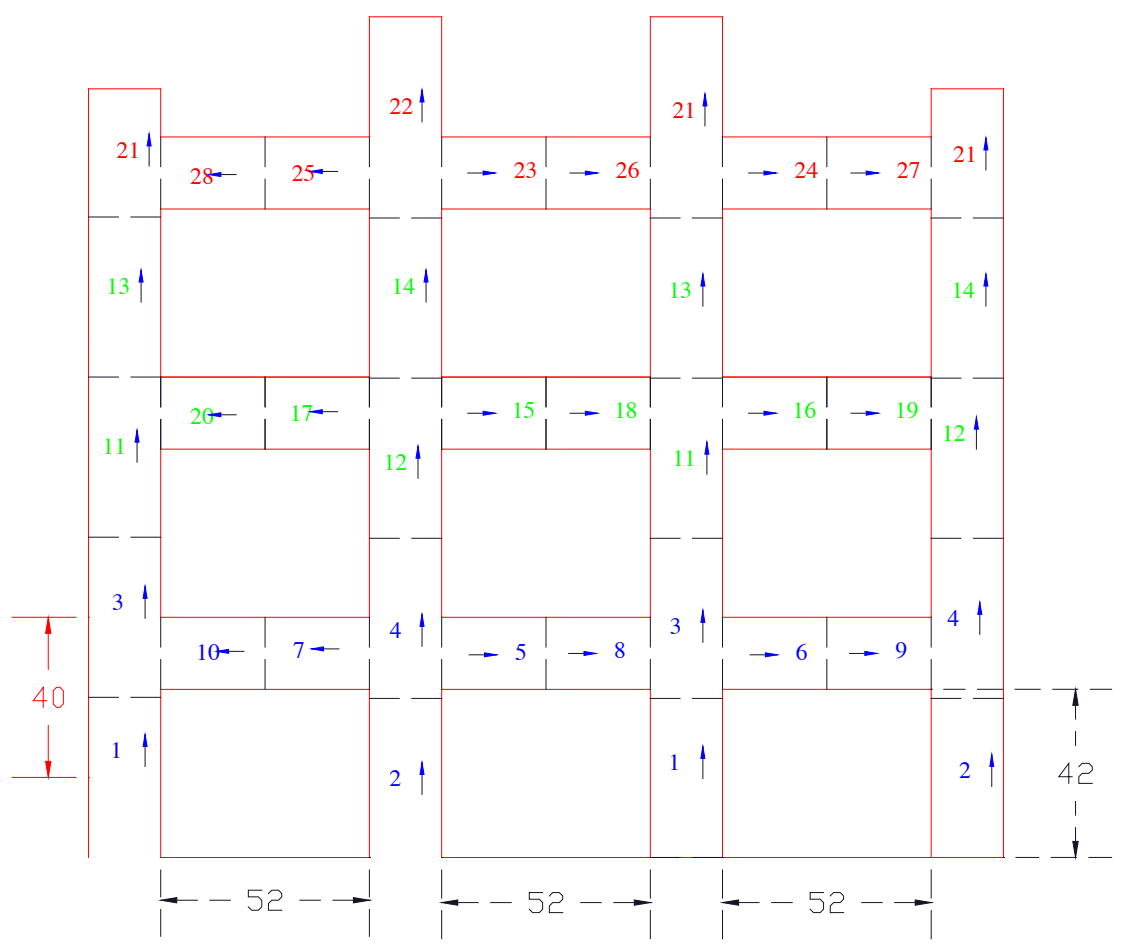

Figure $6.22 \mathrm{~b}$ Cutting sequences for representative 4 entry systems with group of cuts in entry and individual cut in crosscuts 


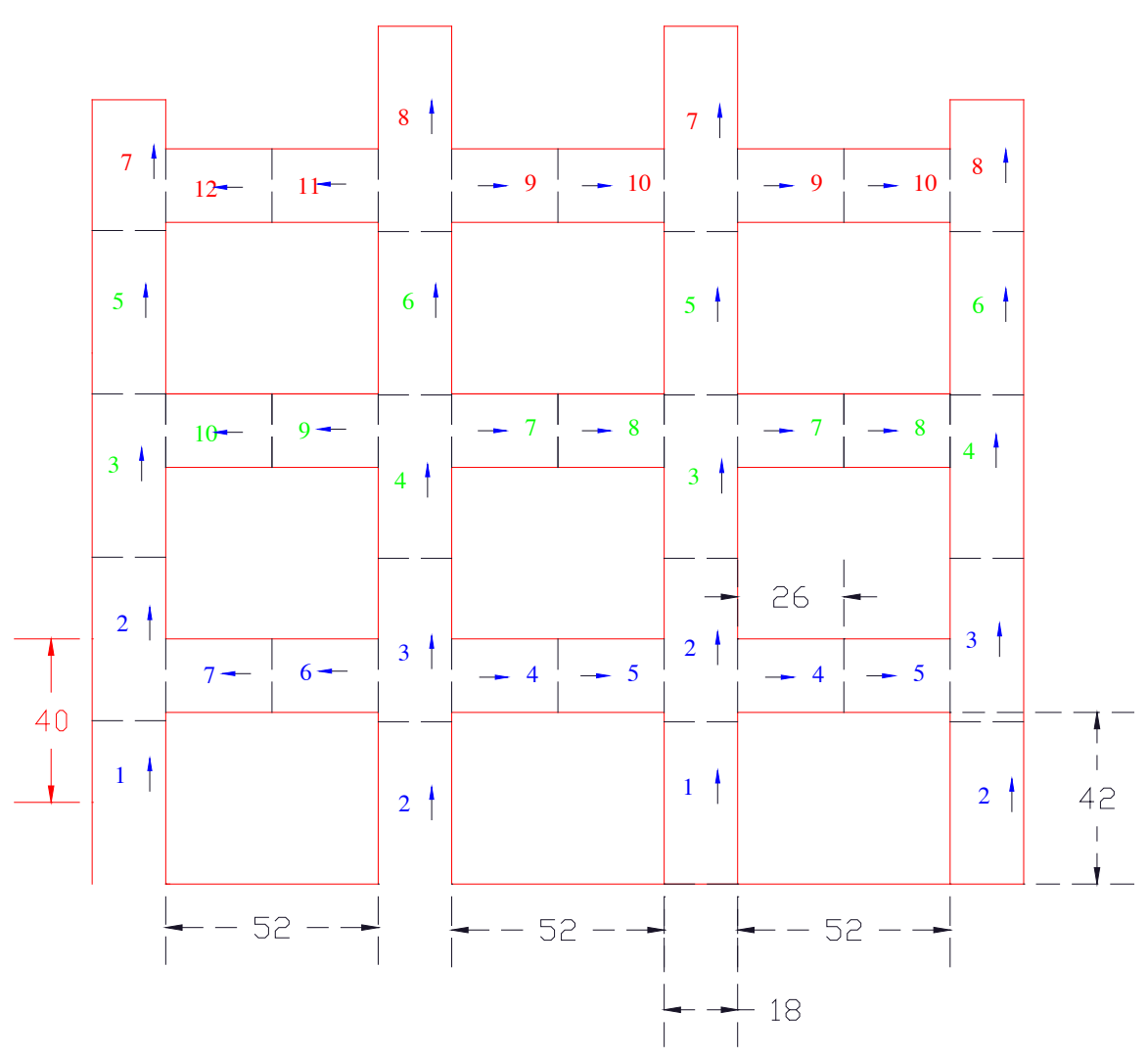

Figure 6.22c Cutting sequences used for the modeling for representative 4 entry systems with 12 group of cuts

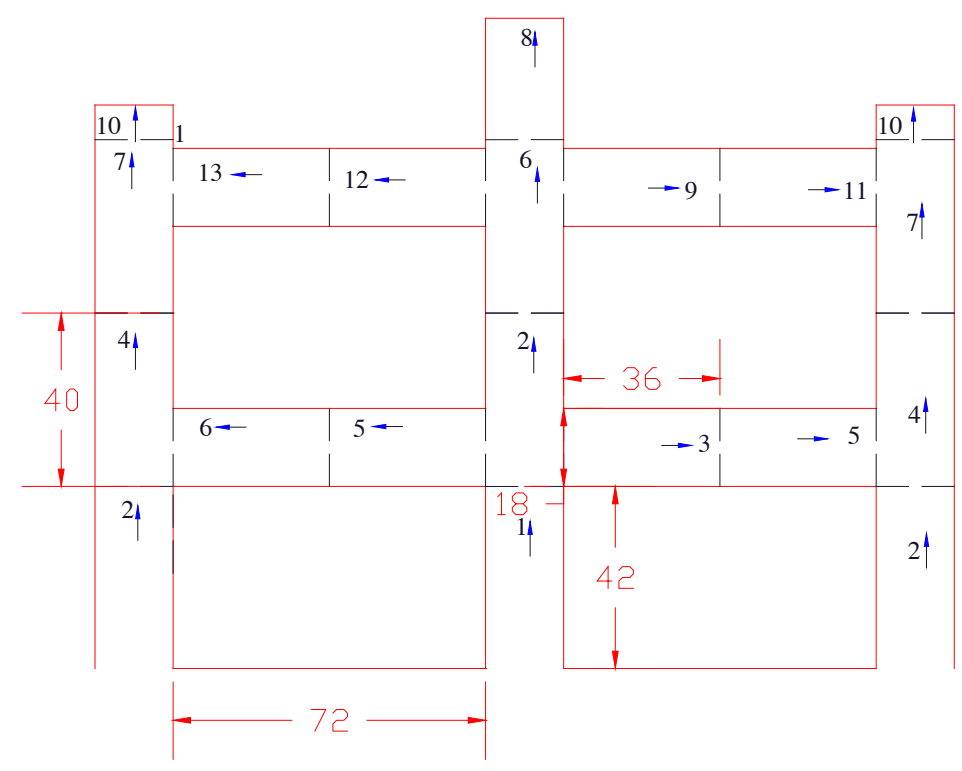

Figure $6.22 \mathrm{~d}$ Cutting sequences for representative 3-entry systems with 13 groups of cut instead of 20 individual cuts 


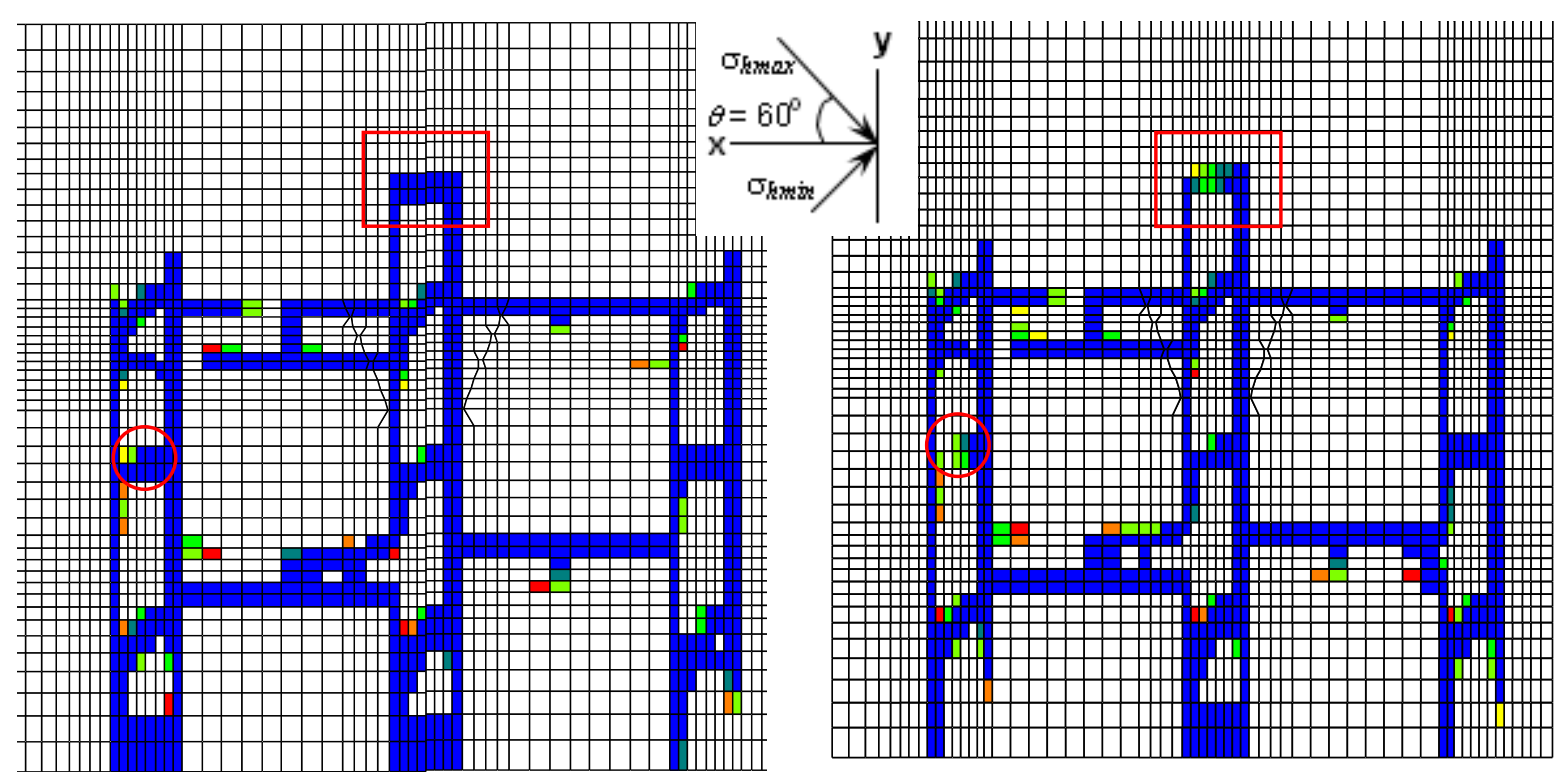

a. Cutter pattern with 18 individual cuts for the cutting sequence shown in Figure 6.21b

b. Cutter pattern with 13 group of cuts for the cutting sequence shown in Figure 6.22d
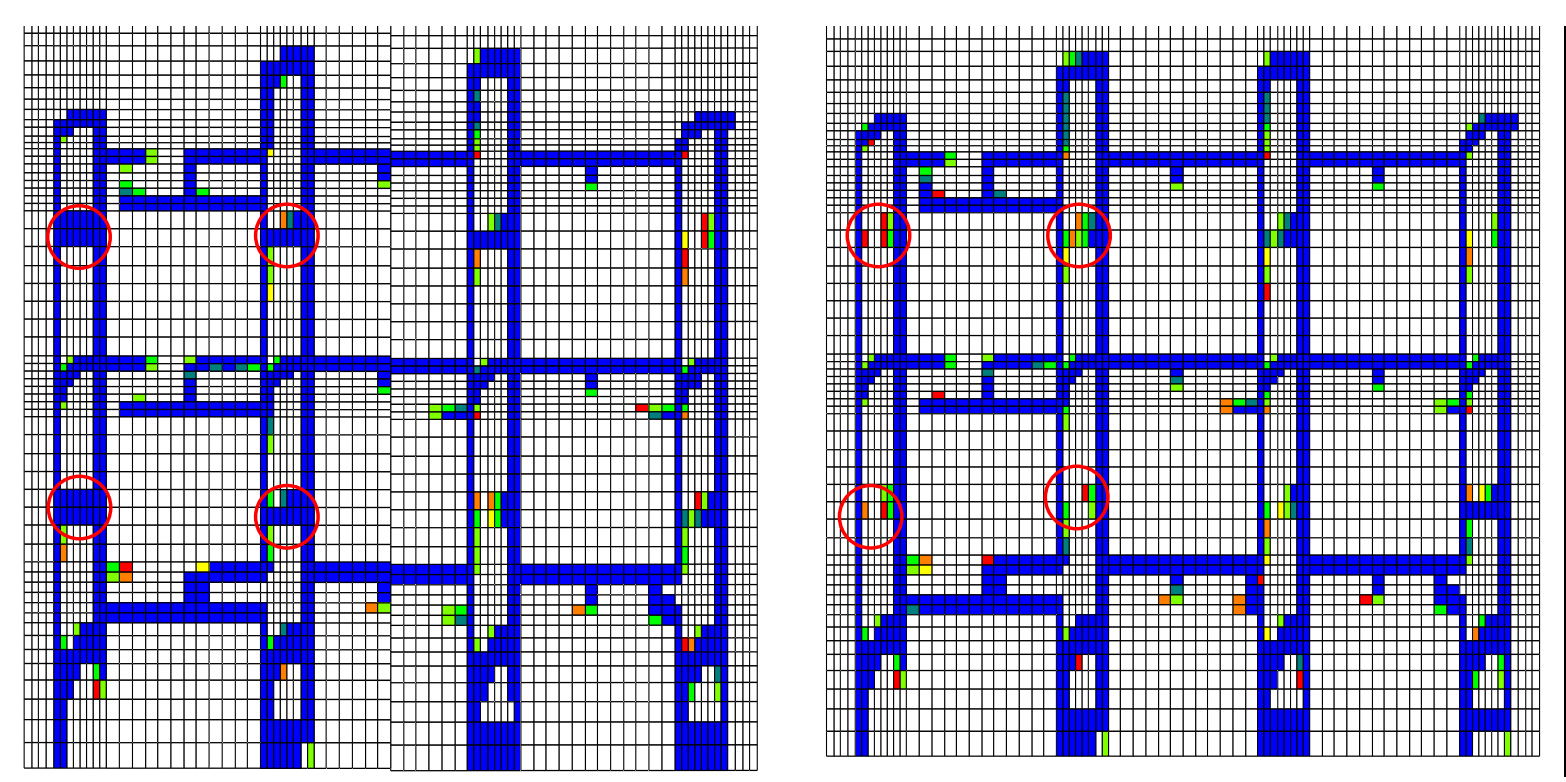

c. Cutter pattern with 38 individual cuts for the cutting sequence shown in Figure 6.22a

d. Cutter pattern with 12 group of cuts for the cutting sequence shown in Figure 6.22c

Figure 6.23 Cohesion distribution pattern for cutting sequence having individual cuts and a group of cuts in a solving step 


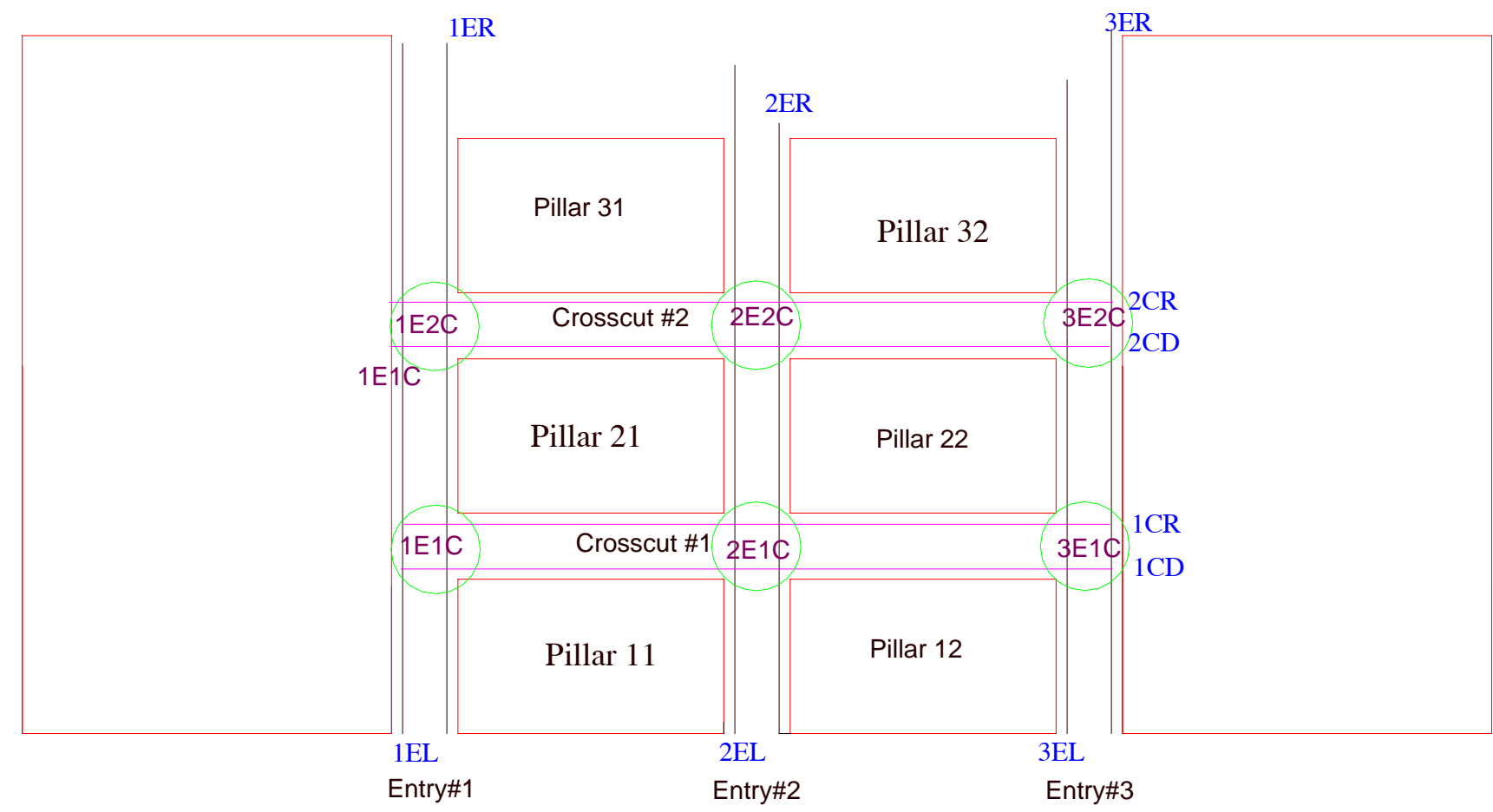

Notations- $1 E L$ - cross section in Entry \#1 on left side 1ER - cross section in Entry \#1 on rightside 1CD - cross section in Crosscut \#1 on down/dip side $1 \mathrm{CR}$ - cross section in Crosscut \#1 on up /rise side 1E2C- Intersection at entry\#1 and crosscut\#2 Pillar 12 - 2nd pillar in first row from left side

Figure 6.24 Nomenclature and locations of cross sections

\subsection{NUMERICAL MODELING FOR CUTTER PATTERN SIMULATION}

From the above case studies it can be seen that the roof falls occurred every where in entries, crosscuts and intersections irrespective of the orientation of the openings. Although the frequency of falls and their extent were different at different locations of the mine. Many cutters were also observed at various part of the mine. One special features of cutter here can be seen as their inconsistent spatial distribution. It can be noticed that cutters starting at one side of an entry and run across its width or an intersection at some angle to continue to develop on the other side. Cutters were also observed in the both sides of the entries and crosscuts. To explain all these 
things numerical modeling has been performed with the modeling technique as described in the chapter-5.

For the case study mentioned above numerical modeling were conducted for the cutting sequences shown in Figure 6.22c for a 4-entry model. The rock lithology, in-situ stress and rock properties were used as described in chapter 5. The final geometry of the model along with entries, crosscuts and all 3-way and 4-way intersections are shown in Figure 6.25. The model was solved as discussed in Chapter 5 for an orientation, $\theta=30^{\circ}$. The models output for cohesion distribution and shear strain rate are plotted for the plan view of immediate roof layer after each cut are shown in Figure 6.26. For cohesion plots the dark blue color shows the zones having zero to 5 psi cohesion which can be termed as the cutters. Similarly the locations where shear strain rate is more than $1 \times 10^{-4}$ can be said as most unstable.

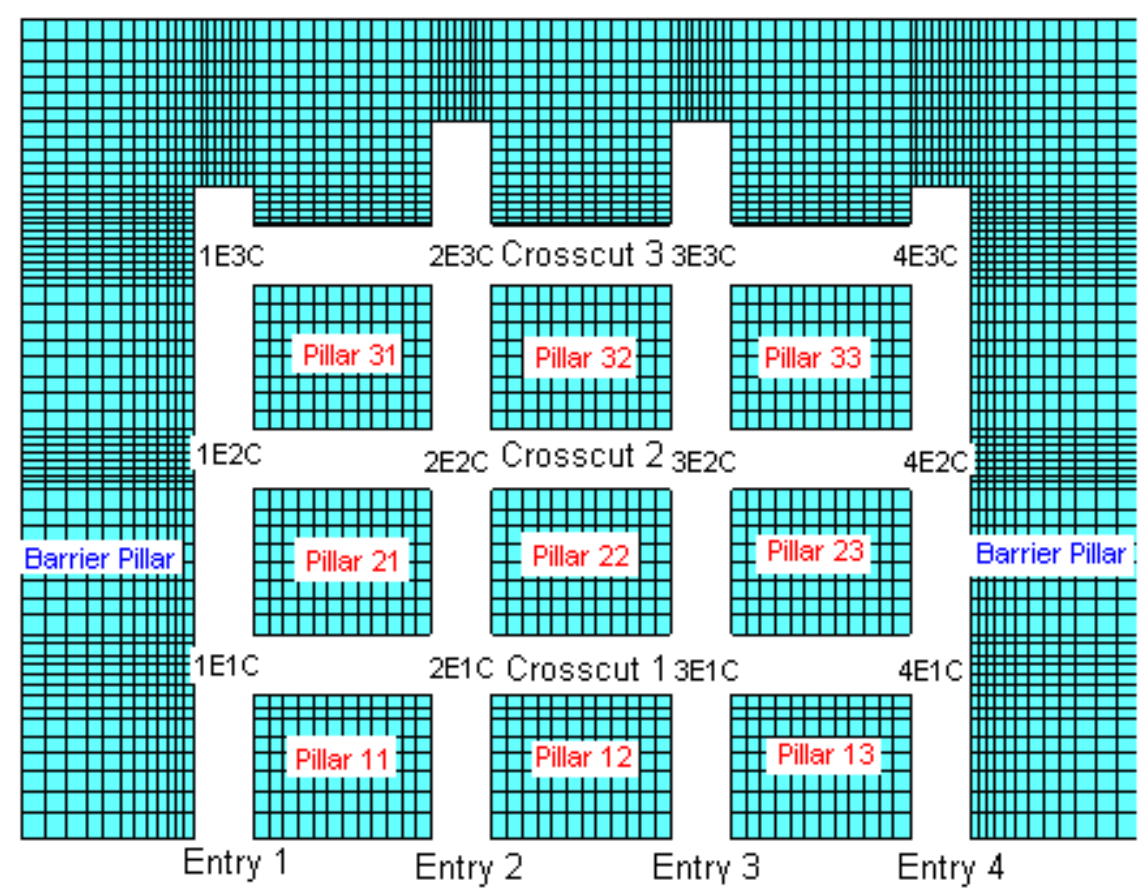

Figure 6.25 Geometry showing entries, crosscuts and intersections 
Figure 6.26 shows the progression of cutter (zero cohesion elements, blue color)) and probable location of roof falls (High shear strain rate, magenta/red color) as the excavation are created in multi cuts. After cut 1 made in entries 1 and 3, the cutters are formed first in the left edge of the entry and then move to right edge at some distance behind the face. The formation of cutter pattern during $1^{\text {st }}$ cut made in all entries looks same. The cutter pattern in first cut is different due to boundary conditions. After initial cuts, the cutters advances at the right edges of the entries as the next cuts are made. After cut 4 made in $1^{\text {st }}$ crosscut the cutter do not form in crosscut behind the face, but the stress concentration or zone in post failure region can be seen at the edge of the face and pillar-23. The zero cohesion zones start to increase in the entries at the locations where during first cut cutter distribution changed from the left to right edge (red circle, figure $6.26 \mathrm{~d}$ ). As soon as cut 5 is made, the cutters formed almost $20 \mathrm{ft}$ behind the face towards edge of the pillar-23 in $1^{\text {st }}$ crosscut. After cut 6 which is made into the direction of maximum horizontal stress in $1^{\text {st }}$ crosscut no cutters formed behind the face but at the edge of face and pillar-11 the few zones are already in post failure zone (blue circle, figure 6.26f). After cut 7 , still in $1^{\text {st }}$ crosscut the cutter develops near the earlier face position in cut 6 (red line, Figure 6.26h). But in contrast to crosscut-1, in $2^{\text {nd }}$ crosscut after cut 7 , cutter develops behind the face towards the edge of the pillar-33. It further extends after cut 8 and connects the intersection 3E2C. The cutter in $1^{\text {st }}$ crosscut between entry 1 and 2, develops towards the edge of the pillar-11. Cut 9 is made in $2^{\text {nd }}$ and $3^{\text {rd }}$ crosscut but in opposite direction. This time cutter forms after cut 9 is made in $2^{\text {nd }}$ crosscut between entry 1 and 2 . The cutter pattern is same for $3^{\text {rd }}$ crosscut like $2^{\text {nd }}$ crosscut. The major development is observed in entry 1 between $1^{\text {st }}$ and $2^{\text {nd }}$ crosscut (red rectangle, Figure 6.26j) and intersection 2E2C. During cut 9, cutter develops 
towards the edge of the pillar-21 in entry 1 between $1^{\text {st }}$ and $2^{\text {nd }}$ crosscut. Cutters also developed at the edge of pillar21 in $1^{\text {st }}$ crosscut between entry 1 and 2.Cutters also increases near the face position during cut 3 made in entry 2 . The elements aligned in a particular direction at intersection 2E2C (violet ellipse, Figure 6.26i) enter into the post failure zone which completely connects with the cutter developed earlier (red circle, Figure $6.26 \mathrm{j}$ ). The direction of this cutter propagation is inclined towards the diagonal of the intersection. After cut 11, cutter increase near the earlier face position in previous cuts. At some face positions it connects the entry width (blue rectangle, Figure $6.26 \mathrm{k}$ ) and the cutters also cross the crosscut width in $1^{\text {st }}$ crosscut between entry 1 and 2 .

In these plots the cohesion has been plotted only in the immediate layer. But the extent of zero cohesion goes upward up to the top of the immediate weak roof. The zero cohesion distribution patterns at a cross section where cutter is observed on both sides of the entries or crosscuts or connects the both edges of the openings, would look like similar to Figure 5.34. The locations where the cutter connects to the both sides of opening, most likely roof fall will occur.

Figure 6.26 also shows the shear strain rate after different step of cutting. From the plots of cohesion distribution and shear strain rate it is evident that both zero cohesion zones and active plastic flow zones are located at same places and exhibit the same pattern. The most important is the location of maximum plastic flow zone i.e. maximum shear strain rate. As explained in chapter that any shear strain rate above $1 \times 10^{-4}$ (pink color in Figure 6.26) can be termed as prone to roof fall. This strain rate is observed after cut 4 in entry 3 . After cut 7 , this strain rate also appears in entries 2 and 3. After cut 8 all entries have some high shear strain zones between crosscut 1 and 2 . This high strain rate zone progresses with further cutting steps. 
After cutting step 12, it can be seen that the worst location from roof fall point of view is intersection 2E1C and entry length between crosscut 1 and 2 (black rectangular zone, Figure $6.26 \mathrm{I}$ ). At intersection 2E2C, high active plastic flow can also be seen.

\section{Cohesion, psi}

\section{A. Cohesion distribution}
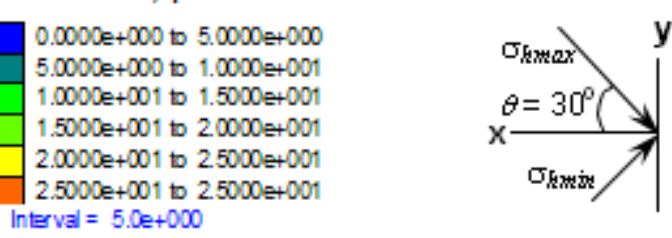

\section{B. Shear strain rate}

Shear strain rate

2 0000e- 005 to 40000 e- 005 40000 e- 05 to 60000 e- 05 $60000 \mathrm{e}-005$ to $80000 \mathrm{e}-005$ 80000 e- 005 to 10000 e- 004 10000 e- 004 to 12000 e- 004 12000 e- 004 to 1.4000 e- 004

1.4000 e- 004 to 1.6000 e- 004 $1.5000 \mathrm{e}-004$ to $1.5000 \mathrm{e}-004$ |rtenal $=20$ e- 005

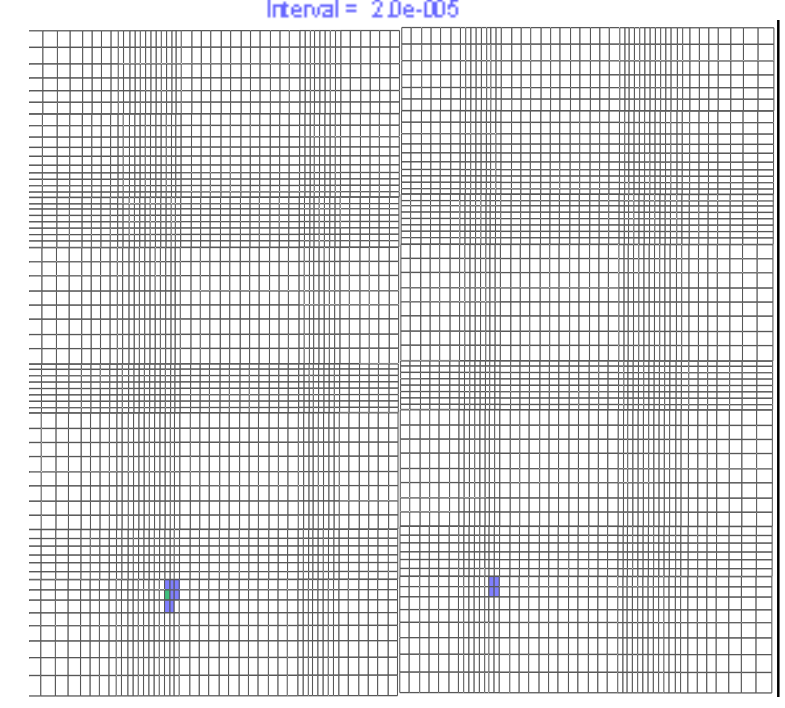

a. after cut 1
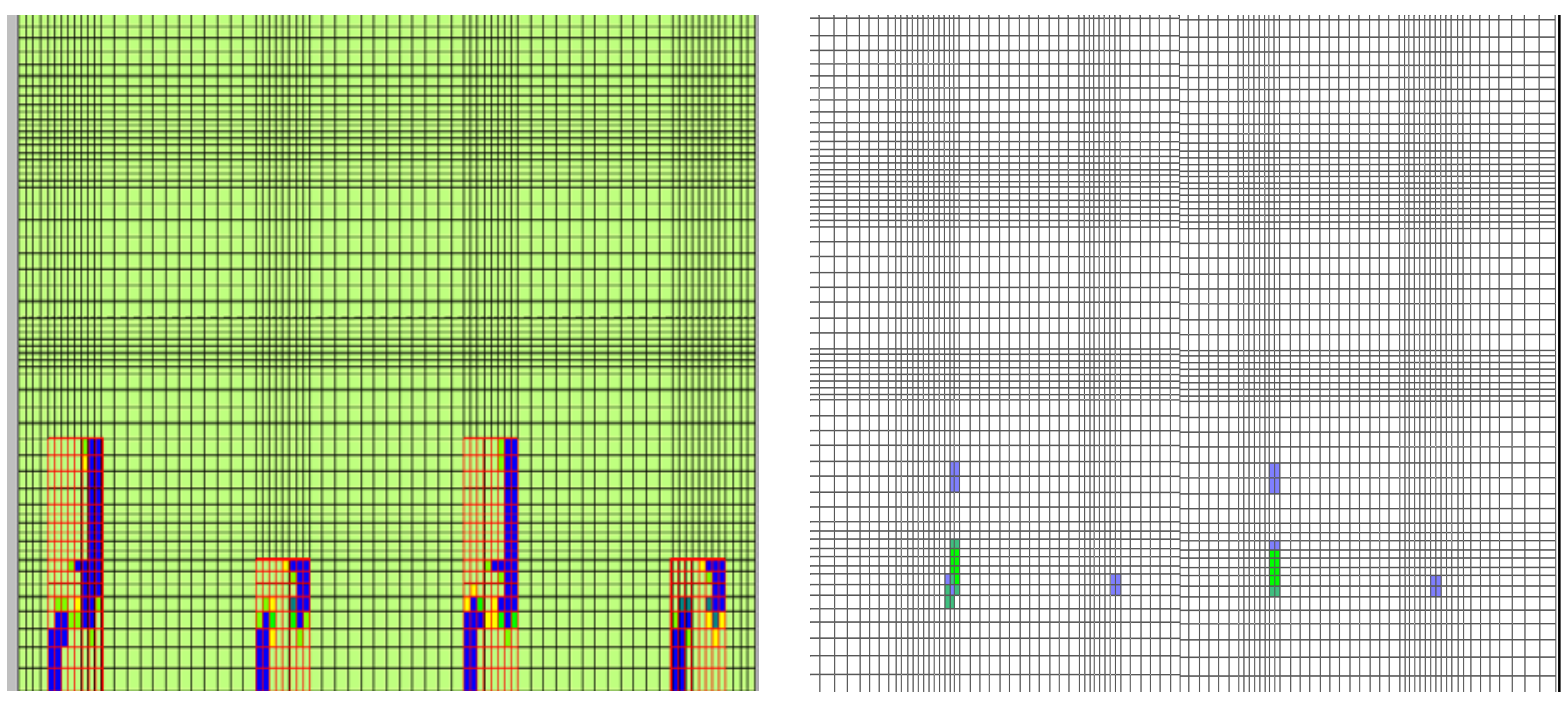

b. after cut 2 

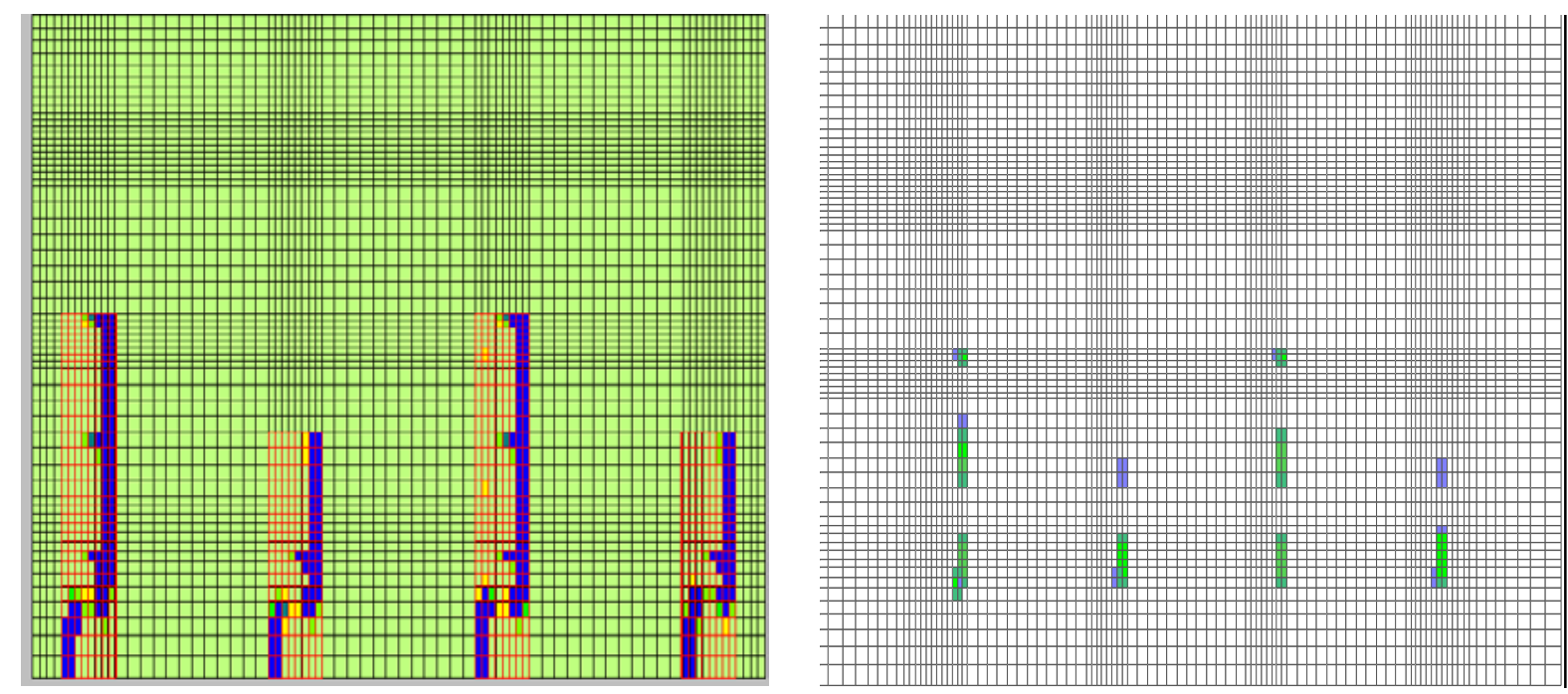

c. after cut 3
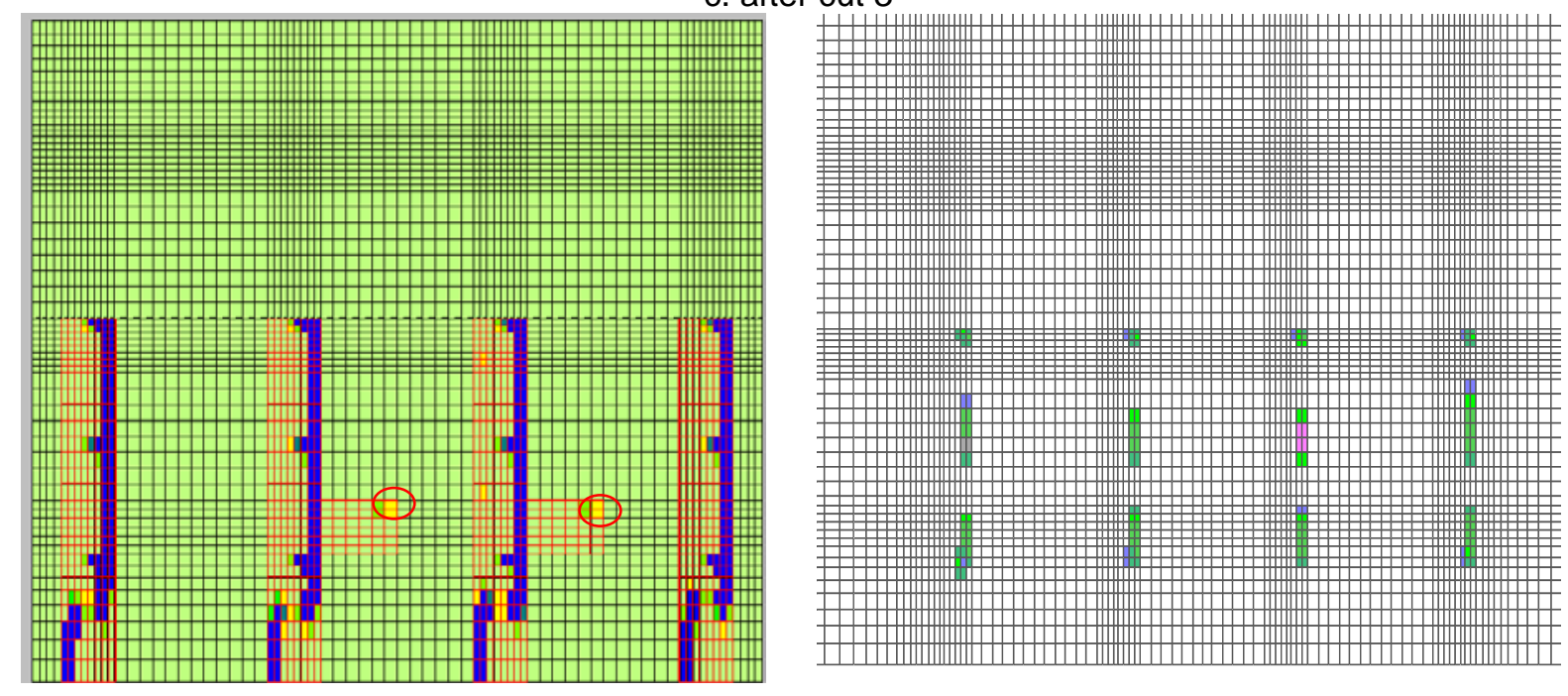

d. after cut 4
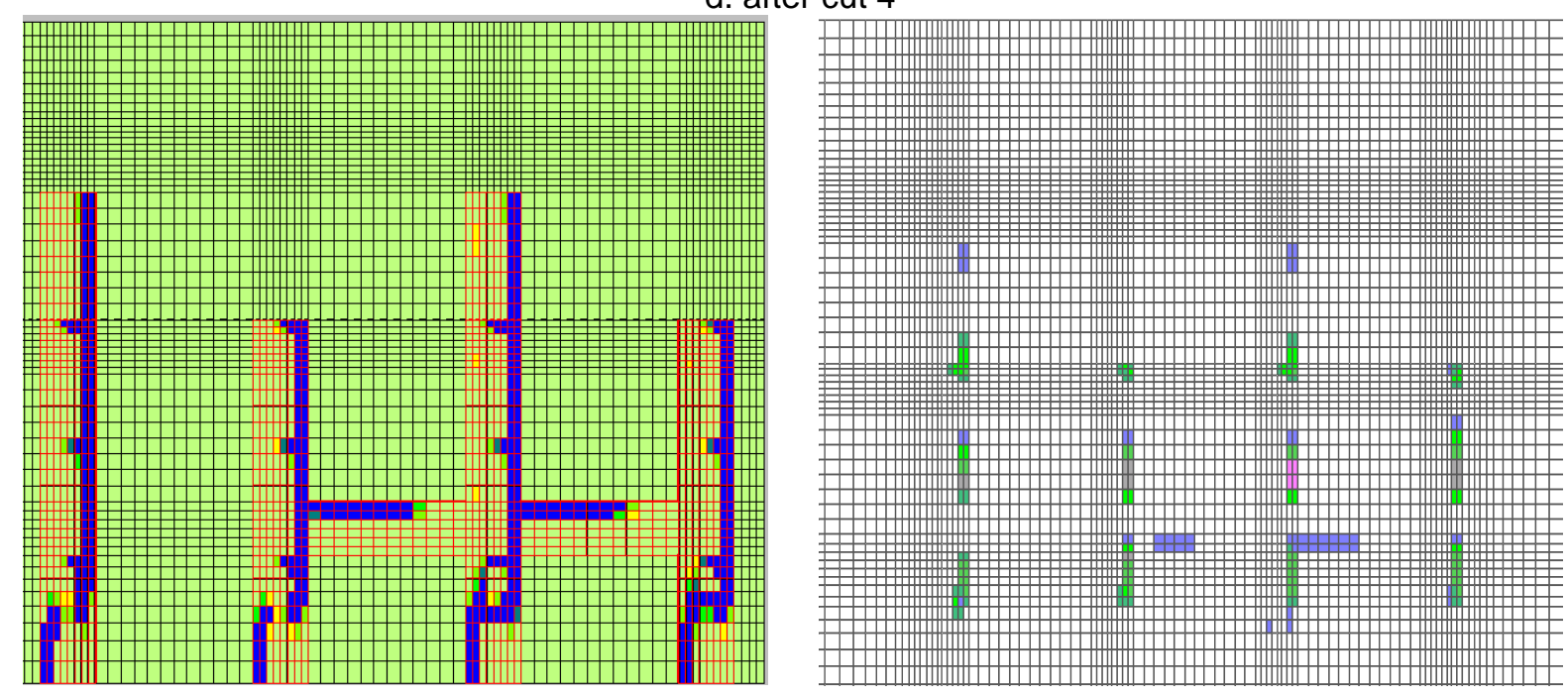

e. after cut 5 

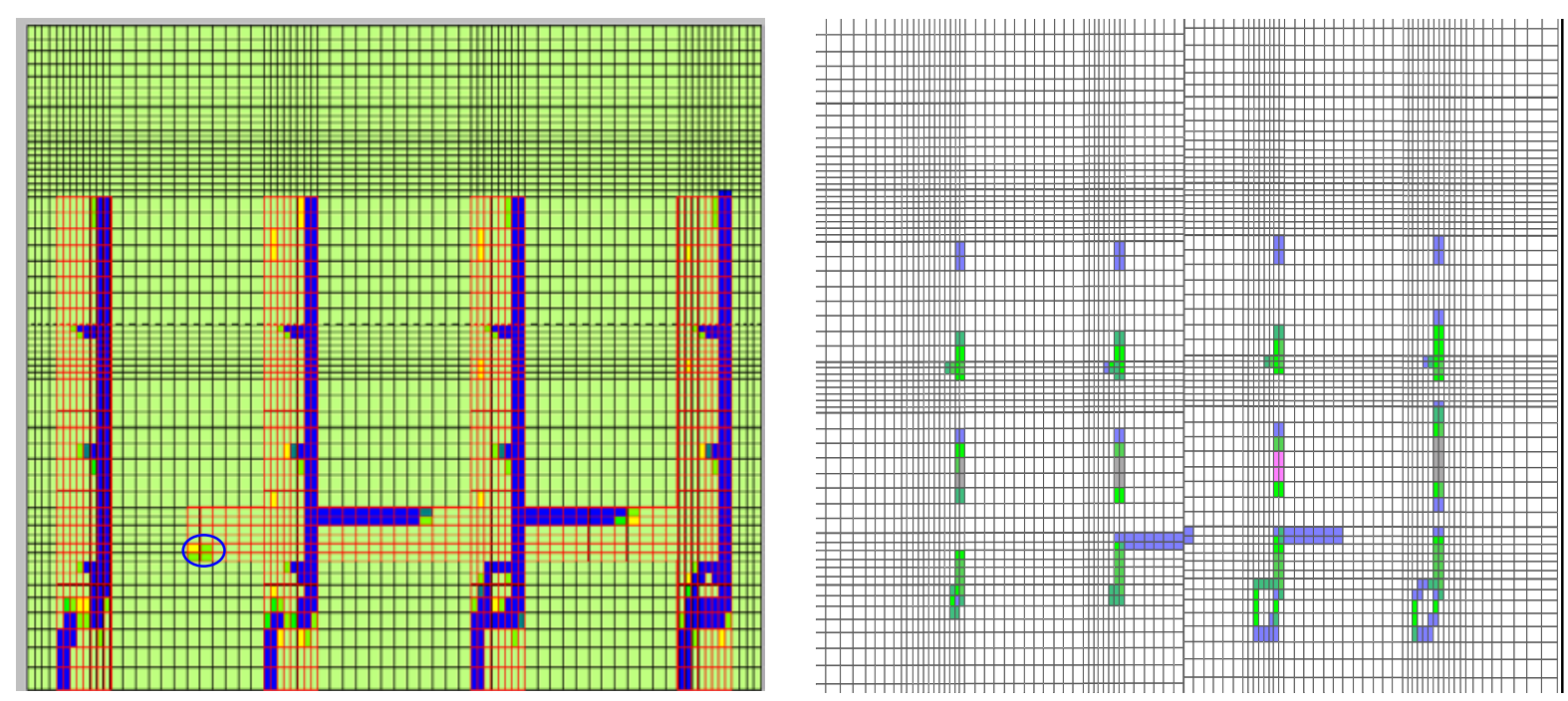

f. after cut 6
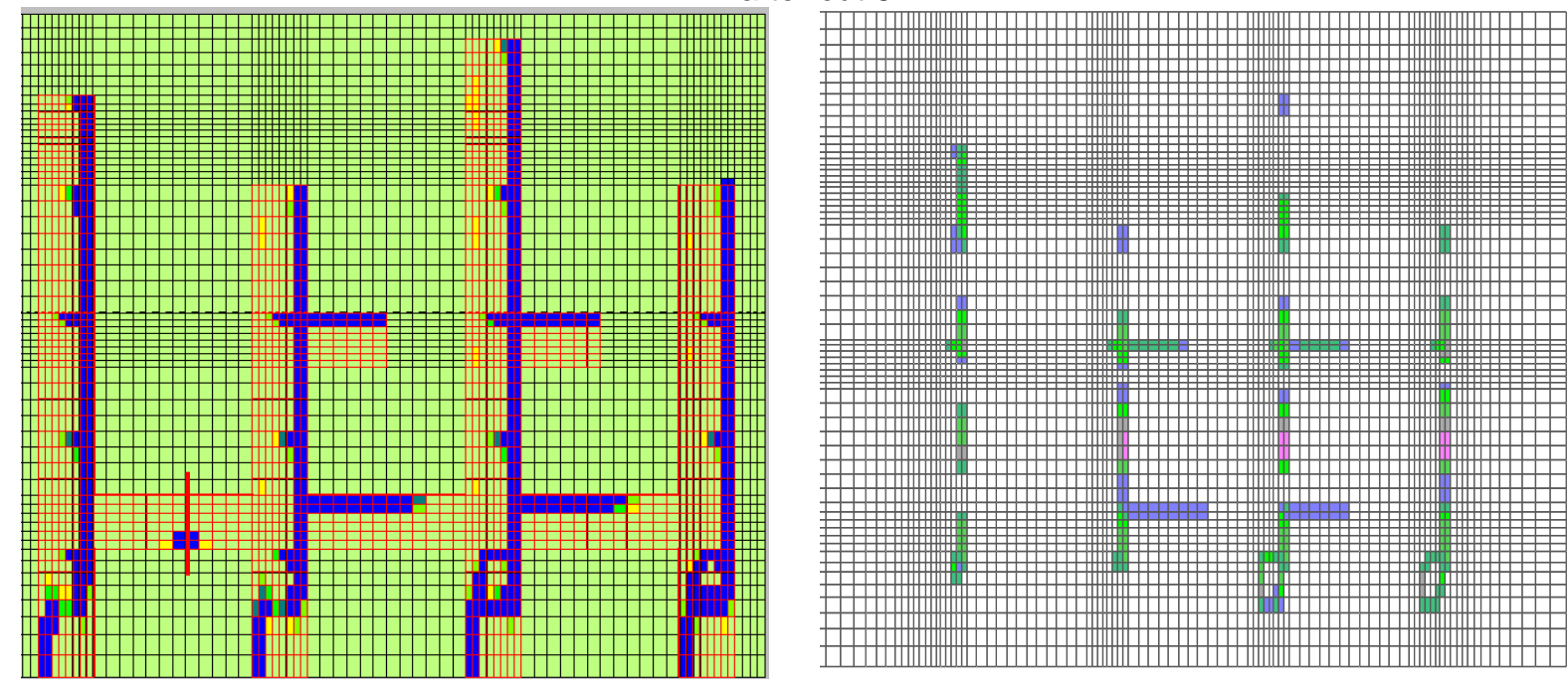

g. after cut 7
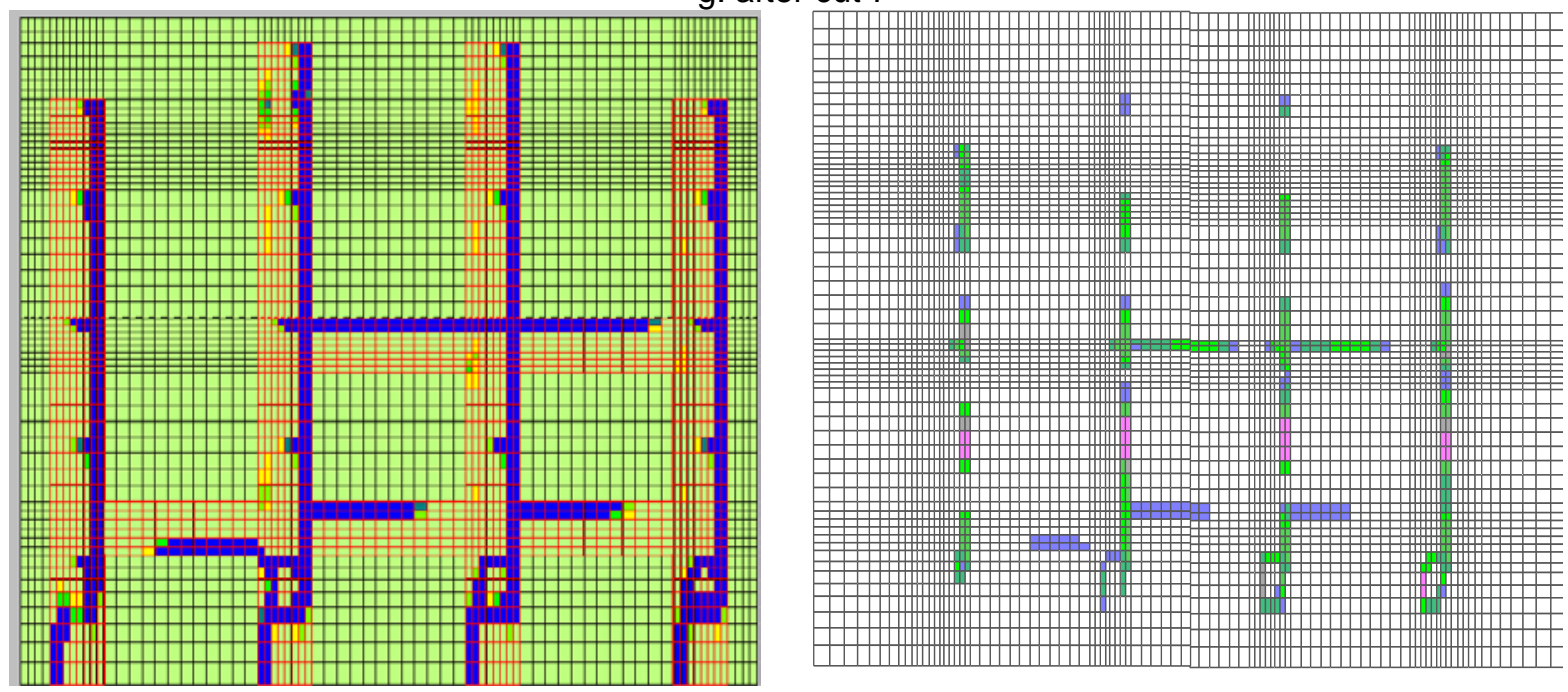

h. after cut 8 

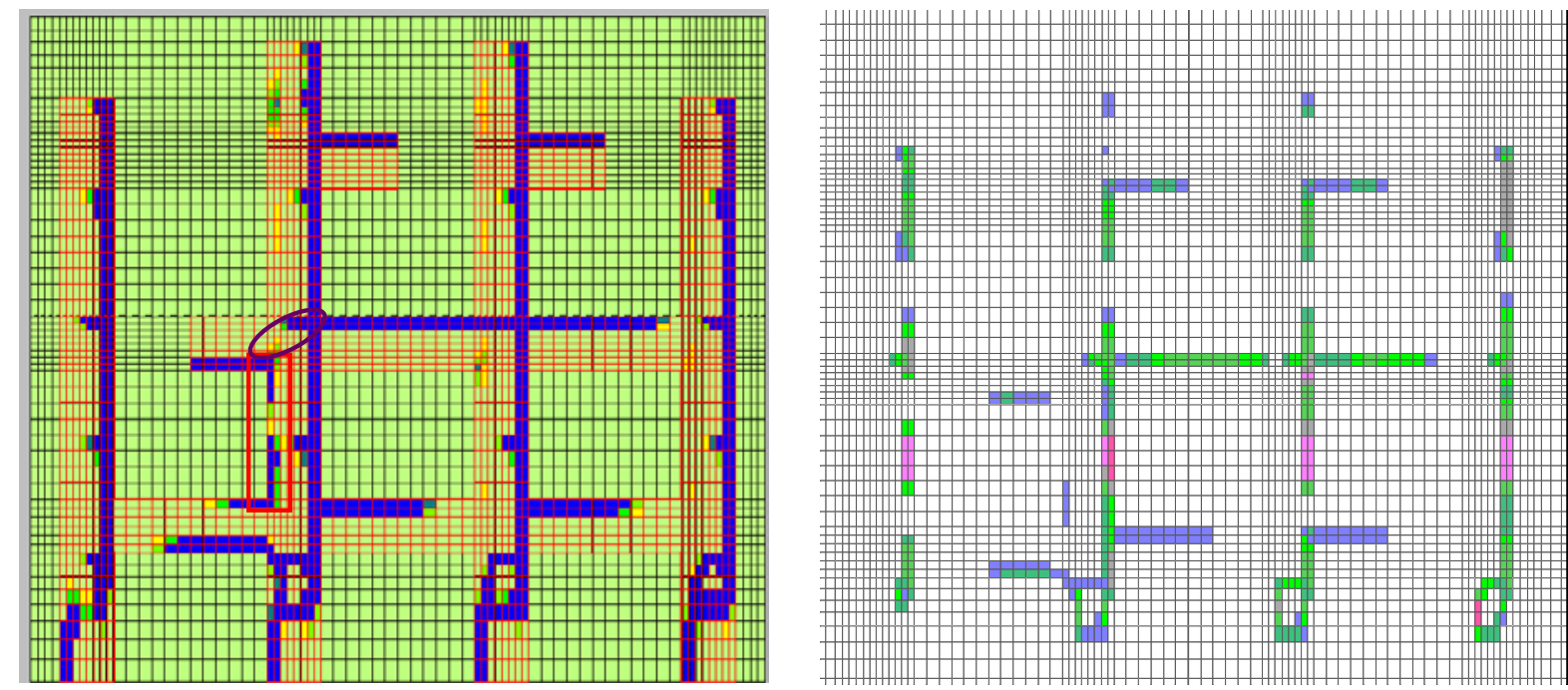

i. after cut 9
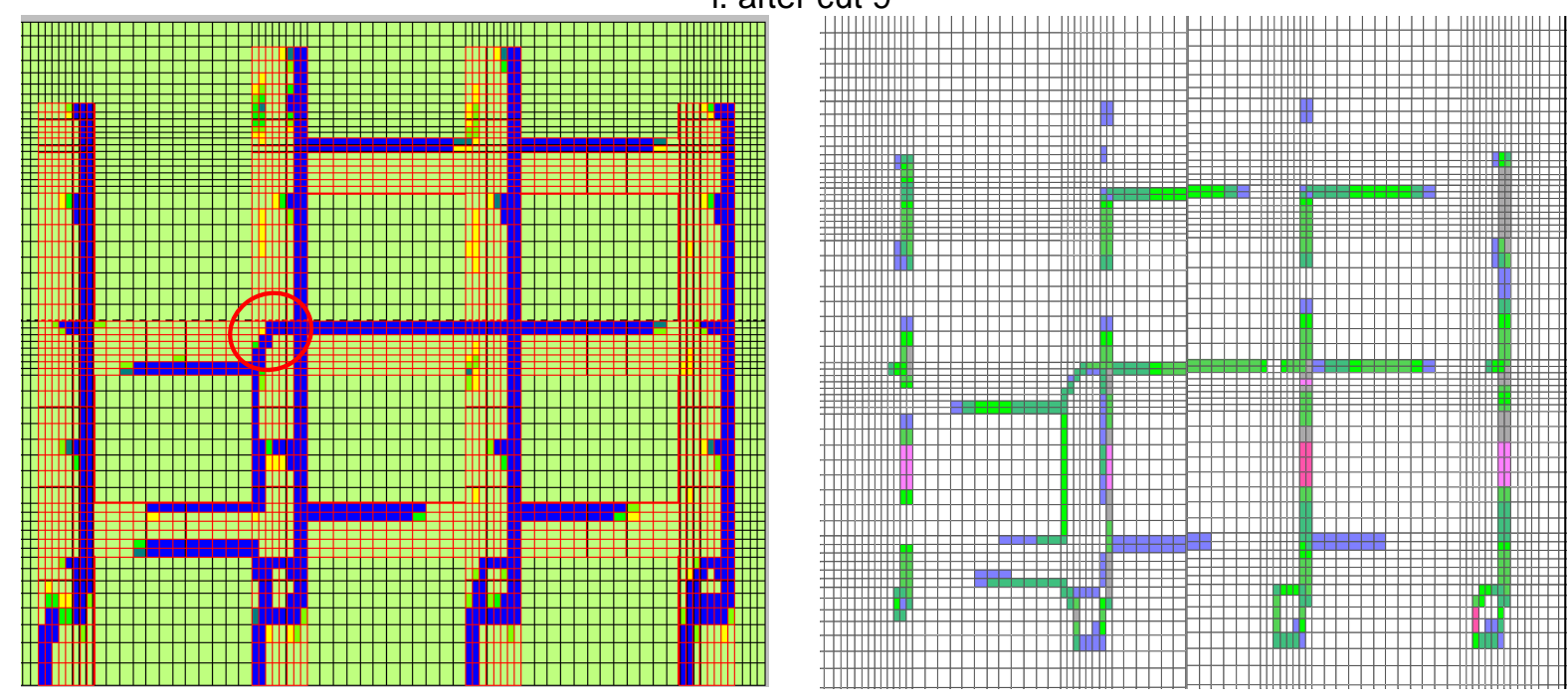

j. after cut 10
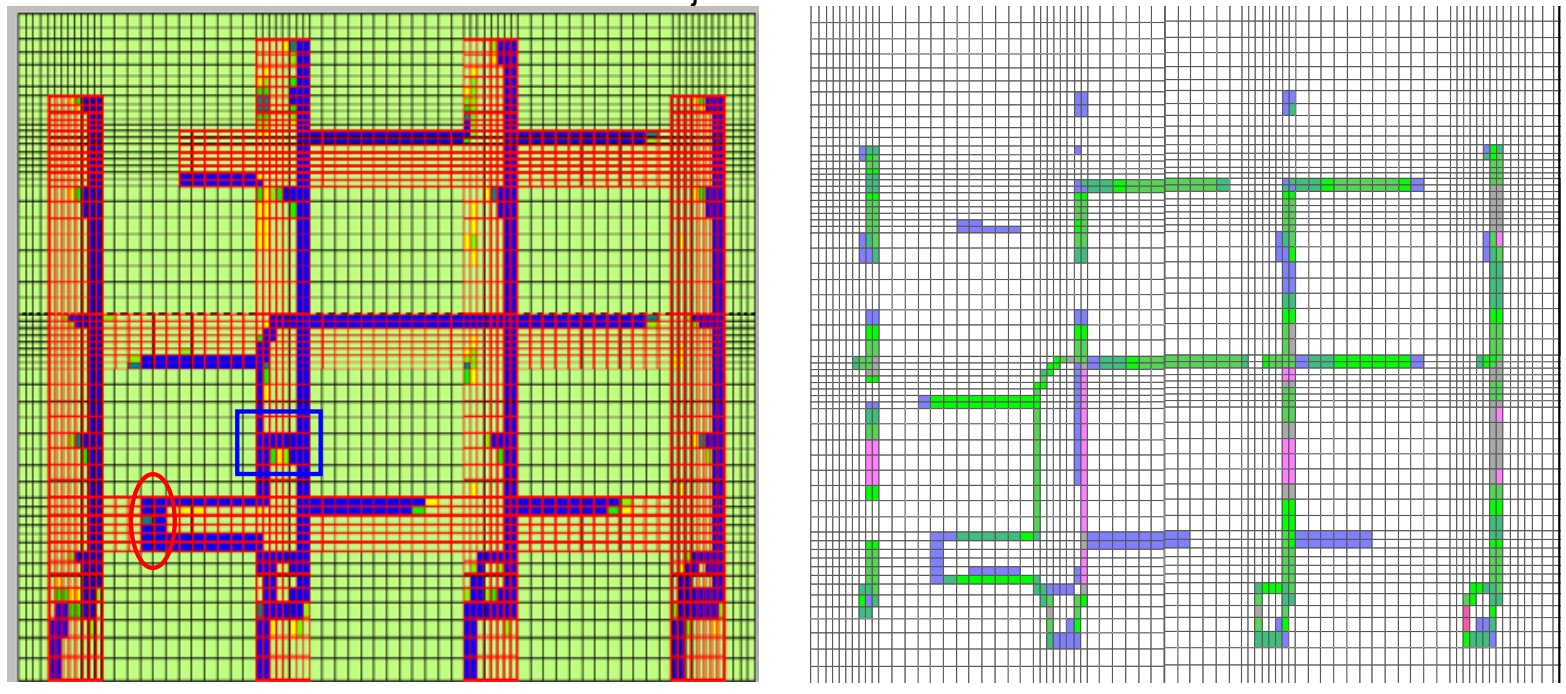

k. after cut 11 

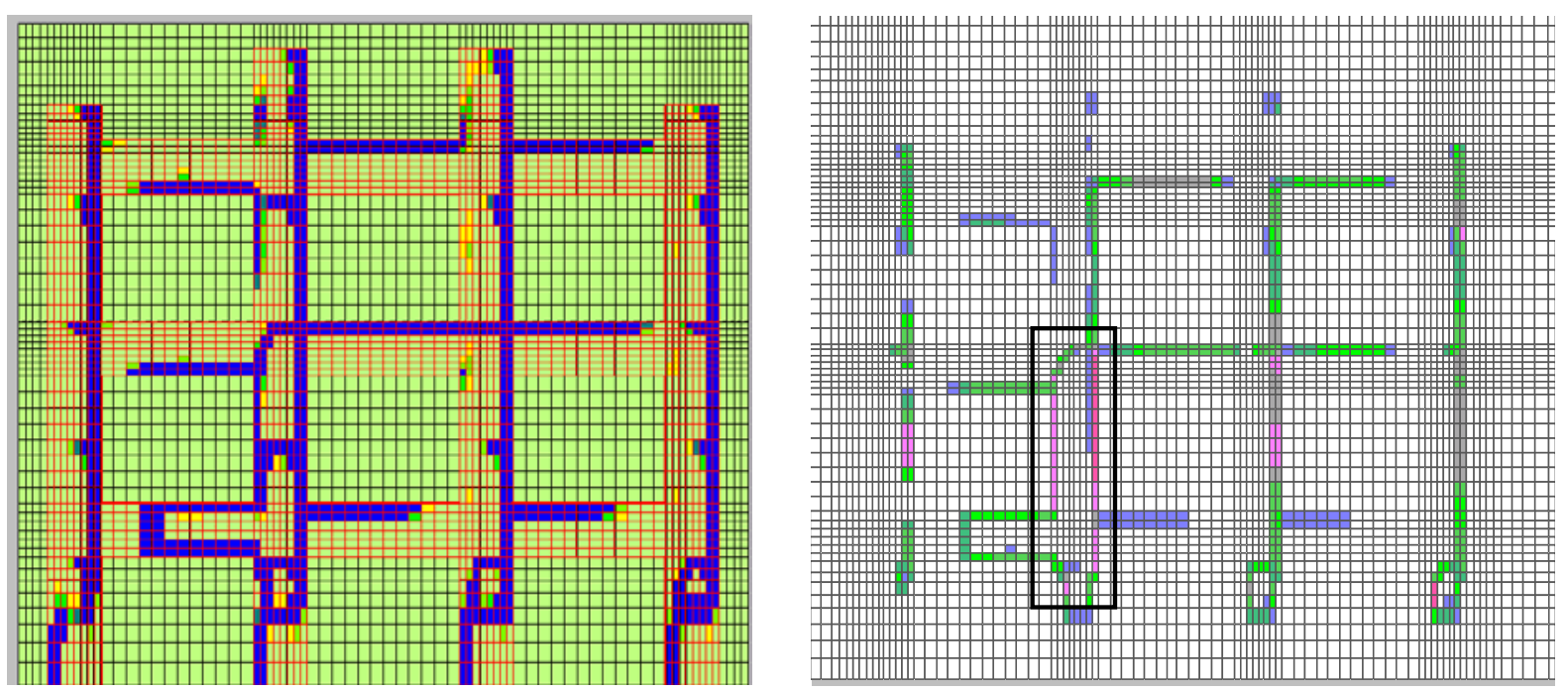

I. after cut 12

Figure 6.26 Development of cutter pattern and shear strain rate step wise during excavation

Following observations can be made from this study in which excavation has been created in several steps-

1. The cutter pattern observed in the beginning is different compare to other cuts and after that it follows a regular pattern during individual cut. This may be due to the boundary conditions.

2. The cutter pattern is not same in all four entries. The pattern is different in side entries 1 and 4 located towards solid barrier and middle entries 2 and 3. The pattern is also different between middle entries 2 and 3. Similar behavior has been observed among crosscuts.

3. The cutter pattern for crosscut between entry 1 and 2 is different in comparison to crosscuts between entries 2 and 4 . This is mainly due to the direction of cutting. This match exactly as expected due to in-situ stress orientation.

4. The cutter pattern in entry 2 and 3 is different. In entry 2 cutters develops towards both edge of the pillar in the roof while in entry 3 it is constrained 
mainly on one side i.e. right edge of the entry. This may be due to either change in cutting direction or smaller pillar width between the crosscuts or combined effect.

5. The cutter crosses the intersection 2E2C obliquely after cut in crosscut 2 and development of cutters at left edge in entry 2 between crosscut 1 and crosscut 2. The cutter crosses and joins the cutter formed at the face position after cut 4 in entry 2 . This pattern was not observed for intersection in entry 3. This phenomenon may take place either due to earlier face position at the intersection or may be influenced by cutting direction.

6. The cutter crosses along the entry width or crosscut width near the face position in previous cuts.

The irregular pattern of cutters observed for the case study mine is again reproduced here to compare the model results observations (Figure 6.27). From the figure it can be seen that cutter pattern is different for different entry and crosscuts as observed from modeling also. From entry 3 , it can be observed that the cutter runs along the opposite direction in the crosscut (a). This may be due to change in cut direction from entry 3 . Same observations have been made from the numerical modeling also. Cutters also cross the intersection along the edge of the pillar in one side of the entry (b). This can be also observed in the model for entry 2 and 3. Cutters also crosses in entry and crosscut from one side to another (c). This is also observed from the modeling results near the face position in a particular cut. In Figure $6.16 a$, many falls can be observed which take place in the entry somewhere away from the intersection. This type of roof fall may be happened due to face stoppage during any cut. As it can be observed from numerical modeling that the 
location where face is positioned in previous cut, the cutters crosses the entry width with passage of next future cuts.

A similar irregular pattern of cutters observed in another mine with almost the same mining conditions as for the previous mine is shown in Figure 6.28. This mine uses the cutting sequence as shown in Figure 6.15. Here also cutters were observed in one and both side of the entry and crosscut.

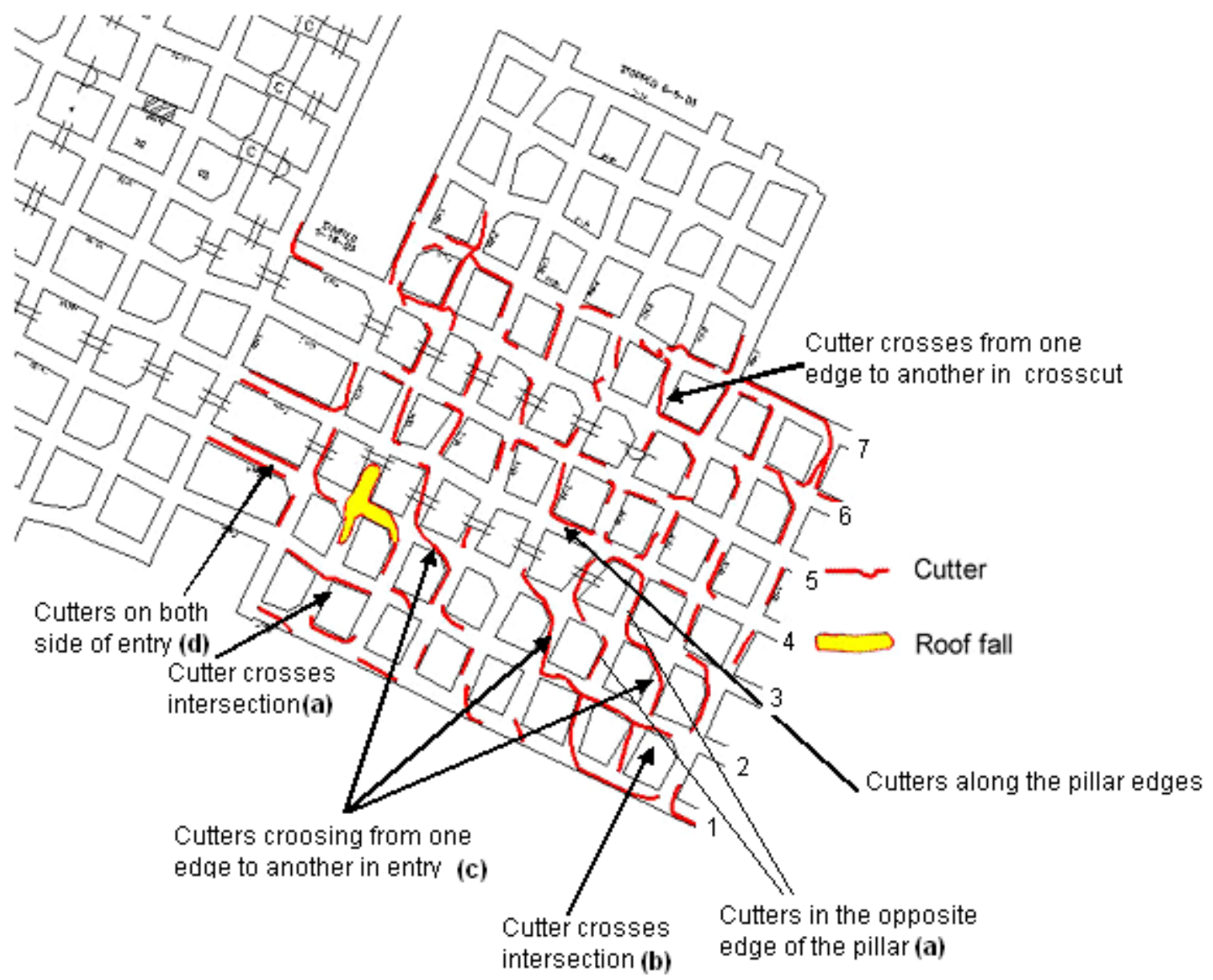

Figure 6.27 Cutter observed at an Illinois mine 


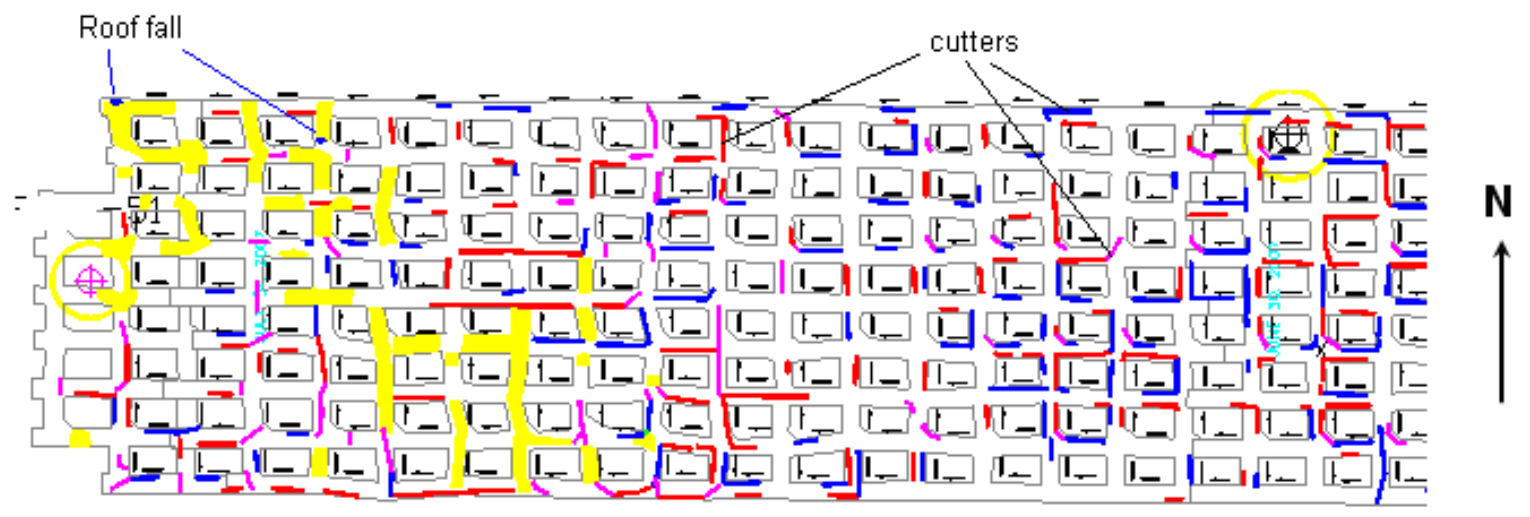

Figure 6.28 Irregular pattern of cutter observed at another Illinois mine using cutting sequence shown in Figure 6.15

Hence it can be said that numerical modeling with strain softening material model and incorporating detail cutting sequence can explain the irregular pattern of cutter observed in the fields. From The modeling results the following factors related to a cutting sequence can be identified which can influence the cutter pattern -

i. Cut length and the face position/location in a particular cut

ii. Cutting sequence (order number of cut)

iii. Cut direction in a sequence (turning a crosscut into and away from major horizontal stress direction)

iv. Step face cutting

Apart from cutting sequence other parameters which may significantly change the cutter pattern are-

i. Immediate roof rock strength/properties

ii. In-situ stress

- Orientation of entry or mine openings with respect to maximum horizontal stress.

- $\quad$ ratio of maximum horizontal to vertical stress, $k$

- ratio of horizontal stresses, I 
- Exceptionally low horizontal stress

iii. change in pillar width/entry width

First the factors mentioned other than cutting sequence parameters will be investigated to study their influence on the cutter pattern. In later sections the cutting sequence parameters will be discussed.

\subsection{EFFECT OF ROOF ROCK STRENGTH AND IN-SITU STRESS RATIO ON CUTTER PATTERN}

\subsubsection{Effect of Strength of the immediate roof and CMRR on cutter pattern}

The model results shown in Figure 6.26 and all others figures so far shown in previous sections, the immediate roof uni-axial compressive strength has been considered as $1580 \mathrm{psi}$. This strength represents really a very weak roof and this may not be the representative strength for entire mine. Table 6.1 shows the variation in the uni-axial compressive strength of the immediate roof rocks and corresponding rock mass cohesion at various part of the mine shown in Figure 6.16. Rock mass cohesion has been estimated as 96 psi for 1,580 psi UCS as per rock mass strength criteria discussed in chapter 5 . The simple unitary method has been used for the estimation of rock mass cohesion for other uni-axial compressive strength values. From Table 6.1, it can be seen that the UCS of immediate roof varies from 1,600 to 3,900 psi which is 2.5 time more stronger than the weakest immediate roof rock. Further, it is well proved and observed in the mines that due to passage of time and weathering effect the rock mass losses its strength, depending upon site specific constraints (Molinda and Klemetti, 2008). Table 6.1 shows the strength of the immediate roof rocks losing $70 \%$ of their peak strength. This strength has been considered to observe the development of cutter with reduction in its peak strength due to the time effect. Further about this will be discussed in the 'chapter 8'. 
To investigate the effect of variation in strength of immediate roof on cutter development, the following 4-entry models with cut sequence shown in Figure 6.22c were solved with the same in-situ stress and cohesion and friction mobilization as used in earlier models-

- Model 1- peak cohesion 110 psi (1.15 times of weakest roof cohesion)

- Model 2- peak cohesion 125 psi (1.30 times of weakest roof cohesion)

- Model 3- peak cohesion 140 psi (1.45 times of weakest roof cohesion)

- Model 4- peak cohesion 160 psi (1.67 times of weakest roof cohesion)

- Model 5- peak cohesion 200 psi (2.08 times of weakest roof cohesion)

Table 6.1 Variation in uni-axial compressive strength of immediate roof at the mine

\begin{tabular}{|c|c|cc|c|c|c|}
\hline $\begin{array}{c}\text { Borehole } \\
\text { Number }\end{array}$ & $\begin{array}{c}\text { Uni-axial } \\
\text { compressive } \\
\text { strength } \\
\text { (Lab tested } \\
\text { value), psi }\end{array}$ & $\begin{array}{c}\text { Young's } \\
\text { modulus, } \\
\times 10^{6}\end{array}$ & $\begin{array}{c}\text { Peak rock } \\
\text { mass } \\
\text { cohesion, } \\
\text { psi }\end{array}$ & $\begin{array}{c}70 \% \text { of } \\
\text { peak } \\
\text { cohesion, } \\
\text { psi }\end{array}$ & $\begin{array}{c}\text { Ratio of } \\
\text { peak } \\
\text { cohesion/ } \\
\text { Weakest } \\
\text { rock } \\
\text { cohesion }\end{array}$ & $\begin{array}{c}\text { Ratio of 70\% of } \\
\text { peak } \\
\text { cohesion/Weakest } \\
\text { rock peak } \\
\text { cohesion }\end{array}$ \\
\hline $16 \mathrm{M} 1$ & $1580^{*}$ & 0.16 & $96^{*}$ & 67 & 1.00 & 0.70 \\
\hline 16 I1 & 1694 & 0.198 & 97 & 68 & 1.01 & 0.71 \\
\hline $15 \mathrm{~F} 9$ & 2336 & 0.172 & 98 & 69 & 1.02 & 0.71 \\
\hline $16 \mathrm{~N} 12$ & 2408 & 0.231 & 146 & 102 & 1.52 & 1.03 \\
\hline $16 \mathrm{M} 1$ & 2654 & 0.309 & 161 & 113 & 1.68 & 1.07 \\
\hline $15 \mathrm{~K} 1$ & 2814 & 0.239 & 171 & 120 & 1.78 & 1.18 \\
\hline $16 \mathrm{~N} 12$ & 2891 & 0.239 & 176 & 123 & 1.83 & 1.28 \\
\hline $16 \mathrm{E} 13$ & 2895 & 0.296 & 176 & 123 & 1.83 & 1.28 \\
\hline $11 \mathrm{C} 13$ & 2910 & 0.747 & 177 & 124 & 1.84 & 1.29 \\
\hline $11 \mathrm{~B} 15$ & 2967 & 0.483 & 180 & 126 & 1.88 & 1.31 \\
\hline $15 \mathrm{E} 5$ & 3393 & 0.335 & 206 & 144 & 2.15 & 1.50 \\
\hline $16 \mathrm{M} 6$ & 3932 & 0.424 & 239 & 167 & 2.49 & 1.74 \\
\hline
\end{tabular}

*- the base UCS for the weakest rock for which rock mass cohesion is $96 \mathrm{psi}$

Figure6.29 show the cohesion distribution in the immediate roof for immediate roof peak cohesion strength of 110, 125, 140, 160 and 200 psi. From cohesion distribution pattern, it can be viewed that the cutter pattern is significantly influenced 
at every part of the excavation by the increase in strength of rock mass. After $15 \%$ increase in the strength, the change in cutter pattern has been observed near the face and in first crosscut (Figure 6.29b).

When strength is increased by $25 \%$ -

- no cutter is formed near the face,

- cutters are restricted to one side of the entry only and at many places in the entry cutter disappears.

- no cutters turning across the intersection from one side to another.

- cutters are crossing in crosscuts and entry from one side to another near the face position.

When strength is increased by $45 \%$, the cutter further reduces in entries and at intersections. For an increase in strength of $67 \%$, no cutters observed in the entries (Figure 6.29e). Cutters are restricted to one side of the entry irrespective of the cutting sequence. It also doesn't have any influence of cutting direction. This pattern looks like similar as expected from the past studies. Since the entry is oriented at $30^{\circ}\left(\theta=60^{\circ}\right)$ from the direction of major horizontal stress, it is expected that entry will be more stable (Gadde 2003). With further increase in strength of immediate roof rock by $100 \%$, no cutters are observed either in entries or crosscuts (Figure 6.29f). But with the passage of time due to time dependency of roof rock, the strength can be degraded and it can show cutter or roof falls.

Hence with these observations it can be concluded that strength of the immediate roof rock can significantly affect the cutter pattern observed in the mine. The irregular pattern is mainly due to the low strength of immediate roof rock and it will gradually disappear as the strength will increase. 

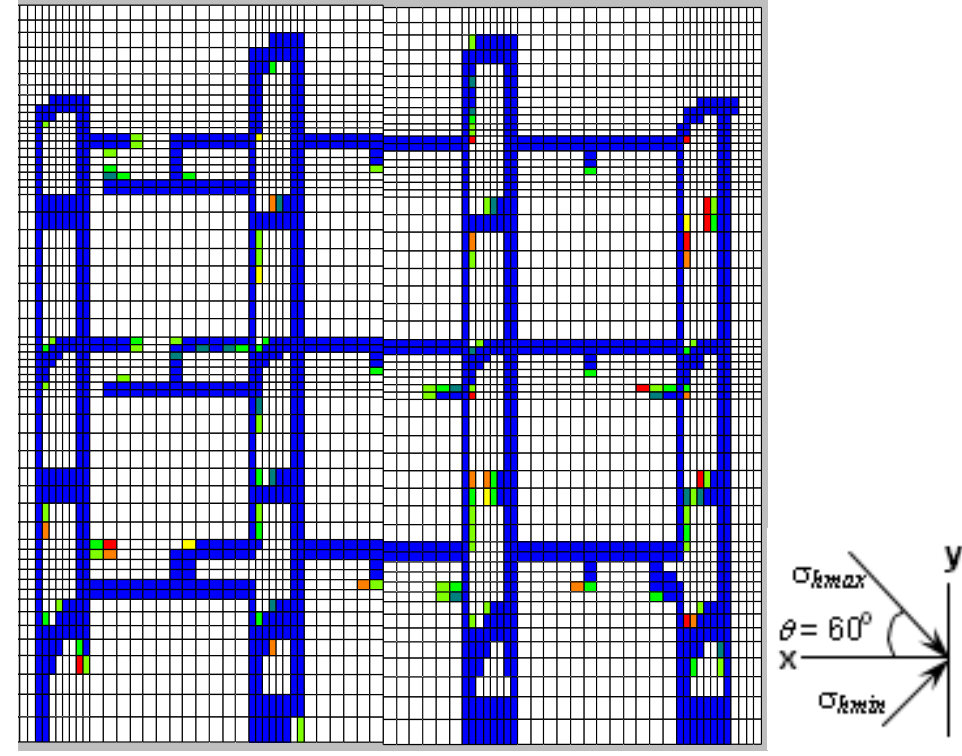

Cohesion, psi

a. Lowest peak cohesion, $\mathrm{C}_{\text {lowest }}=96 \mathrm{psi}$
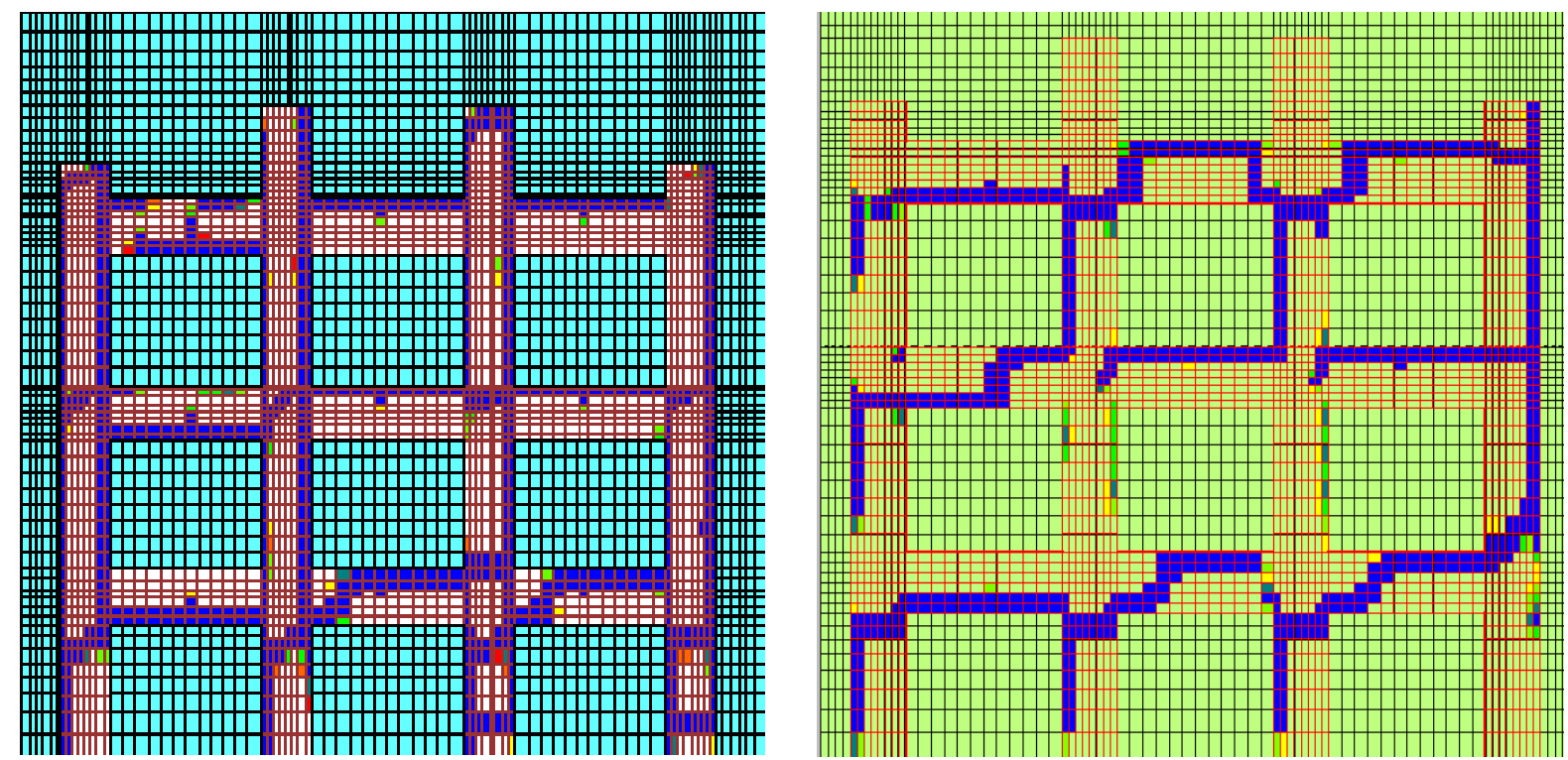

b. Peak cohesion 110 psi (1.15 $\left.\mathrm{C}_{\text {lowest }}\right)$

c. Peak cohesion 125 psi $\left(1.30 \mathrm{C}_{\text {lowest }}\right)$ 


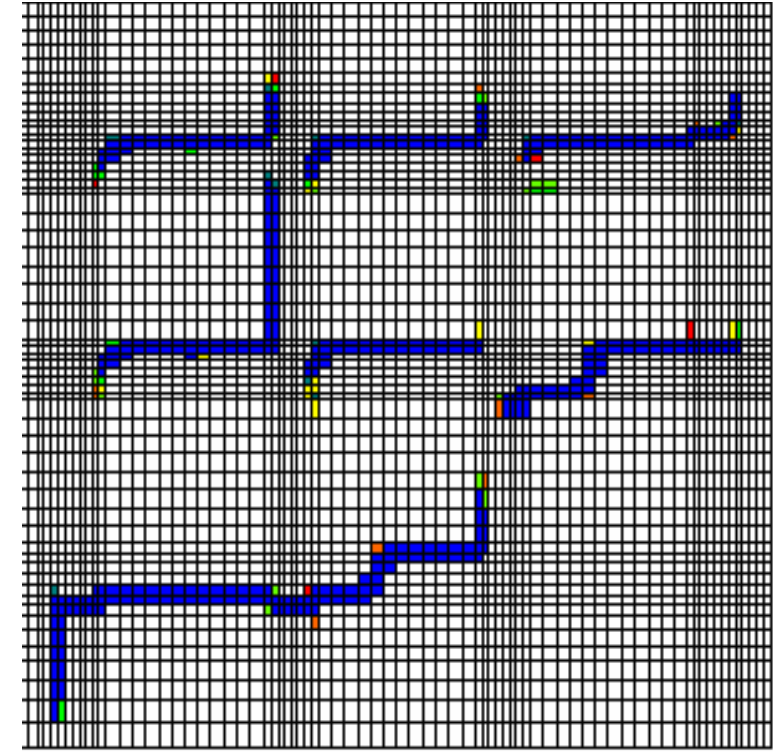

d.Peak cohesion 140 psi (1.47 $\left.\mathrm{C}_{\text {lowest }}\right)$

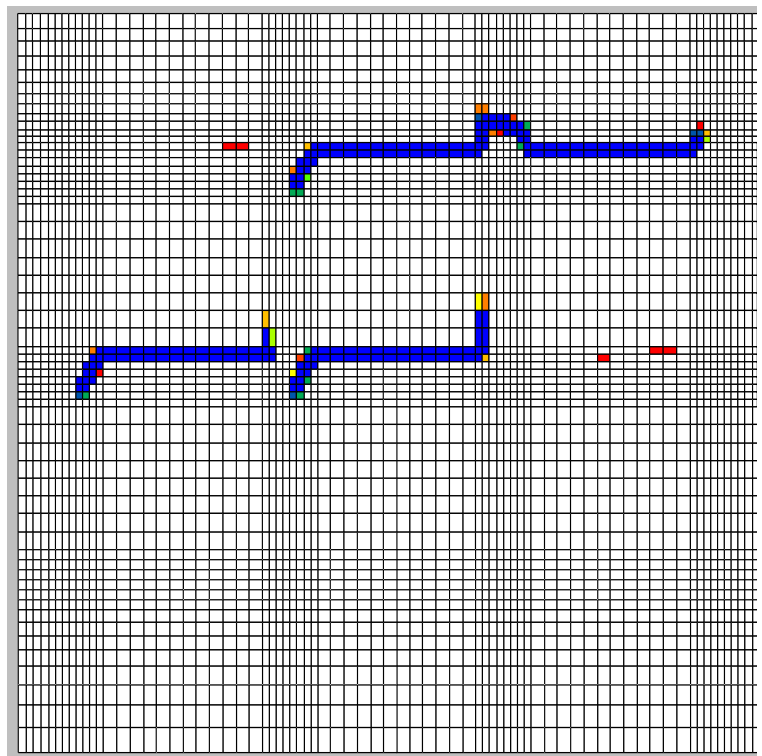

e. Peak cohesion 160 psi (1.67 $\left.\mathrm{C}_{\text {lowest }}\right)$

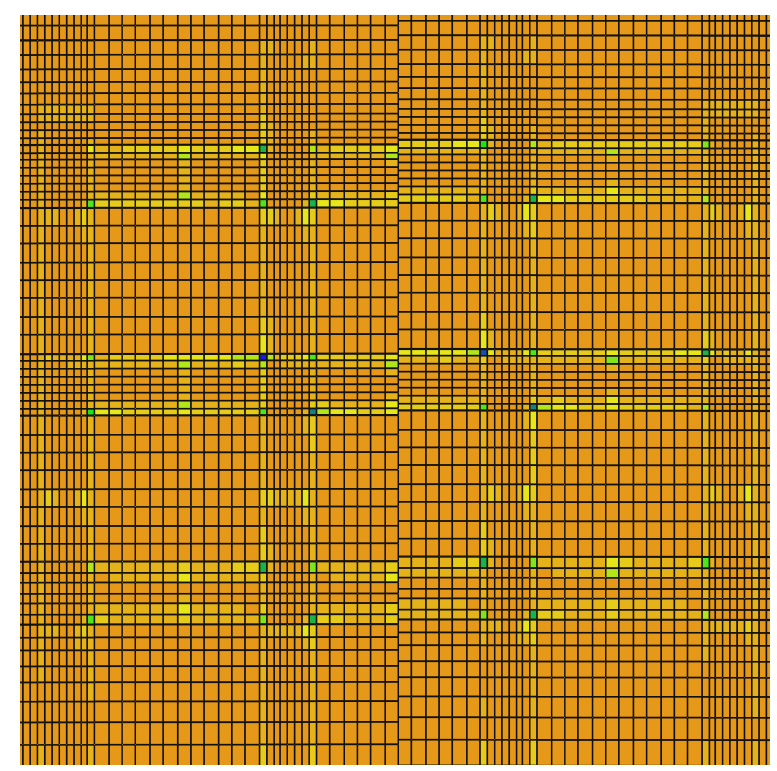

f. Peak cohesion 200 psi $\left(2.08 C_{\text {lowest }}\right)$

Figure 6.29 Effect of increase in strength of immediate roof rock on cutter pattern

\subsubsection{Correlation of Rock mass cohesion with CMRR}

In the USA Coal Mines Roof Rating (CMRR) is extensively used for many mine design purposes. Its represents the qualitative behavior of immediate roof rocks. CMRR less than 45 is termed as weak roof, between $45-65$ as moderate roof and above 65 is treated as strong roof (Molinda and Mark, 1994). CMRR has been 
correlated with gateroad pillar design (ALPS), primary support rating, intersection span, bolt design etc. CMRR is readily available data these days, since in mine CMRR is often estimated at various parts of the working section. But to conduct numerical modeling CMRR can not be used directly as input to define the rock mass properties. Here a simple attempt is made to correlate the CMRR with rock cohesion although it is not so simple affair.

Karl zipf (2005) has made some assumptions related to the rock properties to be used for numerical modeling as inputs. He has divided soils (soil_1 to soil_4), rock (Rock_A to Rock_J) and coal (coal_1 to coal_4) in many types and based on types he assigned the range of rock properties like uni-axial strength, cohesion, friction, young's modulus and CMRR. Soil_1, Rock_A and Coal_1 represent the weak type while Soil_5, Rock_J and Coal_5 are representative for strong type. Based on cohesion and CMRR properties assigned for the rock types, a correlation has been estimated between CMRR and laboratory tested rock cohesion (Figure 6.30).

Cohesion, MPa = 10.906 LN (CMRR) -35.173

Table 6.2 shows the estimated values of rock mass cohesion to be used for the modeling input for different CMRR. From Table 6.1, at case study mine the rock mass cohesion for a CMRR value of 30 to 40 varies from 96 to 180 psi. From regression equation the rock mass cohesion comes to 159 psi corresponding to CMRR of 40 , i.e., $10 \%$ variation with actual values. This much variation can be acceptable. Consequently the model solved for different cohesion strength can be also represented in terms of CMRR. 


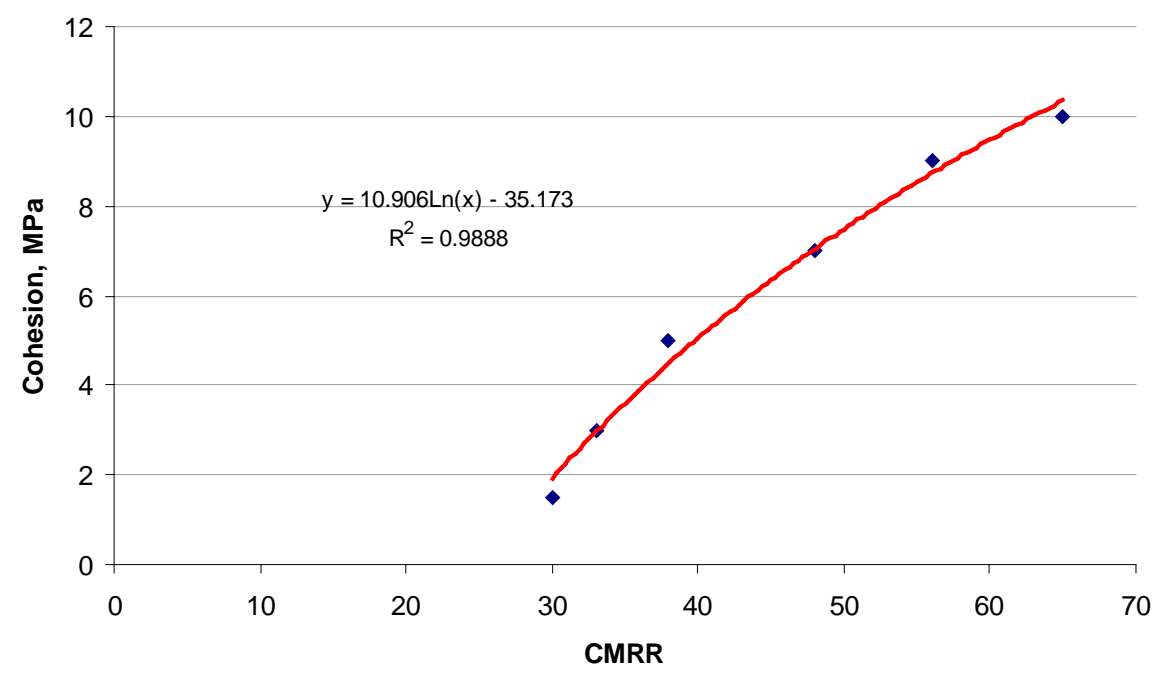

Figure 6.30 Correlation of CMMR with Cohesion (laboratory tested value)

Table 6.2 Rock mass cohesion estimated from CMRR

\begin{tabular}{|c|c|c|c|c|}
\hline CMRR & $\begin{array}{c}\text { Estimated } \\
\text { Lab value } \\
\text { from } \\
\text { Equation } \\
6.1, \mathrm{MPa}\end{array}$ & $\begin{array}{c}\text { Rock } \\
\text { Mass } \\
\text { cohesion, } \\
\text { MPa }\end{array}$ & $\begin{array}{c}\text { Peak rock } \\
\text { mass } \\
\text { cohesion, } \\
\text { psi }\end{array}$ & $\begin{array}{c}70 \% \text { of } \\
\text { peak } \\
\text { cohesion }\end{array}$ \\
\hline 30 & 1.92 & 0.40 & 58 & 41 \\
\hline 35 & 3.60 & 0.75 & 109 & 76 \\
\hline 40 & 5.06 & 1.05 & 153 & 107 \\
\hline 45 & 6.34 & 1.32 & 192 & 134 \\
\hline 50 & 7.49 & 1.56 & 226 & 158 \\
\hline 55 & 8.53 & 1.78 & 258 & 180 \\
\hline 60 & 9.48 & 1.97 & 286 & 200 \\
\hline
\end{tabular}

For the case study mine, the CMRR varies from 30 to 40 which correspond to a maximum value of peak cohesion of 153 psi. From modeling, for peak cohesion of 160 psi (CMRR 40, Figure 6.29 e), cutters are restricted to one side only but cutter pattern shows irregular pattern for peak cohesion of 110 psi (CMRR 35, Figure 6.29b). For peak cohesion of 200 psi (CMRR 45, Figure 6.29f) no immediate cutter is visible but with the time dependency it can behave like any pattern shown for CMRR 35 to 45 depending upon the strength degradation.

Hence roof having CMRR up to 45 cutters may be formed very soon while CMRR above 45 will show significant time dependency subjected to local stress 
conditions and other variable mining parameters. These observations may be valid for shallow depth of working only. Thus for this work extremely weak roof means CMRR less than 35 as for the most of the models the peak cohesion has been used as 96 psi. So a rock can be termed extremely weak if it has CMRR less than 35 and uniaxial compressive strength less than 1800 psi.

At higher depth of working, immediate roof having CMRR 45 or more may behave like roof having CMRR 30 to 35 at shallow depth. With increase in depth the vertical stress and horizontal stress will increase which will enhance the induced principal stresses. The higher induced stresses can cause failure of even stiffer roof which is enough stable at shallower depth of working. Figure 6.31 shows the cohesion distribution in the immediate roof layer for an overburden depth of $600 \mathrm{ft}$ with cohesion value of 250 psi (CMRR 55) keeping all other parameters same. Thus relative magnitude of in-situ horizontal stresses, vertical stress as compared to the strength of the immediate roof may be responsible for the severity and spatial distribution of cutters.

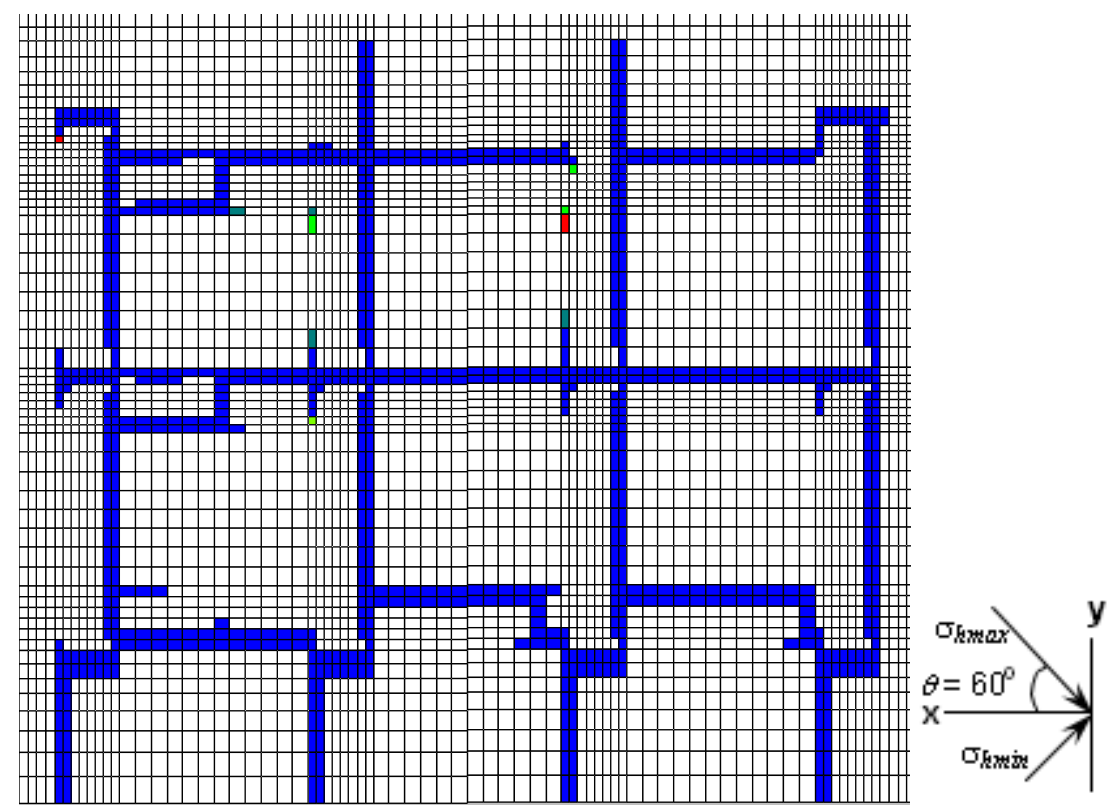

Figure 6.31 Cohesion distributions for peak cohesion of $250 \mathrm{psi}$ (CMRR 55) at depth $600 \mathrm{ft}$ 


\subsubsection{Effect of Supporting}

In the mine after every cut, the freshly exposed roof is properly supported mainly with roof bolts before advancing of the next cut. It can be believed that roof bolts make the immediate roof little bit stiffer irrespective of its working principle of beam formation/ suspension. To understand the effect of increase in roof strength due to supports installed out by, the peak cohesion and friction is increased by 5 to $10 \%$ in supported area. In unsupported areas the properties are kept same. The model are solved as follows-

I. A single cut or group of cuts are made

II. Model is solved with original rock properties

III. After solving, the cohesion and friction is enhanced by 10 or $15 \%$ in zones where cuts were made in step I.

IV. Again next cut is made and model is solved.

Figure 6.32 shows the zero cohesion distribution (cutter pattern) after increasing the cohesion and friction by 5 and $10 \%$ to the original values in supported area. There is significant change in the cutter pattern and amount of zones involved in comparison to Figure 6.7. The cutters are restricted to mostly in one side of the entry and in crosscuts cutters are initiated near the face position in previous cuts. No cutters were observed near the present position of the face (red rectangle). At intersection cutters are still there in a direction almost near to the direction of minimum horizontal stress. So from these models it can be concluded that the models solved without incorporating roof bolting/support may lead to overestimation of cutter formation. But since it is assumed that rocks shows time dependency, i.e., its strength decreases with time, the above models may be valid but after what time interval it can't be figured. 


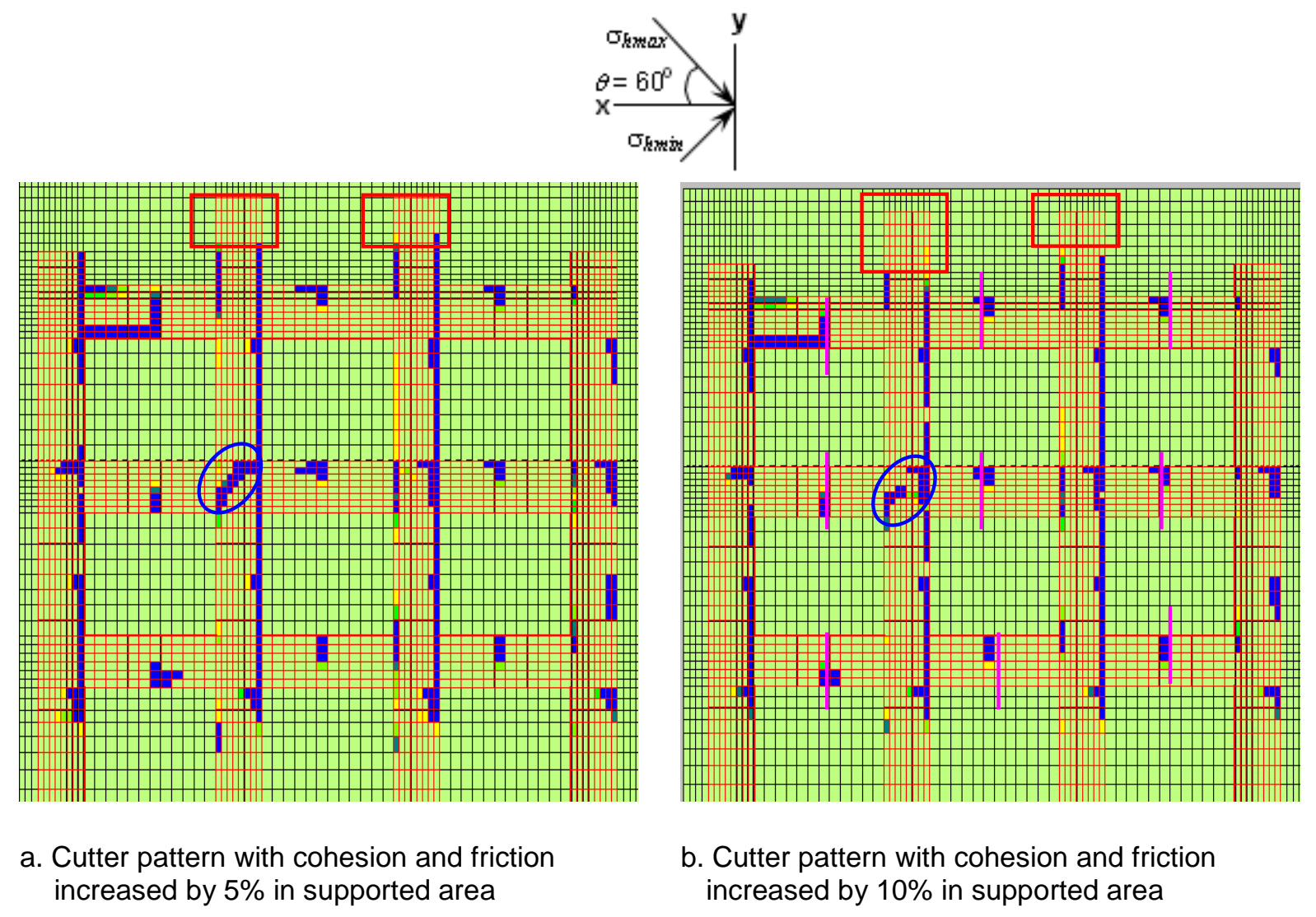

Figure 6.32 Cutter pattern with cohesion and friction increased in supported area

\subsubsection{Irregular pattern of Cutter}

As it has been seen in the field that cutter/roof fall shows very irregular spatial distribution in a mine's mains system or in the panel. Further it has been also observed that there is a wide variation in rock properties and lithology even in a same panel (Table 6.1). This model is intended to understand the effect of change in material properties from one part of a panel to the next. The immediate roof rock properties are changed from one part to another. The cohesion values used in both parts are $c_{1}=96$ psi and $c_{2}=125$ psi. Keeping all other parameters (in-situ stresses magnitude and orientation, pillar and entry dimension) unchanged the two models were solved -

Model I : lower part of panel has comparatively stronger roof 
Model II : upper part of panel has comparatively stronger roof

The models result are shown in Figure $6.33 \mathrm{a}$ and $\mathrm{b}$. The change in cutter pattern at intersection (red circle) and crosscuts (red rectangle) and near the face (cyan ellipse) can be seen for both the models. Hence the change in the strength of the rock is also one of the important factors showing irregular pattern of cutter distribution apart from cutting sequence.

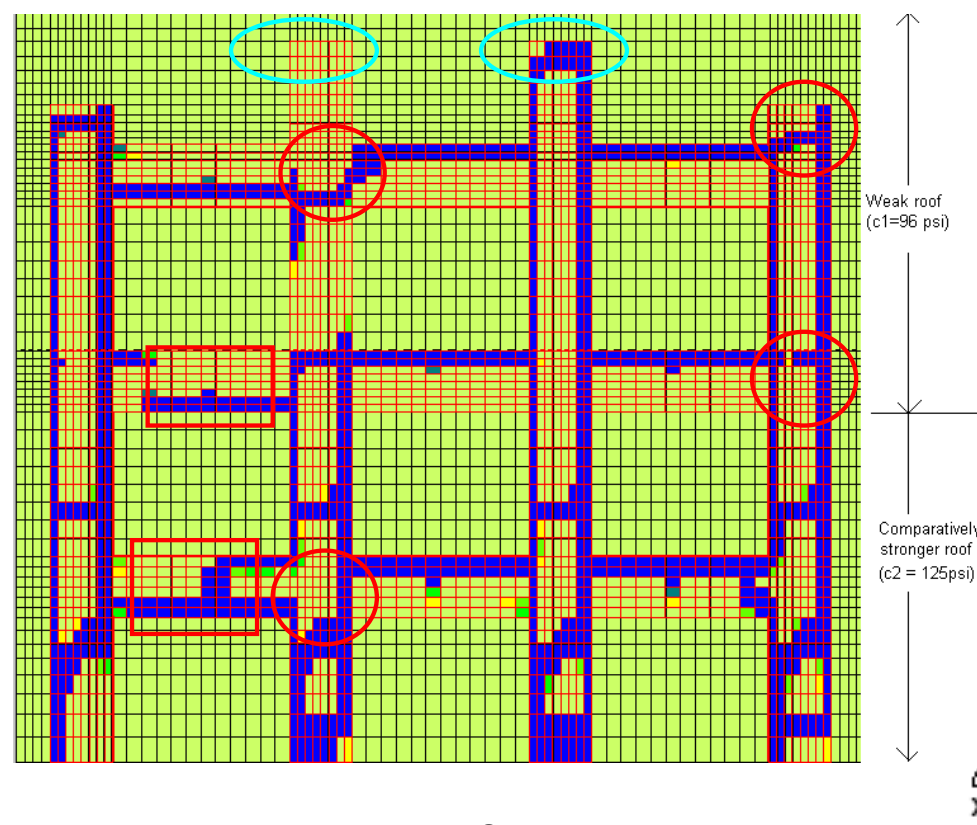

a.
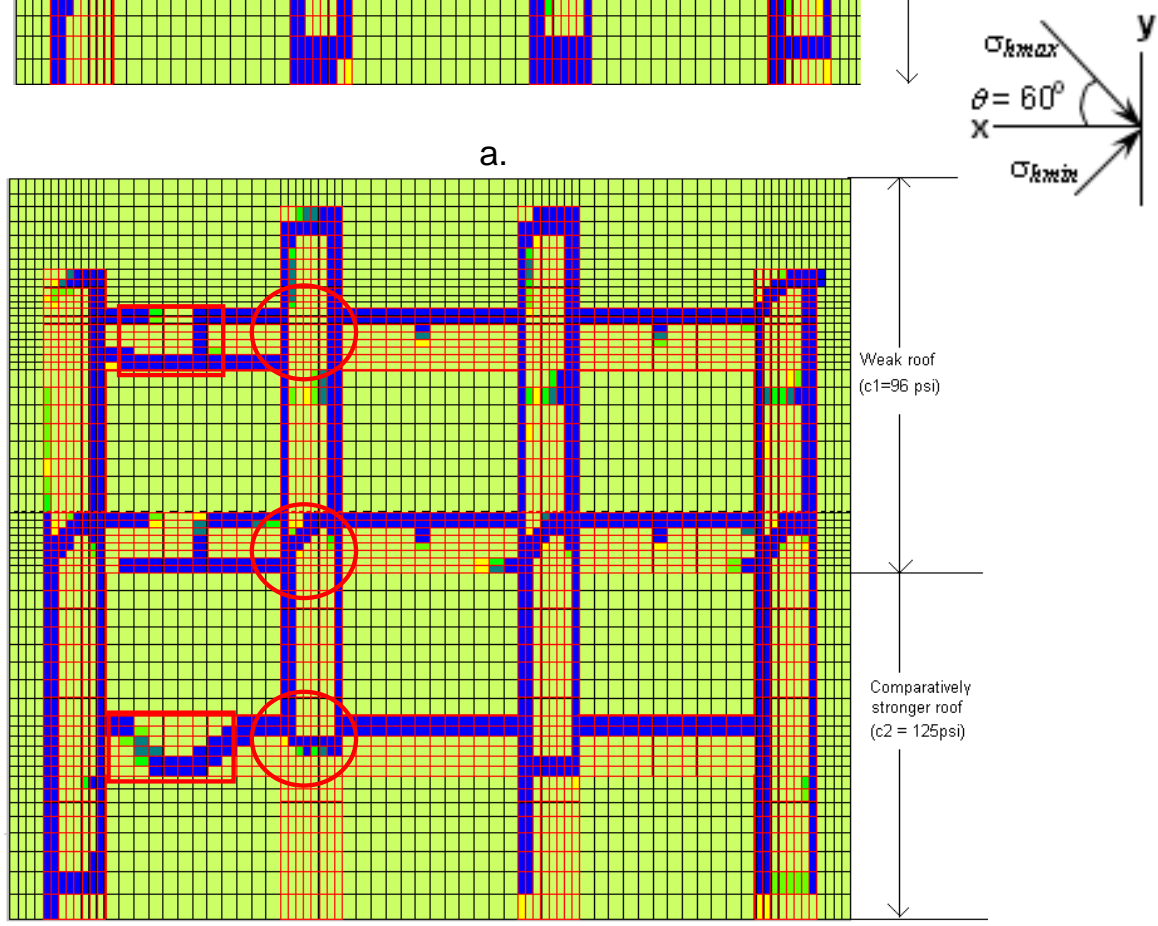

b.

Figure 6.33 Cutter pattern with different material properties in the panel 


\subsubsection{Effect of In-situ Stress Orientation}

A lot of works has been done in the past on the issues of in-situ maximum horizontal stress angle and their effects on mine openings stability. These works includes observational approach as well as some form of analysis methods like -numerical- or analytical. Almost every researcher found that entry will be most stable when maximum horizontal stress is aligned along the entry length. The mine opening will be most unstable when it is oriented in a direction perpendicular to the maximum horizontal stress (Table 6.3). These findings were in accordance with each other irrespective of consideration of different material model (elastic or plastic) and model geometry and in-situ stress condition. Further these studies were restricted to mainly moderate strong to strong roof. To investigate the effect of in-situ stress orientation on mine openings stability for very weak roof, various models were solved incorporating cutting sequences for a fixed in-situ stress ratio for single, 3-entry and 4-entry system.

The cohesion distributions for single entry model are shown in Figure 6.2 whereas same for 3 and 4 entries systems are shown in Figure 6.34 and 6.35 respectively. From all these figures it can be seen that difference in situ stresses orientations changes the cutter patterns at the intersection, entries and crosscuts. Near the face area in the middle entry for 3 entry system, for $\theta=30^{\circ}$, cutters were restricted to a single corner as opposed to two sides for $\theta=60^{\circ}$ (Figure $6.34 \mathrm{~b}, \mathrm{c}$ ). Cutters running across an opening generally near the face position and it may not be necessarily in the direction of minimum horizontal stress as observed from the model results. The angle of cutters running across an opening change with $\theta$ (Figure 6.35 c, d, e) and some of them are oriented nearly in the direction of in situ minimum horizontal stress as for $\theta=60^{\circ}$ (Figures 6.34c and 6.35 e). For same orientation for 
relatively stronger roof, this phenomenon of crossing of cutter disappears near the face (Figure $6.29 \mathrm{e}, \mathrm{f}$ ). In terms of stability of mine openings, it can be observed that under extremely weak roof conditions, changing the orientation of a mine layout may not be always effective as in the case of stronger roof. The cutters are always observed in the mine layout for any orientations but with some change in pattern. Hence the orientation effect is not as significant as it has been felt by past researchers for moderate stronger roof. This can be further verified from the field observations of roof falls which occurred in all direction of the mine openings (Figure 6.18).

Hence changing the orientation of a mine layout to reduce ' $\theta$ ' with respect to direction of major horizontal stress may not always provide improved stability. The actual change or gain in the stability is dependent on the site specific geo-mining conditions, which must be considered for best strategy applicable to that site. 
Table 6.3 Summary of past work on in-situ stress orientation

\begin{tabular}{|c|c|c|c|c|c|c|c|c|c|c|c|}
\hline \multirow[t]{2}{*}{ Researchers } & \multirow{2}{*}{$\begin{array}{l}\text { Numerical } \\
\text { Modeling } \\
\text { program/ } \\
\text { software }\end{array}$} & \multirow[t]{2}{*}{$\begin{array}{l}\text { Material } \\
\text { model }\end{array}$} & \multirow[t]{2}{*}{ Geometry } & \multirow[t]{2}{*}{ Lithology } & \multirow[t]{2}{*}{ k- ratio } & \multirow[t]{2}{*}{ I-ratio } & \multirow[t]{2}{*}{$\begin{array}{l}\text { Locations } \\
\text { of analysis }\end{array}$} & \multicolumn{2}{|c|}{$\begin{array}{c}\text { Orientation } \Theta^{*} \text { for stable } \\
\text { case }\end{array}$} & \multicolumn{2}{|c|}{$\begin{array}{l}\text { Orientation } \Theta^{*} \text { for worst } \\
\text { case }\end{array}$} \\
\hline & & & & & & & & Entry & Crosscut & Entry & crosscut \\
\hline $\begin{array}{c}\text { Galle and } \\
\text { Blackwood, } \\
1987\end{array}$ & $\begin{array}{l}\text { 3D-Boundary } \\
\text { element method }\end{array}$ & Elastic & $\begin{array}{l}\text { single } \\
\text { entry }\end{array}$ & $\begin{array}{l}\text { same } \\
\text { immediate } \\
\text { roof }\end{array}$ & constant & constant & $\begin{array}{l}\text { immediate } \\
\text { roof }\end{array}$ & $\Theta=0^{\circ}$ & -- & $\theta=90^{\circ}$ & -- \\
\hline $\begin{array}{c}\text { Wang and } \\
\text { Stankus, } 1998\end{array}$ & $\begin{array}{l}\text { 3D-finite element } \\
\text { method }\end{array}$ & Elastic & $\begin{array}{l}3 \text { entries } \\
\text { and } 2 \\
\text { crosscuts }\end{array}$ & $\begin{array}{l}\text { same } \\
\text { immediate } \\
\text { roof }\end{array}$ & constant & constant & $\begin{array}{l}\text { immediate } \\
\text { roof }\end{array}$ & $\Theta=0^{\circ}$ & $\theta=90^{\circ}$ & $\theta=70^{\circ}$ & $\theta=0$ to $45^{\circ}$ \\
\hline $\begin{array}{l}\text { Meyre et al., } \\
\text { 1999, } 2001\end{array}$ & $\begin{array}{l}\text { 3d Finite difference } \\
\text { Method (FLAC3D) }\end{array}$ & $\begin{array}{l}\text { Elastic/ } \\
\text { Perfectly } \\
\text { plastic }\end{array}$ & $\begin{array}{l}\text { single } \\
\text { entry }\end{array}$ & $\begin{array}{c}\text { same } \\
\text { immediate } \\
\text { roof }\end{array}$ & constant & constant & $\begin{array}{l}\text { immediate } \\
\text { roof }\end{array}$ & $\Theta=0^{\circ}$ & -- & $\Theta=90^{\circ}$ & - \\
\hline Chen, 1999 & $\begin{array}{l}\text { 3D-finite element } \\
\text { method }\end{array}$ & Elastic & $\begin{array}{l}3 \text { entries } \\
\text { and } 2 \\
\text { crosscuts }\end{array}$ & $\begin{array}{l}\text { same } \\
\text { immediate } \\
\text { roof }\end{array}$ & variable & variable & $\begin{array}{l}\text { immediate } \\
\text { roof }\end{array}$ & $\Theta=0^{\circ}$ & $\theta=0^{\circ}$ & $\Theta=60$ to $75^{\circ}$ & $\begin{array}{c}\Theta=75 \text { to } \\
90^{\circ}\end{array}$ \\
\hline Gadde, 2003 & $\begin{array}{l}\text { 3D-finite element } \\
\text { method (ABAQUS) }\end{array}$ & Elastic & $\begin{array}{l}\text { single } \\
\text { entry and } \\
\text { crosscut }\end{array}$ & $\begin{array}{l}\text { Different } \\
\text { strata in } \\
\text { roof }\end{array}$ & variable & variable & $\begin{array}{l}\text { immediate } \\
\text { and main } \\
\text { roof up to a } \\
\text { height equal } \\
\text { to entry } \\
\text { width } \\
\end{array}$ & $\begin{array}{c}\Theta=90^{\circ}(k< \\
\text { 1) } \Theta=0^{\circ} \\
(k>1)\end{array}$ & $\begin{array}{c}\Theta=90^{\circ}(k< \\
1) \Theta=0^{\circ} \\
(k>1)\end{array}$ & $\begin{array}{c}\Theta=0^{\circ}(k<1) \\
\Theta=90^{\circ} \\
(k>1)\end{array}$ & $\Theta=45^{\circ}$ \\
\hline $\begin{array}{l}\text { Morsey and } \\
\text { Peng, } 2005\end{array}$ & $\begin{array}{l}\text { 3D-finite element } \\
\text { method (ABAQUS) }\end{array}$ & Plastic & $\begin{array}{l}\text { Longwall } \\
\text { gateroad }\end{array}$ & $\begin{array}{l}\text { same } \\
\text { immediate } \\
\text { roof }\end{array}$ & constant & constant & $\begin{array}{l}\text { immediate } \\
\text { and main } \\
\text { roof }\end{array}$ & $\Theta=0^{\circ}$ & -- & $\theta=90^{\circ}$ & -- \\
\hline
\end{tabular}

Note $\Theta^{*}$ - angle is measure from the entry driavge direction 
Cohesion, psi

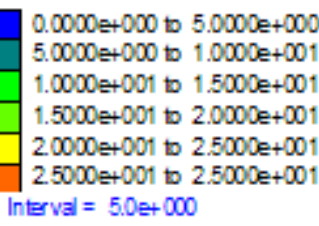

$0.0000 \mathrm{e}+000$ to $5.0000 \mathrm{e}+000$ $5.0000 \mathrm{e}+000$ to $1.0000 \mathrm{e}+001$

$10000=001$ to $1.5000 e+001$

$1.5000 \mathrm{e}+001$ to $2.0000 \mathrm{e}+001$

$2.0000 \mathrm{e}+001$ to $2.5000 \mathrm{e}+001$

2.5000 e+ 001 to $2.5000 \mathrm{e}+00$. Interval $=5.0 \mathrm{e}+000$

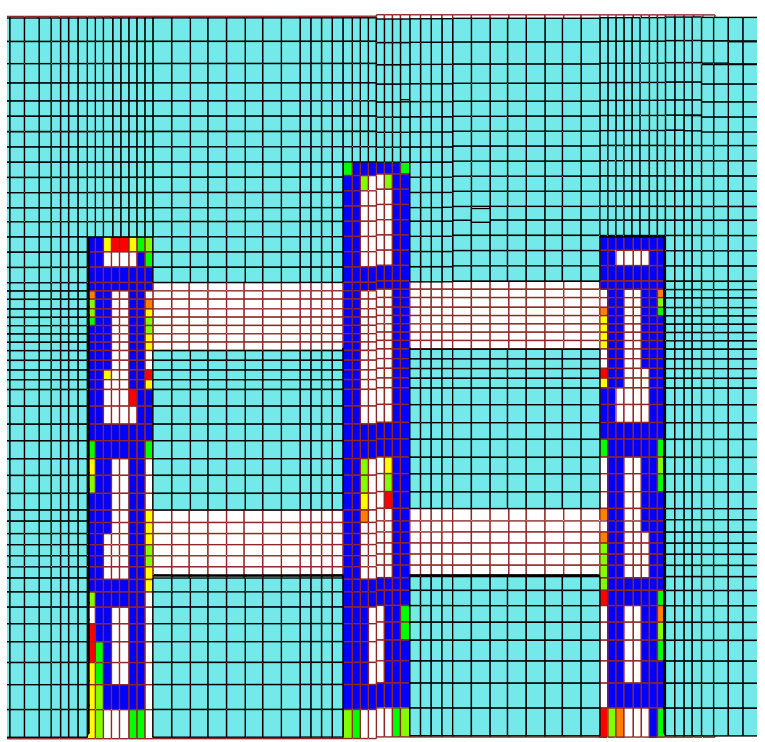

a. $\theta=0^{0}$

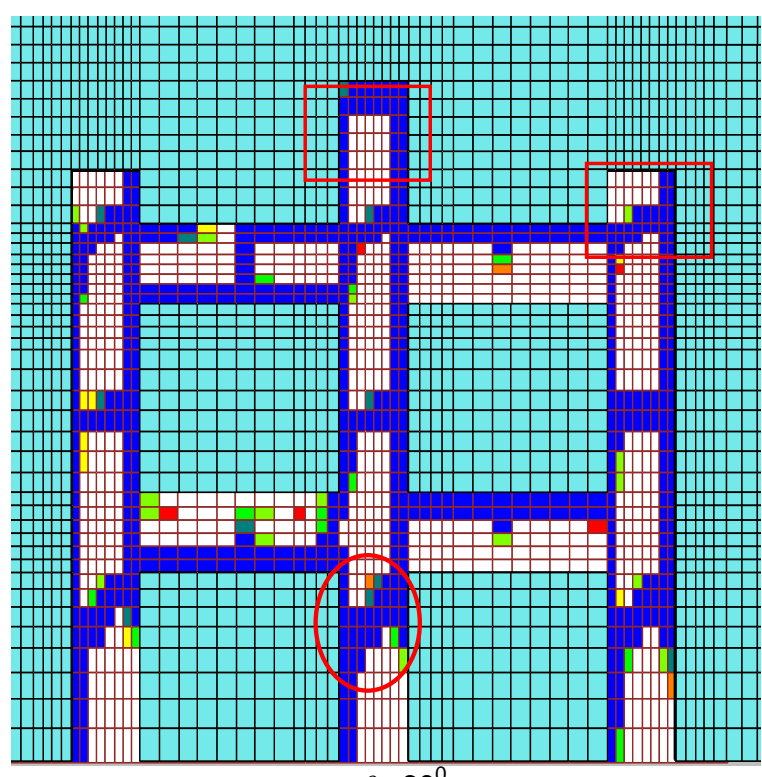

c. $\theta=60^{\circ}$
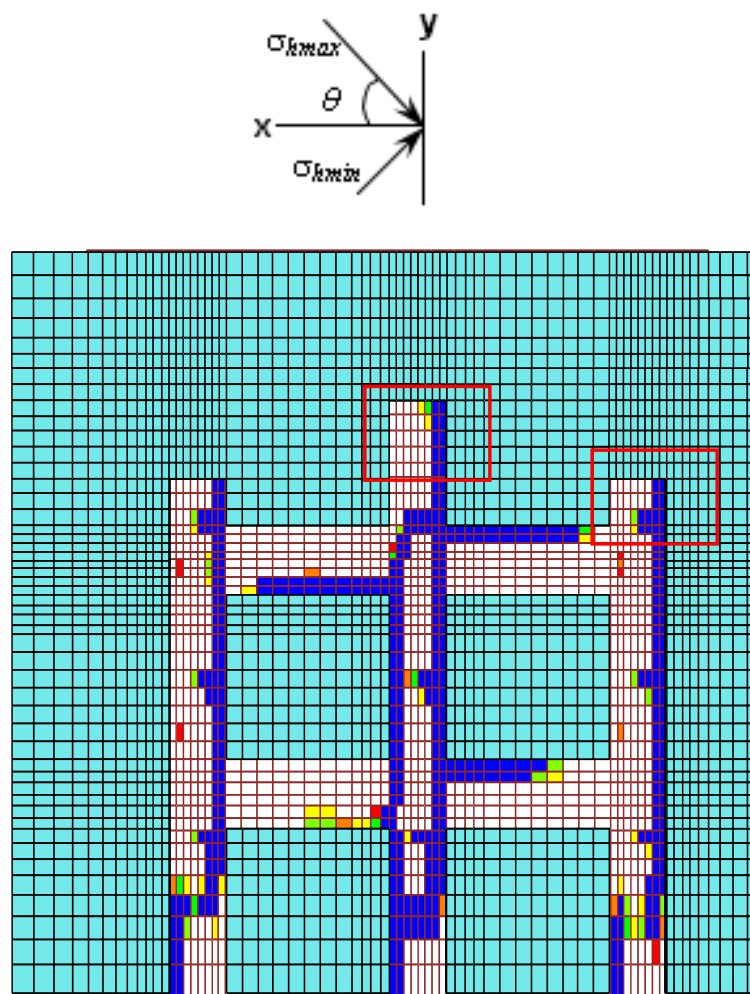

b. $\theta=30^{\circ}$

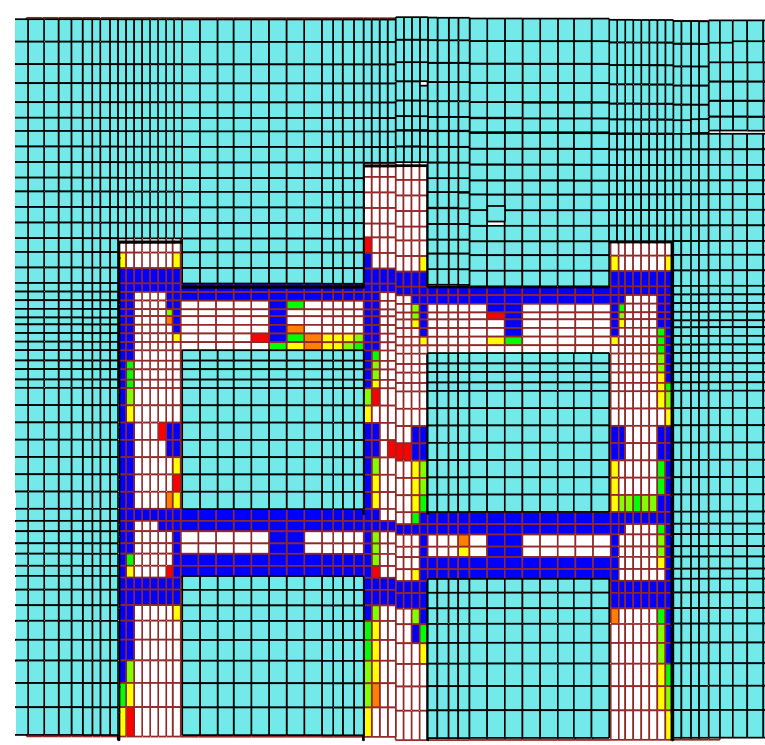

d. $\theta=90^{\circ}$

Figure 6.34 Cohesion distributions for different orientation for weak roof with peak cohesion, 96 psi for a 3-entry system 


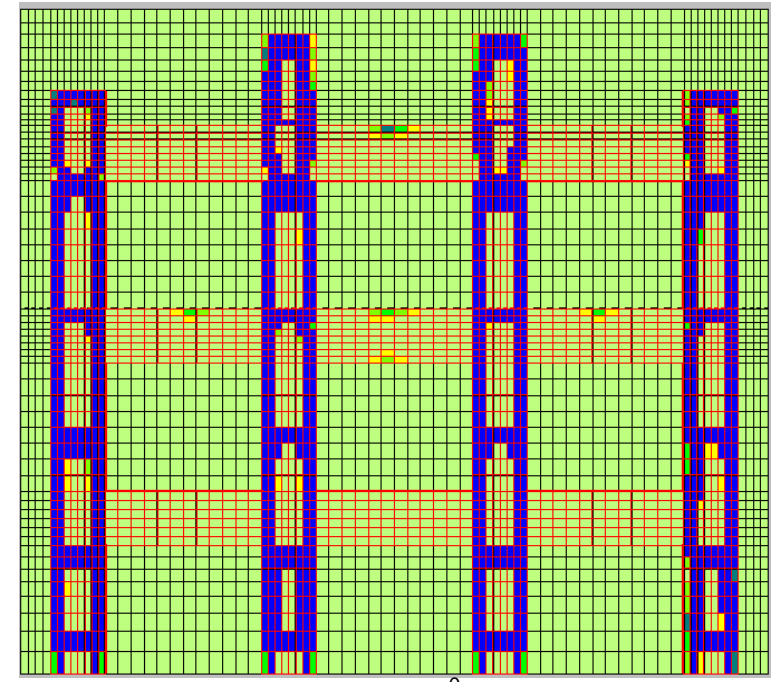

a. $\theta=0^{\circ}$

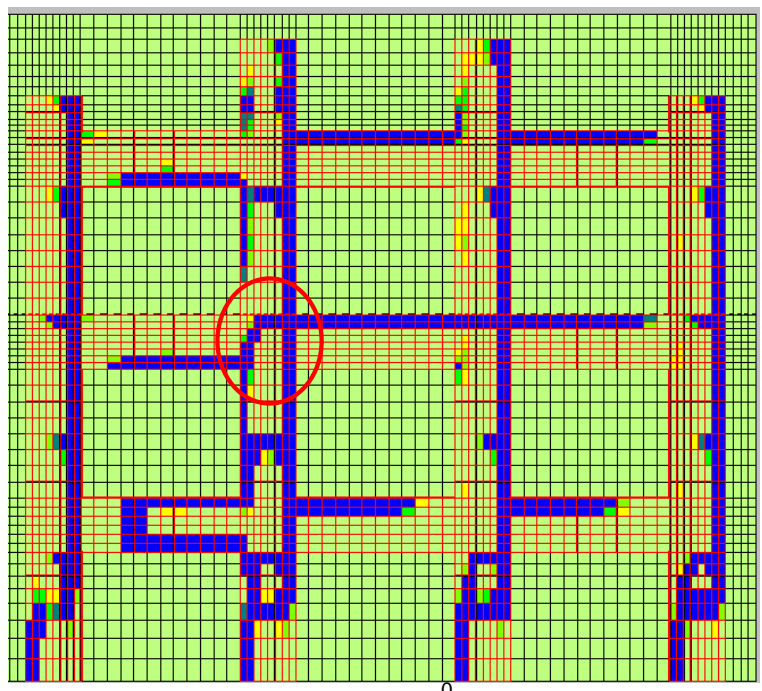

c. $\theta=30^{\circ}$

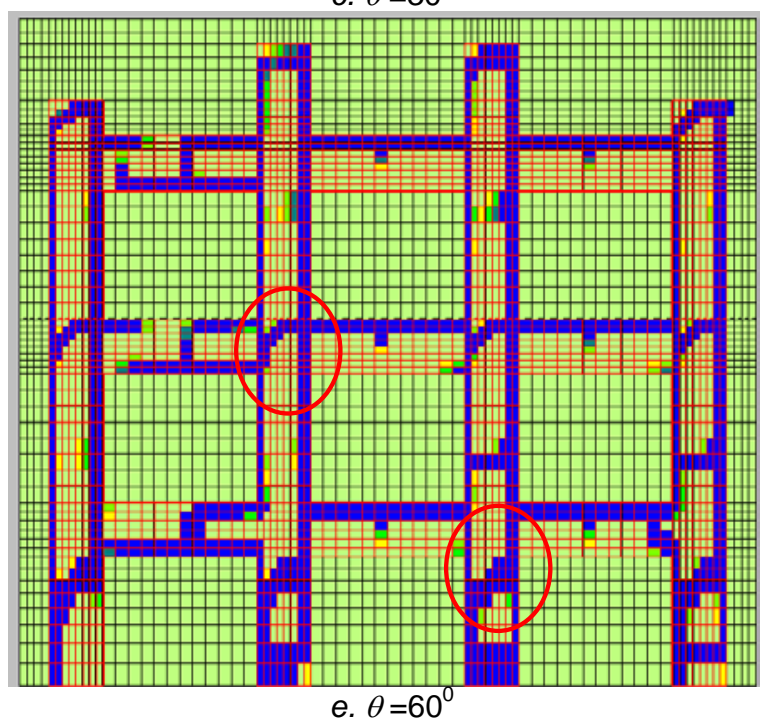

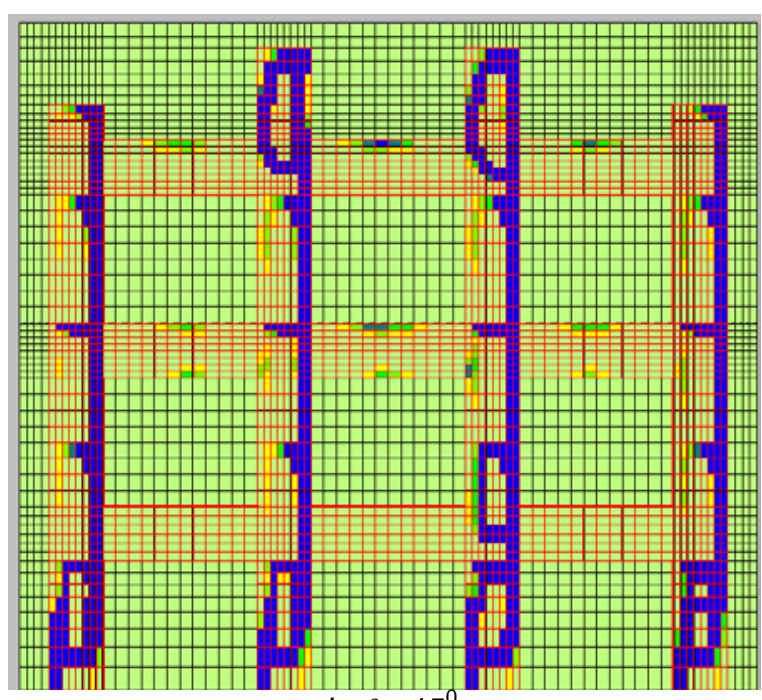

b. $\theta=15^{\circ}$

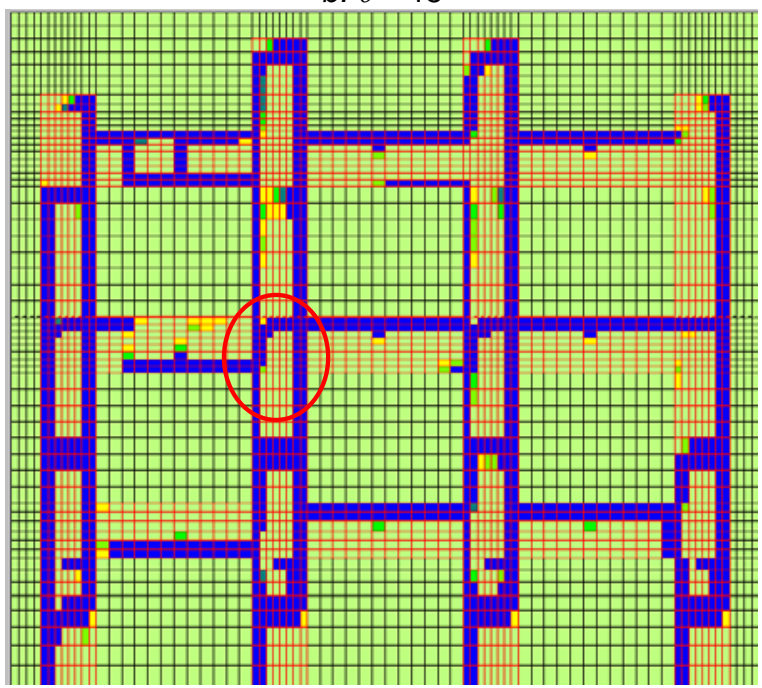

d. $\theta=45^{\circ}$

Figure 6.35 Cohesion distributions for different orientation for weak roof with peak cohesion, 96 psi for a 4-entry system 


\subsubsection{Effect of In-situ Stresses Fields}

In-situ stresses magnitude is an important factor causing the ground control problems. As discussed in the Chapter 3, in USA many in-situ stress measurements have been conducted in the past in various coalfields. These measurements show a wide variation in magnitude of in-situ tresses. Only four measurements out of 93 show that the vertical stress is larger than the horizontal stresses and for the rest of cases its just opposite. But if we consider the regression equations developed by Mark and Gadde (2008), for weak rock at shallow depth the vertical stress is always less than maximum horizontal stress (Table 3.1). Generally it is believed that cutters or roof fall mainly attributed due to high in-situ horizontal stresses. But it can also happen even in low stress environment under weak roof conditions due to time dependency of rock. So the stress magnitude may affect the standup time of the falls. In this section an attempt has been made to investigate the effect of different insitu stress fields on cutter development and their severity during development of underground openings. Since, the in-situ stress state at a point is given in terms of the vertical stress, maximum horizontal stress and minimum horizontal stress, the analysis considers the effect of these parameters expressed as the ratio of maximum horizontal to vertical stress, $k$ and the ratio of maximum horizontal to minimum horizontal stress, $I$.

\subsubsection{Effect of ratio of maximum horizontal stress to vertical stress, $k$}

From Figure 3.7, it can be seen that the ratio ' $k$ ' varies from 0.4 to 10.0 . But more than $70 \%$ data falls within 1.5 To 4.0. The modified Equations 3.5 and 3.6 for prediction of in-situ stress magnitude estimates the value of ' $k$ ' in the range of 1.5 to 2.4 while ' $l$ ' in between 1.2 to 1.5 for this case study mine. Four models were solved for an orientation, $\theta$ of $60^{\circ}$ to see the effect of low and high ' $k$ ' ratio on cutters pattern 
and its severity. Figure 6.36 shows the cohesion distribution in the immediate roof layer for varying ' $k$ ' at a constant ' $l$ '. From Figure $6.36 \mathrm{a}$ and $\mathrm{b}$ it can be seen that for ' $k$ ' $\leq 1$, with the decrease in ' $k$ ' value the post failure cohesion also decreases at the entries/crosscuts edges (red rectangle). Although as per definition of cutter no elements attain zero cohesion for in-situ stress ratio ' $k$ ' $\leq 1$. Similarly with increase in ' $k$ ' value the cutter pattern and severity changes significantly. As ' $k$ ' is increased from 1 to 1.5 , noticeable cutters appear at the edges of the crosscuts. Entries and intersections are free from any cutters. When ' $k$ ' is increased to 2.0 , the cutters are observed everywhere in the mine openings. The cutters severity also increases manifolds compare to that for ' $k$ ' $=1.5$.

Hence from these model results it can be said that cutter and its severity increase as ' $k$ ' increases more than 1 . Similar behavior is observed with ' $k$ ' less than 1. Due to passage of time, cutters can be observed even with low stress ratio ' $k$ ' as the rock already enters in the post failure zone and post failure cohesion is less than peak cohesion. But in general weak roof under shallow depth cover will be relatively much stable for a ' $k$ ' value of $\leq 1.5$.

\subsubsection{Effect of ratio of horizontal stresses, I ( $\left.\sigma_{\mathrm{hmax}} / \sigma_{\mathrm{hmin}}\right)$}

In general the stresses can act at any point in underground space with following there conditions-

1. $\sigma_{\mathrm{hmax}} \geq \sigma_{\mathrm{hmin}} \geq \sigma_{\text {vertical }}$

2. $\sigma_{\mathrm{hmax}} \geq \sigma_{\text {vertical }} \geq \sigma_{\mathrm{hmin}}$

3. $\sigma_{\text {vertical }} \geq \sigma_{\text {hmax }} \geq \sigma_{\text {hmin }}$ 
Hence apart from already studying the effect of ' $k$ ' and ' $l$ ' ratio, these ratios will be chosen such that it full fills the above stress conditions as well the effect of variation in 'l' under high and low stress conditions. Out of these three stress conditions, $3^{\text {rd }}$ condition can only happen under low horizontal stress fields while the first two conditions will be satisfied under high horizontal stress fields.

Figure 6.37 shows the cohesion distribution in immediate roof under high horizontal stress $(k=2)$ with varying ratio ' $l$ ' for an orientation of $60^{\circ}$. These plot shows that the worst stress scenario is one when both maximum and minimum horizontal stresses are same (Figure 6.37a). The cutters are most severe in this case. Cutters are developed in the both side of the entries as well as in crosscuts. As the ratio ' $l$ ' increases, the severity decreases but after a certain value of $l=2.0$, the cutter pattern doesn't change much (Figure $6.37 \mathrm{c}, \mathrm{d}$ ).

Under low horizontal stress condition, the effect of ' $l$ ' is opposite. As ' increases, the minimum post failure cohesion value of elements increases (Figure 6.38). It means for $k<1$, the openings will be more stable for lower value of ' $"$ '.

Further another model were solved with $k=2$ and $l=4$ for different stress orientation to study the effect of higher horizontal stress difference on cutter patterns. Figure 6.39 shows the cohesion distributions in the immediate layer for different stress orientations. From these plots for varying orientation we can see the cutter locations are changing from entries to crosscuts as $\theta$ increases from 0 to $90^{\circ}$. This is the observation which has been observed in the past by all researchers for medium to strong rock.

Hence from these model results it can be said that the orientation effect of stress under extremely weak roof can be observed for a larger value of ' $l$ ', i.e., very high horizontal stress difference. 


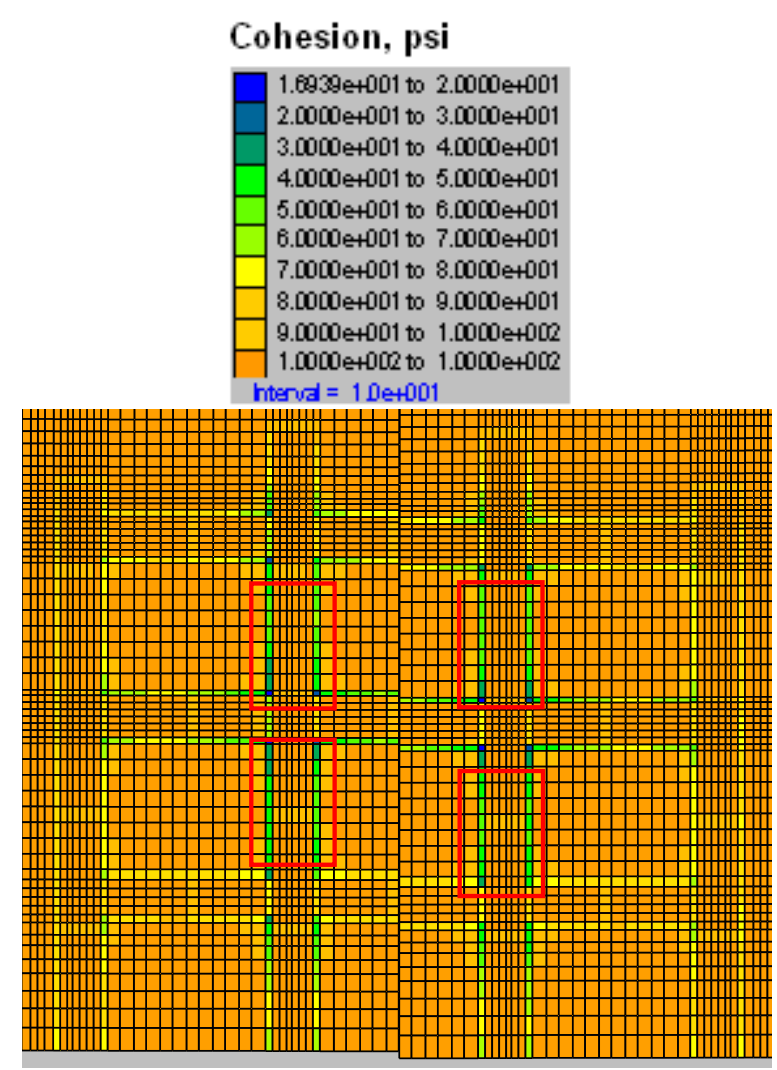

a. Cohesion distribution in immediate roof for $k=0.33$ and $I=1.75$
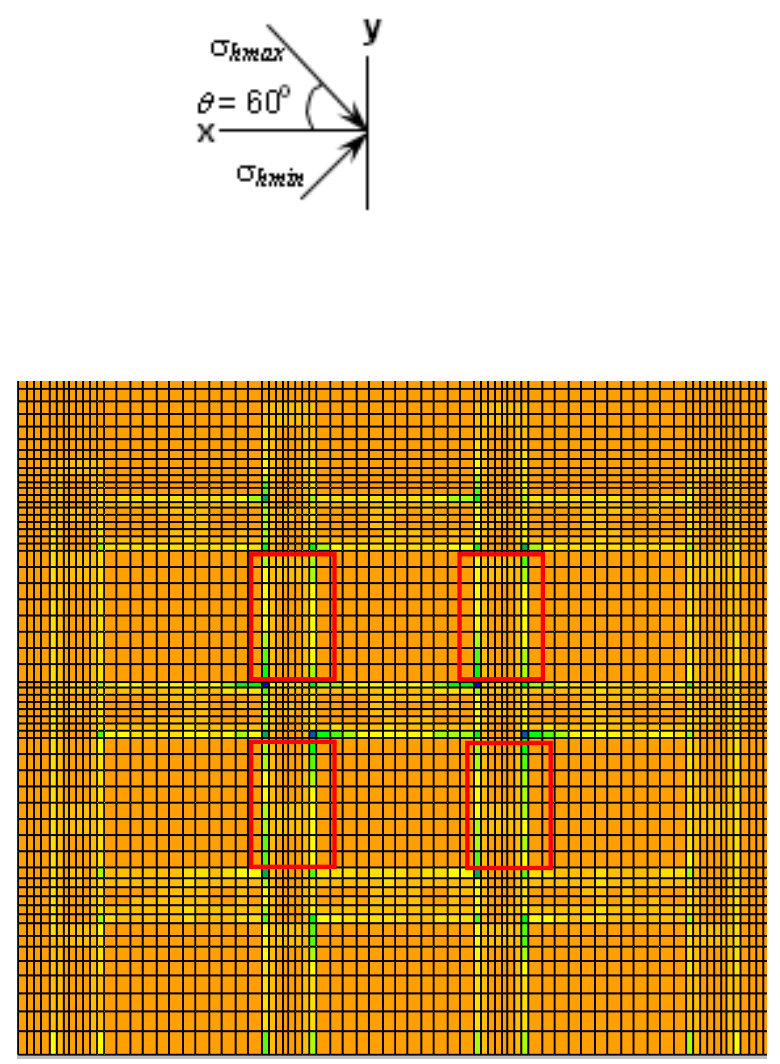

b. Cohesion distribution in immediate roof for $k=1.0$ and $I=1.75$

Cohesion, psi

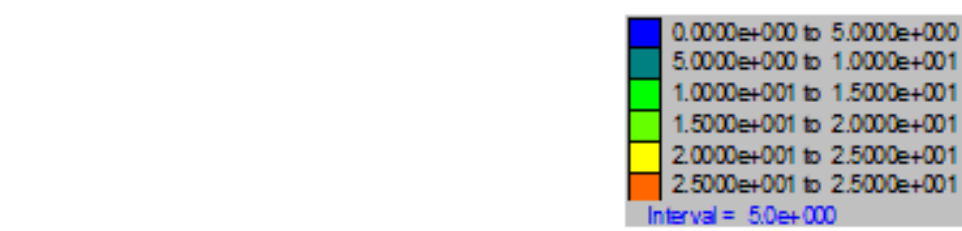

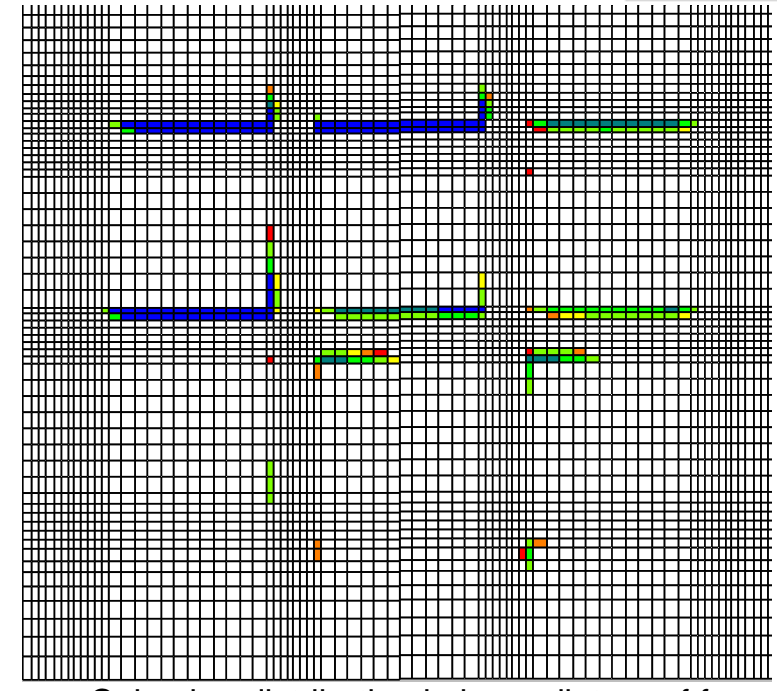

c. Cohesion distribution in immediate roof for $k=1.5$ and $l=1.75$

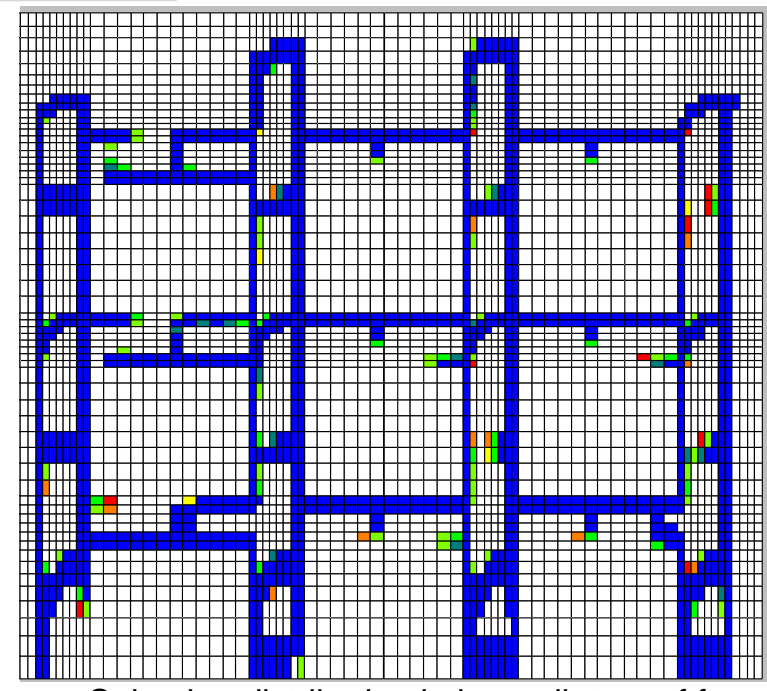

c. Cohesion distribution in immediate roof for $k=2$ and $l=1.75$

Figure 6.36 Effect of variation of ' $k$ ' on cutter development for a constant horizontal stress ratio, 'l' of 1.75 
Cohesion, psi

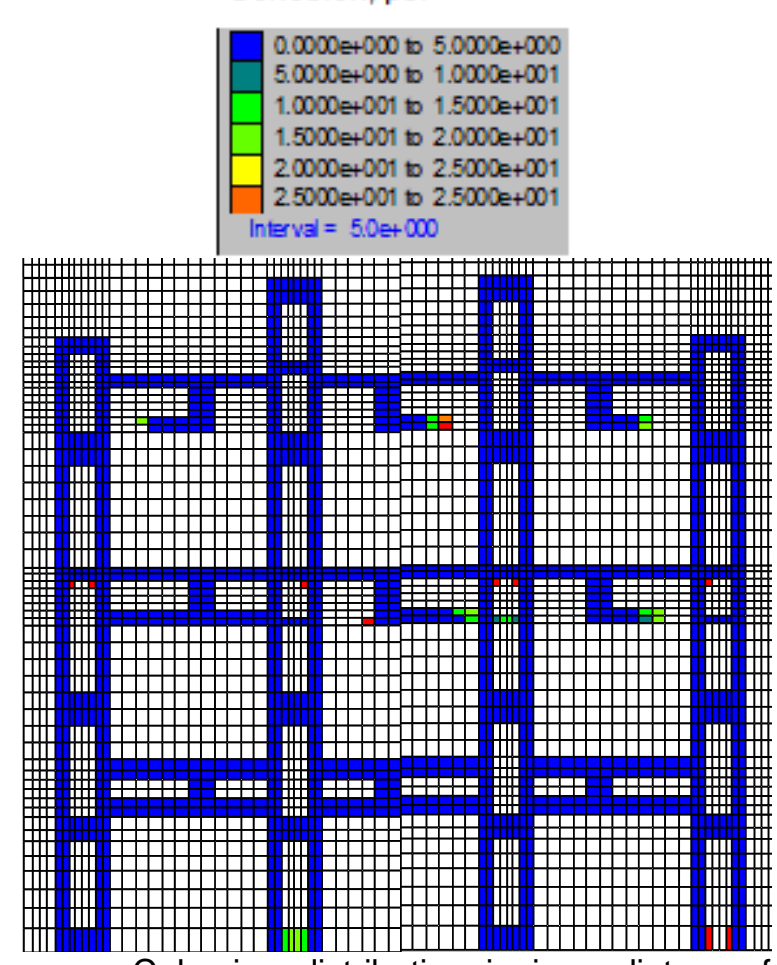

a. Cohesion distribution in immediate roof for $k=2.0$ and $I=1\left(\sigma_{\mathrm{hmax}}=\sigma_{\mathrm{hmin}}>\sigma_{\text {vertical }}\right)$

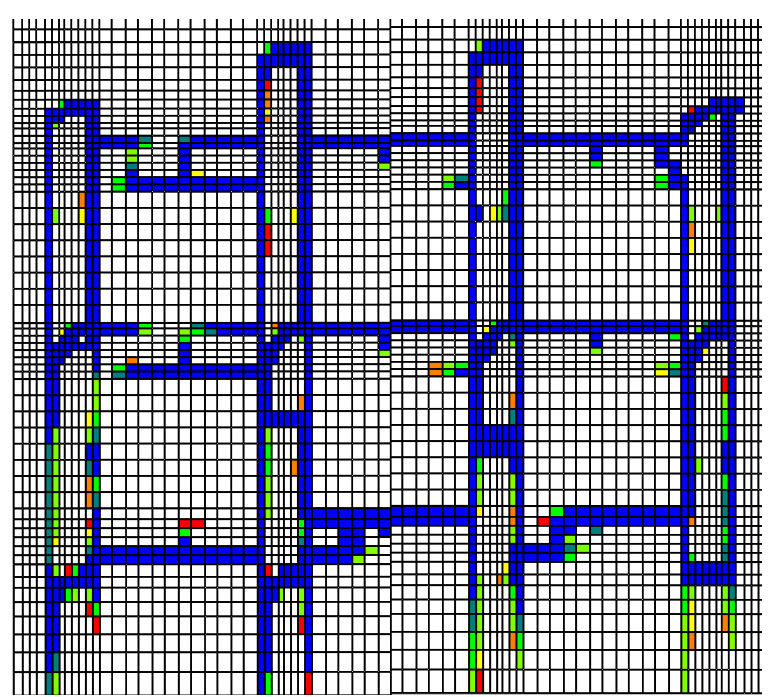

c. Cohesion distribution in immediate roof for $k$ $=2.0$ and $I=2\left(\sigma_{\mathrm{hmax}}>\sigma_{\mathrm{hmin}}=\sigma_{\text {vertical }}\right)$
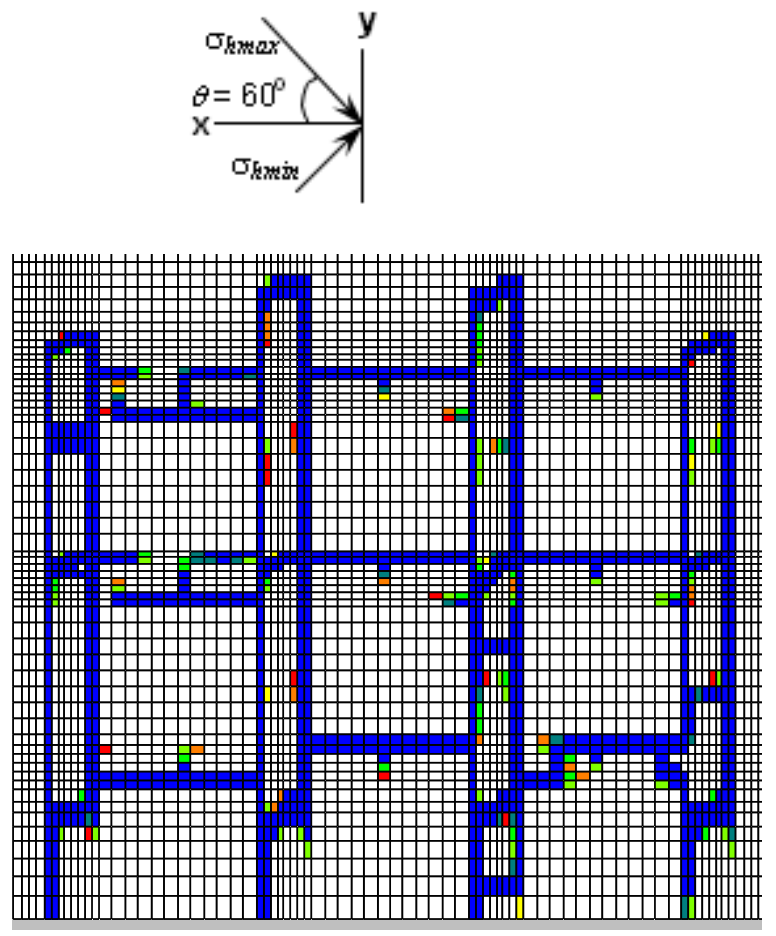

b. Cohesion distribution in immediate roof for $k$ $=2.0$ and $I=1.5\left(\sigma_{\text {hmax }}>\sigma_{\text {hmin }}>\sigma_{\text {vertical }}\right)$

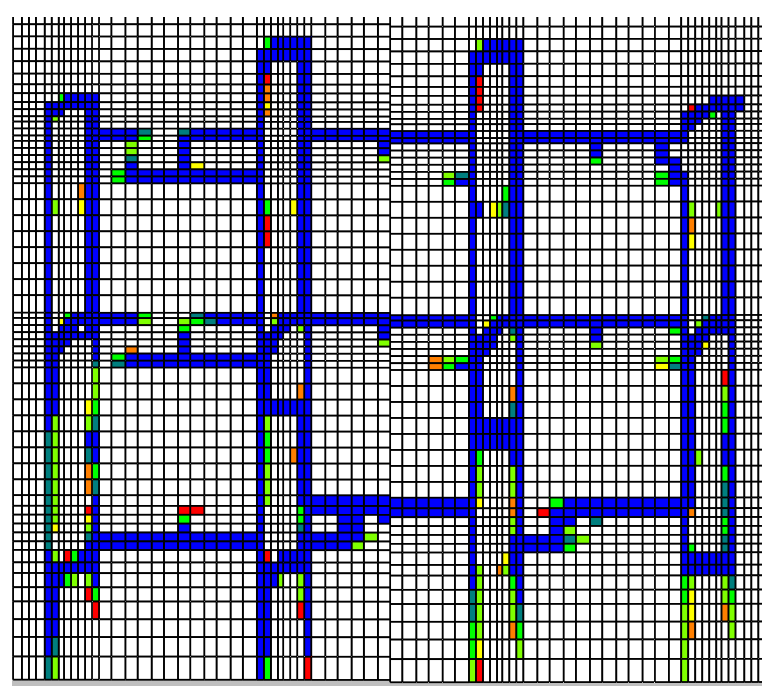

d. Cohesion distribution in immediate roof for $k$ $=2.0$ and $I=3\left(\sigma_{\text {hmax }}>\sigma_{\text {vertical }}>\sigma_{\text {hmin }}\right)$

Figure 6.37 Effect of variation of 'l' on cutter development for high horizontal stress condition $(k=2)$ 
Block Contour of coh

Live mechzones shown

26774e+001 to 3.0000e+001

3.0000 e+001 to $4.0000 \mathrm{e}+001$

4.0000 e+001 to 5.0000 e+001

$5.0000++001$ to $6.0000 e+001$

$6.0000 \mathrm{e}+001$ to $7.0000 \mathrm{e}+001$

7.0000 e+001 to $8.0000 \mathrm{e}+001$

8.0000 e+001 to $9.0000 e+001$

9.0000 e+001 to $9.6000 e+001$

Interval = 10e+001

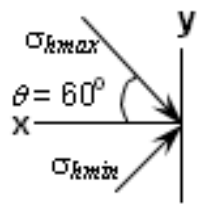
a. $k=0.5, I=2\left(\sigma_{\text {vertical }}>\sigma_{\mathrm{hmax}}>\sigma_{\mathrm{hmin}}\right)$
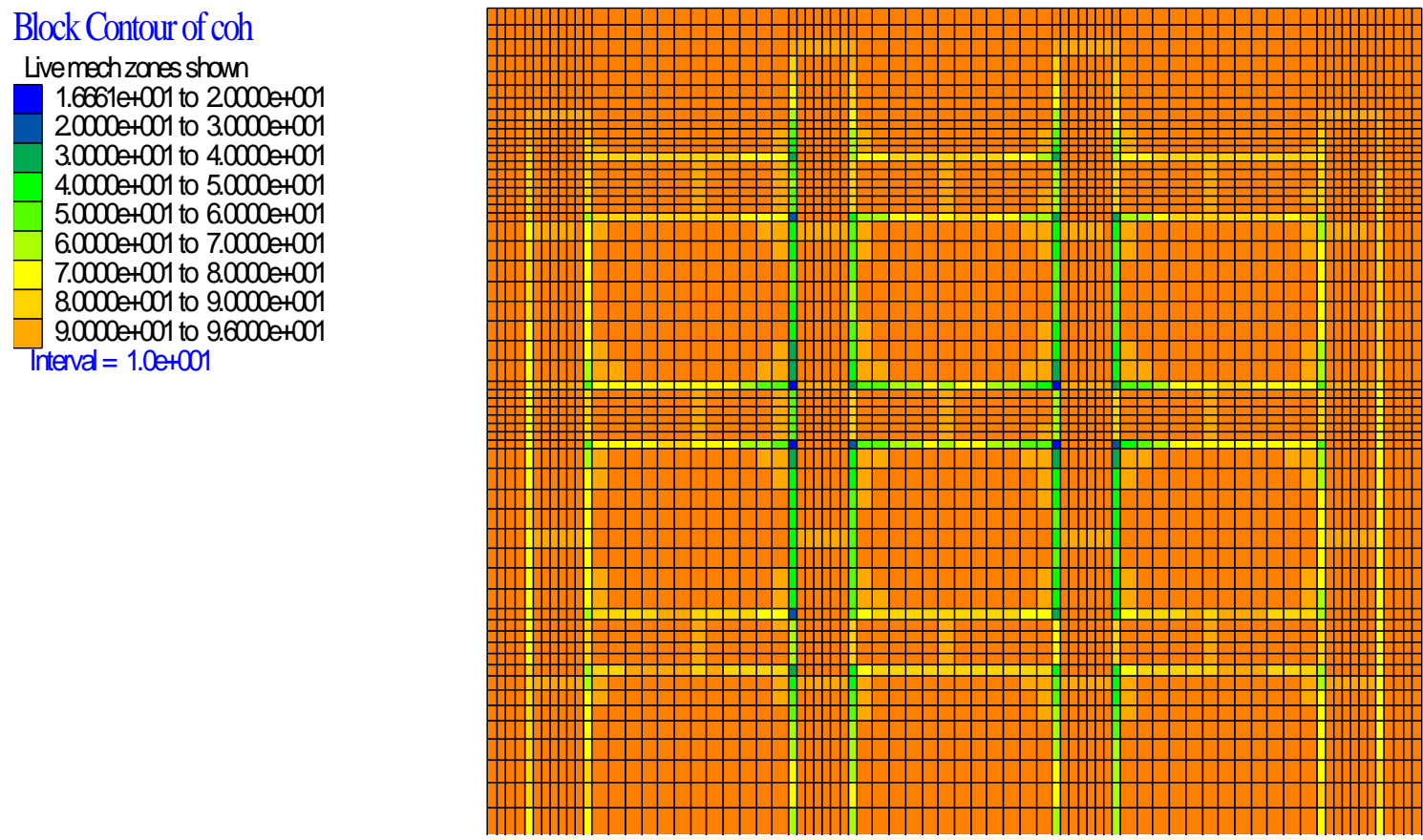

b. $k=0.5, I=3\left(\sigma_{\text {vertical }}>\sigma_{\mathrm{hmax}}>\sigma_{\mathrm{hmin}}\right)$

Figure 6.38 Effect of variation of '" ' on cutter development for low horizontal stress condition $(k=0.5)$ 
Cohesion, psi

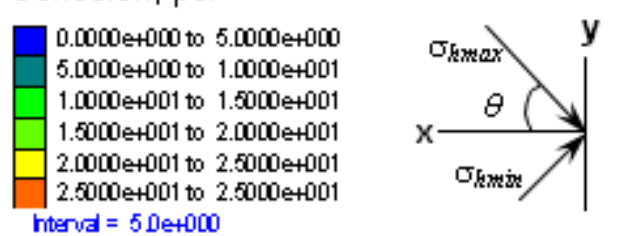

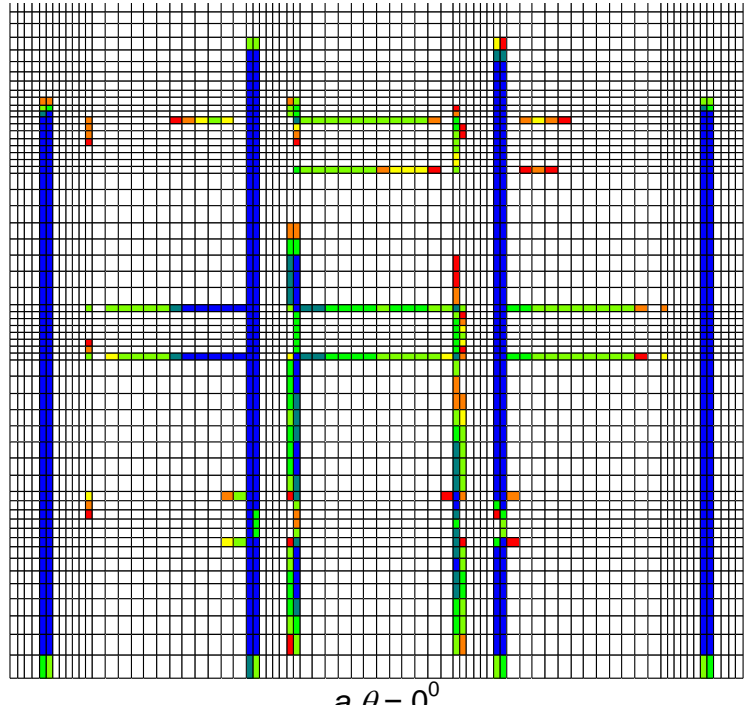

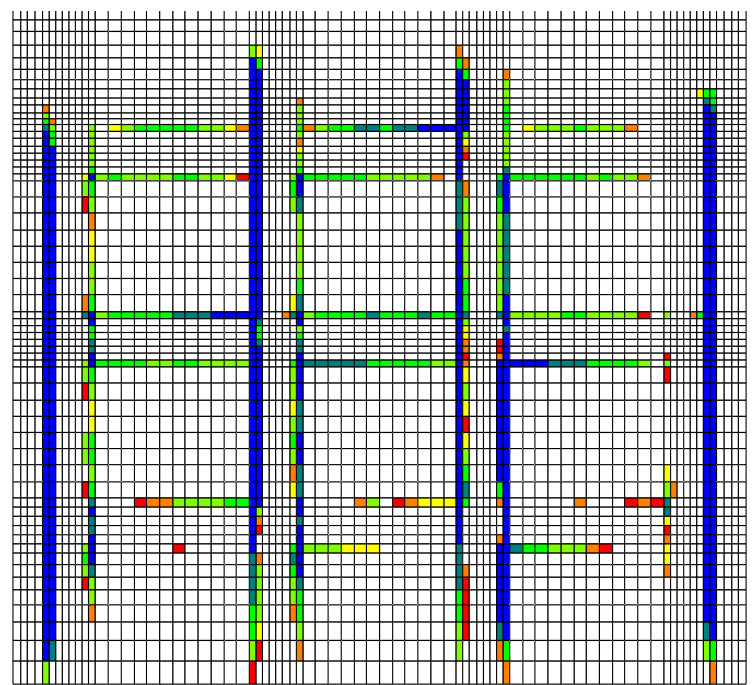

b. $\theta=30^{\circ}$

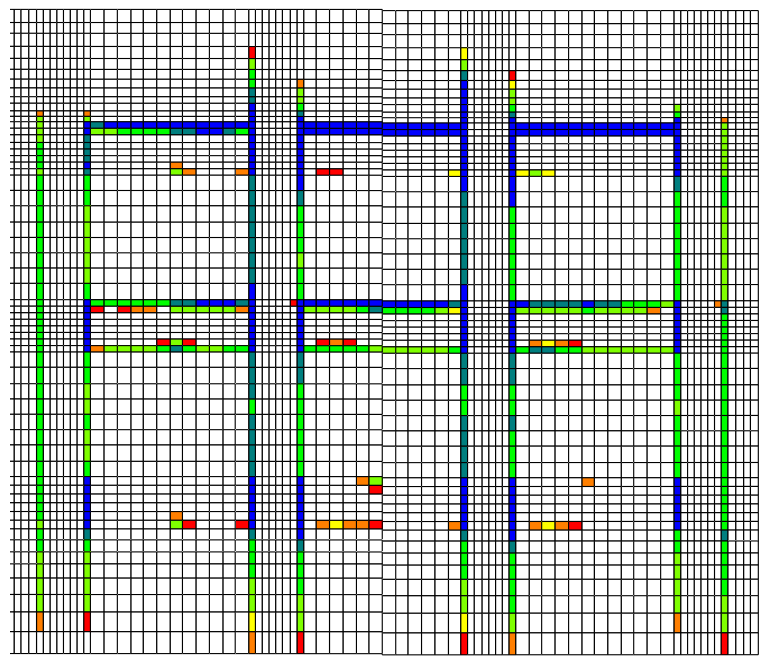

d. $\theta=60^{\circ}$

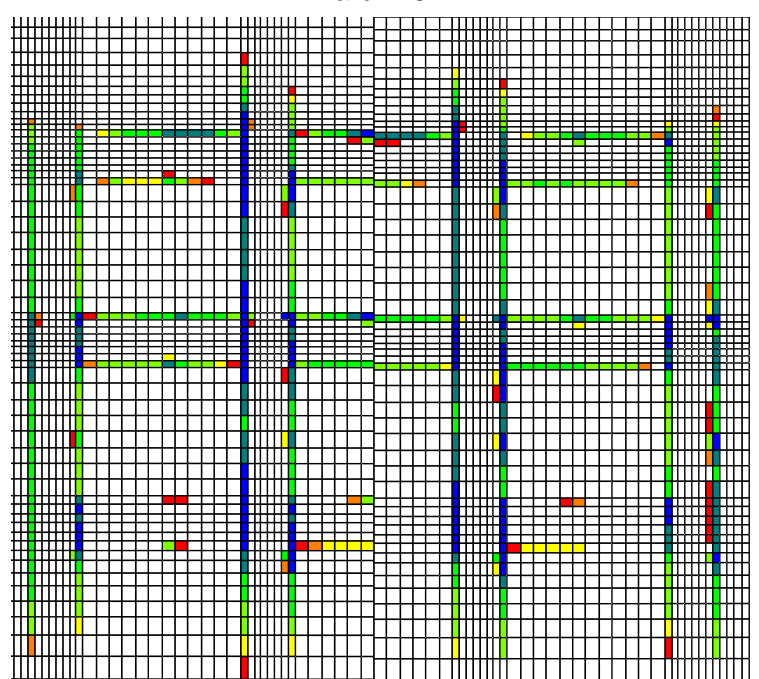

c. $\theta=45^{\circ}$

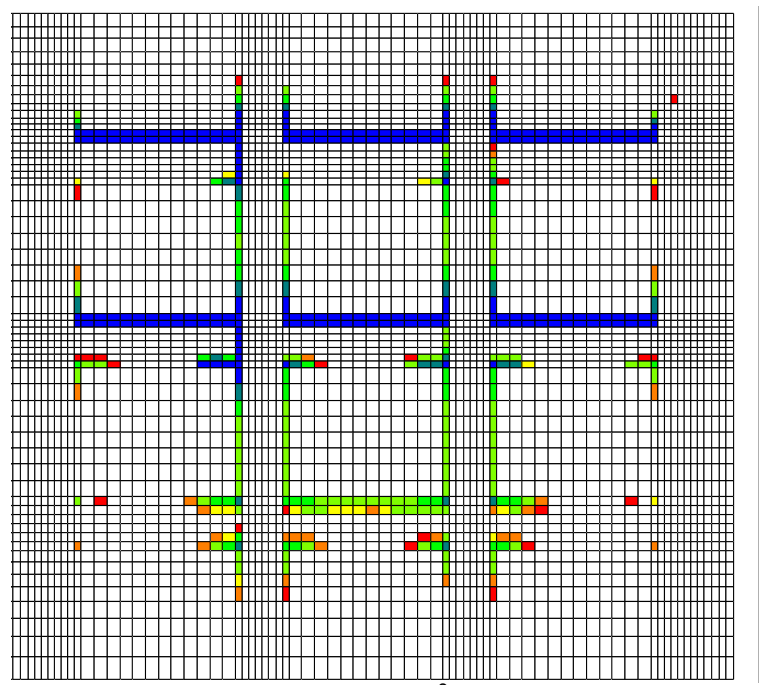

e. $\theta=90^{\circ}$

Figure 6.39 Orientation effect on cutter development for high horizontal stress difference $(k=1.5$ and $l=4)$ 


\subsection{EFFECT OF CUTTING SEQUENCE PARAMETERS ON CUTTER}

\subsubsection{Effect of Cut Length and Face Position}

Globally, there are two terminologies applied for permissible un-supported span by a continuous miner. Australia and UK favours single terminology of cut-out distance while S. Africa defines extended-cut as a cut-out distance more than $40 \mathrm{ft}(12 \mathrm{~m})$ and in USA, extended-cut is defined as a cut-out distance more than $20 \mathrm{ft}(6 \mathrm{~m})$ for remote controlled continuous miners. Maximum cut-out distance approved is $25.6 \mathrm{ft}$ $(7.8 \mathrm{~m})$ in UK, $46 \mathrm{ft}(14 \mathrm{~m})$ in Australia, $64 \mathrm{ft}(19.5 \mathrm{~m})$ in USA and $79 \mathrm{ft}(24 \mathrm{~m})$ in $\mathrm{S}$. Africa (Canbulat and Van der Merwe, 2000). Although in the final project report Canbulat has mentioned that maximum extended cut out distance approved by MSHA for bituminuous coal mines is $64 \mathrm{ft}(19.5 \mathrm{~m})$ but from the cut out distance published in USA literature it is never more than $40 \mathrm{ft}$. It is pertinent to note that limitation imposed on the permissible extent of cut-out distance in various countries is largely based on human and ventilation factors rather than issues related with roof instability (Canbulat and Van der Merwe, 2000). Technically, roof dilation/bed separation stops once the face moved beyond a distance twice of the entry width (Canbulat and Van der Merwe, 2000; Mark, 2007). This observation may be based on certain mining conditions. In no case in USA, the maximum allowable cut out distance is more than $40 \mathrm{ft}$, which is normally equal to twice of a normal entry width of $20 \mathrm{ft}$. Normally cut out distance depends upon the roof rock properties as the stand up time is a function of roof quality (RMR or CMRR).

Empirically CMRR can be used to delineate cut-out distance. There is, however, practical limitation on this cut-out distance. A cut-out distance should only be practised under which there is minimal or no chance of $\mathrm{CM}$ operator to step into unsupported area. Bauer (1998) proposed the following relationship for a safe cut- 
out distance during pre-approval stage of a mine based on NIOSH'S CMRR approach.

Cut Depth $=8.1+0.564($ CMRR $)-0.152$ (entry width) -0.0029 (overburden)

where, entry width and overburden are in feet.

Using the above relationship, cut-out distance comes out to be $24 \mathrm{ft}$ for an entry width of $18 \mathrm{ft}$ for CMRR value of 35 at an overburden depth of $250 \mathrm{ft}$. Mark (1999) reports that $40 \mathrm{ft}$ extended cut will always stable for a CMRR value higher than 55.

Numerical modelling was conducted to understand how the cutters are developed with increase in cut out distance. For this same single entry model (Figure 5.19) with same properties and stress condition were used. Figure 6.40 shows the plan view of the single entry with different cut length varying from 15 to 35 ft.

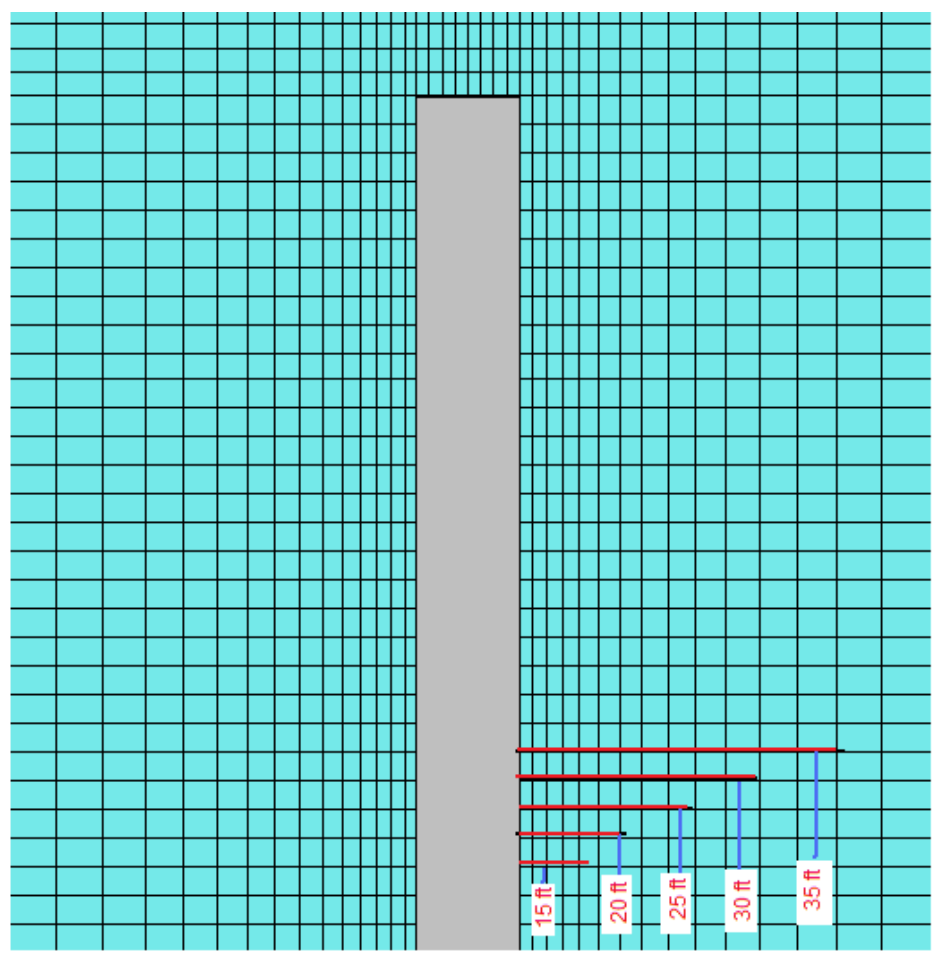

Figure 6.40 Plan view of single entry showing different cut length 
Figure 6.41 shows the cohesion distribution in the plan view of immediate layer and in the roof along right edge of the entry after cut 1 and cut 2 . Cohesion plot shows how cutter propagates upward in the roof and behind the face with change in cut length. For this extremely weak roof case under the stress environment $(k=1.8$, $I=1.3)$ most of the elements in the immediate layer reached to post failure regime even for smallest cut length of $15 \mathrm{ft}$. The minimum cohesion values for the elements near the face for different cut lengths are shown in Figure 6.42. Figure 6.43 shows the roof displacement near the face for a cut length of $30 \mathrm{ft}$. The roof displacement profile shows that the roof movement is more on the right edge side. This is mainly due to stress oriented at $60^{\circ}$. Figure 6.44 shows the maximum roof displacement observed in the roof near the face for different cut length. From cohesion plots and displacement point of view it can be seen that $15 \mathrm{ft}$ cut length is most stable. As the cut length $(20 \mathrm{ft})$ exceeds the entry width $(18 \mathrm{ft})$, the displacement increases sharply almost $77 \%$ just for an increase of $5 \mathrm{ft}$ in cut length. The variation in roof displacement is erratic as from 20 to $25 \mathrm{ft}$ there is no significant change. Further again it increases sharply when cut length is increased from $25 \mathrm{ft}$ to $30 \mathrm{ft}$. From cutter definition point of view up to $30 \mathrm{ft}$ of cut distance, seems fines as no zero cohesion elements is present. Also up to $30 \mathrm{ft}$ cut length (figure 6.41a) just one layer in the immediate roof is in the post failure region while it increases to 3 layers for a cut length of $40 \mathrm{ft}$ (figure 6.41b). For cut length of $50 \mathrm{ft}$ entire immediate roof near the face has zero cohesion and hence cutters formed up to the top of the roof near the face.

Based on the cutter pattern formed, cut length up to $30 \mathrm{ft}$ seems reasonable but for $30 \mathrm{ft}$ cut length displacement is more than double that of $15 \mathrm{ft}$. From both cohesion and displacement, cut length less than or equal to entry width may work 
under very weak roof. Based on modeling to determine the cut out distance may not be realistic as it is a purely time related issue and this modeling don't consider the time effect. The safe cut out distance should be such that it can withstand for a considerable time without supporting.

After cut 1(immediate roof layer)
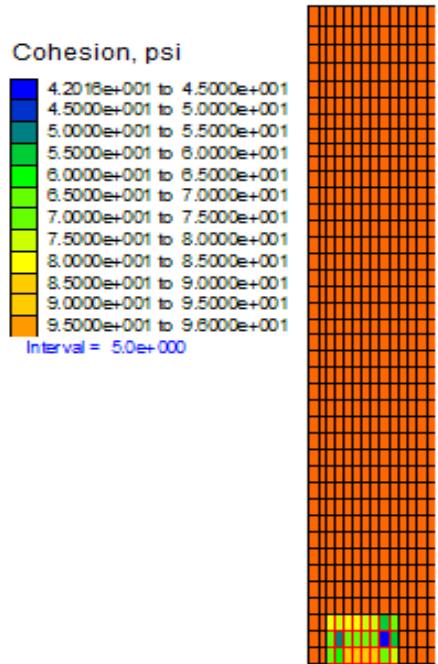

cohesion, psi

1. $1608 \mathrm{e}+001$ to $2.0000 \mathrm{e}+001$ $20000+001$ to $3.0000 \mathrm{e}+001$ $3.0000++001$ to $4.0000 e+001$ $4.0000 \mathrm{e}+001$ to $5.0000 \mathrm{e}+001$ $5.0000 \mathrm{e}+001$ to $6.0000 \mathrm{e}+001$ $6.0000=001$ to $7.0000 \mathrm{e}+001$ $7.0000 \mathrm{e}+001$ to $8.0000 \mathrm{e}+001$ $8.0000=+001$ to $9.0000 \mathrm{e}+001$ $9.0000 \mathrm{e}+001$ to $9.6000 \mathrm{e}+001$ Interval $=1.0 \mathrm{e}+\infty \mathrm{O}$
After cut 2

(immediate roof layer)

Cohesion, psi

$6.5007 \mathrm{e}+000$ to $1.0000 \mathrm{e}+001$ 1.0000e+001 to $2.0000 \mathrm{e}+00$ $2.0000 \mathrm{e}+001$ to $3.0000 \mathrm{e}+001$ $3.0000 \mathrm{e}+001$ to $4.0000 \mathrm{e}+001$ 4.0000 = 001 to $5.0000 \mathrm{e}+\infty 01$ $80000+001$ to $7.00000+00$ $7.0000=001$ to $8.0000=+00$ (30000001 to $90000 \mathrm{e}+001$ (. interval $=1.0 \mathrm{e}+001$
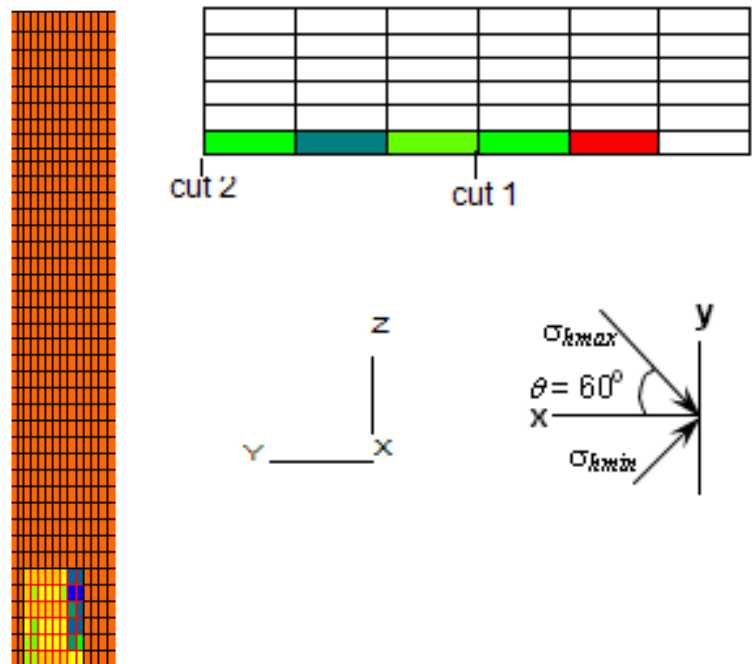

a. Cut length $15 \mathrm{ft}$ and $30 \mathrm{ft}$

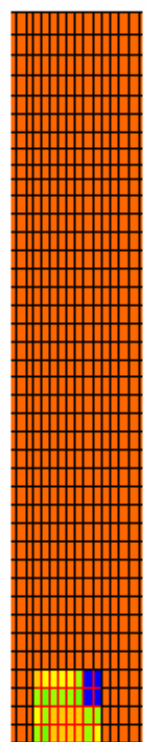

$0.0000 \mathrm{e}+000$ to $1.0000 \mathrm{e}+001$ 1.0000e+t001 to $2.0000 \mathrm{e}+00$ $2.0000 \mathrm{e}+001$ to $3.0000 \mathrm{e}+00$ 3.0000e+001 to $4.0000 \mathrm{e}+\infty$ $4.0000=+001$ to $5.0000 \mathrm{e}+001$ 5.0000 et+001 to $6.0000 \mathrm{e}+\infty$ 6. $0000 \mathrm{e}+001$ to $7.000 \mathrm{ee}+00$ $7.0000 \mathrm{e}+001$ to $8.0000 \mathrm{e}+00$ $.0000 e+001$ to $9.0000 e+\infty 0$ 9.0000 en+001 to $9.8000 \mathrm{e}+001$ Interval $=1.0 e+001$

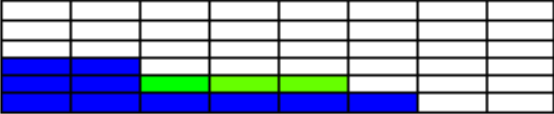

$\stackrel{ }{ت}$

$\stackrel{5}{\Xi}$ 


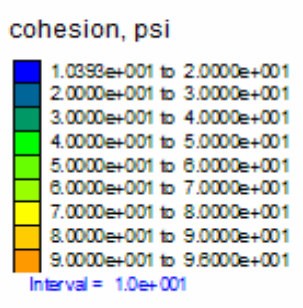

hesion, psi

$9.3097 \mathrm{e}+000$ to $1.0000 \mathrm{e}+001$ 3.0000e+001 to $4.0000 \mathrm{e}+00$ $5.0000=+001$ to $5.0000 \mathrm{e}+00$ $0000=001$ is 7.0000 e $+\infty 01$ $7.0000=+001$ to $8.0000=+001$ $3.0000=+001$ to $9.0000 e+001$ $9.0000=+001$ to $9.6000 \mathrm{e}+00$

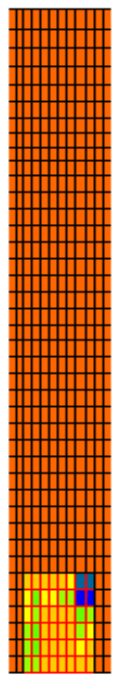

Cohesion, psi

$0.0000 \mathrm{e}+000$ to $1.000 \mathrm{ee}+00$ $2.0000 \mathrm{e}+001$ to $3.0000 \mathrm{e}+00$ 3.0000 e+ 001 to $4.0000 e+00$ 4. $0000 \mathrm{e}+001$ to $5.0000 \mathrm{e}+00$ $.0000=+001$ to $6.0000 e+00$ $0000 \mathrm{e}+001$ to $7.000 \mathrm{e} e+00$ $.0000 \mathrm{e}+001$ to $8.0000 \mathrm{e}+00$ $0000+001$ to $9.0000 e+00$ $9.0000=+001$ to $9.6000 e+00$ Interval $=1.0 e+001$
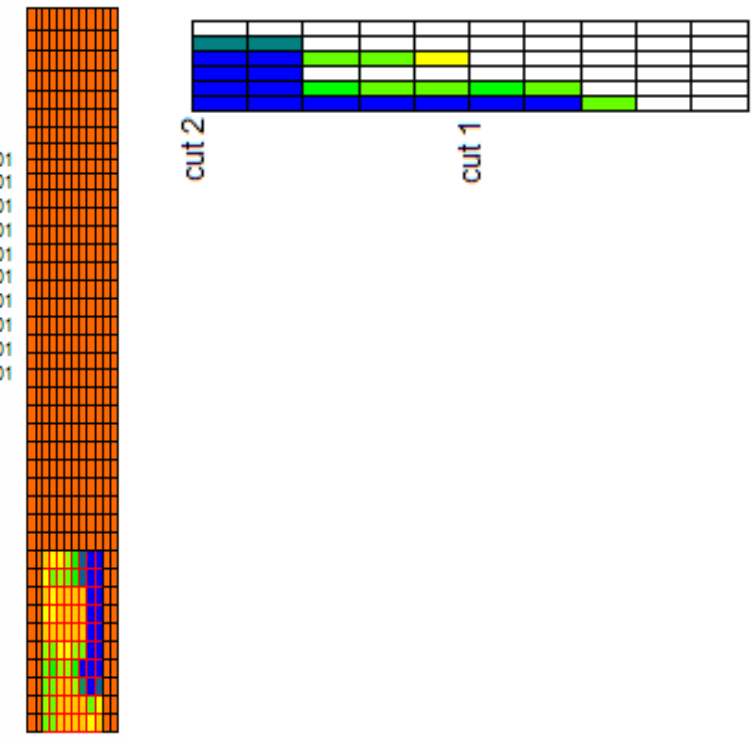

c. Cut length $25 \mathrm{ft}$ and $50 \mathrm{ft}$
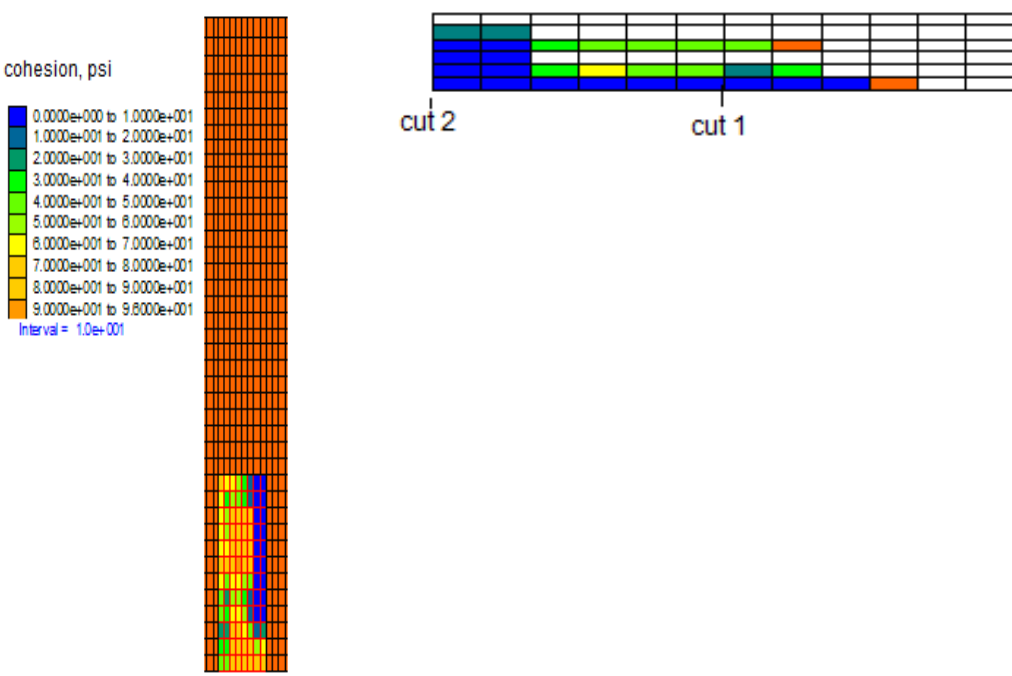

d. Cut length $30 \mathrm{ft}$ and $60 \mathrm{ft}$
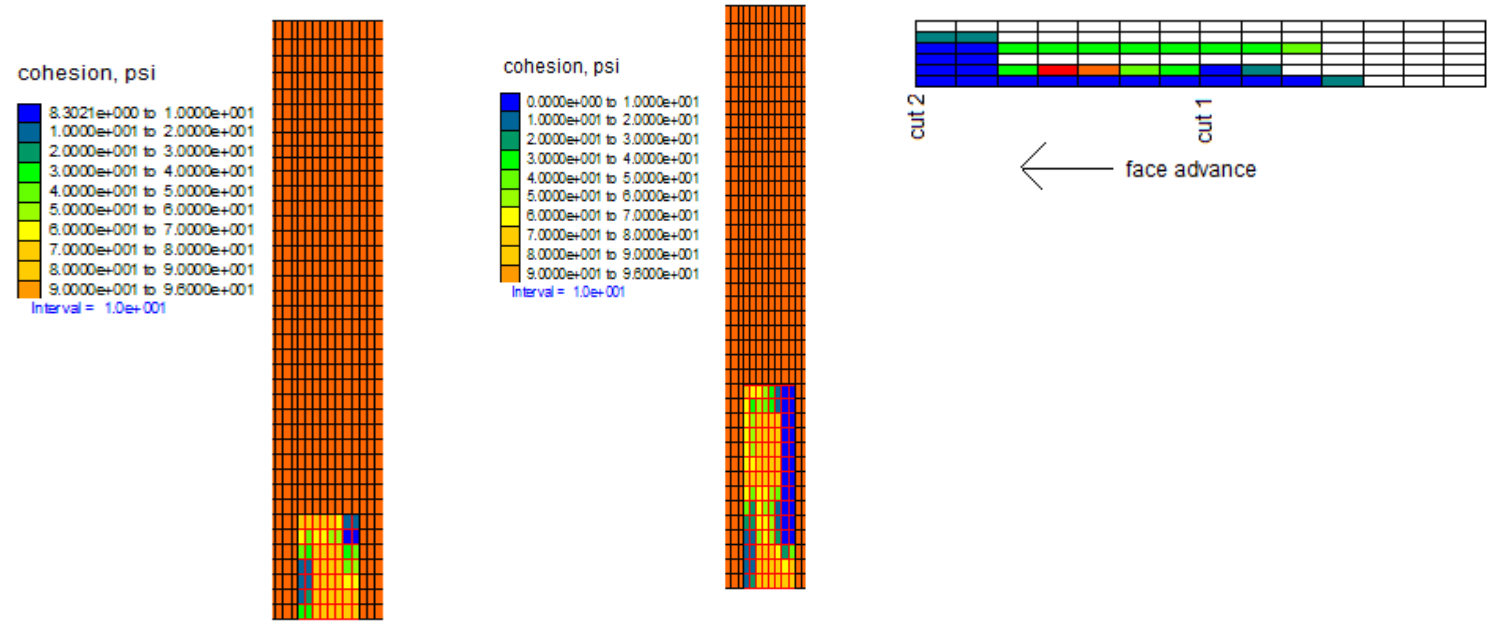

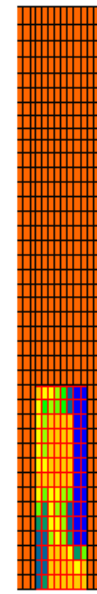

e. Cut length $35 \mathrm{ft}$ and $70 \mathrm{ft}$

Figure 6.41 Effect of cut length on cutter pattern 


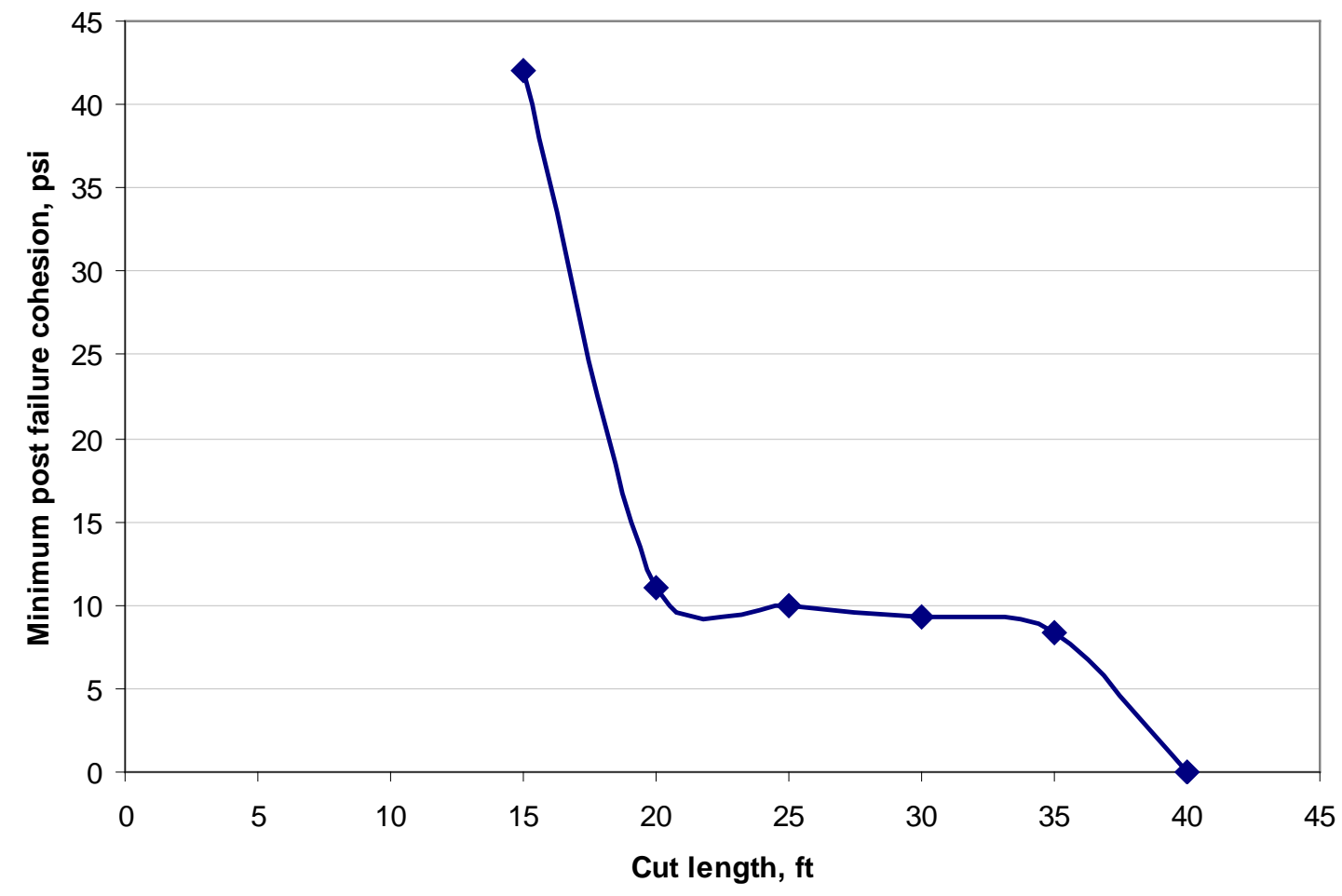

Figure 6.42 Variation in post failure cohesion with cut length

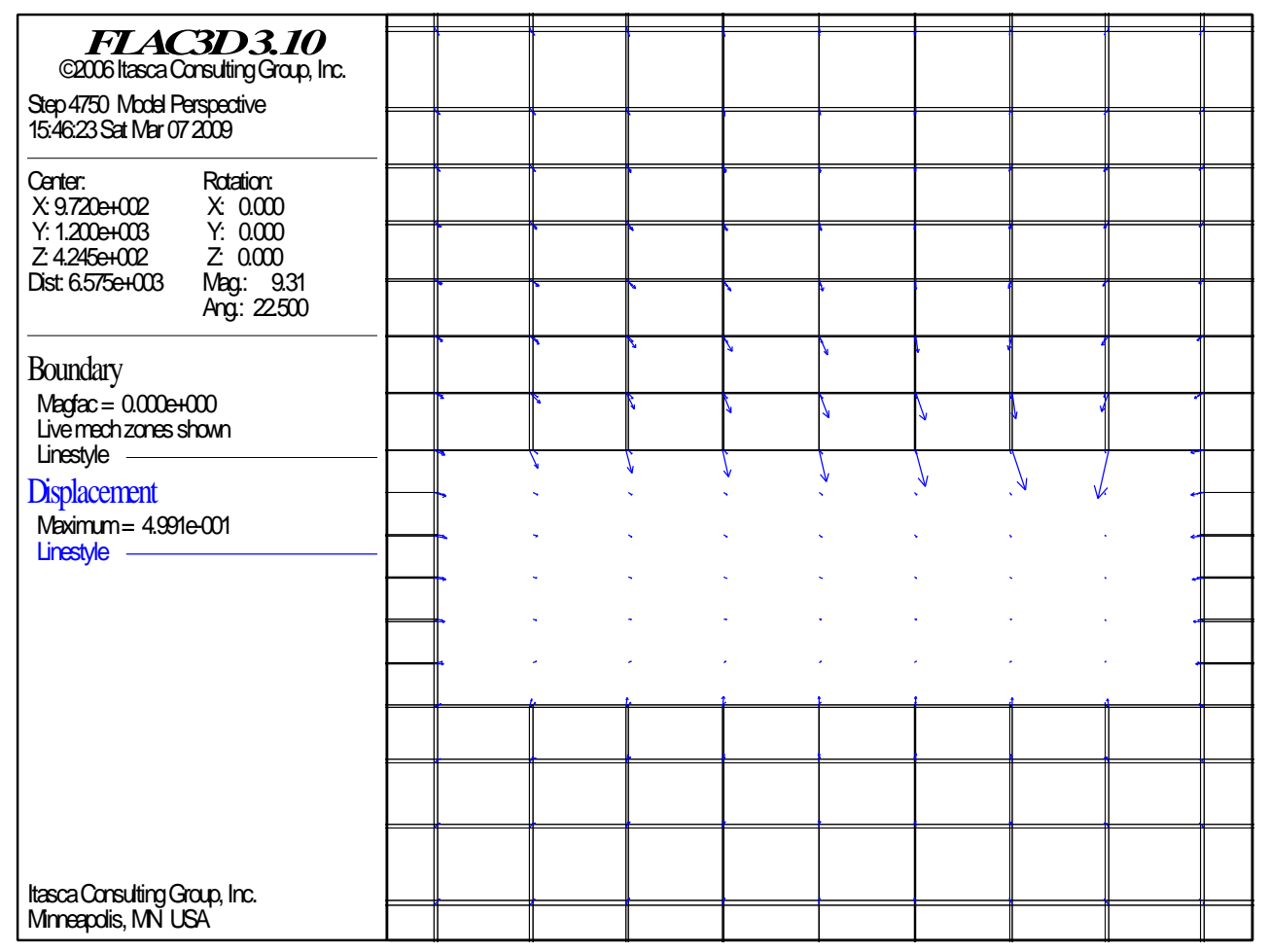

Figure 6.43 Roof displacement near the face for cut length of $30 \mathrm{ft}$ 


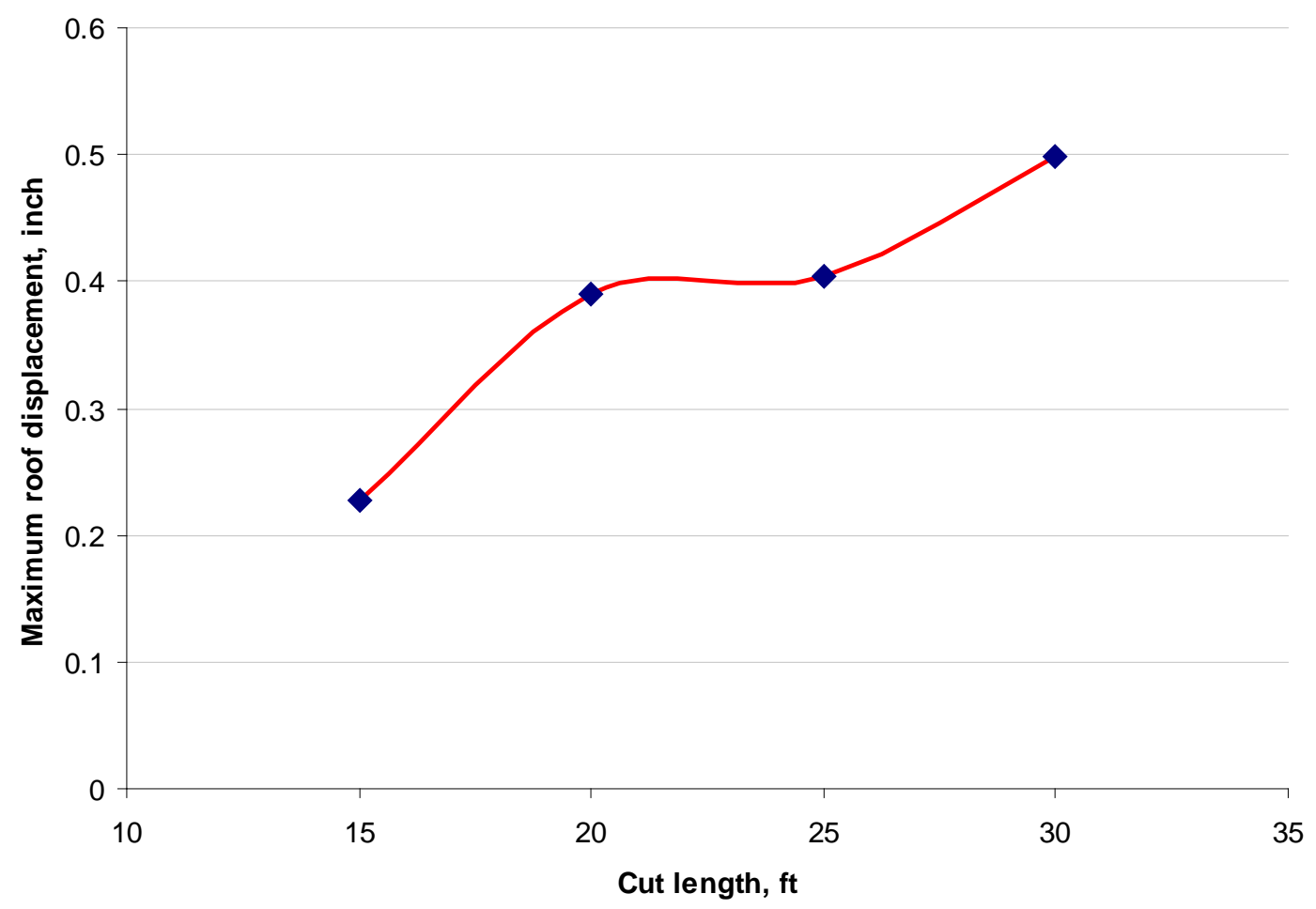

Figure 6.44 Variation in the roof displacement with cut length

Further the change in cut length in a cutting sequence can cause change in the face location with respect to probable intersection location. The location of the face position can cause change in the cutter pattern. From numerical modeling it has been seen that generally cutters crosses the openings near the face position in a cut for a certain combination of stress orientation and immediate roof rock strength.

Figure 6.45 shows the cutter pattern for two different cutting sequence. The face positions are shown as dark black solid line in various cutting steps. For cutting sequence type 1 with cut length of $40 \mathrm{ft}$ each in entry, the face position in all entries lies between crosscut $1 \mathrm{C}$ and $2 \mathrm{C}$ ( $20 \mathrm{ft}$ from intersections) after cut 2 and cut 3 . The face position in entries lies exactly at the intersection edges after cut 3 and cut 4 . In cut sequence type 2, cut lengths are changed to $35 \mathrm{ft}$. Due to change in cut length 
some face positions come closer to intersection and some stops at future intersection as shown in Figure 6.45b.

From Cohesion plot of these two cutting sequences shown in Figures 6.45a and $6.45 \mathrm{~b}$, it can be clearly observed that when face in entries are located near or at the edge of the intersection (cut 3 in $1 \mathrm{E}$, cut 4 in $2 \mathrm{E}$, cut 3 in $3 \mathrm{E}$ and cut 4 in $4 \mathrm{E}$, Figure 6.45a) in a cutting step, the cutters run across the intersection. Similarly observations were found for cutting sequence type 2 (face position 5 in all entries, Figure 6.45b). When face is $10 \mathrm{ft}$ or more ahead the intersections (face position 2 in entries, Figure $6.45 b)$ no cutters run across the intersection.

So from this model results it can be suggested that the cutting sequence should be made such that the face position in a particular step should not fall at future intersection or within $10 \mathrm{ft}$ of the edge of the intersection. To achieve this either mix cutting length in a cutting sequence may be used or the spacing between crosscuts should be adjusted by changing the pillar length especially when working under very weak roof. This phenomenon of cutter running across the openings or at intersection may disappear with increase in immediate roof rock strength as observed in previous section. 


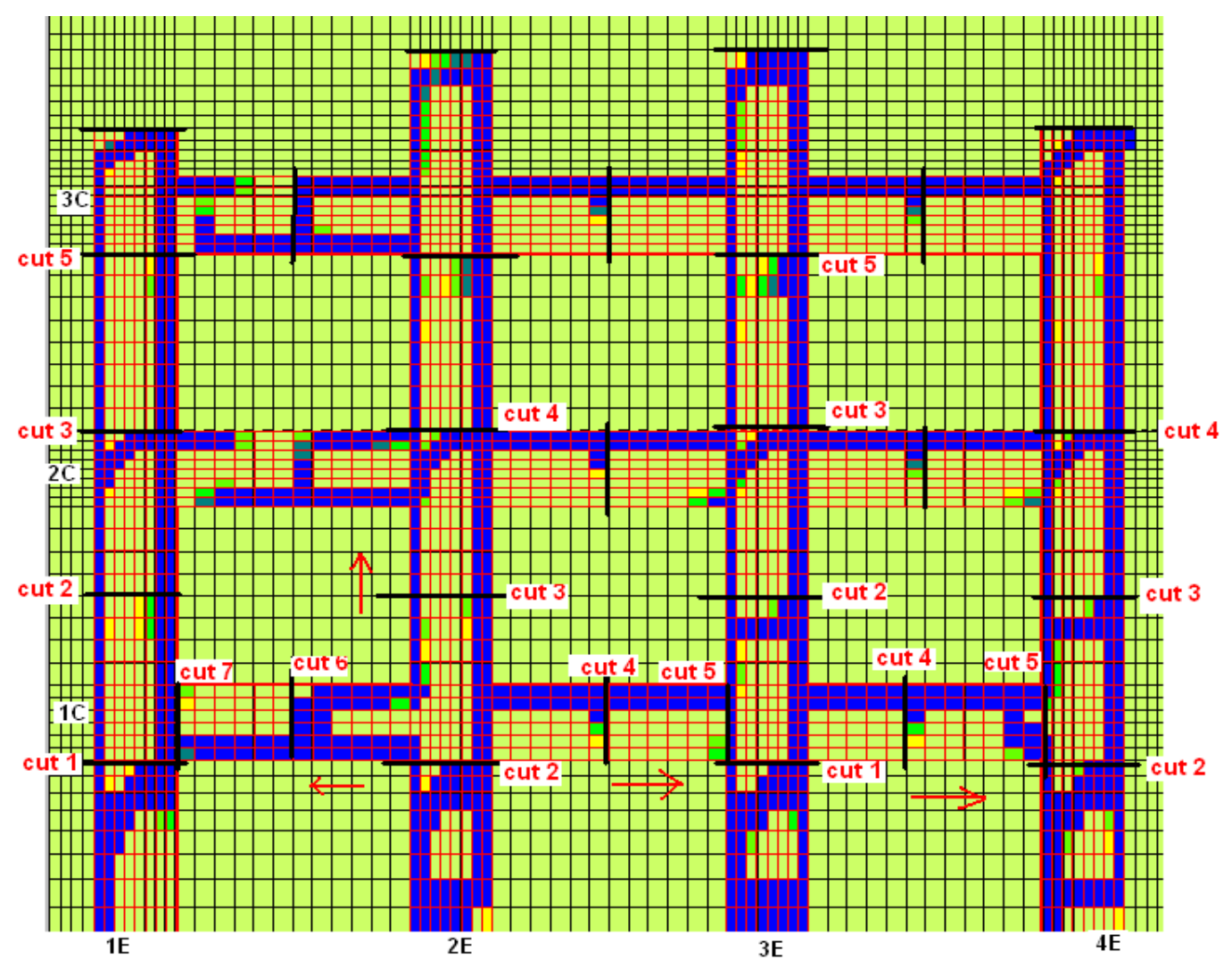

a. face position (cut sequence type 1)

b.

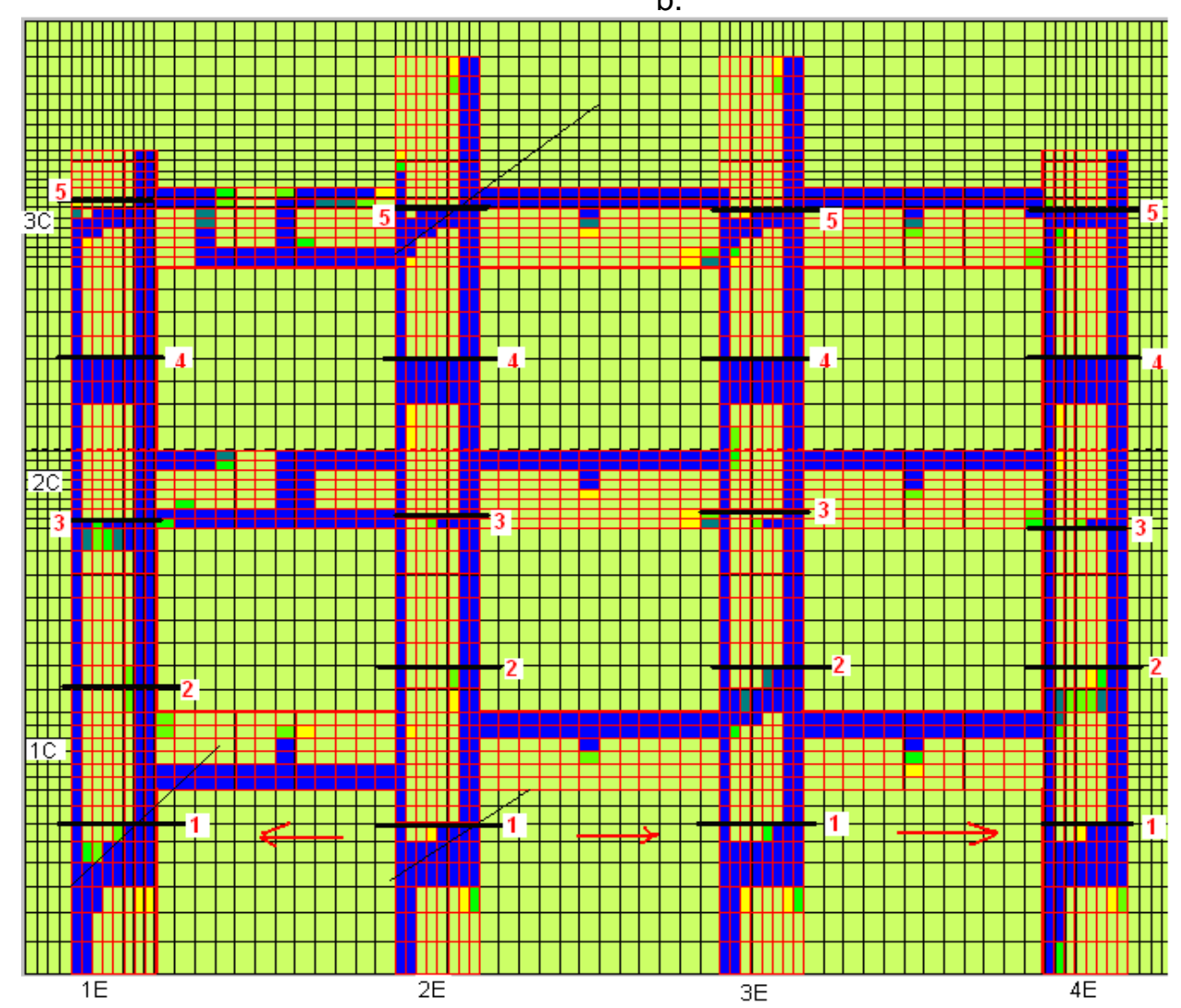

b. face position (cut sequence type 2)

Figure 6.45 Effect of face location on cutter pattern 


\subsubsection{Effect of Turn Out Direction in Crosscut}

When $\mathrm{CM}$ turns into crosscut from the entry, the cutting direction in a sequence may be towards (Figure 6.46a) or away (Figure 6.46b) from the maximum horizontal stress direction.
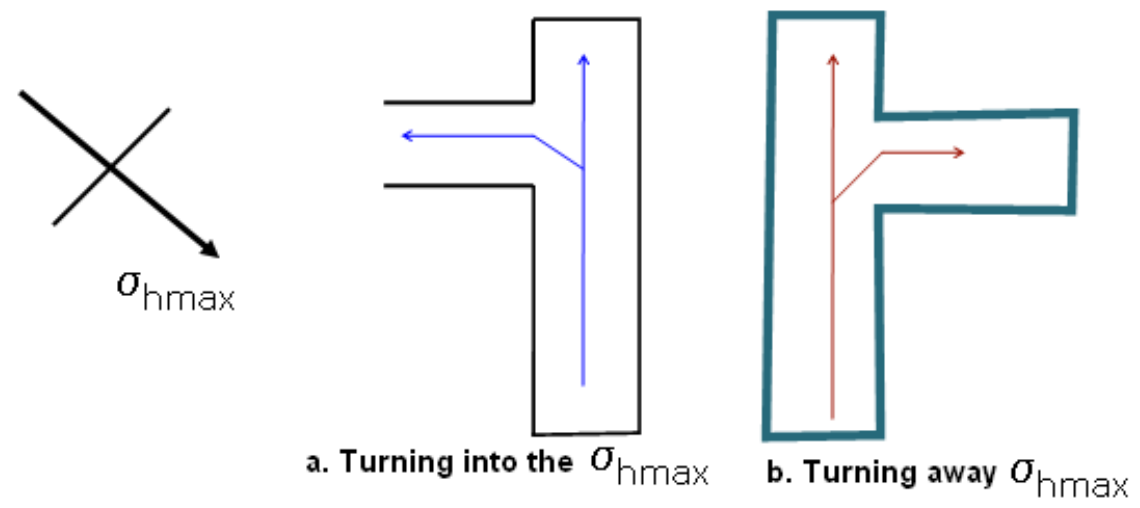

Figure 6.46 CM turn out direction in crosscut

The direction in which crosscuts are turned with respect to the direction of insitu horizontal stress may affect the cutter pattern in the crosscuts or at intersections. Two models were solved for the cutting sequences shown in Figure 6.47 for the same stress ratio and rock properties for a stress orientation of $60^{\circ}$. In one cutting sequence the cut direction in crosscuts are away from the maximum horizontal stress between entries 2 and 4 while this is into the maximum horizontal stress direction between entry 1 and 2 (Figure 6.47a). In another cutting sequence (Figure 6.47b) all cut direction in crosscuts are in a direction away from the maximum horizontal stress direction.

Figure 6.47 shows the cutter pattern observed due to change in cut direction in the crosscuts. Due to change in cut direction in crosscuts the first obvious difference is in the location of the cutter. The cutters occurred towards the left edge of the crosscuts between entry 1 and 2 while on right edge of the crosscuts between 

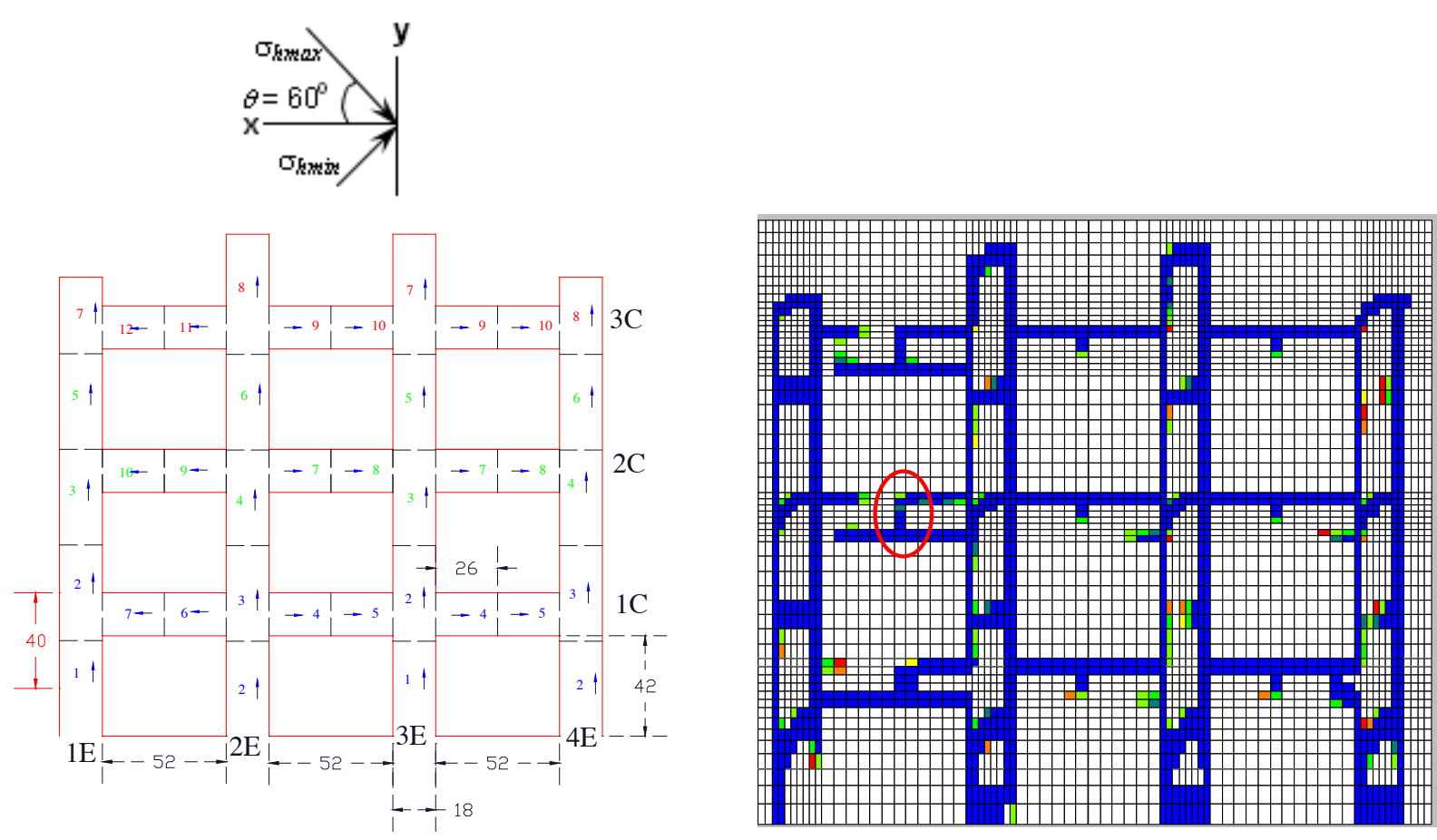

a. Cutter pattern when cross cuts are turned both into and away from maximum horizontal stress
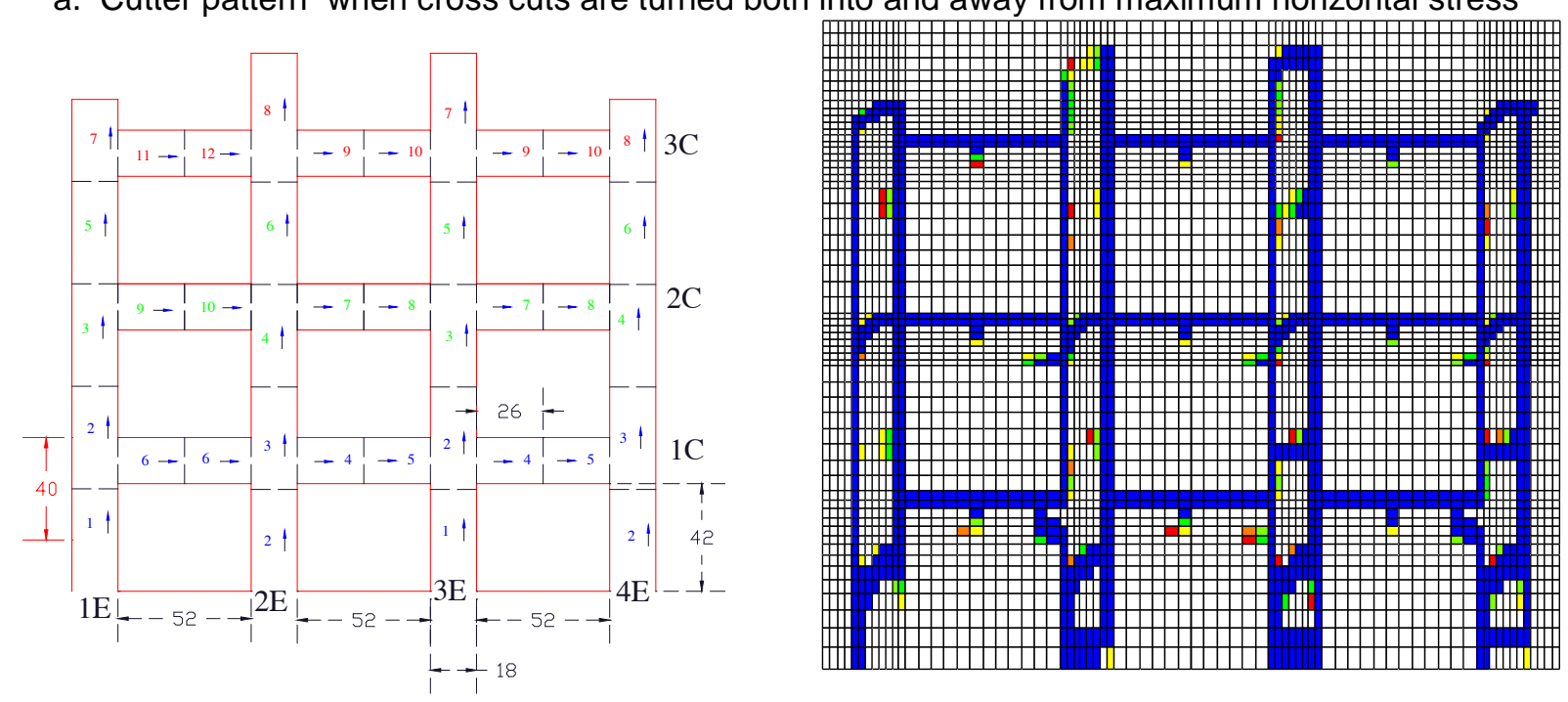

b. Cutter pattern when cross cuts are turned away from maximum horizontal stress

Figure 6.47 Variation in cutter pattern due to change in turn out direction

entries 2 and 4 . When cut direction is into the direction of maximum horizontal stress, the cutter forms on both edges of the crosscuts and it also joins near the face position. Thus the cutter severity is more when turn outs are made into the direction of maximum horizontal stress in comparison to that when the direction of turn outs 
are away from the maximum horizontal stress. However, these observations are valid for very weak roof. As we can see with increase in peak cohesion strength of immediate roof, the cutter severity and cutter location doesn't change with cut direction (Figure $6.29 \mathrm{~d}$ or e).

\subsubsection{Effect of Step Face Cutting on Cutter Severity}

A step-face method of development is one in which a block of coal is left on the side of stress concentrations at the face, thus forming a stair-step type of face area as compared to the regular straight face as shown in Figure 6.48. It may be noted that the step-face will still have stress concentrations due to the sharp corners; but because of the chunk of coal left, the magnitude of stress concentrations will be reduced. The design of the required size of the 'step' (length ' $d$ ' only, since the width of the step is fixed by the entry size and boxcut width) is dependent on the site specific conditions and numerical modeling may be the right way to evaluate its viability and effectiveness to reduce the cutter or roof falls.

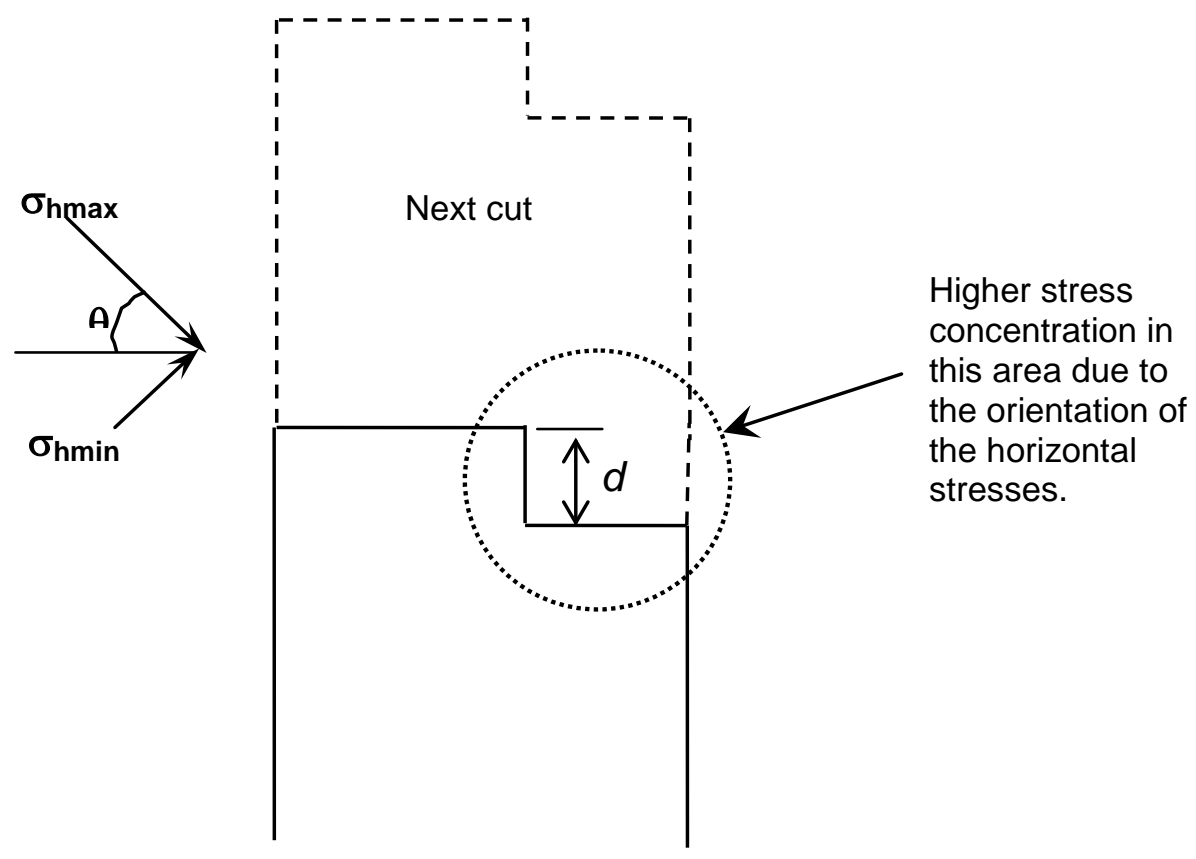

Figure 6.48 Step-face method of development to reduce the chances of cutter initiation 
Numerical modeling was carried out for single entry model (Figure 5.19) with same properties and stress ratios for an orientation, $\theta$ of $60^{\circ}$. Models were solved for cut length $20 \mathrm{ft}$ and $30 \mathrm{ft}$ with step length from 10 to $30 \mathrm{ft}$. Figure 6.49 shows the cohesion distribution for different step length. From model results it can be seen that for a cut length and step length of $20 \mathrm{ft}$ no cutters are observed either near the face or at the edges of the entry in the roof (Figure 6.49a). Similar observations were found for cut length of $30 \mathrm{ft}$ with a step length of $20 \mathrm{ft}$ (Figure 6.49c). For step length of $10 \mathrm{ft}$ with cut length as $30 \mathrm{ft}$, the cutters are formed at the left edges of the entry (Figure 6.49b). Further with increase in step length to $30 \mathrm{ft}$ no cutters appears but the post failure cohesion value is very less (5 to 15 psi). Hence from stability point of view step length of $20 \mathrm{ft}$ is much better than $30 \mathrm{ft}$ for a cut length of $30 \mathrm{ft}$.

Figure 6.50 shows the major principal stress plots for a regular and step face with step length of $20 \mathrm{ft}$ for a cut length of $30 \mathrm{ft}$. For normal cut (Figure 6.50a), many elements in the immediate roof have tensile stress and very low compressive principal stress which indicates a stress relieve zone in the immediate roof. But when step face is used the stress relieve zone is very small compare to normal straight face. This indicates that the rock can still withstand more stress and the elements have not reached in the post failure region. Similar behaviour were observed with minor principal stress (Figure 6.51)

Hence from the modelling results it is obvious that under very weak roof, the cutters can be avoided by developing mine openings as step face with suitable step length. For this case $20 \mathrm{ft}$ step length is best either for $20 \mathrm{ft}$ or $30 \mathrm{ft}$ cut length. 
Cohesion, psi

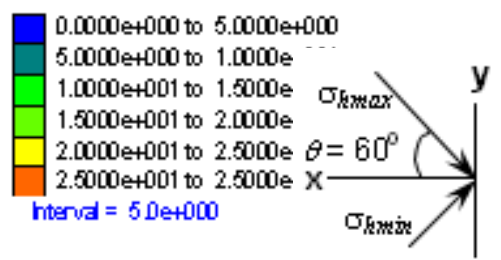

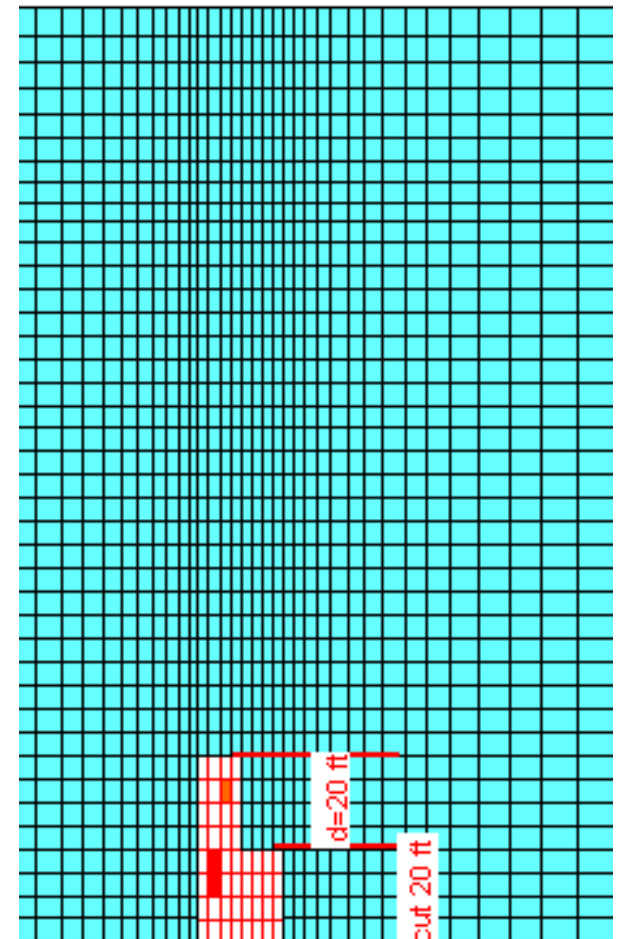

a. cut length $20 \mathrm{ft}$ with step length of $20 \mathrm{ft}$
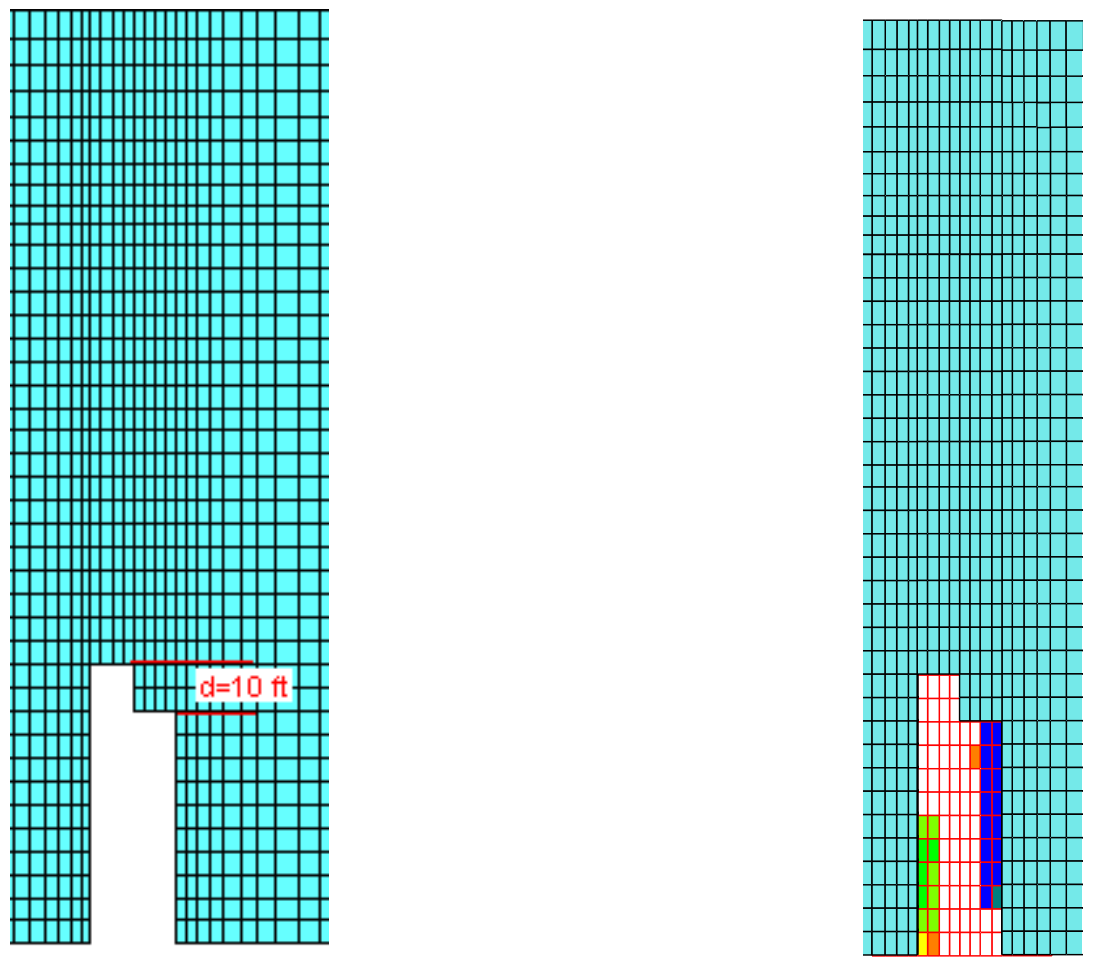

b. cut length $30 \mathrm{ft}$ with step length of $10 \mathrm{ft}$ 

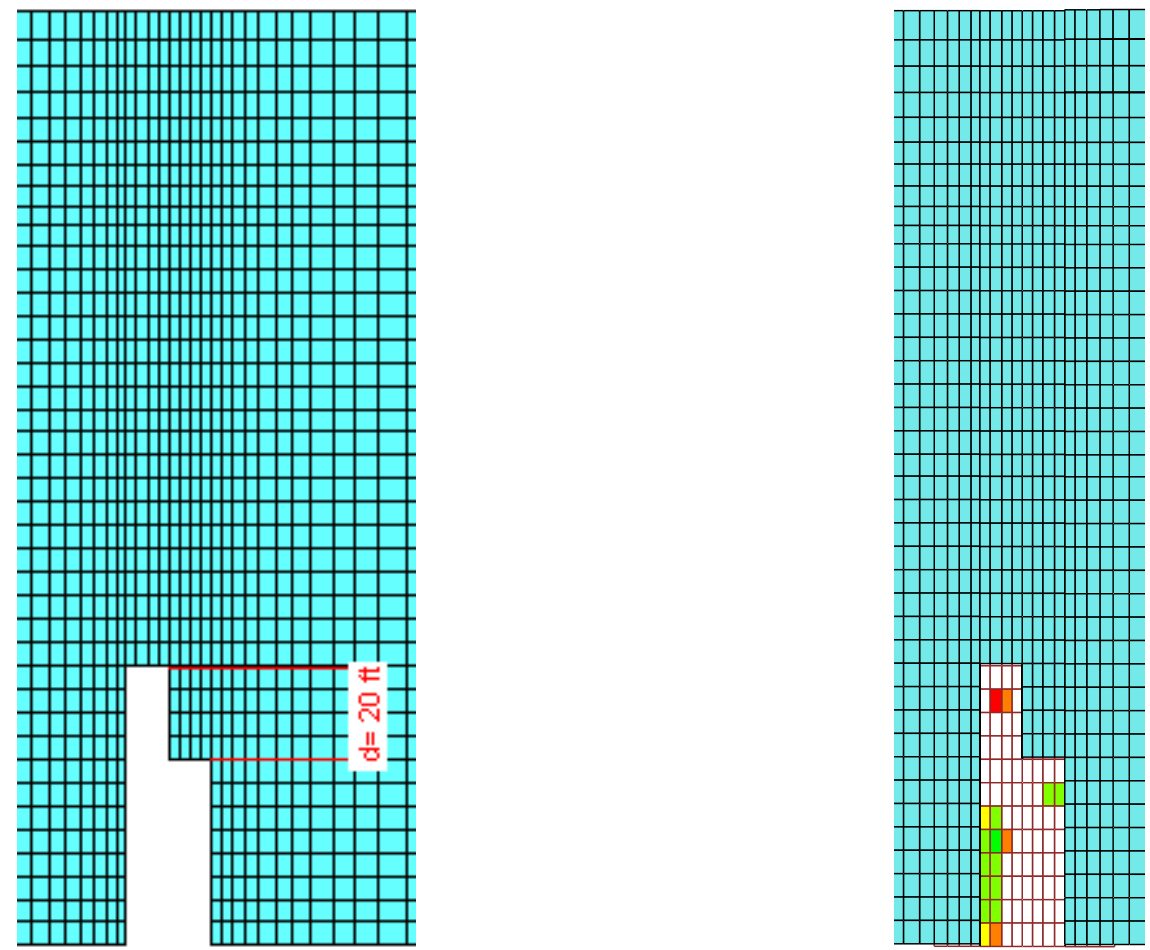

c. cut length $30 \mathrm{ft}$ with step length of $20 \mathrm{ft}$
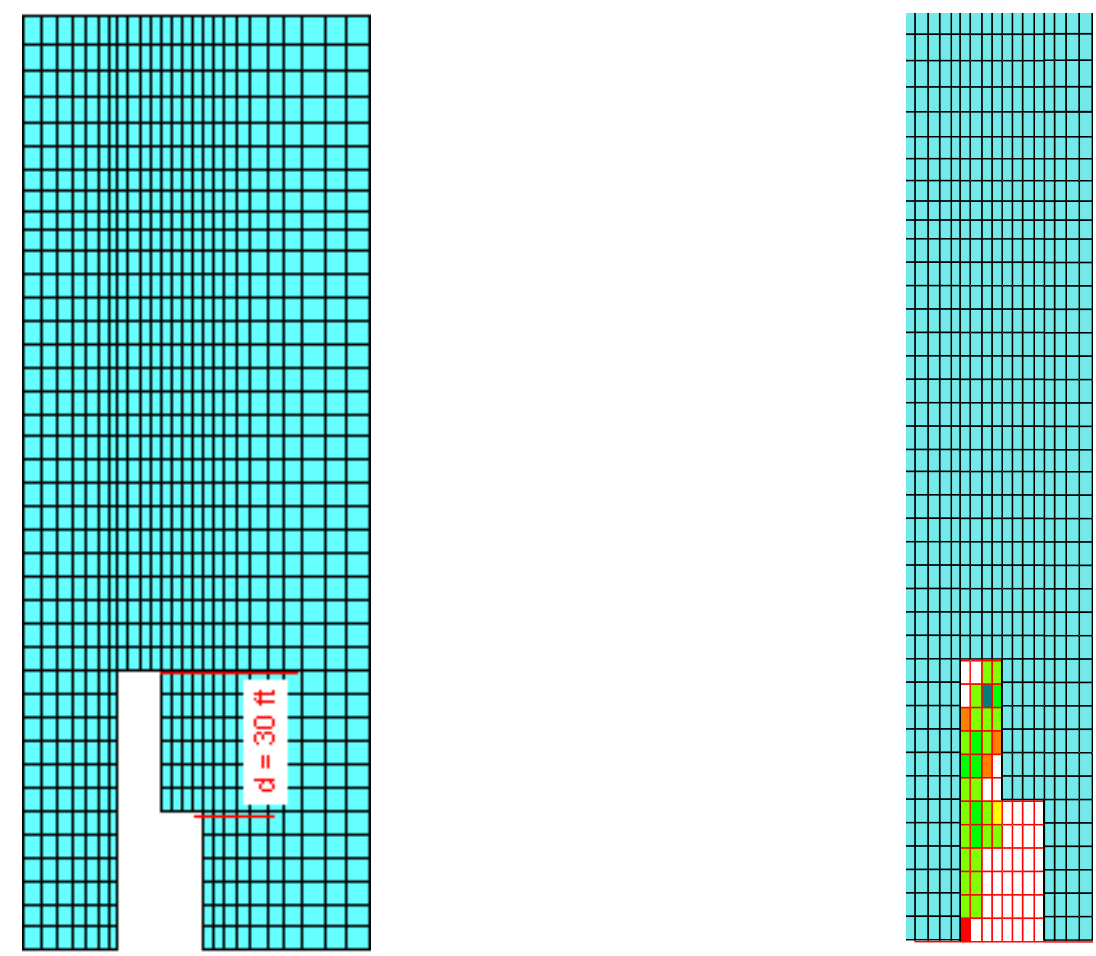

d. cut length $30 \mathrm{ft}$ with step length of $30 \mathrm{ft}$

Figure 6.49 Cohesion (cutter) distributions in plan view of immediate layer in the roof 


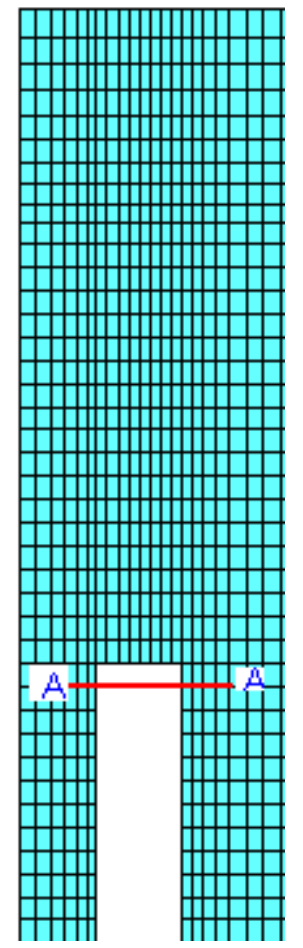

major principal stress, psi
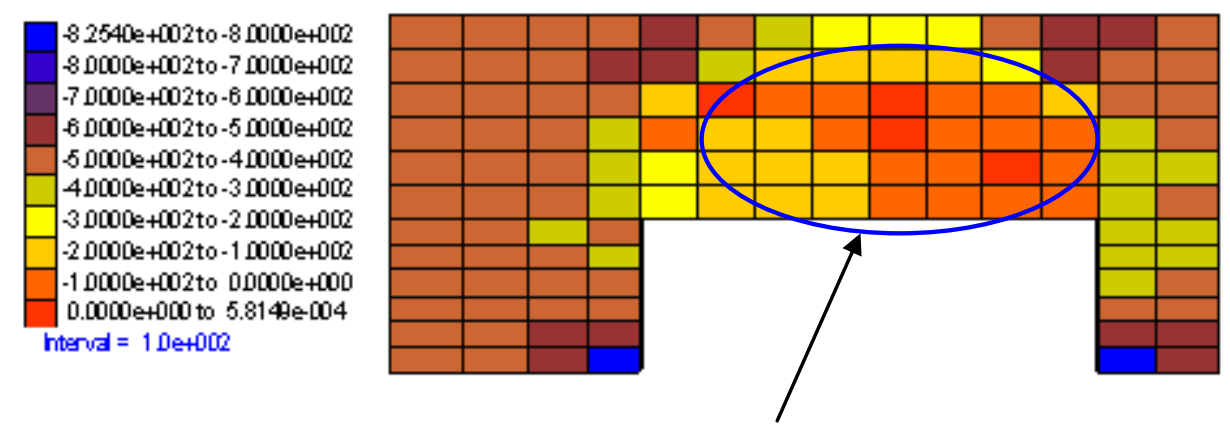

Stress relief zone

a. Major principal stress distribution in the roof near the face (AA) for regular $30 \mathrm{ft}$ cut

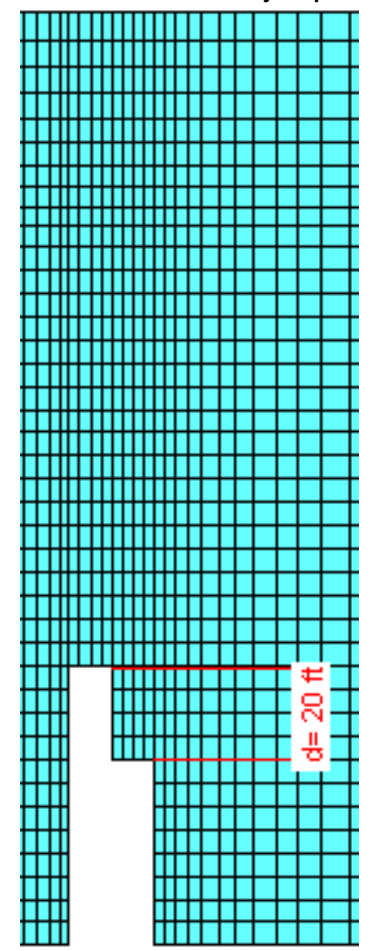

major principal stress, psi

$-70168 \mathrm{e}+002$ to $-7000 \mathrm{e}+00 \mathrm{cos}$ $-70000 \mathrm{e}+102$ to $-6.000 \mathrm{e}+002$ $-60000 \mathrm{e}+002$ to $-51000 \mathrm{e}+002$

$50000 \mathrm{e}+002$ to $-4000 \mathrm{e}+002$

40000 e +02 to $-30000+002$

30000 e +02 to -20000 e+002

-20000 e +02 to-1.4270e+002

intervad $=10 \mathrm{et002}$

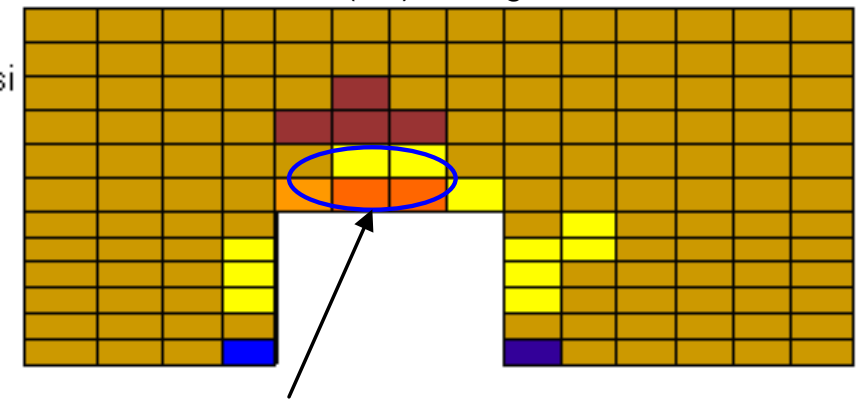

Stress relief zone

b. Major principal stress distribution in the roof near the face for step cut

Figure 6.50 Major principal stress for normal and step face 

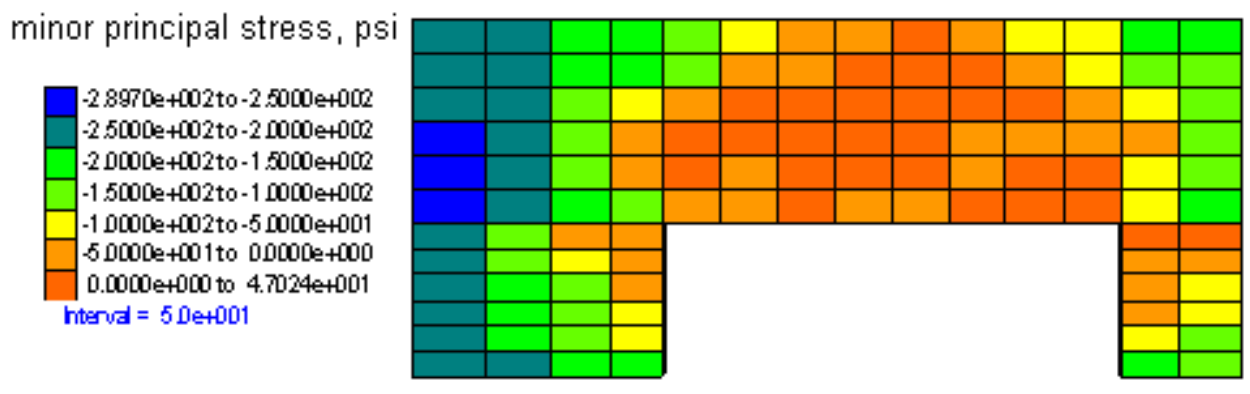

a. Minor principal stress distribution in the roof near the face for regular $30 \mathrm{ft}$ cut

minor principal stress, psi
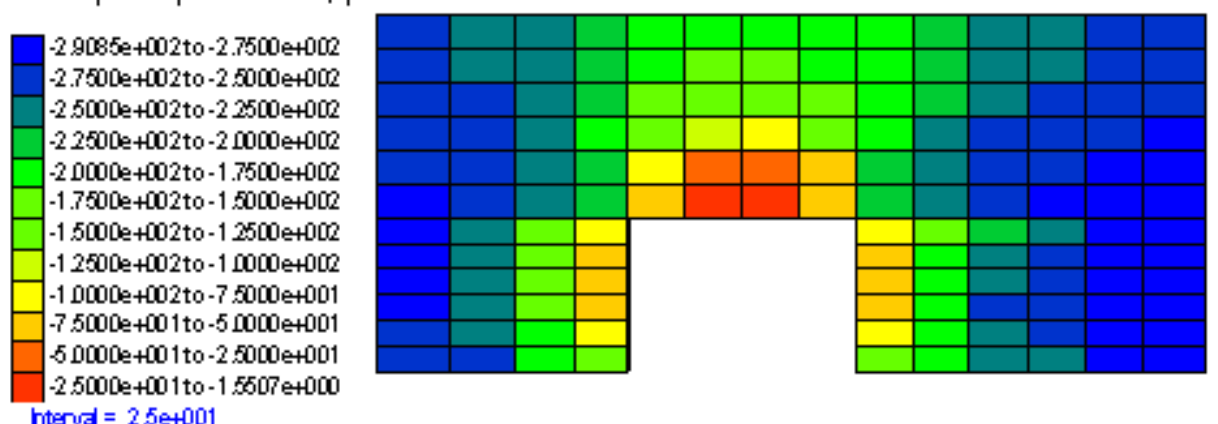

b. Major principal stress distribution in the roof near the face for regular step cut

Figure 6.51 Minor principal stresses for normal and step face

\subsubsection{Effect of Pillar Size}

Although at this time the exact influence of pillar size on cutter failures is not completely known, it is anticipated that pillar size will indirectly influence such failures as the degree of interaction between entries depends on the spacing between them. Further, the extent of rib yielding also depends on pillar size and hence under similar conditions, it is probable that a smaller pillar may trigger more cutter failures than a larger pillar. On the contrary, if the stiffness difference between coal and the immediate roof is large, then a stronger pillar may cause more roof failures than a smaller one. Similarly under very weak floor which is generally encounters in Illinois basin, the bigger pillar can be advantageous from both floor and roof stability point of view. The smaller pillar can cause floor heave which may initiate entry roof stability problems. 
For the case study mine, generally pillars were $40 \times 50 \mathrm{ft}$. rib-to-rib in mains and $40 \mathrm{x}$ $40 \mathrm{ft}$. rib-to-rib in production panels. The stability factor of these pillars during development is in the range of 4.3 to 5.0 for an entry width of $20 \mathrm{ft}$ and at an overburden depth of $250 \mathrm{ft}$. Hence these pillars are very stiff from ALPS or ARMPS stability factor point of view, but still lot of roof falls are taking place in this mine. In all cases of course pillars are stable and no pillar rib sloughing is observed in the mine. So far the authors has the knowledge, in development case there is no direct correlation with the pillar stability factor and entry roof stability. Entry roof stability is much more influenced by the entry width rather than pillar width. Under size pillar can cause pillar rib sloughing and in turn will increase the entry span and may lead to entry stability problems. Hence particularly at higher depth the bigger pillar size can avoid any pillar sloughing and thus can enhance the entry stability.

Two models with pillar sizes of $52 \times 42$ and $72 \times 62 \mathrm{ft}$ were solved to see how the cutter patterns are affected due to change in pillar size. The cutting sequence used for these models are shown in Figure 6.52. Figure 6.53 show the cohesion distribution plots for two pillar size. From the cohesion plots, the only major difference which was observed is that with increase in pillar size the cutters are formed only in one side of the entry whereas it was on both sides for smaller pillar (red ellipse in Figure 6.53). Apart from that no visible difference was observed in entries/crosscuts for these two sizes of pillars. Hence based on cutter pattern no definite conclusion can be made regarding the effect of pillar size.

To further investigate the effect of pillar size, for these two model shear strain rate were plotted (Figure 6.54). As we know that shear strain rate is an indicator of active plastic flow. From shear strain rate significant difference can be noticed for two pillar size. The maximum strain rate for smaller pillar is $2.16 \times 10^{-4}$ and that for 
bigger pillar is $1.5 \times 10^{-4}$ which is almost $35 \%$ less. Further at every location where flow is taking place, the shear strain rate has lower value for bigger pillar in comparison to smaller pillar. The location where flow is taking place is located both in entries and crosscuts for the pillars. However, the extent of active flow is less for larger pillar. This nature of strain rate indicates that although cohesion reduced to zero but the lower strain rate can cause delay in cutter or roof fall.

Hence it can be concluded that although pillar size is not showing significant change in cutter pattern and severity but larger pillar can have larger standup time before the fall in relation to smaller pillar. This was also observed with the case study presented in the next chapter 7 .

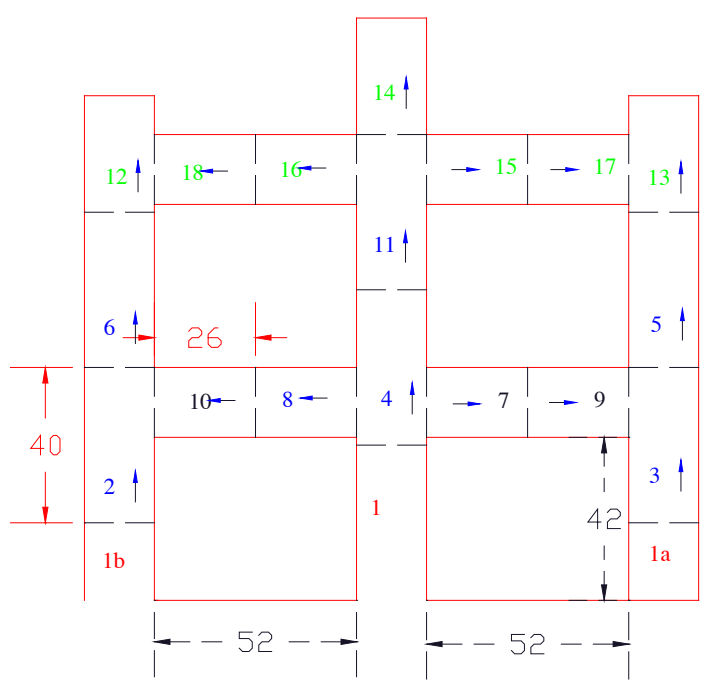

a. Cut sequence for $52 \times 42 \mathrm{ft}$ size pillar

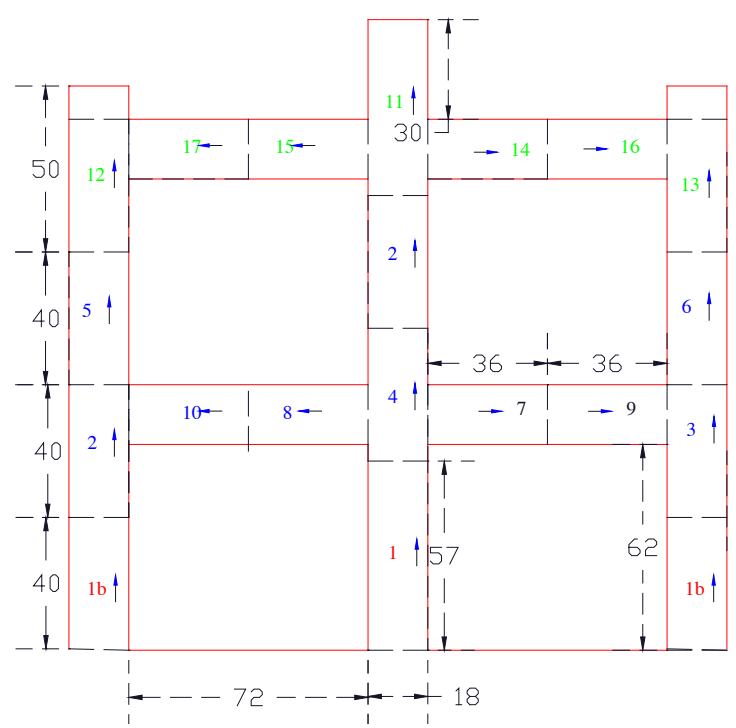

b. Cut sequence for $72 \times 62 \mathrm{ft}$ size pillar

Figure 6.52 Cutting sequence for different size of pillar 
Cohesion, psi
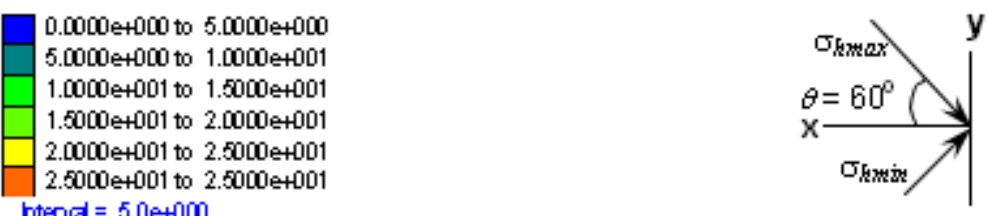

hiterud $=50$ e+000

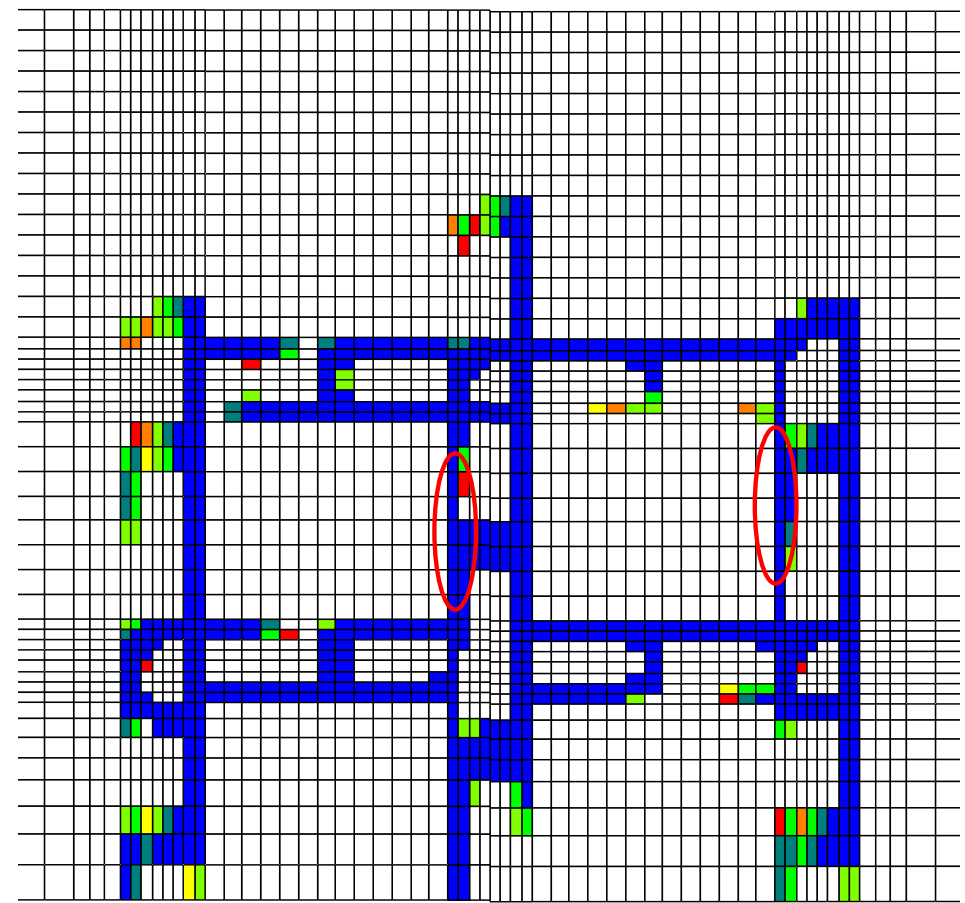

a. Pillar width $52 \mathrm{ft}$ and length $42 \mathrm{ft}$

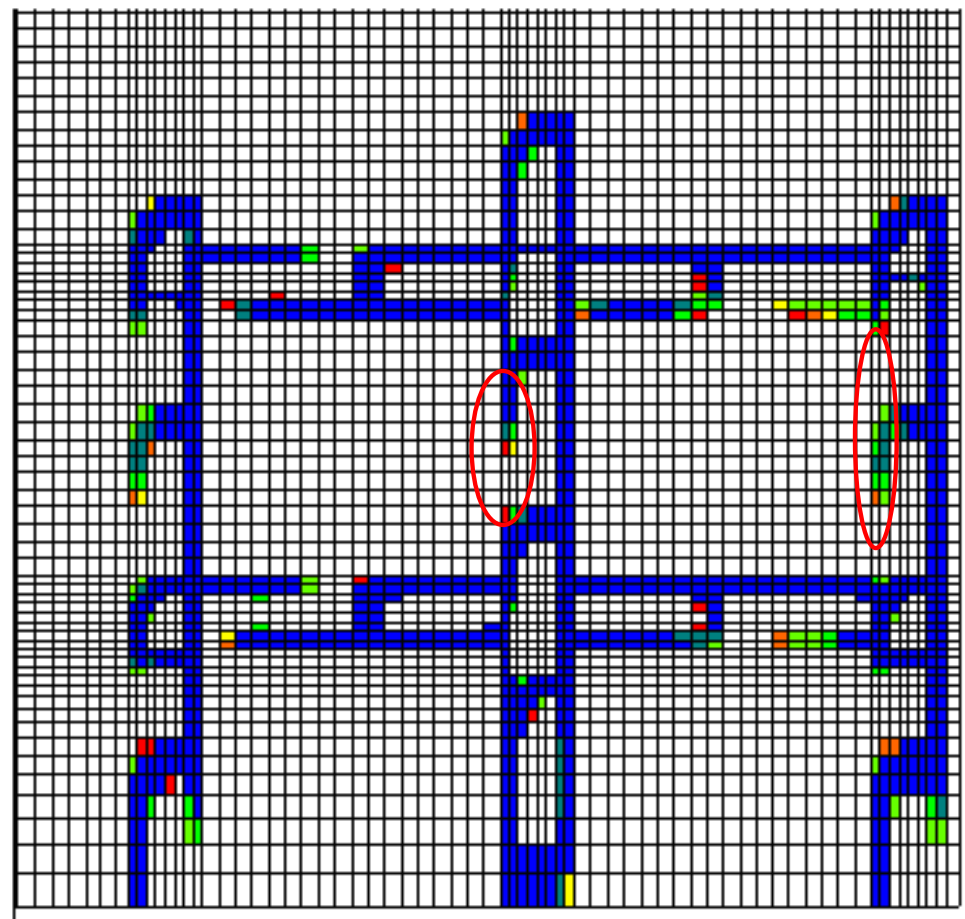

b. Pillar width $72 \mathrm{ft}$ and length $62 \mathrm{ft}$

Figure 6.53 Cohesion distributions in immediate roof layer for different pillar size for cut sequence shown in Figure 6.52 
shear strain rate

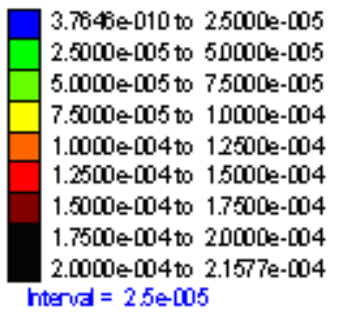

shear strain rate

$3.1676 \mathrm{e}-09$ to $20000 \mathrm{e}-005$ $2.0000 \mathrm{e}-005$ to $40000 \mathrm{e}-005$ 4.0000 e 005 to $60000 \mathrm{e}-005$ 6. $0000 \mathrm{e}-005$ to $80000 \mathrm{e}-005$ 8.0000 e 005 to $10000 \mathrm{e}-004$ 1.0000 e 004 to $12000 \mathrm{e}-04$ 1.2000 e- 004 to 1.4000 e- 004 $1.400 \mathrm{e}-04$ to $1.4988 \mathrm{e}-004$ hterval $=20 \mathrm{e} 005$

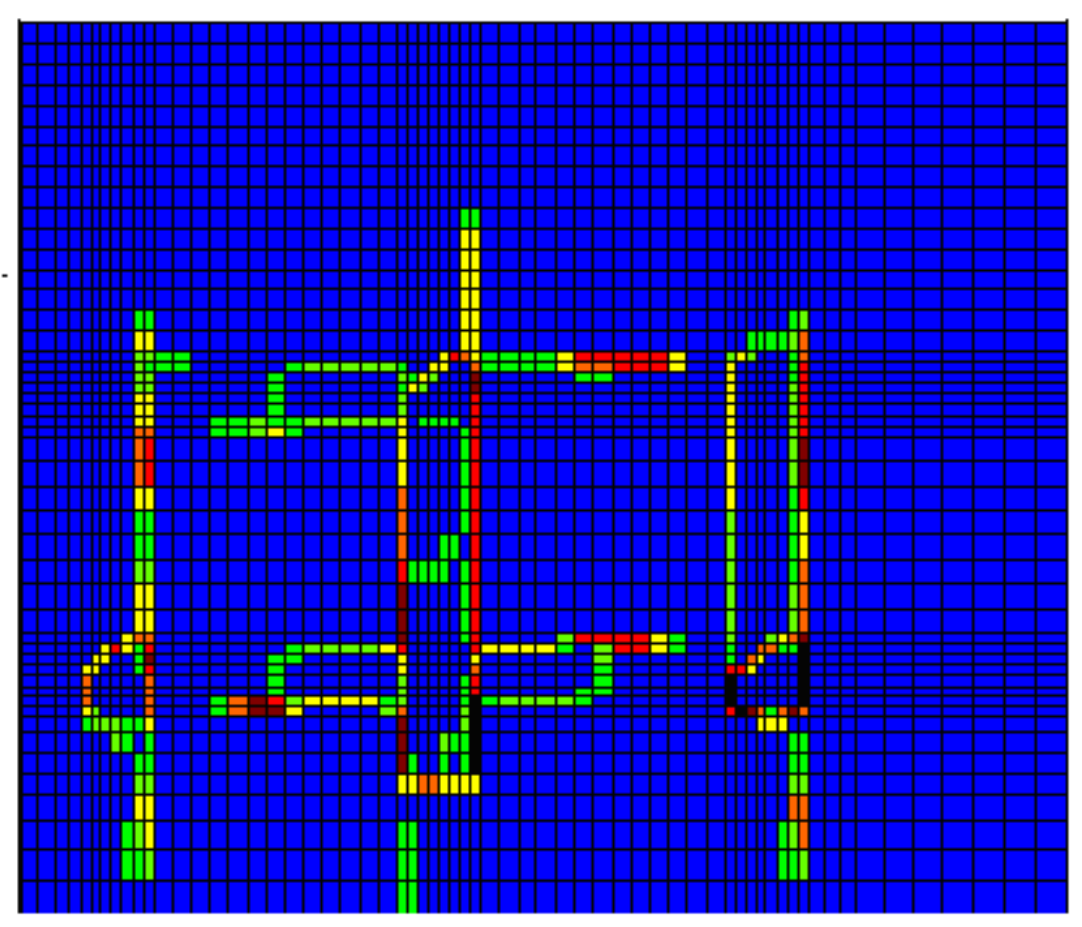

a. Pillar width $52 \mathrm{ft}$ and length $42 \mathrm{ft}$

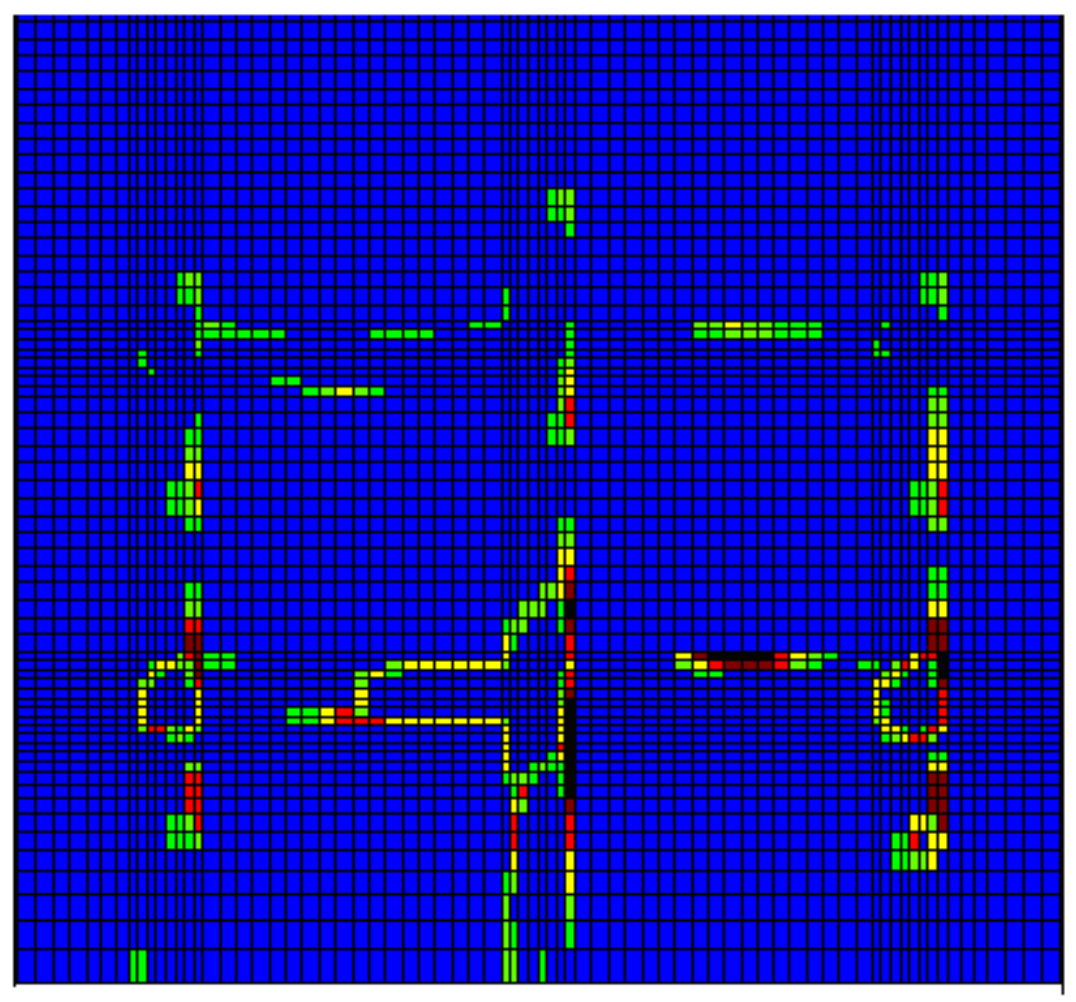

b. Pillar width $72 \mathrm{ft}$ and length $62 \mathrm{ft}$

Figure 6.54 Shear strain rate in immediate roof layer for different pillar size for cut sequence shown in Figure 6.21b 


\subsection{CHAPTER SUMMARY}

From the modeling results performed in this chapter following conclusions can be drawn:

For horizontal stress angles other than $0^{\circ}$ and $90^{\circ}$, the cutter patterns differed significantly between the models where all the excavations were created in a single step and when the cutting sequence was considered. With sequential cutting in the model, the cutter patterns appeared more realistic. Therefore, it is extremely important to solve numerical models while including the proper cutting sequence to get realistic cutter patterns. This is especially true when the immediate roof rocks are weak. For assessing the short-term stability of the face area during a cut, the cut sequence may not have a significant influence on the model results. Multiple cuts appear to affect the stress distributions outby the face more than near the working area.

There is a significant difference in the failure patterns obtained from a singleentry and a multiple-entry model. Since in reality there are always multiple excavations in close proximity to each other to have some interaction effects, for a realistic cutter simulation, multiple openings must be considered in the numerical models.

Among all the factors that could affect cutter distribution in a panel, the modeling results suggest that it is the cutting sequence and the spatial variability of rock strength that play the overriding roles. The erratic spatial distribution of cutters noticed in underground coal mines can be reasonably reproduced in numerical models if proper cutting sequence and change in rock properties with location are included along with the strain-softening constitutive model in the simulation. 
$>$ It is the relative magnitude of the in-situ stresses as compared to the rock mass strength that determine the severity of the cutter problem. Just the values of horizontal and vertical stresses by themselves do not mean much if the rock is stronger.

For very weak immediate roof, modeling shows that right at the location of the face during each cut, some fracturing in the roof may occur before the next cut is taken. The bridging effect created by these fractures at the face location may connect the cutters developed at the two ribs of an entry or crosscut. Similarly, if the face location happens to be the next intersection, then the fracturing occurred at the face area may be the primary reason why cutters cross across the intersection. Depending on how the roof yields near the face location during a cut, the cutters running across an intersection may or may not align with in-situ minor horizontal stress direction.

For everything else being the same, the model results show that the severity and spatial distribution of cutters in a panel primarily depend on the two in-situ stress ratios: $k$ and $l$. Irrespective of the rock strength used in the models, no cutters were found for very low $k$ values. This is not to say that cutters can not occur in a low stress environment. Owing to time-dependent strength degradation, cutters may still develop when $k$ is low. However, the processes involved are not well understood when the time effects are important. From a relative comparison of the modeling results in this research, it may be qualitatively stated that in a low in-situ stress environment, the stand-up time of excavations will be higher as compared to a high pre-mining stress situation.

The modeling results show that severity of cutters may be high even when $l=1$, if the ratio of in-situ horizontal to vertical stress is greater than 1.0. 
$>$ In order to observe the biased distribution of cutters concentrated in either entries or crosscuts, modeling shows that the ratio of maximum to minimum horizontal stress should be high. As $l$ value comes closer to 1.0 , cutters will be found everywhere in a panel.

$>$ If the value if $l$ is such that the minimum horizontal stress is greater than the vertical stress, then very severe cutters can occur. In this situation, orientation of the panel with respect to horizontal stresses will not matter in minimizing the roof instability.

The modeling results in this dissertation suggest that whether altering the orientation of a panel with respect to regional stresses will provide improved roof conditions or not depends on several site specific factors like the magnitude of $k$, $l$, rock mass strength, cutting sequence etc. In order to arrive at the best orientation of the panel, it is recommended to conduct site-specific numerical modeling as the general guidelines may not always work for every possible real world situation.

From a purely theoretical consideration, it appears that for exceptionally weak roof situations, cut lengths equal to or less than the entry width will provide the best possible roof stability. While productivity in such cases will be severely impacted by the small cut lengths, it is believed that the time saved in cleaning roof falls and improved safety in such mining conditions may compensate for the loss.

The location of the working face in a particular cut with respect to a future intersection in that area is responsible for cutters running across an intersection. By adopting proper cutting sequence and different cut lengths, it may be possible 
to improve ground control in intersections by limiting the number of times the working face has to stop in a future intersection. Cutting sequence by itself can not eliminate cutters. But, it can help minimize the spatial extent of the cutters.

For both weak and strong roof conditions, turning the crosscuts away from the maximum horizontal stress direction will help improve the roof stability.

$>$ Even though some practical issues may need to be resolved, purely from a ground control view point, the step-face cutting pattern suggested in this dissertation may improve the ground stability in weak roof conditions.

Development of an optimum cutting pattern may be critical for extremely weak to weak roof stability. 


\section{CHAPTER 7}

\section{TIME EFFECT ON ROOF FALLS}

\subsection{INTRODUCTION}

Change in the local stress state due to mining disturbs the stability of the surrounding rock mass. The subsequent readjustment of the rock towards a new equilibrium does not occur instantaneously but as a gradual process over time. Thus process can include two types of inelastic deformation namely "creep" movements and "roof fall". Depending on the rock type and the stress conditions, excavations can show propensity towards either of the two phenomenons. It is necessary to determine the conditions associated with the transition from stable deformation of the opening to roof fall. Although stable deformation is preferred, excessive creep like movements are also undesirable as they may significantly affect long term stability of the underground mine. This chapter attempts to include the time dependent effect in coal measure rocks.

Rock exhibit time dependent deformation which is evident from the few laboratory studies conducted and field observations. It is well known fact now that the coal mine structure like roof and floor above the entries and coal pillars do not fail immediately after the excavation but sometimes later depending upon the nature of the rock and stress environment. This can be well supported with the case studies presented in following sections. Two special time dependent phenomenon are of interest to ground control investigation: 'creep' and 'relaxation'. In creep, a material continues to exhibit increasing strain with time at the same stress level. Whereas in relaxation, the material stress decreases with time when the strain on the specimen 
is kept constant. But creep is most common time dependent phenomenon associated with rocks in coal mine.

\subsection{CREEP PHENOMENON IN ROCKS}

Figure 7.1 schematically illustrates the form of creep curves as obtained with uniaxial creep tests, which are unconfined compression tests with a constant load, $\sigma$ (Erichsen and Werfling, 2003). The stress $\sigma$ leads to elastic deformations $\varepsilon^{e}$ independent on time and creep deformations $\varepsilon^{c}$ depending on time. If the creep stress ' $\sigma$ ' is smaller than a stress $\sigma_{F}$ (uni-axial yield stress), the increase of the creep

deformation with time, i.e. the creep rate, $\varepsilon^{c}$ is largest after applying the creep stress and then converges to a constant value. The creep deformation during this period can be subdivided into two components. One is called primary component of the creep deformation $\varepsilon^{p}$, which converges to a constant value and does practically not anymore increase after a certain time. Therefore, the primary creep is also called transient (non-steady) creep. The other component is known as secondary or steady state component of the creep deformation $\varepsilon^{s}$. It increases linearly with time in a uniaxial creep test $\left(\varepsilon^{s}=\right.$ constant). If the creep stress is larger than the yield stress $\sigma_{F}$, the creep curve usually has a point of inflection. After a delayed creep at the beginning, an accelerated creep process starts as soon as the inflection point is passed finally leading to a creep failure (Figure 7.1). This behavior can be interpreted by a tertiary creep portion $\varepsilon^{t}$, increasing over proportionally with time and being superimposed to the elastic, primary and secondary deformation components.

A general equation for the creep is given by-

$$
\varepsilon=\varepsilon_{e}(t)+\varepsilon(t)+A t+\varepsilon_{T}(t)
$$

where, $\varepsilon$ is total strain, $\varepsilon_{\mathrm{e}}$ is the elastic strain, $\mathrm{t}$ is time and $\mathrm{A}$ is a constant. 
$\varepsilon_{T}(t)$ is a function expressing the accelerating creep of the tertiary stage and $\varepsilon(t)$ is a function expressing the decelerating creep of the primary stage

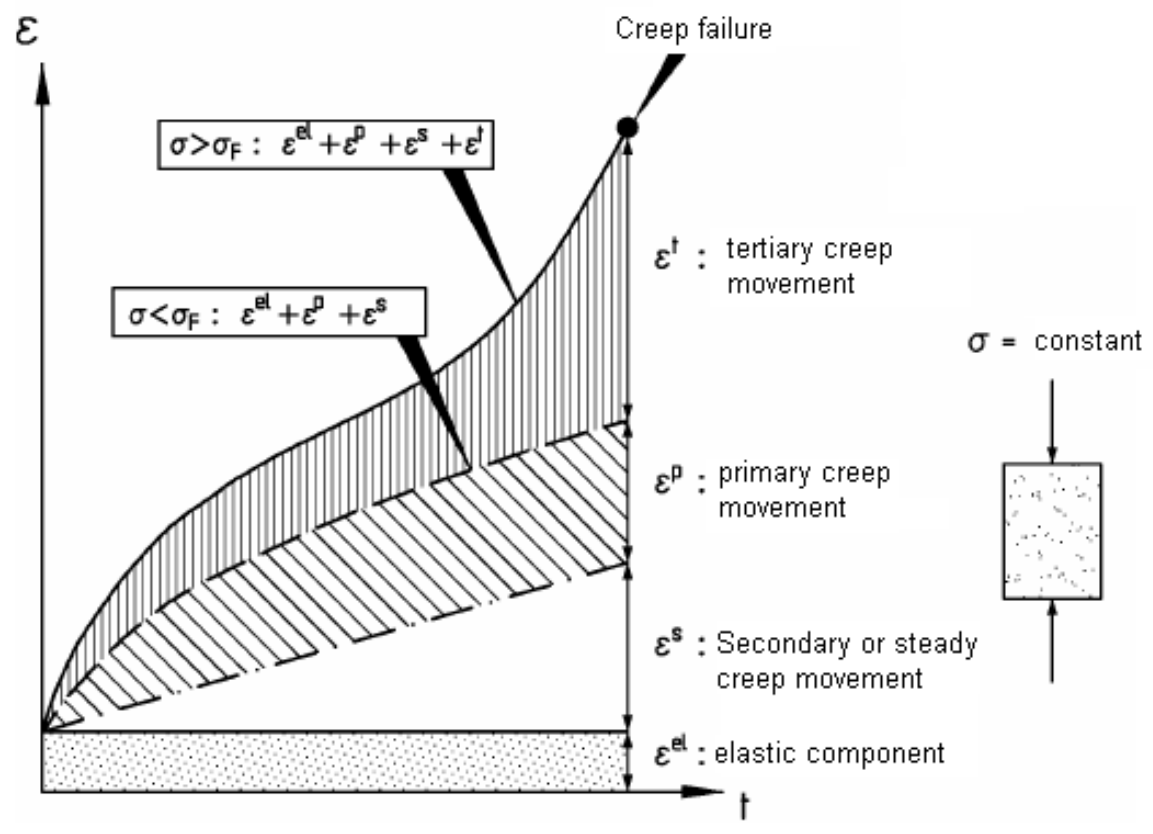

Figure 7.1 Primary, secondary and tertiary creep in a uni-axial creep test (after Erichsen and Werfling, 2003)

Price (1964) conducted uni-axial compression experiment on rock specimen with an aim to get information for the secondary creep. He generated a time-strain relation for a single specimen subjected to a number of different stress levels during the test. The specimen was first subjected to a compressive stress of 8600 psi and this stress level was maintained for 30 days. After that stress level increased to 9600 psi and continued up to 68 days. The stress level after 68 days increased to 10,300 psi and maintained for a total time of 230 days. After 230 days the stress increased to 11,800 psi and maintained this level for the remainder of the test. Figure 7.2 shows the overall time-strain data observed during uni-axial compression creep test or the rock specimen 'calcareous siltstone'. The rate of secondary creep during various stress levels are given in Table 7.1. 


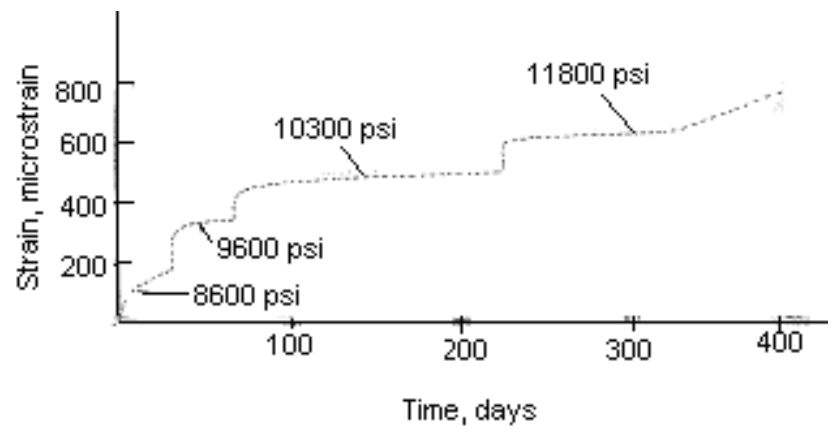

Figure 7.2 Time-strain data for calcareous siltstone at different stress level (after Price, 1964)

Table 7.1 Rate of secondary creep with stress level

\begin{tabular}{cc}
\hline $\begin{array}{c}\text { Stress level, } \\
\text { psi }\end{array}$ & $\begin{array}{c}\text { Rate of secondary creep, } \\
\text { S/day }\end{array}$ \\
\hline \hline 8600 & 1.5 \\
9600 & 1 \\
10,300 & 1 \\
11,800 & 0.5 \\
\hline
\end{tabular}

Normally the creep rate increases with increase in stress level. But in this test the reduction in secondary creep rate with increase in stress level can not be explained theoretically. The reduction in creep rate indicates that the rock will behave strain-hardening with time. But there is no evidence to indicate that rocks undergo strain hardening and even in metals where strain hardening is observed, it is greatly reduced by creep. It was apprehended that the deformation of the specimen at a low level of stress may have affected subsequent time-strain data obtained at a higher stress level. But it again contradicts the normal behavior of rock under creep test. Actually if it is assumed that at low stress level the specimen is partially deformed then at higher stress level, this partial failure can enhance to a disproportionately higher rate of creep. So this type of test doesn't signify any thing. It may be better to do the creep test on differ rent rock specimen at different stress level to avoid this type of confusion. 
Schwartz and Kolluru (1982) have studied the influence of stress level on the creep of unfilled rock joints. The creep tests were conducted on the intact and jointed samples, made from gypsum plaster. He studied the effect of applied stress for different joint orientations i.e. joint normal to applied stress and inclined to applied stress. Figure 7.3 shows the intact specimen creeps at different applied stress $\sigma$ in terms of uni-axial compressive strength $\left(\sigma_{c}\right)$. The axial creep strains increases with increase in creep stress. Figure 7.4 shows the increase in additional creep axial strain due to presence of joints/bedding planes in a direction normal to the applied stress, $\sigma$. The joints add another 20 to 40 millistrain due to presence of joints. Similarly Figure 7.5 shows the increase in additional creep axial strain for joint oriented at different angle with respect to direction of applied stress. The creep strain attains maximum value for $\theta$ between 15 to $20^{\circ}$.

Amadei (1979) hypothesized that the ratio of applied joint shear stress to peak joint shear strength (stress ratio) is the critical factor governing joint creep. But after few testing conducted by Schwartz and Kolluru (1982) found that both the stress ratio and the average absolute stress level exert a strong influence on joint creep.

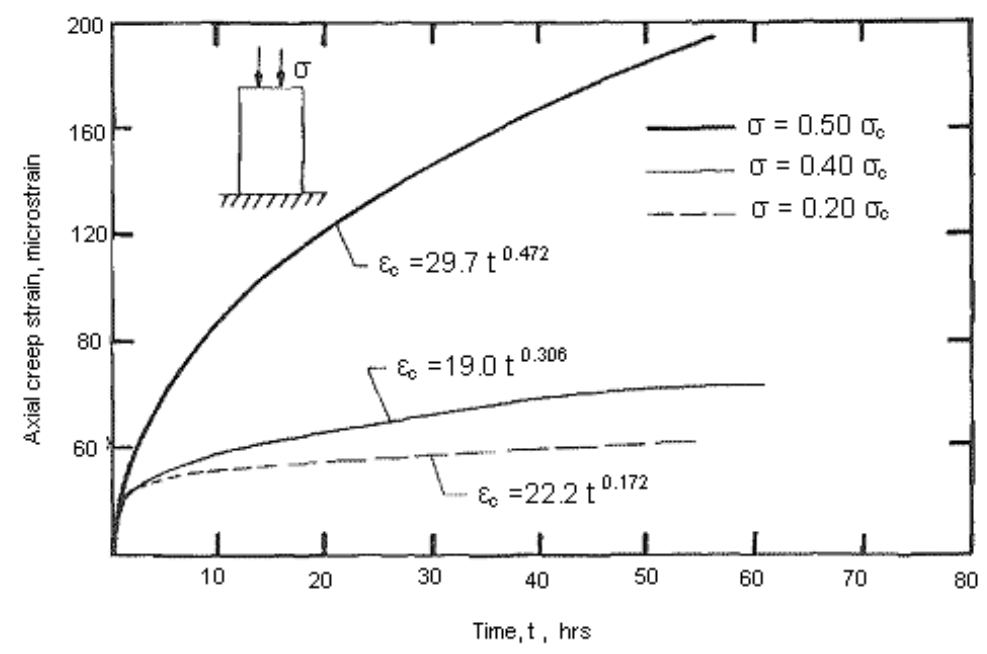

Figure 7.3 Intact specimen creep at three different stress levels (after Schwartz and Kolluru, 1982) 


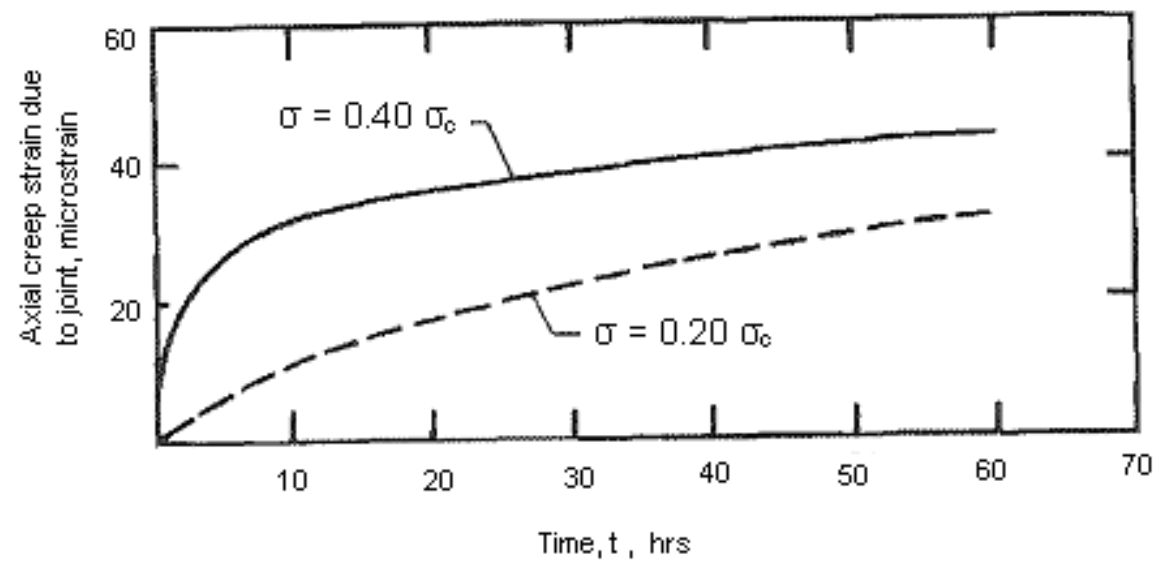

Figure 7.4 Effect of single joint normal to applied stress (after Schwartz and Kolluru, 1982)

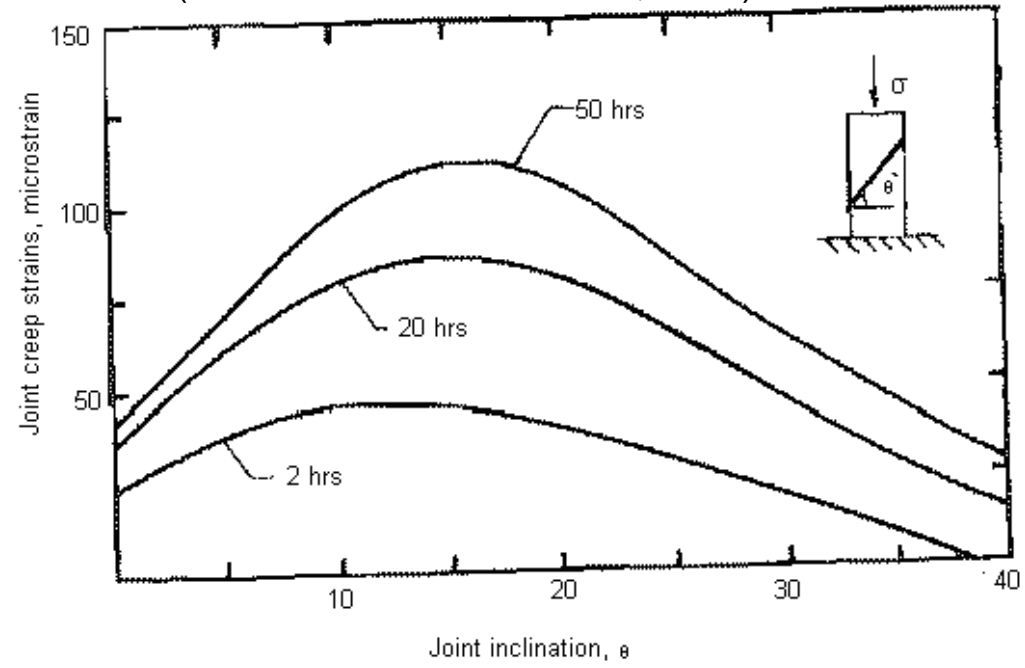

Figure 7.5 Effect of joint inclination on axial creep strain (after Schwartz and Kolluru, 1982)

Larson and wade (2001) have conducted direct-shear, constant velocity tests and direct-shear creep tests on 6 inch diameter mudstone cores to measure friction and creep characteristics of weak planes in the mudstone. He conducted the tests in similar fashion as conducted by Schwartz and Kolluru (1982) but considered the variation in the shear load, $\sigma_{\mathrm{s}}$, in conjunction with the normal applied load, $\sigma_{\mathrm{s}}$. He doesn't found any consistent correlation between creep rate and stress ratio $\left(\sigma_{s} / \sigma_{n}\right)$ He used rheological model as used by Bourkharov eta al. (1995). This rheological model defines one strength $\left(\sigma^{*}\right)$ above which only constant-rate creep (secondary creep) takes effect along weakness planes. For a simulation he has used this 
strength $\sigma^{*}$ as $58 \%$ of the applied normal stress. Although he also stated that it is not known whether this $\sigma^{*}$ is dependent on normal stress but test results suggested that weakening along bedding plane is dependent on total shear displacement.

Creep of rocks has been studied since the early $20^{\text {th }}$ century, resulting in large amount of data. However most of the studies have focused on the softer salt rocks because they show significant creep under stress and temperature conditions easily tested in the laboratory. In coal measure rocks, the amount of data from creep test is almost negligible. This chapter describes the advancement of creep testing, data calibration and mine monitoring of creep rates in salt mines. The chapter also describes the famous creep model Munson and Dawson, extensively used for predicting salt closure in caverns and salt mines and the power law which has been used for predicting creep deformation in coal measure rocks.

\subsection{TIME DEPENDENCY OF ROOF FALL AT MINE 'A'}

This mine ' $A$ ' is located in the Illinois basin of the USA. A partial map of the mine is shown in Figure 7.6. The mine is working in the Springfield seam by the conventional room and pillar mining method. The mine extracts coal from the development which is performed by two sets of continuous miner unit as a super section with each continuous miner turning out of the \#3 and \#5 entries. The north-south, south-east and $1^{\text {st }}$ south-west mains have been developed with 8 entries system while the $2^{\text {nd }}$ south-west mains have been developed with $11 / 12$ entries system. In the mains the entries and crosscuts are developed on $100 \times 100 \mathrm{ft}$ centers. The entries and crosscuts are 18 to $19 \mathrm{ft}$ wide. The submains are developed as 11 to 15 entries system. The pillars in submains are normally $80 \times 80 \mathrm{ft}$ centers. The mining height is between 5.5 to $6 \mathrm{ft}$. The surface topography is almost flat hence the overburden thickness is relatively uniform ranging from 250 to $360 \mathrm{ft}$. 


\subsubsection{Standup time of Roof Falls Observed at Mine ' $A$ '}

In this mine more than 55 roof falls have taken place in the last 4 years after the inception of the mine (Figures $7.7 \mathrm{a}$ and $\mathrm{b}$ ). The roof fall locations on the plan are shown as red circled zone. The roof falls are located in all mains and submains with some variation in the frequency of roof fall. Among these falls most number of the falls is located at the intersections. The stand-up times before the roof falls have a lot of variation. The standup time has been observed maximum in SE mains and it was least for the $1^{\text {st }}$ East panel. Figure 7.8 shows the stand-up time for the roof falls observed in the mine. The Figure 7.9 shows the roof fall distribution based on stand up time. It can be seen that more than $50 \%$ of roof falls have stand-up time in between 1 to 2 year whereas 12\% roof falls have less than 2 months. Among these falls more than $95 \%$ of fall initiated at intersections and then extended to the entry/crosscut at few locations. The roof falls dimension were also different from place to place in the mine. The maximum dimensions of the fall were $80 \times 80 \times 15 \mathrm{ft}$ and the least fall was having a dimension of $16 \times 18 \times 5 \mathrm{ft}$. Figure 7.10 shows the height of the roof falls observed. The maximum height of fall was $22 \mathrm{ft}$ and minimum as $5 \mathrm{ft}$ with an average value of $11 \mathrm{ft}$.

Some of the roof falls pictures from the mine 'A' are shown in Figures $7.11 \mathrm{a}$ to $h$. It can be seen that there is a lot of variation in the immediate roof rock characteristics. Most of the falls were started right from the edge of the entries. The roof fall debris appeared to have settled down in correct stratigraphic order, bounded by two vertical shear failures above the rib line. Generally it is believed that the rock failure takes place in shear but from Figure 7.11c, it can be observed that it may be a combination of shear and tension. Although shear failure is dominant one. In weak 
and thinly laminated rock, the tensile failure takes place between the roof bolts while shear failure initiates near the bolt.

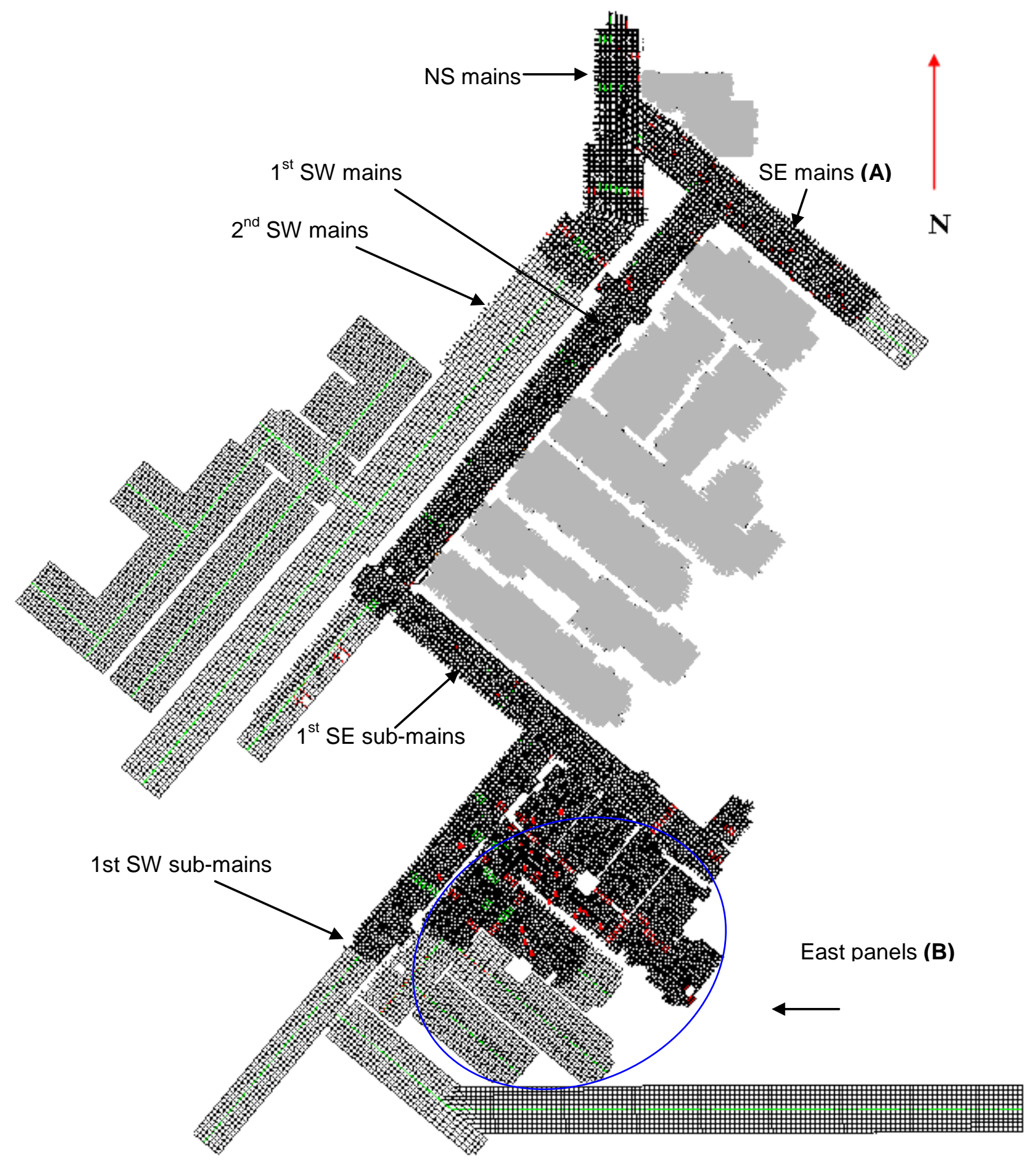

Figure 7.6 Part plan of the Mine 'A' showing roof falls location (Red patch denotes roof fall) 


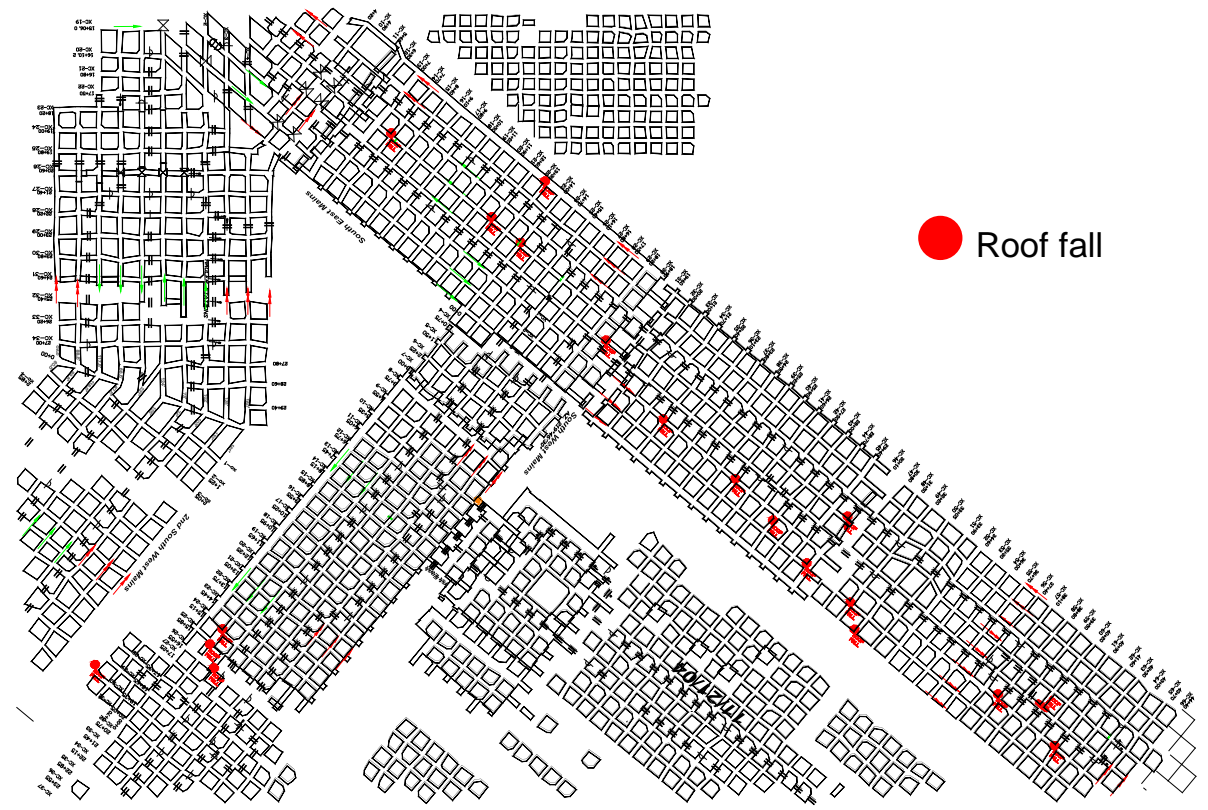

Figure 7.7a Enlarged view of ' $\mathrm{A}$ ' as shown in Figure 7.6

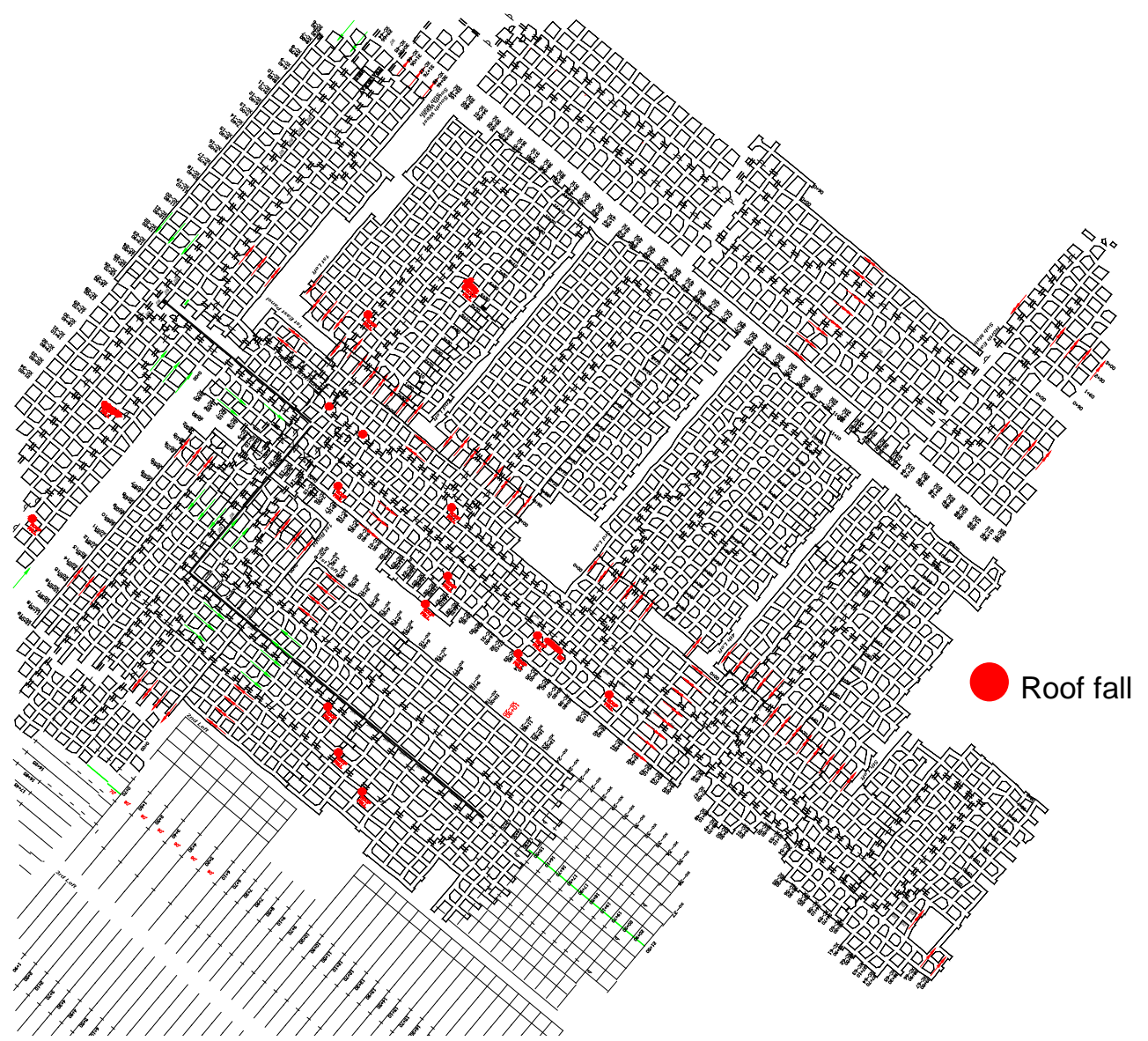

Figure 7.7b Enlarged view of 'B' (east panel) as shown in Figure 7.6 


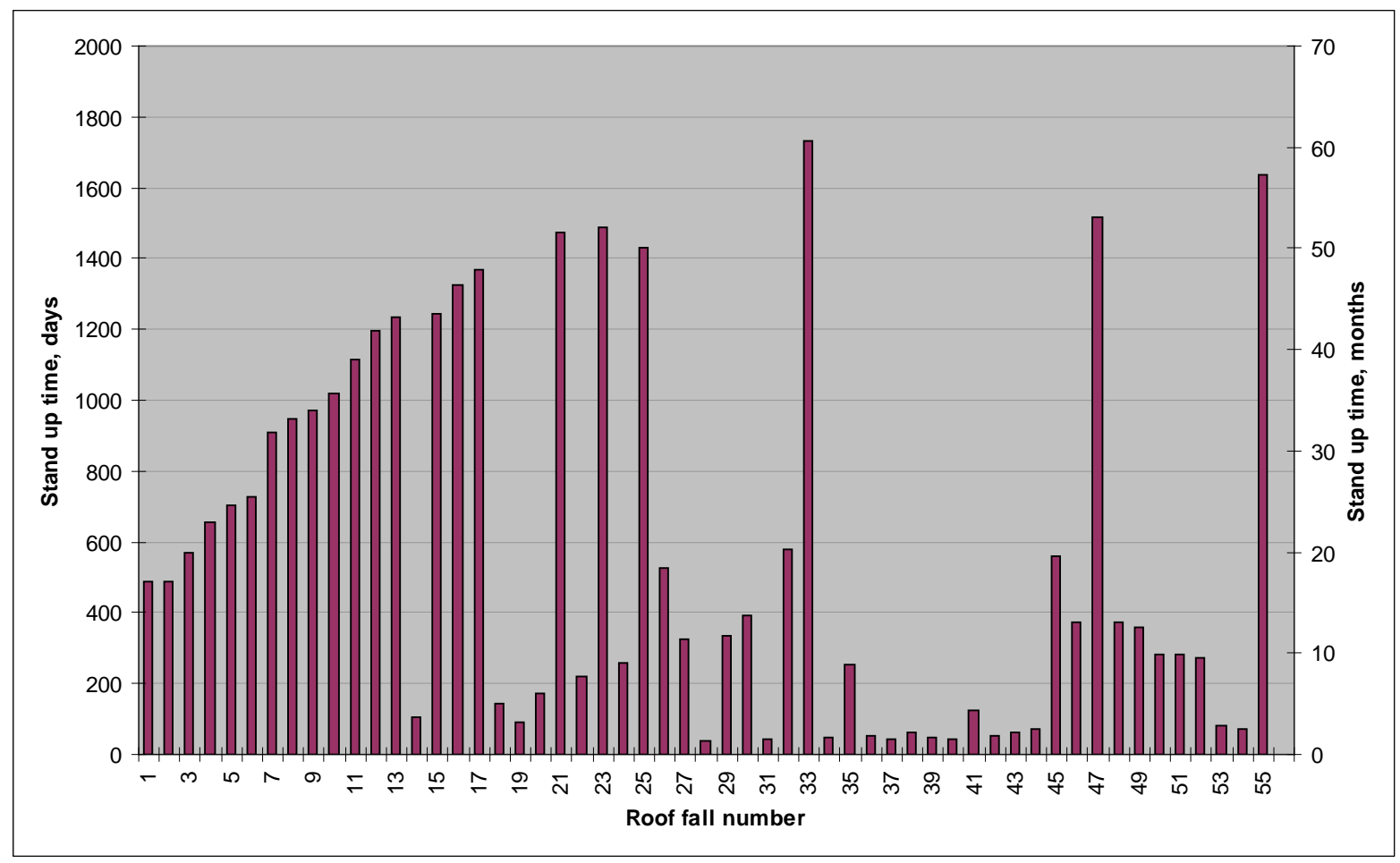

Figure 7.8 Standup time of the falls observed at the mine

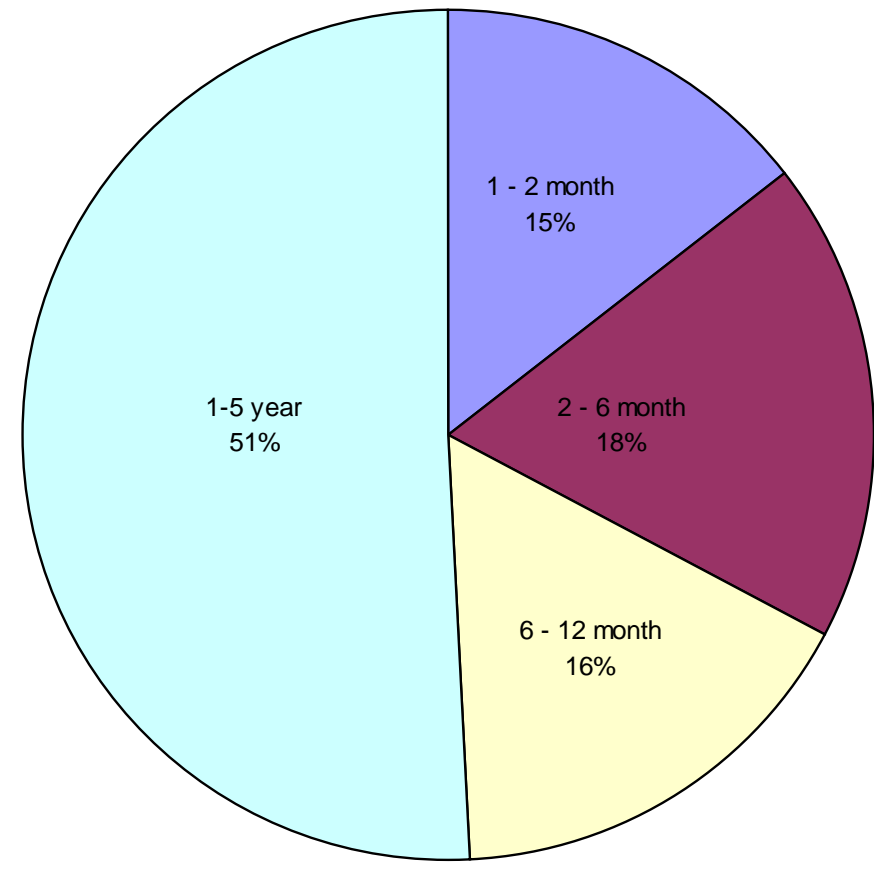

Figure 7.9 Variation in the standup time for the roof falls 


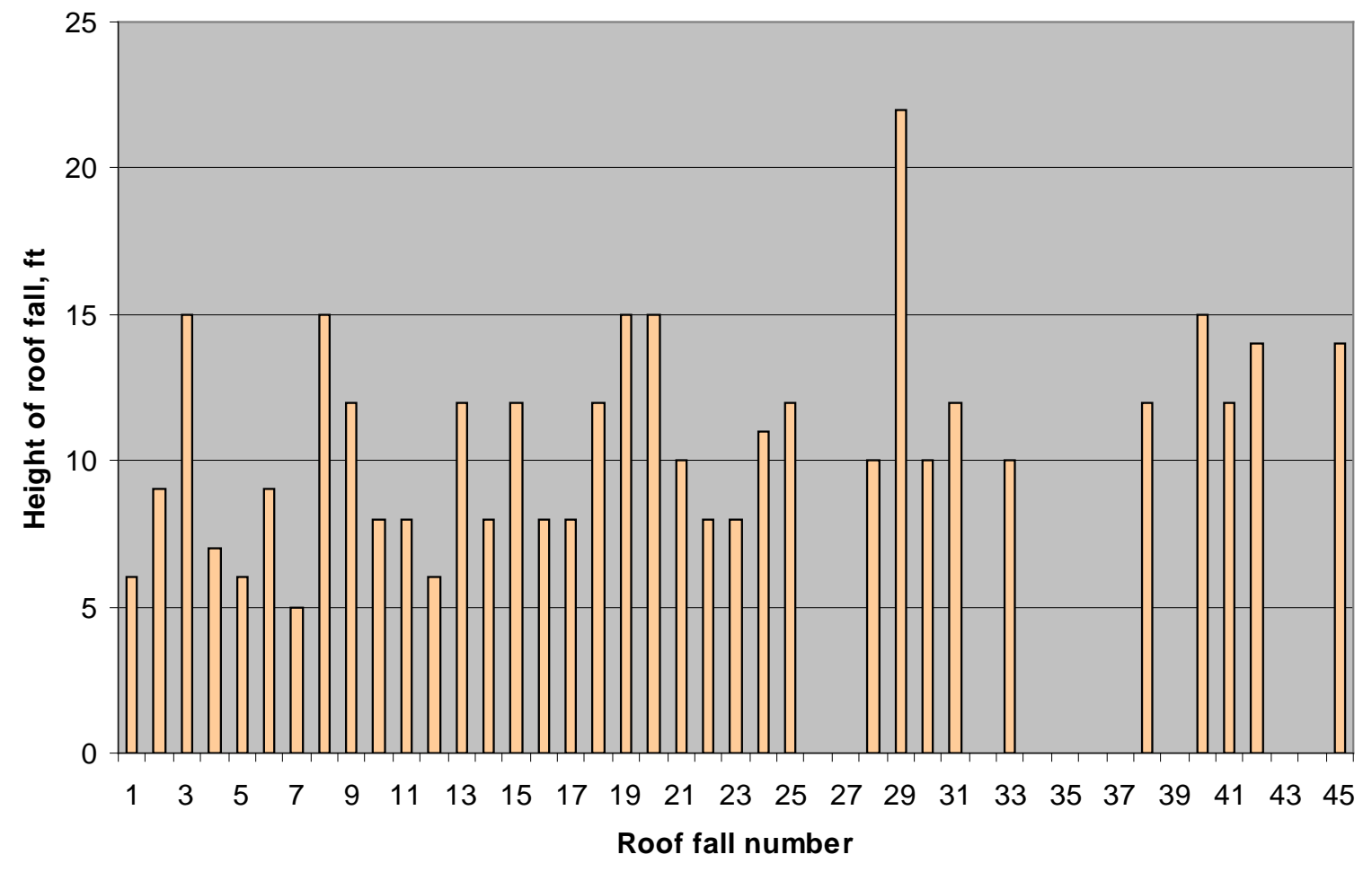

Figure 7.10 Variation in the height of the roof falls

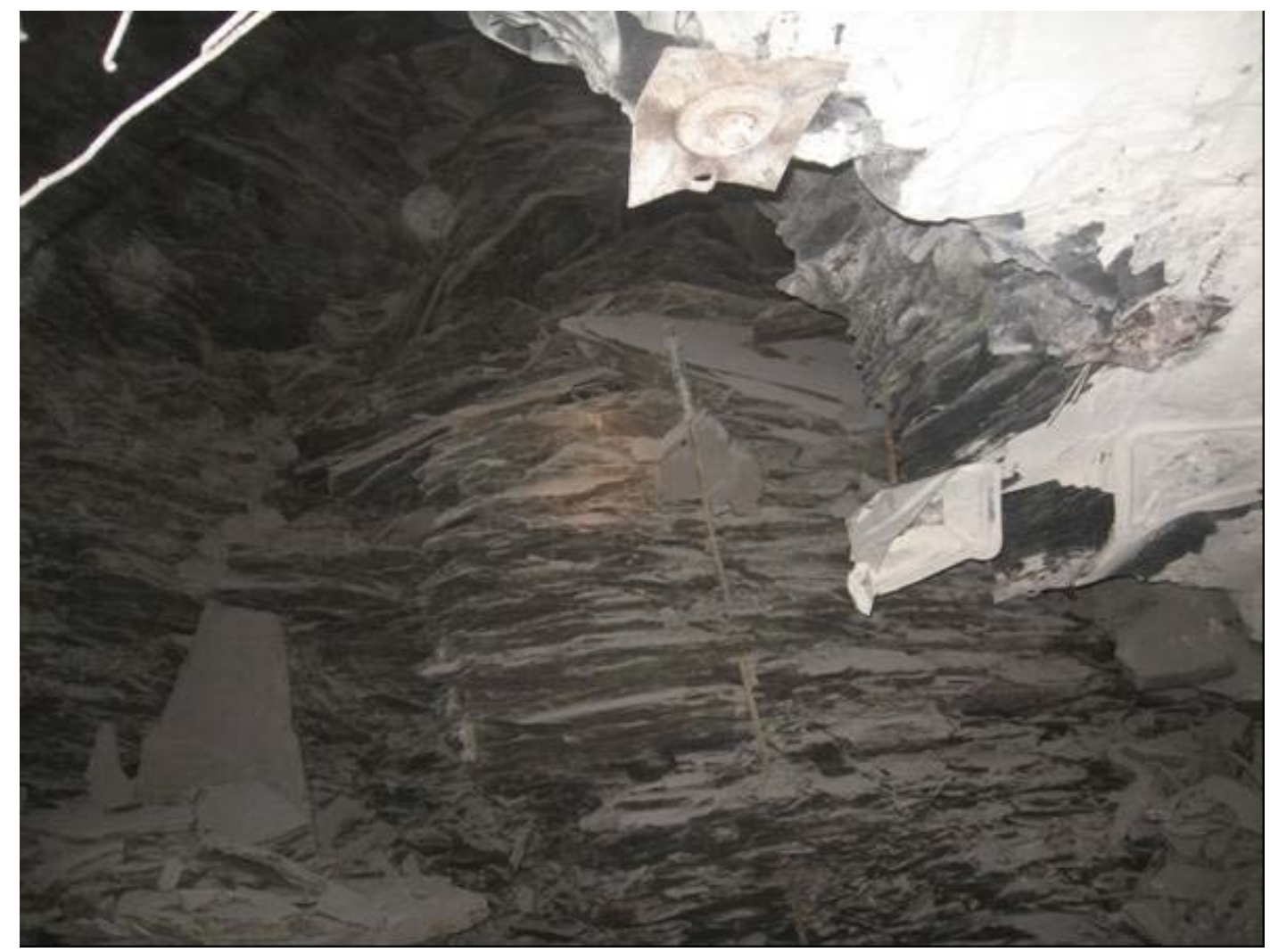

Figure 7.11a Roof fall showing highly laminated rocks (stack rocks) 


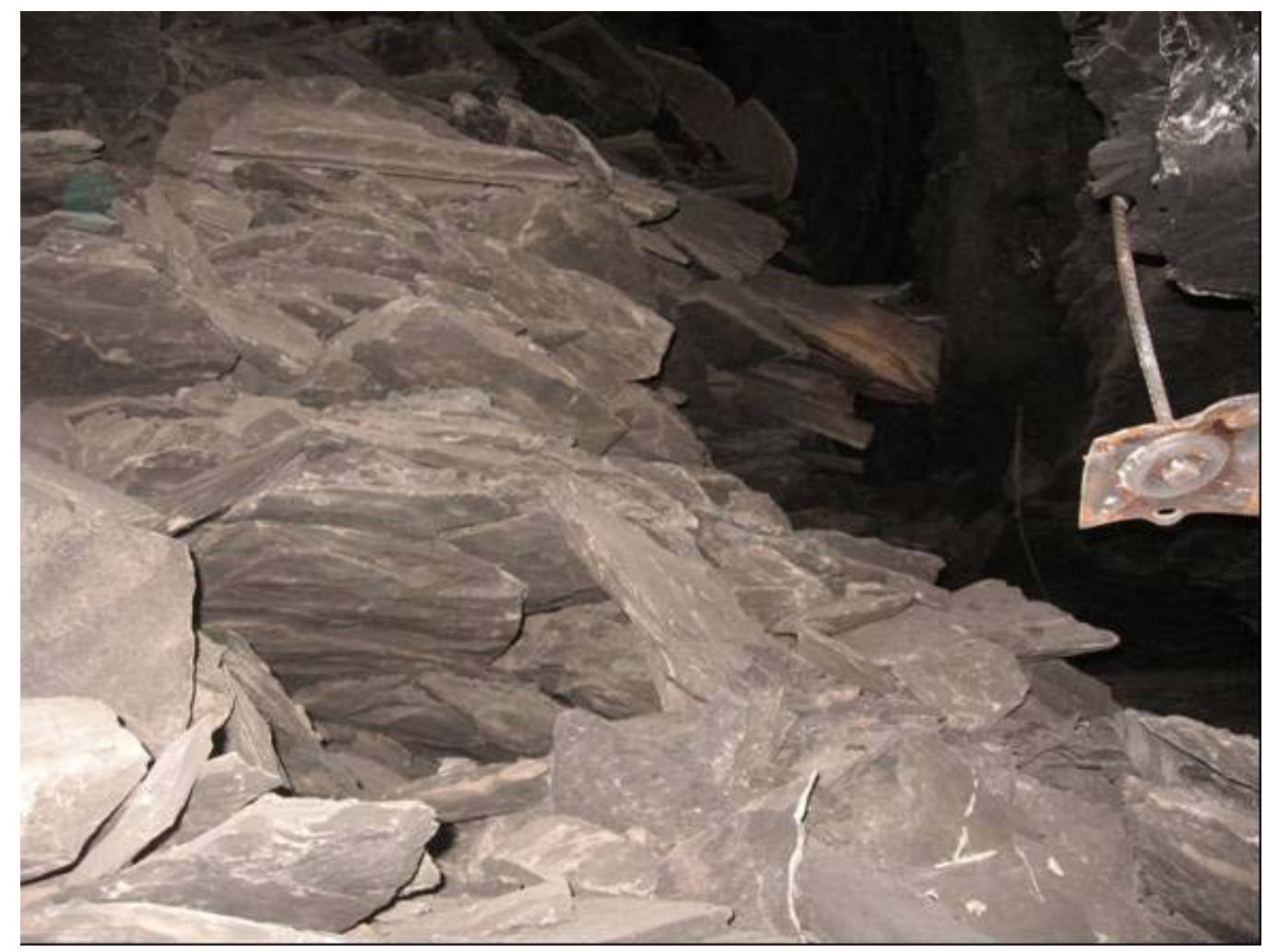

Figure 7.11b Roof fall showing irregular fractured rock layers

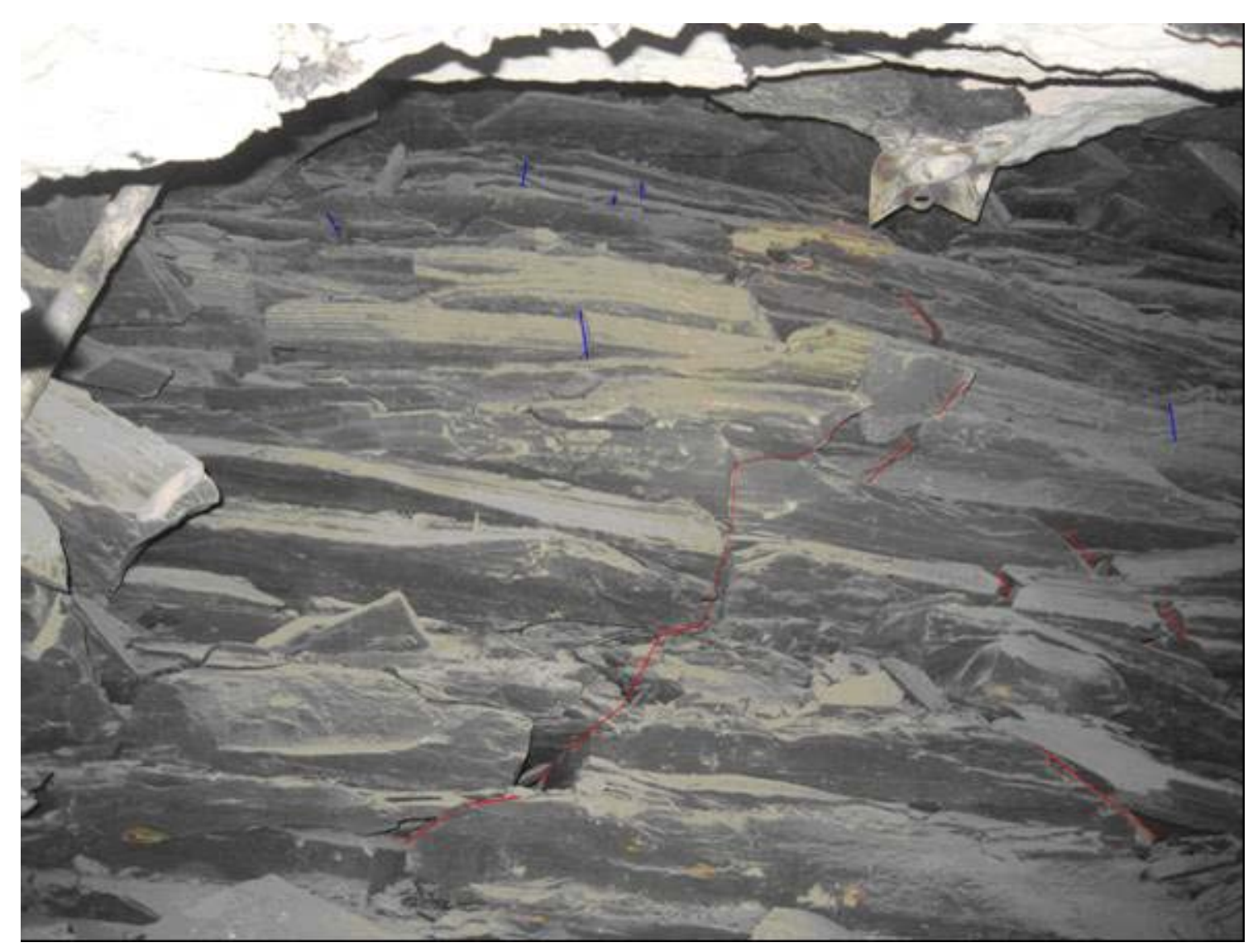

Figure 7.11c Roof falls with highly laminated rock (rock failing both in shear, red color line and tension, blue color line) 


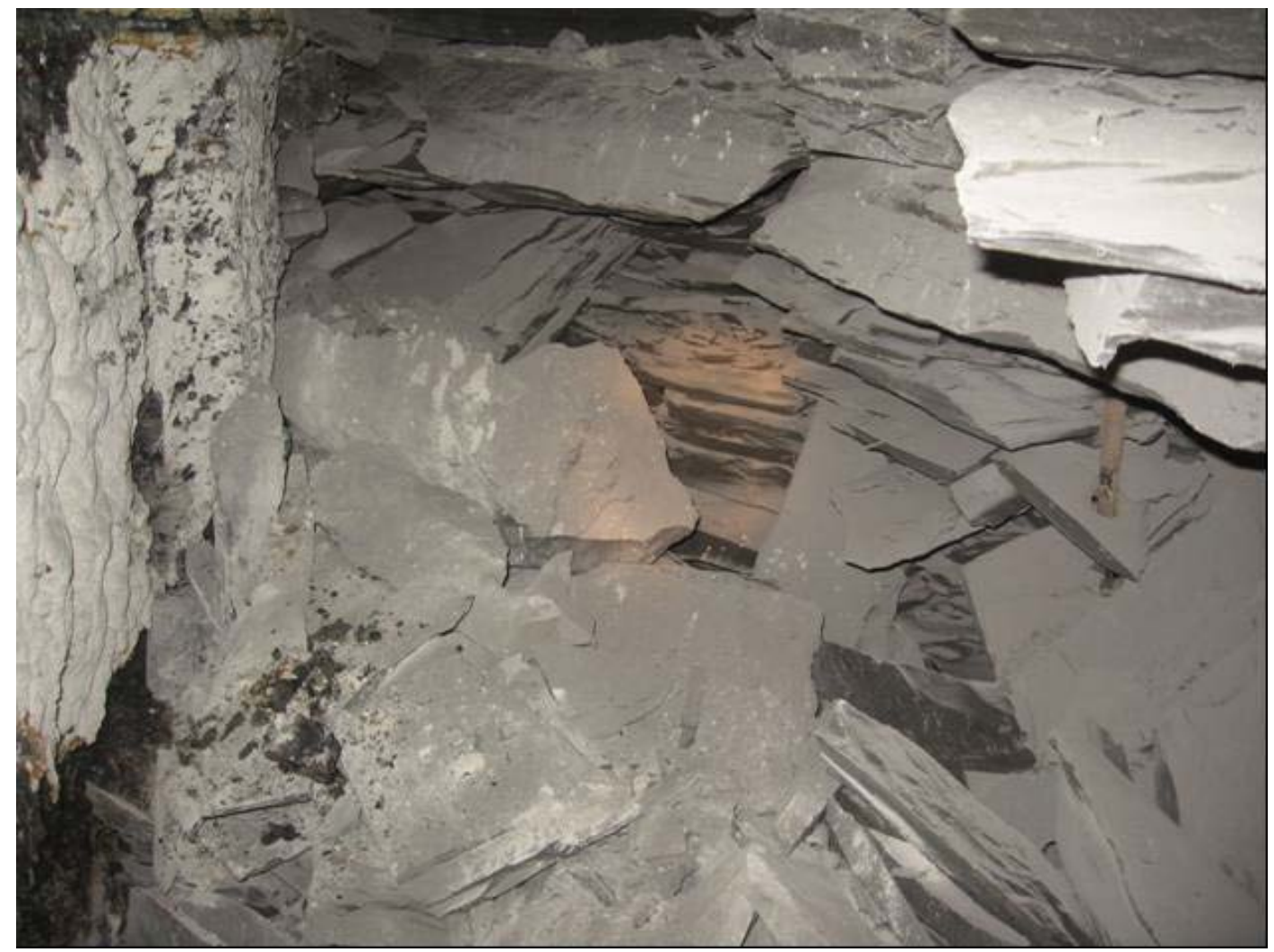

Figure 7.11d Roof fall starting right from the edge of the entry (roof rocks better than stack rock)

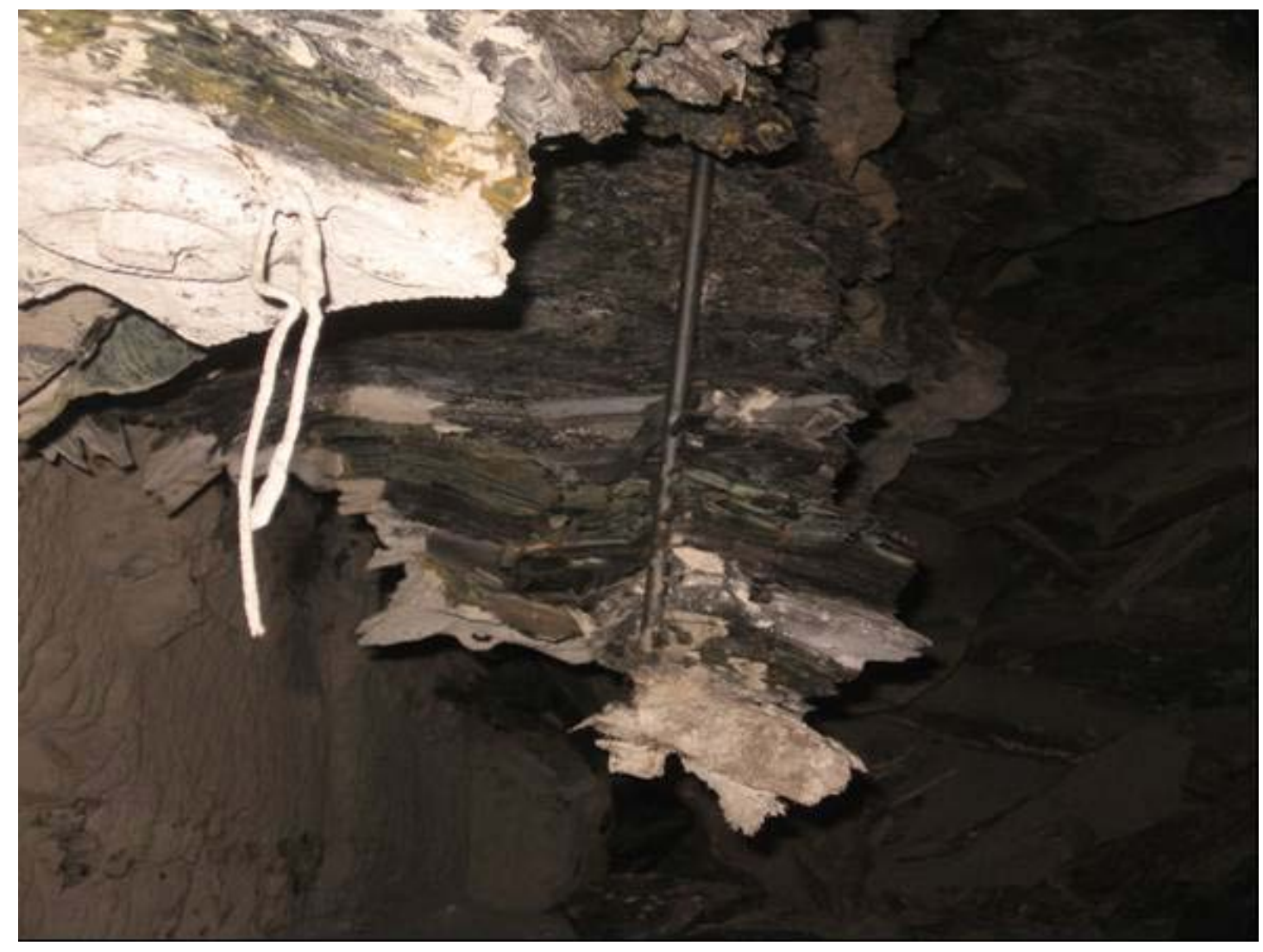

Figure 7.11e Roof falls at intersection and bolts exposed in the entry 


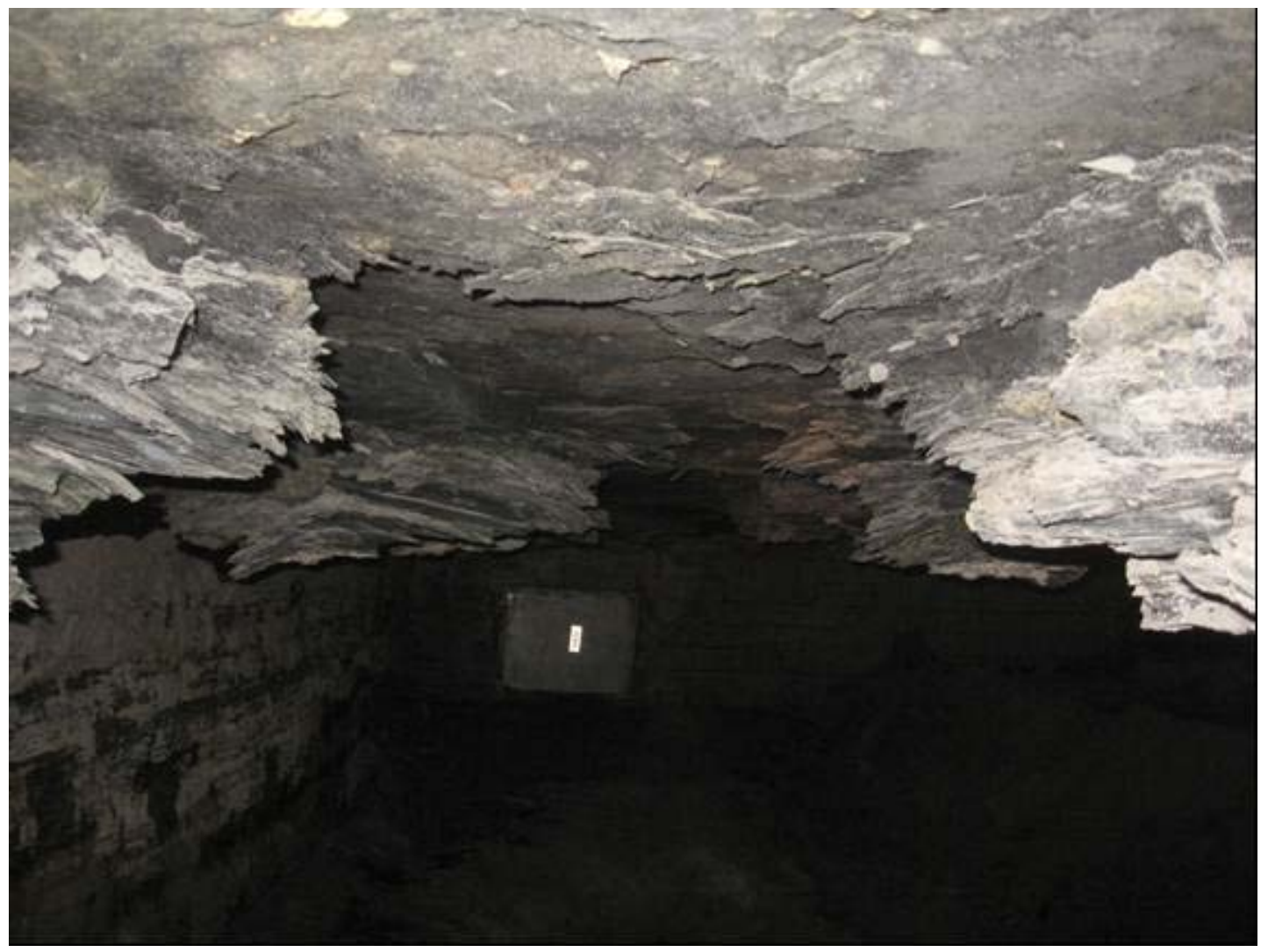

Figure 7.11f Minor roof failure up to the competent strata

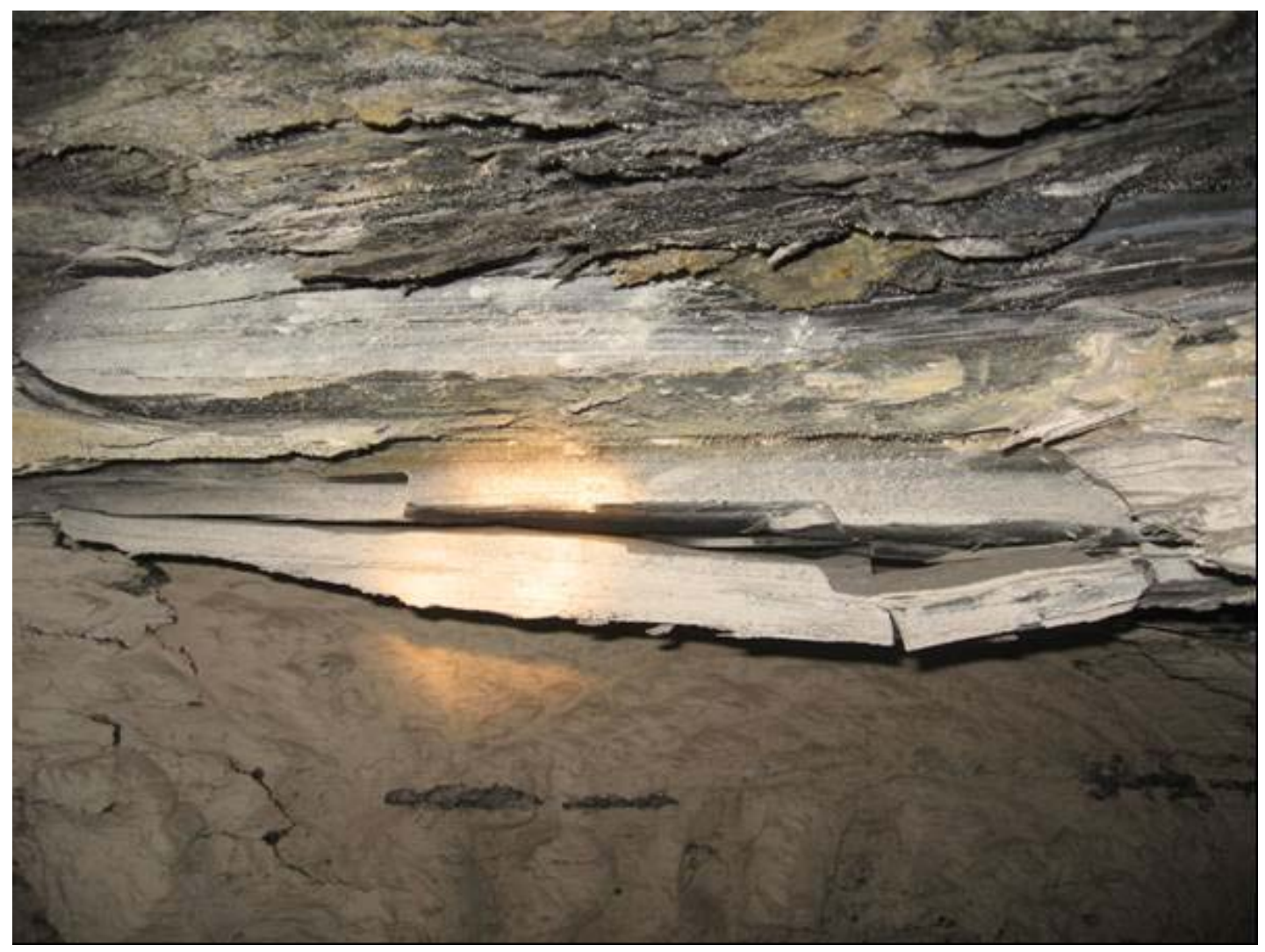

Figure $7.11 \mathrm{~g}$ Separation started in the immediate roof 


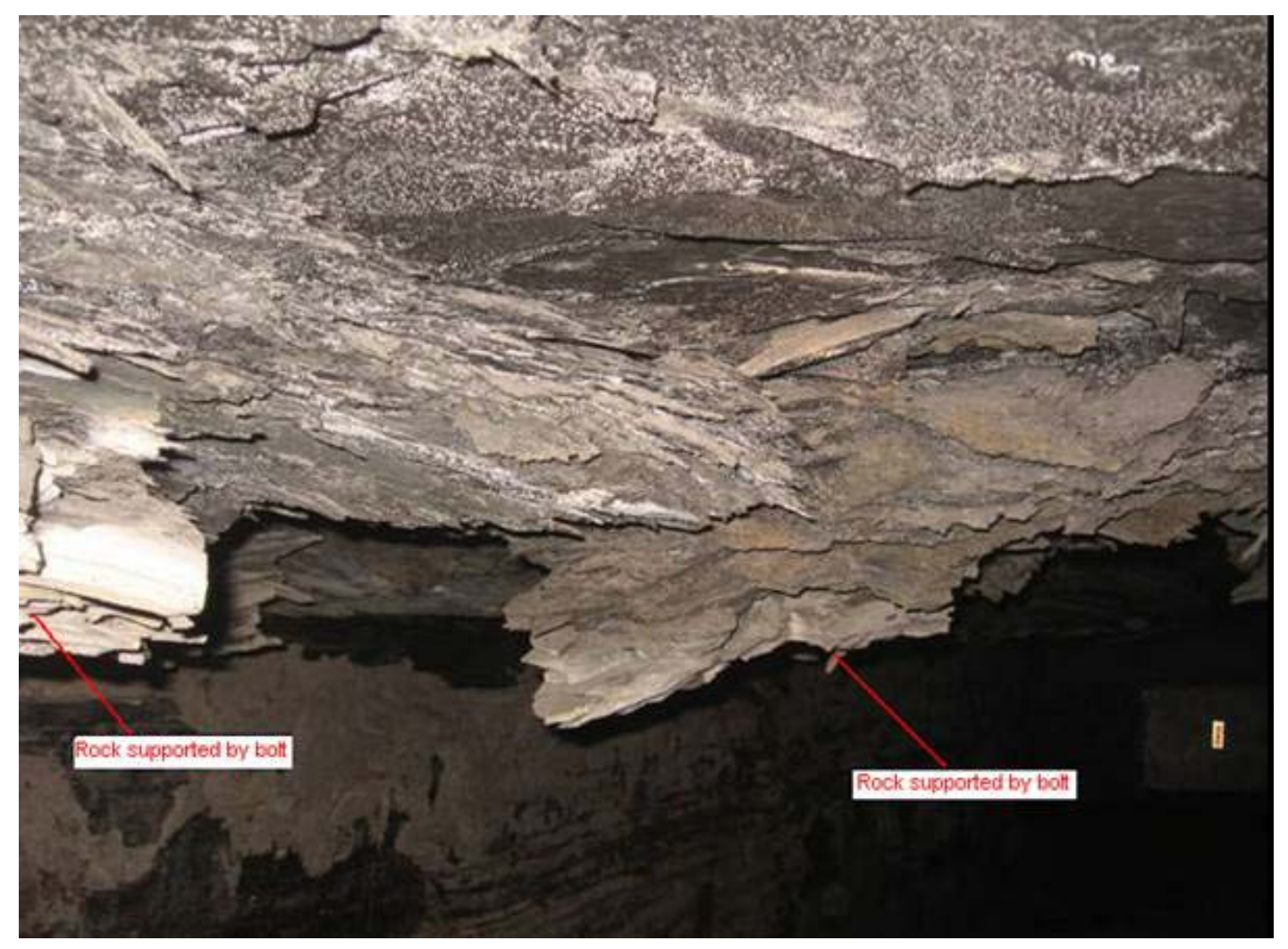

Figure $7.11 \mathrm{~h}$ Already failed roof rock and rock holded by bolts in the entry

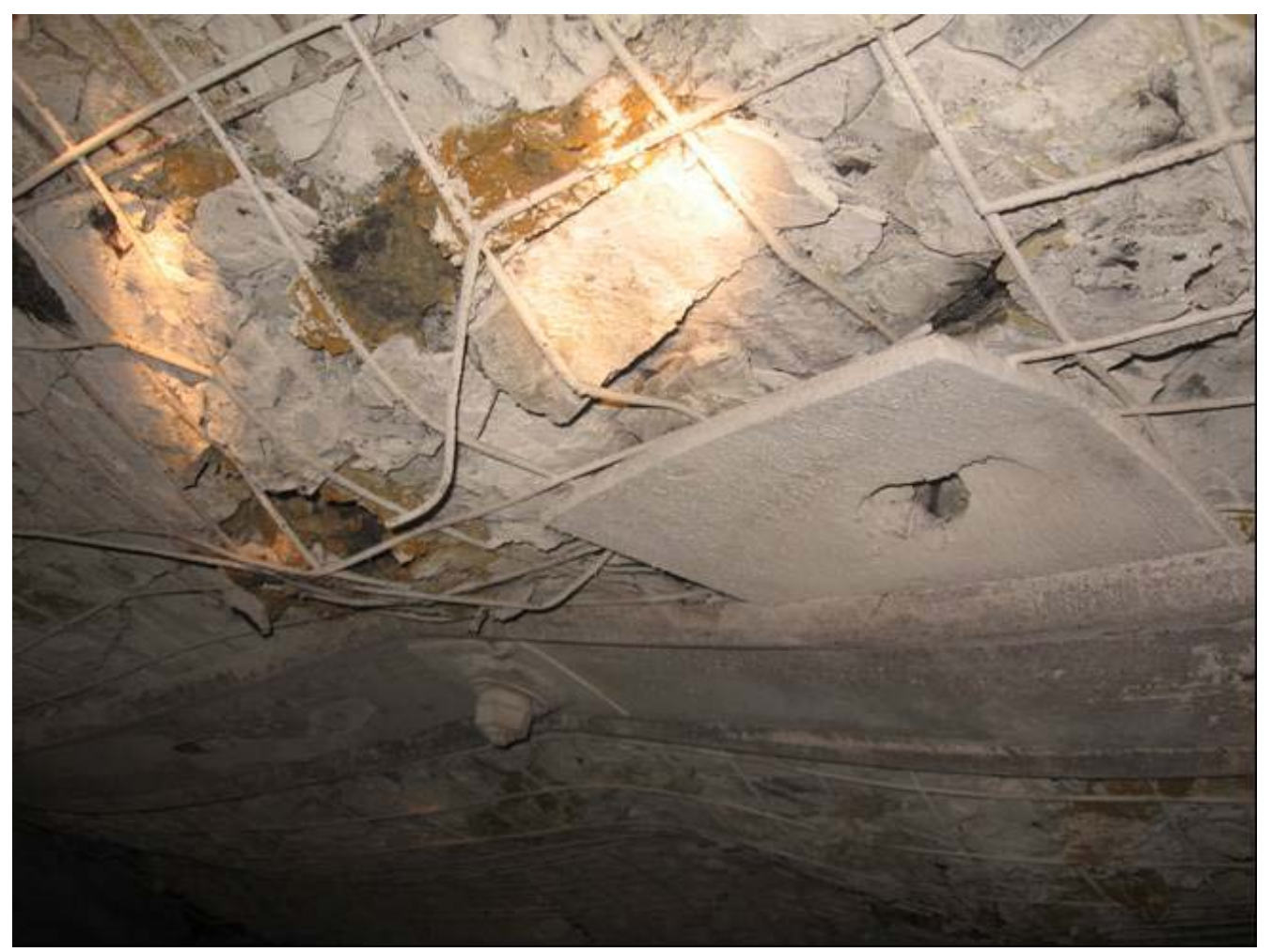

Figure 7.11i Immediate fractured roof supported by Roof bolts with W-straps 


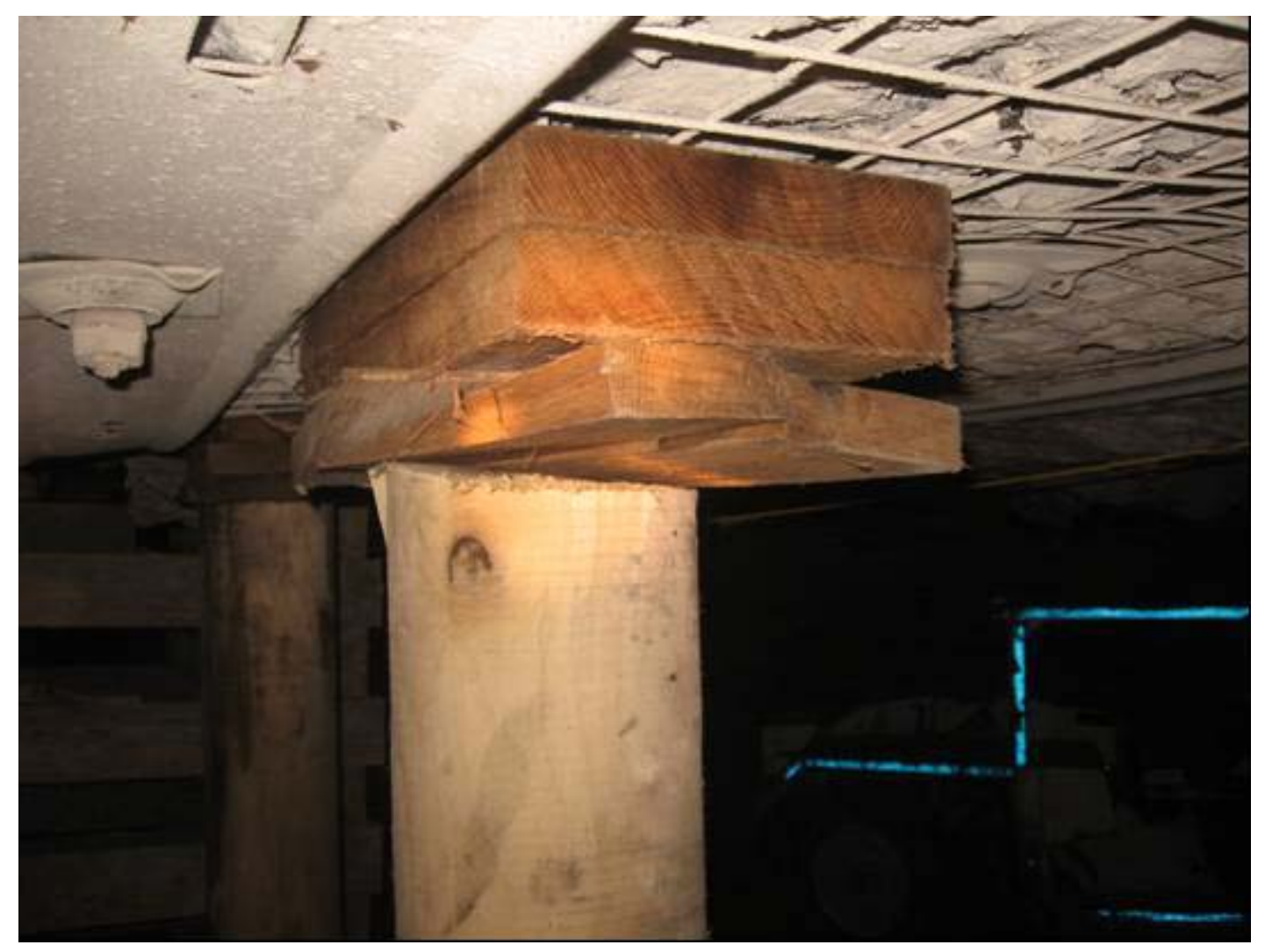

Figure 7.11j Stable Immediate roof supported by W-strap, wooden prop with header and wire mesh

\subsection{FACTORS AFFECTING STANDUP TIME FOR THE ROOF FALL}

The standup time of roof fall may be governed by the nature of roof and floor rocks and the panel geometry i.e. pillar size, entry width and intersection geometry. In the following section the variation in standup time has been studied with the case study presented above. Figures 7.12 and 7.13 show the standup time of roof falls for SE \& SW and East panels respectively.

\subsubsection{Effect of pillar size and Entry width on standup time and roof fall}

In mine ' $A$ ' various pillar configurations were tried in different sections of the mine. In South Mains pillar size was $80 \times 80 \mathrm{ft}$ where as SE mains were developed with pillar size of $80 \times 70 \mathrm{ft}$. The pillar size in SW mains was $70 \times 70 \mathrm{ft}$. In east panel most of the pillars were of dimension $60 \times 60 \mathrm{ft}$ but few of them were also of $60 \times 90 \mathrm{ft}$. 
Figures 7.14 to 7.18 show the standup times for different roof falls with varying pillar sizes. From these roof fall data it can not be said that the increase in pillar size will eliminate or prevent from any roof fall but it can increase significantly the standup time. Figure 7.19 shows the average standup time for different pillar configuration. Many falls occurred with different pillar sizes but just one fall took place where the pillar size was 80x80 ft and that also after 1731 days (approximately 5 years)

In the mine 'A' at East panel the entry width was 19 to $20 \mathrm{ft}$. Except this panel everywhere the entry width was 18 to $19 \mathrm{ft}$. The standup time is significantly lower for the east panel where the pillar size was $60 \times 60 \mathrm{ft}$. In east panel where these pillars were used the hazard ratings were maximum. Hence this extremely low standup time may be due to combined effect of entry wider by $1 \mathrm{ft}$, high hazard ratings and smaller pillar size. The entry width becomes important as it significantly influences the intersection diagonal span. The increase in standup time can be compared from $70 \times 70$ to $80 \times 80$ size pillars as in these zones the entry widths and the hazard ratings are almost in the same range. The standup time is almost double for $80 \times 80$ size pillar in comparison to $70 \times 70$ pillars.

\subsubsection{Effect of Turn outs/ slab on Roof Fall}

At mine ' $A$ ' most of the falls initiated at the intersection and then extended towards the crosscut or entry. Generally it is believed that intersection of the entry where continuous miner makes turns to cut in cross cut is most vulnerable from aspects of the ground control (Figure 6.20). At turn out locations, the diagonal span becomes larger than the other regular intersections. It will be further enhanced if the entry 
developed is wider. Hence there is more probability of roof failure at these intersections.

From the roof fall observations at Mine 'A' it has been observed that out of 55 falls, 23 falls occurred at CM turnout intersections while 32 falls were at regular intersection. Although the number of falls at turnout intersection is less but its frequency will be more in compare to regular turnout as the number of regular intersections are at least 4 times more. Figures 7.20 and 7.21 shows the standup times for fall occurred at intersections with and without turn outs. The turnout location not only influence on the frequency of the fall but the statistics of roof fall shows it has considerable influence on the standup time before the fall. The average standup duration is $36 \%$ more for intersection without turn outs.

\subsubsection{Effect of intersection way}

The intersection can be 4-way, 3-way and 2-way. The 4-way intersection is most common; it forms when entry and crosscuts meet. 3-way intersection is generally formed towards the barrier pillar side of the panel and 2-way intersection forms at panel corner.

In this mine $82 \%$ of fall occurred at 4-way intersection while $17 \%$ fall took place at 3-way intersection. Only 1 number of fall took place at panel corner i.e. at 2way location. Therefore 3-way cross section can be an effective tool where immediate roof rock is very weak and frequency of fall occurring at intersection is more. Although this can not be a fare comparison as the number of 3-way intersections are very less compare to 4-way intersection.

From above discussion 


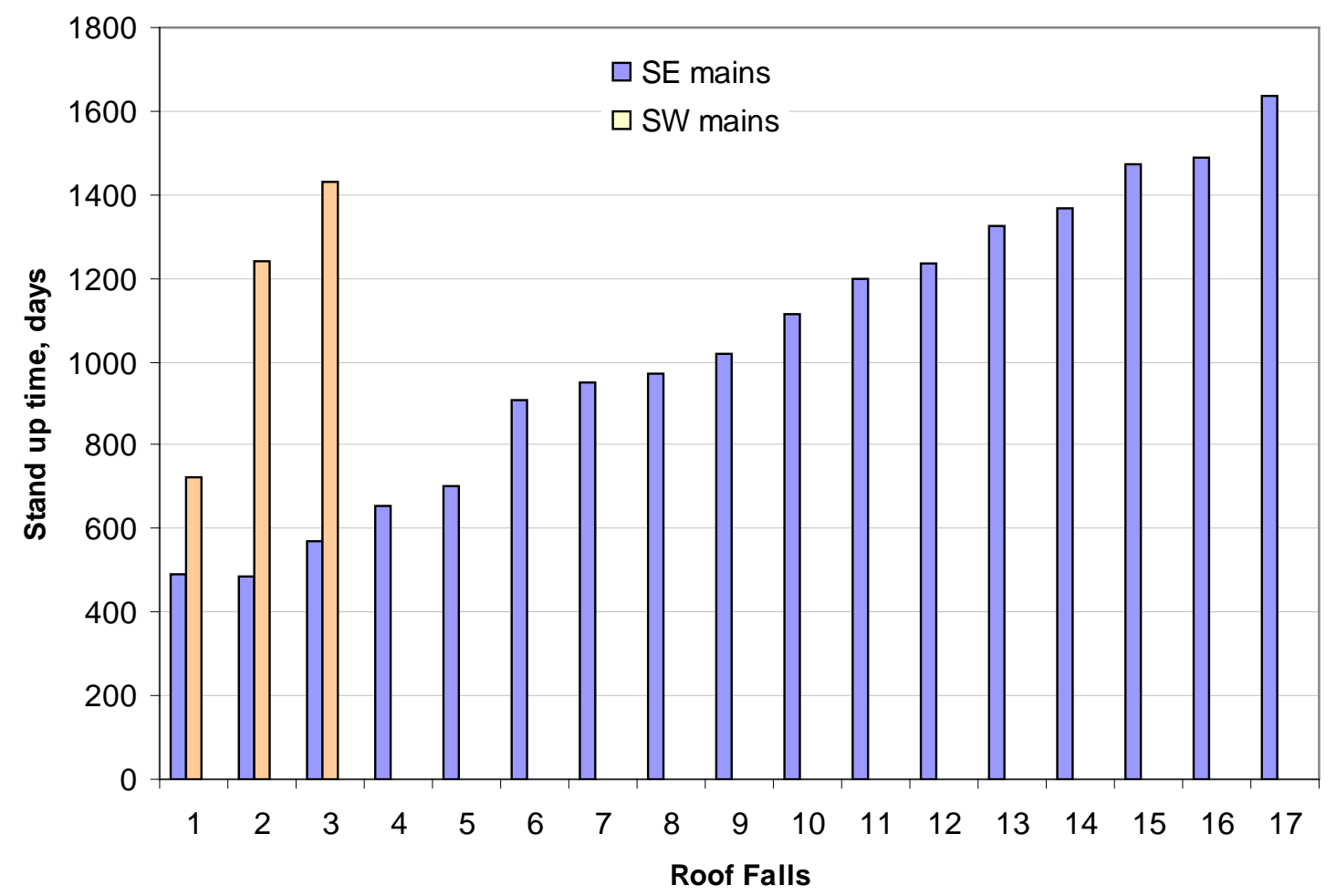

Figure 7.12 Stand up times for the roof falls observed in SE and SW mains

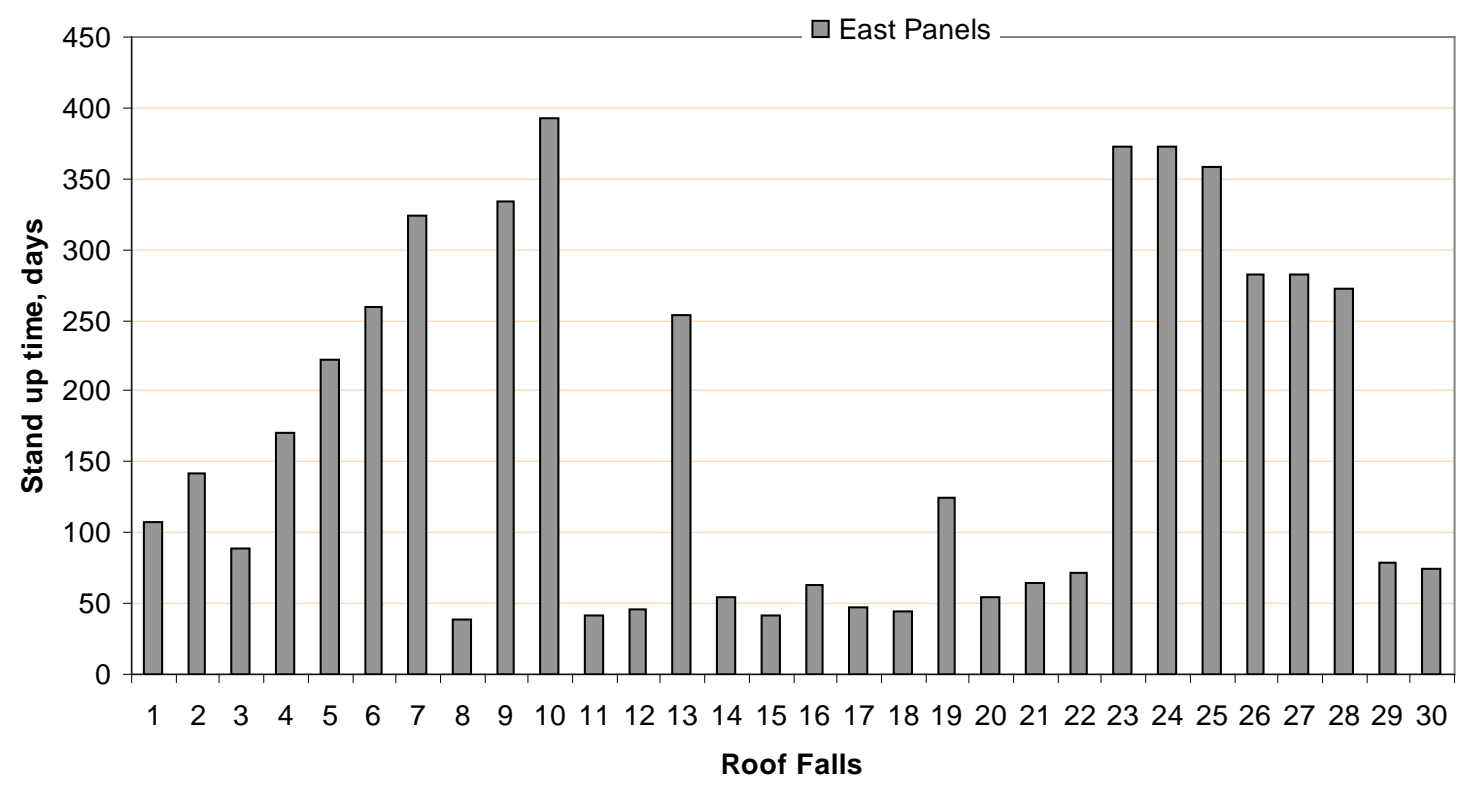

Figure 7.13 Stand up times for the roof falls observed in East panels 


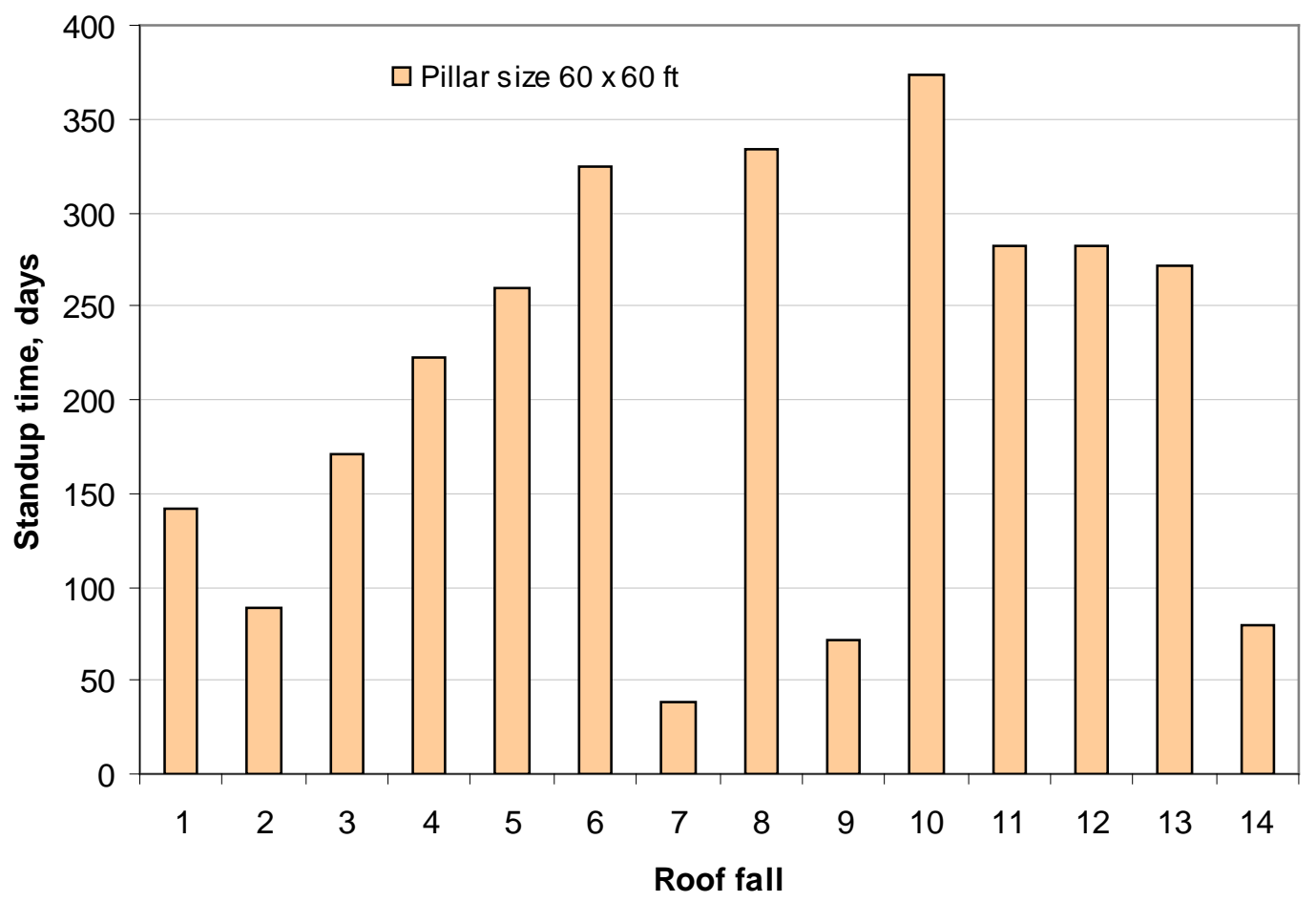

Figure 7.14 Stand up times for the roof falls with Pillar size $60 \times 60 \mathrm{ft}$

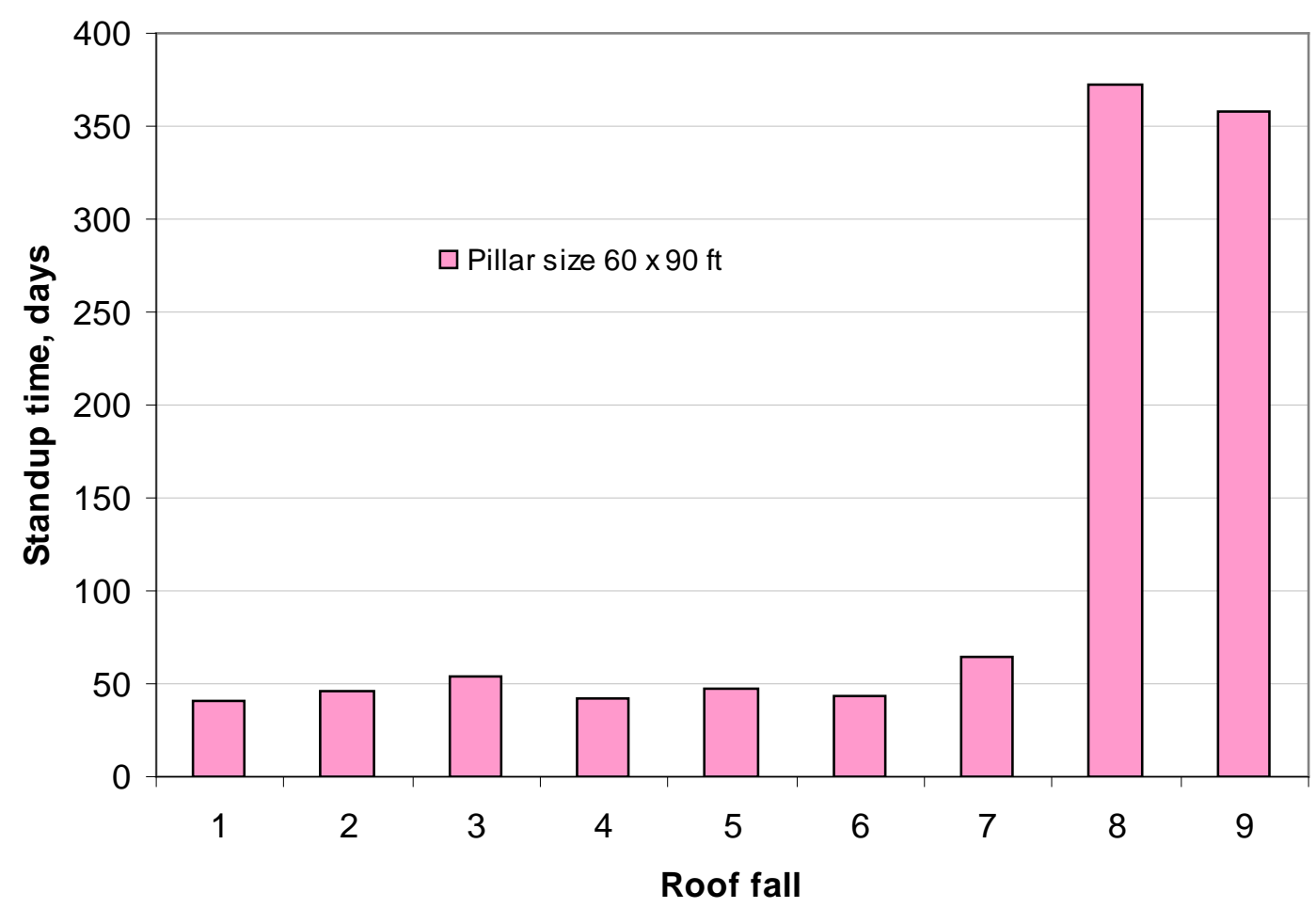

Figure 7.15 Stand up times for the roof falls with Pillar size $60 \times 90 \mathrm{ft}$ 


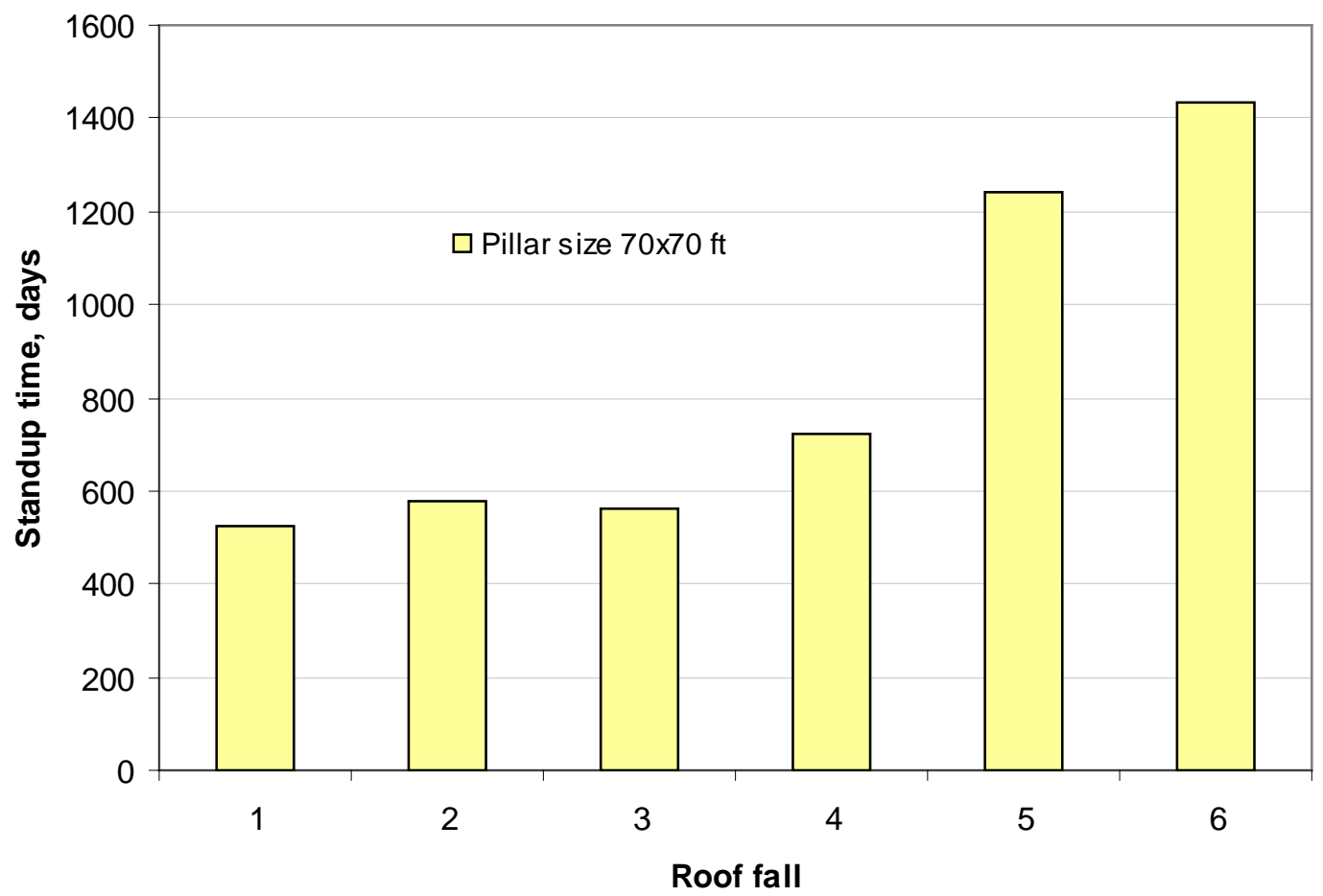

Figure 7.16 Stand up times for the roof falls with Pillar size $70 \times 70 \mathrm{ft}$

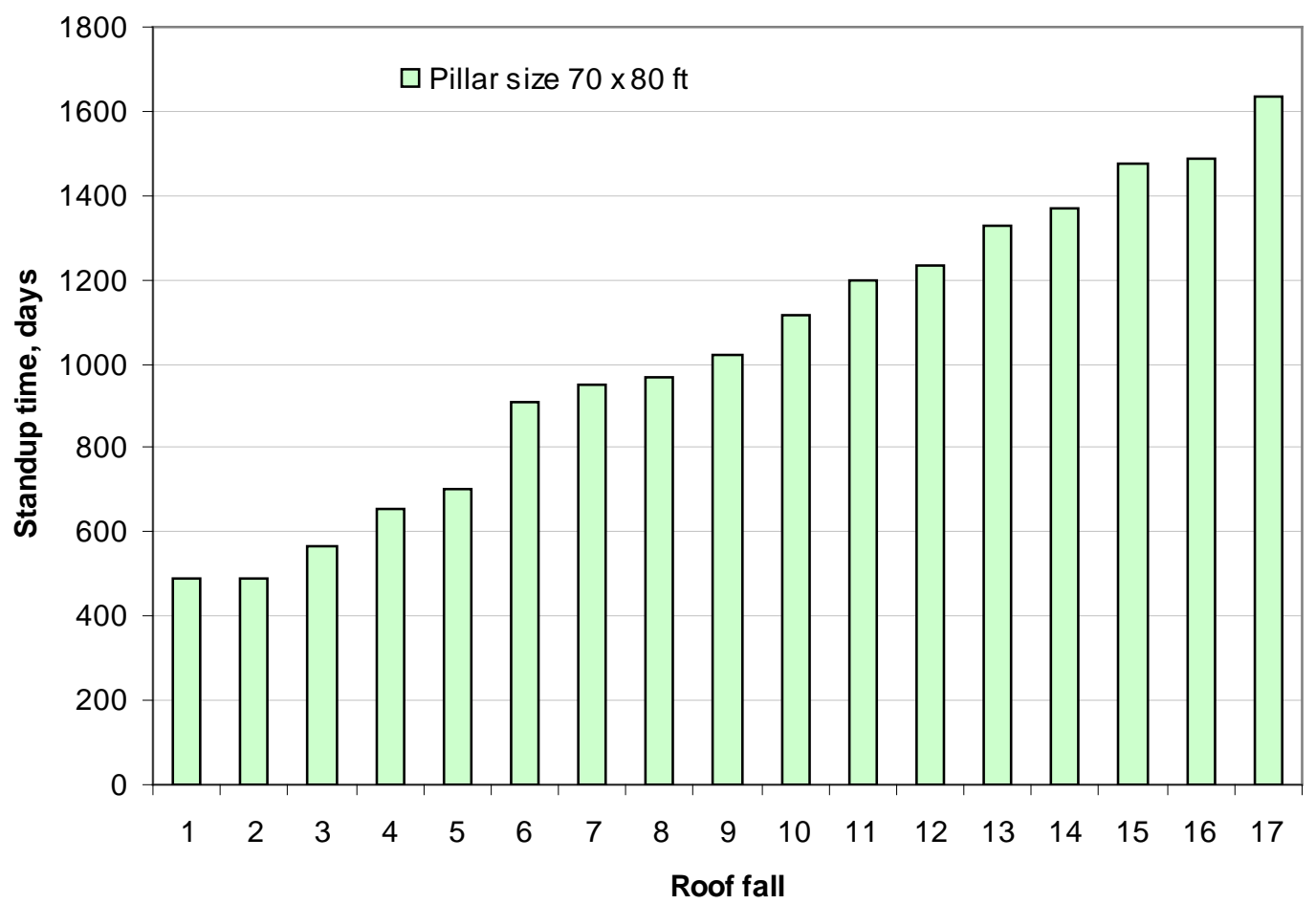

Figure 7.17 Stand up times for the roof falls with Pillar size $80 \times 70 \mathrm{ft}$ 


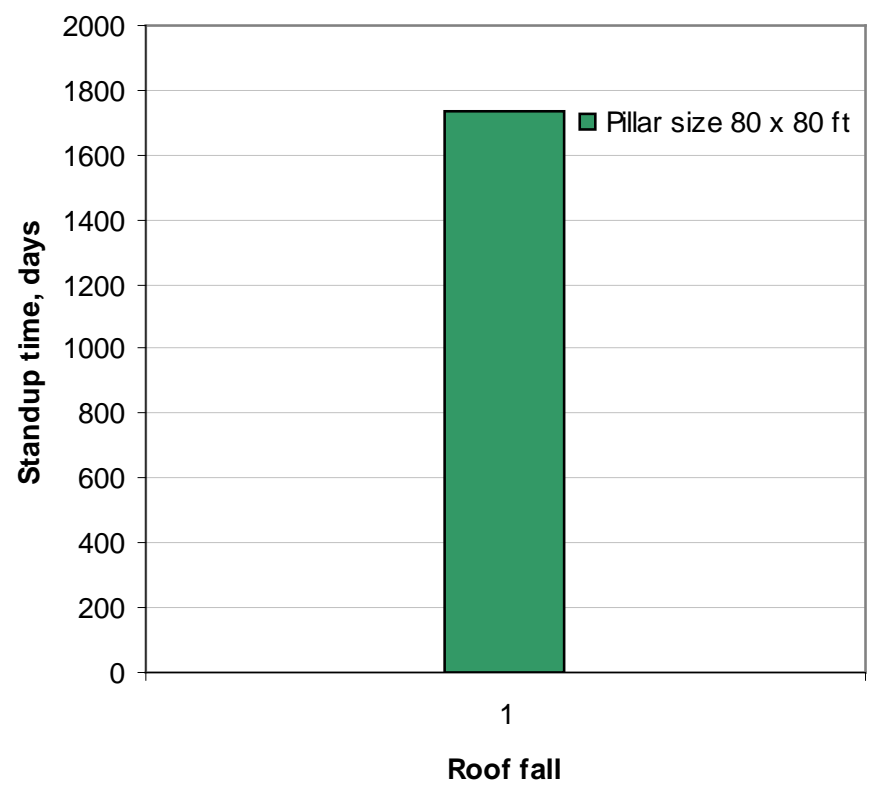

Figure 7.18 Stand up times for the roof falls with Pillar size $80 \times 80 \mathrm{ft}$

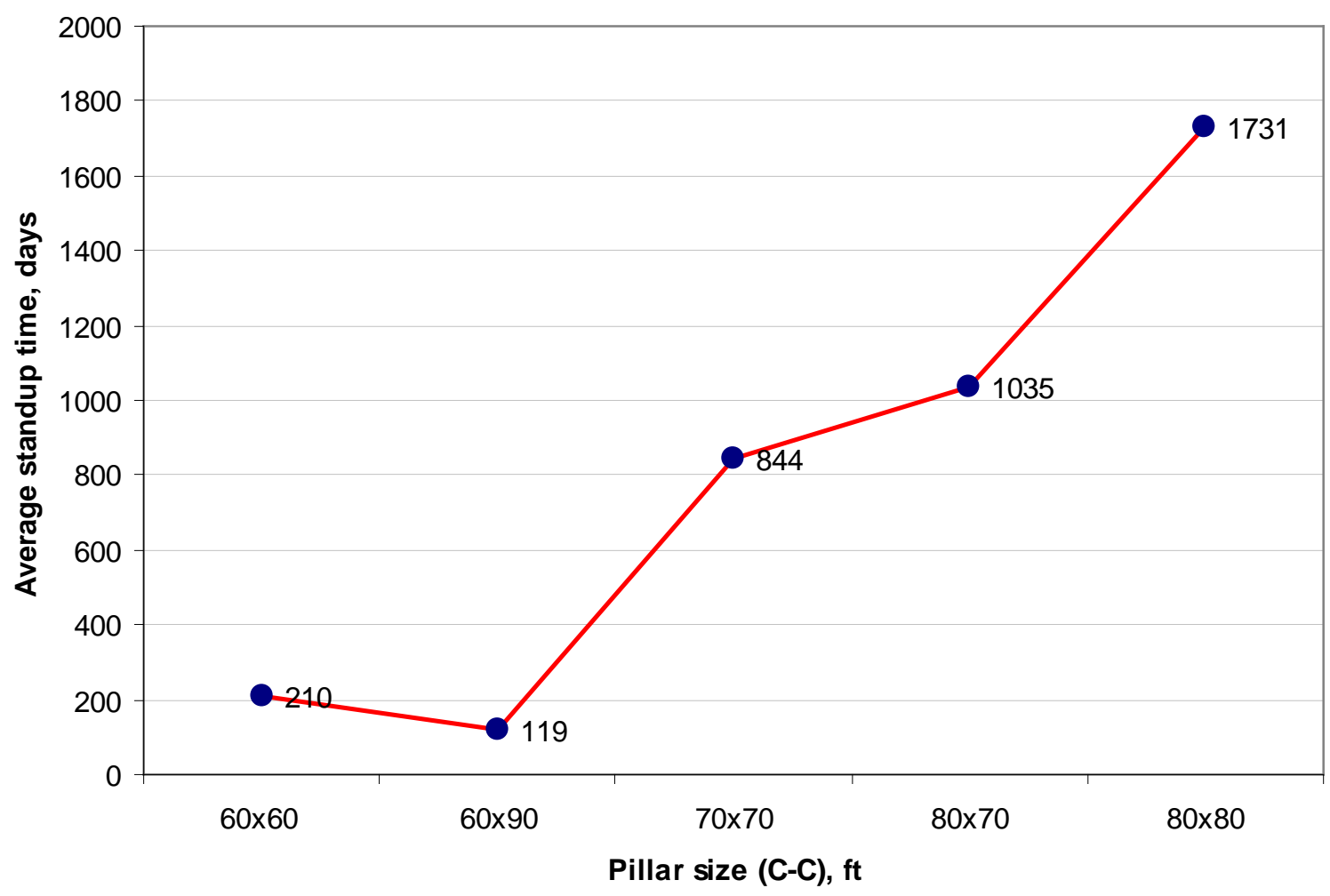

Figure 7.19 Average standup time of the roof falls with different pillar size 


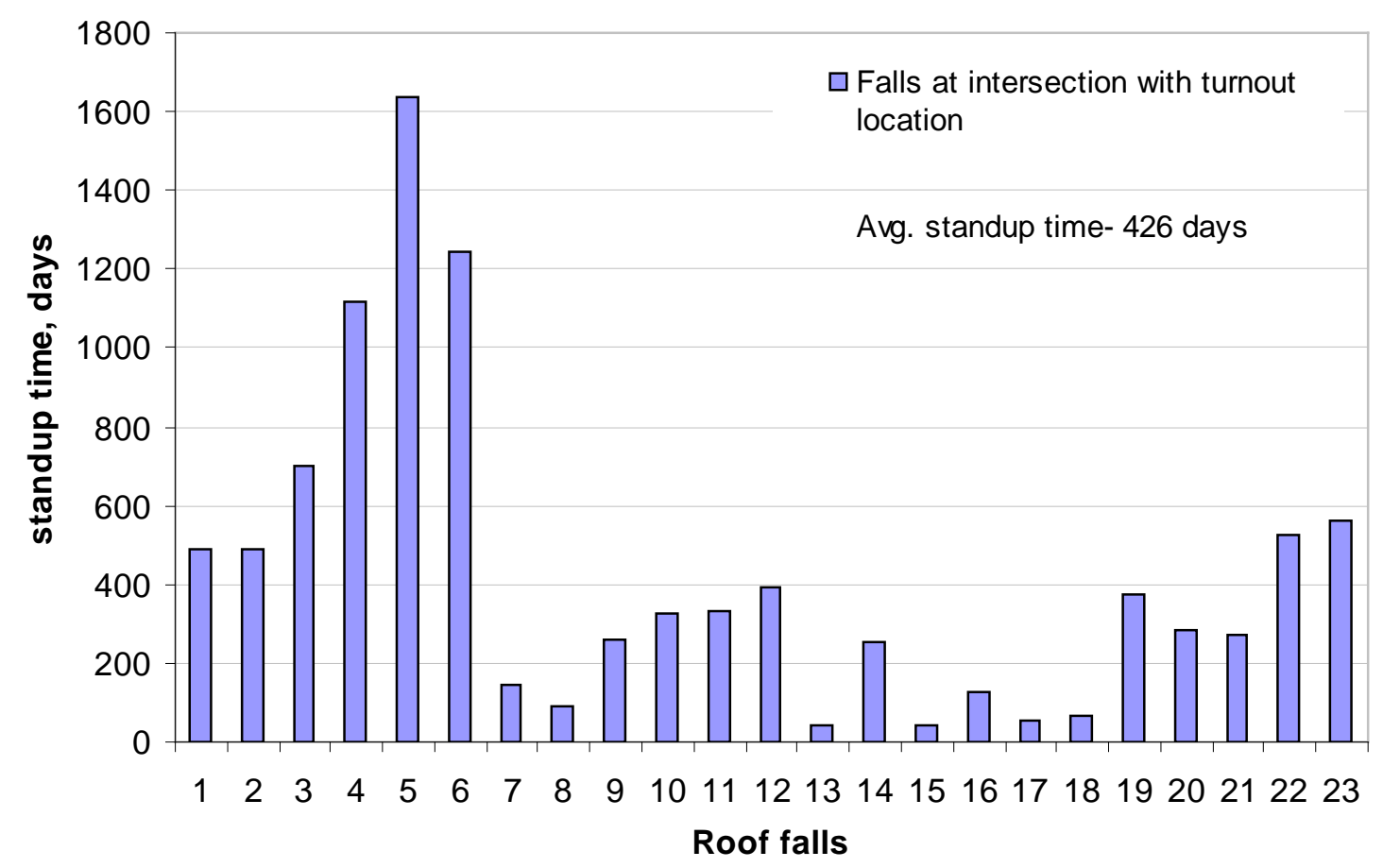

Figure 7.20 Standup time of the roof falls at intersection with turnout

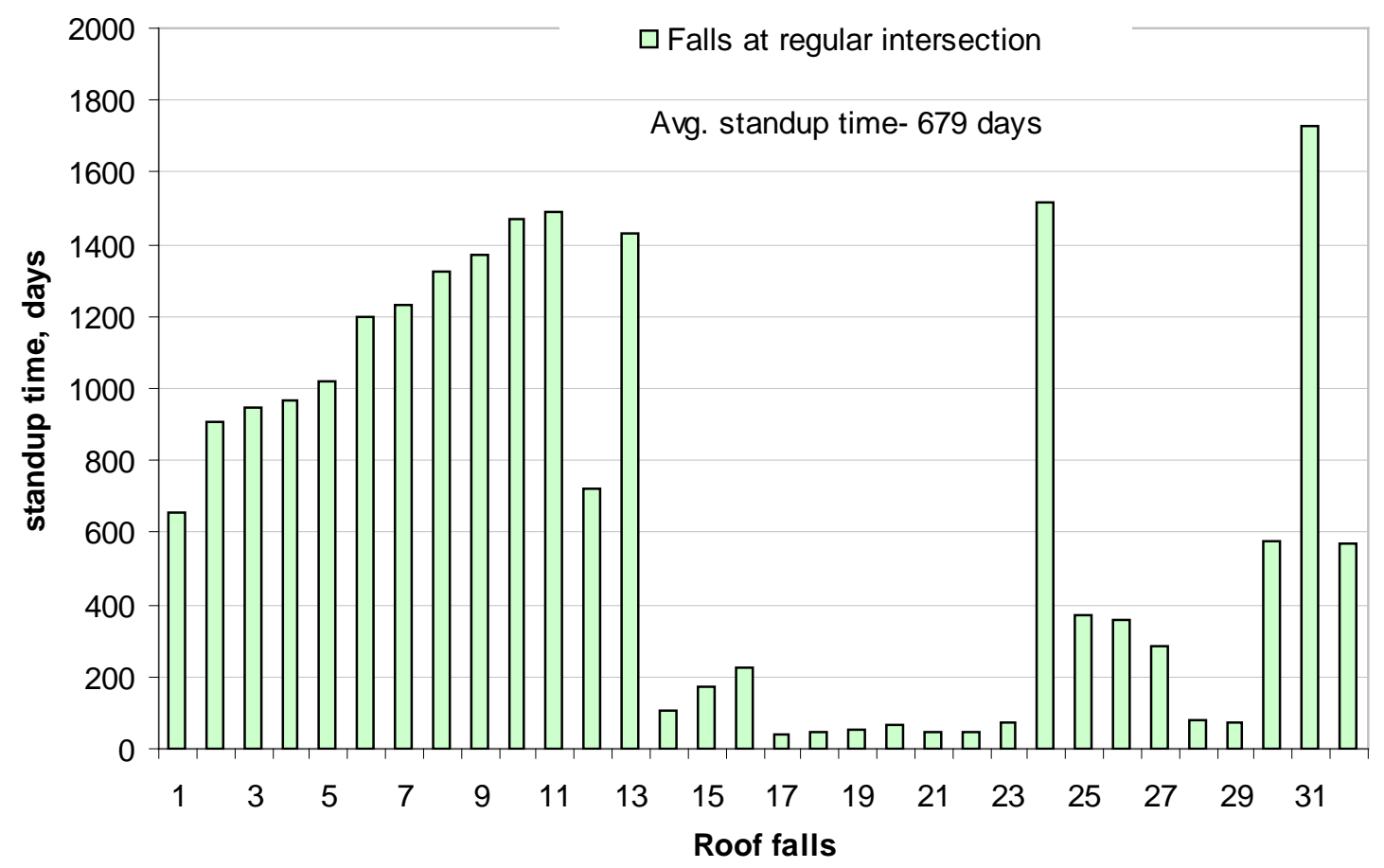

Figure 7.21 Standup time of the roof falls at normal intersection without turnout 


\subsection{NUMERICAL SIMULATION OF TIME EFFECT ON ROOF FALL}

\subsubsection{Single-Component Power Law}

FLAC3D has several built-in constitutive models to simulate salt creep. A power law, similar to the Norton power law (Norton, 1929, Itasca 2007), is commonly used to model salt creep at isothermal conditions. This same power law can be used for rock creep in coal measure rocks. The single-component power law, which is independent of temperature, is described below:

$$
\dot{\varepsilon}_{i j}^{v p}=\frac{\partial \sigma_{e}}{\partial \sigma_{i j}} \dot{\varepsilon}_{e q}^{d}
$$

where:

$$
\begin{aligned}
\dot{\varepsilon}_{i j}^{v p} & =\text { viscoplastic strain-rate tensor } \\
\dot{\varepsilon}_{e q}^{d} & =A\left(\sigma_{\mathrm{e}}\right)^{n} \\
\sigma_{i j} & =\text { stress tensor } \\
\sigma_{e} & =\sqrt{3 J_{2}} \text { (effective stress) } \\
J_{2} & =\frac{1}{2} s_{i j} s_{j i} \\
s_{i j} & =\sigma_{i j}-\delta_{i j} \sigma_{m} \text { (deviatoric stress tensor) } \\
\sigma_{m} & =\frac{1}{3} \sigma_{k k}(\text { mean stress) } \\
\delta_{i j} & =\text { Kronecker delta } \\
A, n & =\text { material properties }
\end{aligned}
$$

\subsubsection{Creep in Coal Measure Rocks}

Coal mine roof continually poses significant challenge to the mining engineer as the stress distribution in the roof is aggravated by time dependent deformation. Time dependency of the coal measure rocks is well known since the start of mechanized coal excavation. However the number of data is almost negligible. Any structural analysis performed in coal mines inadvertently excludes the time dependent effect of 
coal measure rocks. The nature of the problem as well as the time constraint prevents any experimental analysis in this area. With sophisticated numerical models we can definitely include time dependent deformation however extensive laboratory tests and in-situ convergence measurements are needed to validate and generate meaningful practical results.

\subsubsection{Difficulty in Mathematical Modeling of Creep of Coal Measure Rocks}

The greatest challenge in modeling coal measure rocks arise from number of factors such as actual stress state in the immediate roof, bedding planes, unavailability of convergence data. It is well known that the stress state in the immediate roof is affected by the development of the entry and adjoining entries. Thus the true stress state which would have existed before the mine was developed is unknown. Any convergence measurement will include the effect of the modified stress state. Bedding planes increase the complexity of models which would induce errors in the predicted result. Laboratory tests are usually conducted on intact rock specimens which are free from discontinuities such as faults and bedding planes. The results are then fitted with mathematical equations for generating material constants. However such attempt excludes the effect of bedding planes which are important element in prediction of stability of immediate roof.

A numerical model was developed in FLAC3D simulating a single coal mine entry. The immediate coal measure rock was assigned as a creep material and Norton's single power law was used for predicting creep strain. The material properties for the creep equation were selected from the creep properties of salt for just a trial run and model was calibrated to produce reasonable roof convergence over a year creep time. 


\subsubsection{Modeling Methodology}

The accuracy of results predicted from numerical models depend entirely on the material properties used for solving the continuum equation. Each material property governs the response of the system. It is imperative for a thorough search and selection of material properties for producing meaningful and practical results. A procedure for deriving and calibrating material properties based on rock salt testing is suggested here for coal measure rocks. The steps involved were exclusively used in the FLAC models described in subsequent section. The lack of availability of creep data in coal measure rocks provided a major constraint in creep modeling of coal measure rocks. Price (1964) perhaps was the researcher who performed extensive creep test on coal measure rocks. Creep experiments using the bending beam apparatus were conducted on specimens of Pennant Sandstone and on specimens of calcareous sandstone. Creep tests in uni-axial compression were also conducted on specimens of sandstone. A primitive apparatus was used for the testing of rocks as compared to the modern servo controlled testing frames. All the tests were conducted in uni-axial compression; however a mining scenario exhibits tri-axial state of stress redistribution. Thus it is imperative to use tri-axial test conditions for producing creep results.

Munson (1996) conducted extensive tests on Avery island salts and produced set of material properties for fitting creep values. A low stiffness salt model having material properties similar to the coal measure rock was selected. The creep constants 'A' and ' $n$ ' described by Munson et al. (1996) was adjusted for power law model as most of the parameters were initialized to fit Munson and Dawson creep model. These constant values were used in the FLAC3D model. Points in the model along the center of the entries were selected to measure displacement. Based on the 
field results 'A' and ' $n$ ' values were calibrated to produce the measured displacement. Although such attempt decreases the accuracy of the result however it provided a better understanding of the modeling results with limited creep test data for coal measure rocks.

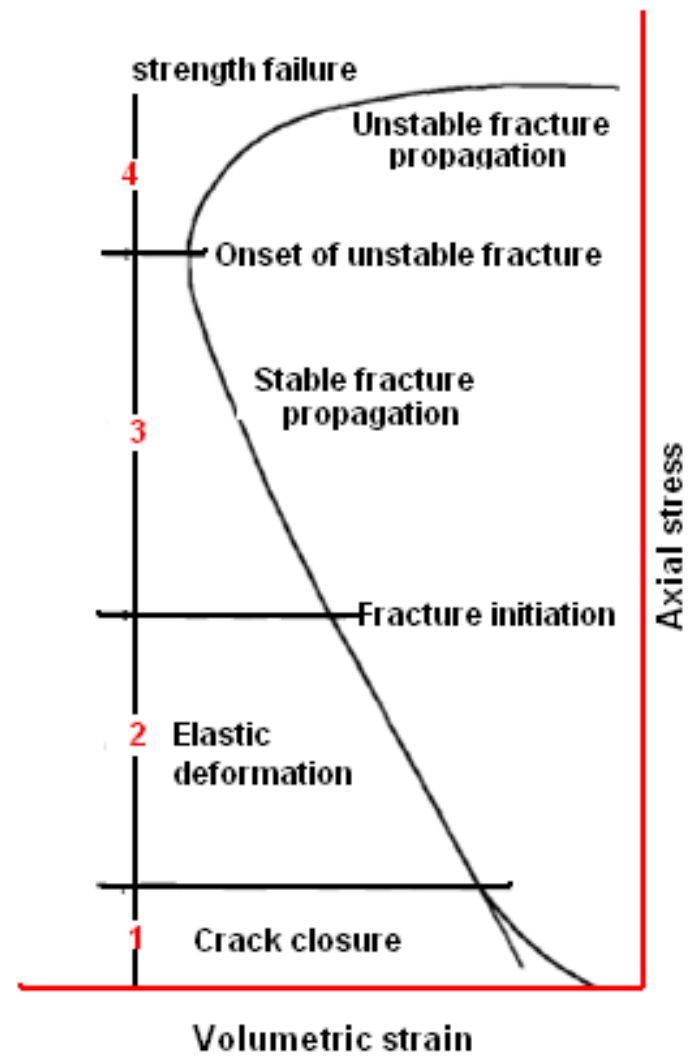

Figure 7.22 Stress-Volumetric Strain curve for hard rock (after Ladanyi)

The creep equations described in previous section were derived to predict creep strains. Stress difference is conceived to increase the creep strain (Munson, 1986, Schwartz and Kolluru, 1982). Thus if the stress state remains constant then the accumulated strain would induce crack which would propagate to produce failure of rock. However most failure criteria are stress based and are able to predict onset of failure only when a certain stress condition is overwhelmed. Predicting creep failure necessitates the development of strain based failure criterion and will be explained in 
next section. Although such work is out of scope of the thesis but the methodology towards the development of such criterion is described below.

1. Use of triaxial test systems for prediction of creep by maintaining load below yield stress for different state of stress

2. Measuring volumetric deformation of the sample each day until failure initiates in the sample as shown in Figure 7.22

3. Measuring the amount of volumetric deformation after failure and using the same as a limiting condition in the numerical model for predicting failure due to volumetric strain.

4. To achieve accuracy a statistical approach is needed for eliminating errors produced during sample selection.

The method described above would indicate realistic behavior of the roof undergoing time dependent deformation.

\subsubsection{Numerical Simulation of Creep Behavior for Coal Measure Rocks}

As explained above to simulate the creep phenomenon it requires some basic creep properties of rock but unfortunately there is not any data set available as per information of the author. Fortunately FLAC 3D numerical software has incorporated different types of creep material model (Itasca 2007).

In coal mines there is a wide variation in the rock characteristics in floor and roof apart from presence of many weakness/bedding planes. Therefore without comprehensive monitoring plan it's really difficult to say whether creep phenomenon is responsible due to bedding planes failure or due to roof or floor rock creep. Further it may also happen due to weathering or presence of moisture or water, roof or floor rock's strength may be degraded and may fail without taking place any creep effect. 
Where mine openings fail after a considerable long time there is definitely the role of creep and it can not be ignored. But when mine openings fail within a very short span like few days/weeks/month, the creep may not have any significant role. Further in many cases if we won't support the openings immediately the roof would fail, but with installation of artificial supports roof fall is prevented. This type of early failures without any supporting, indicates that stresses are very near to or attain the yield strength. The additional supporting avoids the active plastic flow or reducing the further strain in the rock.

In absence of sophisticated rock creep testing data, the easiest way to simulate the creep phenomenon in an underground mine is to simulate the convergence (opening closure) or roof displacement. Normally in a mine after excavation the convergence in the openings increases with time and after some time when convergence exceeds a threshold limit, the roof fails. Roof convergence under normal roof conditions would be small and steady, but it accelerates rapidly immediately before a roof fall. Figure 7.23 shows roof convergence monitored with time in conjunction with micro-seismic emissions (Iannacchione et al., 2004, Peng 2008). The convergence profile looks exactly similar like creep strain profile with time. From this observation its looks like during secondary creep, the convergence increases from 0.6 to 1.5 inches and after that the rate of convergence increases sharply (tertiary creep) and roof fall takes place after a cumulative convergence of 4 inches. 


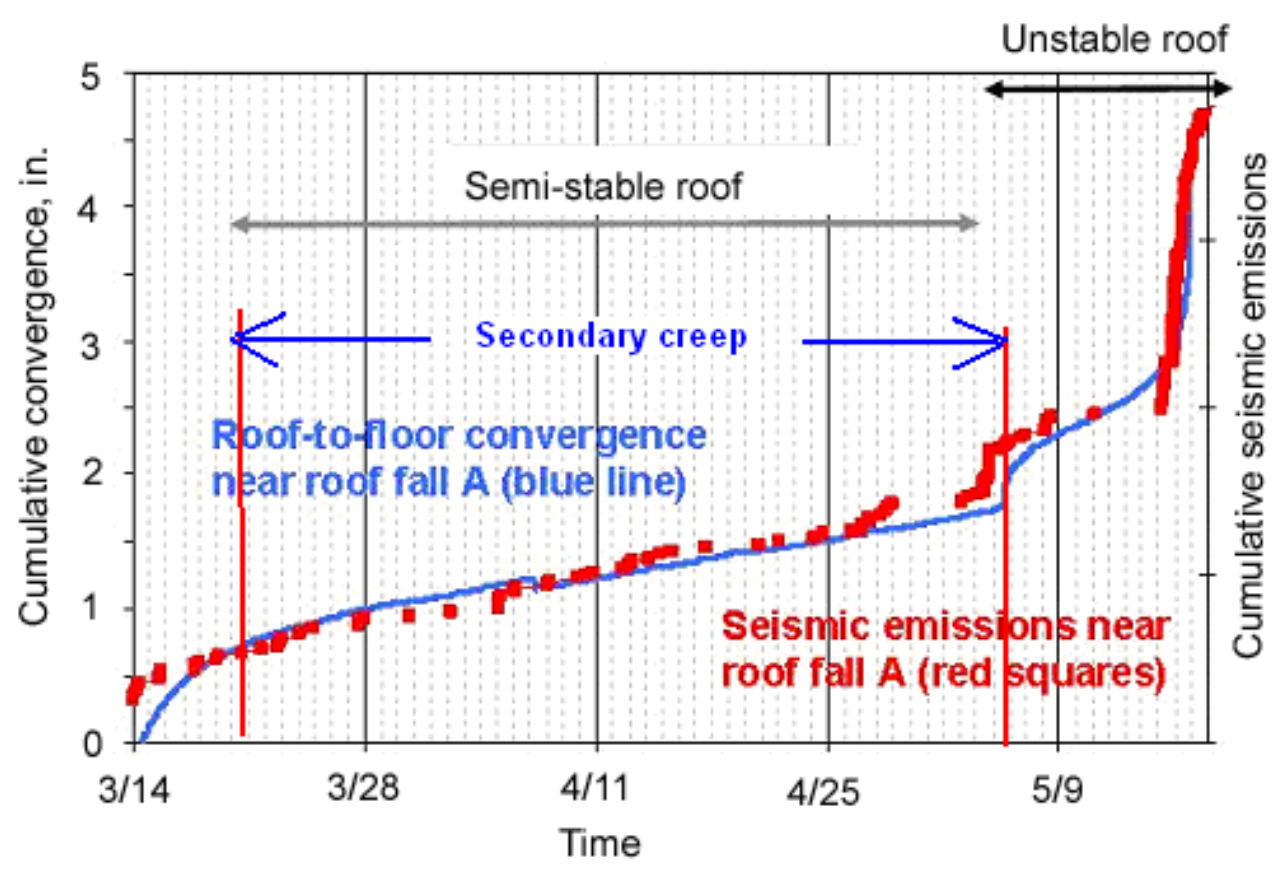

Figure 7.23 Comparison between roof convergence, micro-seismic event frequency, and local stability conditions (Iannacchione et al., 2004; Peng 2008)

Figure 7.24 shows the displacement rate and cumulative displacement with time. This figure again shows that for initial period, the displacement rate is almost constant and after a lapse of time it increases with time.

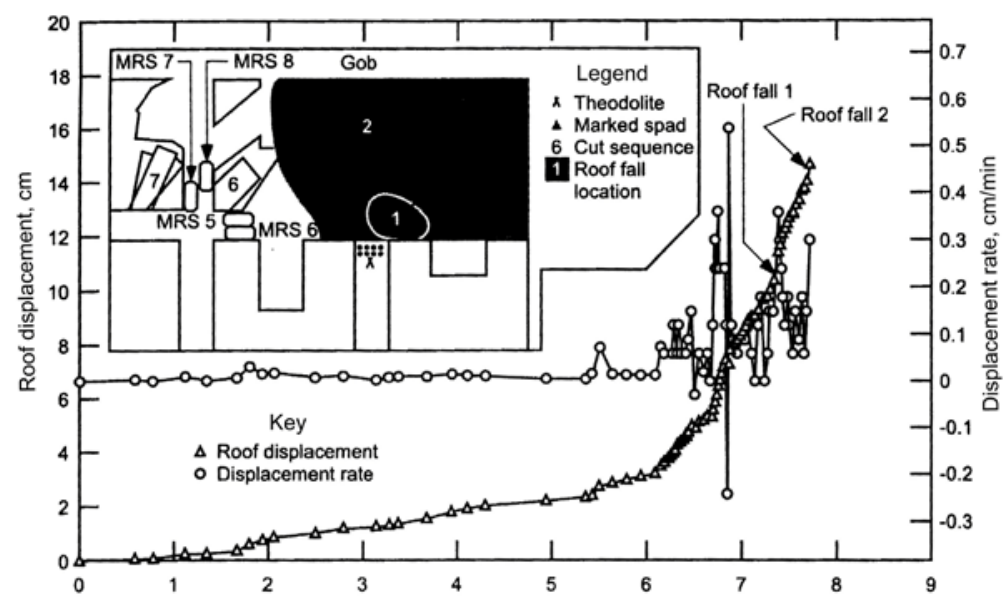

Figure 7.24 Roof displacement history prior to roof falls during panel retreat (Maleki et al., 2001; Peng 2008) 
So the major task is to calibrate the numerical model with these types of convergence or roof displacement profiles measured with time in the fields. Due to lack of any details geology and other mining parameters required for modeling of these case, the above two cases can not be simulated. On the other hand the roof fall data gathered from the case study mine discussed in Chapter 7 have all details but no convergence or roof displacements are available. This makes it really tough to simulate the standup time of roof fall. Again in case study mine, it was observed that the standup time varies from 1 month to 5 years. So in follow up section using power law creep model in-built in FLAC3D has been described with a simple 2D model to show how using proper ' $A$ ' and ' $n$ ' constants the desired roof displacement can be matched with known standup time.

A 2D elastic model with same lithology and rock properties shown in Figure 7.25 and Table 7.2 were used. Figure 7.26 shows the 2D model with location of points where displacement and stresses were monitored with time. From the creep rate Equation 7.2, it is obvious that creep rate or total strain will increase with increase in material constant ' $A$ ' and ' $n$ '. Initially the ' $A$ ' $\left(3.12 \times 10^{-17}\right)$ and ' $n$ ' (3) value were used same as for soft salt rock but no significant roof displacement were observed even after a long time period of more than 10 years. The same models were solved for increased value of ' $A$ ' with varying ' $n$ ' as 3, 4 and 5. For coal seam, very low value of ' $A$ ' $\left(3.12 \times 10^{-19}\right)$ and ' $n$ ' (3) were used assuming that the coal pillar does not fail with time. The displacements were monitored at locations in the roof and floor as shown in Figure 7.26b. The models were solved from 1 month to 5 years. The Figure 7.27 shows the variation in the roof displacement at location ' 1 ' in the roof for different time period. The change in displacement with variation in 
material constants ' $A$ ' and ' $n$ ' under low and high stress conditions are given in Table 7.3.

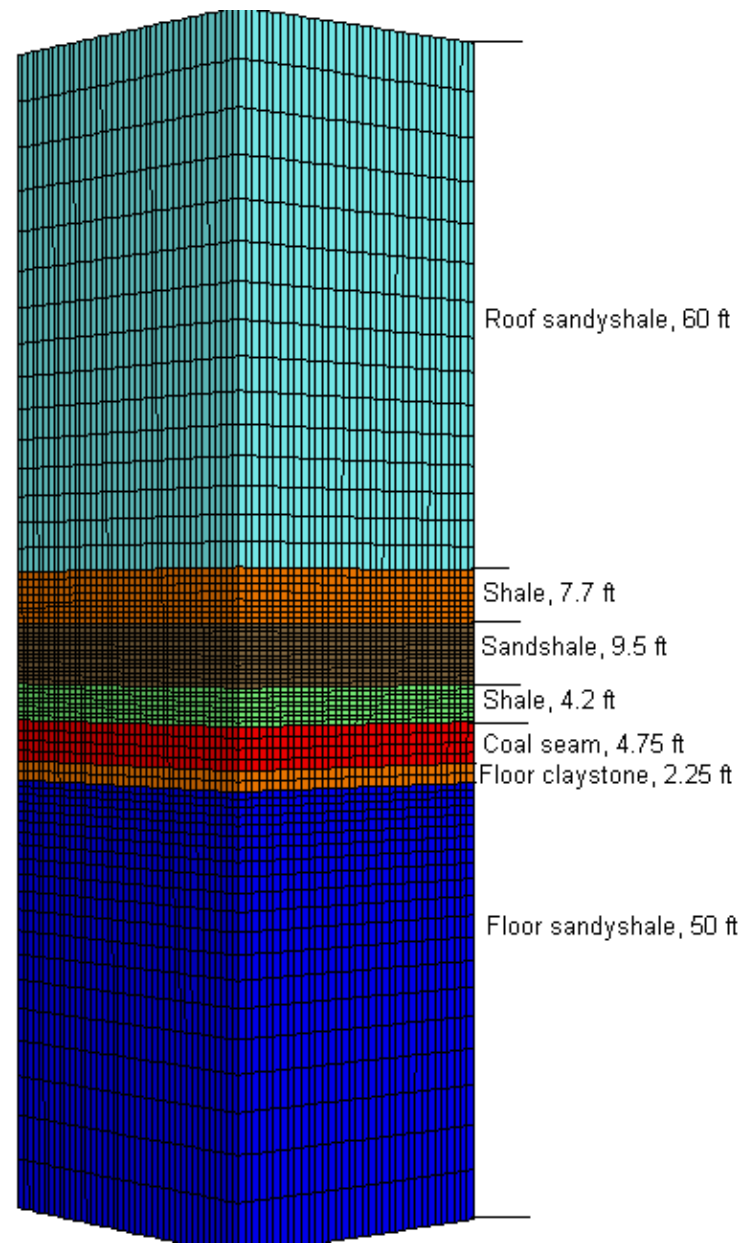

Figure 7.25 Model rock beds description

Table 7.2 Rock properties used for the creep model

\begin{tabular}{|c|c|c|c|c|c|c|}
\hline Rock Type & $\begin{array}{c}\text { UCS, } \\
\text { psi }\end{array}$ & $\begin{array}{c}\text { Tensile } \\
\text { strength, } \\
\text { psi }\end{array}$ & $\begin{array}{c}\text { Young's } \\
\text { modulus, } \\
10^{6} \mathrm{psi}\end{array}$ & $\begin{array}{c}\text { poison's } \\
\text { ratio }\end{array}$ & $\begin{array}{c}\text { Rock mass } \\
\text { friction, } \\
\text { degree }\end{array}$ & $\begin{array}{c}\text { Rock mass } \\
\text { cohesion, } \\
\text { psi }\end{array}$ \\
\hline Sandstone & 3023 & 300 & 1.53 & 0.25 & 36 & 237 \\
\hline Sandyshale & 3771 & 400 & 1.08 & 0.25 & 32 & 296 \\
\hline $\begin{array}{c}\text { Immediate Shale } \\
\text { roof }\end{array}$ & 1969 & 200 & 0.45 & 0.3 & 28 & 154 \\
\hline coal & 2411 & 145 & 0.36 & 0.3 & 28 & 190 \\
\hline Floor clay & 1400 & 109 & 0.15 & 0.27 & 28 & 112 \\
\hline $\begin{array}{c}\text { Floor } \\
\text { Sandyshale }\end{array}$ & 3771 & 400 & 1.08 & 0.25 & 32 & 296 \\
\hline
\end{tabular}




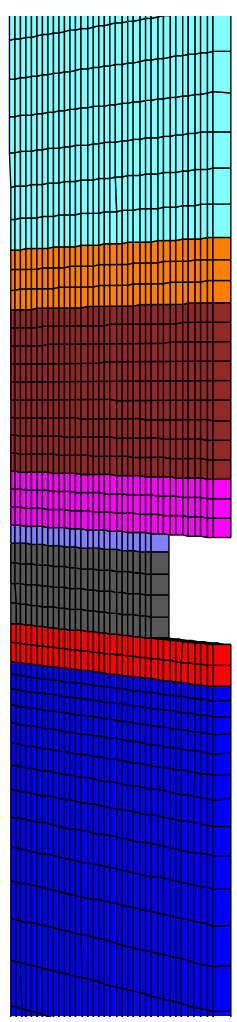

a. 2D model with half entry width

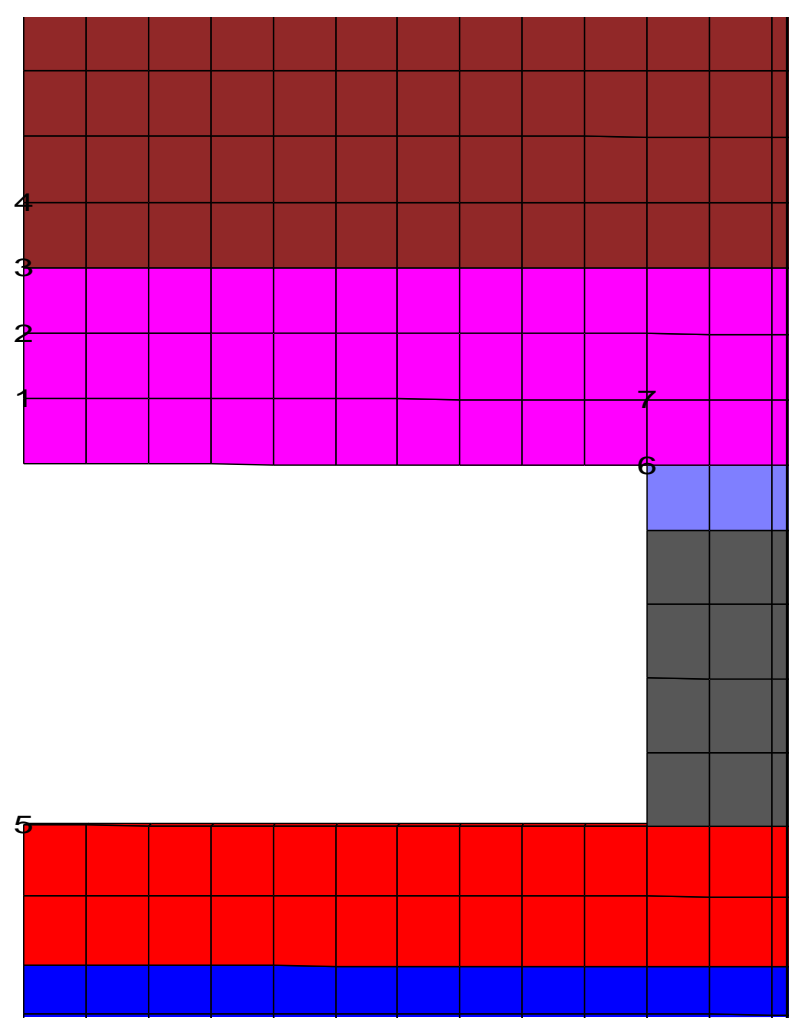

b. Location of points where displacement and stresses monitored

Figure 7.26 2D elastic model for creep study

Table 7.3 Variation in roof displacement with change in material constants ' $A$ ' and ' $n$ '

\begin{tabular}{|c|c|c|c|c|c|c|c|c|c|c|}
\hline \multirow{2}{*}{$\begin{array}{c}\text { Stress } \\
\text { condition }\end{array}$} & \multicolumn{2}{|c|}{ Material constant } & \multicolumn{7}{|c|}{ Roof displacement, inch } \\
\cline { 2 - 11 } & $\mathrm{A}$ & $\mathrm{n}$ & $\begin{array}{c}1 \\
\text { month }\end{array}$ & $\begin{array}{c}3 \\
\text { month }\end{array}$ & $\begin{array}{c}6 \\
\text { month }\end{array}$ & 1 year & 2 year & 3 year & 4 year & 5 year \\
\hline$k=0.66, l=1.5$ & $3.13 \times 10^{-13}$ & 3 & 0.2368 & 0.2368 & 0.2368 & 0.2372 & 0.2376 & 0.238 & 0.2384 & 0.2388 \\
\hline$k=0.66, l=1.6$ & $3.13 \times 10^{-13}$ & 4 & 0.2436 & 0.2436 & 0.2436 & 0.2866 & 0.3169 & 0.3411 & 0.362 & 0.3809 \\
\hline$k=0.66, l=1.7$ & $3.13 \times 10^{-13}$ & 5 & 0.4612 & 0.4612 & 0.4612 & 1.208 & 1.797 & 2.372 & 2.943 & 3.514 \\
\hline$k=2.0, l=1.5$ & $3.13 \times 10^{-13}$ & 5 & 0.8236 & 0.8236 & 0.8236 & 1.566 & 2.151 & 2.723 & 3.296 & 3.867 \\
\hline$k=0.66, l=1.5$ & $3.13 \times 10^{-13}$ & 3 & 0.2371 & 0.2371 & 0.2371 & 0.2407 & 0.2443 & 0.2478 & 0.2511 & 0.2543 \\
\hline$k=0.66, l=1.6$ & $3.13 \times 10^{-13}$ & 4 & 0.2799 & 0.2799 & 0.2799 & 0.4592 & 0.5819 & 0.6834 & 0.7733 & 0.8557 \\
\hline$k=0.66, l=1.7$ & $3.13 \times 10^{-13}$ & 5 & 1.093 & 1.093 & 1.093 & 6.368 & 12.08 & 17.77 & 23.49 & 29.2 \\
\hline
\end{tabular}

From the Table 7.3, it can be observed that ' $\mathrm{n}$ ' value has more influence than ' $\mathrm{A}$ ' and also if we know the total convergence or displacement before the fall, 'A' and ' $n$ ' can 
be selected to match those observations in the field. It can be noted here that when horizontal stress is high the displacement almost becomes double in early stage. Hence same rock under high stress condition can fail much earlier.

Figure 7.27 and 7.28 shows the variation in roof displacement with creep time and step time respectively for material constant value of 'A' as $3.13 \times 10-13$ and ' $n$ ' as 5 for low horizontal stress condition. Figure 7.29 and 7.3 shows the variation in major and minor principal stress with creep time respectively. For high stress condition the behavior is same but the magnitude of displacement increases significantly during early creep time.

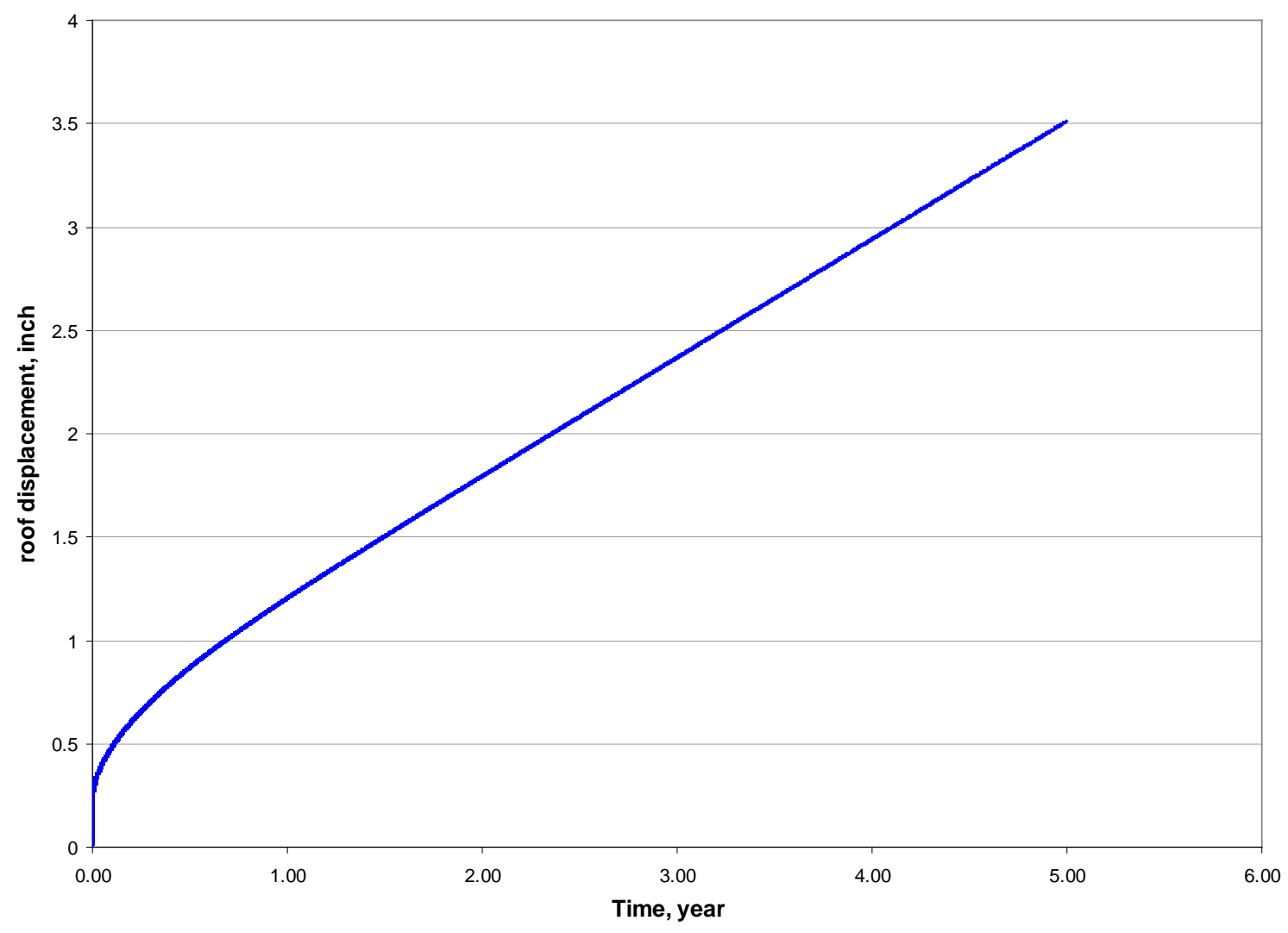

Figure 7.27 Change in roof displacement with time 


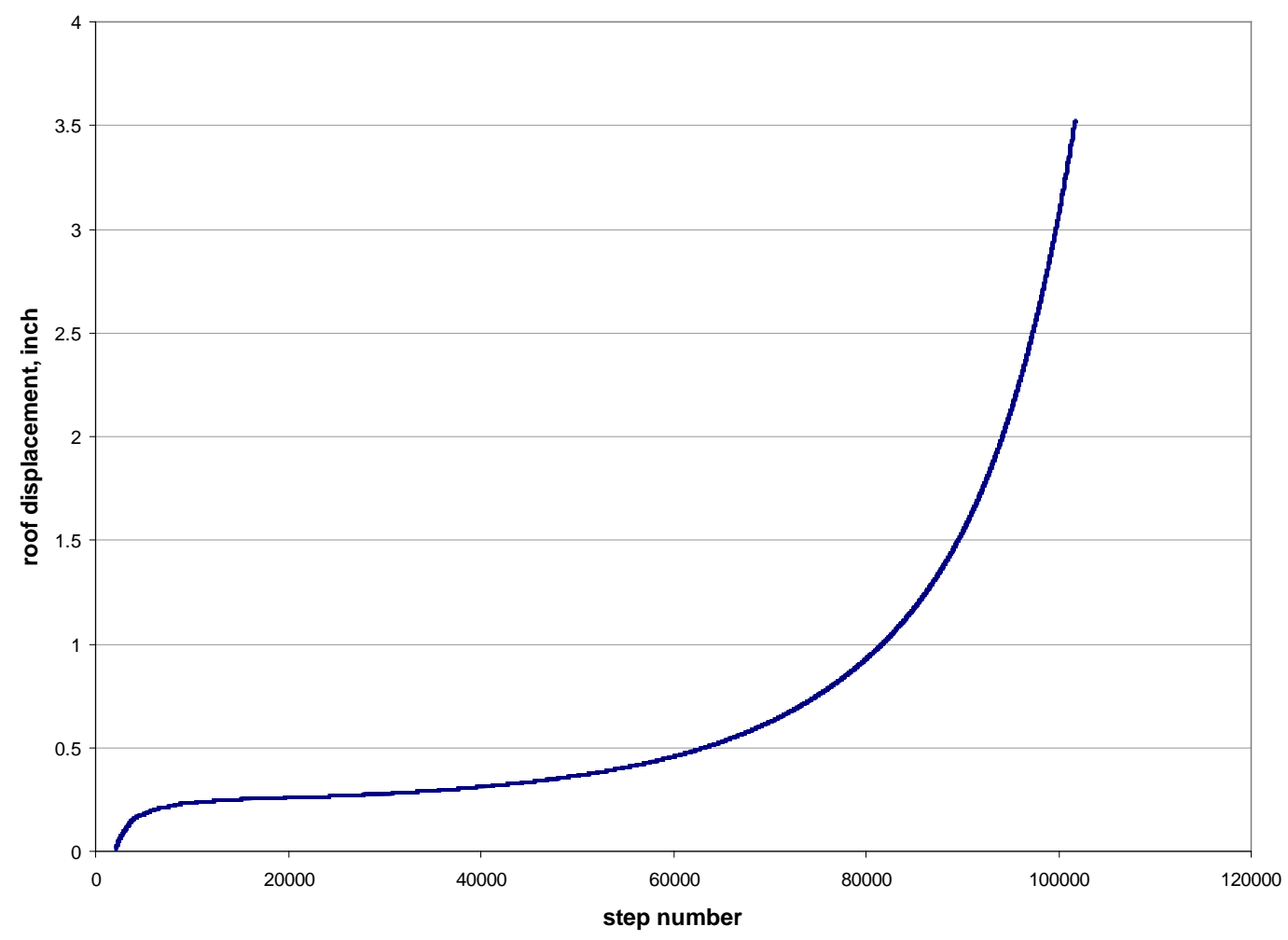

Figure 7.28 Change in roof displacement with step number

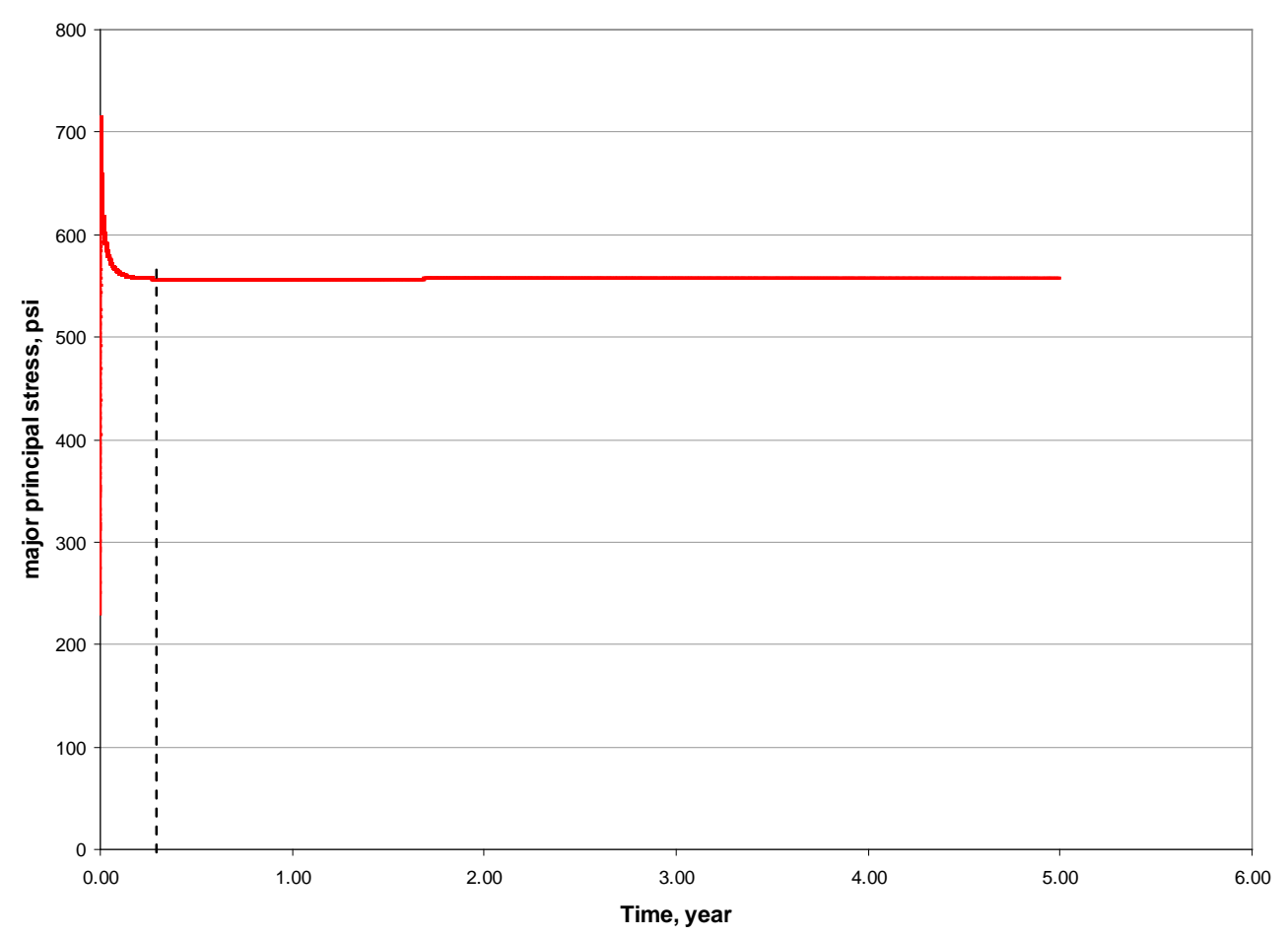

Figure 7.29 Change in major principal stress with time 


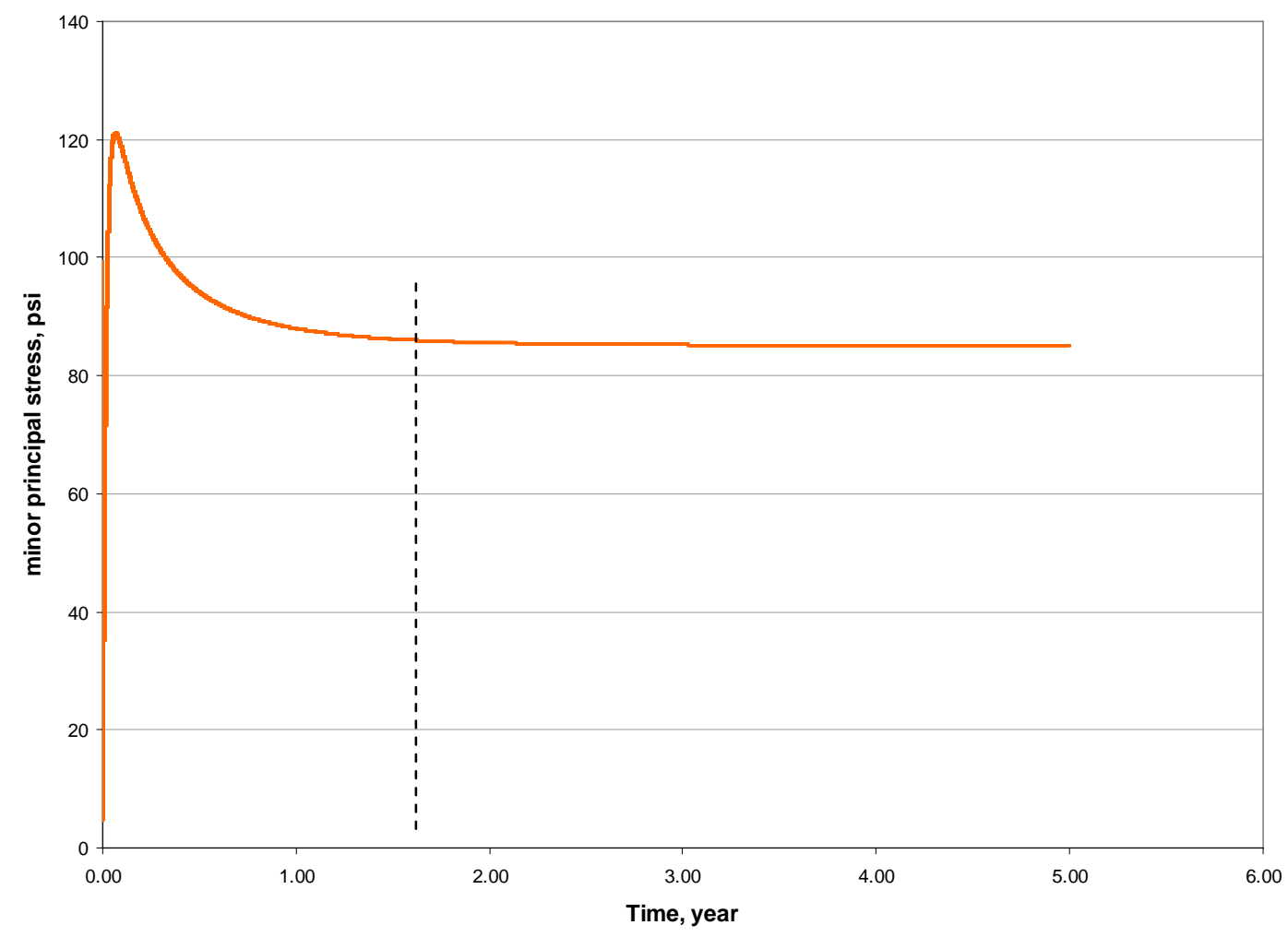

Figure 7.30 Change in minor principal stress with time

Figures 7.29 and 7.30 show that major and minor principal stresses become constant after some time. Major principal stress becomes constant just after 2 to 3 months while minor principal stress becomes constant after approximately 1.5 year. So when the stress becomes nearly constant and it is much less than the yield strength of rock, the secondary creep starts and it continues until there is no change in stress due to adjacent workings or any other reason.

Figures 7.31 and 7.32 show the safety factor calculated after 3 months and 2 year of creep time. The safety factor has been estimated using Mohr-Coulomb strength formula (Gadde 2003). From the safety factor plots we can see that in the immediate roof and floor safety factor is more than 3.0 for both time span of 3 months and 2 years. This makes sense as since there is no change in major and minor principal stresses with time, the safety factor won't change with time although 
rock can go under high strain/deformation with time and ultimately fail. The same behavior will be observed even for plastic models as stress doesn't change with time, either no yielding will be observed or it won't increase with time.

Therefore a failure criterion should be developed based on strain rather on stress to study the creep effect and to estimate the time of failure.

Safety factor

$7.4255 e-001$ t $1.00000+000$ $1.0000++\infty 00$ t $2.00000++\infty 00$ $2.0000 \mathrm{e}+\infty 000$ t $3.0000 \mathrm{e}+\infty 000$ $3.0000++\infty 00$ t $4.00000+\infty$ $1.0000++\infty 00$ t $500000+\infty$ $5.0000++\infty 00$ o $5.00000++\infty 00$ IItenal- 1 det +000

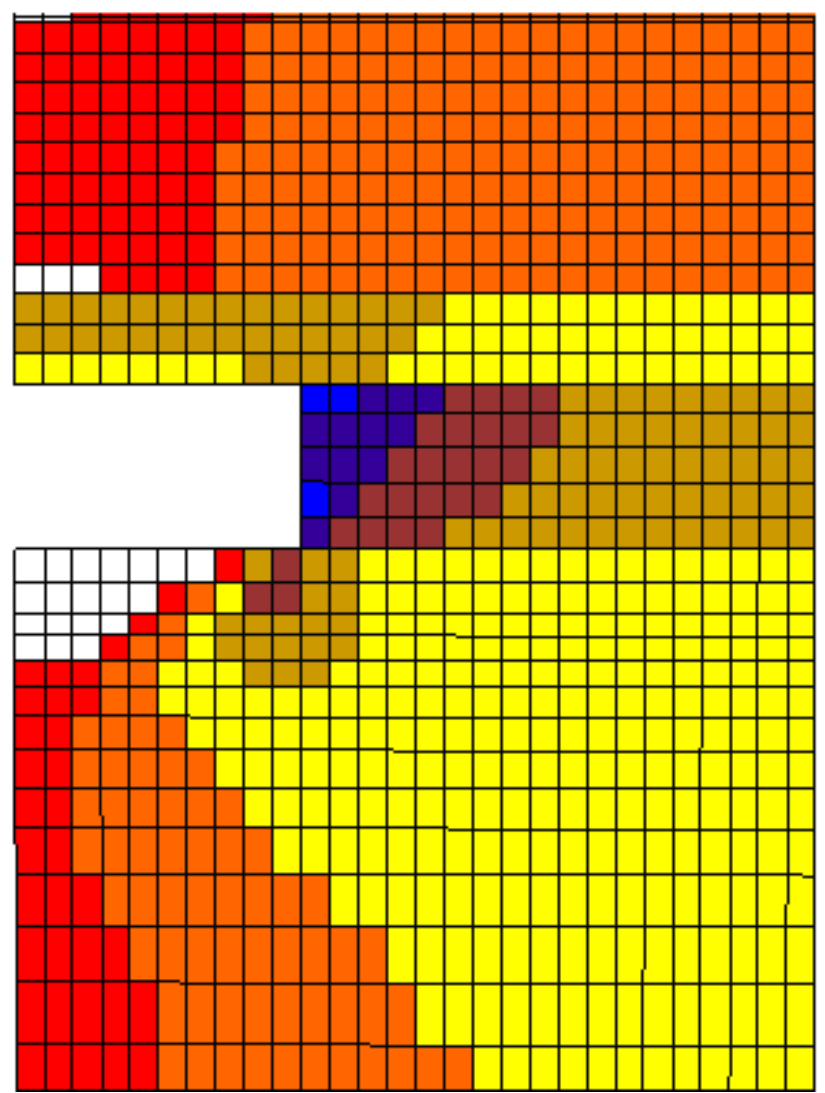

Figure 7.31 Safety factor contours after 3 months (white zones have SF more than 5) 


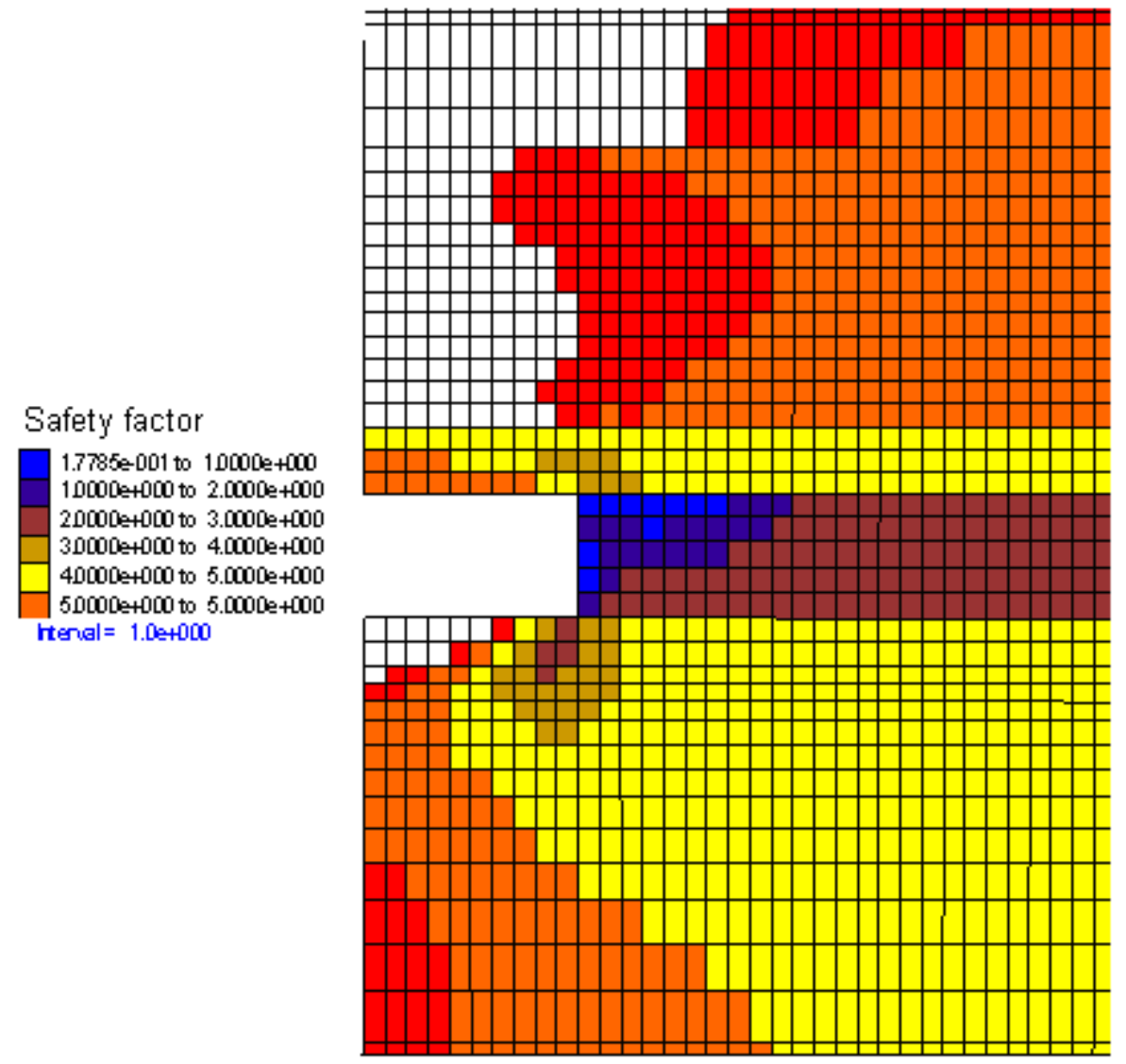

Figure 7.32 Safety factor contours after 2 years (white zones have SF more than 5)

\subsubsection{Strength Degradation of the Rock with Time}

In underground coal mine the roof and floor is always subject to weathering due to water, moisture in ventilating air which can reduce the strength of the rock. Further due to time effect the strain will cause to deform the rock and consequently reduction in the strength. Hence if a constitutive behavior which can incorporate the reduction or weakening of the strength of the rock mass with time or deformation, then the yield criteria based on stress can be conveniently used. Fakhimi and Fairhurst (1994) have used visco-elasto-plastic model to incorporate the time dependent material degradation. Both cohesion and friction are assumed to evolve with plastic and viscous strain in order to incorporate strain softening and time dependent material degradation. As there is not enough rock test data available, describing the 
change in cohesion and friction with plastic strain in post failure regime, lot of assumption will be required. The rock testing to get input for this type of constitutive model will be very tedious as still even after so many years of research the basic creep properties for the rocks are not available.

From uni-axial creep tests, it is known that new cracks start to develop in the sample only when the applied stresses are about $60 \%$ of the uni-axial compressive strength of the rock (Fakhimi and Fairhurst, 1994). It means if the applied stress is less than $60 \%$ of uni-axial rock strength of rock mass no crack will develop and rock will be quite stable. So if entry is stable with solving the model with its peak strength may become unstable when its strength reduces to $60 \%$ of its original intact strength due to time effect.

We have seen in chapter 6 that under low horizontal stress conditions and for comparatively stronger roof, no cutters were observed. Few models were solved with reduction in its peak strength to see whether cutters are formed or not. Figure $7.33 \mathrm{a}$ and $\mathrm{b}$ shows the cutter pattern with peak strength and $67 \%$ of peak strength for same stress condition. It can be seen that with $20 \%$ strength reduction, sever cutters forms. Similarly Figure 7.34 shows the increase in cutter severity due to reduction in strength under low horizontal stress condition. There is no cutter observed with in-situ peak strength but it gradually starts to develop as the peak strength is reduced.

Hence in any condition if we find that with 60 or $70 \%$ reduction there is no much change in cohesion pattern, the mine openings can be treated as stable with time. But the actual influence of time can be only estimated with the strain based rock failure criteria. 


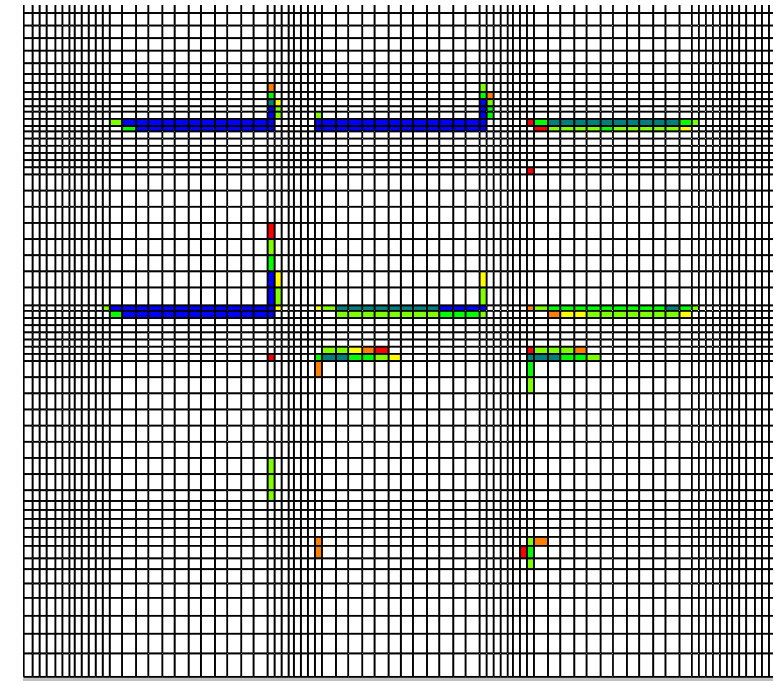

a. $k=1.5 \quad I=1.75$, peak cohesion $96 \mathrm{psi}$, $\theta=60^{\circ}$

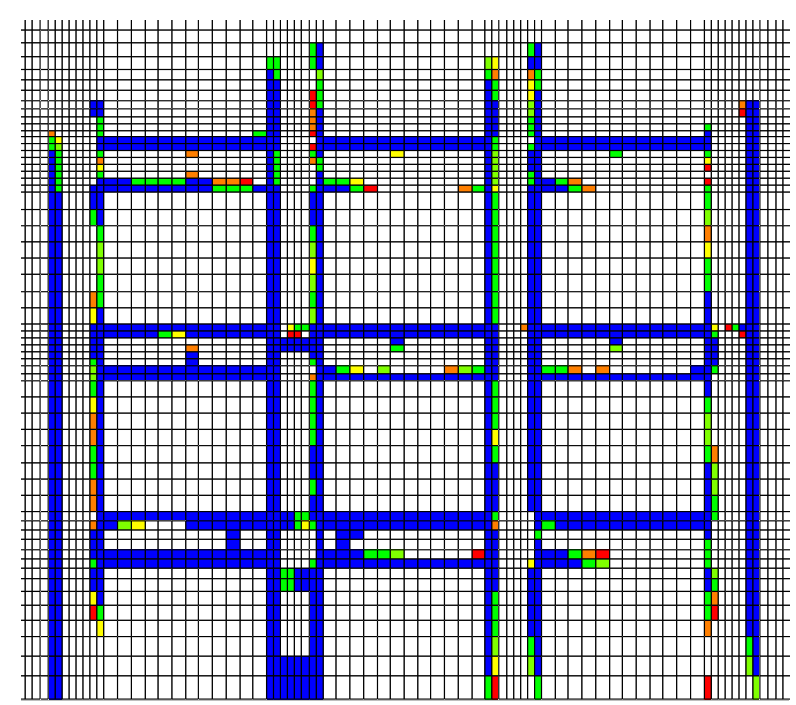

b. $k=1.5 \quad l=1.75$, peak cohesion $65 \mathrm{psi}$, $\theta=60^{\circ}$

Figure 7.33 Effect of strength reduction on cutter pattern under high stress

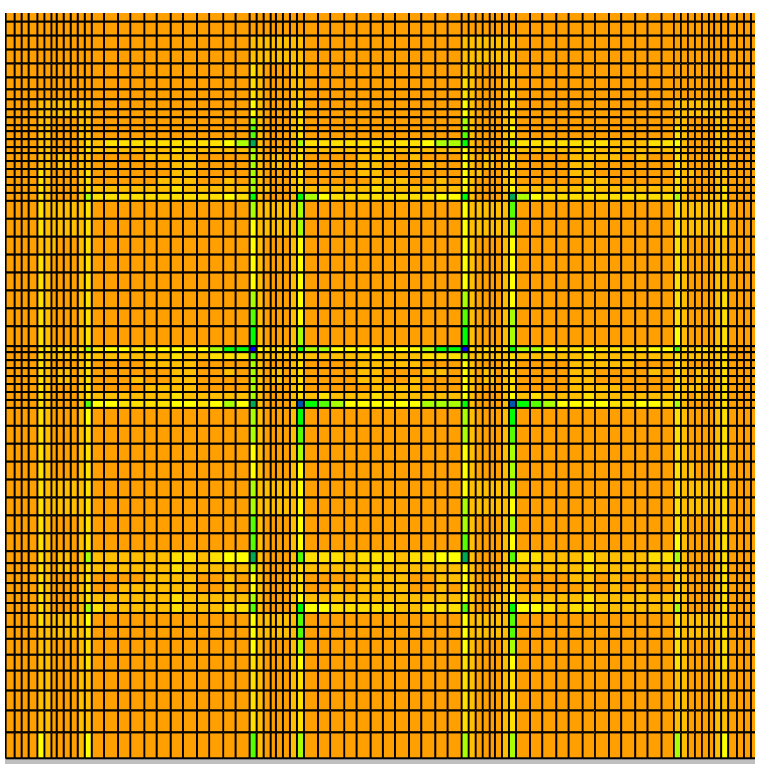

a. Peak strength 96 psi

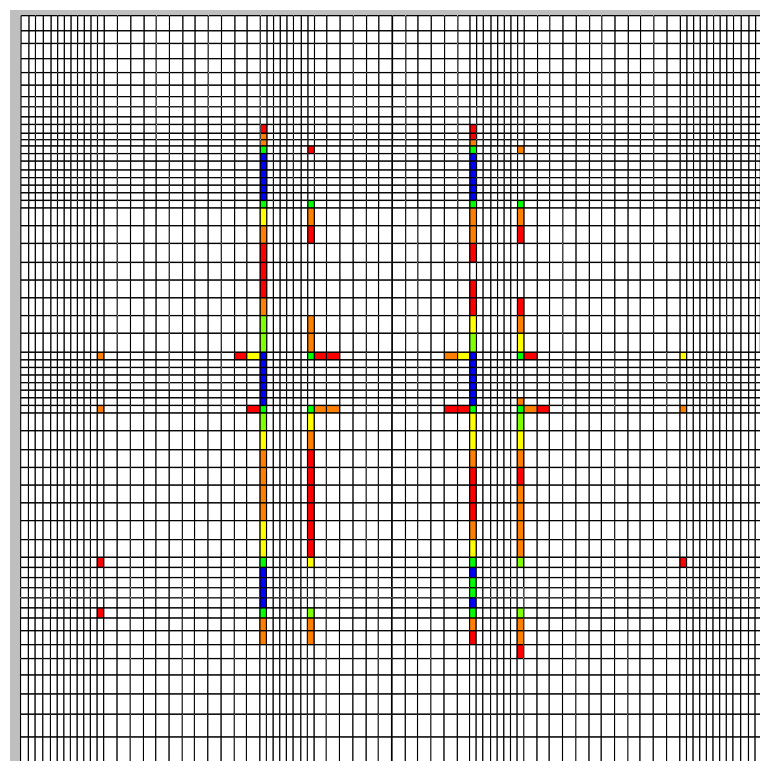

b. strength $=0.75$ times of peak strength

Fig 7.34 contd. 


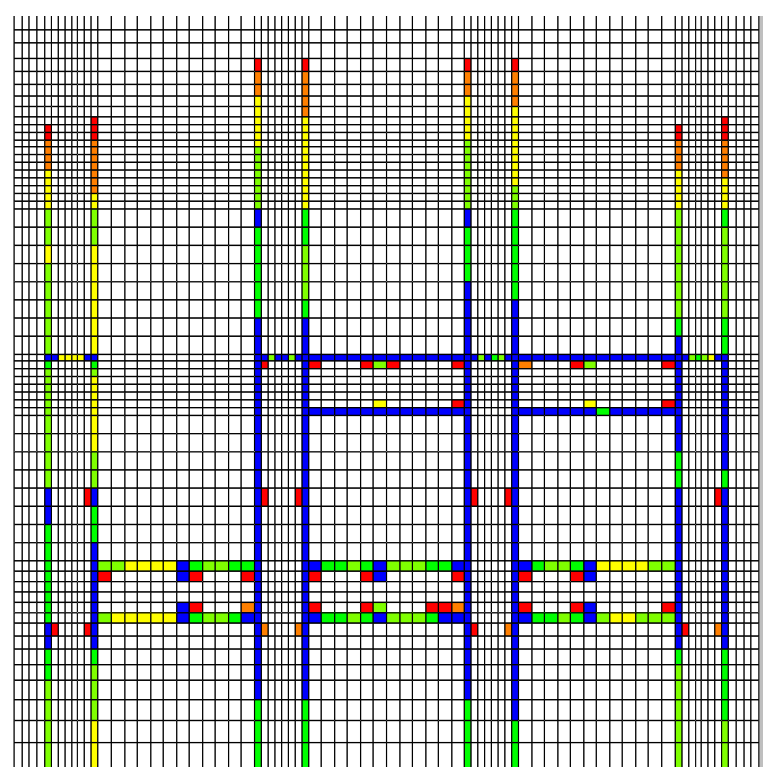

c. strength $=0.6$ times of peak strength

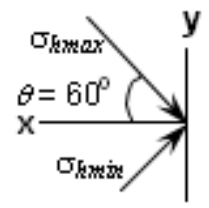

Figure 7.34 Effect of strength reduction on cutter pattern under low horizontal stress

\subsection{CHAPTER SUMMARY}

1. Time dependent deformation of immediate coal measure rock requires significant amount of creep testing of rocks with different stress difference states.

2. It appears that pillar size by itself may not significantly alter the roof stability under weak roof conditions. Increasing the pillar size, however, will provide longer standup times.

3. Numerical simulation with adjusted creep data provided confidence of simulating such phenomenon in coal measure rocks.

4. In-Situ deformation/convergence measurement is necessary for validating model outcomes. However laboratory tests should be performed for different stress-difference conditions.

5. Development of strain based failure criteria may be useful for predicting failure due to time dependent deformation of coal measure rock. 
6. In absence of available knowledge on time-dependent rock properties for coal measure rocks, as a first step, it is suggested that some idea on the chances of time-dependent roof failure can be gained by solving some numerical models where the rock mass strength is assigned a value equal to about 60$70 \%$ of its peak strength. This reduction factor is suggested based on the past laboratory investigations which showed that time-dependent rock failures are unlikely if the stress on the rock samples is kept below $70-80 \%$ of the rock strength. 


\section{CHAPTER 8}

\section{CONCLUSIONS AND RECOMMENDATIONS}

\subsection{CONCLUSIONS}

The numerical modeling results described in this dissertation and the practical experience gained at the case study mine lead to the following conclusions:

* In continuum numerical models, assigning the strain-softening constitutive behavior to the roof rocks provides the most realistic cutter patterns.

For horizontal stress angles other than $0^{\circ}$ and $90^{\circ}$, the cutter patterns differed significantly between the models where all the excavations were created in a single step and when the cutting sequence was considered.

Among all the factors that could affect cutter distribution in a panel, the modeling results suggest that it is the cutting sequence and the spatial variability of rock strength that play the overriding roles.

It is the relative magnitude of the in-situ stresses as compared to the rock mass strength that determine the severity of the cutter problem.

For everything else being the same, the model results show that the severity and spatial distribution of cutters in a panel primarily depend on the two in-situ stress ratios: $k$ and $l$.

* The modeling results show that severity of cutters may be high even when $I=1$, if the ratio of in-situ horizontal to vertical stress is greater than 1.0.

* The modeling results in this dissertation suggest that whether altering the orientation of a panel with respect to regional stresses will provide improved roof 
conditions or not depends on several site specific factors like the magnitude of $k, I$, rock mass strength, cutting sequence etc. In order to arrive at the best orientation of the panel, it is recommended to conduct site-specific numerical modeling as the general guidelines may not always work for every possible real world situation.

* From a purely theoretical consideration, it appears that for exceptionally weak roof situations, cut lengths equal to or less than the entry width will provide the best possible roof stability.

* By adopting proper cutting sequence and different cut lengths, it may be possible to improve ground control in intersections by limiting the number of times the working face has to stop in a future intersection.

* Cutting sequence by itself can not eliminate cutters. But, it can help minimize the spatial extent of the cutters

For both weak and strong roof conditions, turning the crosscuts away from the maximum horizontal stress direction will help improve the roof stability

* Even though some practical issues may need to be resolved, purely from a ground control view point, the step-face cutting pattern suggested in this dissertation may improve the ground stability in weak roof conditions.

* It appears that pillar size by itself may not significantly alter the roof stability under weak roof conditions. Increasing the pillar size, however, will provide longer standup times.

In order to successfully analyze the creep effect on roof falls, it is imperative to develop some strain-based rock failure criteria as opposed to the current stressbased ones. Research on this subject at this is almost non-existent. 
* The time elapsed after creating an excavation is a very important factor in the development of cutters and roof falls. Available knowledge on time-dependent rock properties for coal measure rocks is meager. As a consequence of this knowledge gap, as a first step, it is suggested that some idea on the chances of time-dependent roof failure can be gained by solving some numerical models where the rock mass strength is assigned a value equal to about $60-70 \%$ of its peak strength. This reduction factor is suggested based on the past laboratory investigations which showed that time-dependent rock failures are unlikely if the stress on the rock samples is kept below $70-80 \%$ of the rock strength.

\subsection{RECOMMENDATIONS FOR PREVENTION OF CUTTERS/ROOF FALLS}

In general, to alleviate cutters and roof falls in underground coal mines, the following measures are normally taken by coal operators:

- Change the orientation of the entries/crosscuts;

- Reduce the entry width. Some times pillar length may also be increased.

- Even after reducing the entry width, if the problem does not go away, then increase the primary or secondary support density.

In addition to these common sense measures, the research in this dissertation shows that by simple change in cutting sequence and the pillar and intersection geometry, the roof falls can be further reduced.

Cutters and roof falls have higher chances to occur in weak or highly laminated moderately strong rocks with passage of time irrespective of the entry/crosscuts orientation and in-situ stress field. It appears that bulk of the past research focused on studying the effect of stress orientation on cutter development. 
Granted that stress orientation can have some positive effect on mine excavation stability in moderate to strong rocks, research in this dissertation showed that its effects in weak roof conditions may not be substantial. There are several practical cases where changing the panel orientation did not produce much beneficial effect on roof stability. Since the in-situ stress environment and the rock mass strength are natural factors that can not be altered, emphasis is normally placed on cost-effective artificial measures.

Based on the understanding gained on the mechanism of cutters and roof falls in this research, the following remedial measures focusing on the cutting sequence are suggested. While these measures alone can not eliminate the cutter problem, in addition the existing measures commonly adopted by operators, the following will help alleviate the intensity:

(i) Selection of suitable cut length. Smaller cut length reduces the probability of immediate bed separation/movement and can also stand stable for a longer time. It is not unconceivable that during shift changes or during holidays it may happen that after the last cut, the area is left unsupported (without bolting). In these situations, where practical, it is suggested to keep the last cut length smaller to take the advantage of longer standup times without supporting.

(ii) To use mixed cut length in a cutting sequence - As we have seen in the modeling that the location of face position in relation to a future intersection can affect the stability of the intersection. Where possible, the cut length should be chosen such that the face does not stop near a future intersection. Hence the cut length in a cutting sequence should be made such that it neither stops at an intersection nor within 10 to $15 \mathrm{ft}$ of it. 
(iii) Cut sequence should be such that no two consecutive cuts are made in adjacent entries. As an example of this suggestion, the cut sequence shown in Figures 6.10, 6.11 and 6.15 should be avoided. Cut sequence mentioned in Figures 6.12 or 6.14 may be used. It appears that the cut pattern in Figure 6.14 may be the best for any type of roof conditions.

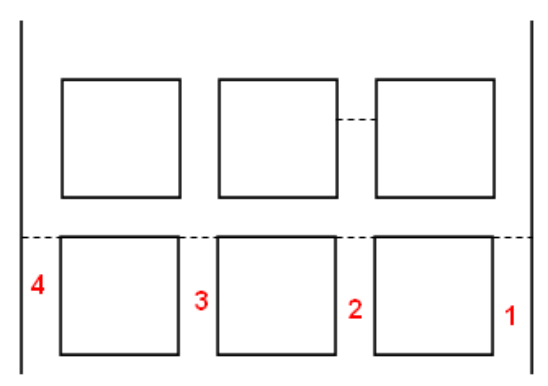

AVoID

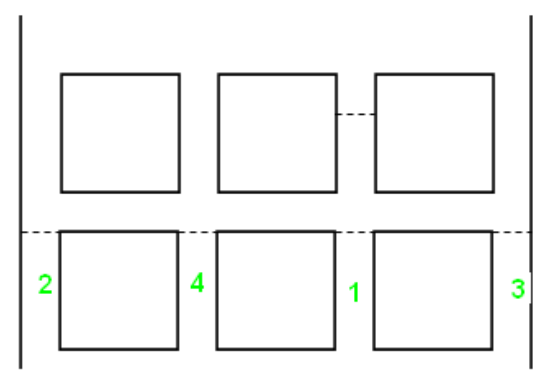

USE

(iv) Turning into or away from high horizontal stress direction - From the modeling it has been observed that the direction in which crosscuts are turned with respect to the direction of in-situ horizontal stress affects the cutter development. For a certain in-situ stress ratios $(k$ and $l)$ and for a particular panel orientation under weak roof conditions, turning away from the maximum horizontal stress produces less severe cutters as compared to when the crosscuts are turned into the stress. Hence the cutting sequence should involve this preferable turning direction as much as possible. It must be reminded that crosscut turn direction alone can not eliminate cutters. But, the incremental gains due to each measure could add up to minimize or eliminate the cutter problem at a mine. 


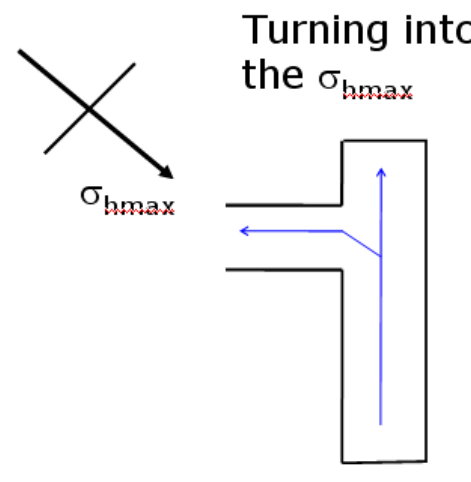

AVOID

\section{Turning away}

from the $\sigma_{\text {hmax }}$

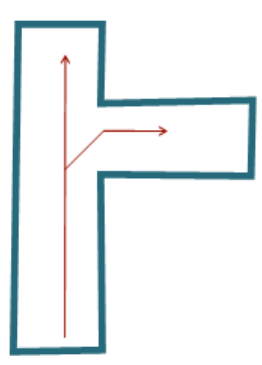

USE

(v) To use step face - The step face as shown in Figure below can be effective under very weak roof and very high stress conditions. The exact step distance can be estimated by numerical modeling such as that discussed in this research so that all the pertinent site-specific conditions could be considered. For example, under the geo mining conditions for the case study described in the dissertation, the step distance, $d=20 \mathrm{ft}$ may work well for a cut length of $20 \mathrm{ft}$ or $30 \mathrm{ft}$.

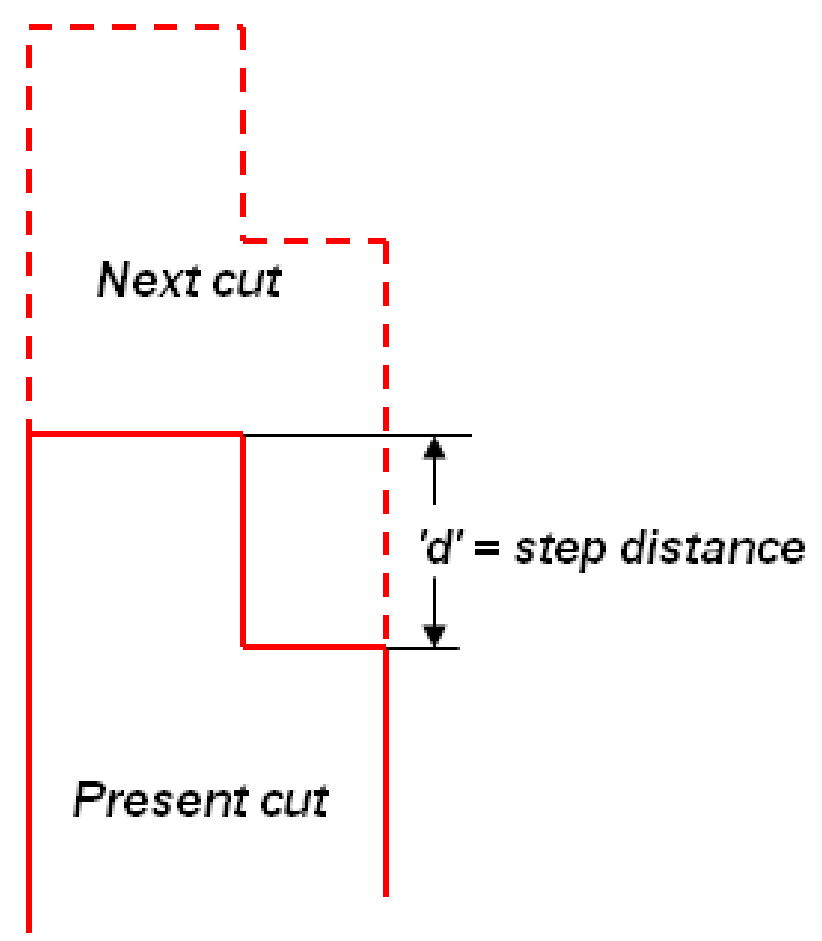


(VI) Intersection geometry- From the case study discussed in this dissertation and from the past research, it is quite evident that the intersection geometry not only influences the fall initiation but also affects the stand up time of the fall. When the continuous miner turns to make a slab in the crosscut, it produces a rounded corner on the pillar as shown in Figure 6.20. This results in a longer intersection span. For example in Figure 6.20, one slab cut intersection was measured as $33.5^{\prime}$ by 28.8 ', while the regular intersection was 27 ' by 29.2 '. MSHA roof fall data (Molinda et al., 1998) showed that intersections were, on a foot by foot basis, about 8-10 times more likely to have roof falls than entries/crosscuts. A four-way intersection is 1.28 times more likely to have roof falls than a three-way intersection. Based on extensive case history analysis, Mark et al. (2001) proposed the following relationship to estimate the maximum diagonal distance of a coal mine intersection based on the CMRR.

$$
I S_{G}=20+0.26(C M R R)
$$

where, $I \mathrm{~S}_{\mathrm{G}}$ is mean diagonal distance of the intersection in feet.

From the above relationship, a safe diagonal distance of $29.1 \mathrm{ft}$ is recommended for the intersection for a $C M R R=35$. This diagonal distance can be maintained by suitable cutting sequence design. Figure 8.1 shows the CM turnout into crosscut from entry. Cutting pattern ' $\mathrm{B}$ ' is the most common one used in practice but in this method one diagonal span becomes almost $20.8 \%$ more than the other. With wider slabs, for an entry width of $20 \mathrm{ft}$, one diagonal distance becomes $34.2 \mathrm{ft}$ which is more than the suggested $29.1 \mathrm{ft}$ if the roof's CMRR is 35 . To minimize the diagonal span and to provide enough room for the miner turnout, it is suggested to adopt 'C' type of turn out where possible. This can be very effective as 
the diagonal span will remain the same as for the regular square intersection. Similarly to avoid 4-way intersections, the pillars can be developed as shown in Figure 8.2 with some offset. The offset can be made either in one entry (Figures 8.2 b and c) or in all entries (Figures $8.2 \mathrm{a}$ and d). This type of 3-way intersection instead of the regular 4-way one can reduce the roof fall probability or increase the standup time.
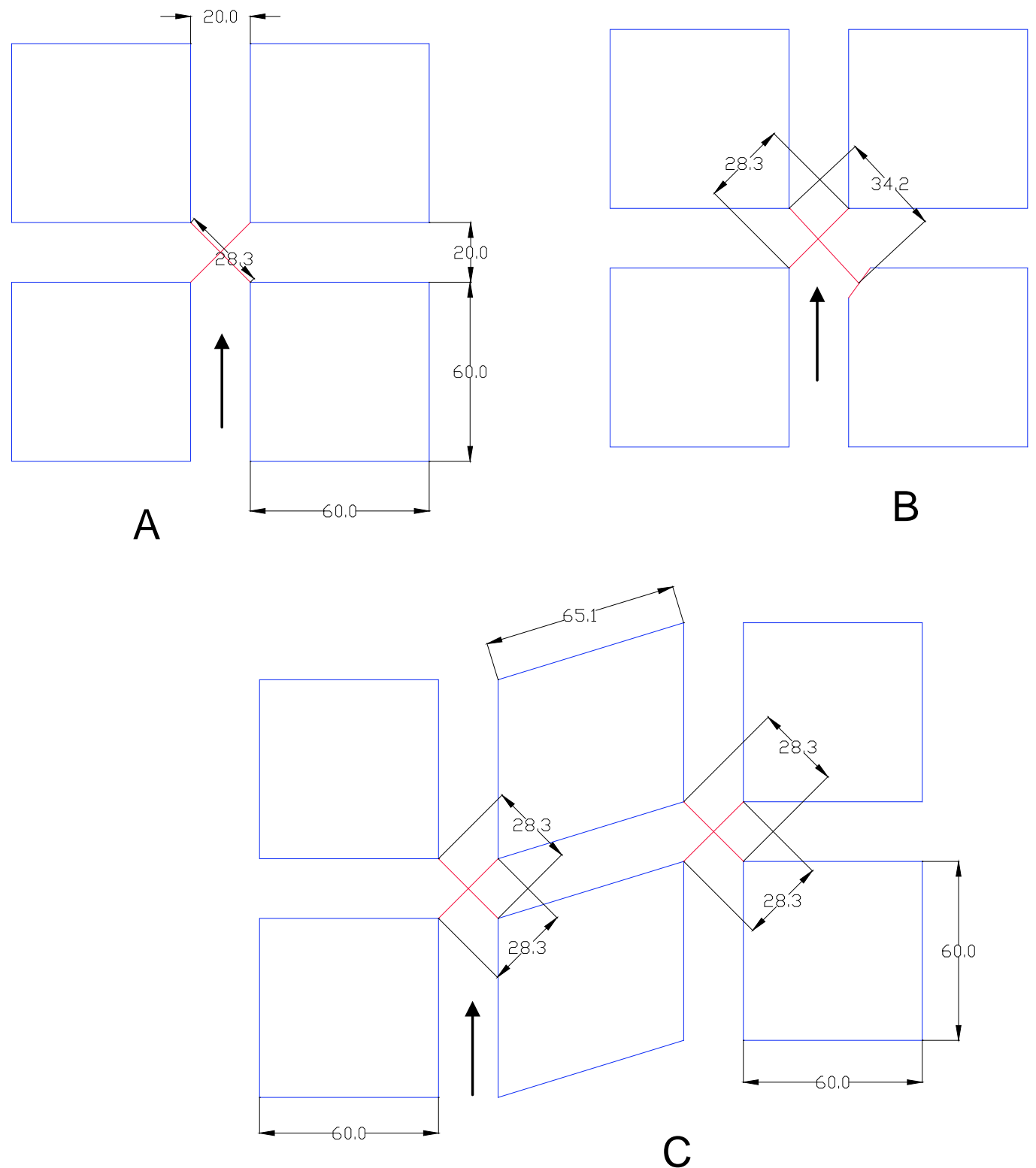

Figure 8.1 Direction of turning into crosscuts to avoid longer diagonal span at intersection; A. Normal cut B. CM Turn (generally practiced) C. Modified CM Turn (arrow marks the entry from which turn out will be made) 


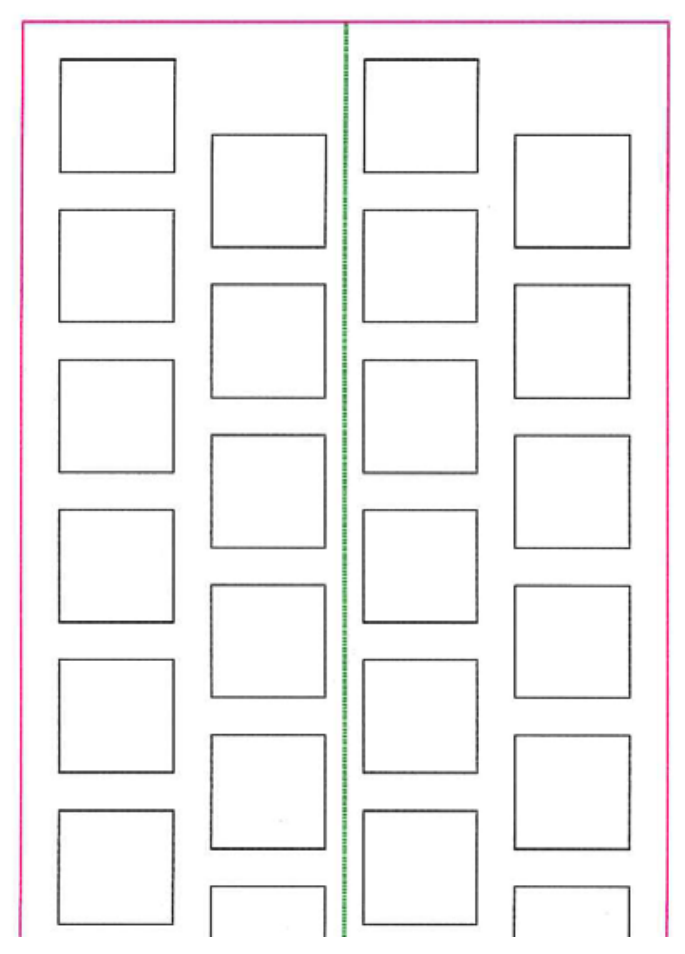

a. Pillar with $40 \mathrm{ft}$ offset in all entries for a pillar size of $80 \times 80 \mathrm{ft}$

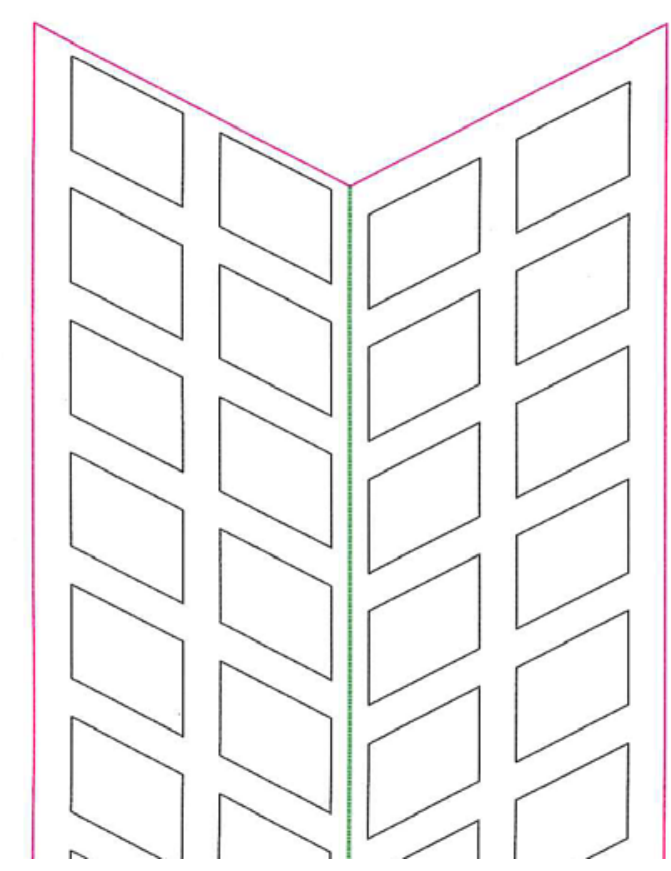

c. Pillar with $15 \mathrm{ft}$ offset in central (belt entry) for a pillar size of $80 \times 80 \mathrm{ft}$

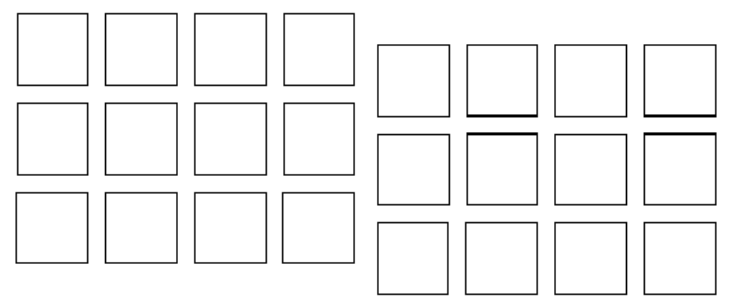

b. Pillar with $20 \mathrm{ft}$ offset in one entry for a pillar size of $80 \times 80 \mathrm{ft}$

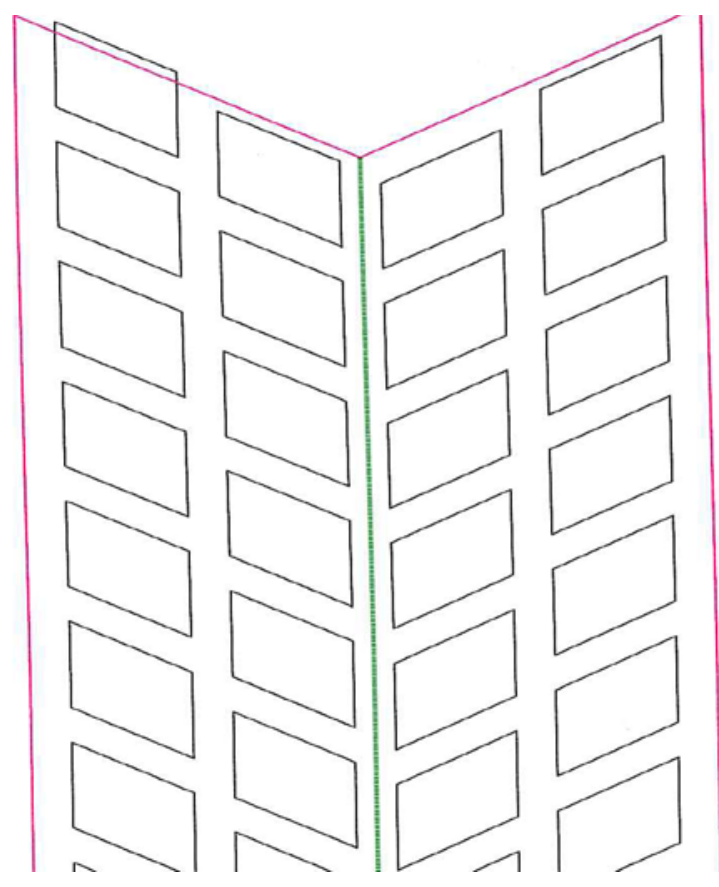

d. Pillar with $15 \mathrm{ft}$ offset in each entry for a pillar size of $80 \times 80 \mathrm{ft}$

Figure 8.2 Layout of pillars to avoid 4-way intersections 
(VII)Bigger pillar size during development and splitting during retreating - From the case study mine discussed in this dissertation, it has been observed that even though roof falls occurred at pillars of all sizes, the longer and wider pillars enhanced the standup time of the roof significantly. To utilize the positive effects of increased size, during development of a panel, bigger pillars could be made. Once the panel is developed to the most inby end, the bigger pillars could be split into smaller pillars on retreat such that the split pillars will have long- or short-term stability as the conditions dictate. As a consequence of the lesser area developed and increased stand up time, longer panels could be mined. This approach to panel development will be very useful particularly for the Illinois basin and under high depth cover in eastern or western US mines. The bigger pillars will transmit lower vertical stress to the floor below and thus even very weak floor with lower bearing capacity can experience stable conditions. Similarly, at higher depth the bigger development pillar which has lower vertical will experience lower rib sloughage leading to better roof conditions.

As an example of the bigger pillar development scheme, Figure 8.3 shows a typical room and pillar panel layout. The panel on the left side of this figure shows the normal pillars size used for the shallow depth at this Illinois basin mine. Even this smaller pillar (35x70 ft) has stability factor of 5.2 and 1.6 during development with mining height of $6 \mathrm{ft}$ and entry width of $20 \mathrm{ft}$ at an overburden depth of 250 and $800 \mathrm{ft}$, respectively. This pillar can be stable under competent floor rock. But the small pillar size may not provide stable roof if the rock strength is low. If the floor strength is low, the smaller pillar can result in some floor failures, which in turn will trigger roof falls. From this perspective, bigger 
pillar size will have much more added advantages. Hence it is advisable to develop the panels/ mains with bigger size pillars. While retreating, the pillar can be reduced to the normal size. Different retreat layout options with cutting sequence during pillar splitting are given in Figures 8.4 and 8.5. In all figures ' $A$ ' and ' $\mathrm{B}$ ' are the inter-panel barrier pillars. Pillar1-2 in Figure 8.3 indicates that during retreat this pillar will be split in two parts 1 and 2 or $2 a \& 2 b$. These layouts can be used depending on whether the mine has weak roof or working at higher overburden depth. To avoid any damage or roof fall in the belt entry, in the center either two or three pillar rows can be left without any pillar splitting. One major advantage of this system is less consumption of roof bolts. From Figure $8.5 \mathrm{~b}$, it can be seen that with proposed cutting sequence while pillar splitting, roof bolting may be used only after cut 1 . For the remaining cut 2 and cut 3 roof bolting may not be required.

(VIII) Avoid making very long sub-mains /mains- The length of sub-mains may be designed based on the standup time of roof fall observed at site specific.

(IX) Since the large amount of input data needed for modeling on a mine scale is typically not available, it is recommended that the roof stability mapping (Wang and Heasley, 2005) approach together with numerical models may be used to achieve the best ground control at a mine. 


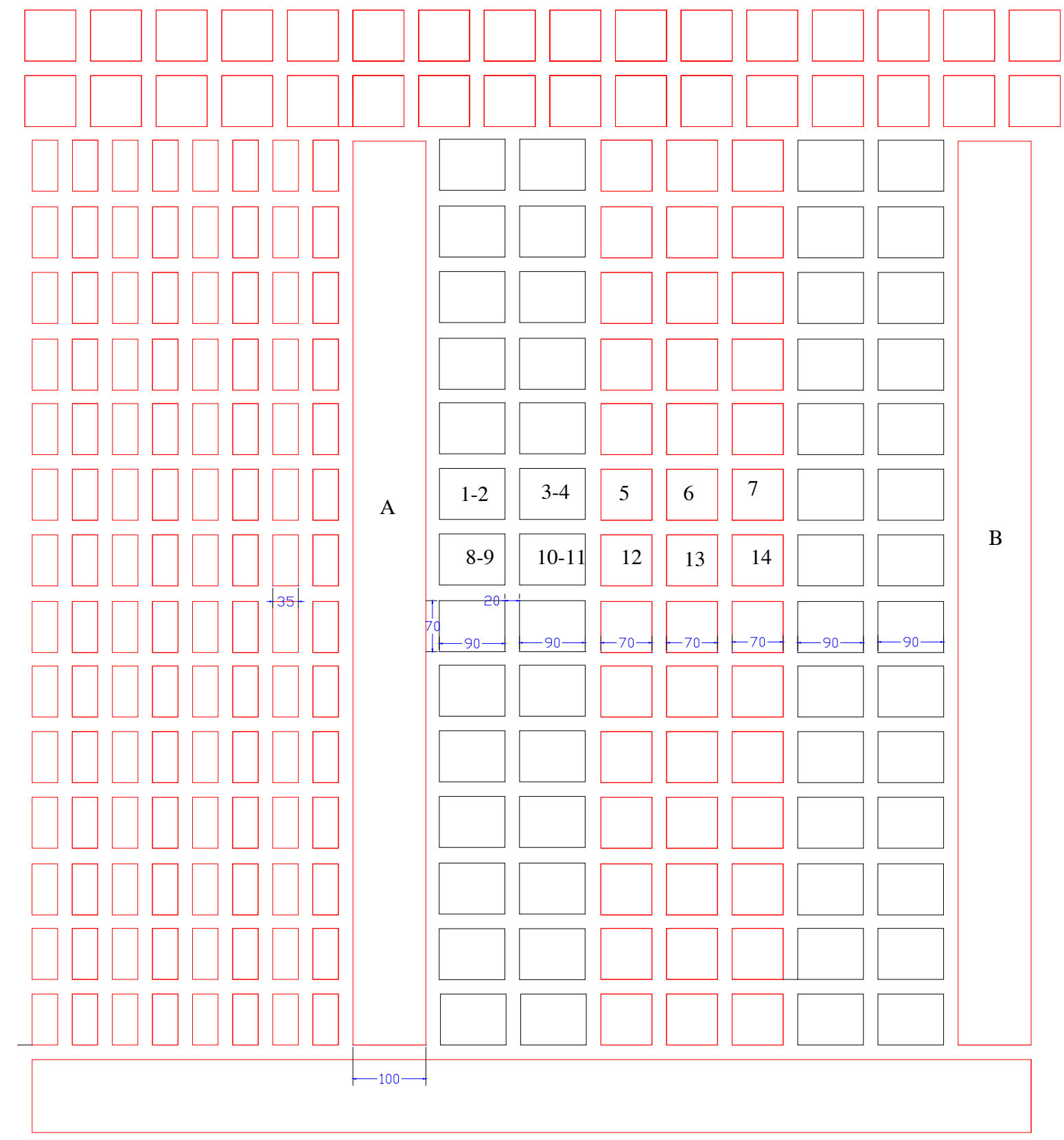

Figure 8.3 Development with smaller pillar (left) and bigger pillar (right) 


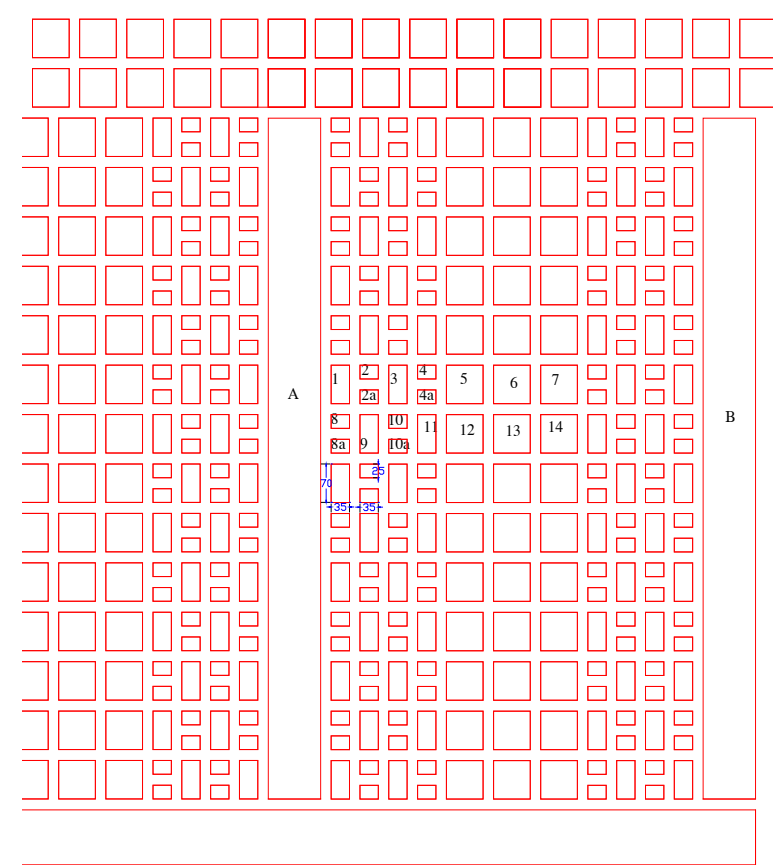

a. Retreat option I

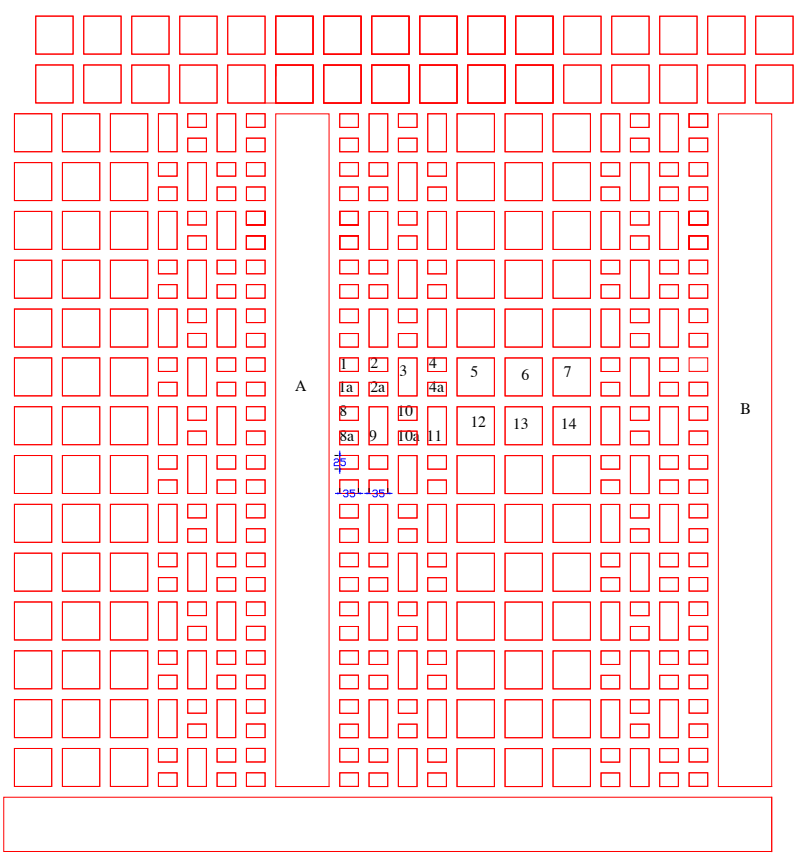

b. retreat option II

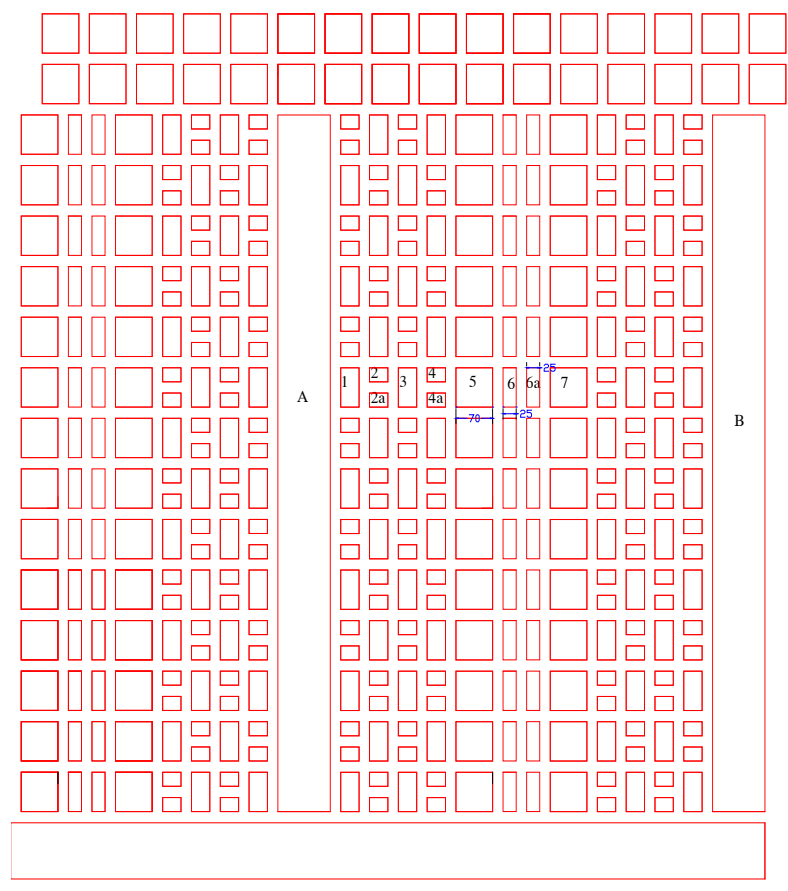

Retreat option III

Figure 8.4 Pillar retreat options 1 with bigger pillars during development 


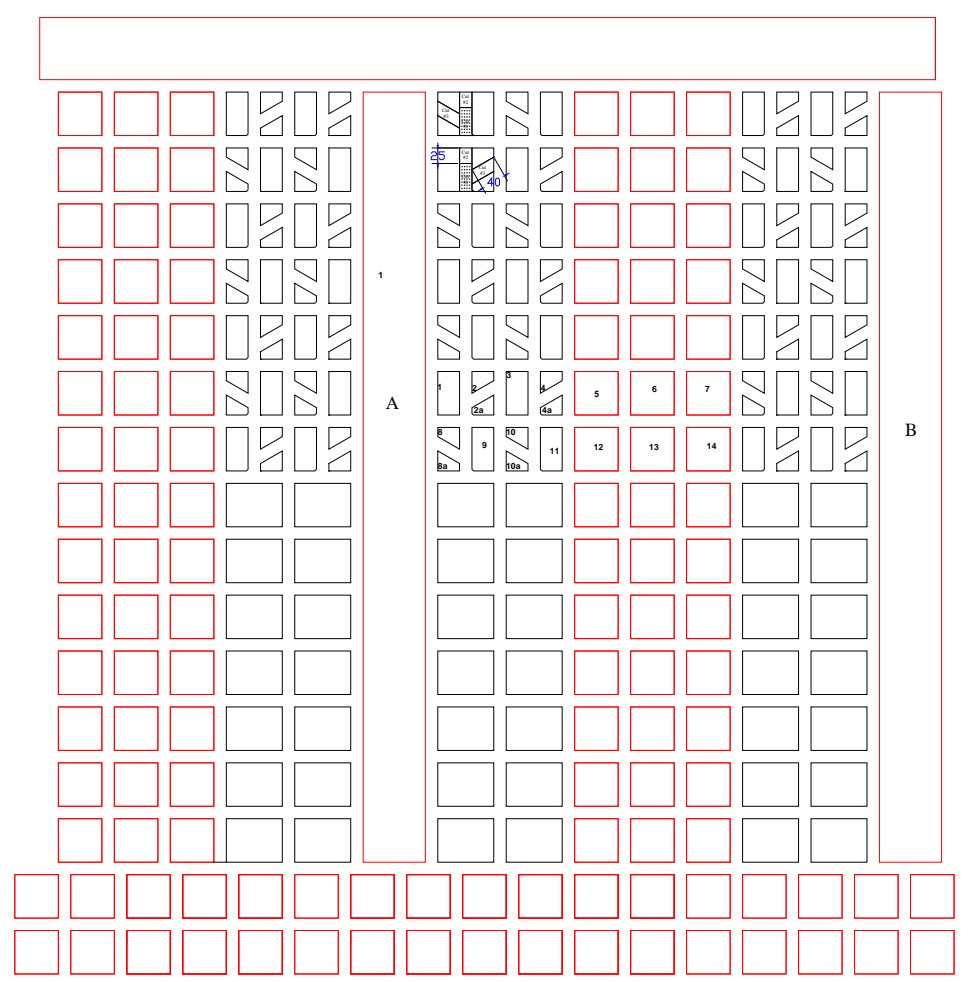

a. Pillar splitting in half of the panel leaving center rows of pillar intact
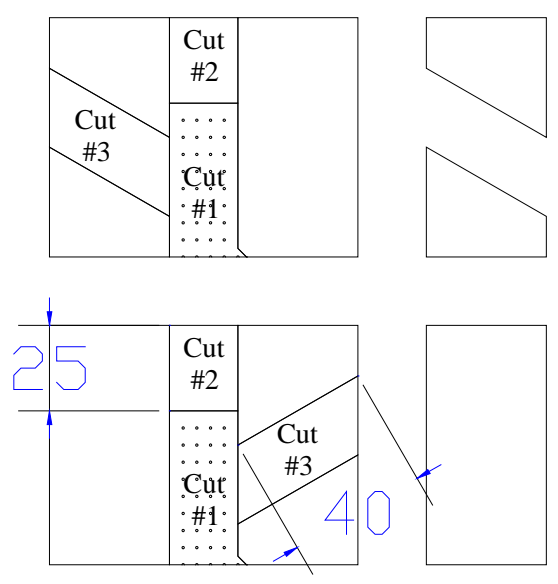

b. Cut sequence for pillar splitting

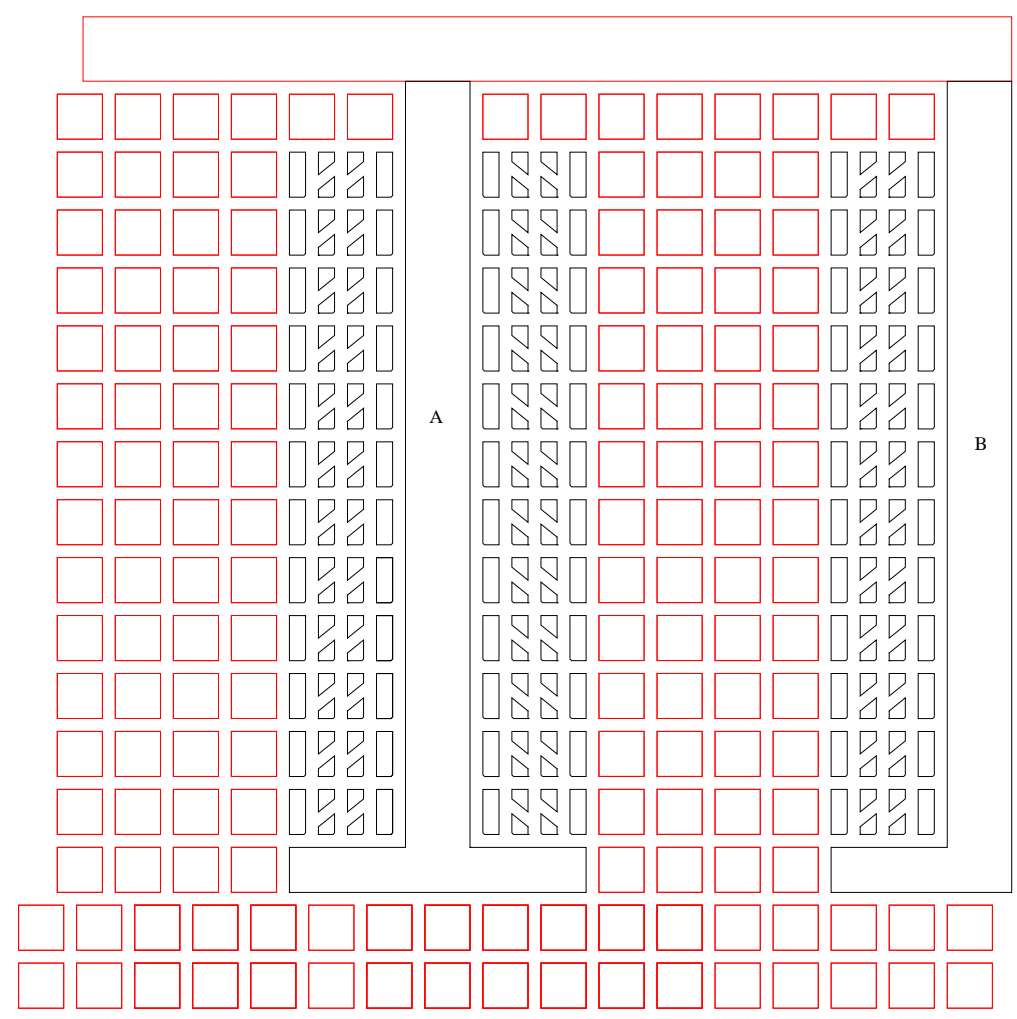

c. Pillar splitting in the panel leaving center rows of pillar intact

Figure 8.5 Pillar retreat options 2 with bigger pillars during development 


\subsection{FUTURE RESEARCH}

Based on the investigations carried out in this research, the following work is identified for any future studies:

* Sufficient rock testing is required to create a database of strain softening properties like the cohesion and friction angle. This requires the complete post failure testing of sample with varying confinement pressure. The cohesion and friction mobilization in post failure region can adversely affect the modeling results.

* The time aspects of the cutter roof problem require extensive further research. It is important to collect data on cutter development at some coal mines as a function of time to see if any temporal changes indeed exist. Laboratory testing of different coal measure rocks as a function of time is necessary to develop the necessary model inputs. Such lab experiments will also help develop better rock failure criteria that accurately reflect the time-dependent deformations. It can be appreciated that any research on time-dependent rock properties can only be effectively conducted as a part of a multi-phase study over several years. While extremely challenging, studies on the time effects on rock stability must be initiated at some point. Otherwise, the necessary data will never be obtained and this very important topic of underground ground control will continue to remain an unsolved puzzle. 


\section{REFERENCES}

1. Agapito, J. F. T., Mitchell, S. J., Hardy, M. P., and Hoskins, W. N. (1980) Determination of In Situ Horizontal Rock Stress on Both a Mine-Wide and District-Wide Basis (contract J0285020, Tosco Research Inc., and J.F.T. Agapito \& Associates). USBM OFR 143-80, pp 174.

2. Agapito, J.F.T., and Gilbride, L.J. (2002) Horizontal Stresses as Indicator of Roof stability, SME Annual Meeting 2002, Phoenix, Arizona.

3. Agapito, J.F.T., Gilbride, L.J., and Koontz, W.A. (2005) Implication of Highly anisotropic Horizontal Stresses on Entry stability at The West ELK Mine, Somerset, Colorado, Proceedings of the 24th International Conference on Ground Control in Mining, West Virginia University, Morgantown, West Virginia.

4. Agarwal, R., and Mayer, S. L. (1979) Longwall Subsidence Measurement Using Photogrammatric and Surface Surveying Techniques, Final report submitted to U.S. Bureau of Mines under contract J0366031, Bethlehem Steel Corporation, pp 99.

5. Aggson, J. R. (1978) Coal Mine Floor Heave in the Beckley Coalbed, An Analysis, USBM RI 8274, pp 32.

6. Aggson, J. R. (1979) Stress-Induced Failures in Mine Roof, Bureau of Mines RI 8338, pp 16.

7. Ahola, M.P., Donato, D.A., and Kripakov, N.P. (1991) Application of Numerical Modeling techniques to Analysis of Cutter Roof Failure, USBM IC 9287.

8. Alam, M.R. et. al. (2008) Mechanical and physical properties of slate from Britannia Cove, Newfoundland, Canadian Journal of Civil Engineering, Vol. 35, pp 751-755.

9. Amadei, B., and Stephansson, O. (1997) Rock stress and its Measurement, Chapman and Hall, pp 490.

10. Badr, S., Mendoza, R., Kieffer, S., Salamon, M.D.G., and Ozbay, U. (2003) Numerical Modeling of Longwalls in Deep Coal Mines, Proceedings of the 22nd International Conference on Ground Control in Mining, West Virginia University, Morgantown, West Virginia, pp 37-43.

11. Bandis, S.C. (1990) Mechanical properties of rock joints, Proceedings of the International symposium on Rock joints, Norway, Balkema, Rotterdam, pp 125-140.

12. Bandis, S.C., Lumsden, A.C., and Barton N.R. (1983) Fundamentals of rock joint deformation, International journal of Rock Mechanics and Mining sciences, Vol. 20, pp 249-268

13. Banerjee, G (2006) Numerical Modeling studies for Prediction of Longwall roof behavior, PhD dissertation.

14. Barron, K., and Baydusa, A. (1999) Theory of cutter roof failure and its application, CIM Bulletin, Vol 92, No. 1032, pp 45-49.

15. Bauer, E. R. (1990) Cutter Roof Failure: Six Case Studies in the Northern Appalachian Coal Basin, USBM IC 9266, pp 18. 
16. Bauer, E. R. (1998) The impact of extended depth-of-cut mining on coal mine ground control and worker safety, PhD dissertation, The Pennsylvania State University, Department of Mineral Engineering.

17. Blevins, C. T., and Dopp, D. (1985) Ground Control Experiences in A High Horizontal Stress Field at Inland Steel Coal Mine No.2., Proceedings of the 4th International Conference on Ground Control in Mining, West Virginia University, Morgantown, West Virginia, pp 227-233.

18. Brown, E.T., and Hoek, E. (1978) Trends in relationships between measured in situ stresses and depth, International Journal of Rock Mechanics, Mining Science and Geomechanics, pp 211-215.

19. Canbulat, I., and van der Merwe, J.N. (2000) Safe mining face advance and support installation practice in mechanical miner workings under different geotechnical conditions, SIMRAC Report, COL 609. 100p.

20. Chen, H. J. (1999) Stress Analysis in Longwall Entry Roof under High Horizontal Stress, Ph.D. dissertation, West Virginia University, pp 278.

21. Chen, Jing-wen and Lin, Chih-ying (2003) Dilative Behavior of Granular materials, International Journal of Offshore and Polar Engineering, Vol. 13, No. 4.

22. Chugh, Y.P., and Pytel, W.M. (1992) Design of Partial Extraction Coal Mine Layouts for Weak Floor Strata Conditions, U.S. Bureau of Mines, IC 9315, pp 32-49.

23. Dahl, H.D., and Parsons, R.C. (1972) Ground Control studies in the Humphrey No. 7 Mine, Christopher Coal Division, Consolidation Coal Company. SME/AIME Transaction, Vol. 253, pp 211-222.

24. Dolezalova, M., (2004) Numerical analysis of an old masonry dam using UDEC, 1st International UDEC/3DEC Symposium: Numerical Modeling of Discrete Materials in Geotechnical Engineering, Civil Engineering and Earth Science Bochum, Germany.

25. Dolinar, D., Mucho, T.P., Oyler, D.C., and Pablic, J. (2000) Utilizing the "Advance and Relief" Method to Reduce Horizontal Stress Affects on the Mine Roof, A Case Study, Proceedings of 19th International Conference on Ground Control in Mining, West Virginia University, Morgantown, West Virginia, pp 137-148.

26. Enever, J.R., and McKay, J. (1980) Stress measurements at Nattai North Colliery and their interpretation in terms of sedimentological and topographic features, CSIRO Division of Applied Geomechanics, Australia, Rep. 29, pp 12.

27. Erichsen, C., and Werfling, J. (2003) Stability of underground openings in rock salt, ISRM 2003 - Technology roadmap for Rock Mechanics, South African Institute of Mining and Metallurgy.

28. Fakhimi, A., and Fairhurst, C. (1994) A model for the time-dependent behavior of rock, International Journal of Rock Mechanics, Mineral Science and Geomechanics, pp 117126.

29. Frith, R. (2002) Survey of horizontal stresses in coal mines from available measurements and mapping, SIMRAC project COL 802, pp 61.

30. Gadde, M. M. (2003) Effect of In Situ Stresses on the Stability of Coal Mine Development Workings, M. S. Thesis, West Virginia University.

31. Gadde, M. M., and Peng, S. S. (2004) Effect of in situ stresses on the stability of coal mine development workings, Proceedings of the 23rd International Conference on 
Ground Control in Mining, West Virginia University, Morgantown, West Virginia, pp 92102.

32. Gadde, M. M., and Peng, S. S. (2005) Numerical simulation of cutter roof failures under weak roof conditions, SME annual meeting 2005, Salt Lake City, Utah.

33. Gadde, M. M., and Peng, S. S. (2005) Recent Advances in Numerical simulation of Cutter Roof Failure in Underground Coal Mines, Proceedings of the 24th International Conference on Ground Control in Mining, West Virginia University, Morgantown, West Virginia, pp 162-168.

34. Gadde, Murali (2008a) Personal communications.

35. Gale, W. J., and Blackwood, R. W. (1987) Stress distributions and rock failure around coal mine roadways, International Journal of Rock Mechanics, Mining Science and Geomechanics, Vol. 24, No.3, pp 165-173.

36. Gale, W.J., Mark, C., Oyler, D.C., and Chen, J. (2004) Computer simulation of Ground control behavior and Rock Bolt Interaction at Emerald Mine, Proceedings of the 23rd International Conference on Ground Control in Mining, West Virginia University, Morgantown, West Virginia, pp 27-34.

37. Glamheden, R., Hökmark, H., and Christiansson, R. (2004) Modeling creep in jointed rock masses, 1st International UDEC/3DEC Symposium: Numerical Modeling of Discrete Materials in Geotechnical Engineering, Civil Engineering and Earth Science, Bochum, Germany.

38. Hajiabdolmajid, V., Kaiser, P.K., and Martin, C.D. (2002) Modeling Brittle failure of Rock, International Journal of Rock Mechanics \& Mining Sciences, pp 731-741.

39. Hasenfus, G.J., and Su, D.W.H., (2006) Horizontal stress and Coal Mines: Twenty-Five Years of experience and Perspective, Proceedings of 25th International Conference on Ground Control in Mining, West Virginia University, Morgantown, West Virginia, pp 256267.

40. Herget, G. (1988) Stresses in rock, Rotterdam, Balkema.

41. Hill III, J. L. (1986) Cutter Roof Failure: An Overview of the Causes and Methods for Control, USBM IC 9094, pp 27.

42. Hoek, E. (2007) Insitu and induced stress, Practical Rock Engineering, $3^{\text {rd }}$ Edition, Chapter 10,

43. Hoek, E., and Brown, E.T. (1980) Underground Excavations in Rock, London, Inst. Min. Metall.

44. Iannacchione, A.T., Coyle, P. R., Prosser, L. J., Marshall, T. E., and Litsenberger, J. (2004) Relationship of Roof Movement and Strata-induced Microseismic Emissions to Roof Falls, Mining Engineering, pp 53-60.

45. Ingram, D. K., and Molinda, G. M. (1988) Relationship between Horizontal Stresses and Geologic Anomalies in Two Coal Mines in Southern Illinois, USBM RI 9189.

46. Itasca (2007) Fast Lagrangian Analysis of Continua in 3 Dimensions, Version 3.1, User's guide, Minneapolis, USA.

47. Jaeger, J. C., and Cook, N. G. W. (1979) Fundamental of Rock Mechanics, Chapman and Hall, London, pp 585 and 593. 
48. Jeremic, M. L. (1981) Coal Mine Roadway Stability in Relation to Lateral Tectonic Stress-Western Canada, Mining Engineering, pp 704-709.

49. Karmis, M., and Kane, W. (1984) An analysis of the geomechanical factor influencing coal mine roof stability in Appalachia, Proceedings of the 2nd International Conference on stability in underground mining, Lexington, Kentucky, pp 311-328.

50. Kent, F.L., Coggan, J.S., and Altounyan, P.F.R. (1999) Investigation into factors affecting roadway deformation in the Selby coalfield, Geotechnical and Geological Engineering, pp 273-289.

51. Kester, W.M., and Chugh, Y.P. (1980) Premining investigations and their use in planning ground control in the Illinois coal basin, Proceedings of the 1st Conference on Ground Control Problem in the Illinois Coal Basin, pp 33-43.

52. Khair, A. W. (1990) Engineering to reduce the cost of roof support in a coal mine experiencing complex ground control problems, Mining Engineer, pp 1062-1066.

53. Kripakov, N. P. (1982) Alternatives for controlling cutter roof in coal mines, Proceedings of the 2nd International Conference on Ground Control in Mining, West Virginia University, Morgantown, West Virginia, pp 142-151.

54. Krupa, E.D., and Khair, W.A. (1991) Assessment of Underground Structural Design, Proceedings of the 10th International Conference on Ground Control in Mining, West Virginia University, Morgantown, West Virginia, pp 15-25.

55. Kushwaha, A., Gadde, M. M., Singh, S.K., and Sheorey, P.R. (2003) Effect of in situ horizontal stresses on roadway stability, Journal of Mines Metals and Fuels, Vol. 51, No. 3, pp 134-142.

56. Ladnyi, B. (1993) Time dependent response of rocks around tunnels, Comprehensive Rock Engineering, pp 77-112.

57. Larson, M. K., and Wade, R. G. (2000) Creep Along Weak Planes In Roof And How It Affects Stability, SME Annual Meeting, Salt Lake City, Utah.

58. Laubscher, D. H. (1990) Geomechanical classification system for the ratings of the rock mass in mine design, South African institute of Mining and Metallurgy, Vol. 10, pp 257273.

59. Lendel, U. (2004) Rock bolting and rock support and their combination in hard coal mining - a comparative study made with UDEC, 1st International UDEC/3DEC Symposium: Numerical Modeling of Discrete Materials in Geotechnical Engineering, Civil Engineering and Earth Science, Bochum, Germany.

60. Lizak, J. B., and Sembourski, J. E. (1985) Horizontal Stresses and Their Impact on Roof Stability at the Nelms No. 2 Mine, Proceedings of the 4th International Conference on Ground Control in Mining, West Virginia University, Morgantown, West Virginia, pp 7.

61. Maleki, H. N., Owens, J. K., and Endicott, M. (2001) Evaluation of Mobile Roof Support Technologies, Proceedings of the 20th International Conference on Ground Control in Mining, West Virginia University, Morgantown, West Virginia, pp 67-77.

62. Mark C., and Gadde M. M. (2008) Global trends in coal mine horizontal stress measurements, Proceedings of the 27th International Conference on Ground Control in Mining, West Virginia University, Morgantown, West Virginia.

63. Mark, C. (1991) Horizontal stress and its effects on longwall ground control, Mining Engineering, Vol. 43, No. 11, pp 1356-1360. 
64. Mark, C. (1999) Application of the Coal Mine Roof Rating (CMRR) to Extended Cuts, Mining Engineering, pp 52-56.

65. Mark, C. and Barczak, T. M. (2000) Fundamentals of coal mine roof support, Proceedings of the New Technology for Coal Mine Roof Support, NIOSH Open Industry Briefing, NIOSH IC 9453, pp. 23-42

66. Mark, C., and Mollinda, G. M. (1994) Evaluating roof control in underground coal mines with the coal mine roof rating, Proceedings of the 13th International Conference on Ground Control in Mining, West Virginia University, Morgantown, West Virginia.

67. Mark, C., and Mucho, T. P. (1994) Longwall Mine Design for Control of Horizontal Stress, Proceedings of the Buro of the Mines Technical Transfer Seminar on New Technology for Longwall Ground Control, pp 53-76.

68. Mark, C., Molinda, G., Burke, L. M. (2004) Preventing Falls of Ground in Coal mines with exceptionally low strength Roof: Two case studies, Proceedings of the 23rd International Conference on Ground Control in Mining, West Virginia University, Morgantown, West Virginia.

69. Mark, C., Molinda, G., Burke, L., and Padgett, P. (2004) Preventing falls of ground control in coal mines with exceptionally low-strength roof: two case studies, Proceedings of the 23rd International Conference on Ground Control in Mining, West Virginia University, Morgantown, West Virginia, pp 220-227.

70. Mark, C., Molinda, G., Mark, C. (2000) Assessing coal mine roof stability through roof fall analysis, IC 9453, NIOSH, pp 53-71.

71. Mark, C., Mucho, T. P., and Dolinar, D. (1998) Horizontal stress and longwall headgate ground control, Mining Engineering, Vol. 50, No. 1, pp 61-68.

72. McLamore, R., and Gray, K. E. (1967) The mechanical behavior of anisotropic sedimentary rocks, Transaction of American Society of Mechanical Engineers, Series B, 1967, pp. 62-76.

73. Meyer, L. H. I., Coggan, J. S., and Stead, D. (1999) Three dimensional non-linear modeling of the effects of high horizontal stress on underground excavation face-end stability, Proceedings of the 37th US rock mechanics symposium, pp 147-152.

74. Meyer, L. H. I., Stead, D., and Coggan, J. S. (1999) Three dimensional modeling of the effects of high horizontal stress on underground excavation stability, Proceedings of the IRSM 9th International Congress on Rock Mechanics, pp 411-416.

75. Mitani, Y., Esaki, T., and Cai, Y. (2004) Numerical study about flexure toppling phenomenon on rock slope, 1st International UDEC/3DEC Symposium: Numerical Modeling of Discrete Materials in Geotechnical Engineering, Civil Engineering and Earth Science, Bochum, Germany.

76. Mogi, K. (1966) Pressure dependence of rock strength and transition from brittle fracture to ductile flow, Bulletin of Earthquake Resources Institute (Tokyo University), pp 215232.

77. Mogi, K. (1974) On the pressure dependence of strength of rocks and the Coulomb criterion, Techtonicphysics 21, pp 273-285.

78. Mogi, K. (2006) Experimental rock mechanics, Taylor and Francis Publication.

79. Molinda, G. M., Heasley, K. A., Oyler, D. C. and Jones, J. R. (1991) Effects of Surface Topography on the Stability of Coal Mine Openings, Proceedings of the 10th 
International Conference on Ground Control in Mining, West Virginia University, Morgantown, West Virginia, pp 151-160.

80. Molinda, G., and Klemetti, T. (2008) Diagnosing and controlling moisture-sensitive roof in coal mines, The electronic Journal of engineering geology, Vol. 13, Bundle A.

81. Molinda, G., Mark C., Bauer E., Babich D., and Pappas, D. (1998) Factors influencing intersection stability in US coal mines, Proceedings of the 17th International Conference on Ground Control in Mining, West Virginia University, Morgantown, West Virginia.

82. Morsy, K., and Peng, S. S. (2001) Typical Complete Stress-Strain Curves of Coal, Proceedings of the 20th International Conference on Ground Control in Mining, West Virginia University, Morgantown, West Virginia, pp 210-217.

83. Morsy, K., and Peng, S. S. (2005) Detailed Stress Analysis of Longwall Panels, Proceedings of the 24th International Conference on Ground Control in Mining, West Virginia University, Morgantown, West Virginia, pp 18-32.

84. Mucho, T. P., and Mark, C. (1994) Determining Horizontal Stress Direction Using Stress Mapping Technique, Proceeding of 13th International Conference on Ground Control in Mining, West Virginia University, Morgantown, West Virginia, pp 277-289.

85. Munson, D. E., Fossum, A. F., and Senseny, P. E. (1996) Advances in Resolution of Discrepancies between Predicted and Measured In Situ WIPP Room Closures, SAND88-2948, Sandia National Laboratories, Albuquerque, NM.

86. Nagwa, R., El-Sakhawy (2002) Shearing Behavior of Joints in Load-Bearing Masonry Wall, Journal of Materials in Civil Engineering, Vol. 14, No. 2, pp 145-150

87. Ndlovu, X., and Stacy, T. R. (2007) Observations and analyses of roof guttering in a coal mine, The Journal of the Southern African Institute of Mining and Metallurgy, pp 477491.

88. Nicholas, B. (1978) Pillar extraction on the Advance at Oakdale Colliery, Proceedings of the 1st International Symposium on Stability in Coal Mining, Vancouver, British Columbia, Canada, pp 182-196.

89. Peng, S. S. (2006) Longwall Mining, 2nd edition, S.S. Peng publisher.

90. Peng, S. S., and Chen, H. J. (2000) Stress Distributions in Three-Entry Development under High Horizontal Stress, SME Transactions 2000, Vol. 308, pp 91-96.

91. Peng, S. S., and Kelley, J. H. (1990) An Engineering Analysis of the Longwall Plan and the Continuous Mining Plan for the Camp Complex, Final report submitted to Peabody Coal Company, pp 85.

92. Peng, S.S. (2004) Report on Roof Fall observations, West Virginia University.

93. Peng, S.S. (2007) Ground Control failures- a Pictorial view of case studies, S.S. Peng publisher.

94. Peng, S.S. (2008) Coal Mine ground Control, 3rd Edition, S.S. Peng publisher.

95. Philips, D.W. (1947) American coal mining, The colliery guardian, vol. 175, pp 37.

96. Price, N.J. (1964) A study of the time-strain behavior of coal measure rocks, International Journal of Rock Mechanics and Mining Science, Vol. 1, pp 277-303.

97. Rashed, G. R. M. (2007) Design Considerations for Underground Excavations Subjected to High Horizontal Stresses, MS Dissertation, Suez Canal University, Egypt. 
98. Reinecker, J., Heidbach, O., Tingay, M., Sperner, B., and Müller, B. (2005) The release 2005 of the World Stress Map (available online at www.world-stress-map.org).

99. Roberts, A. A. (1945) A review of the problems of Strata control in Pillar workings, The Colliery Guardian, Vol. 170, pp 631.

100.Roley, R. W. (1948) "Pressure-Cutting": A phenomenon of Coal-Mine Roof Failures, Mechanization, v. 12, No. 12, pp 69-74.

101.Schlegel, R. K. Rautenstrauch and J. Will (2004) Comparative computations of masonry arch bridges using continuum and discontinuum mechanics, 1st International UDEC I 3DEC Symposium: Numerical Modeling of Discrete Materials in Geotechnical Engineering, Civil Engineering and Earth Science, Bochum, Germany.

102.Schlegel, R., and Rautenstrauch, K. (2004) Failure analysis of masonry shear walls, 1st International UDEC/3DEC Symposium: Numerical Modeling of Discrete Materials in Geotechnical Engineering, Civil Engineering and Earth Science, Bochum, Germany.

103.Schwartz, Charles W., Kolluru, Subash (1982) The influence of stress level on the creep of unfilled rock joints, Proceedings of the 23rd Symposium On Rock Mechanics.

104.SCT (1995) Ground Control in Longwall manuals, Australia.

105.Sheorey, P.R. (1994) A theory for in situ stresses in isotropic and transversely isotropic, rock, International Journal of Rock Mechanics, Mining Science and Geomechanics, pp 23-34.

106.Sheorey, P.R. (1997) Empirical Rock Failure Criteria, Rotterdam, Balkema, pp 176.

107.Smart, B.G.D. (1992) Control exerted by dominant parting planes over the deformation of tabular deposits, Effects of Geomechanics on mine design, Edited by Kidybinski and Dubinski, Balkema, Rotterdam, pp 3-9.

108.Smith, A.D. (1984) Mine Roof condition and the occurrence of roof falls in coal mines, Ohio journal of science, pp 133-141.

109.Stacey, T. R., and Wesseloo, J. (1997) In situ stresses in mining areas in South Africa, The Journal of the Southern African Institute of Mining and Metallurgy, pp 365-368

110.Su, D., and Hasenfus, G. (1995) Regional horizontal stress and its effect on longwall mining in the Northern Appalachian coal field, Proceedings of the 14th International Conference on Ground Control in Mining, West Virginia University, Morgantown, West Virginia, pp 39-45.

111.Su, W. H., and Peng, S. S. (1987) Cutter roof and its causes, Mining Science and Technology, No. 4, pp 113-132.

112.Su, W. H., and Peng, S. S., (1985) Cutter roof and its causes, Preprint No. 85-133, SME-AIME Annual Meeting 1985, New York, pp 23.

113.Terzaghi, K., and Richart, F.E. (1952) Stresses in rock about cavities, Geotechnique 3, pp 57-90.

114.Van de merwe, J. N., Van Vuuren, J. J., Butcher, R., and Canbulat (2001) Causes of Roof falls in South African Collieries, Safety in Mines Research advisory Committee.

115.Vermeer, P. A., and De Borst, R. (1984) Non-associated plasticity for soils, concrete and rock, Heron, pp 1-64.

116.Vutukuri, V. S., Lama, R. D., and Saluja, S. S. (1974), Handbook on mechanical properties of rocks, Transtech Publications. 
117.Wang, F. D., Ropchan, D. M. and Sun, M. C. (1974) Structural Analysis of a Coal Mine Opening in Elastic Multilayered Material, USBM RI 7845, pp 36.

118.Wang, Q., and Heasley K. (2005) Stability mapping system, Proceedings of the 24th International Conference on Ground Control in Mining, West Virginia University, Morgantown, West Virginia, pp 243-249.

119.Wang, Y., and Stankus, J. (1998) Roof Control Under Conditions of Shallow Depth and High Horizontal Stress Field - A Case Study, Proceedings of the 17th International Conference on Ground Control in Mining, West Virginia University, Morgantown, West Virginia, pp 113-118.

120.Wang, Y.J., and Peng, S. S. (1996) High horizontal stress effects on longwall gate entry stability, Proceedings of 15th International Conference on Ground Control in Mining, Colorado School of Mines, Golden, Colorado, pp 179-191.

121.Zipf, R. K. (2005) Failure Mechanics of Multiple seam Mining Interactions, 24th International Conference on Ground Control in Mining, West Virginia University, Morgantown, West Virginia, pp 93-106. 